\title{
IntechOpen
}

\section{Modeling, Simulation and \\ Optimization of Wind Farms and Hybrid Systems}

Edited by Karam Y. Maalawi 



\section{Modeling, Simulation and Optimization of Wind Farms and Hybrid Systems \\ Edited by Karam Y. Maalawi}



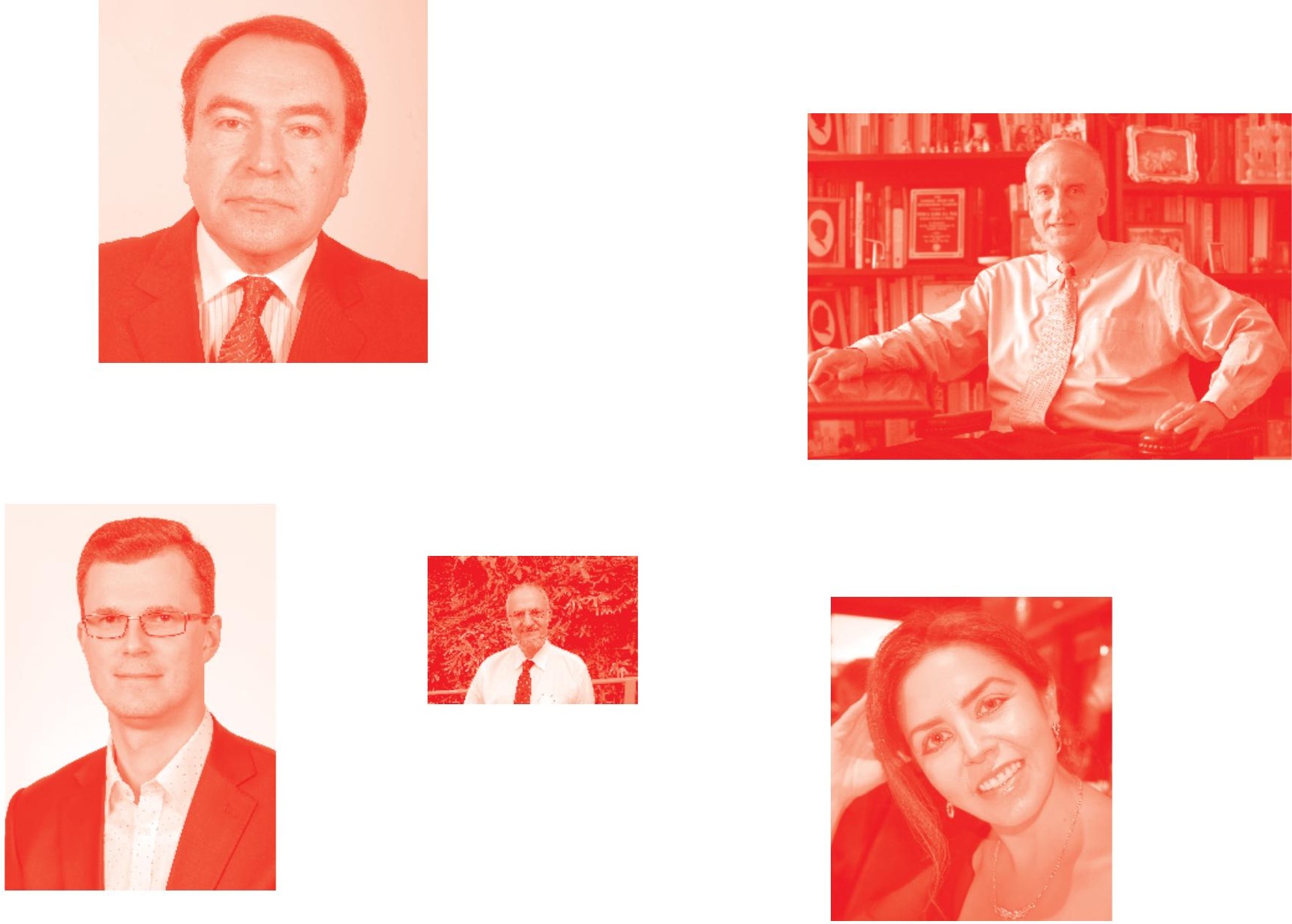

Supporting open minds since 2005
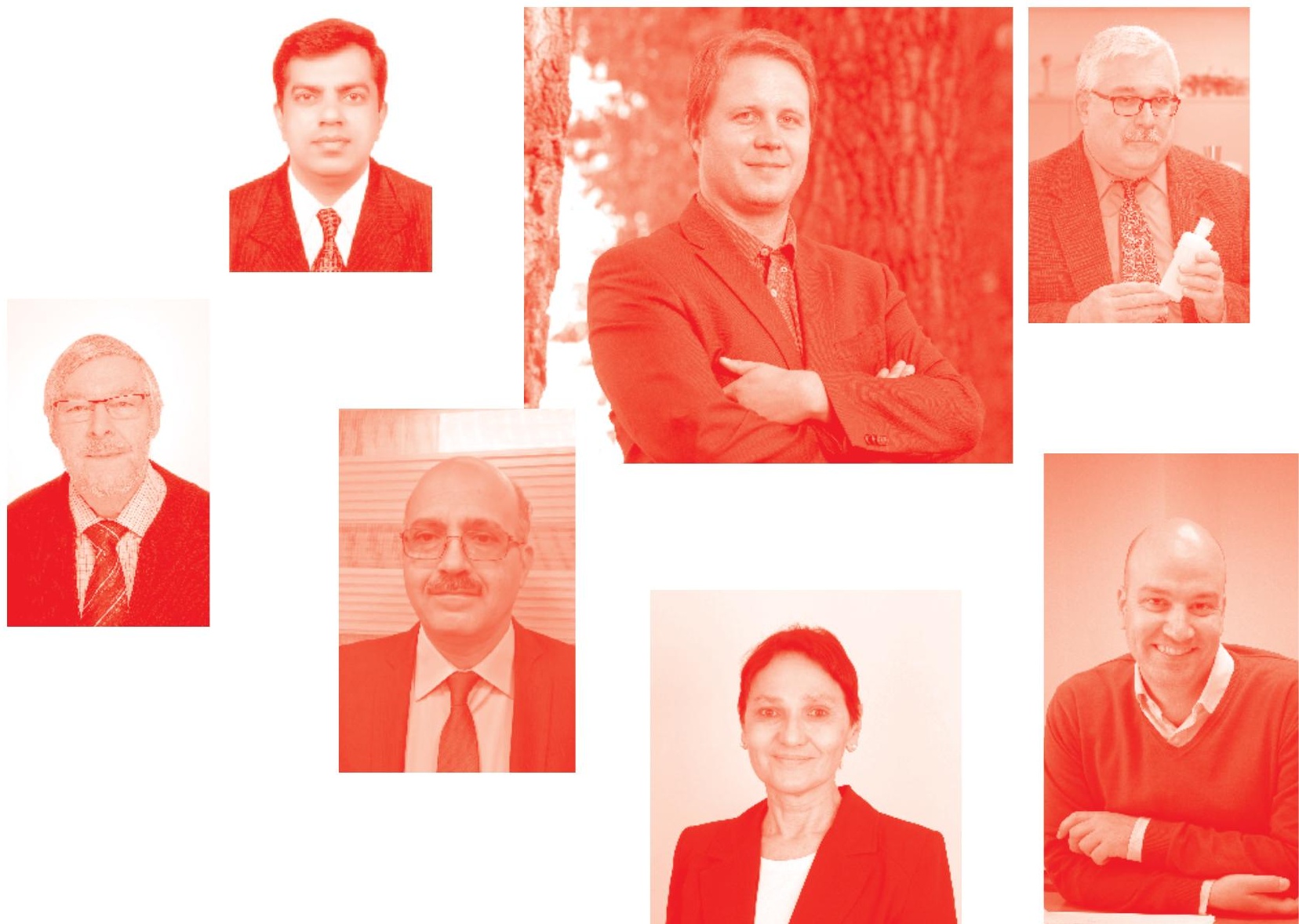
Modeling, Simulation and Optimization of Wind Farms and Hybrid Systems

http: //dx. doi.org/10.5772/intechopen. 91639

Edited by Karam Y. Maalawi

\section{Contributors}

Marwa Ibrahim, Essam El Shenawy, Nagwa Khattab, Mervat Badr, Hassan Shaarawy, Marwa Shalaby, Mariola Jureczko, Tony Stephens, David Walwyn, Alexandre Brouste, Alain Bensoussan, Grażyna Łaska, Biao Wang, Elias Tsoutsanis, Cheng Siong Chin, Chu Peh, M Venkateshkumar, Enas Shouman

(๑) The Editor(s) and the Author(s) 2020

The rights of the editor(s) and the author(s) have been asserted in accordance with the Copyright, Designs and Patents Act 1988. All rights to the book as a whole are reserved by INTECHOPEN LIMITED. The book as a whole (compilation) cannot be reproduced, distributed or used for commercial or non-commercial purposes without INTECHOPEN LIMITED's written permission. Enquiries concerning the use of the book should be directed to INTECHOPEN LIMITED rights and permissions department (permissions@intechopen.com).

Violations are liable to prosecution under the governing Copyright Law .

\section{(c)) BY-NC}

Individual chapters of this publication are distributed under the terms of the Creative Commons Attribution - NonCommercial 4.0 International which permits use, distribution and reproduction of the individual chapters for non-commercial purposes, provided the original author(s) and source publication are appropriately acknowledged. More details and guidelines concerning content reuse and adaptation can be found at http : //www . intechopen . com/copyright-policy . html .

\section{Notice}

Statements and opinions expressed in the chapters are these of the individual contributors and not necessarily those of the editors or publisher. No responsibility is accepted for the accuracy of information contained in the published chapters. The publisher assumes no responsibility for any damage or injury to persons or property arising out of the use of any materials, instructions, methods or ideas contained in the book.

First published in London, United Kingdom, 2020 by IntechOpen

IntechOpen is the global imprint of INTECHOPEN LIMITED, registered in England and Wales, registration number: 11086078 , 7th floor, 10 Lower Thames Street, London,

EC3R 6AF, United Kingdom

Printed in Croatia

British Library Cataloguing-in-Publication Data

A catalogue record for this book is available from the British Library

Additional hard and PDF copies can be obtained from orders@intechopen.com

Modeling, Simulation and Optimization of Wind Farms and Hybrid Systems

Edited by Karam Y. Maalawi

p. $\mathrm{cm}$.

Print ISBN 978-1-78985-611-8

Online ISBN 978-1-78985-612-5

eBook (PDF) ISBN 978-1-78985-645-3

An electronic version of this book is freely available, thanks to the support of libraries working with Knowledge Unlatched. KU is a collaborative initiative designed to make high quality books Open Access for the public good. More information about the initiative and links to the Open Access version can be found at www. knowledgeunlatched. org 


\section{We are IntechOpen, \\ the world's leading publisher of Open Access books}

Built by scientists, for scientists

\section{$4,700+$}

Open access books available

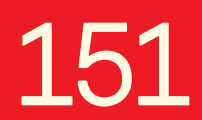

Countries delivered to

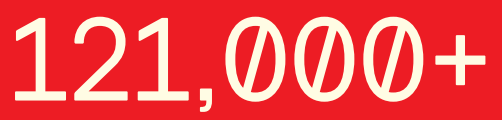

International authors and editors

Our authors are among the

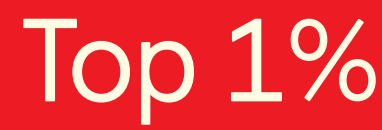

most cited scientists

Contributors from top 500 universities
40010

Downloads

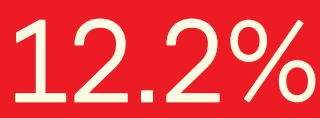

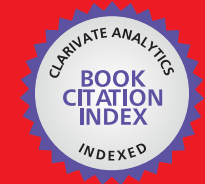

WEB OF SCIENCE ${ }^{\text {MM }}$

Selection of our books indexed in the Book Citation Index in Web of Science ${ }^{\mathrm{TM}}$ Core Collection (BKCI)

Interested in publishing with us?

Contact book.department@intechopen.com

Numbers displayed above are based on latest data collected.

For more information visit www.intechopen.com

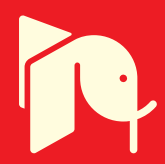





\section{Meet the editor}

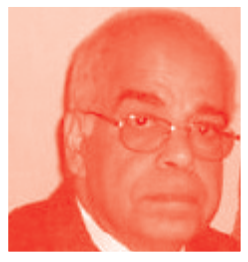

Karam Y. Maalawi is a professor of Aeronautics and Mechanics at the Mechanical Engineering Department, National Research Centre in Cairo, Egypt. He holds a Bachelor of Science, a Master of Science and a Doctor of Philosophy in Aerospace Engineering from Cairo University. Dr. Maalawi has published extensively in the field of structural optimization and wind turbine design and performance. Likewise, he has utilized the vast range of knowledge at his disposal to contribute to several research projects regarding aerospace engineering technology, wind turbine structures and renewable energy applications. For his outstanding contributions to his profession, the National Research Centre has recognized him with two awards for engineering sciences. He has been presented with the Albert Nelson Marquis Lifetime Achievement Award and endorsed by Marquis Who's Who as a leader in the aerospace engineering industry. 



\section{Contents}

Preface

Section 1

Wind Farms Modeling Simulation and Optimization

Chapter 1

Global Prediction of Wind Energy Market Strategy for Electricity

Generation

by Enas Raafat Maamoun Shouman

Chapter 2

Modeling and Simulation of Offshore Wind Farms for Smart Cities

by Cheng Siong Chin, Chu Ming Peh and Mohan Venkateshkumar

Chapter 3

Wind Energy and Multicriteria Analysis in Making Decisions on the Location of Wind Farms: A Case Study in the North-Eastern of Poland by Grażyna Łaska

Chapter 4

Development of Mathematical Models to Explore the Potential of Wind Fleets to Decarbonize Electricity Grid Systems

by Anthony D. Stephens and David R. Walwyn

Chapter 5

Optimal Bidding in Wind Farm Management

by Alain Bensoussan and Alexandre Brouste

Chapter 6

Urban Wind Energy Evaluation with Urban Morphology

by Biao Wang

\section{Section 2}

Optimization of Hybrid and Micro-Grid Systems

Chapter 7

Hybrid Wind and Solar Systems Optimization

by Mervat Abd El Sattar Badr 
Chapter 8

Optimization of Stand-Alone Hybrid Solar-Wind System by Using

General Morphological Analysis

by Mariola Jureczko

Chapter 9

A Dynamic Performance Model for Hybrid Wind/Gas Power Plants by Elias Tsoutsanis

Chapter 10

Economic Analysis of Stand-Alone Hybrid Wind/PV/Diesel Water

Pumping System: A Case Study in Egypt

by Nagwa M. Khattab, Mervat A. Badr, Essam Tawfik El Shenawy,

Hassan H. Sharawy and Marwa S. Shalaby

Chapter 11

Optimization of Renewable Energy-Based Smart Micro-Grid System by Marwa Mohsen Ibrahim Abd El-Rahman 


\section{Preface}

The reduction of greenhouse gases emissions is a major governmental goal worldwide. The European Union, United Kingdom, United States and Canada have embraced a goal of achieving "net-zero" greenhouse gas emissions economy-wide by 2050. The main target is to move away from fossil fuels in the electricity sector, and then switch to clean power to fuel transportation, buildings and industry. Therefore intensive research and collaborative projects dealing with the installation of many wind turbines and solar panels, both onshore and offshore, are taking place with the main objective of decarbonizing electricity grid systems through the exploitation of wind and solar power. In fact, the rapidly plunging costs of wind and solar resources makes renewable energy the least costly option for new clean and reliable power.

This book presents relevant achievements in the expanding field of wind farms modeling and hybrid systems optimization. The contributing authors combine simulation and optimization of wind farms and hybrid wind/solar systems with description of the implemented mathematical approaches. All chapters were reviewed for their technical contents as stated by the individual authors. As such, the editor assumes no responsibility for the accuracy and completeness of the typing itself.

Section I is comprised of six chapters tackling the global wind energy market and design optimization of wind farms, which is a multidisciplinary engineering challenge and mainly consists of selecting and distributing wind turbines on the wind farm site as well as analyzing energy production. Chapter 1 provides an overview of the world wind energy market, current and forecasting development globally, and cost of wind energy historical growth. Chapter 2 presents a systematic approach to simulate an offshore wind farm for smart cities. The subsystems of several variable-pitch wind turbines, namely rotor blades, drive train, and induction generator, are modeled to form a wind farm. The total output power of the wind farm by considering multiple wind turbines with the wake losses (using the Jensen wake model) can be simulated with any input wind speed. In order to validate the accuracy of the simulation, a case study on a German offshore wind farm called NordseeOst is presented. The simulation shows promising results with an average error of approximately $5 \%$ when compared with the real-time output of the wind farm. The results also show that simulation of a wind farm, which is often impeded by lack of exact information, is feasible before any site implementation for smart cities. Another important work to take into account before deciding the location of a wind farm is addressed in Chapter 3. The study investigates different methods of multi-criteria analysis and different procedural rules in north-eastern Poland. Ten multi-criteria analyses are discussed, taking into account the main criteria on which they are based, such as utility functions, relationships outranking, distances and decision support. The implementation in Krynki and Szudzialowo communities proved that the planned construction of wind farms would have a positive effect on the production of energy from renewable sources. The choice of the optimum location of wind turbines is shown to have no negative impact on the natural environment, which is of key importance in application of sustained technologies to ensure a balance between economic and environmental factors and the needs of society. 
Chapter 4 explains why wind fleets, which compete for limited access to a grid, can only be modelled using real-time grid records, and why grids should be considered as acting towards wind fleets as time-varying low-pass filters. Models of the UK and German grid systems are described using their real-time records, which are available online. The study describes a number of important scenarios likely to be faced by the grids in the future. It provides a particularly useful quantitative insight into the ability/limitations of wind and solar fleets to decarbonize their grids. It is shown that the level of wind curtailment, which will be deemed to be economic, depends on the economic circumstances of the time, and of the cost of reducing carbon emissions using alternative approaches.

The problem of wind farm management is tackled in Chapter 5. It is shown that the consequences of uncertainty of using a storage facility (a battery for instance) can be substantially reduced. The study considers a simplified model in discrete time, in which the commitment is for the next period. An optimal control problem to define the optimal bidding decision is formulated and solved. Application to a real data set is done and the optimal size of the battery (or the overnight costs) for the wind farm is determined. The chapter ends by describing a continuous time version involving a delay between the time of decision and the implementation. Considering urban wind development for sustainable cities, Chapter 6 evaluates wind energy potential by studying urban form in a block scale $(500 \mathrm{~m} \times 500 \mathrm{~m})$. The CFD method is used for wind flow simulation, where all parameter settings have been validated and evaluated via a wind tunnel experiment. Simple building forms are tested for exploring the impact of building form on wind potential. Space over roof is proved to be the most effective and practical position for developing wind energy in the urban environment. Ideal urban forms are tested for evaluating the impact of a single morphological parameter on wind potential over roof. Real urban forms are then evaluated and compared in order to reveal the impact of different urban form parameters on wind potential. Finally, a block model in Beijing is given for an urban wind evaluation case study, including wind potential evaluation of every building roof in the model, wind turbine position evaluation and economic cost analysis.

The main disadvantage of using wind alone or solar alone is the fluctuation of power output. To overcome these disadvantages, hybrid renewable energy and smart micro-grid system technologies can be a practical solution. Part II considers important issues associated with optimizing hybrid and micro-grid systems. In order to solve sustainability and power quality problems, the power transfer from the renewable sources to load must be managed in a proper way. Chapter 7 proposes an energy management process to prevent power discontinuity or power wasting so that the loads operate properly. The major goal is to reach the suitable size of each component of the hybrid wind/solar system and the control strategy that provides reliability, efficiency and cost-effectiveness. Optimization is performed by minimizing (or maximizing) an objective-function using a suitable criterion, such as net present cost (NPC) and/or the generated electricity price (EP). The study shows that the cost of avoided $\mathrm{CO}_{2}$ emissions should be taken into consideration.

A brief introduction to the issue of energy sources is given in Chapter 8, with a discussion of the crucial aspects that should be taken into consideration when choosing a location for both solar systems and wind turbines. The chapter also discusses climatic, environmental, social, health and ecologic aspects that should be considered as well. The next part of the chapter briefly introduces the theory of General Morphological Analysis, including optimization of the structure of hybrid 
solar wind farms through the MATLAB/Simulink environment. Based on the data from the simulations carried out, it has been concluded that the difference between the demand and the energy generated by the modeled system, amounting to $15.67 \%$, is a very satisfactory result. Therefore observing the further development of solar cells and batteries, such energy sources for countries without very favorable climate conditions, for example in Poland, should be treated as a cost-effective alternative to non-renewable energy sources.

Chapter 9 demonstrates the challenges of partnering wind turbines with gas turbines in order to assess the performance of hybrid power plants. A dynamic engine model of a gas turbine along with a wind turbine model is developed to simulate a number of scenarios for optimizing operation in terms of efficiency, fuel consumption and NOx emissions. Moreover, a comparison between the hybrid power plant and a twin gas turbine power plant is carried out to assess the improvement in both NOx emissions and fuel consumption. The results show that dynamic performance modeling has to be considered in the optimization process and controller design of a hybrid power plant.

In the context of standalone hybrid renewable energy systems, Chapter 10 presents an interesting study for pumping underground water for small farm irrigation. Given environmental conditions, system specifications and daily load demand data, the optimal size of the main system components are obtained using a sizing algorithm. Different systems are compared using yearly simulations on an hourly basis via specialized commercial software simulation packages PVSYST and HOMER. The criteria used in economic optimization are the net present cost and the cost of energy, with the percentage of the capacity shortage. The simulation has also been carried out for different load patterns for optimum operation. The study is illustrated for climatic conditions of an isolated area in El-Tour City, Sinai, Egypt.

Another new significant consideration in renewable energy technology is the optimization of renewable energy-based micro-grids. Chapter 11 evaluates the technical and economic performance of a micro-grid system comparing two operation modes: standalone and grid connected. For the grid-connected system, the suggested components are PV panels, wind turbine(s), inverter, and control unit. In the standalone model, a diesel generator and short-term storage are added to the renewable generators. Detailed models for each component are presented and economic evaluation is performed by comparing the system net present cost and the generated electricity cost for the two modes of operation.

I wish to express my gratitude and thanks to all authors and other individuals who have contributed to this book and made it possible. I am thankful for the help and support of IntechOpen staff members, particularly Senior Commissioning Editor Ms. Ana Pantar and Publishing Process Managers Mr. Josip Knapic, Ms. Dajana Pemac and Ms. Maja Bozicevic.

Karam Y. Maalawi 

Section 1

\section{Wind Farms \\ Modeling Simulation and Optimization}





\title{
Global Prediction of Wind Energy Market Strategy for Electricity Generation
}

\author{
Enas Raafat Maamoun Shouman
}

\begin{abstract}
Global warming and increasing electricity consumption trends in many parts of the world pose a serious challenge to most countries from a climate change and energy security perspective. Wind power is the only one that offers a mature technique, as well as promising commercial prospects, and is now generally applied in large-scale electricity generation. Continued technological improvements will assist to boost the on-shore and off-shore wind farms' ability by improving micro turbine, enhancing reliability with predictive maintenance models. At the same time, as global and regional markets for wind power technologies grow, economies of scale are being reaped in manufacturing. With increased market scale, opportunities to improve the efficiency of supply chains arise. Technological improvements and cost reductions have led wind energy to become one of the most competitive options for new generation capacity. Wind energy still has significant potential for cost reduction. Indeed, by 2025, the global weighted average levelized cost of electricity (LCOE) of onshore and offshore wind could see declines of 26 and 35\%, respectively. This chapter aims to provide an overview of the world wind energy market, current and forecasting development globally of wind energy, and LCOE historical growth Ffor wind energy.
\end{abstract}

Keywords: wind energy, market strategy, electricity, energy cost

\section{Introduction}

Sustainable development needs judicious utilization of energy sources, which are integral inputs to modern society. Renewable energy (RE) sources, such as solar, wind, biomass, etc., are of paramount importance when considering economic development.

The global renewable energy market was valued at $\$ 928.0$ billion in 2017 and is expected to reach $\$ 1512.3$ billion by 2025 , registering a compound annual growth rate (CAGR) of $6.1 \%$ from 2018 to 2025. Renewable energy technologies convert the energy from different natural sources, such as sun, tides, wind, and others, into its usable forms such as electricity [1].

The global renewable energy market is anticipated to grow significantly during the forecast period owing to increased emissions of greenhouse gases (GHGs), particularly $\mathrm{CO}_{2}$ due to utilization of fossil fuels for generation of energy. In addition, limited presence of fossil fuel on the earth as well its volatile prices fuels the 
renewable energy market. However, generation of energy from renewable sources requires huge investment. This factor is anticipated to hamper the market growth during the forecast period. Furthermore, in the Middle East, fossil fuels are majorly used to generate energy owing to its cost-effective nature as compared to other regions. This hampers the growth of the market. On the contrary, due to continuous advancement in technologies and increased government funding in renewable energy sector to offer lucrative growth opportunities during the assessment period, the renewable energy market size will be increasing because of rise in stringent government regulations regarding climate change in the developed and developing economies.

"Now that the Paris Agreement is coming into force, countries need to get serious about what they committed to last December. Meeting the Paris targets means a completely decarbonizes electricity supply well before 2050, and wind power will play the major role in getting us there," said Steve Sawyer, Global Wind Energy Councils (GWEC), Secretary General.

The increasing investment in wind energy (WE) is not only significant from the point of view of bridging the demand-supply gap but also from considering environmental issue. Currently, wind energy is one of the fastest developing RE technologies around the world including Egypt.

Wind energy dominates as an immediate viable, cost-effective option that promotes energy conservation and avoids equivalent utilization of fossil fuels and avoids millions of tons of gas emission causing ozone depletion and other environmental impacts like global warming. Wind turbines do not need any type of fuel after installation, so there are no environmental risks or degradation from the exploration, extraction, transport, shipment, processing, or disposal of fuel.

\section{Electricity and energy demand}

World energy demand is growing by over $50 \%$ and will continue to grow up to year 2030. Figure 1 shows the energy consumption per person till the year 2050. Today, climate change is a major global concern. The main cause of global warming is CO2, at least $90 \%$ of it is a result of the combustion of fossil fuels for energy generation, and it is the cause for climate change, which is the main global concern [2].

By 2050, Europe will achieve an electricity system that depends on renewable energy without carbon, so it will require the replacement of much of the existing

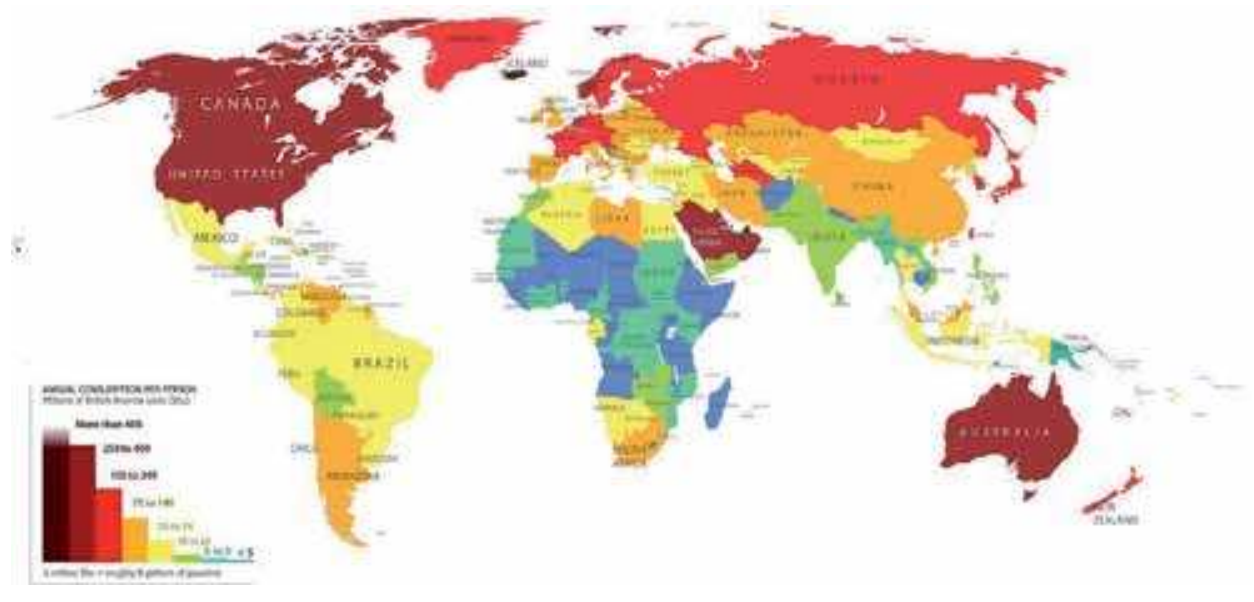

Figure 1.

Consumption of energy per person [1]. 


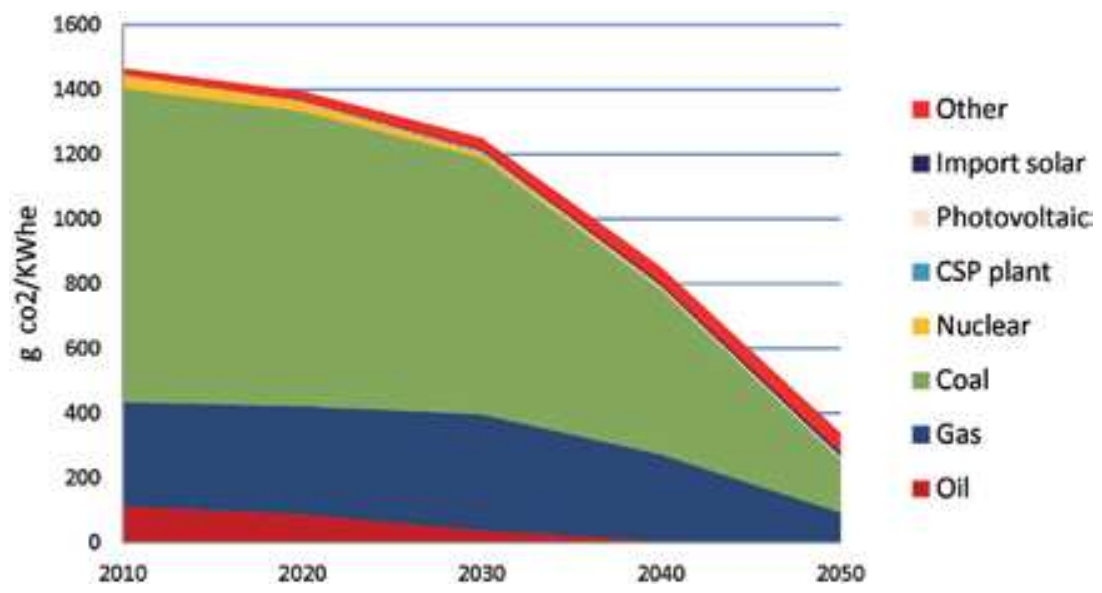

Figure 2.

$\mathrm{CO}_{2}$ emissions from the various sources of energy [3].

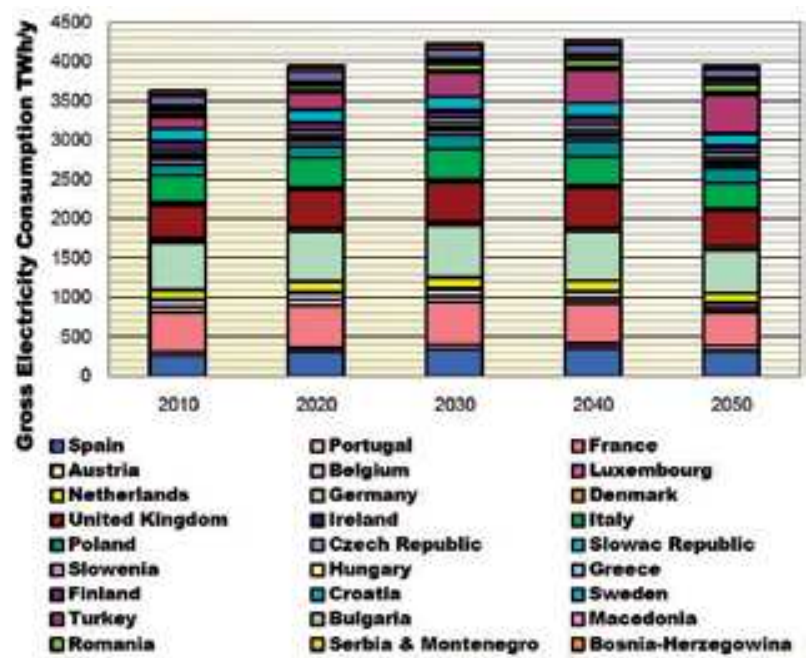

Figure 3.

Electricity consumption of the European countries analyzed between 2010 and 2050 [3].

electricity-generating capacity, and the price volatility in traditional energy has forced nearly all countries to review their energy policy (Figure 2). This is prompting countries that depend on imported fossil fuels to explore and evaluate alternative sources of energy to generate electricity [3].

In Europe, the thirty analyzed countries refer to the total electricity demand starting with roughly $3530 \mathrm{TWh} / \mathrm{y}$ in the year 2010 and will reach a maximum of $4300 \mathrm{TWh} / \mathrm{y}$ in 2040 [2]. Figure 3 represents the expected future electricity demand in Europe to 2050 that is available to cover the demand with a surplus of $45 \%[3]$.

\section{Wind energy market forecasting}

The annual market will expect to grow in 2020, breaching the $60 \mathrm{GW}$, and continue to grow in the beginning of the new decade. And the total cumulative installations will reach 840 GW by the end of 2022 (Figures 4 and 5) [4]. 


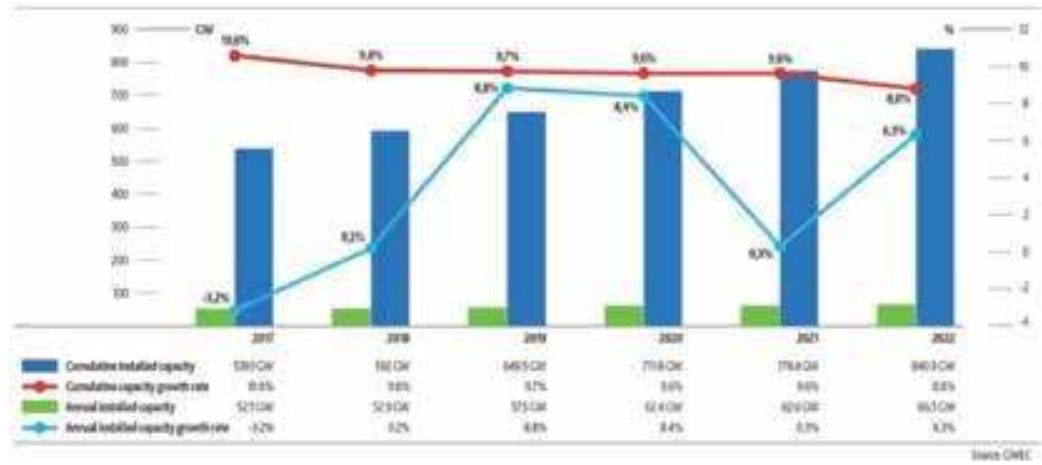

Figure 4.

Current and forecast market wind energy 2018-2022 [4].

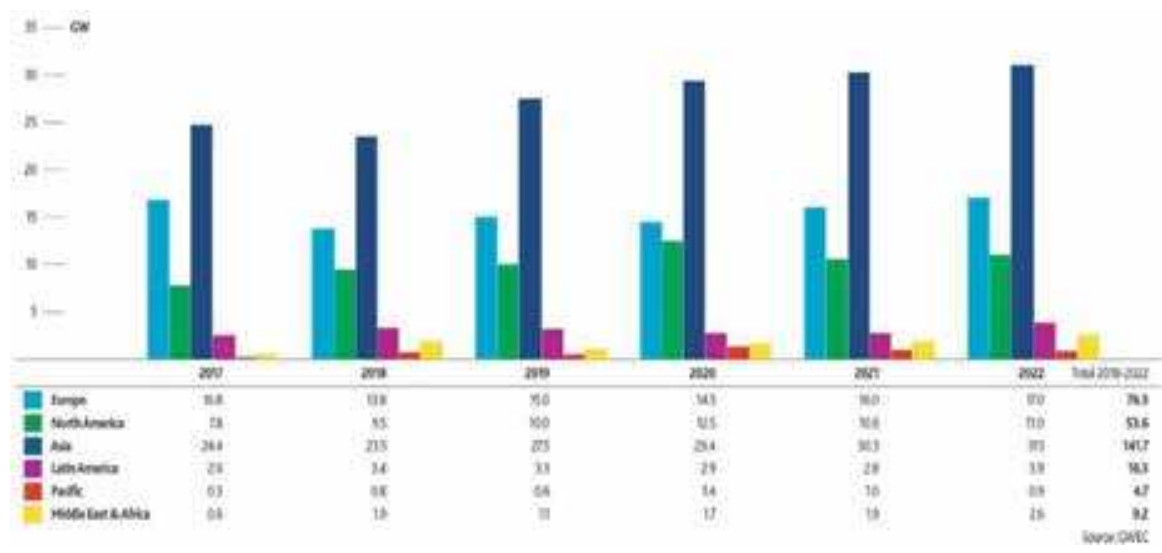

Figure 5.

Annual market forecast by region 2018-2022 (GW) [4].

\begin{tabular}{|c|c|c|}
\hline Europe today: & & Europe in 2030: \\
\hline 47,000 & $\begin{array}{l}\text { mose } \\
\text { turbinos: }\end{array}$ & 90,000 \\
\hline $\begin{array}{l}\text { turbines } \\
\text { generate }\end{array}$ & & $\begin{array}{l}\text { turbines could } \\
\text { generate }\end{array}$ \\
\hline $\begin{array}{l}83 \mathrm{TWh} \\
\text { meeting }\end{array}$ & $\begin{array}{l}\text { eicetricity } \\
\text { generated }\end{array}$ & $\begin{array}{l}965 \mathrm{TWh} \\
\text { meeting }\end{array}$ \\
\hline $\begin{array}{l}2,8 \% \\
\text { of European } \\
\text { power demand }\end{array}$ & $\begin{array}{l}\text { B2: } \\
\text { more powor } \\
\text { aceds for } \\
\text { Eloropi: }\end{array}$ & $\begin{array}{l}23 \% \\
\text { of European } \\
\text { power demand }\end{array}$ \\
\hline
\end{tabular}

Figure 6.

More power from fewer turbines in Europe.

Europe intended to estimate installation of 47,000 wind turbines at the end of 2005. In 2004, the average size of turbines delivered to the market was about 1.3 and 2.1 MW for onshore and offshore, respectively (Figure 6). By 2030, the assumption of average size of a wind turbine will be $2 \mathrm{MW}$ onshore and $10 \mathrm{MW}$ offshore, and only 90,000 turbines (75,000 onshore and 15,000 offshore) would be needed to fulfill the $300 \mathrm{GW}$ target.

By 2030, Germany expects to have 15,000 MW of offshore wind capacity. The Economy Japanese Ministry, Trade and Industry (METI) has assumed a demand of wind power at $10 \mathrm{GW}$, which is including $820 \mathrm{MW}$ offshore wind power by 
2030, in its future energy plan called the Energy Mix Plan, which was released in 2015. The Japan Wind Power Association (JWPA) has requested a more aggressive target for wind power, calling for $36.2 \mathrm{GW}$ by 2030, including $10 \mathrm{GW}$ of offshore [5].

The Dutch government has intended to install $6000 \mathrm{MW}$ of onshore wind energy power by 2020 and $4500 \mathrm{MW}$ of offshore wind energy power by 2023. By 2030, the Dutch Wind Energy Association (NWEA) will estimate to reach 15 and 18.5 GW of onshore and offshore wind energy, respectively [4].

Taiwan's initial offshore wind target of $3 \mathrm{GW}$ by 2025 was quickly exceeded by oversubscription of projects proposed by developers, which led to an upward adjustment of the target in 2017 to $5.5 \mathrm{GW}$ by 2025. The target of $520 \mathrm{MW}$ by 2020 was maintained, while the target for 2030 was raised to $17 \mathrm{GW}$ [3].

South Korea aims to triple the share of renewable energy in the country's power mix by 2030, which translates to adding about $47 \mathrm{GW}$ of new wind and solar capacity, according to the government's latest draft policy roadmap.

New York State has become the new climate leader in the US, after California, with a series of government measures and targets being introduced to boost the clean energy industry. An offshore wind target has been set at $2.4 \mathrm{GW}$ by 2030. In January 2018, New York State also released its long-awaited Offshore Wind Master Plan, encompassing 20 in-depth studies on a variety of factors that will affect the state's ability to reach its $2.4 \mathrm{GW}$ offshore wind target by 2030 [6].

The Vietnamese government has set a target for wind development at $800 \mathrm{MW}$ by 2020, 2000 MW by 2025, and 6000 MW by 2030 [6].

By 2030, wind power could reach $2110 \mathrm{GW}$ and supply up to $20 \%$ of global electricity, creating 2.4 million new jobs and reducing $\mathrm{CO}_{2}$ emissions by more than 3.3 billion tons per year, and attract annual investment of about $€ 200$ billion [7].

2018 is a solid year with a total installed capacity of $51.3 \mathrm{GW}$, which decreased $4.0 \%$ over the previous year and reached total installed capacity of $591 \mathrm{GW}$ (9\% more than 2017). In the onshore wind energy market, new plants reached 46.8 and 4.5 GW was installed in the global offshore market, bringing the global share to $8 \%$. The Chinese onshore market installed $21.2 \mathrm{GW}$ in 2018 and has been the market leader since 2008. China is the first market to exceed $200 \mathrm{GW}$ of total installed capacities at the end of 2018, achieving the target of 200 GW 2 years early (based on the 5 Year Plan 2016-2020), with 206 GW of total installations [5].

The second-largest market in the US in 2018 was with $7.6 \mathrm{GW}$ of new onshore installations and $96 \mathrm{GW}$ total onshore installations. Future demand will be linked to RPS and increasing onshore wind power competitiveness by 2020 and 2030. In the US market, new financial models will most likely drive the volume of new installations further: Germany will be the top five wind markets with $2.4 \mathrm{GW}$ in 2018, India with 2.2 GW, and Brazil with 1.9 GW in addition to the USA and China. Figure 7 shows the top 5 wind energy markets, and Figure 8 shows the global wind energy consumption beside renewable energy in 2017-2023 [8].

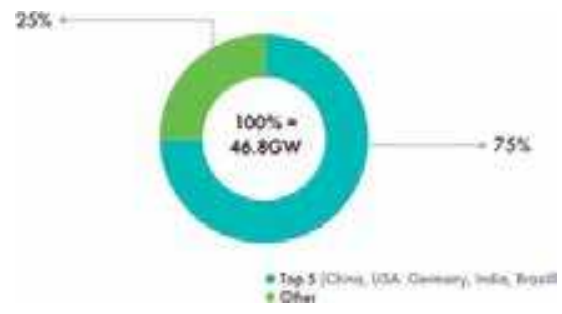

Figure 7 .

New capacity in 2018 and share of top five wind energy markets [8]. 


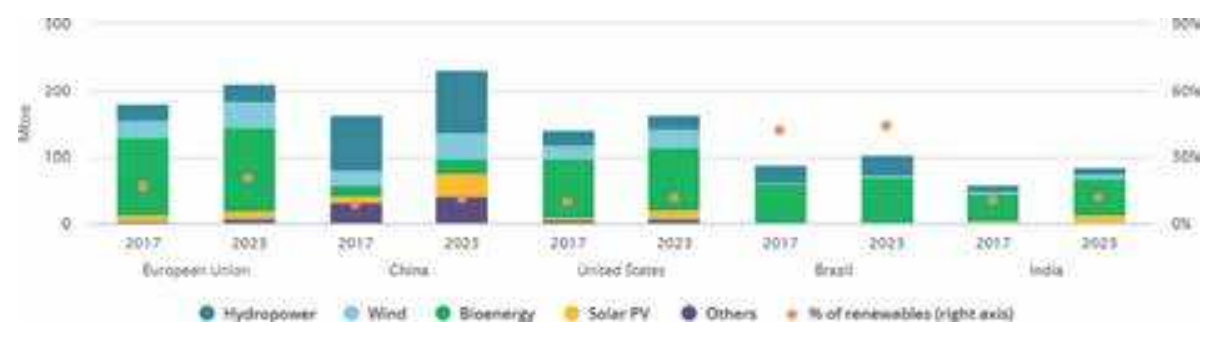

Figure 8.

Wind energy beside renewable energy consumption in major markers, 2017-2023 [8].

\section{Wind power deployment globally out to 2020-2030}

At the end of 2015, the globally total installed onshore wind energy capacity reached to $420 \mathrm{GW}$ [9]. Cumulative installed capacity has increased to $25 \%$ /year over the last decade. At the end of 2015, China maintained the largest share of onshore wind energy capacity in the world, at 34\%. This is followed by the United States, which share with 17\%; Germany, 10\%; India, 6\%; and Spain, 5\%. Onshore wind energy has set a record of $59 \mathrm{GW}$ in 2015, which is twice as high as in 2014. In 2015 , China accounted for $51 \%$ of global new additions, followed by the USA with 13\%; Germany, 6\%; Brazil 5\%; and India, 4\%. Strong growth in China about 30 GW and the United States about $7.7 \mathrm{GW}$ accounted for around $63 \%$ of net additions in 2015 [9].

China is expected to add more than $20 \mathrm{GW}$ a year from 2016 to 2020 [10]. With policy support renewed for the medium-term, the United States will add on average more than 7 GW a year up to 2020 [11]. In 2015, Brazil had a solid installation record around $2.8 \mathrm{GW}$ and is set to continue installing more than $2.5 \mathrm{GW}$ a year, and Germany installed more than $3.5 \mathrm{GW}$ of onshore wind energy in the same year [12].

The world installed $46.8 \mathrm{GW}$ of onshore wind energy turbines last year, down by $3.9 \%$ from 2017 , and $4.49 \mathrm{GW}$ of offshore wind farms, up by $0.5 \%$. China led growth in both cases, installing $21.2 \mathrm{GW}$ onshore and 1.8 GW offshore. For the first time, it built more offshore wind capacity than any other country. Table 1 shows the top five onshore wind energy and offshore wind markets in 2018 [13].

The 2018 total of $51.3 \mathrm{GW}$, a decrease of 3.6\% year-on-year, boosted the cumulative global wind power generation capacity to $591 \mathrm{GW}$. Energy is fundamental to any economy; wind energy can be a driver for European growth. With the right kind of investment and collaboration, electricity production from wind for European electricity consumption could raise from 83 TWh to 965 TWh from 2005 to 2030, respectively, supplying 23\% of European electricity. This projection takes into account that consumption is expected to increase by half over the same

\begin{tabular}{lccc}
\hline Top onshore markets in 2018 & $\begin{array}{l}\text { MW } \\
\text { built }\end{array}$ & Top offshore markets in 2018 & MW built \\
\hline China & 21,200 & China & 1800 \\
\hline USA & 7588 & United Kingdom & 1312 \\
\hline Germany & 2402 & Germany & 969 \\
\hline India & 2191 & Belgium & 309 \\
\hline Brazil & 1939 & Denmark & 61 \\
\hline
\end{tabular}

Table 1.

Top five onshore wind energy and offshore wind markets in 2018 [13]. 
period [14]. Figure 9 shows wind energy contribution to European electricity consumption in 2005-2030 [15].

Offshore wind has reached maturity in Europe, and costs have decreased decisively, with committed projects scheduled to start generating in the early 2020s likely to produce at a levelized cost of energy (LCOE) below €70/MWh by 2017 prices, including the cost of offshore and onshore grid connection. This has lead to increased confidence in the deployment of offshore wind around the world. By 2030, the forecasting for total installed capacity will be $120 \mathrm{GW}$, with an installation rate of over $10 \mathrm{GW} /$ year being achieved before then. Much of this growth will come in Europe, building on the established capability and proven low cost. The significant capacity in China and the US will be smaller than significant volumes in Japan, Taiwan, and South Korea. By 2030, LCOEs below €60/MWh will be achieved by many newly installed offshore wind farms, which could be well below the average wholesale power price in many electricity networks, driving higher levels of deployment and the spread to currently uncharted waters.

Floating offshore wind has seen the first multiturbine demonstration project, but floating is likely to remain a niche sector throughout the 2020s. It will become cost-competitive by the end of the decade, giving it strong potential in the 2030s, especially through enabling new markets. Early deployment of floating offshore wind projects needs support mechanisms in multiple markets specifically targeted at enabling commercial-scale floating deployment. France and Japan are the most likely candidates, assuming governments are able to see clear long-term benefits. On this basis, the expectation of floating deployment will exceed $500 \mathrm{MW}$ a year by 2026, increasing to over $1 \mathrm{GW}$ a year by 2030 to give a total installed capacity of over $5 \mathrm{GW}, 5 \%$ of the offshore market. In addition to France and Japan, commercial floating projects are also likely in Korea, Taiwan, the UK, and the US by 2030. If cost reductions are achieved quicker than currently expected and floating becomes cost effective much faster, the market could really 'take off' with up to $12 \mathrm{GW}$ installed by the end of 2030, setting the 2030s up for substantial further global offshore wind deployment [14].

The European Commission assumes that the cost of onshore wind power will decrease to $€ 826 / \mathrm{kW}$ and $€ 788 / \mathrm{kW}$, respectively between 2020 and 2030 in its renewable energy roadmap [16].

Figure 10 shows the estimates of the European Commission on offshore and onshore cost capacity development by 2030, reflecting the capacity expenditure of wind turbine price effects in recent years. Figure 11 shows the expected annual wind power investments from 2000 to 2030, based on the European Wind Energy Association's scenarios $[17,18]$ at the price of $€ 1300$ per $\mathrm{kW}$ onshore wind farms and offshore prices of $€ 2300$ per KW. The sharp rise in offshore wind costs reflects
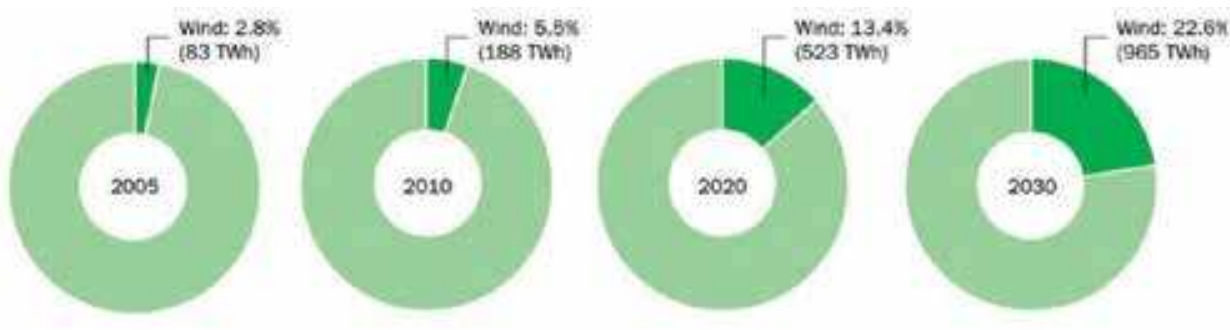

Wrid (GW instaled)

Figure 9.

Contribution of wind energy to European electricity consumption, 2005-2030 [15]. 


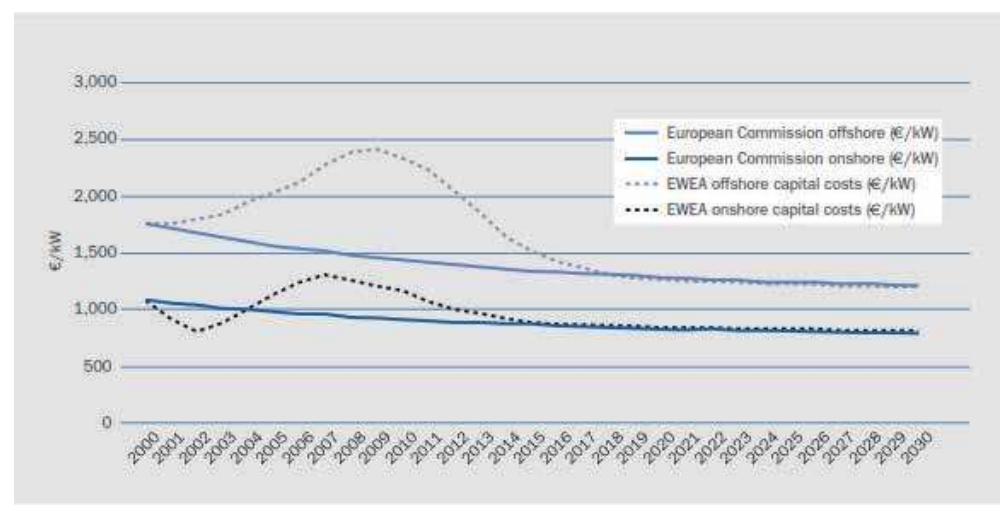

Figure 10.

Cost of onshore and offshore wind $(€ / k W)$ European Commission/EWEA assumptions [17, 18].

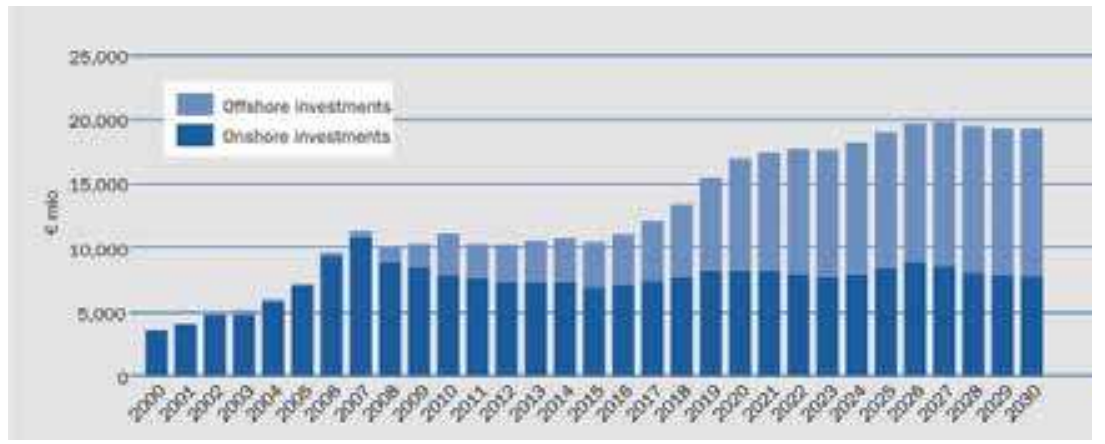

Figure 11.

Wind energy investments, 2000-2030 (€mio.) [17, 18].

the few producers in the overseas market, the lack of economies of scale as a result of low market deployment, and supply chain bottlenecks [14].

By 2020, the annual wind energy market will have increased to $€ 17$ billion per year. About half of the investments go offshore. Annual wind energy investment in the EU-27 will reach $€ 20$ billion by 2030 , with $60 \%$ of offshore wind energy investments [11].

GWEC said it expects stable capacity additions from mature regions in Europe and the US in the next few years. Significant growth is also forecast to come from developing markets in South East Asia and the global offshore market.

Globally, offshore wind deployment is to reach up to 7-8 GW during 2022 and 2023 [19], and offshore wind energy installations in Asia could surpass 5 GW per year if governments remain committed and projects and investments continue. The US offshore wind market is seen to hit 1 GW by 2022-2023 [20].

\section{Wind energy economics}

One of the main economic advantages of wind power is that it reduces economic volatility of fuel prices. Table 2 shows cost structure of a typical $2 \mathrm{MW}$ wind turbine installed in Europe (2006) [16].

The rapid European and global development of wind power capacity has had a strong influence on the cost of wind power over the last 20 years. To illustrate the trend toward lower production costs of wind-generated power, a case in Figure 12 


\begin{tabular}{|c|c|c|}
\hline & $\begin{array}{l}\text { INVESTMENT } \\
(€ 1,000 / \mathrm{MW})\end{array}$ & $\begin{array}{l}\text { SHARE OF } \\
\text { TOTAL } \\
\text { COST } \%\end{array}$ \\
\hline Turbine (ex works) & 928 & 75.6 \\
\hline Grid connection & 109 & 8.9 \\
\hline Foundation & 80 & 6.5 \\
\hline Land rent & 48 & 3.9 \\
\hline Electric installation & 18 & 1.5 \\
\hline Consultancy & 15 & 1.2 \\
\hline Financial costs & 15 & 1.2 \\
\hline Road construction & 11 & 0.9 \\
\hline Control systems & 4 & 0.3 \\
\hline TOTAL & 1,227 & 100 \\
\hline
\end{tabular}

Table 2.

Cost structure of a typical 2 MW wind turbine installed in Europe (2006) [16].

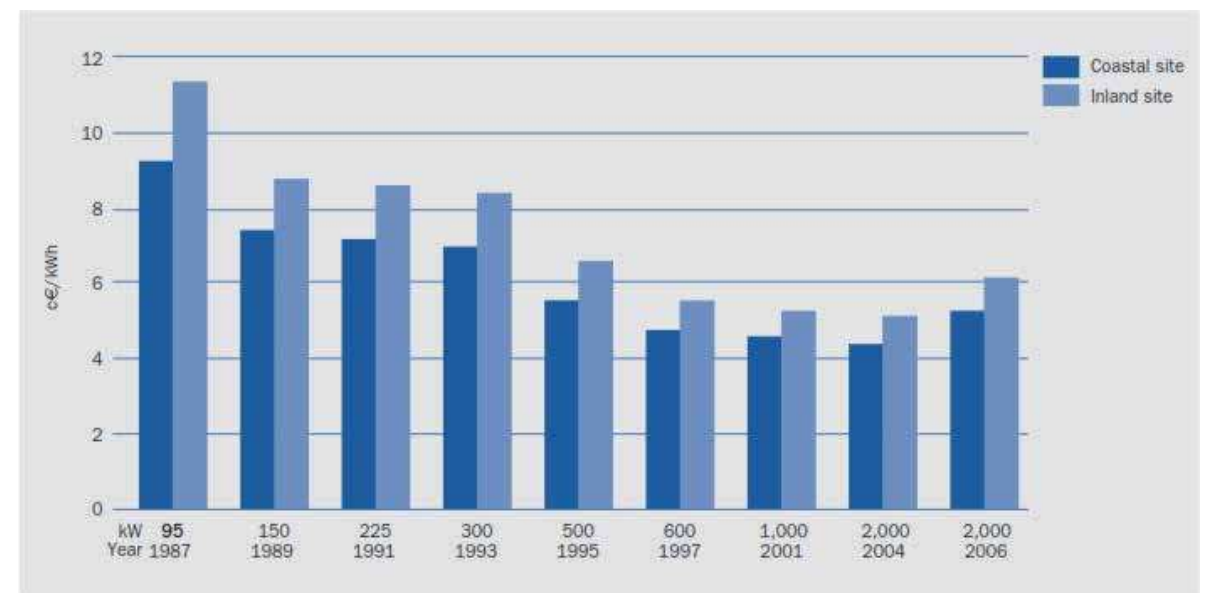

Figure 12.

Total wind energy costs per unit of electricity produced, by turbine size (c€/kWh, constant € prices), and assuming a $7.5 \%$ discount rate [21].

that shows the production costs for different sizes and models of turbines is presented, which are constructed for Denmark [21].

The economic consequences of the trend toward larger turbines and improved cost-effectiveness are clear. For a coastal site, for example, the average cost of the turbine (mainly installed in the mid-1980s) has dropped from around $9.2 \mathrm{c} € / \mathrm{kWh}$ to approximately $5.3 \mathrm{c} € / \mathrm{kWh}$ for a relatively fresh $2.000 \mathrm{~kW}$, an improvement of more than $40 \%$ in 2006 [21].

The estimated progress ratios range from 0.83 to 0.91 , which corresponds with the learning rates of 0.17 to 0.09 based on special energy expenses (expenses per $\mathrm{kWh}$ generated). This means that if the total wind power installed doubles, the cost per $\mathrm{kWh}$ produced for new turbines decreases by 9 to $17 \%$ [22].

The total installed wind turbines worldwide account for a small amount of offshore wind: about 1\%. In the northern European countries of the North sea and the Baltic Sea, there have primarily been developments in offshore winds, with approximately 20 projects implemented. The capability was located offshore at the end of 2008 at $1471 \mathrm{MW}$ [23]. 
Offshore wind capacity is still approximately 50\% higher than onshore wind. However, with higher wind speeds and a lower visual impact on large turbines expected to benefit, several countries-mainly in the Member States of the European Union-have ambitious off shore wind goals.

While investments in offshore energy farms are significantly higher than those in the onshore wind farms, the overall electrical output from turbines is partially offset, given the high offshore wind speeds. The energy production indicator normally amounts to approximately 2000 to 2500 full charge hours annually for onshore operations, while the figure for a typical offshore facility reaches up to four thousand full charge hours per year, according to location [24].

The market remained stable with an estimated $€ 10$ billion per year until 2015, and investment in the offshore market gradually increased. By 2020, the wind power annual market will have grown to $€ 17$ billion per year, with roughly half of the offshore investment. By 2030, annual EU investments in wind energy are expected to reach nearly $€ 20$ billion with $60 \%$ of offshore investment [25].

\subsection{Wind energy investments and total avoided lifetime cost for the fuel and emission of $\mathrm{CO}_{2}$}

In the reference price equivalent of $\$ 118 /$ barrel in 2010 for natural gas, the price of coal is expected to double, and the price of $\mathrm{CO}_{2}$ is expected to increase by $50 \%$ and by $35 € / t$ in 2008 to $60 € / t$ [26]. Figure 13 shows sensitivity analysis of costs of generated power comparing conventional plants to wind power, assuming increasing fossil fuel and $\mathrm{CO}_{2}[15,27]$.

To determine the amount of $\mathrm{CO}_{2}$ and fuel costs avoided from wind turbine investments over the entire life of a given year, it is important to remember that in a given year, investment in wind energy capacity will continue to avoid fuel cost and carbon costs over the 20 to 25 years of life of wind turbines. Wind farms installed throughout 2030 will continue, for example, to avoid costs until and after 2050. Figure 14 shows the total costs of $\mathrm{CO}_{2}$ and fuel avoided during the lifetime of the installed wind turbine capacitance of 2008-2030, taking into consideration the technical life of onshore wind power turbines of 20 years and offshore wind turbines of 25 years in accordance with EWEA reference scenarios [22]. It is also presumed that the average price of a $\mathrm{CO}_{2}$ allowance for wind energy is $€ 25 / \mathrm{tCO}_{2}$, and $€ 42$ million in fuel is prevented for every TWh of wind power, which is the

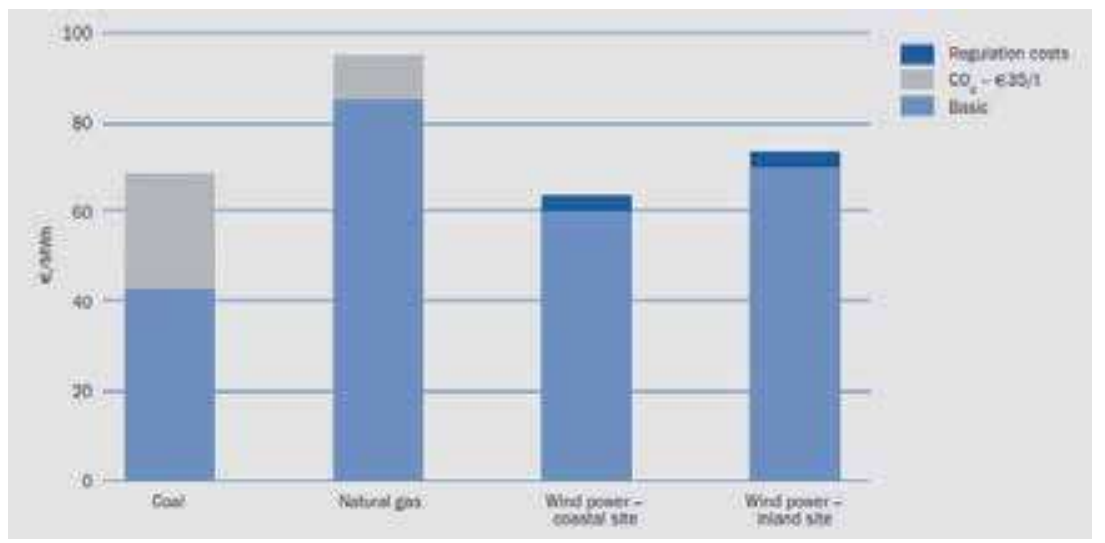

Figure 13.

Sensitivity analysis of costs of generated power comparing conventional plants to wind power, assuming increasing fossil fuel and $\mathrm{CO}_{2}[15,27]$. 
equivalent of $€ 90$ per barrel of oil during the period. The average cost of the allowance for $\mathrm{CO}_{2}$ is $€ 42$ million. For example, the $8554 \mathrm{MW}$ of wind energy installed in the EU in 2007 had an investment value of $€ 11,3$ billion and will avoid $€ 6,6$ billion of $\mathrm{CO}_{2}$ emissions over the whole lifetime and $€ 16$ billion in the cost of fuel, assuming an average $\mathrm{CO}_{2}$ cost of $€ 25$ per ton and an average price of fuel for gas, coal, and oil based on $\$ 90 /$ barrel of oil. Likewise, between 2008 and 2020, the $€ 152$ billion investment in wind power will avoid $\mathrm{CO}_{2}$ cost of $€ 135$ billion and fuel costs of $€ 328$ billion in the same way. Wind energy expenditure of $€ 339$ billion is avoiding $€ 322$ billion of $\mathrm{CO}_{2}$ and $€ 783$ billion of fuel for the period up to 2030 .

As price reductions on wind, solar, and other renewables drop dramatically in recent years, energy decarburization is not only technically feasible but also economically competitive. African, Asian, and Latin American markets are quickly evolving, providing clean energy to promote sustainable development.

The IEA has amended its assumptions, both fuel prices and building costs, in its 2008 edition of World Energy Outlook. It therefore increased its new building cost estimates. It was also assumed for the EU that a $\$ 30$ carbon price per ton of $\mathrm{CO}_{2}$ would add $\$ 30 / \mathrm{MWh}$ to coal production and that it could generate $\$ 15 / \mathrm{MWh}$ to combined cycle gas turbines (CCGT)-generated plants. Figure 15 shows the assumption of the IEA that in 2015 and 2030 new coal, gas, and wind power will

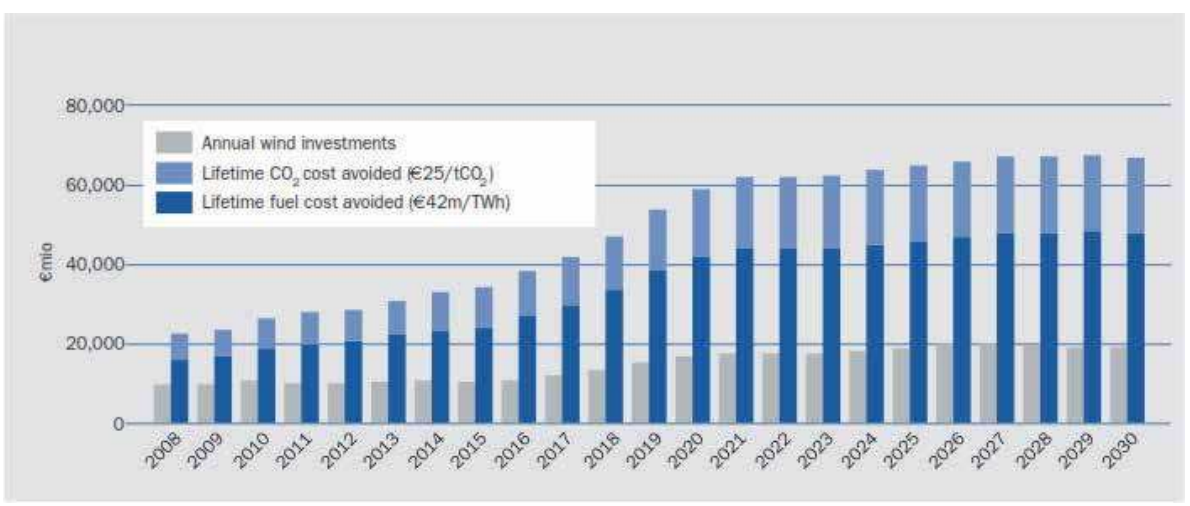

Figure 14 .

Wind investments compared with lifetime avoided fuel and $\mathrm{CO}_{2}$.

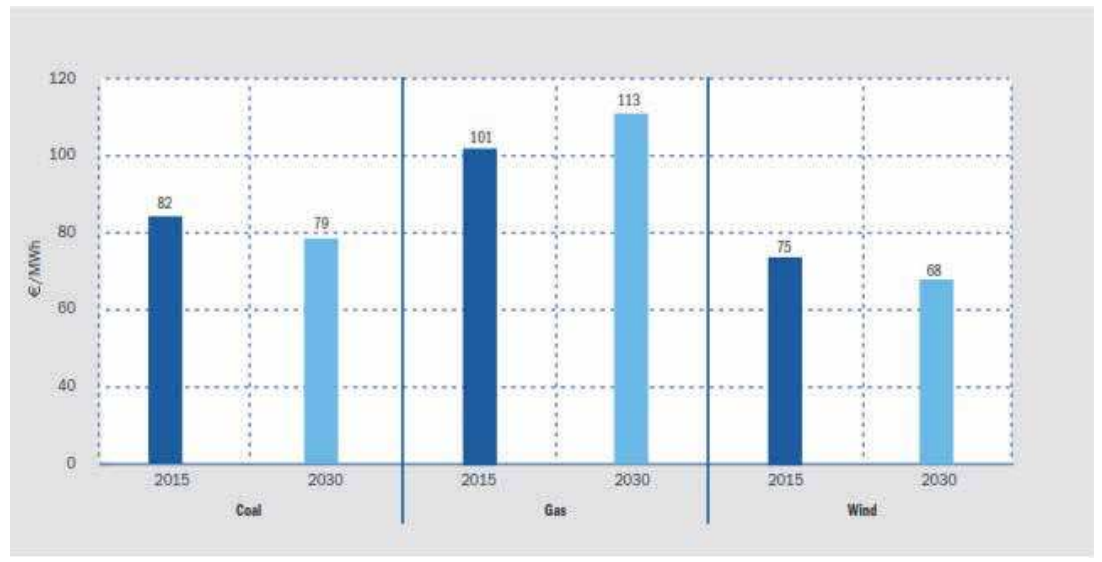

Figure 15.

Costs of electricity generating in the EU, 2015 to 2030. 
generate future costs in the EU. It shows that the IEA expects new wind capacity in 2015 and 2030 to be cheaper than coal and gas [28, 29].

\subsection{Wind power cost for electricity production}

Conventional electricity production general cost is determined by four components:

1. Fuel cost

2. $\mathrm{CO}_{2}$ emissions cost

\section{Cost of O\&M}

\section{Investment costs, planning, and construction work}

The capital costs of wind energy projects are dominated by the cost of the wind turbine itself. Figure 16 shows the typical cost structure for wind energy [22].

The share of the turbine costs is around $76 \%$, while the grid link accounts for around $9 \%$ and the base for around $7 \%$. The costs of obtaining a turbine site differ greatly from one project to the next, so the information provided in Table 3 is an instance. Other cost elements, such as land and control systems, represent only a small proportion of total expenses.

The total cost per $\mathrm{kW}$ of installed wind power varies greatly from country to country and the costs per $\mathrm{kW}$ were the lowest in Denmark and somewhat higher in Greece and the Netherlands, as shown in Figure 17 [31]. Typically, the cost per $\mathrm{kW}$ varies between $€ 1000 / \mathrm{kW}$ and $€ 1350 / \mathrm{kW}$. It should, however, be noted that Figure 17 is based on limited data so the findings for the countries mentioned may not be fully representative. In addition, there are significant variances among nations in "other expenses," such as foundation and grid connection, which vary from approximately $32 \%$ of total turbine expenses in Portugal, about $24 \%$ in Germany, about $21 \%$ in Italy, and only about $16 \%$ in Denmark. Cost varies however

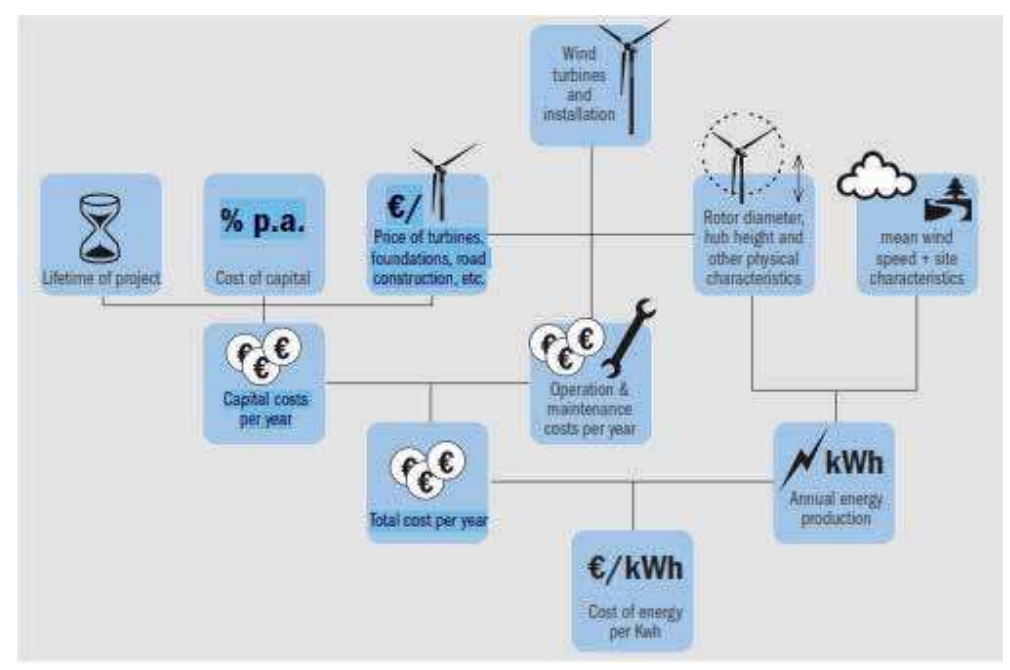

Figure 16.

Cost of wind energy. 


\begin{tabular}{|l|c|c|}
\hline & $\begin{array}{c}\text { SHARE } \\
\text { OF TOTAL } \\
\text { COST (\%) }\end{array}$ & $\begin{array}{c}\text { TYPICAL } \\
\text { SHARE OF } \\
\text { OTHER COST } \\
(\%)\end{array}$ \\
\hline Turbine (ex works) & $68-84$ & - \\
\hline Grid connection & $2-10$ & $35-45$ \\
\hline Foundation & $1-9$ & $20-25$ \\
\hline Electric installation & $1-9$ & $10-15$ \\
\hline Land & $1-5$ & $5-10$ \\
\hline Financial costs & $1-5$ & $5-10$ \\
\hline Road construction & $1-5$ & $5-10$ \\
\hline Consultancy & $1-3$ & $5-10$ \\
\hline
\end{tabular}

Table 3.

Medium-sized wind turbine cost structure [30].

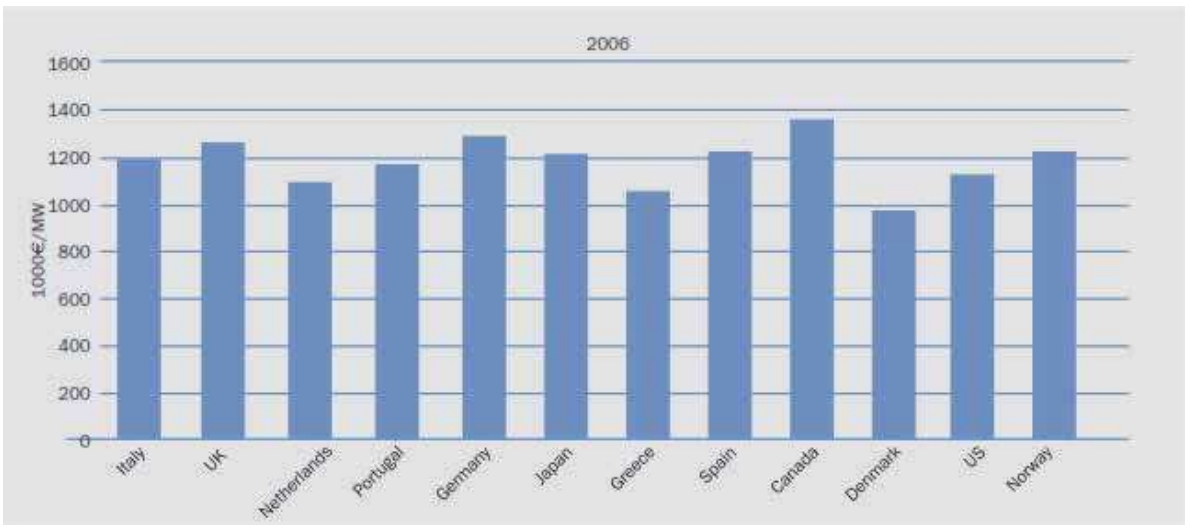

Figure 17.

Total investment cost, including turbine, foundation, and grid connection, shown for different turbine sizes and countries of installation [31].

depending on the size of the turbine and the nation of installation, grid distance, property ownership, and soil nature [31].

The typical ranges of these other cost components as a share of the total additional costs are shown in Table 3 [30]. The only major extra aspect in terms of variation is the cost of the grid connection, which in certain instances can account for almost half of the auxiliary expenses, followed by typically lower shares of the basic and electrical installation expenses. These subsidiary costs can therefore add up to the overall turbine costs to significant amounts. Cost elements, such as consultancy and land, usually account for only a small share of extra costs.

\subsection{Levelized cost of energy}

\subsubsection{Estimation of the LCOE}

The LCOE energy cost, also known as the levelized electricity cost, is an economic evaluation of the average overall cost of building and operating an energy generation system over its lifetime divided by overall system power over this lifetime [1]. LCOE is the definition of the price that will be equivalent to the total 
life-cycle cost (LCC), if it is allocated to each unit of energy generated by the device during the analysis period [32].

$$
L C O E=\frac{\sum_{t=1}^{n} \frac{I_{t}+M_{t}+F_{t}}{(1+r)^{t}}}{\sum_{t=1}^{n} \frac{E_{t}}{(1+r)^{t}}}
$$

where LCOE is the average lifetime levelized cost of electricity generation, It is the year $t$ investment expenditures, Mt. is the year $\mathrm{t}(\mathrm{O} \& \mathrm{M})$ expenditures, Ft is the year $t$ fuel expenditures, Et is the year t electricity generation, $r$ is the discount rate, and $\mathrm{n}$ is the system lifetime.

The LCOE of a wind power project is determined by total capital costs:

- Wind resource quality

- Wind turbines' technical characteristics

- O\&M costs

- Economic life of the project and the cost of capital

As with today's range of installed costs, the LCOE also varies by country and region. Figure 18 presents cost metrics contributing to the calculation of the LCOE [32].

\subsection{LCOE historical growth for wind energy}

By depending on one of the most significant steps within the power sector, levelized cost of electricity (LCOE), the wind sector can demonstrate its growing maturity, price competitiveness, and effectiveness.

For several years, LCOE has been the common measure to define wind and other power sources' price. Industry stakeholders and politicians use LCOE to evaluate objectives and levels of support.

LCOE's important role will not change and will continue to show the progress of wind power. With the aid of LCOE, wind energy is one of the cheapest sources of energy. As the energy industry is changing, the scope is expanding and wind energy is now also offering maximum system value. This enhanced emphasis on value comprises the knowledge of an energy source's effectiveness, how to integrate an

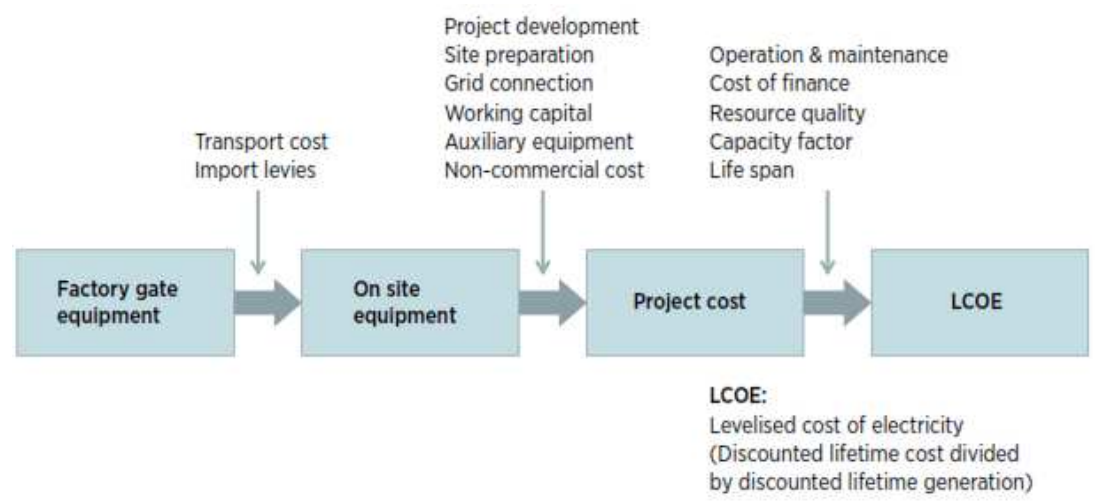

Figure 18.

Cost metrics contributing to the calculation of the LCOE [32]. 


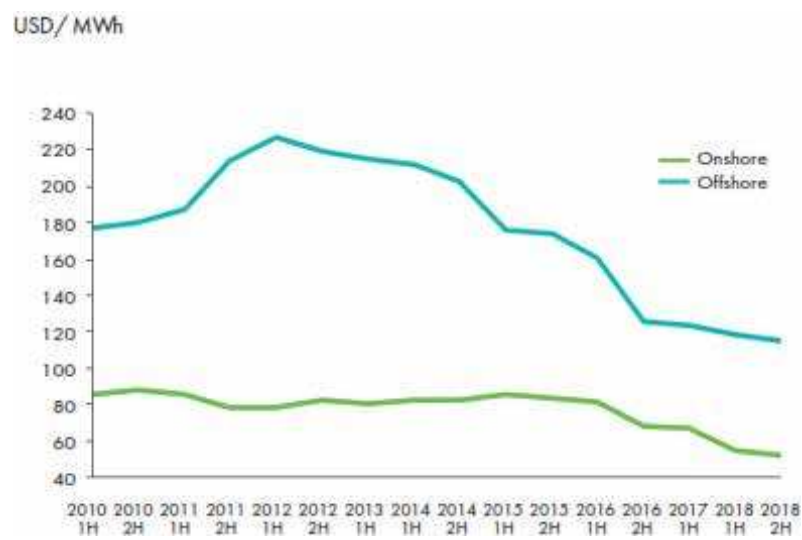

Figure 19.

LCOE-historical development [34].

energy source, and the time frame for supply and demand [33]. Figure 19 depicts LCOE-onshore and offshore wind power historical growth.

The weighted average LCOE for onshore by country or region ranged from $\$ 0.053 / \mathrm{kWh}$ in China to $\$ 0.12 / \mathrm{kWh}$ in Asia. North America had the second lowest LCOE after China, with $\$ 0.06 / \mathrm{kWh}$. Eurasia $(\$ 0.08 / \mathrm{kWh})$, Europe $(\$ 0.07 / \mathrm{kWh})$, and India $(\$ 0.08 / \mathrm{kWh})$ had slightly higher average LCOEs than China and North America. Onshore wind energy is a highly competitive source of renewable energy generation capacity, with low and medium wind speeds becoming economically competitive [35].

The potential improvement in capacity factors by 2025 could result in reducing the global weighted average LCOE of onshore wind energy by around $\$ 0.01 / \mathrm{kWh}$, or $49 \%$ of the total projected reduction in onshore wind LCOE of $\$ 0.018 / \mathrm{kWh}$ as the global weighted average LCOE falls to $\$ 0.053 / \mathrm{kWh}$ by 2025 [35].

Reductions in total installed costs, driven mostly by cost reductions for towers, turbines, and wind farm development, contribute around $\$ 0.006 / \mathrm{kWh}$ or $34 \%$ of the total reduction in the LCOE. Improvements in turbine reliability, improved predictive maintenance schedules, and the more widespread application of best practice (O\&M) strategies reduce the LCOE by around $\$ 0.003 / \mathrm{kWh}$ by 2025 , or $17 \%$ of the total reduction [35].

\section{Current and predicted LCOE for wind power}

In 2018, the global weighted-average LCOE commissioned onshore wind energy projects, at $\$ 0.056 / \mathrm{kWh}$, was $13 \%$ below 2017's level and 35\% below 2010, when it was at $\$ 0.085 / \mathrm{kWh}$. The onshore wind electricity expenses are now at the lesser end of the price range of fossil fuel [36].

The continuous reduction of total installed expenses and the improvement of the average capacity factor led to electricity expenses to lower onshore wind energy in 2018, as in Figure 20. Continuous improvements in turbine design and production, competitive worldwide supply chains, and a growing variety of turbines intended to minimize LCOE in a range of working circumstances are key drivers of this trend, with rises of 18.5 and $6.8 \mathrm{GW}$, respectively; China and the United States accounted for the largest development in onshore wind power. GW or greater capacity additions have endorsed deployment in Brazil, around 2.1 GW; France 1.6 GW; Germany about 2.7 GW; and India, 2.4 GW, respectively [37]. 
The LCOE's worldwide weighted average of 13\% decrease in 2018 relative to 2017 represents a culmination of a large number of countries' experiences. The weighted average LCOE in 2018 in China and the United States for newly commissioned wind farms was 4\% lower than in 2017, as Figure 21. However, both India and Brazil faced slight increases in the weighted average LCOE for 2018 projects, partly due to currency weaknesses in the last several years. Such rises are also motivated by an estimated average slightly reduced weighted lifetime factor for projects started in 2018 [36].

Onshore wind farms operated in China and the USA in 2018 had the same weighted average LCOE of $\$ 0.048 / \mathrm{kWh}$. While China has lower capacities than the USA, lower installed costs offset this. In 2018, the average LCOE weighted onshore wind farms commissioned in Brazil was $\$ 0.061 / \mathrm{kWh}$; in France, it was $\$ 0.076 /$ $\mathrm{kWh}$; in Germany, it was $\$ 0.075 \%$; in India, it was $\$ 0.062 / \mathrm{kWh}$; and in the UK, it was $\$ 0.063 / \mathrm{kWh}[38]$.

The number of LCOE projects that have been commissioned with a volume from $\$ 0.03$ to $\$ .04 / \mathrm{kWh}$ has increased since 2014 . The combinations of competitive installed costs in regions with excellent wind resources are becoming an increasing proportion of new installations in some markets. The projects are much cheaper than even the cheapest fossil fuel-fired options for new energy production, and the variable operating costs of certain existing generators of fossil fuel are undercut.

The global weighted average total installed cost for onshore wind farms decreased by $6 \%$ year-on-year from $\$ 1600 / \mathrm{kW}$ in 2017 to $\$ 1500 / \mathrm{kW}$ in 2018 , when price rates for wind turbines continued to drop. The reduction in total installation costs still depends on reductions in wind turbine prices. Figure 22 shows wind turbine price indices and price trends, 1997-2018, which decreased by around 10 to $20 \%$ between 2017 and 2018 and also on reductions in the project cost balance. Improved technical and process technologies, regional infrastructure, and competitive supply chains all contribute to keeping turbine pricing under pressure [39, 40].

The average turbine prices of 2018, China and India excluded, varied between $\$ 790$ and $\$ 900$ per kW and decreased between $\$ 910$ and 1050/kW in 2017, respectively. In 2018 for the onshore wind farms installed in China, there was approximately $\$ 1170 / \mathrm{kW}$, approximately $\$ 1200 / \mathrm{kW}$ in India, around $\$ 1660 / \mathrm{kW}$ in the United States, $\$ 1820 / \mathrm{kW}$ in Brazil, approximately $\$ 1830 / \mathrm{kW}$ in Germany, and around $\$ 2030 / \mathrm{kW}$ in Europe that shows in Figure 23. Australia added $940 \mathrm{MW}$ and installed costs were a competitive $1640 \$ / \mathrm{kW}[39,40]$.

The worldwide weighted average capacity factor of onshore wind energy farms commissioned in 2018 grew to $34 \%$ of $32 \%$ in 2017 , due to the trend toward greater turbine hub heights, bigger sweeping regions, and greater capabilities and harvesting more electricity from the same wind resource. While the final data for 2018 cannot be accessible, between 2010 and 2017, both turbine diameter and turbine size were significantly increased, and this is expected to continue until 2018. Higher hub heights allow access to higher wind speeds, while larger swept areas can increase output across the range of operating wind speeds.

There is a slightly greater cost for longer blades and taller towers, but with the correct optimization, a total decrease in LCOE can be accomplished. Ireland's continuous trend toward larger turbines with larger swept areas is distinguishing, but for both these metrics, Denmark is still absolutely behind the market leader [39, 40].

Between 2010 and 2017, Ireland improved its average plate capabilities by 95\%, with its rotor diameter by $76 \%$. Denmark had an average $118 \mathrm{~m}$ rotor diameter and a turbine capability of 3.5 MW for projects launched in 2017. Brazil, Canada, France, 
Global Prediction of Wind Energy Market Strategy for Electricity Generation DOI: http://dx.doi.org/10.5772/intechopen.89968
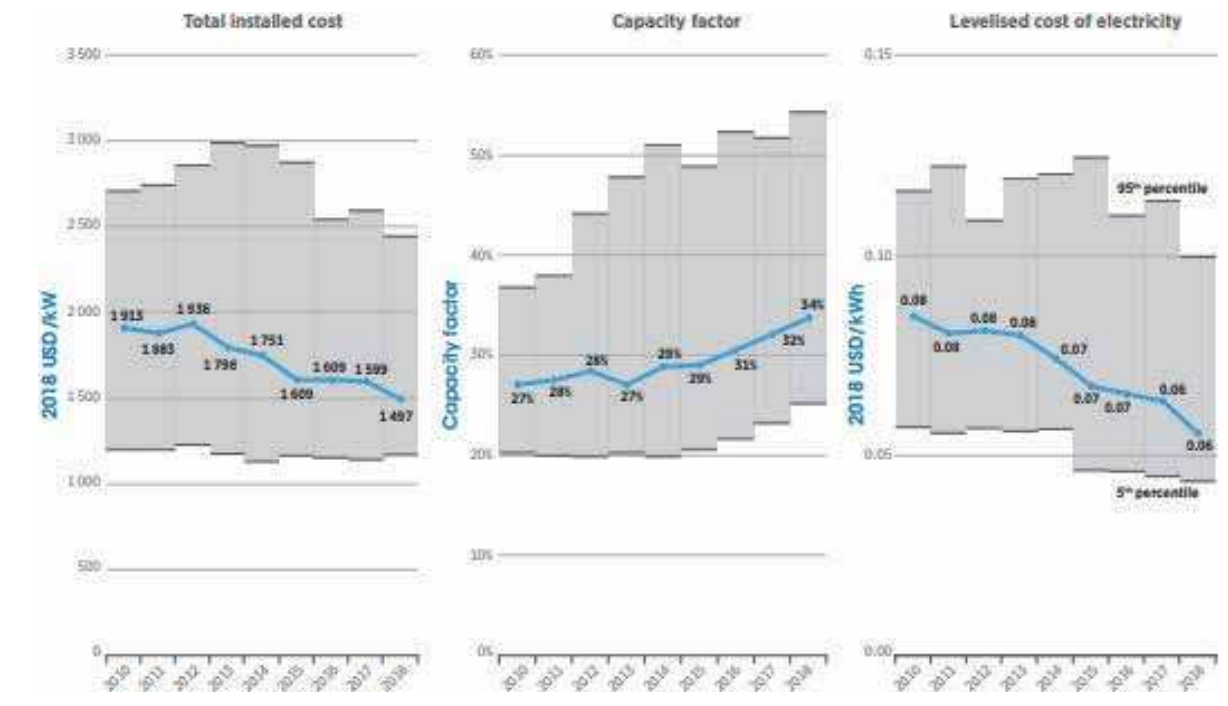

Figure 20.

Global average total installed costs, capacity factors, and LCOE for onshore wind, 2010-2018 [36].
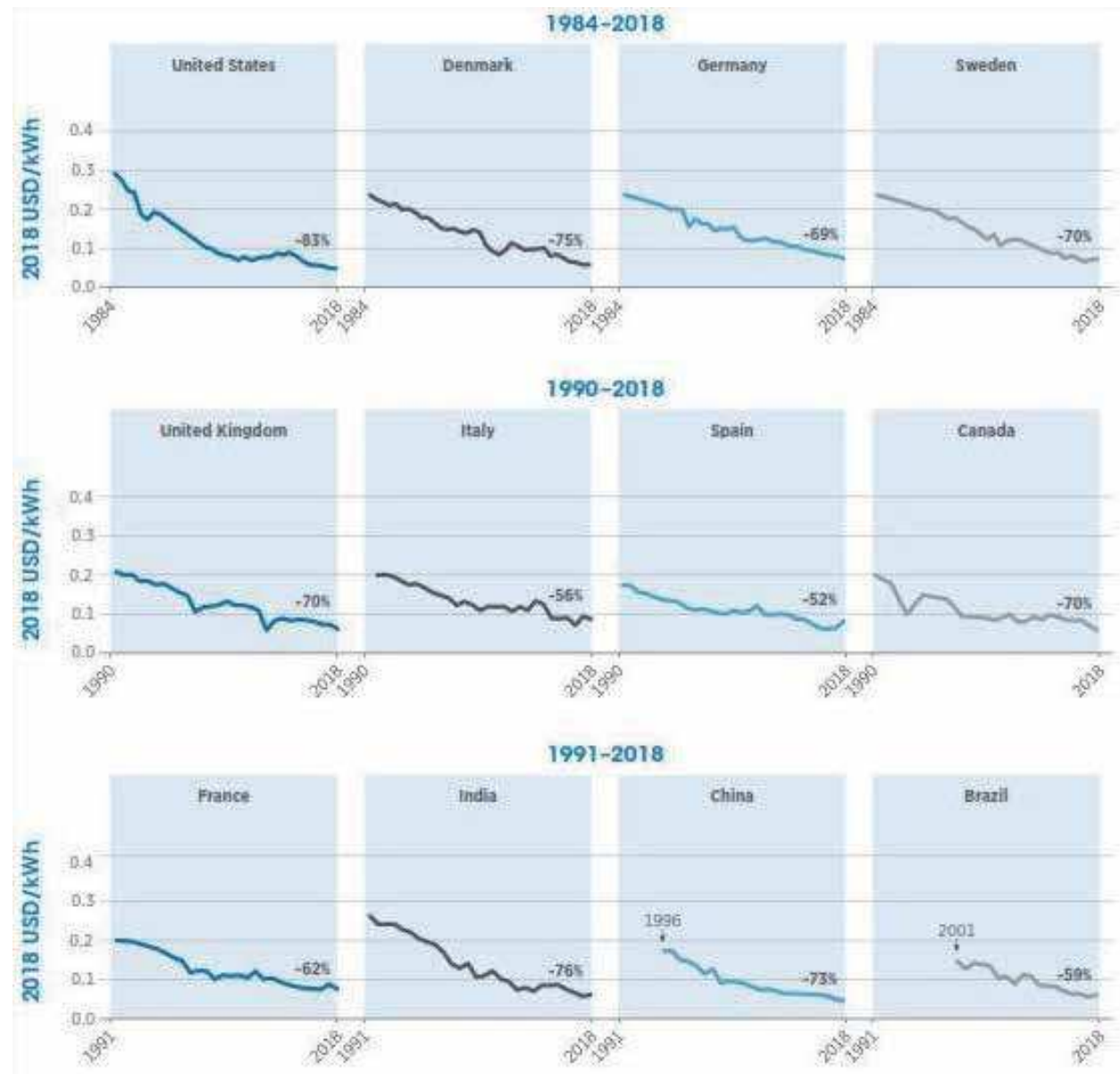

Figure 21.

Weight average LCOE of commissioned onshore wind energy projects in 12 countries, 1984-2018 [36]. 

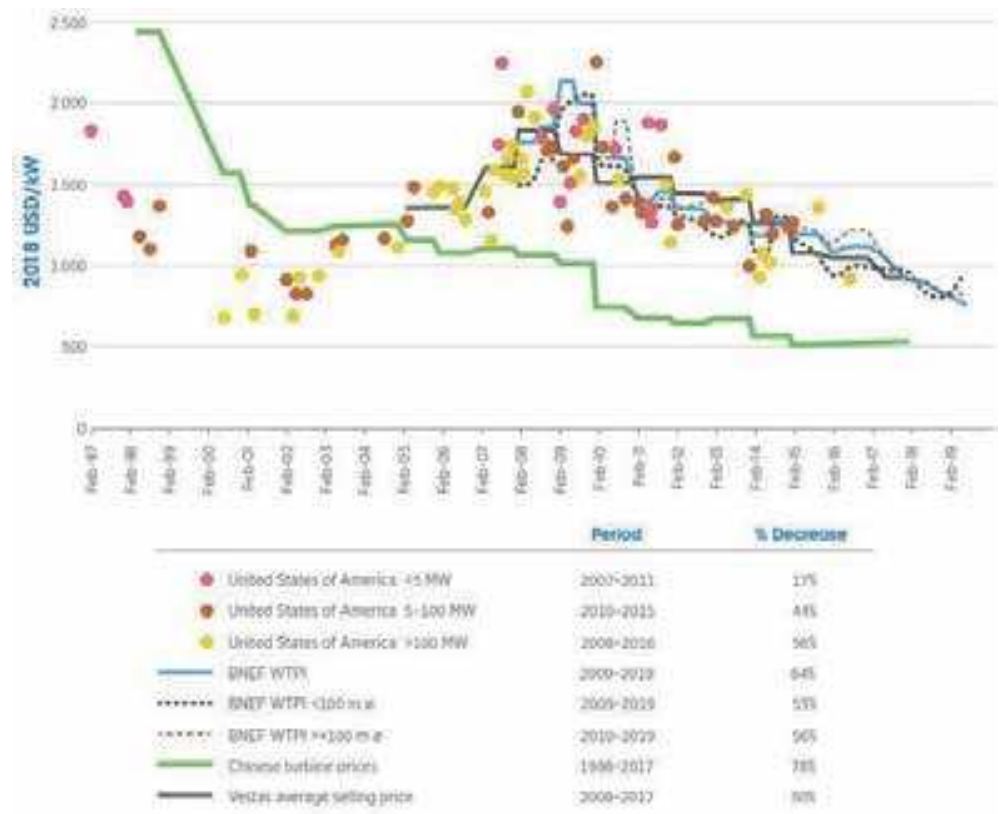

Figure 22.

Wind turbine price indices and price trends, 1997-2018 [39, 40].
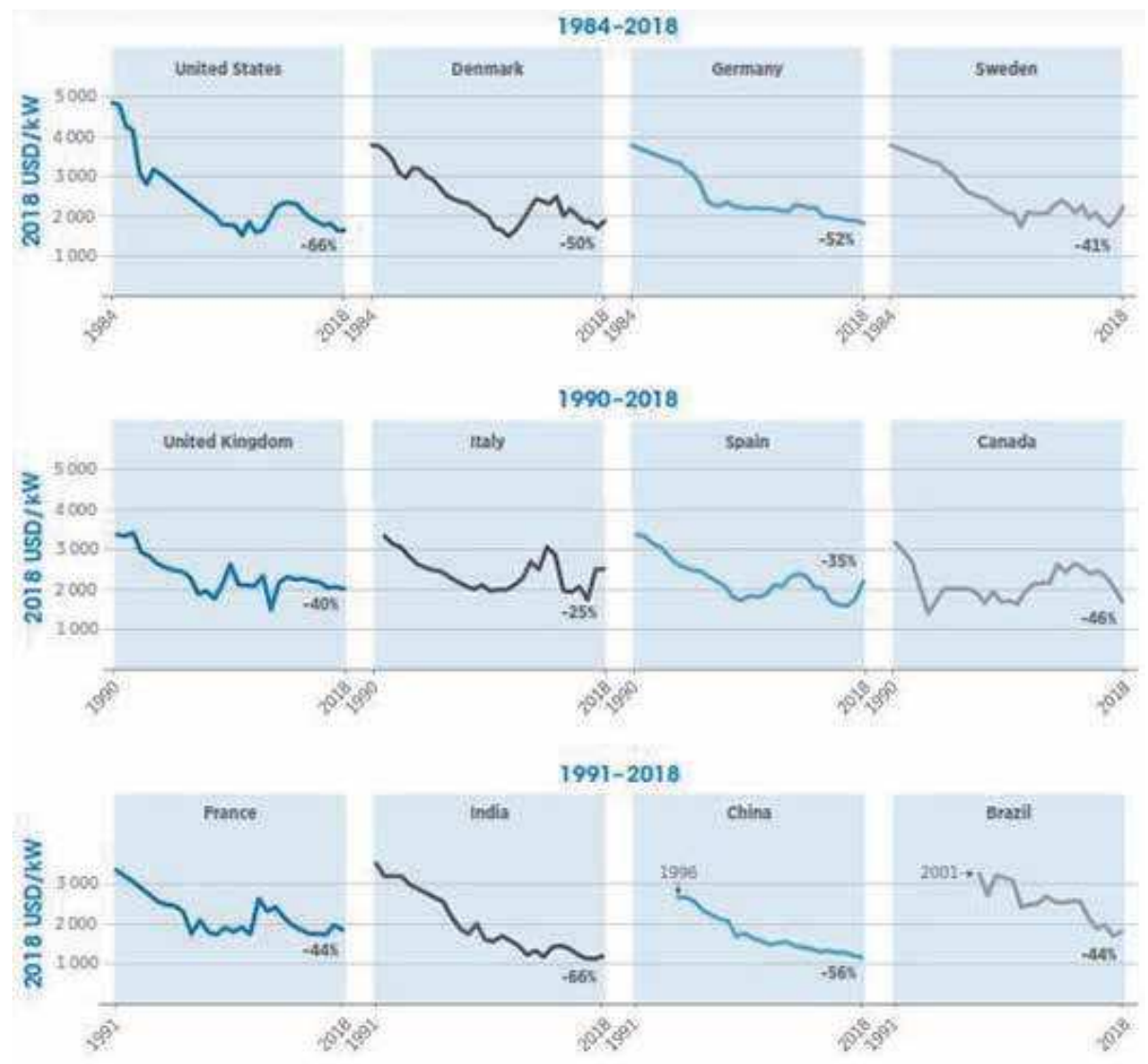

Figure 23.

Onshore wind energy weighted average installed costs in 12 countries, 1984-2018 [39, 40]. 
and the United States are interesting examples of markets that have increased the rotor diameter faster than the nameplate capacity. The newly commissioned rotor diameter has risen 42\% in Brazil, 64\% in Canada, 25\% in France, and 34\% in the United States between 2010 and 2017, while the growth in nameplate capability is $31 \%, 41 \%, 16 \%$, and $29 \%$, respectively $[39,40]$.

The average rotor diameters in 2017, in Brazil, Denmark, Germany, India, Sweden, Turkey, and the United States, were over $110 \mathrm{~m}$ compared to 2010 when the range was from $77 \mathrm{~m}$ in India to $96 \mathrm{~m}$ in Denmark. In 2018, onshore wind farms commissioned $46 \%$ in Brazil, $44 \%$ in the United States, $40 \%$ in Britain, 37\% in Australia, and 29\% in China; France and Germany had a weighted average capacity factor of 46\% (Figures 24 and 25). In 2018, the country's particular weighted average capacity factor decreased slightly from 48 to $46 \%$ in Brazil, year-on-year. In 2018, there was an increase in most other significant markets.

The worldwide weighted average LCOE for offshore wind power projects started to slightly decrease by $1 \%$ relative to 2017 (Figures 26 and 27). This leads to an increase from $\$ 0,159 / \mathrm{kWh}$ to $\$ 0,127 / \mathrm{kWh}$ in LCOE offshore winds from 2010 to 2018 to $20 \%$. In 2018, the full construction expenses for offshore wind projects built were $5 \%$ smaller than those in 2010 . Innovative wind turbine technology, installations, and logistics have led to the reduction in the cost of electricity from offshore wind energy; economies of scale in O\&M (from large turbines and offshore wind power clustering); and improved capacity factors from higher hub heights, better wind resources (despite increasing cost in deeper waters offshore wind energy), and larger rotor diameters (Figures 28-30).

In 2018, a total of $4.5 \% \mathrm{GW}$ of global offshore wind power plants is mostly in Europe and China. Global average weighted LCOE offshore wind energy was 0.127 $\$$ per kWh, which was 1\% below 2017 and 20\% below the 2010 average. A further $4.5 \mathrm{GW}$ of new offshore power was concentrated in China by $40 \%$ in 2018 , with an important share of the UK capacity growth of approximately $29 \%$ and Germany of approximately $22 \%$. The market is therefore limited to a small number of major players. In the coming years, projects will be implemented in North America and Oceania [39, 40].
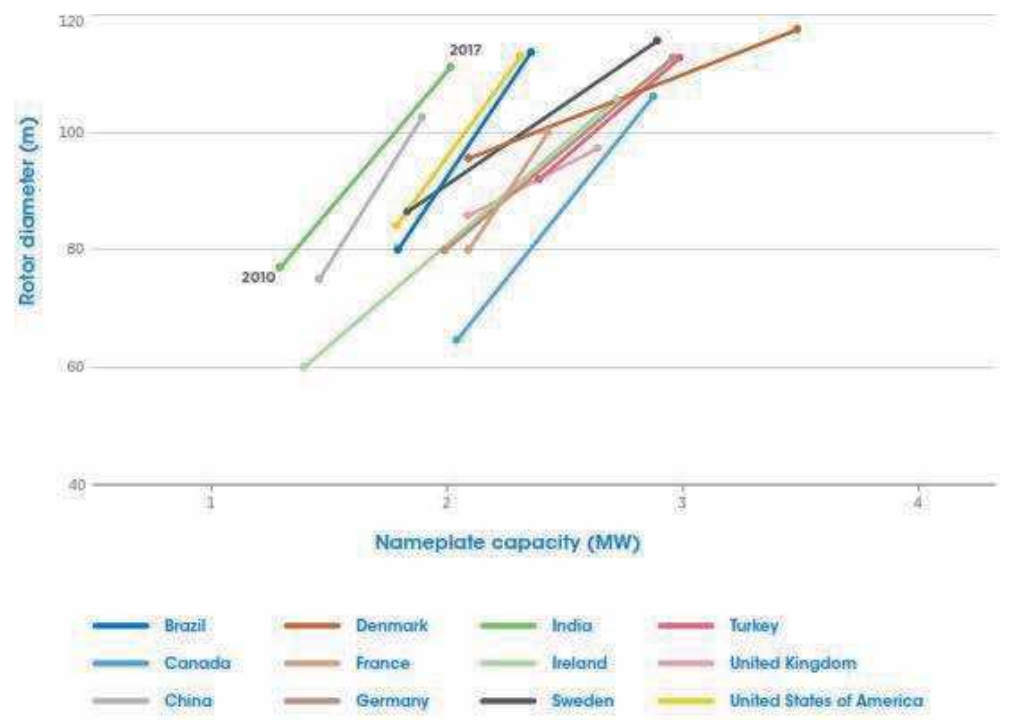

Figure 24.

Weighted average rotor diameter and nameplate capacity evolution, 2010-2018 [39, 40]. 

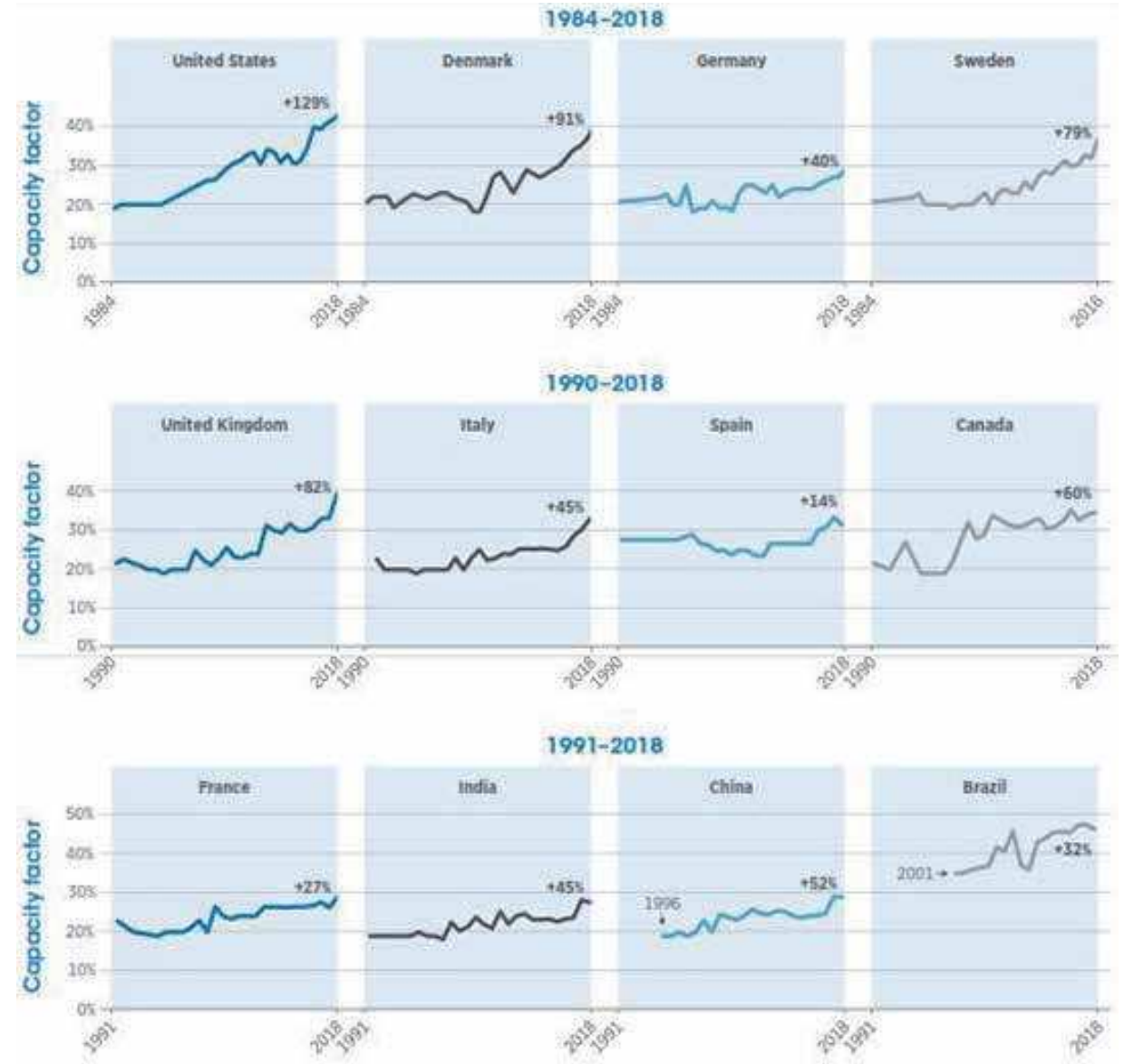

Figure 25.

Historical onshore wind energy weighted average capacity factors in a sample of 12 countries by year of commissioning, 1984-2018 [39, 40].
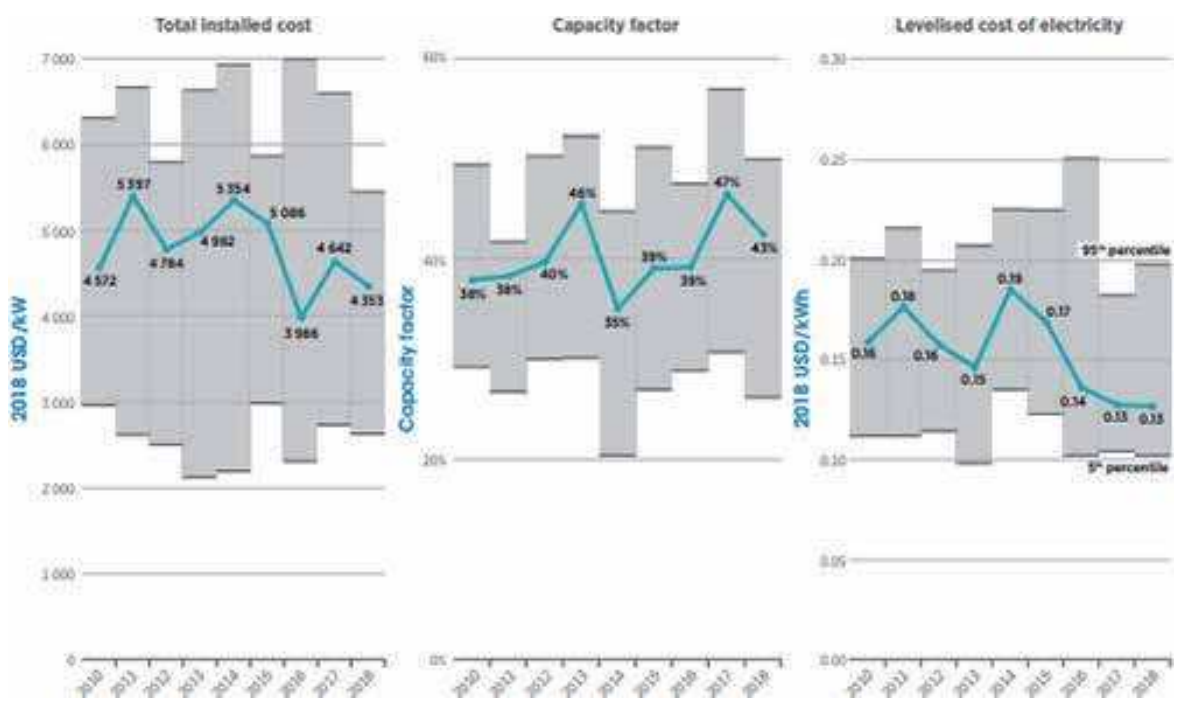

Figure 26.

Global weighted average total installed costs, offshore wind capacity factors, and LCOE, 2010-2018 [39, 40]. 


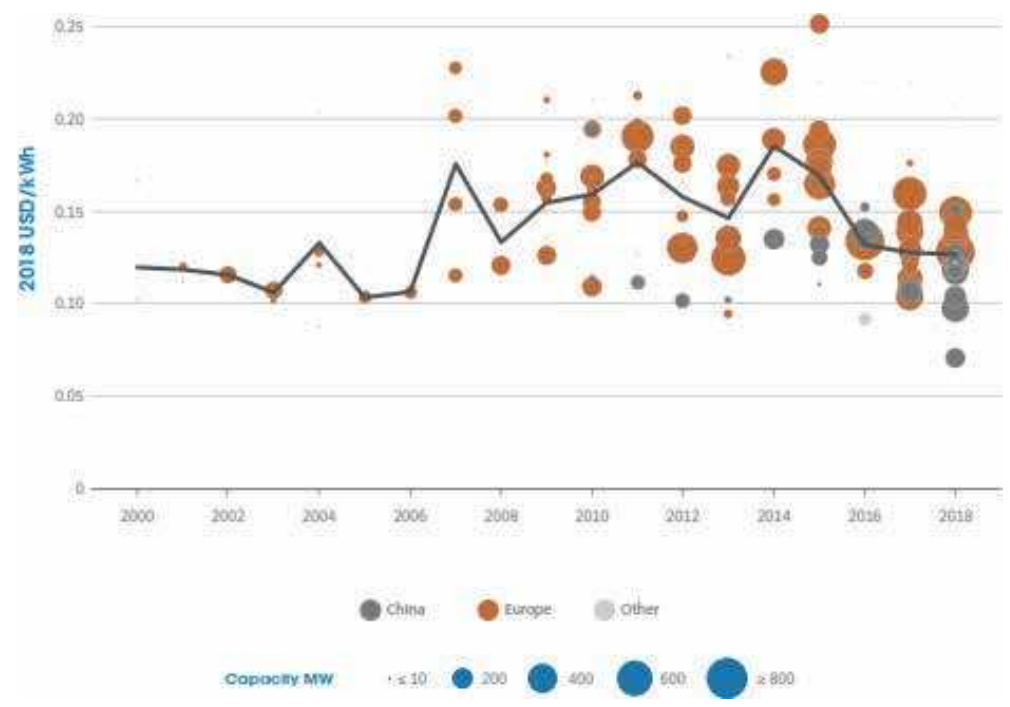

Figure 27.

LCOE for commissioned offshore wind energy projects and global weighted average, 2000-2018 [39, 40].

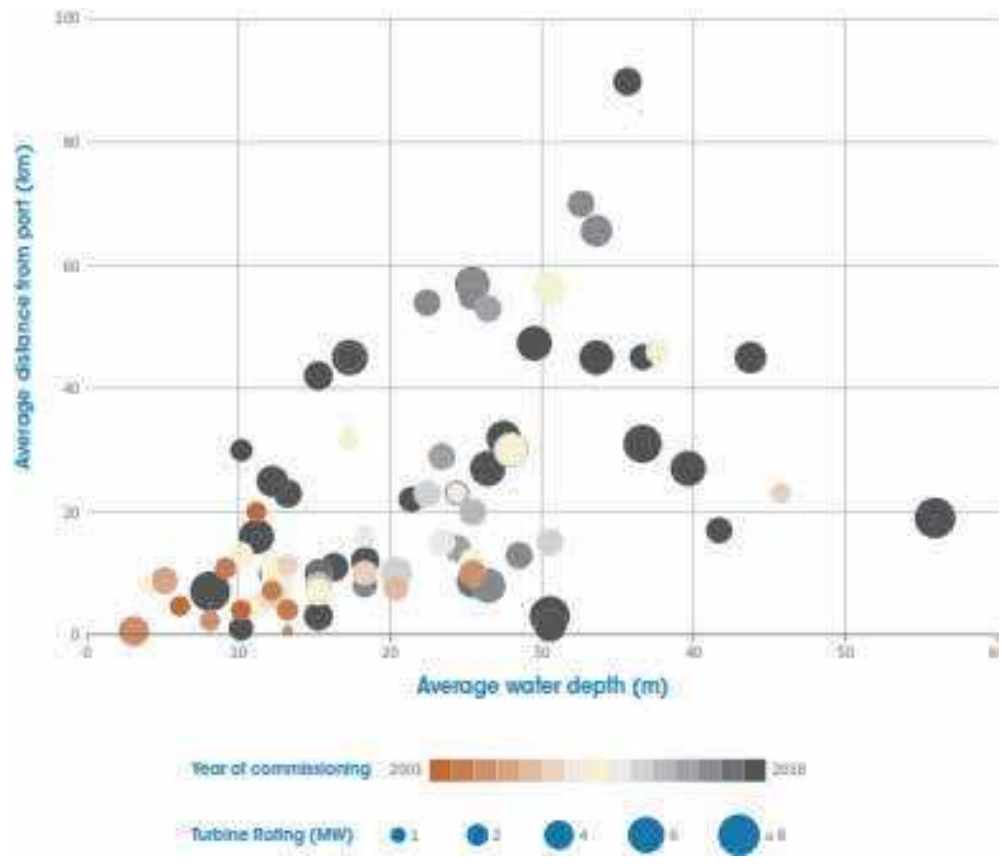

Figure 28.

Average distance from port and water depth for commissioned offshore WE projects, 2001-2018 [39, 40].

The trend to larger turbines, which increases wind farm capacity and/or reduces the number of turbines required for a given capacity, has contributed to lower installation and project development costs. But the change to offshore wind farms in deeper waters away from ports has compensated for this decrease, to a higher or lesser extent-but often with a more stable and better wind regime. This has contributed to the rise of offshore wind farms and the global weighted average offshore wind turbines increased from 38 to $43 \%$ in 2010 to $43 \%$ in 2018. Meanwhile, the cost of O\&M has been reduced with the optimization of the O\&M strategies; preventive 


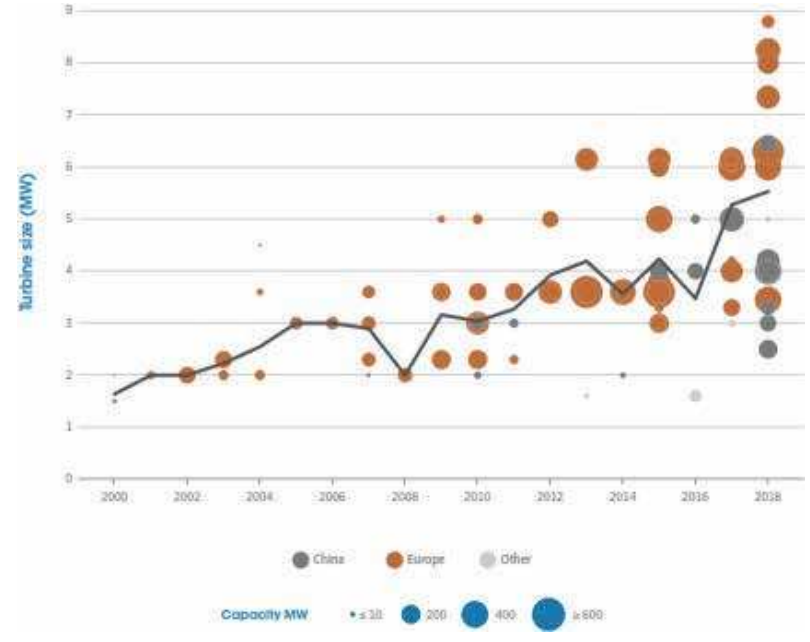

Figure 29.

Turbine sizes for commissioned offshore WE projects and global weighted average, 2000-2018 [39, 40].

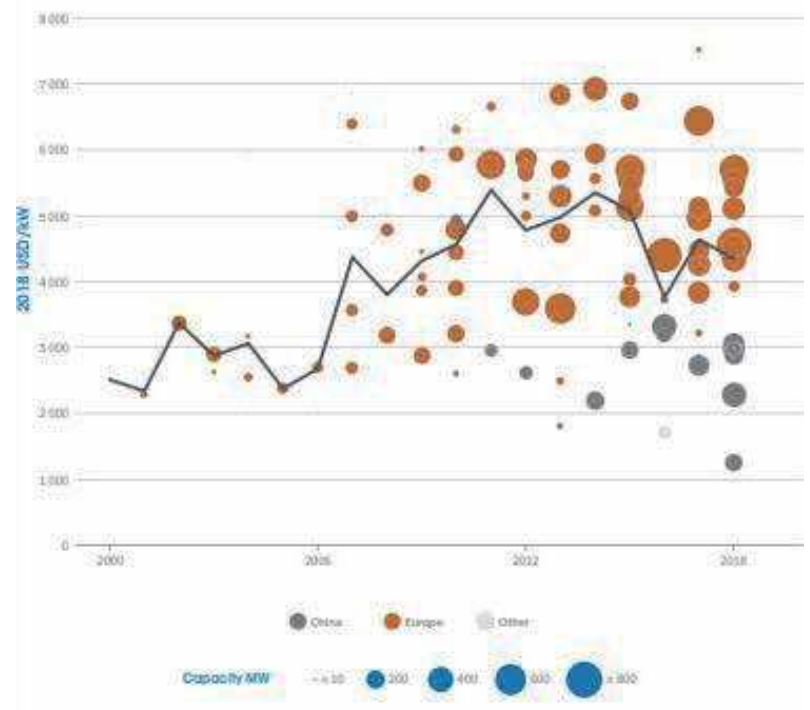

Figure 30.

Total installed costs for commissioned offshore WE and global weighted average, 2000-2018 [39, 40].

maintenance programs based on predictive failure rates analysis; and economies of scale in offshore wind energy service rather than in individual wind farms.

The offshore wind power sector remains relatively thin and LCOE declines have varied widely since 2010 . LCOE fell by $14 \%$ from $\$ 0.156 / \mathrm{kWh}$ to $\$ 0.134$ / $\mathrm{kWh}$ in Europe, the biggest offshore wind energy deployment between 2010 and 2018 projects. Between 2010 and 2018, the largest drop was in Belgium, with LCOE falling from $\$ 0.195 / \mathrm{kWh}$ to $\$ 0.141 / \mathrm{kWh}$. Between 2010 and 2018, there were 24\% and $14 \%$ drops, with LCOE in Germany and the UK drop-offs of $\$ 0.125 / \mathrm{kWh}$ and $\$ 0.139 / \mathrm{kWh}$ in 2018 , respectively. The LCOE decrease from $\$ 0.178 / \mathrm{kWh}$ to $\$ 0.106 /$ $\mathrm{kWh}$ was 40\% in Asia between 2010 and 2018. This was pushed by China, which has more than $95 \%$ of Asia's offshore wind power systems. The LCOE in Japan has an estimated $\$ 0.20 / \mathrm{kWh}$ in contrast to China, as projects to date are low and may be better classified as demonstration projects. 
Since 2010, total costs installed on offshore wind farms have decreased modestly. In view of the relatively low yearly capacity adds over a few years, a significant level of volatility exists in the total cost installed of the newly commissioned offshore wind farms. Between 2010 and 2018, the average global weighted installed cost for offshore wind power decreased by $5 \%$, from $\$ 0.4572 / \mathrm{kW}$ to $\$ 0.4353 / \mathrm{kW}$.

The general evolution in cost installations is based on a complex range of variables, with some causing costs to fall and others causing them to increase. Europe's initial small-scale and logistical capacity and challenges as well as the shift to more offshore and more deepwater deployment have, in some cases, increased the cost of installation, foundation, and grid connection costs. In latest years, however, the sector has increased and some of these stresses have been reduced. At the same moment, turbine innovation, higher turbine ratings, more project development experience, and cost savings have contributed equally to the reduction of expenses.

\section{Prediction of Potential reductions in LCOE by 2025}

Overall reductions could be around 12\% in 2015 to 2025, taking into account the trend for larger turbines with higher hub heights and greater swing spaces, for the global average cost installed for onshore wind farms. This estimate falls within the range of $7 \%$ for the total installed costs, as identified by the updated onshore wind power curve and the IRENA Remap projections for 2030.

Figure 31 shows total installed cost reductions for onshore wind energy farms, 2015-2025. These account for $27 \%$ and $29 \%$, respectively, of the total reduction in the global weighted average installed cost of onshore wind energy farms. Yet, the increased application of best practices in wind farm development by project developers and regulators could yield around one quarter of the total cost reduction. Overall, the global weighted average total installed cost for onshore wind energy could fall from around $\$ 1560 / \mathrm{kW}$ in 2015 to $\$ 1370 / \mathrm{kW}$ in 2025 [41].

The combination of the technological and process innovations in the development and operation of offshore wind energy farms could potentially see the average cost of electricity from these fall by around 35\% from around $\$ 0.17 / \mathrm{kWh}$ in 2015 to $\$ 0.11 / \mathrm{kWh}$ in 2025 (Figure 32). This represents a central estimate of the cost reduction potential [43].

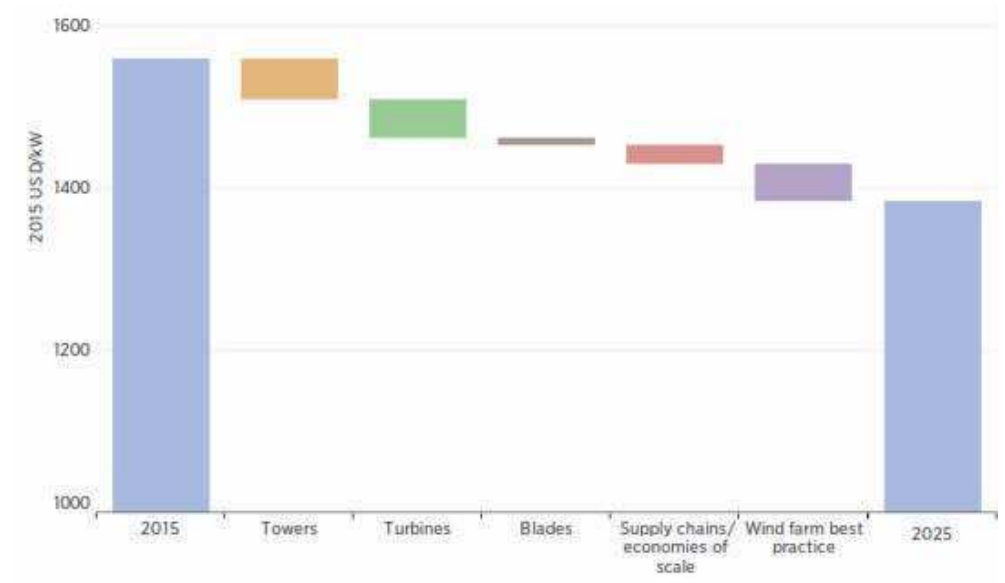

Figure 31.

Total installed cost reductions for onshore wind energy farms, 2015-2025 [41]. 


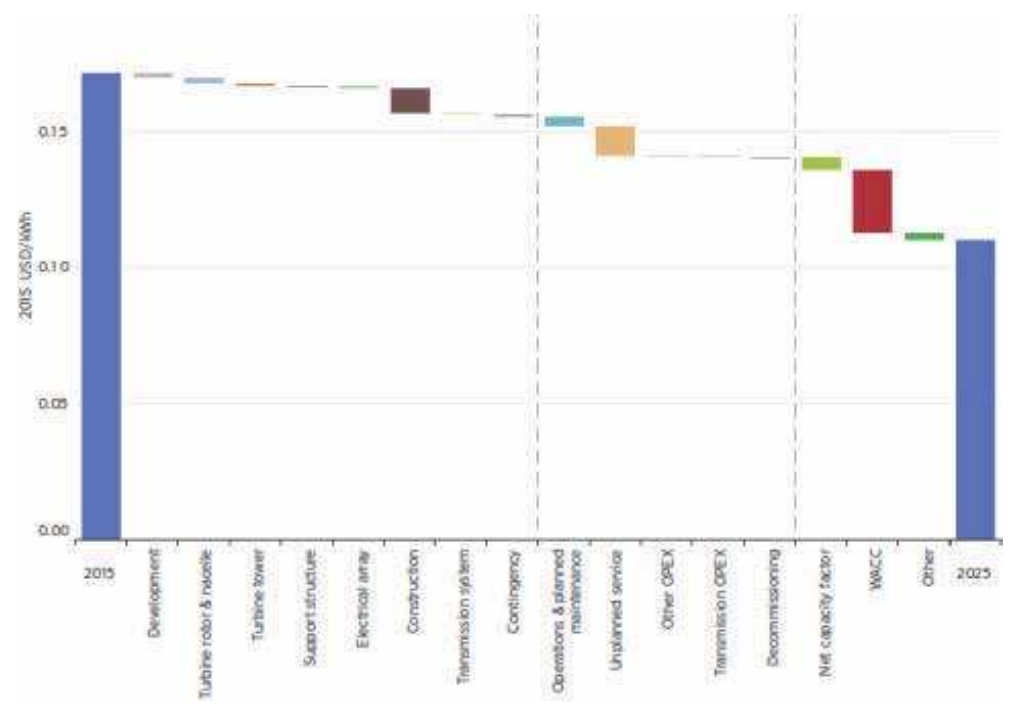

Figure 32.

Offshore wind energy levelized cost of electricity reduction potential, 2015-2025 [42].

By the year 2025, the LCOE of offshore wind farms could drop by $35 \%$ due to the deployment of advanced large offshore wind turbines. Future wind farms are going to have higher capacity factors while financial institutions are developing in a larger industry. The decrease in LCOE will also result from lower installation and building costs and more efficient project development practices [39, 40].

Reductions of total installed costs for offshore wind farms account for about $24 \%$ of LCOE's overall reduction potential and a $57 \%$ decrease in construction and installation costs. Innovations regarding turbine reliability, O\&M strategies, and prevention should significantly improve the LCOE as unplanned installation needs have been reduced. The reduction in unplanned service could account for about $17 \%$ of the total cost-cutting potential for LCOE between 2015 and 2025 [43].

The reduction in planned operations and maintenance expenditures will account for $6 \%$ of the total cost reduction potential. In total, the O\&M $\$ 0.018 /$ $\mathrm{kWh}$ decrease will bring down the total share of LCOE from $30 \%$ today to $23 \%$ by 2025 . The capacity factors of offshore wind farms will be enhanced by technological developments in turbine design and manufacturing, as well as control strategies and enhanced efficiency. This is roughly $8 \%$ of the complete decrease in LCOE [44].

Combination of current technological trends, increased availability due to enhanced reliability and innovation in turbine control, improved efficiency of blades, and enhanced growth of micrositting and the growth of wind farms could result in a worldwide average weighted capacity factor rising from $27 \%$ in 2015 to $32 \%$ by 2025 [42].

At a global level, the average contribution of increased capacity factors would be to reduce the global weighted average LCOE by around $\$ 0.01 / \mathrm{kWh}$. There are, however, a variety of variables that may lead to a higher or lower real weighted average capacity factor value in 2022 (represented in Figure 33). This is due to uncertainty about the pace of growth of hub heights and rotor diameters in main markets, such as India and China, which significantly influence the globally weighted average adoption rate for bigger machinery. The trends for the quality of the resources for wind farms up to 2025 may remain as the biggest uncertainty [35].

Onshore wind energy is now a highly competitive source of new power generation capacity, with medium- and even low-wind speed sites now available 
Global Prediction of Wind Energy Market Strategy for Electricity Generation DOI: http://dx.doi.org/10.5772/intechopen.89968

economically. The potential improvement in capacity factors by 2025 could result in reducing the global weighted average LCOE of onshore wind by around $\$ 0.01 /$ $\mathrm{kWh}$, or $49 \%$ of the total projected reduction in onshore wind LCOE of $\$ 0.018$ /

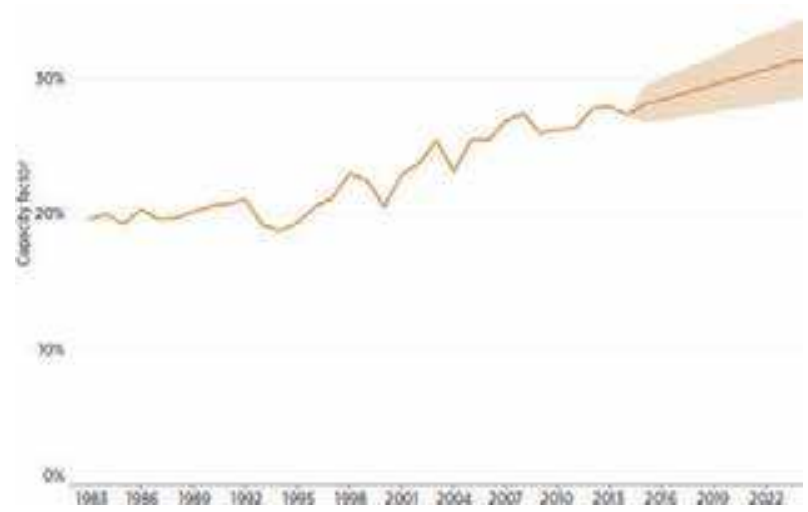

Figure 33.

Global weighted average onshore wind energy farm, 1983-2022 [35].

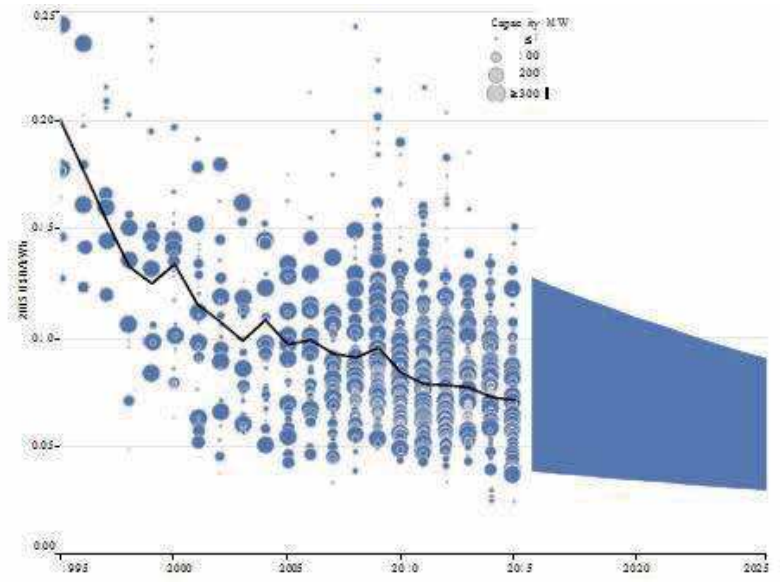

Figure 34 .

Levelized cost of electricity of onshore wind, 1995-2025 [35, 45].

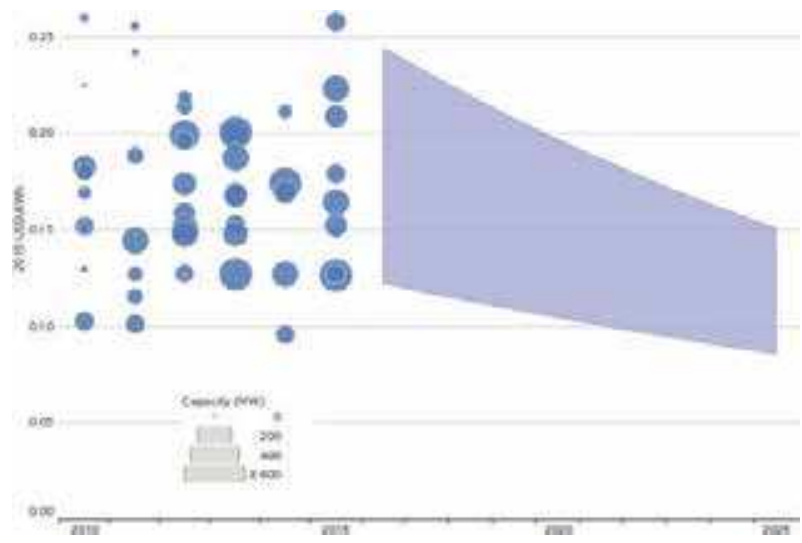

Figure 35 .

Historical offshore wind energy cost by projections to 2025 [35]. 
$\mathrm{kWh}$ as the global weighted average LCOE falls to $\$ 0.053 / \mathrm{kWh}$ by 2025 . Figure 34 shows levelized cost of electricity of onshore wind, 1995-2025 [35, 45].

Reductions in total installed costs, driven mostly by cost reductions for towers, turbines, and wind farm development, contribute around $\$ 0.006 / \mathrm{kWh}$, which means $34 \%$ of the total reduction in the LCOE. Improvements in turbine reliability, improved predictive maintenance schedules, and the more widespread application of best practice O\&M strategies reduce the LCOE by around $\$ 0.003 / \mathrm{kWh}$ by 2025 , or $17 \%$ of the total reduction [28].

Reducing the weighted average capital cost of offshore wind energy project from the current $8-10 \%$ to an average of around $7.5 \%$ will account for around $43 \%$ of the total potential reduction in the LCOE of offshore wind energy by 2025. Figure 35 presents the LCOE historical evolution of offshore wind in 2010 to 2015 for the data available in the IRENA Renewable Cost Database. It also shows offshore wind LCOE projection evolution to 2025. Offshore wind energy projects in tidal or near-shore locations could see costs fall to as little as $\$ 0.08 / \mathrm{kWh}$ by $2025[17,46,47]$.

\section{Conclusions}

Wind energy market is set to grow subject to effective economic feasibility across remote areas when compared with grid-connected networks. Government incentives toward rural electrification coupled with growing adoption of microgrid networks will further boost the business landscape.

Low installation costs along with government incentives including net metering and feed in tariff will positively impact the on-grid wind energy market share. Rapid expansion of utility-based electricity networks to cater growing energy demand across suburban areas will further complement the industry's growth.

Growing demand for renewable energy coupled with rising awareness toward environmental conservation will stimulate the global market size. National targets for clean energy along with ongoing depletion of fossil fuel reserves will further propel the industry's growth. In 2016, France set its target of renewable energy capacity to $70 \mathrm{GW}$ by 2023 including $23 \mathrm{GW}$ from onshore wind.

Declining project development cost subject to fall in component prices favored by government incentives will stimulate the market share. In addition, utility scale installations tend to bear lower operational costs when compared to auxiliary generation technologies. Rapid technological enhancements in line with the integration of smart monitoring and sensing units across turbines have reduced overall system losses. Therefore, economical cost structure in addition to improved efficiencies will positively influence the industry landscape. 
Global Prediction of Wind Energy Market Strategy for Electricity Generation

DOI: http://dx.doi.org/10.5772/intechopen.89968

\section{Author details}

Enas Raafat Maamoun Shouman

Information Systems Department, Engineering Division, National Research Center, Cairo, Egypt

*Address all correspondence to: enascora@gmail.com

\section{IntechOpen}

(C) 2020 The Author(s). Licensee IntechOpen. Distributed under the terms of the Creative Commons Attribution - NonCommercial 4.0 License (https://creativecommons.org/ licenses/by-nc/4.0/), which permits use, distribution and reproduction for non-commercial purposes, provided the original is properly cited. (cc) BY-NC 


\section{References}

[1] REN, Renewable energy policy network for the 21st century, Renewables 2016 Global Status Report, REN21; 2016

[2] Global Status Report 2017-Towards a zero-emission, efficient, and resilient buildings and construction sector, United National (UN) Environment; 2017

[3] Shouman ER, Ezz H. Forecasting transition electricity solar energy from MENA to Europe, International Journal of Applied Engineering Research (IJAER). 2015;11:3029-3040

[4] Global Wind Report, Annual Market Updated; 2017

[5] Annual Market Update 2017, Global Wind Report, Global Wind Energy Council (GWEC); 2017

[6] Musial W et al. Offshore Wind Technologies Market Report. U.S. Department of Energy Office of Scientific and Technical Information; 2018

[7] Slettenhaar R. Global Trends in Wind Power. Wassenaar: Holanda Home Wind Energy (HHWE); 2018

[8] IEA, Renewable 2018- Market analysis and forecast from 2018 to 2023, International Energy Agency (IEA). 2018, Available from: https://www.iea. org/renewables2018/

[9] IRENA. Renewable Capacity Statistics 2016. 3rd ed. International Renewable Energy Agency (IRENA); 2016

[10] MAKE Consulting. Q1 Global Wind Power Market Update. 1st ed. Aarhus, Denmark: MAKE Consulting; 2016

[11] Renewable Energy, Medium-terms, market report, market analysis and forecasts to $2021 ; 2016$
[12] IRENA. REmap: Roadmap for a Renewable Energy Future. 1st ed. Abu Dhabi: International Renewable Energy Agency; 2016

[13] Capros P, Mantzos L, Papandreou V, Tasios N, European energy and transport trends to 2030, update 2007 European Commission, general for energy and transport, European Communities; 2008

[14] Rothe M, Thomsen B, et al. TPWind advisory council, wind energy: A vision for Europe in 2030; 2018

[15] Contribution of wind power to electricity generation and generation capacity in the EU-27, Wind energy (The fact), EWIA; 2017

[16] European Commission (2007), Communication from the Commission to the Council and the European Parliament, prospects for the internal gas and electricity market; 2006

[17] European Wind Energy Association. Wind at work: Wind energy and job creation in the EU; 2008

[18] Blanco M’a I. The economics of wind energy. Renewable and Sustainable Energy Reviews. 2009;13:1372-1382

[19] Ohlenforst K, Sawyer S, Dutton A, et al. Global Wind Report 2019, Global Wind Energy Council (GWEC); 2018

[20] David S. Ottesen, Global Offshore Wind Market Report 2018, Norwegian Energy Partners; 2018

[21] European Wind Energy Association (EWEA), Pure power: Wind Energy Scenarios up to 2030, Report; 2008

[22] Europe's onshore and offshore wind energy potential: An assessment of environmental and economic 
constraints, European Environment Agency, EEA Technical report No 6/2009

[23] Hüffmeier J, Goldberg M. Baltic liner-coherent linear infrastructures in baltic maritime spatial plans, 2030 and 2050 baltic sea energy scenarios, Swedish Agency for Marine and Water Management and Research Institutes of Sweden, SwAM, RISE; 2019

[24] European Wind Energy Association, Wind energy scenarios for 2030 , Report; 2015

[25] EWEC, Wind force 12, Global Wind Energy Council; 2005

[26] Festiû M, Repina S, Volýjak R. Estimating coal price dynamics with the principal components method. Romanian Journal of Economic Forecasting. 2010;2:188-212

[27] IEA. Wind Energy, Annual Report. Paris; 2007

[28] IEA. World Energy Outlook, Paris; 2004, 2006, 2007 and 2008

[29] IEA (2009 and 2010): World energy outlook. Paris; 2010

[30] Renewable energy technologies: COST ANALYSIS SERIES-Wind Power, International Renewable Energy Agency (IRENA); 2012

[31] World Energy Council, World energy perspectives renewables integration, variable renewables integration in electricity systems: How to get it right; 2016

[32] Short W, Packey D, Holt T. A manual for the economic evaluation of energy efficiency and renewable energy technologies, NREL/TP-4625173; 1995

[33] Ohlenforst K, Sawyer S, Dutton A, et al. Global Wind Report; 2018
[34] Bloomberg NEF H2 LCOE updatewind; 2018

[35] Renewable Power Generation Costs in 2017. KEY FINDINGS AND EXECUTIVE SUMMARY, International Renewable Energy Agency (IRENA); 2018

[36] Schiffer H-W. World Energy Resources 2016. World Energy Council; 2016

[37] India's CST Sector Vision $2022-$ MNRE-GEF-UNIDO, United Nation Industrial Development Organization (UNIDO); 2017

[38] Kost C, Shammugam S, Jülch V, et al. LEVELIZED cost of electricity renewable energy technologies, Fraunhofer Institute for Solar Energy Systems (ISE); 2018

[39] Ased on Wiser and Bollinger, 2018; BNEF, IEA Wind, 2019; Vestas Wind Systems, 2005-2017; Global Data, 2018; and the IRENA Renewable Cost Database. 1st Edn; 2018

[40] Renewable Power Generation Costs in 2018. International Renewable Energy Agency (IRENA); 2019

[41] Lantz E, Wiser R, Hand M, IEA wind task 26: The past and future cost of wind energy, Technical Report, National Renewable Energy Laboratory (NREL); 2012

[42] MAKE Consulting. Wind Energy Levelised Cost of Electricity (LCOE): Globally Competitive. 2nd ed. Aarhus, Denmark: MAKE Consulting; 2015

[43] The Power to Change: Solar and W cost Reduction Potential to 2025, International Renewable Energy Agency (IRENA); 2016

[44] Variable Renewable Energy Sources (VRES) deployment and role of interconnection lines for their optimal 
exploitation: The Chile-Argentina case study, Inception Report, Enel Foundation; 2018

[45] Future Cost of Onshore Wind Recent auction results, long-term outlook and implications for upcoming German auctions, Analysis, Agora Energiewende; 2017

[46] KIC InnoEnergy. Future Renewable Energy Costs: Onshore Wind. How Technology Innovation is Anticipated to Reduce the Cost Of Energy from European Onshore Wind Energy Farms. 1st ed. Eindhoven, The Netherlands: KIC InnoEnergy; 2014

[47] BVG Associates. Offshore Wind Cost Reduction Pathways Technology Work Stream. London: Crown Estate; 2012 


\title{
Modeling and Simulation of Offshore Wind Farms for Smart Cities
}

\author{
Cheng Siong Chin, Chu Ming Peh \\ and Mohan Venkateshkumar
}

\begin{abstract}
Wind turbine models and simulations are widely available, but the simulation of a wind farm is scarce. This chapter presents a systematic approach to simulate an offshore wind farm for smart cities. The subsystems of several variable-pitch wind turbines, namely, rotor blades, drivetrain, and induction generator, are modeled to form a wind farm. The total output power of the wind farm by considering multiple wind turbines with the wake losses (using the Jensen wake model) can be simulated with any input wind speed. In order to validate the accuracy of the simulation, a case study was performed on a German offshore wind farm called NordseeOst. The simulation shows promising results with an average error of approximately $5 \%$ when compared with the real-time output of the wind farm. The results showed that the simulation of a wind farm that often impeded by the lack of exact information is feasible before any site implementation for smart cities.
\end{abstract}

Keywords: variable-pitch wind turbine, modeling and simulation, offshore wind farm, smart cities

\section{Introduction}

As a measure to resolve the declining rate of fossil fuels and the current state of emission levels, renewable energy has become an attractive source of clean and sustainable energy. The wind is a powerful and abundant source of renewable energy. Wind power installations, both onshore and offshore, have expanded rapidly over the world to harness the energy from wind. However, these wind power plants are not cheap for offshore installations. Hence, the inception of a wind farm entails many considerations and careful planning to justify the associated high cost. As a result, alternative consideration is the wind farm layout that can be optimized to increase the profitability [1].

However, the optimization of the layout is a complicated and challenging process due to a phenomenon known as wake effect. After a turbine extracts wind energy [2], the downstream wind will be turbulent and reduced in speed. It is essential to consider the wake losses when positioning the turbines to maximize energy production taking into account the additional costs for infrastructure if they are spaced far apart. By using modeling and simulation as a tool, analysis can assist 
in managerial and technical decisions [3]. It is to be mentioned that manufacturerspecific models are sometimes not easy to obtain [4].

Presently, there are few studies performed on wind turbine modeling. Some examples of these studies are available [5-7]. The focus of their works was primarily on the wind turbine dynamics and its efficiency. They did not consider the implementation of a wind farm or multiple wind turbines. Nevertheless, there are a few researches conducted on wind farm simulation. For instance, the wake loss was not taken [8] into account. Hence, there is a need to systematically model the wind farm instead of just a wind turbine with the wake losses. The wind farm simulation tool should be widely available to users to simulate the feasibility of the wind turbines on the specific site before actual implementation. The approach adopted in this study encompasses the different wind speed for each turbine with consideration of wake losses. The main contribution is to provide a systematic approach to model the output power from the wind farm by considering the wake losses before implementing the wind turbines on the actual site for smart cities.

The chapter is organized as follows. In Section 2, a proposed modeling methodology is presented followed by Section 3 on a simulation model of NordseeOst wind farm. Section 4 describes the results and discussion followed by the conclusion in Section 5 .

\section{Modeling methodology}

The NordseeOst, an operational offshore wind farm in Germany, will be used here as a case study, and the wind turbines are modeled based on the governing equations that can be implemented through the function block available in the Simulink Library. The parameters for the wind turbine model will be based on manufacturer Senvion 6.2M126 used in the German farm. The turbine model is duplicated and positioned to follow the layout of NordseeOst wind farm. By considering the wake losses of each turbine using the Jensen wake model, the wind speed input for the turbines can be computed. The wind conditions and temperature in the wind farm site will be obtained from an online resource. For any given timeframe, the output power of the simulated farm can be determined and verified with the real-time data obtained from the actual farm.

\subsection{Wind turbine modeling}

Multiple wind turbine models were created to form the wind farm. From a modeling viewpoint, the turbine model can be broken down into three blocks, aerodynamic, mechanical, and electrical, as shown in Figure 1. When the passing wind interacts with the rotor blades, lift and drag forces create the rotation of the turbine blades. This turning force is high in torque, but the speed is low. The speed of the rotating rotor shaft will be increased using a gearbox. The purpose of increasing the rotational speed is to match the requirements of the generator. The turbine and generator shaft is coupled as a drivetrain to transmit the driving force to the generator. The electrical block consists of the generator that creates a magnetic field from the rotor into electrical energy. Each block is modeled using few differential and algebraic equations that describe their functions.

\subsubsection{Aerodynamic block}

The aerodynamic block is characterized by three subsystems, namely, the tip speed ratio, power coefficient, and rotor torque, that are developed. The maximum 


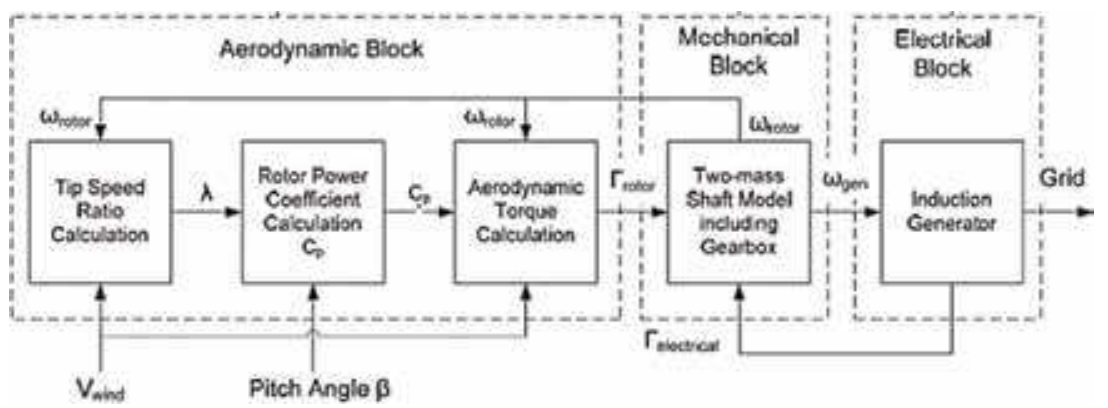

Figure 1.

Wind turbine model [4].

power that can be extracted from the wind is $59.26 \%$ [9]. The power coefficient $C_{P}$ expresses the ratio of extractable power by the rotor to the available power in the wind. The amount of power that can be extracted is given as follows:

$$
P_{r}=\frac{1}{2} \cdot \rho \cdot A \cdot v^{3} \cdot C_{P}(\lambda, \beta)
$$

where $\rho$ is the density of air in $\mathrm{kg} / \mathrm{m}^{3}, A$ is the rotor swept area in $\mathrm{m}^{2}, v$ is the wind speed in $\mathrm{m} / \mathrm{s}$, and $\mathrm{C}_{\mathrm{P}}$ is the power coefficient.

The density of air can be determined from the turbine elevation above sea level [3]:

$$
\rho=\rho_{o}-1.194 \times 10^{-4} \cdot H
$$

where $\rho_{o}$ is the density of air at the sea level at a specific temperature in $\mathrm{kg} / \mathrm{m}^{3}$ and $H$ is the hub height in $\mathrm{m}$.

The efficiency of the rotor can be described by power coefficient $C_{P}$ since it is a ratio of extracted power to available wind power. It is usually expressed as a function of tip speed ratio and blade pitch angle. The ratio of linear speed at the rotor blade tip to the wind speed is defined as tip speed ratio $\lambda$ as shown:

$$
\lambda=\frac{\omega_{r} \cdot r}{v}
$$

where $\omega_{r}$ is the rotor angular velocity in $\mathrm{rad} / \mathrm{s}, r$ is the radius of the rotor (blade length + hub radius) in $\mathrm{m}$, and $v$ is the wind speed in $\mathrm{m} / \mathrm{s}$.

For a specific airfoil type, the power coefficient may be expressed as a function of the tip speed ratio and blade pitch angle as follows [8]:

$$
C_{P}(\lambda, \beta)=c_{1}\left(c_{2} / \lambda_{i}-c_{3} \beta-c_{4}\right) e^{-c_{5} / \lambda_{i}}+c_{6} \lambda
$$

where $c_{1}=0.5176, c_{2}=116, c_{3}=0.4, c_{4}=5, c_{5}=21$, and $c_{6}=0.0068$ with $\lambda_{i}$ defined as

$$
\frac{1}{\lambda_{i}}=\frac{1}{\lambda+0.08 \beta}-\frac{0.035}{\beta^{3}+1}
$$

where $\lambda$ is the tip speed ratio and $\beta$ is the blade pitch angle.

The rotor torque developed by the turbine can be calculated as follows:

$$
\Gamma_{r}=\frac{P_{r}}{\omega_{r}}
$$


where $\Gamma_{r}$ is the torque developed at the rotor in $\mathrm{Nm}, P_{r}$ is the power developed by the rotor in $\mathrm{W}$, and $\omega_{r}$ is the rotor angular speed in $\mathrm{rad} / \mathrm{s}$.

\subsubsection{Mechanical block}

The purpose of a drivetrain is to transmit the torque generated by the rotor blades from the rotor hub to the generator. The torque generated is filtered by the drivetrain via the gearbox and ultimately drives the generator shaft. In this mechanical block, the drivetrain is modeled by a two-lumped-mass model as shown in Figure 2. The two-mass model [10] is accurate enough for the analysis of transient stability in wind power generation systems when compared with higher-order drivetrain model with three or six masses:

The stiffness and damping of the low-speed shaft are represented by a spring and damper with coefficient $k_{l s}$ and $c_{l s}$, respectively. The equation of motion for the turbine rotor is expressed as follows:

$$
\dot{\Omega}_{r}(t)=\frac{T_{a}(t)-T_{l s}(t)-c_{f} \Omega_{r}(t)}{J_{r}}
$$

where $\Omega_{r}$ is the rotor angular speed in $\mathrm{rad} / \mathrm{s}, T_{a}$ is the aerodynamic torque developed by rotor in $\mathrm{Nm}, \Gamma_{l s}$ is the torque of the low-speed shaft in $\mathrm{Nm}, c_{f}$ is the frictional damping, and $J_{r}$ is the inertia of rotor in $\mathrm{kgm}^{2}$.

The mechanical torque of the shaft is modeled as follows:

$$
T_{l s}(t)=k_{l s}\left[\theta_{r}(t)-\theta_{l s}(t)\right]+c_{l s}\left[\Omega_{r}(t)-\Omega_{l s}(t)\right]
$$

where $T_{l s}$ is the torque of low-speed shaft in $\mathrm{Nm}, k_{l s}$ is the stiffness coefficient, $\theta_{r}$ is the rotor angular position in rad, $\theta_{l s}$ is the angle of low-speed shaft in rad, $\mathrm{c}_{\mathrm{ls}}$ is the damping coefficient, $\Omega_{\mathrm{r}}$ is the rotor angular speed in $\mathrm{rad} / \mathrm{s}$, and $\Omega_{\mathrm{ls}}$ is the angular speed of low-speed shaft in $\mathrm{rad} / \mathrm{s}$.

Assuming an ideal gearbox, the step-up ratio of the transmission speed is shown:

$$
\eta_{g}=\frac{T_{l s}(t)}{T_{h s}(t)}=\frac{\Omega_{g}(t)}{\Omega_{l s}(t)}=\frac{\theta_{g}(t)}{\theta_{l s}(t)}
$$

where $\Gamma_{l s}$ is the torque of the low-speed shaft in $\mathrm{Nm}, T_{h s}$ is the torque provided to the generator in Nm, $\Omega_{g}$ is the angular speed of generator shaft in $\mathrm{rad} / \mathrm{s}, \Omega_{l s}$ is the angular speed of the low-speed shaft in $\mathrm{rad} / \mathrm{s}, \theta_{g}$ is the angle of generator shaft in $\mathrm{rad}$, and $\theta_{l s}$ is the angle of the low-speed shaft in rad.

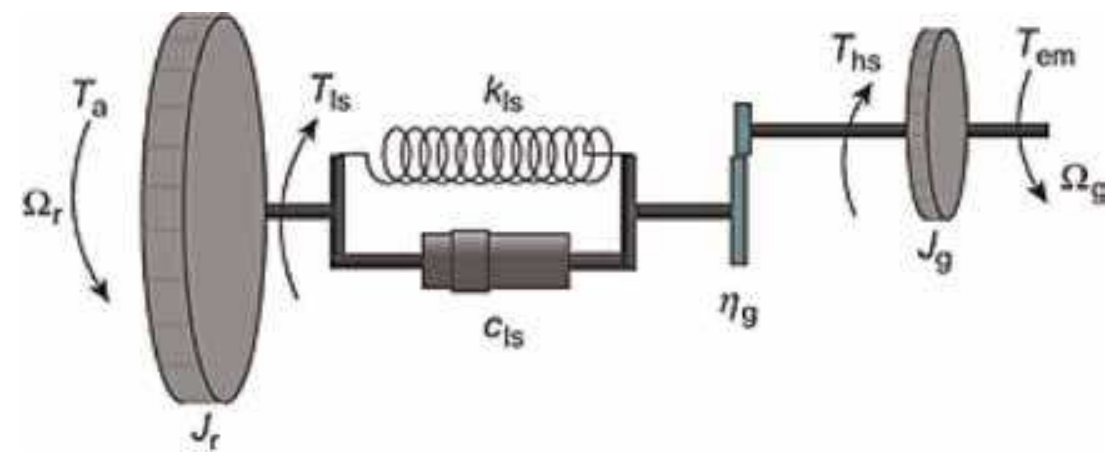

Figure 2.

Two-mass model [10]. 
The equation of motion for the shaft at induction generator is written as shown:

$$
\dot{\Omega}_{g}(t)=\frac{T_{h s}(t)-T_{e m}(t)-c_{g} \Omega_{g}(t)}{J_{g}}
$$

where $T_{h s}$ is the torque provided to the generator in Nm, $T_{e m}$ is the electromagnetic torque in $\mathrm{Nm}, c_{\mathrm{g}}$ is the damping experienced at the generator, $\Omega_{\mathrm{g}}$ is the angular speed of generator shaft in $\mathrm{rad} / \mathrm{s}$, and $J_{g}$ is the inertia generator in $\mathrm{kgm}^{2}$.

\subsubsection{Electrical block}

The ideal induction generator dynamic model consists of three stators and three winding rotors. The differential equations are derived from the state space vector representation using synchronous reference frame for the $\mathrm{d}$-q model. The modeling is simplified and preferable when represented as DC values. In order to do so, the stator and rotor are each transferred onto a direct and quadrature axis ( $\mathrm{d}-\mathrm{q}$ model). The direct and quadrature axes for the stator are represented by $d s$ and $q s$, respectively. The same axis for the rotor can also be represented by $d r$ and $q r$. To simulate the induction generator, an equation to represent both the direct and quadrature axis voltages for the stator $V_{d s}, V_{q s}$ and current $I_{d s}, I_{q s}$ is required. Eqs. (11)-(18) are the models of an induction generator expressed in a d-q reference frame [3].

The stator and rotor magnetic flux linkages are given as follows:

$$
\begin{aligned}
& \varphi_{d s}=X_{s} \cdot I_{d s}+X_{m} \cdot I_{d r} \\
& \varphi_{q s}=X_{s} \cdot I_{q s}+X_{m} \cdot I_{q r} \\
& \varphi_{d r}=X_{r} \cdot I_{d r}+X_{m} \cdot I_{d s} \\
& \varphi_{q r}=X_{r} \cdot I_{q r}+X_{m} \cdot I_{q s}
\end{aligned}
$$

where $X_{s}$ is the stator reactance in $\Omega, X_{r}$ is the rotor reactance in $\Omega, X_{m}$ is the mutual reactance in $\Omega, I_{d s}$ is the stator current at d axis in A, $I_{q s}$ is the stator current at $\mathrm{q}$ axis in $\mathrm{A}, I_{d r}$ is the rotor current at $\mathrm{d}$ axis in $\mathrm{A}$, and $I_{q r}$ is the rotor current at $\mathrm{q}$ axis in $\mathrm{A}$.

The stator and rotor voltage equations are given by Eqs. (15)-(18). During startup, the rotor in an induction generator does not require a supply of voltage. Hence the rotor voltage $V_{d r}$ and $V_{q r}$ are equal to zero [3]:

$$
\begin{aligned}
& V_{d s}=-R_{s} \cdot I_{d s}+\omega_{s} \cdot \varphi_{q s}-\frac{d \varphi_{d s}}{d t} \\
& V_{q s}=-R_{s} \cdot I_{q s}-\omega_{s} \cdot \varphi_{d s}-\frac{d \varphi_{q s}}{d t} \\
& 0=-R_{r} \cdot I_{d r}+s \cdot \omega_{s} \cdot \varphi_{q r}-\frac{d \varphi_{d r}}{d t} \\
& 0=-R_{r} \cdot I_{q r}-s \cdot \omega_{s} \cdot \varphi_{d r}-\frac{d \varphi_{q r}}{d t}
\end{aligned}
$$

where $R_{s}$ is the stator resistance in $\Omega, R_{r}$ is the rotor resistance in $\Omega, I_{\mathrm{ds}}$ is the stator current at $\mathrm{d}$ axis in $\mathrm{A}, I_{\mathrm{qs}}$ is the stator current at q axis in $\mathrm{A}, I_{d r}$ is the rotor current at $\mathrm{d}$ axis in $\mathrm{A}, I_{q r}$ is the rotor current at q axis in $\mathrm{A}, \varphi_{d s}$ is the stator magnetic flux at $\mathrm{d}$ axis in weber, $\varphi_{q s}$ is the stator magnetic flux at q axis in weber, $\varphi_{d r}$ is the 
rotor magnetic flux at $\mathrm{d}$ axis in weber, $\varphi_{q r}$ is the rotor magnetic flux at $\mathrm{q}$ axis in weber, $\omega_{s}$ is the synchronous speed in rad/s, and $s$ is the slip.

The rotor slip can be calculated as follows:

$$
s=\frac{\omega_{s}-\omega_{g}}{\omega_{s}}
$$

where $\omega_{s}$ is the synchronous speed in $\mathrm{rad} / \mathrm{s}$ and $\omega_{r}$ is the rotor speed in $\mathrm{rad} / \mathrm{s}$. The electrical torque developed by the generator is given as follows:

$$
T_{e}=\varphi_{q r} \cdot I_{d r}-\varphi_{d r} \cdot I_{q r}
$$

where $\varphi_{q r}$ is the rotor magnetic flux at q axis in weber, $I_{d r}$ is the rotor current at $\mathrm{d}$ axis in $\mathrm{A}, \varphi_{d r}$ is the rotor magnetic flux at $\mathrm{d}$ axis in weber, and $I_{q r}$ is the rotor current at $\mathrm{q}$ axis in $\mathrm{A}$.

The power equations for the generator can then be expressed by Eqs. (21)-(23). The true power can be computed as shown:

$$
P=V_{d s} \cdot I_{d s}+V_{q s} \cdot I_{q s}
$$

The reactive power is calculated as follows:

$$
Q=V_{q s} \cdot I_{d s}-V_{d s} \cdot I_{q s}
$$

The apparent power can be written:

$$
S=V_{d s} \cdot I_{d s}+V_{q s} \cdot I_{q s}+V_{q s} \cdot I_{d s}-V_{d s} \cdot I_{q s}
$$

where $V_{d s}$ is the stator voltage at $\mathrm{d}$ axis in $\mathrm{V}, V_{q s}$ is the stator voltage at q axis in $\mathrm{V}, I_{d s}$ is the stator current at $\mathrm{d}$ axis in A, and $I_{q s}$ is the stator voltage at q axis in V.

\subsubsection{Jensen wake model}

The Jensen wake model was used to calculate the wind speed after subjecting to wake loss. The model is simplified for a single wake where the diameter of the wake is assumed to be expanding linearly. For a single wake model, the resulting wake of a wind turbine is treated to be turbulent where the near field behind the turbine is neglected. The spread of the resulting wake can be represented by the linear dimension (radius $r$ ) which is proportional to the downwind distance, $x$ as shown in Figure 3. The start of the wake, $u$, that is directly behind the turbine is assumed to be equal to the turbine diameter:

A balance of momentum gives the following equation:

$$
\pi r_{0}^{2} u+\pi\left(r^{2}-r_{0}^{2}\right) v_{0}=\pi r^{2} v_{1}
$$

where $r_{0}$ is the rotor blade length in $\mathrm{m}, u$ is the wake speed in $\mathrm{m} / \mathrm{s}, r$ is the radius of wake cone in $\mathrm{m}, v_{0}$ is the incoming wind speed in $\mathrm{m} / \mathrm{s}$, and $v_{1}$ is the resultant wake speed in $\mathrm{m} / \mathrm{s}$.

The radius of the wake cone $r$ that represents the path of incoming wind after passing through the turbine is shown:

$$
r=r_{0}+\alpha x
$$

where $r_{0}$ is the rotor blade length in $\mathrm{m}, \alpha$ is the dimensionless scalar, and $x$ is the distance from a wind turbine in $\mathrm{m}$. 


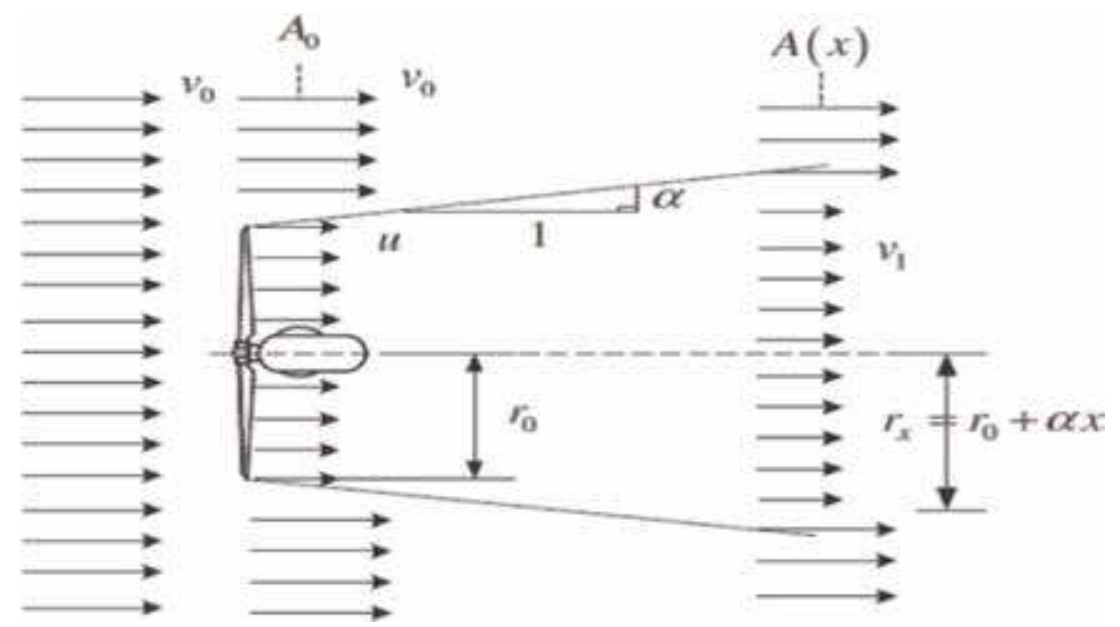

Figure 3 .

Linear expansion of wake cone for a single wake model.

The speed of wake expanding with distance which depends on the dimensionless scalar $\alpha$ is defined as follows:

$$
\alpha=\frac{1}{2 \ln \left(\frac{z}{z_{0}}\right)}
$$

where $z$ is the hub height in $\mathrm{m}$ and $z_{0}$ is the surface roughness.

The surface roughness constant is dependent on the characteristics of the local terrain, while the dimensionless scalar $\alpha$ depends on both the local terrain and wind climate conditions. The paper [2] had mentioned that a value of 0.04 can be used for $\alpha$ for free stream wind which has yet to pass through any wind turbine or otherwise the value of 0.08 can be assumed.

By solving Eq. (25) in terms of $v_{1}$, the velocity of the wake at a downwind distance $\mathrm{x}$ from the wind turbine can be calculated:

$$
v_{1}=v_{0}+v_{0}\left(\sqrt{1-C_{T}}-1\right)\left(\frac{r_{0}}{r}\right)^{2}
$$

where $v_{1}$ is the wake speed in $\mathrm{m} / \mathrm{s}, v_{0}$ is the incoming wind speed in $\mathrm{m} / \mathrm{s}, C_{\mathrm{T}}$ is the thrust coefficient, $r_{0}$ is the rotor blade length in $\mathrm{m}$, and $r$ is the radius of wake cone in $\mathrm{m}$.

A thrust coefficient is a dimensionless number that defines the thrust of a wind turbine. The value of thrust coefficient varies with wind speed, and the paper [11] has shown that it has a maximum value of 1 .

\section{Simulation model of NordseeOst wind farm}

NordseeOst is a $295 \mathrm{MW}$ offshore wind farm located $35 \mathrm{~km}$ northeast of Heligoland, a German archipelago in the North Sea region. The wind farm consists of 48 turbines [12]. The site has an average wind speed of $9.77 \mathrm{~m} / \mathrm{s}$ and an area of approximately $36 \mathrm{~km}^{2}$. The site coordinates are $54^{\circ} 26^{\prime} 24^{\prime \prime} \mathrm{N}$ and $7^{\circ} 40^{\prime} 48^{\prime \prime} \mathrm{E}$ that are used to determine the wind condition. The layout of the wind farm used in the simulation is shown in Figure 4. 


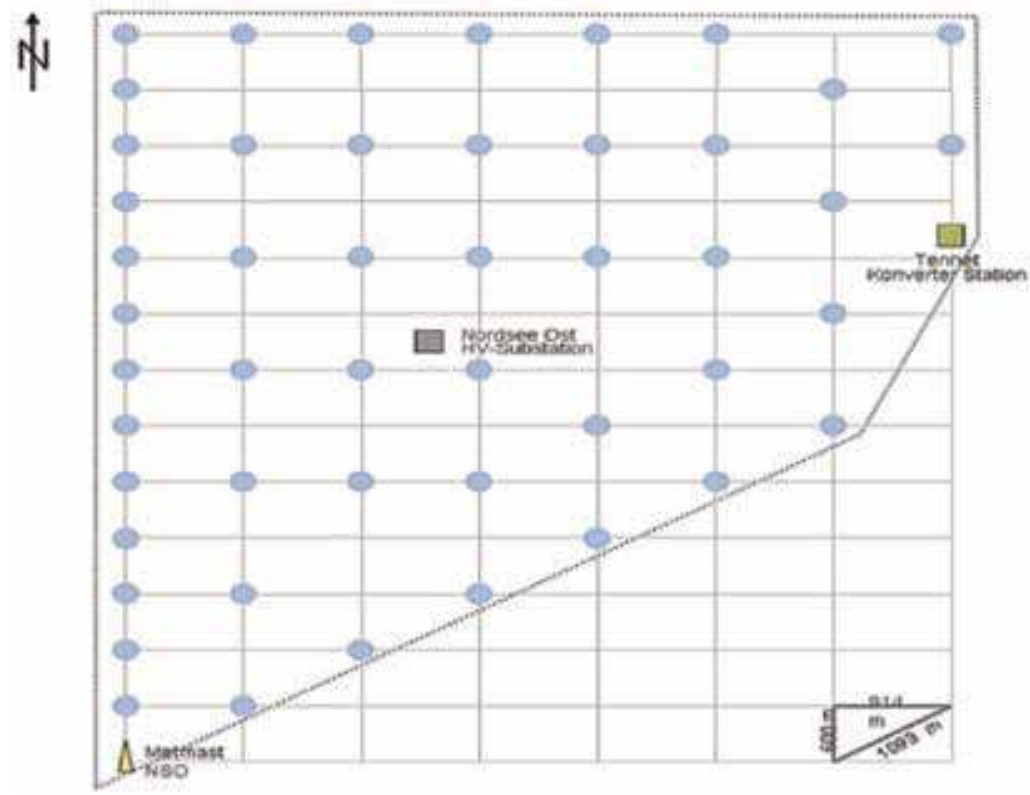

Figure 4.

Wind turbine layout of NordseeOst (RWE international SE, 2016).

The wind turbines used in the German wind farm was manufactured by Senvion. The 6.2M126 wind turbine model has a rated power of 6.15 MW and a designed rotor diameter of $126 \mathrm{~m}$. The parameters for the wind turbine model presented are based on the design data provided by the manufacturer in Tables 1 and 2. The data from Table 1 are the specifications for the wind turbine used in the aerodynamic and mechanical blocks. The data in Table 2 are the parameters of the electrical system used in the induction generator block.

With all the structure and framework laid out, the next step is to implement the model in the Simulink environment. The mathematical model for each block was created and coupled together to form a wind turbine as shown in Figure 5. Within each respective block, few mathematical equations governing their functions as

\begin{tabular}{lc}
\hline Nominal power $(\mathrm{kW})$ & 6150 \\
\hline Cut-in wind speed $(\mathrm{m} / \mathrm{s})$ & 3.5 \\
\hline Nominal wind speed $(\mathrm{m} / \mathrm{s})$ & 14 \\
\hline Cutout wind speed $(\mathrm{m} / \mathrm{s})$ & 25 \\
\hline Tip speed $(\mathrm{m} / \mathrm{s})$ & 79.8 \\
\hline Rotor diameter $(\mathrm{m})$ & 126 \\
\hline Rotor area $\left(\mathrm{m}^{2}\right)$ & 12,469 \\
\hline Rated rotor speed $(\mathrm{rpm})$ & 12.1 \\
\hline Hub height $(\mathrm{m})$ & 92 \\
\hline Blade length $(\mathrm{m})$ & 61.5 \\
\hline Gear ratio & $1: 97$ \\
\hline
\end{tabular}

Table 1.

Design data for the 6.2M126 [13]. 


\begin{tabular}{lc}
\hline Nominal power $(\mathrm{kW})$ & 6150 \\
\hline Nominal voltage $(\mathrm{kV})$ & $20 / 30 / 33$ \\
\hline Nominal frequency $(\mathrm{Hz})$ & 50 \\
\hline Stator voltage $(\mathrm{kV})$ & 6.6 \\
\hline Nominal speed $(\mathrm{rpm})$ & 1170 \\
\hline Speed range $(\mathrm{rpm})$ & $750-1170$ \\
\hline
\end{tabular}

Table 2.

Parameters for the generator [13].

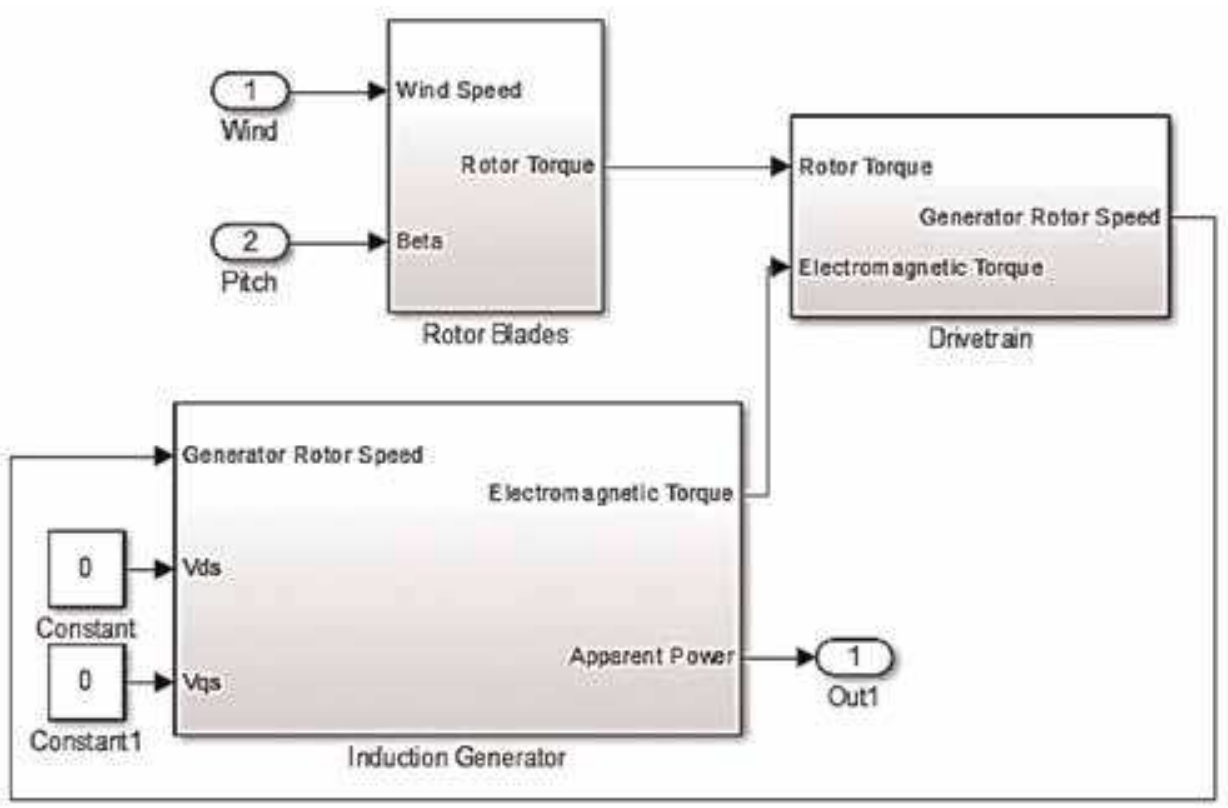

Figure 5 .

Wind turbine model in Simulink.

described in Section 2.1 were modeled. The parameters available from both Tables 1 and 2 were used in the equations.

The same approach was applied to the Jensen wake model. In the Simulink environment, the wind turbine model in blue and the wake model in red were duplicated and arranged to mimic the NordseeOst in Figure 6. The wake model was used when there is a wind turbine directly ahead of another. There is a spacing of one or two grid lines that corresponds to $914 \mathrm{~m}$ and $1828 \mathrm{~m}$, respectively, with reference to Figure 4. For instance, the first column of wind turbines is not affected by any wake losses; hence the wake model is not required. The wind speed for the second column of turbines that are influenced by the wake effect from the first column is calculated from the first wake model block in Figure 6. The process is repeated for the remaining wind turbines. With a user-defined wind input, the simulation will compute the output of each turbine and collectively will be summed up to give the total power production of the wind farm.

The wind data is gathered from an online resource known as Earth. It is a visualization of global weather and ocean conditions forecasted by supercomputers. The platform is a hub of information from collective national agencies. The weather 


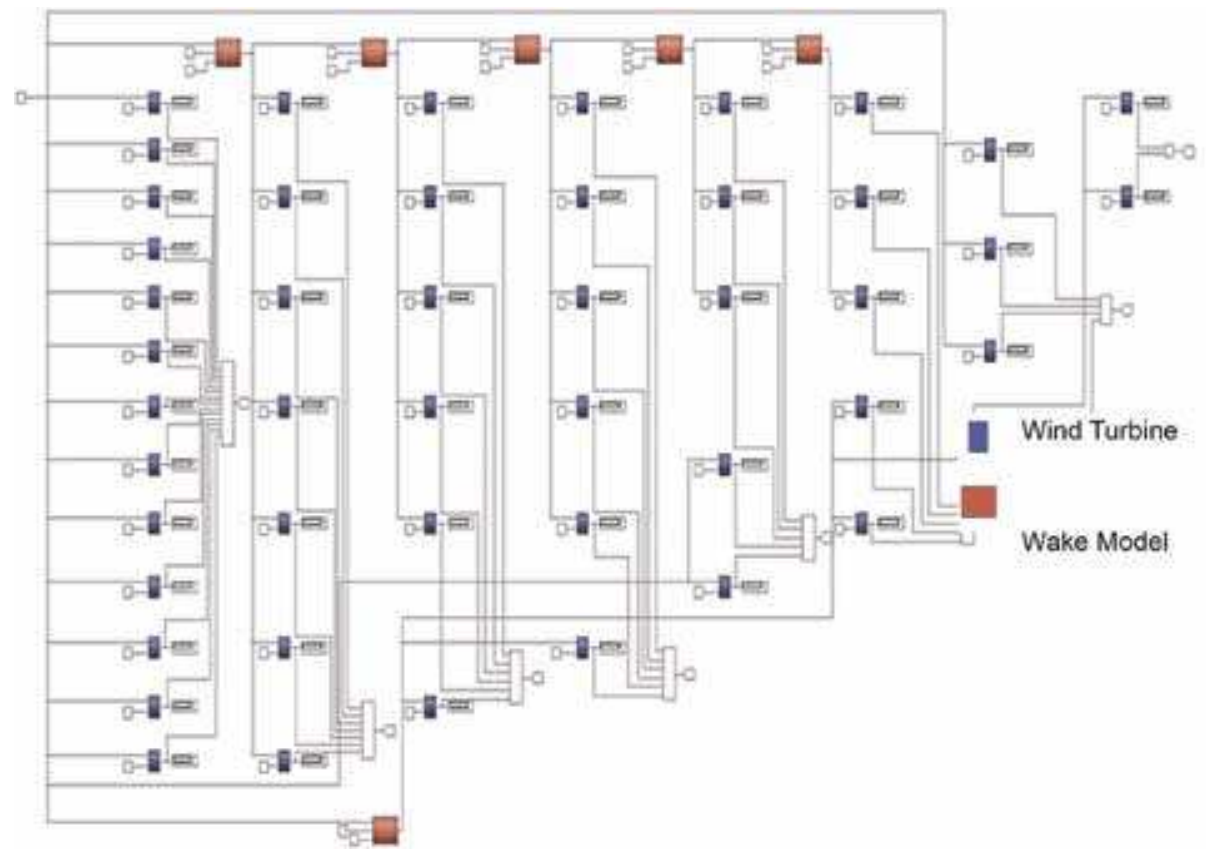

Figure 6.

Simulated NordseeOst in Simulink.

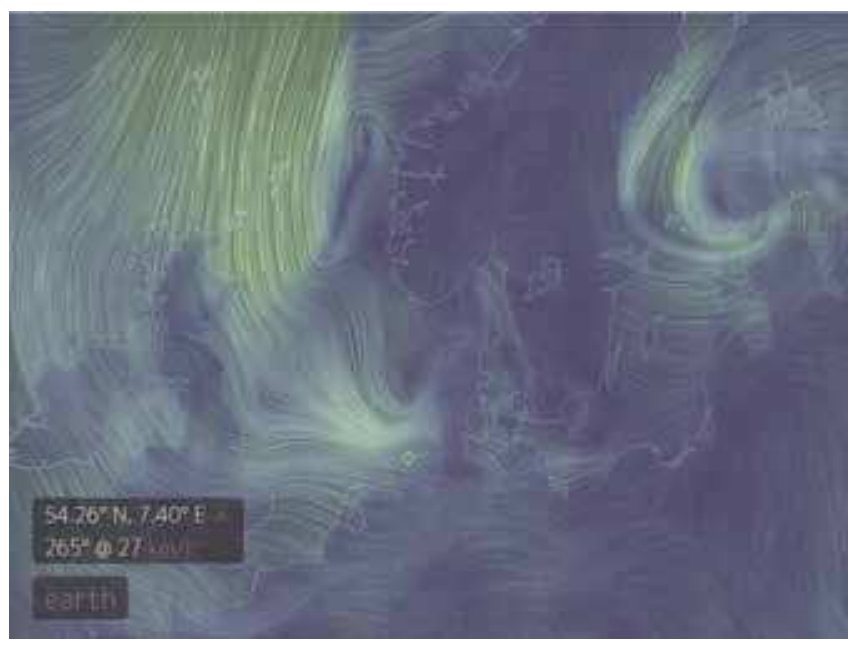

Figure 7.

Wind speed at NordseeOst from earth online.

and the wind information were obtained from the National Weather Service in the United States of America. Using the platform, the wind speed for the simulation input at any time frame was gathered from the NordseeOst coordinates as shown in Figure 7.

The live production data of NordseeOst in Figure 8 is available online through an interactive map by RWE Innogy, the owner of the mentioned wind farm. This value is used as cross-reference in conjunction with the simulated results. The accuracy and functionality of the simulation can be validated by comparing the results. 


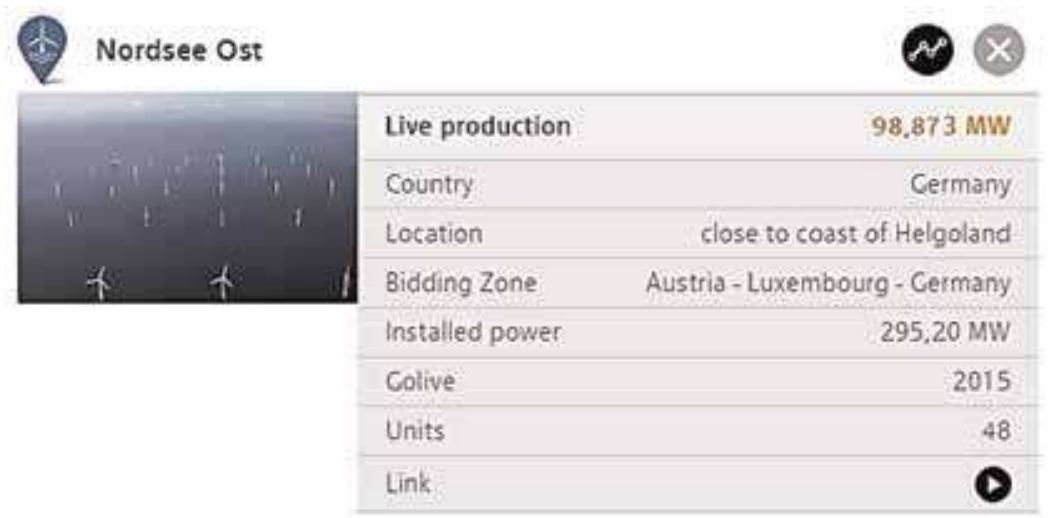

Figure 8.

Real-time output of NordseeOst [14].

\section{Results and discussion}

A simulation is performed over a range of wind speed $3-25 \mathrm{~m} / \mathrm{s}$ at an interval of $1 \mathrm{~m} / \mathrm{s}$. The range is determined by the specified cut-in and cutout wind speed of Senvion 6.2M126 offshore wind turbine. The projected power output for the simulated farm can be seen in Figure 9. It indicates an upward trend over the increase of wind speed. From a logical standpoint, the higher the wind speed, the higher the power is generated. In the simulation, it shows the power increases with the speed of the wind. The graph shows a steady rise from the specified cut-in speed of $3 \mathrm{~m} / \mathrm{s}$ where the turbine can produce useful work. It is evident that the gain begins to stabilize and reach the specified cutout speed of $25 \mathrm{~m} / \mathrm{s}$. The peak power of $300 \mathrm{MW}$ is quite close to the capacity of NordseeOst at $295 \mathrm{MW}$.

Theoretically, the $295 \mathrm{MW}$ should be attained at the nominal wind speed of $14 \mathrm{~m} / \mathrm{s}$ according to the Senvion 6.2M126 offshore wind turbine data sheet. However, the graph included the wake losses. With the required additional wind speed

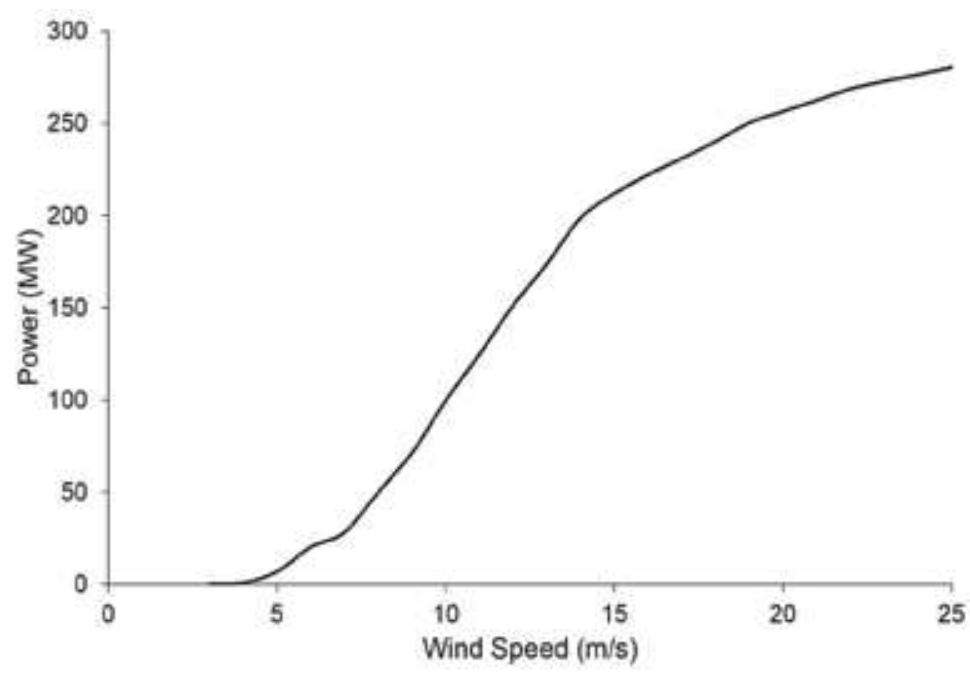

Figure 9.

Projected power output of simulated wind farm. 


\begin{tabular}{lcccc}
\hline Time (24 hours) & Wind speed $(\mathbf{m} / \mathbf{s})$ & Simulated $(\mathbf{k W})$ & Actual $(\mathbf{k W})$ & Difference (\%) \\
\hline 0800 & 5.1 & 8099 & 7816 & 3.49 \\
\hline 1100 & 7.4 & 35,958 & 33,339 & 7.86 \\
\hline 1400 & 10.5 & 112,555 & 110,678 & 1.70 \\
\hline 1700 & 10.0 & 99,691 & 95,611 & 4.27 \\
\hline 2000 & 6.4 & 23,686 & 22,434 & 5.58 \\
\hline 2300 & 6.6 & 25,104 & 23,297 & 7.76 \\
\hline & & & Average & 5.11 \\
\hline
\end{tabular}

Table 3.

Three hourly data log.

of $11 \mathrm{~m} / \mathrm{s}$ to achieve a rated output, it is evident that wake losses play a significant role in power efficiency. It emphasizes the importance of optimizing the wind turbine position to reduce the effect of wake losses. From the results gathered in the study of NordseeOst, it can be observed that the wind farm layout optimization can be further improved.

As seen in Table 3, a test run was performed with a wind speed of $5.10 \mathrm{~m} / \mathrm{s}$ in a particular period. The resulted power output of the simulation is $8099 \mathrm{~kW}$, while the actual power from the wind farm is $7816 \mathrm{~kW}$. There exists a difference of $3.5 \%$ in the results. Due to the limitation of the Earth where the weather forecast was updated every 3 hours, reading was taken every 3 hours for 18 hours to check for consistency. The average difference of $5.11 \%$ can be seen in Table 3 . There are several possible reasons for the discrepancy. One possible reason could be due to the sizing of components in the mechanical and electrical systems. With the absence of a physical system, the parameter of inertia, damping and stiffness coefficient in the drivetrain, and components such as resistance, inductance, and reactance in the induction generator are not readily available.

Another possible reason is the lapse in representing wake losses in a wake model. The Jensen wake model provides a simple and reasonably accurate representation. The orientation of turbine layout and wind direction will affect the direction and position of the wake cone. As a result, it caused the interaction of wake cones and altered the effect on wake loss. It is indicative that the Jensen wake model may have underestimated the effect of wake loss. Hence, further studies in improving the Jensen wake model are needed.

Another reason is the limitations of the wind forecast that is updated only every 3 hours. It is not synchronized with the live production data from RWE. It could cause some slight deviation in the simulated results. The availability of the actual wind speed at the wind farm site will be useful. It will allow a better and more accurate model validation.

However, the results attained are valid and have the potential for simulating and analyzing a wind farm. This methodology offers a solution in modeling the wind farm before any site implementation. It can contribute to future wind energyrelated studies that have not been addressed in the literature of wind farm modeling and simulation for smart cities.

\section{Conclusions}

The systematic approach in simulating an offshore wind farm model was presented. The simulation tool was used to predict the output power projection with 
consideration of the wake loss using Jensen wake model. The wind turbine model was adapted from Senvion 6.2M126 offshore wind turbine. Based on the case study of NordseeOst wind farm in Germany, the wind farm was replicated with multiple completed wind turbines with consideration of the wake model. The application of the wind farm was validated with wind speed ranging from 3 to $25 \mathrm{~m} / \mathrm{s}$. The simulated results were compared with the real-time data from the NordseeOst wind farm. The average difference is approximately $5.11 \%$. The same approach can be used in the design and developmental phase of any wind farm to predict the output power for smart cities.

For future works, the wind turbine model can be enhanced by incorporating details and intricate representative of various systems used in the modeling. The simulation results can be verified by comparing with other simulation tools such as Wind Atlas Analysis and Application Program (WAsP). An improved wake loss model and layout optimization will be considered in future studies.

\title{
Acknowledgements
}

The author would like to express his sincere gratitude to the staff of Newcastle University in the United Kingdom for their continuous support and encouragement.

\section{Conflict of interest}

There is no conflict of interest in this chapter.

\section{Author details}

\author{
Cheng Siong Chin ${ }^{1 *}$, Chu Ming $\operatorname{Peh}^{1}$ and Mohan Venkateshkumar ${ }^{2}$ \\ 1 Faculty of Science, Agriculture, and Engineering, Newcastle University in \\ Singapore, Singapore
}

2 Department of Electrical and Electronics Engineering, The Aarupadai Veedu Institute of Technology, Chennai, India

*Address all correspondence to: cheng.chin@ncl.ac.uk

\section{IntechOpen}

(C) 2020 The Author(s). Licensee IntechOpen. Distributed under the terms of the Creative Commons Attribution - NonCommercial 4.0 License (https://creativecommons.org/ licenses/by-nc/4.0/), which permits use, distribution and reproduction for non-commercial purposes, provided the original is properly cited. (cc) BY-NC 


\section{References}

[1] Sun X, Huang D, Wu G. The current state of offshore wind energy technology development. Energy. 2012; 41(1):298-312

[2] González-Longatt F, Wall P, Terzija V. Wake effect in wind farm performance: Steady-state and dynamic behavior. Renewable Energy. 2012; 39(1):329-338

[3] Martinez J. Modelling and control of wind turbines [Master thesis]. UK: Imperial College London; 2007

[4] Singh M, Santoso S. Dynamic Models for Wind Turbines and Wind Power Plants. Texas: National Renewable Energy Laboratory; 2011

[5] Bekker J. Efficient modelling of a wind turbine system for parameter estimation applications [Master thesis]. South Africa: Stellenbosch University; 2012

[6] Ahmadi M. Analysis and study of floating offshore wind turbines [Master thesis]. US: University of Toledo; 2013

[7] Saheb-Koussa D, Haddadi M, Belhamel M, Koussa M, Noureddine S. Modeling and simulation of Windgenerator with fixed speed wind turbine under Matlab-Simulink. Energy Procedia. 2012;18:701-708

[8] Gagnon R. 2016. Wind Farm (IG) MATLAB \& Simulink Example. Mathworks.com. Available at: http:// www.mathworks.com/help/physmod/ sps/examples/wind-farm-ig.html [Accessed: 02 January 2018]

[9] Betz A. Wind-Energie und ihreausnutzungdurchWindmühlen. Göttingen: Vandenhoeck; 1926

[10] Chong N, Ran L. Offshore Wind Farms: Technologies, Design and Operation. United Kingdom: Woodhead
Publishing; 2016. https://www.amazon. com/Offshore-Wind-Farms-TechnologiesPublishing/dp/0081007795

[11] Manwell J, McGowan J, Rogers A. Wind Energy Explained. Chichester, UK: Wiley; 2009

[12] RWE. 2016. NordseeOst. Available at: http://www.rwe.com/web/cms/en/ 400596/rwe-innogy/sites/wind-offshore/ in-operation/nordsee-ost/ [Accessed: 02 January 2018]

[13] Wind Turbine Model 6.2M126. 2016. Available at: https://www. senvion.com/global/en/wind-energysolutions/wind-turbines/ $6 \mathrm{xm} / 62 \mathrm{~m} 126 /$ [Accessed: 02 January 2018]

[14] RWE Innogy. 2016. Rwerenewableslive.com. Available at: http://rwe-renewableslive.com/\#/map/ EU/NSO1 [Accessed: 02 January 2018] 


\title{
Wind Energy and Multicriteria Analysis in Making Decisions on the Location of Wind Farms: A Case Study in the North-Eastern of Poland
}

\author{
Grażyna Easka
}

\begin{abstract}
This chapter presents an investigation of different methods of multicriteria analysis and different rules of proceedings that have to be taken into account for making decision about location of a wind farm with application in the north-eastern (NE) Poland. Ten multicriteria analyses were discussed taking into account the main criteria on which they are based on utility functions (MAUT, AHP, and DEMATEL), relationship outranking (ELECTRE, PROMETHEE, and ARROW-RAYNAUD), distances (TOPSIS), and decision support (BORDA ranking methods and their modified and COPELAND). Taking into account of nine criteria that should be met by the location of 15 wind turbines in Krynki and Szudzialowo communities, the main three criteria (C3, C8, and C9) were found to differentiate location of eight wind turbines (T-6-T-13), according to two variants (I and II). The Borda ranking method proved that from among the two variants considered, the more suitable location of wind turbines is second variant W II than first variant W I. Variant W II had a higher altitude of the terrain (C3) and less risk of impact on birds (C8) and bats species (C9) than variant W I.
\end{abstract}

Keywords: wind energy, wind farms, multicriteria decision analysis, optimum variant, ranking methods

\section{Introduction}

Management in conditions of sustainable development requires making rational decisions $[1,2]$. Each decision-making process has multicriteria character due to the complexity of the problem, and the selection of the optimal solution is complicated $[3,4]$. The use of multicriteria analyses, during which a set of related criteria and variants are analyzed, enables creating, justifying, and transforming preferences in the decision-making process [5, 6]. Multicriteria Decision Making (MCDM) or Multicriteria Decision Analysis (MCDA) methods were used to support decision making in case of problems where conflicting environmental, technical, economic, societal, and esthetic objectives are involved [7-13]. MCDA is suitable for supporting decision making dealing with sustainability issues and 
can use the location of wind turbines, which should meet a number of criteria in development of wind energy production $[14,15]$.

Multiple criteria decision analysis for energy and environmental security, as well as planning the location of wind turbines, depends on many factors [16-20]. Decision problems associated with determining the suitability of the site for the location of the wind farm can be solved by using multicriteria analysis, which allow to select the optimal solution of the many available options $[16,17]$. The selection is made on the basis of established criteria, which have a significant impact on the implementation and operation of the project $[21,22]$. This chapter presents the discussion of different methods of multicriteria analysis and different rules of proceedings that have to be taken into account for making decision about location of a wind farm made of 15 turbines in the area of Krynki and Szudzialowo communities in the NE Poland.

There are numerous methods of multicriteria decision; therefore, the choice of optimal method for the decision-making process is very important [23, 24]. Each of the presented methods has its advantages as well as disadvantages and limitations, which makes it necessary to examine them to find the best solution [25]. The choice of particular method can itself reach the dimension of a multicriteria problem [26]. In this study, 10 multicriteria decision analysis (MCDA) methods were discussed taking into account the main criteria on which they are based on utility functions (MAUT, AHP, and DEMATEL) [27, 28], relationship outranking (ELECTRE, PROMETHEE, and ARROW-RAYNAUD) [29, 30], distances (TOPSIS) [31], and decision support (BORDA ranking methods and their modified and COPELAND) [32] (Figure 1). The final location of the wind farm made up of 15 turbines in the NE Poland was solved on the basis of multicriteria analysis and choosing the optimum variant.

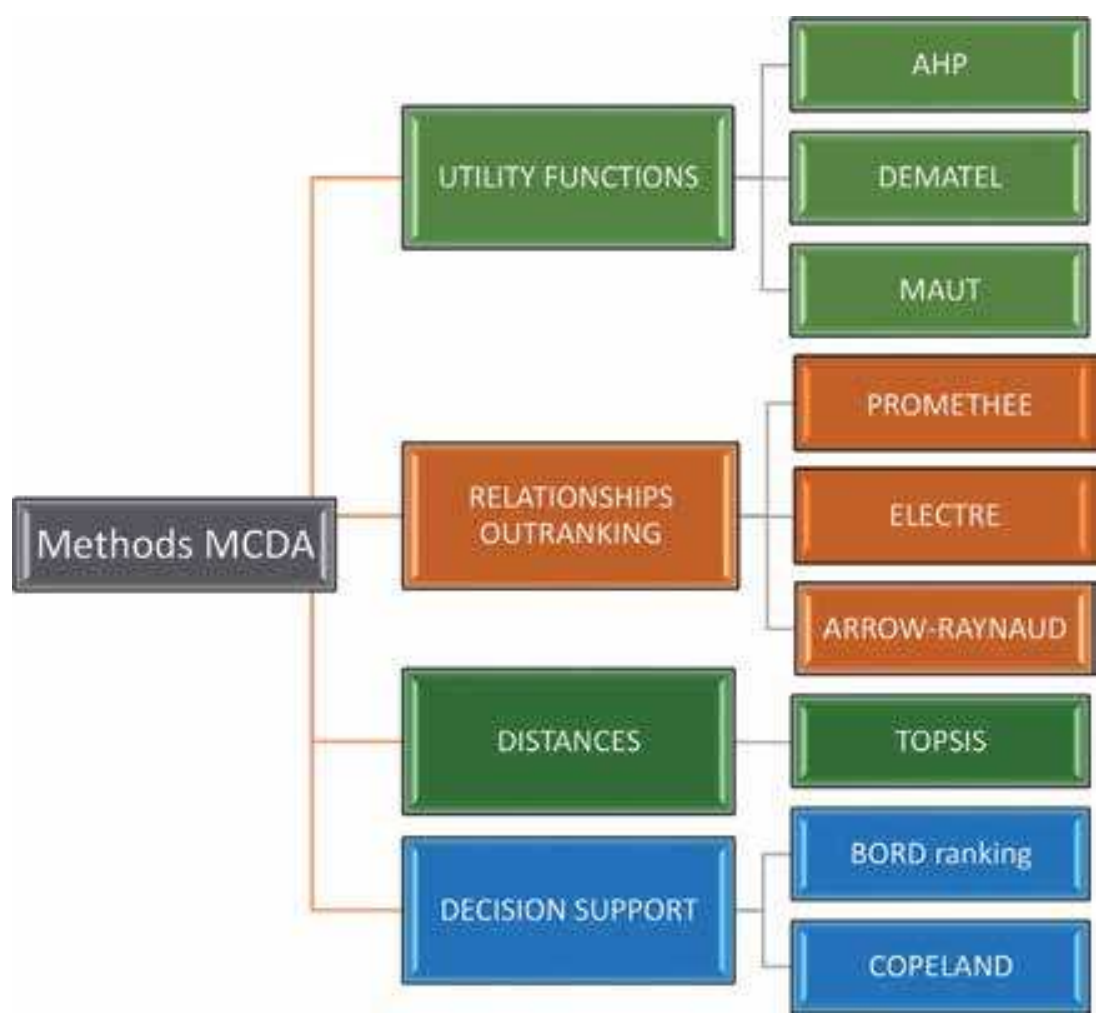

Figure 1.

Ten multicriteria decision analysis (MCDA) in making decisions on the location of wind farms 


\section{Methods of multi-criteria analysis}

The problems with making decision on farm location were analyzed taking into account the nine criteria having essential effect on the realization of a given investment [15]:

- Criterion 1 (C1) - The presence of natural environment elements under legal protection, including nature reserves, protected landscape, and monuments of nature determined based on the interactive map of protected areas [33] and results of a year-long vegetation inventory [34]; C1 was present or absent.

- Criterion 2 (C2) - Evaluation of wind energy resources on the basis of maps defining the area of wind energy in Poland [35] and maps illustrating the wind speed in the area of the country [36]; C2 was analyzed as very highly favorable, very favorable, favorable, little favorable, or unfavorable.

- Criterion 3 (C3) - Difference in the altitude of the terrain of turbine possible location on the basis of topographic maps from Geoportal [37]; C3 was expressed in meters above mean sea level (AMSL).

- Criterion 4 (C4) - Terrain roughness on the basis of the table class roughness [18]; C4 had a value of 0 (water surface) to 4 (urban agglomerations).

- Criterion 5 (C5) -No risk of floods or flooding on the basis of the flood risk maps [38]; C5 was present or absent.

- Criterion 6 (C6) — Technological infrastructure and communication possibilities on the basis of "Local Developmental Plans" in Krynki [39] and Szudzialowo communities [40]; C6 was analyzed as very good, good, bad, and very bad.

- Criterion 7 (C7) —Culture and landscape valors of Krynki [41] and Szudzialowo communities [42] on the basis of "Theories of urban planning"; C7 was present or absent.

- Criterion 8 (C8)—Results of a year-long ornithological monitoring [34]; C8 was analyzed as the number (1-5) of protected bird species occurring in a given area.

- Criterion 9 (C9) - Results of a year-long chiropterological monitoring [34]; C9 was analyzed as the level of activity of bats expressed on the scale-very high, high, low, or very low.

The field study of the vegetation inventory, ornithological, and chiropterological monitoring was performed from July 2017 to July 2018. The field study included the phytosociological analyses of plant communities, cartographic study of vegetation, and sites of protected plant species with the use of GPS technique and identification of habitats of the plant patches studied. In field study in the location of 15 wind turbines in Krynki and Szudzialowo communities, 132 phytosociological BraunBlanquet releves were taken [34].

\section{Selection of MCDA in making decisions on the location of wind farms}

The purpose of the analysis is to find the way that will lead to a better solution than the others. Multicriteria decision support is usually defined as making 
decisions in the presence of many criteria, taking into account several, often contradictory, points of view $[4,43]$. The goal is to achieve such an effect that maximizes the multicriteria objective function, which can be written as follows (Eq. (1)):

$$
F(x)=\max (f 1(x), f 2(x), \ldots, f j(x)),
$$

with restriction $x \in A^{\text {dop }}$,

where $A^{\text {dop }}$ is a set of acceptable solutions; and $f j(x)$ is the individual partial criterion functions for $j=1,2, \ldots, J$.

The analysis begins with a selection of decision variants that will be considered during the decision procedure [44-48]. The next step is the selection of criteria that are the measures of evaluation and the ranking of criteria according to their importance (by assigning weights to them) [21,22]. Criteria that are benefits are called stimulants $[49,50]$. They allow the variants to be ordered, so that the more benefits they bring, the higher the weight values in the light of a given criterion. On the other hand, the criteria, which are of a cost nature, are referred to as destimulants $[51,52]$. In assigning weights to individual criteria, the decision-maker preferences are expressed, and they often determine the choice of a particular variant. In these types of cases, it is recommended to perform a sensitivity analysis that focuses on considering changes in function coefficients or free words. The result of the multicriteria decision support process also depends on the accuracy of the option assessments $[53,54]$. It is important to carry out a synthetic assessment of individual variants by appropriate aggregation of partial assessments [55].

In this study, 10 multicriteria methods were used, with their names used the acronym for the English or French word. The effectiveness of the multicriteria method for the choice of location of 15 wind turbines in the NE Poland was evaluated. The multicriteria analysis was discussed taking into account the main criteria on which they are based on utility functions (MAUT, AHP, and DEMATEL), relationship outranking (ELECTRE, PROMETHEE, and ARROW-RAYNAUD), distances (TOPSIS), and decision support (BORDA ranking methods and their modified and COPELAND method; Figure 1).

\subsection{Analytic Hierarchy Process (AHP)}

Analytic Hierarchy Process ( $A H P$ ) was created by Thomas L. Saaty at the University of Pittsburgh in the 1970s [56-58]. This method is based on a linear additive utility function [58]. The basis of AHP is hierarchical decomposition evaluation criteria, which allows to connect the criteria quantified and not quantified and objectively measurable with subjective [59-61]. AHP is based on three basic rules $[57,58]$ as follows:

- The structure of the decision problem is presented in the form of a hierarchy of goals, criteria, subcriteria, and variants.

- Preference modeling is carried out by comparing pairs of elements at each level of the hierarchy.

- Ordering of variants takes place through the synthesis of preference assessments from all levels of the hierarchy.

AHP method involves a hierarchic decomposition of the problem decomposed into components and followed by evaluation of criteria and variants by their comparison in pairs (Figure 2). The AHP method is based on functionality and is 


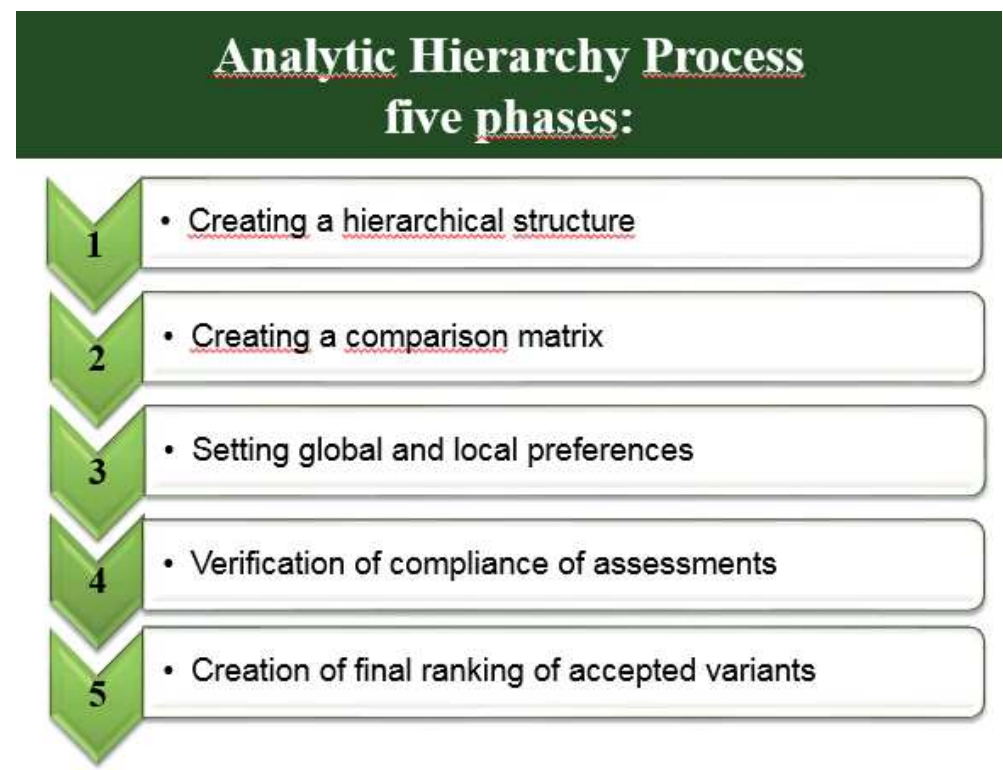

Figure 2.

The five phases of Analytic Hierarchy Process.

hierarchical approach to the problem. The concept of hierarchy has its application on different levels of analyses [62,63]. Hierarchical problem analysis is useful when not you can determine the functional relationship between the components of the dilemma decision making. The method is characterized by the occurrence of subjective criteria assessments and variants because they result from the decisionmaker's nonobjective assessments. Characteristic of this method is to compare the criteria adopted with each other, what the result is a comparison matrix (Figure 2). The next step is determining global and local preferences based on a comparison matrix and calculating the compliance factor. The final stage is to create a final ranking of the alternatives adopted. It is possible by calculating the utility function of given variants (Figure 2).

The hierarchy of values in the AHP method is well-defined, at the highest level is the superior aim, which is the choice of wind farm location, the lower levels are the criteria that must be met for making the right decision presented in the methodology, and the lowest levels are the variants of decision. The evaluation of criteria and variants is exclusively subjective and depends on decision-making body, which can hardly be accepted for the proper choice of wind farm. The AHP method allows the use of a nine-level verbal scale transformed on a numerical scale. This should facilitate making decisions, however, often leads to situations where relationships are difficult to define between variants and criteria due to their nature. The final assessment in AHP may not give an unequivocal answer as to which of the analyzed variants is the most advantageous too, because with a slight change in the decisionmaker preferences the ranking will change, which does not guarantee the choice of the best solution.

\subsection{Multiattribute Utility Theory (MAUT)}

Multiattribute Utility Theory (MAUT) is used to evaluate trade-offs between alternatives and their effects on objectives $[3,4,53]$. MAUT is applied to identify variants of locations. It is based on the defined function of utility $u_{i}\left(K_{j}\right)$ and helps settle the hierarchy and ranks of particular variants, and then it orders the criteria 
which a given location must meet. This method cannot be applied for the choice of location of wind turbines depending on many environmental criteria as the criteria of this method need to be normalized, i.e., their units must be uniform. It is then necessary to define partial function of utility, hence the preferences of the decision-making organ (persons) regarding the variants. The preferences are always subjective and do not take into account the limitations imposed by significant environmental factors.

\subsection{DEcision MAking Trial and Evaluation Laboratory (DEMATEL)}

The next method is to DEcision MAking Trial and Evaluation Laboratory (DEMATEL) used for direct analysis and intermediate cause-and-effect relationships between elements of the system (factors or criteria) with respect to its kind and severity [64-68]. DEMATEL is a good tool for evaluating the direct and indirect cause and effect relations between the criteria. The method assumes the three types of relations between two criteria: the first criterion has impact on the second one, and the second one has impact on the first one, or they are not related. In the DEMATEL method, it is possible to model the interactions between the criteria taking into account the direct and indirect relations between them. This method was found to be inadequate for making decisions about location of wind turbines as it is totally subjective and the decision depends on the opinions of the deciding body. In this method, the relations between criteria are analyzed, but the list of criteria and the assigned values describing their interaction in pairs depend on the information provided by the decision-making persons in the form of interviews or questionnaires.

\subsection{ELimination and Choice Translating REality (ELECTRE)}

The another method named ELECTRE is the acronym for the French word for the ELimination Et Choix Traduisant la REalité. In this method, the preferences of the decision maker were modeled on the basis of binary relation outranking $[4,48,69]$. ELECTRE methods are most often used when dealing with a greater set of criteria that can be assigned to much differing values. At the first step, the values of particular criteria are established and assessed to certain weights, so that the sum of the weights gives one. Then, all the variants are compared in pairs using the outranking relation, which boils down to the acceptance of the risk of treating one variant as definitely better than the other one even if the two variants are similar. The ordering of variants on the basis of the outranking relation and recommendation of one variant over the other depends entirely on the preferences of the decision-making persons, which is a definite limitation of the objective choice [70, 71].

\subsection{Preference Ranking Organization METHod for Enrichment Evaluations (PROMETHEE)}

The method of Preference Ranking Organization METHod for Enrichment Evaluations (PROMETHEEs) was used to determine the synthetic ranking alternatives and pairwise comparisons and outranking relation $[5,72,73]$.

PROMETHEE is also based on outranking relation. This method involves construction of a decision matrix in which particular variants are compared in the light of established criteria. On the basis of a comparison of variants, the preferences of the decision-making body are expressed by the preference function taking values from 0 to 1 . The result of 1 corresponds to a strong preference of one variant 
over the other, and the value of 0 informs about no relation between the variants. The last stage of PROMETHEE is determination of preference indices referring to each pair of variants. This method is also inadequate for the objective choice of wind farm location because of the limitation of employing the preferences of the decision-making body [74].

PROMETHEE methods are characterized by the analysis of the diversity of assessments of individual variants for all criteria. The more varied the assessments are in the light of a given criterion, the better one of the variants is, whereas when the difference does not take large values, the equivalence of the variants occurs or one of the variants slightly outweighs the others. The criteria are assigned to a preference function that measures the strength of preferences. The function presents the transformation of the difference in evaluation of the analyzed alternatives due to the given criterion (Trzaskalik 2014). The final ranking is obtained on the basis of flows, which are determined using aggregated preference indices [75].

The PROMETHEE method takes into account the decision-maker preferences without the need for a series of onerous comparisons and points. The disadvantage of this method is the need to determine the value and dependence of individual specific parameters, of which the interpretation can cause great difficulties.

\subsection{Arrow-Raynaud method}

Arrow and Raynaud belong to the "Outranking methods" and constitute a class of ordinal ranking algorithms for multicriteria decision making [9]. The authors of this method argue that the axiomatic formulation offers the surest path to a solution that is as objective as possible, minimally distorted by the unwitting imposition of personal values [29]. They then develop a system of consistent and appealing axioms, confront the paradoxes that put axiomatic systems in general at risk, and demonstrate the applicability of their system to realistic industrial outranking problems. Even within the axiomatic framework, however, some leeway remains for subjective choice and conscious value decisions [49]. One ad-hoc criterion of choice the authors selected was that their method should be neither so flexible and open that personal biases might easily slip in nor so artificially rigid that the play of intuition and creativity was systematically excluded.

\subsection{Technique for Order Preference using Similarity to Ideal Solution (TOPSIS)}

TOPSIS is a Technique for Order Preference using Similarity to Ideal Solution. This is a multicriteria method developed in the early 1980s by C.L. Hwang and K. Yoon, and its other variation —fuzzy model—proposed by C.T. Chen in 2000 [6]. Among other multicriteria methods, it is distinguished by the use of the relative distance value of individual decision alternatives to the reference (ideal) and worst (anti-ideal) solution. In this situation, the most advantageous variant is one that is relatively closest to the pattern and relatively furthest anti-patterner [64]. The calculation procedure in the TOPSIS method consists of six phases (Figure 3).

The TOPSIS method is a similarity method to an ideal solution, which is one of the distance methods. Variants are assessed by determining their distance from the pattern (ideal) and anti-pattern (anti-ideal) [76, 77]. Determination of the preferential sequence requires taking into account the weightings of the criteria and normalizing the option assessments in the light of the criteria. The best solution is characterized by the closest position to the ideal and the furthest relative to the anti-ideal. It allows to determine the values of the synthetic measure, which indicates the place of individual variants in the ranking $[76,77]$. 


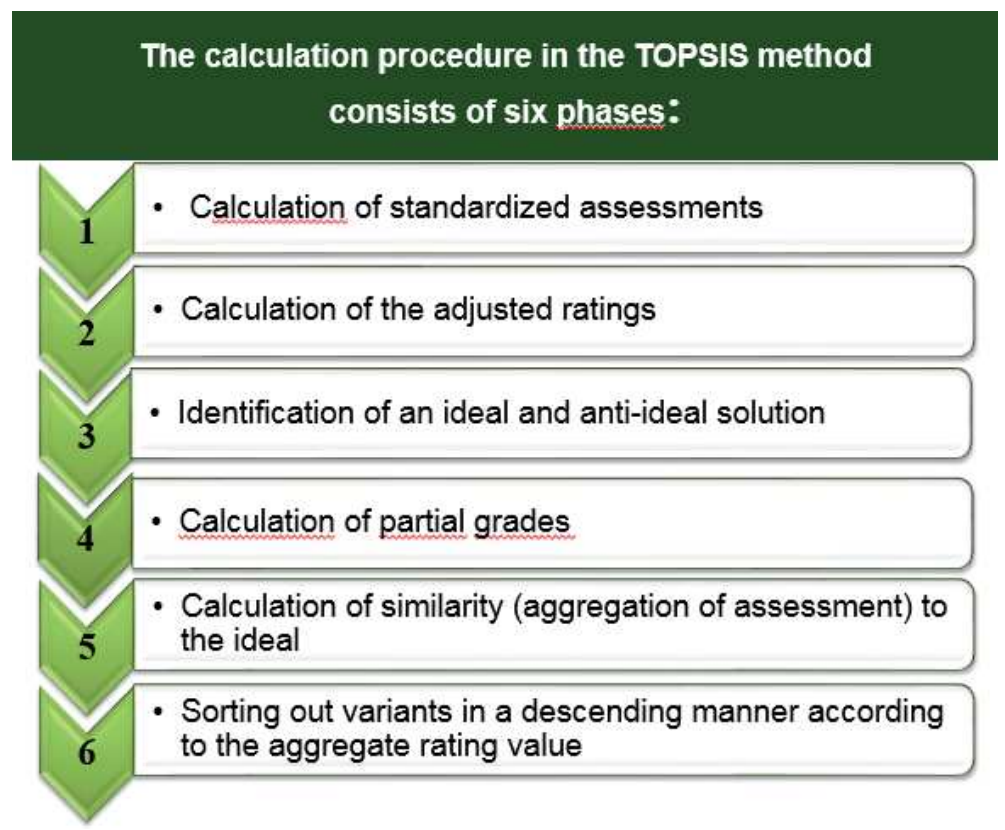

Figure 3.

The calculation procedure in the TOPSIS method.

The TOPISIS method does not take into account the subjective feelings of the decision maker at all, which results in obtaining a ranking and choosing the location of the investment that is not entirely in the most favorable position.

\subsection{The Borda count ranking method}

The very important for decision support was Borda ranking method, which did not use standardized assessments to the criteria and giving them weights in order to determine their validity $[14,15,19,20]$.

In the Borda method, all criteria are numbered according to their importance. Particular variants are considered taking into account subsequent criteria numbered from the most to the least important one, with the numbers making a scale from 1 to $n$. If a few variants have the same score, so take the same position, the averaging of score is made $[78,79]$. The best variant is that to which the maximum Borda count is assigned. Simple criteria do not require normalization and do not take into account the preferences of decision-making body, which excludes the subjective character of decision on the location of wind farm.

\subsection{Copeland's method}

Copeland's method belongs to the decision support, but it concerns the choice of the winning option [4]. It consists in comparing variant $A$ with $B$ and determining the number of criteria for which variant $A$ is better than variant $B(s+)$, as well as the number of those criteria for which variant $A$ is worse than variant $B(s-)$. In this case, the variable $A$ is incremented (the value of the variable increases by one), when $s+>s-$, or the variable B is incremented otherwise. This follows the designation of the number of wins for all determined criteria and selected of the winner variant, which means (Copeland rule) that the winner is the one for whom the difference in the number of wins and the number of lost with other candidates (pair comparisons) is maximum. 
Wind Energy and Multicriteria Analysis in Making Decisions on the Location of Wind Farms... DOI: $h$ ttp://dx.doi.org/10.5772/intechopen.90450

\section{Multicriteria analysis of a wind farm location by the Borda method}

The problems with making decision on farm location were analyzed taking into account the nine criteria having essential effect on realization of a given investment $[14,15]$. Taking into account of nine criteria that should be met by the location of 15 wind turbines in Krynki and Szudzialowo communities (Tables 1 and 2), the main three criteria (C3, C8, and C9) were found to differentiate location of eight wind turbines (T-6-T-13), according to two variants (I and II). Criterion 3 (C3stimulant) regards the difference in the terrain altitude expressed in meters above sea level. Criterion 8 (C8-destimulant) is the number of protected bird species occurring in a given area, and Criterion 9 (C9-destimulant) is the level of activity of bats expressed on the scale from low to very high (Tables 1 and 2).

\begin{tabular}{|c|c|c|c|c|c|c|c|c|c|}
\hline $\begin{array}{l}\text { Criteria } \\
\text { turbines }\end{array}$ & C1 & $\mathrm{C} 2$ & $\begin{array}{c}\text { C3 } \\
\text { [AMSL*] }\end{array}$ & C4 & C5 & C6 & C7 & $\mathrm{C} 8$ & C9 \\
\hline 1 & Absent & Favorable & 185 & 0.5 & Absent & $\begin{array}{l}\text { Very } \\
\text { good }\end{array}$ & Absent & 2 & Low \\
\hline 2 & Low & Favorable & 170 & 0.5 & Absent & $\begin{array}{l}\text { Very } \\
\text { good }\end{array}$ & Absent & 2 & Low \\
\hline 3 & Absent & Favorable & 170 & 0.5 & Absent & $\begin{array}{l}\text { Very } \\
\text { good }\end{array}$ & Absent & 2 & Low \\
\hline 4 & Absent & Favorable & 170 & 0.5 & Absent & $\begin{array}{l}\text { Very } \\
\text { good }\end{array}$ & Absent & 2 & Low \\
\hline 5 & Absent & Favorable & 180 & 0.5 & Absent & $\begin{array}{l}\text { Very } \\
\text { good }\end{array}$ & Absent & 2 & Low \\
\hline 6 & Absent & Favorable & 170 & 0.5 & Absent & $\begin{array}{l}\text { Very } \\
\text { good }\end{array}$ & Absent & 4 & High \\
\hline 7 & Absent & Favorable & 170 & 0.5 & Absent & $\begin{array}{l}\text { Very } \\
\text { good }\end{array}$ & Absent & 4 & High \\
\hline 8 & Absent & Favorable & 175 & 0.5 & Absent & $\begin{array}{l}\text { Very } \\
\text { good }\end{array}$ & Absent & 4 & High \\
\hline 9 & Absent & Favorable & 180 & 0.5 & Absent & $\begin{array}{l}\text { Very } \\
\text { good }\end{array}$ & Absent & 5 & $\begin{array}{l}\text { Very } \\
\text { high }\end{array}$ \\
\hline 10 & Low & Favorable & 180 & 0.5 & Absent & $\begin{array}{l}\text { Very } \\
\text { good }\end{array}$ & Absent & 5 & $\begin{array}{l}\text { Very } \\
\text { high }\end{array}$ \\
\hline 11 & Absent & Favorable & 185 & 0.5 & Absent & $\begin{array}{l}\text { Very } \\
\text { good }\end{array}$ & Absent & 4 & High \\
\hline 12 & Absent & Favorable & 185 & 0.5 & Absent & $\begin{array}{l}\text { Very } \\
\text { good }\end{array}$ & Absent & 5 & $\begin{array}{l}\text { Very } \\
\text { high }\end{array}$ \\
\hline 13 & Absent & Favorable & 185 & 0.5 & Absent & $\begin{array}{l}\text { Very } \\
\text { good }\end{array}$ & Absent & 5 & $\begin{array}{l}\text { Very } \\
\text { high }\end{array}$ \\
\hline 14 & Absent & Favorable & 177.5 & 0.5 & Absent & $\begin{array}{l}\text { Very } \\
\text { good }\end{array}$ & Absent & 1 & High \\
\hline 15 & Low & Favorable & 187.5 & 0.5 & Absent & $\begin{array}{l}\text { Very } \\
\text { good }\end{array}$ & Absent & 1 & High \\
\hline
\end{tabular}

*AMSL_above mean sea level.

Table 1.

Adopted criteria in relation to the location of a wind farm made up of 15 turbines in the area of Krynki and Szudzialowo communities-Variant I. 


\begin{tabular}{|c|c|c|c|c|c|c|c|c|c|}
\hline $\begin{array}{l}\text { Criteria } \\
\text { turbines }\end{array}$ & $\mathrm{C} 1$ & $\mathrm{C} 2$ & $\begin{array}{c}\text { C3 } \\
{\left[\mathrm{AMSL}^{*}\right]}\end{array}$ & $\mathrm{C} 4$ & C5 & C6 & C7 & $\mathrm{C} 8$ & C9 \\
\hline 1 & Absent & Favorable & 188.5 & 0.5 & Absent & $\begin{array}{l}\text { Very } \\
\text { good }\end{array}$ & Absent & 0 & Low \\
\hline 2 & Absent & Favorable & 175 & 0.5 & Absent & $\begin{array}{l}\text { Very } \\
\text { good }\end{array}$ & Absent & 0 & Low \\
\hline 3 & Absent & Favorable & 175 & 0.5 & Absent & $\begin{array}{l}\text { Very } \\
\text { good }\end{array}$ & Absent & 0 & Low \\
\hline 4 & Absent & Favorable & 175 & 0.5 & Absent & $\begin{array}{l}\text { Very } \\
\text { good }\end{array}$ & Absent & 0 & Low \\
\hline 5 & Absent & Favorable & 182.5 & 0.5 & Absent & $\begin{array}{l}\text { Very } \\
\text { good }\end{array}$ & Absent & 0 & Low \\
\hline 6 & Absent & Favorable & 175 & 0.5 & Absent & $\begin{array}{l}\text { Very } \\
\text { good }\end{array}$ & Absent & 1 & Low \\
\hline 7 & Absent & Favorable & 172.5 & 0.5 & Absent & $\begin{array}{l}\text { Very } \\
\text { good }\end{array}$ & Absent & 1 & Low \\
\hline 8 & Absent & Favorable & 180 & 0.5 & Absent & $\begin{array}{l}\text { Very } \\
\text { good }\end{array}$ & Absent & 1 & Low \\
\hline 9 & Absent & Favorable & 190 & 0.5 & Absent & $\begin{array}{l}\text { Very } \\
\text { good }\end{array}$ & Absent & 2 & High \\
\hline 10 & Absent & Favorable & 190 & 0.5 & Absent & $\begin{array}{l}\text { Very } \\
\text { good }\end{array}$ & Absent & 2 & High \\
\hline 11 & Absent & Favorable & 187.5 & 0.5 & Absent & $\begin{array}{l}\text { Very } \\
\text { good }\end{array}$ & Absent & 1 & Low \\
\hline 12 & Absent & Favorable & 195 & 0.5 & Absent & $\begin{array}{l}\text { Very } \\
\text { good }\end{array}$ & Absent & 1 & High \\
\hline 13 & Absent & Favorable & 195 & 0.5 & Absent & $\begin{array}{l}\text { Very } \\
\text { good }\end{array}$ & Absent & 1 & High \\
\hline 14 & Absent & Favorable & 180 & 0.5 & Absent & $\begin{array}{l}\text { Very } \\
\text { good }\end{array}$ & Absent & 0 & Low \\
\hline 15 & Absent & Favorable & 192.5 & 0.5 & Absent & $\begin{array}{l}\text { Very } \\
\text { good }\end{array}$ & Absent & 0 & Low \\
\hline
\end{tabular}

Table 2.

Adopted criteria in relation to the location of a wind farm made up of 15 turbines in the area of Krynki and Szudzialowo communities-Variant II.

Criterion 3 (stimulant) and criteria 8-9 (destimulant) in the Borda method proved that from among the two variants considered the more suitable location of wind turbines is second variant W II than first variant W I (Table 3). Variant W II had a higher altitude of the terrain (C3) and less risk of impact on birds (C8) and bats species (C9) than variant W I. The analysis was made on the basis of the initial data, ordering of variants, determination of Borda count, and final ranking of variants.

\section{Conclusions}

The different methods of multicriteria analyses (MAUT, AHP, DEMATEL, ELECTRE, PROMETHEE, ARROW-RAYNAUDA, TOPSIS, and COPELAND) are to a high degree subjective. Their final outcome often depends exclusively on 
Wind Energy and Multicriteria Analysis in Making Decisions on the Location of Wind Farms... DOI: http://dx.doi.org/10.5772/intechopen.90450

\begin{tabular}{|c|c|c|c|c|c|c|}
\hline \multirow[t]{4}{*}{ Turbines } & \multicolumn{6}{|c|}{ Criteria } \\
\hline & \multicolumn{2}{|c|}{ C3 } & \multicolumn{2}{|c|}{$\mathrm{C} 8$} & \multicolumn{2}{|c|}{ C9 } \\
\hline & \multicolumn{6}{|c|}{ Variants } \\
\hline & I & II & I & II & I & II \\
\hline $\mathrm{T} 6$ & 3 & 6 & 3 & 6 & 3 & 6 \\
\hline $\mathrm{T} 7$ & 3 & 6 & 3 & 6 & 3 & 6 \\
\hline $\mathrm{T} 8$ & 3 & 6 & 3 & 6 & 3 & 6 \\
\hline T9 & 3 & 6 & 6 & 5 & 3 & 6 \\
\hline T10 & 3 & 6 & 3 & 6 & 3 & 6 \\
\hline T11 & 3 & 6 & 3 & 6 & 3 & 6 \\
\hline T12 & 3 & 6 & 3 & 6 & 3 & 6 \\
\hline $\mathrm{T} 13$ & 3 & 6 & 3 & 6 & 3 & 6 \\
\hline
\end{tabular}

Table 3.

The Borda count ranging for two Variants - I and II in relation to the location of wind farms in the area of Krynki and Szudzialowo communities.

the preferences and priorities of decision-making persons [4]. For this reason to analyze the choice of location of wind farm in the area of Krynki and Szudzialowo communities, the Borda ranking method was used. This method does not require standardization of evaluations following from the criteria and endowing the criteria with weights. A uniform ordering scale is assumed, and all criteria are treated as equally important. The method provided an objective result that really depends on the criteria that should be met by the wind farm location [20].

The study in Krynki and Szudzialowo communities proved that the planned construction of wind farm would have a positive effect on the production of energy from renewable sources [80-85]. The choice of the optimum location of wind turbines was shown to have no negative impact on the natural environment, which is of key importance in the application of sustained technologies, that is to ensure a balance between economic and environmental factors and the needs and expectations of society [86-91].

\section{Acknowledgements}

This study was supported by a grant no. S/WBiIS/5/16 from the Ministry of Science and Higher Education of Poland.

\section{Conflict of interest}

The authors declare no conflict of interest. 


\section{Author details}

Grażyna Łaska

Faculty of Civil and Environmental Sciences, Białystok University of Technology, Białystok, Poland

*Address all correspondence to: g.laska@pb.edu.pl

\section{IntechOpen}

(C) 2020 The Author(s). Licensee IntechOpen. Distributed under the terms of the Creative Commons Attribution - NonCommercial 4.0 License (https://creativecommons.org/ licenses/by-nc/4.0/), which permits use, distribution and reproduction for non-commercial purposes, provided the original is properly cited. (cc) BY-NC 
Wind Energy and Multicriteria Analysis in Making Decisions on the Location of Wind Farms... DOI: http://dx.doi.org/10.5772/intechopen.90450

\section{References}

[1] Begić F, Afgan NH. Sustainability assessment tool for the decision making in selection of energy system-Bosnian case. Energy. 2007;32:1979-1985

[2] Carrera D, Mack A. Sustainability assessment of energy technologies via social indicators: Results of a survey among European energy experts. Energy Policy. 2010;38:1030-1039

[3] Keeney RL, Raiffa H. Decision with Multiple Objectives. New York: Wiley; 1976

[4] Figueira J, Greco S, Ehrgott M. Multiple criteria decision analysis: State of the art surveys. In: International Series in Operations Research \& Management Science. Boston: Springer Science + Bussines Media; 2005

[5] Peng Y, Wang G, Wang H. User preferences based software defect detection algorithms selection using MCDM. Information Sciences. 2012;191:3-13

[6] Chen JQ, Lee SM. An exploratory cognitive DSS for strategic decision making. Decision Support Systems. 2003;36:147-160

[7] Roy B. Paradigms and challenges. In: Figueira J, Greco S, Ehrgott M, editors. Multiple Criteria Decision Analysis: State of the Art Surveys. Boston: Springer Science + Bussines Media; 2005. pp. 3-24

[8] Belton V, Stewart TJ. Multiple Criteria Decision Analysis. Dordrecht: Kluwer Academic Publishers; 2002

[9] Arrow KJ, Raynaud H. Social Choice and Multicriterion Decision-making [Internet]. 1986. Available from: https:// mitpress.mit.edu/books/social-choiceand-multicriterion-decision-making [Accessed: 06 February 2019]

[10] Giampietro M, Mayumi K. Multiplescale integrated assessment of societal metabolism: Integrating biophysical and economic representations across scales. Population and Environment. 2000;22:155-210

[11] Giampietro M, Mayumi K. Multiplescale integrated assessment of societal metabolism: Introducing the approach. Population and Environment. 2000;22:109-154

[12] De Marchi B, Funtowicz SO, Lo Cascio S, Munda G. Combining participative and institutional approaches with multi-criteria evaluation. An empirical study for water issue in Troina, Sicily. Ecological Economics. 2000;34:267-282

[13] De Marchi B, Ravetz J. Participatory approaches to environmental policy, Concerted Action EVE. Policy Research Brief. 2001;10

[14] Wind in Power, European statistics, European Wind Energy Association [Interned]. 2015. Available from: http: european/wind-energy/association [Accessed: 08 February 2019]

[15] Synowiec W, Luc M. Multicriteria analysis of the suitability of land for wind energy development on the example of Rymanów commune. Geographical Review. 2013;85:323-352

[16] Karvetski CW, Lambert JH, Linkov I. Scenario and multiple criteria decision analysis for energy and environmental security of military and industrial installations. Integrated Environmental Assessment and Management. 2010;7:228-236

[17] Greening L, Bernow S. Design of coordinated energy and environmental policies: Use of multi-criteria decisionmaking. Energy Policy. 2004;32:721-735

[18] Olech S, Juchnowska U. Natural and Spatial Aspects of the Location of Wind 
Energy in the Warmia-Mazury. Elbląg: Biuro Planowania Przestrzennego; 2006

[19] Gamboa G, Munda G. The problem of windfarm Location: A social multicriteria evaluation framework. Energy Policy. 2007;35:1564-1583

[20] Rodman LC, Meentemeyer RK. A geographic analysis of wind turbine placement in Northern California. Energy Policy. 2006;34:2137-2149

[21] Salo A, Punkka A. Rank inclusion in criteria hierarchies. European Journal of Operational Research. 2005;163:338-356

[22] Karsu Ö, Morton A. Incorporating balanc concerns in resource allocation decisions: A bicriteria modeling approach. OMEGA — The International Journal of Management Science. 2014;44:70-82

[23] Weistroffen HR, Smith CH, Narula SC. Multiple criteria decision support software. In: Figueira J, Greco S, Ehrgott M, editors. Multiple Criteria Decision Analysis: State of the Art Surveys. Boston: Springer Science + Bussines Media; 2005. pp. 60-84

[24] Bernardon DP, Garcia VJ, Ferreira ASQ, Canha LN. Multicriteria distribution network reconfiguration considering subtransmission analysis. IEEE Transactions on Power Delivery. 2010;25:2684-2691

[25] Bhattacharya A, Roy PK. Solution of mulita-objective optimal power flow using gravitation search algorithm. IET Generation, Transmission \& Distribution. 2012;6:751-763

[26] Brar YS, Dhillon J, Kothari DP. Genetic-fuzzy logic based weightage pattern search for multiobjective load dispatch problem. Asian Journal of Information Technology. 2003;2:364-372

[27] Yang JB. Rule and utility based evidential reasoning approach for multiattribute decision analysis under uncertainties. European Journal of Operational Research. 2001;131:31-61

[28] Wallenius J, Dyer JS, Fishburn PC, Steuer RE, Zionts S, Deb K. Multiple criteria decision making, multiattribute utility theory: Recent accomplishments and what lies ahead. Management Science. 2008;54:1336-1349

[29] Lansdowne ZF. Outranking methods for multicriterion decision making: Arrow's and Raynaud's conjecture. Social Choice and Welfare. 1997;14:125-128

[30] Haurant P, Oberti P, Muselli M. Multicriteria selection aiding related to photovoltaic plants on farming fields on Corsica Island: A real case study using the ELECTRE outranking framework. Energy Policy. 2011;39:676-688

[31] Amiri M, Zandieh M, Vahdani B, Soltani R, Roshanaei V. An integrated eigenvector-DEA-TOPSIS methodology for portfolio risk evaluation in the FOREX spot market. Expert Systems with Applications. 2010;37:509-516

[32] Cho KT. Multicriteria decision methods:Anattempttoevaluateandunify. Mathematical and Computer Modelling. 2003;37:1099-1119

[33] Available from: www.geoservis.gov. pl [Accessed: 08 February 2019]

[34] Łaska G, Ruczyński I, Polakowski M. The final report on the environmental impact of the planned project the construction of 15 turbines EW01-15 localized in the Krynki and Szudzialowo communities. Białystok. 2018. 63 p

[35] Available from: www.biomasa.org.pl [Accessed 08 February 2019]

[36] Available from: www. greenpolsystem.pl [Accessed 08 February 2019] 
[37] Available from: www.geoportal.gov. pl [Accessed: 08 February 2019]

[38] Available from: www.isok.gov.pl [Accessed: 08 February 2019]

[39] Local Development Plan

Krynki commune for 2005-2009

[Internet]. 2019. Available from: http://ug-krynki.pbip.pl/index. php? event $=$ informacja\&id $=1023$ [Accessed: 08 February 2019]

[40] Development Strategy of the Szudzialowo commune for 2015-2025 [Internet]. 2019. Available from: http://bip. ug.szudzialowo.wrotapodlasia.pl/resource/ file/pdf [Accessed: 08 February 2019]

[41] Resolution No. XXII/173/02 dated 27 July 2002, to draw up Theories of urban planning Krynki commune [Internet]. 2019. Available from: http://ug-krynki. pbip.pl [Accessed: 08 February 2019]

[42] Resolution No. XXV/134/09 dated 10 September 2009, to draw up Theories of urban planning Szudzialowo commune [Internet]. 2019. Available from: http://bip.ug.szudzialowo. wrotapodlasia.pl > stud_zago_prze [Accessed: 08 February 2019]

[43] Vicke P. Multicriteria Decision-aid. Chichester: John Wiley \& Sons; 1992

[44] Hsu Y-G, Tzeng W-H, Shyu JZ. Fuzzy multiple criteria selection of government-sponsored frontier technology projects. R\&D Management. 2003;33:539-551

[45] Gutjahr WJ, Katzensteiner S, Reiter P, Stummer C, Denk M. Multiobjective decision analysis for competence-oriented project portfolio selection. European Journal of Operational Research. 2010;205:670-679

[46] Gutjahr WJ, Reiter P. Bi-objective project portfolio selection and staff assignment under uncertainty. Optimization. 2010;59:417-445
[47] Gomes A, Antunes CH, Martins A. A multiple objective evolutionary approach for the design and selection of load control strategies. IEEE Transactions on Power Systems. 2004;19:1173-1180

[48] Abdelaziz FB, Aouni B, El-Fayedh R. Multi-objective stochastic programming for portfolio selection. European Journal of Operational Research. 2007;177:1811-1823

[49] Roy B. Multicriteria Methodology for Decision Analysis. Dordrecht: Kluwer Academic Publishers; 1996

[50] Chelst K, Canbolat YB. Value-Added Decision Making for Managers. Boca

Raton: CRC Press; 2012

[51] Kangaspunta J, Liesiö J, Salo A. Costefficiency analysis of weapon system portfolios. European Journal of Operational Research. 2012;223:264-275

[52] Gustafsson J, Salo A. Contingent portfolio programming for the management of risky project. Operations Research. 2005;53:946-956

[53] Braga ASD, Saraiva JT. A multiyear dynamic approach for transmission expansion planning and long-term marginal costs computation. IEEE Transactions on Power Systems. 2005;20:1631-1639

[54] Buchholz T, Rametsteiner E, Volk T, Luzadis VA. Multi criteria analysis for bioenergy systems assessments. Energy Policy. 2009;37:484-495

[55] Burton J, Hubacek K. Is small beautiful? A muliticriteria assessment of small-scale energy technology applications in local goverments. Energy Policy. 2007;35:6402-6412

[56] Saaty TL. How to make a decision:

The analytic hierarchy process.

European Journal of Operational

Research. 1990;48:9-26 
[57] Saaty TL. The analytic hierarchy and analytic network processes for the measurement of intangible criteria and for decision-making. In: Figueira J, Greco S, Ehrgott M, editors. Multiple Criteria Decision Analysis: State of the Art Surveys. Boston: Springer Science + Bussines Media; 2005. pp. 345-405

[58] Saaty TL. Relative measurement and its generalization in decision making. Why pairwise comparisons are central in mathematics for the measurement of intangible factors the Analytic Hierarchy/Network Process. RACSAM. 2008;2:251-318

[59] Forman EH, Gass SI. The analytic hierarchy process-An exposition. Operations Research. 2001;49:469-486

[60] Vaidya OS, Kumar S. Analytic hierarchy process: An overview of applications. European Journal of Operational Research. 2006;169:1-29

[61] Vidal LA, Marle F, Bocquet J-C. Using a Delphi process and the Analytic Hierarchy Process (AHP) to evaluate the complexity of projects. Expert Systems with Applications. 2011;38:5388-5405

[62] Seixedo C, Tereso A. A muliticriteria decision aid software application for selecting MCDM software using AHP. In: Prooceedings of the 2nd International Conference on Engineering Optimization. Lisbon; 2010

[63] Huang CC, Chu PY, Chiang YH. A fuzzy AHP application in governmentsponsored R\&D project selection. OMEGA - The International Journal of Management Science. 2008;36:1038-1052

[64] Chiu YJ, Chen HC, Tzeng GH, Shyu JZ. Marketing strategy based on customer behavior for the LCD-TV. International Journal of Management and Decision Making. 2006;7:143-165
[65] Liou JJH, Tzeng GH, Chang HC. Airline safety measurement using a novel hybrid model. Journal of Air Transport Management. 2007;13:243-249

[66] Tzeng GH, Chiang CH, Li CW. Evaluating intertwined effects in e-learning programs: A novel hybrid MCDM model based on factor analysis and DEMATEL. Expert Systems with Applications. 2007;32:1028-1044

[67] Wu WW, Lee YT. Developing global managers' competencies using the fuzzy DEMATEL method. Expert Systems with Applications. 2009;32:499-507

[68] Lin CL, Tzeng GH. A value-created system of science (technology) park by using DEMETEL. Expert Systems with Applications. 2009;36:9683-9697

[69] Figueira JR, Greco S, Roy B, Slowinski R. ELECTRE methods: main feature and recent developments. Applied Optimization. 2010;103:1-39

[70] Figueira JR, Roy B. Determining the weights of criteria in the ELECTRE type methods with a revised Simos' procedure. European Journal of Operational Research. 2002;139:317-326

[71] Brito AJ, Almeida AT, Mota CM. A muliticriteria model for risk sorting of natural gas pipelines based on ELECTRE TRI intergrating utility theory. European Journal of Operational Research. 2010;200:812-821

[72] Behzadian M, Kazemzadeh RB, Albadvi A, Aghdasi M. PROMETHEE: A comprehensive literature review on methodologies and applications. European Journal of Operational Research. 2010;200:198-215

[73] Brans JP, Mareschal B. Promethee methods. In: Figueira J, Greco S, Ehrgott M, editors. Multiple Criteria Decision Analysis: State of the Art Surveys. Boston: Springer Science + Bussines Media; 2005. pp. 163-195 
[74] Albadvi A, Chaharsooghi SK, Esfahanipour A. Decision making in stock trading: An application of PROMETHEE. European Journal of Operational Research. 2007;177:673-683

[75] Goumas M, Lygerou V. An extension of the PROMETHEE method for decision making in fuzzy environment: Ranking of alternative energy exploitation projects. European Journal of Operational Research. 2000;23(3):606-613

[76] Behzadian M, Otaghsara SK, Yazdani M, Ignatius J. A state-of theart survey of TOPSIS applications. Expert Systems with Applications. 2012;39:130-151

[77] Roszkowska E. Multi-criteria decision making models by applying the TOPSIS method to crisp and interval data. MCDM. 2011;6:200-230

[78] Haralambopoulos DA, Polatidis H. Renewable energy projects: Structuring a mulit-criteria group decision making framework. Renewable Energy. 2003;28:961-973

[79] Bhattacharyya SC. Review of alternative methodologies for analyzing off-grid electricity supply. Renewable and Sustainable Energy Reviews. 2012;16:677-694

[80] Borges A, Antunes CH. A fuzzy multiple objective decision support model for energy-economy planning. European Journal of Operational Research. 2010;45:304-316

[81] Jayanthi S, Witt EC, Singh V. Evaluation of potential of innovations: A DEA-based application to us photovoltaic industry. IEEE Transactions on Engineering Management. 2009;56:478-493

[82] Borghetti A, Bosetti M, Grillo S, Massucco S, Nucci CA, Paolone M, et al. Short-term scheduling and control of actice distribution system with high penetration of renewable resources. IEEE Systems Journal. 2010;4:313-322

[83] Browne D, O’Regan B, Moles R. Use of multi-criteria decision analysis to explore alternative domestic energy and electicity policy scenarios in na Irish city-region. Energy. 2010;35:518-528

[84] Gu X, Zhong H. Optimisation of network reconfiguration based on a two-layer unit-restarting framework for power system restoration. IET Generation, Transmission \& Distribution. 2012;6:693-700

[85] Guo C, Bai Y, Zheng X, Zhan J, Wu Q. Optimal generation dispatch with renewable energy embedded using multiple objectives. International Journal of Electrical Power \& Energy Systems. 2012;42:440-447

[86] Ganguly S, Sahoo N, Das D. Muliobjective planning of electrical distribution systems using dynamic programming. International Journal of Electrical Power \& Energy Systems. 2013;46:65-78

[87] Ghafgazi S, Sowlati T, Sokhansanj S, Melin S. A multicriteria approach to evaluate districts heating system options. Applied Energy. 2010;87: 1134-1140

[88] Gitizadeh M, Vahed A, Aghaei J. Multistage distribution system expansion planning considering distributed generation using hybrid evolutionary algorithms. Applied Energy. 2013;101:655-666

[89] Gomes A, Antunes CH, Martins A. A multiple objective approach to electric load management using an interactive evolutionary algorithm. IEEE Transactions on Power Systems. 2007;22:1004-1011

[90] Farahani HF, Shayanfar HA, Ghazizadeh MS. Muli-objective clearing 
of reactive power market including plug-in hybrid electric vehicle. Electric Power Components and Systems.

2013;41:197-220

[91] Guedes LSM, Lisboa AC, Vieira DAG, Saldanha RR. A multiobjective heuristic for reconfiguration of the electrical radial network. IEEE Transactions on

Power Delivery. 2013;28:311-319 


\title{
Development of Mathematical Models to Explore the Potential of Wind Fleets to Decarbonize Electricity Grid Systems
}

\author{
Anthony D. Stephens and David R. Walwyn
}

\begin{abstract}
Real-time records of energy generation in the UK and Germany have been used to develop models for each country's electricity generation system, the objective being to provide a means of determining the likely economic limits of wind fleets and their consequent ability to decarbonise their grids. The results from the models, expressed in the form of marginal efficiencies, have then been codified in a pair of simple look-up tables, obviating the need for further reference to the models and providing a simple means of assessing the implications for the grids and their wind fleets of a range of future grid configurations, including increases in wind and solar fleet capacities, anticipated future loss in both countries of nuclear-generating capacity, possible replacement of petrol and diesel passenger vehicles with electric vehicles, and, for the UK only, the conversion of domestic boilers from gas to electricity. It is apparent that headroom, being the difference between annual average grid demand and base generation, is the single most important factor in determining how much wind capacity may be economically deployed in decarbonising grids.
\end{abstract}

Keywords: variable renewable energy, decarbonisation, upper economic limit, wind energy, carbon emissions

\section{Introduction}

Significant decarbonisation of electricity grids will, in many cases, necessitate considerable investment in wind fleets in order to displace generation from hydrocarbon sources. Wind fleets are ultimately limited in size by the highly variable nature of wind generation which causes wind shedding and loss of efficiency when generation exceeds what the grid is able to accept [1].

It is apparent that grids act towards their wind fleets as low-pass filters, and, as a result, when wind competes for limited access to their grids, it may only be properly analysed using real-time records. This chapter describes, with reference to the UK and Germany grid systems, the use of such records to build mathematical models for each system [2]. The models are then used to determine the upper economic level of deployment of wind fleets and the limits on their ability to decarbonise their grids. It is shown that the upper economic levels are determined by two factors headroom, a concept defined in the chapter, and the amount of wind shedding which is acceptable before further investment in capacity becomes uneconomic. 
In this discussion, and indeed throughout the chapter, a distinction is made between generated wind power, which is referred to as GWe, and installed wind capacity, which is referred to as GWc. For small wind fleets (i.e. no wind shedding), the two important variables are related by the expression shown in Eq. (1):

$$
\mathrm{GWe}=\text { load factor } \times \text { GWc }
$$

It is also noted that all references to carbon dioxide emissions are stated as carbon emissions, for the sake of simplicity.

\section{Managing wind variability}

Electricity grids cope with the variable output from small wind fleets by continually adjusting the output of dispatchable sources of generation under their control $[1,3]$. These sources are mainly gas-fired generation in the UK and coal-fired generation in Germany. Ignoring problems such as failure of transmission systems, the grids should be able to accommodate all of the output from wind fleets which are small relative to the size of their grids. This will not, however, be the case for the large wind fleets envisaged in future.

The highly variable nature of wind generation creates two different but complementary problems for grids being served by very large wind fleets. When there are settled weather patterns, there are fairly frequent occasions when there will be sensibly no wind generation for several days, regardless of the size of the wind fleet. At the other extreme, for the large wind fleets envisaged in the future, there will be occasions when wind generation will be at least twice what the grids are able to accommodate, such as excesses of 40 GWe for the UK and 80 GWe for Germany. For each 24-hour period, a UK wind fleet would therefore be either unable to supply around $1000 \mathrm{GWh}$ of energy or would be generating $1000 \mathrm{GWh}$ in excess of demand on the grid. For Germany the daily deficits/excesses would be of the order of $2000 \mathrm{GWh}$.

It is sometimes suggested that energy storage is the solution to wind generation deficits and surpluses, but the problem with this approach is that while energy storage is technically feasible for small amounts of excess generation, it is unsuitable for large energy excesses. This assertion may be put into perspective by comparing the need to store and return to the grid multiples of $1000 \mathrm{GWh}$ of energy with the capability of the world's largest storage array, Tesla's $0.13 \mathrm{GWh}$ in South Australia [4]. It would require nearly 8000 Tesla-sized storage arrays to store $1000 \mathrm{GWh}$ of excess produced in a day.

The cost of lithium-ion storage arrays is falling and may even reach $\$ 350 \mathrm{M}$ per GWh by 2024 [5], but, even if this was the case, a 1000 GWh storage array would cost of the order of $\$ 350 \mathrm{Bn}$. Moreover, it is not just the extremely high capital cost which would prohibit such an investment; it is also the low utilisation of the facility itself. For long periods, the facility would be inactive through lack of wind, and during extended periods of high wind, the facility would become fully charged quickly and then inactive because the wind generation was still in excess of demand on the grid. Lithium-ion arrays will undoubtedly have a role to play in providing standby energy storage to cover for outages of a few hours (as in South Australia) or, perhaps, in storing excess solar generation to smooth grid demand over a 24-hour period, but they are unlikely ever to solve the problems created by the highly variable and largely unpredictable nature of wind generation $[6,7]$.

The UK has four pumped storage systems with a storage capacity of $30 \mathrm{GWh}$, capable of charging/discharging at around $2 \mathrm{GW}$. Because of their high capital cost 
and inherently low efficiencies, electricity from pumped storage systems is expensive. The high cost of pumped storage electricity is justified by the premium which may be charged; the storage reservoirs are charged at night, when electricity prices are low, and discharged each day during periods of peak demand and high prices. Pumped storage systems also play an important role in providing grid stability. MacKay [8] discussed the possibility of using pumped storage systems to address the problem of large energy surpluses/deficits which are an inevitable consequence of employing large wind fleets but concluded that flooding every potential storage site in Scotland would only provide a storage capacity of around $400 \mathrm{GWh}$.

An alternative to energy storage is to export surpluses to neighbouring countries which are in deficit. However, interconnectors are costly, particularly for a country like the UK which is surrounded by sea, and wind surpluses are inherently unreliable. Furthermore, as the Royal Academy of Engineering pointed out in 2014 [9], the UK weather is reasonably well correlated with that in neighbouring countries; it is likely that when the UK has wind surpluses, its continental neighbours will have wind surpluses of their own. The UK has around $4 \mathrm{GW}$ of interconnectors, a $2 \mathrm{GW}$ interconnector with France, a $1 \mathrm{GW}$ interconnector with the Netherlands and, as of January 2019, a 1 GW interconnector with Belgium. All normally run at high capacity importing some $10 \%$ of the UK's electricity needs, mainly nuclear energy [10]. Germany is much more highly interconnected with its neighbours and mainly uses its interconnectors to export surplus solar generation. The models to be discussed in the next sections will assume that UK wind generation which is surplus to the requirements of the grid will be curtailed.

The models also assume that the grid distribution system is perfectly matched to the wind generation system and that whenever there is sufficient grid demand, all wind generation will be accommodated by the grid. This is clearly an oversimplification; data from the Renewable Energy Foundation suggests that even at UK wind penetration as low as $6 \%$, there is wind curtailment every month, with wind curtailment payments in 2015 being $£ 90 \mathrm{M}$ increasing at $£ 30 \mathrm{M}$ per annum (p.a.) [11].

\section{The modeling approach}

Wind fleet load factors, which typically vary by $\pm 10 \%$ depending on the windiness of the year, are available for the UK from government records [12] and for Germany on a Fraunhofer website [13]. In recent years the UK load factor has averaged around 0.3 and that of Germany around 0.2 , the difference being accounted for by the UK being generally windier and having a higher portion of its wind fleet offshore. Histograms, load distribution curves and other statistical techniques are often useful when exploring the relationships between small wind fleets and the grids they serve [1], but once a wind fleet increases above the size at which wind generation has to be curtailed, wind generation is no longer linearly related to wind fleet capacity, and such techniques are not applicable.

The starting point for predicting GWe under circumstances of wind curtailment is the recognition that the grid acts towards the wind fleet as a low-pass filter; wind generation is accepted if it can be accommodated by the grid but must be curtailed if in excess. Because the total demand on the grid, which we shall call grid demand, is ever-changing, the low-pass filtering action the grid imposes on wind generation is also ever-changing. Logic dictates therefore that a model to simulate the interaction between a grid and a wind fleet large enough to incur wind curtailment must analyse real-time grid records, checking at each recording interval whether wind generation can be accepted or must be curtailed. 
The authors have previously reported the empirical finding that four separate models produced using 2013, 2014, 2015 and 2016 records led to sensibly the same model, enabling them to conclude that only a single year's records are required to generate a model of general applicability [2]. 2017 was the first year for which UK solar generation records became available on the Gridwatch website and the year when solar generation started to compete with wind generation for access to the UK grid [14]. The UK model in the next section uses 2017 grid records.

The components of UK generation are recorded every 5 minutes, resulting in 104,832 data sets over the period of a year but are relatively easy to access since they may be downloaded directly from the web. German records on the other hand, available at hourly intervals, result in only 8760 data sets over the period of a year but are more time-consuming to access since they must be transcribed manually. To provide real-time graphical representations of results, it was decided to access the records a week at a time. The models, which are in spreadsheet form, first predict by extrapolation what wind generation would have been for a range of larger wind fleets, initially ignoring the need to curtail generation which the grid is unable to accommodate. The next step, for each time period and each wind fleet capacity of interest, is for the model to identify how much of the predicted generation the grid is able to accommodate. These predictions are averaged for each week, then for the year, to generate a prediction of annual average generation, GWe, for each GWc of interest. It will be shown that the GWe versus GWc relationships derived using the models provide a basis for quantifying the efficiency of the wind fleet and a means of exploring the extent to which the wind fleet will be able to decarbonise the grid for a range of different scenarios likely to be encountered in future years.

In order to undertake the modeling, the variable GWs, being the generated solar power in GW, must also be used. The sum (GWe + GWs) is then the combined wind and solar (generated) power.

\section{Modeling the UK wind fleet}

Table 1 summarises the main components of UK electricity generation (GW); the analogous solar and wind fleet capacities, for the years 2014-2017, a period during which wind capacity increased by $51 \%$ and solar capacity by $131 \%$, are shown in Table 2. The data are obtained from the UK government records [15], with the exception of grid demand and wind generation records, which were calculated by averaging the real-time records downloaded from Gridwatch [12].

\begin{tabular}{lcccc}
\hline Year & $\mathbf{2 0 1 4}$ & $\mathbf{2 0 1 5}$ & $\mathbf{2 0 1 6}$ & $\mathbf{2 0 1 7}$ \\
\hline Grid demand & 34.3 & 33.1 & 32.4 & 33.0 \\
\hline Wind & 2.44 & 2.65 & 2.44 & 3.70 \\
\hline Solar & 0.462 & 0.860 & 1.188 & 1.316 \\
\hline Gas & 11.52 & 11.40 & 16.36 & 15.61 \\
\hline Coal & 11.44 & 8.66 & 3.50 & 2.57 \\
\hline Nuclear & 7.28 & 8.03 & 8.18 & 8.03 \\
\hline Bio & 2.58 & 3.34 & 3.43 & 3.63 \\
\hline Hydro & 0.67 & 0.71 & 0.615 & 0.676 \\
\hline
\end{tabular}

Table 1.

Sources of generated UK electricity: 2014-2017 (GW). 
Development of Mathematical Models to Explore the Potential of Wind Fleets to Decarbonize... DOI: http://dx.doi.org/10.5772/intechopen.88885

\begin{tabular}{lcccc}
\hline Year & $\mathbf{2 0 1 4}$ & $\mathbf{2 0 1 5}$ & $\mathbf{2 0 1 6}$ & $\mathbf{2 0 1 7}$ \\
\hline Wind & 13.07 & 14.31 & 16.2 & 19.84 \\
\hline Solar & 5.53 & 9.54 & 11.90 & 12.78 \\
\hline
\end{tabular}

Table 2.

Installed UK wind and solar capacities: 2014-2017 (GW).

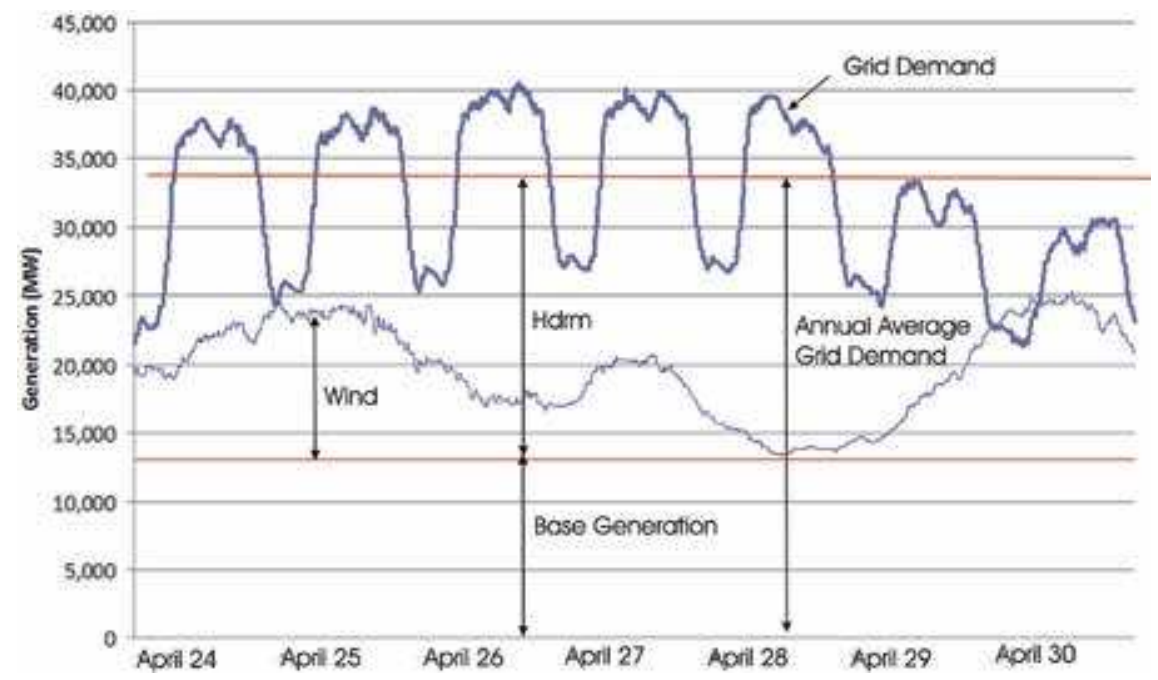

Figure 1.

Graphical representation of grid demand, wind generation and base generation, week 17 (April 24-30) of 2017.

In the simplified schematic of Figure 1, the calculated wind generation from a wind fleet of capacity 20 GWc (close to the actual capacity of 19.83 GWc in 2017) is shown sitting above the base generation, which is a composite of sources considered to be given preferential access to the grid over wind and solar generation. The elements of base generation are not fixed but will vary according to the operational strategy of the grid at the time. For some years, nuclear generation, which averaged $8.03 \mathrm{GW}$ in 2017, was the largest component of base generation followed by imports. As mentioned earlier, by January 2019 the UK had 4 GW of interconnectors within the continent, which have run at close to full capacity importing mainly nuclear electricity from the continent, the latter being cheaper than UK electricity since it is not a subject to carbon tax [10]. These sources contributed $4 \mathrm{GW}$ to base generation, but this may not always be the case in the future, particularly after the planned decommissioning of the German nuclear reactors in 2022 [16] and of the Belgian nuclear reactors in 2025 [17]. Because of the uncertainty about the future level of base generation, it is treated as a model input variable, allowing the consequences of a wide range of future base generation values to be investigated. In the illustration of Figure 1, base generation was set at $13 \mathrm{GW}$.

The difference between grid demand and base generation, which varied during week 17 of 2017 between a maximum of 27 GW during the day of April 26 and a minimum $8 \mathrm{GW}$ on the night of April 30, was traditionally served by coal- and gasfired generation. It is now the operational area to which wind and solar generations are given preferential access, dispatchable sources of generation only being used when there is insufficient wind and solar generation to satisfy grid demand. An important objective of the modeling study will be to provide a means of examining the efficiency with which the wind and solar fleets are able to satisfy grid demand, 
thereby displacing dispatchable generation and minimising the generation of carbon emissions.

Although Table 1 shows the grid demand being relatively unchanged during the period 2014-2017, this will not always be the case for the future grid configurations we shall wish to investigate. As we shall discuss later, converting the UKs petrol and diesel cars to electric vehicles (EVs) would increase grid demand by around 10 GWe, and a much larger increase would result from a recent proposal by the UK Climate Change Committee that domestic gas heating should be replaced by electric heating by 2050 [18]. Although grid demand is not a model input, it is possible to simulate a change in grid demand by recognising that the operational area of the wind and solar fleets lies between base generation and grid demand and a $1 \mathrm{GW}$ change in grid demand has the same impact on this operational area as a $1 \mathrm{GW}$ change in base generation in the opposite direction. It is possible therefore to simulate a change in grid demand by an equal and opposite change in base generation.

The authors have previously reported their finding that replacing the real-time records of grid demand with a constant annual average grid demand in all 52 weekly models had only a minimal effect on the calculated annual average GWe [2]. An explanation for this finding is that curtailing wind generation at annual average grid demand rather than the actual ever-changing grid demand overestimates wind shedding for approximately $50 \%$ of the year and underestimates it for the other $50 \%$ of the year, the two effects cancelling each other out. This result leads to the conclusions that not only may we ignore the cyclic component of grid demand as a model variable but we can also visualise the operational area of the wind and solar fleets as lying between base generation and annual average grid demand, which is known as headroom [19] and in this chapter is referred to as Hdrm. The variable Hdrm provides a means of visualising the operational headroom available to the wind and solar fleets and is defined as

$$
\text { Hdrm = Annual average grid demand }- \text { base generation }
$$

Since annual average grid demand in 2017 was 33 GWe, Eq. (2) requires the choice of base generation values of $13,3,-7,-17$ and -27 GWe as model inputs when using 2017 grid records to generate GWe vs. GWc curves for Hdrm values of 20, 30, 40, 50 and $60 \mathrm{GW}$.

It is possible to make a simple model which produces reasonably accurate GWe vs. GWc predictions using annual wind generation histograms in the absence of solar generation. However, statistical methods may not be used when wind and solar fleets are of such a size that not all their output can be accommodated by the grid. This observation may be understood by comparing the two wind generation predictions in Figure 2 for a wind fleet of 20 GWc. The upper graphic, which does not include solar generation, shows that the high winds during the early hours of Sunday of April 30 would have caused a small amount of wind shedding at a time when grid demand fell to only 21 GWe but ceased when grid demand rose during the day. The lower graphic in Figure 2 which includes solar generation shows wind shedding even at a time when grid demand had increased to 30 GWe because wind generation was being displaced by solar generation. Only models which analyse real-time data are able to assess such interactions which, when averaged over the year, allow calculations to be made of wind fleet efficiency.

Each of the 52 weekly models for 2017 was run with base generation values of $13,3,-7,-17$ and $-27 \mathrm{GW}$, and the weekly results averaged to yield the annual average GWe vs. GWc curves of Figure 3 for Hdrm values of 20, 30, 40, 50 and 60 GW. In the weekly models, the solar generation was set at twice the levels recorded in 2017. The reason for this decision, and not any higher, is that the models show the 
Development of Mathematical Models to Explore the Potential of Wind Fleets to Decarbonize... DOI: http://dx.doi.org/10.5772/intechopen.88885
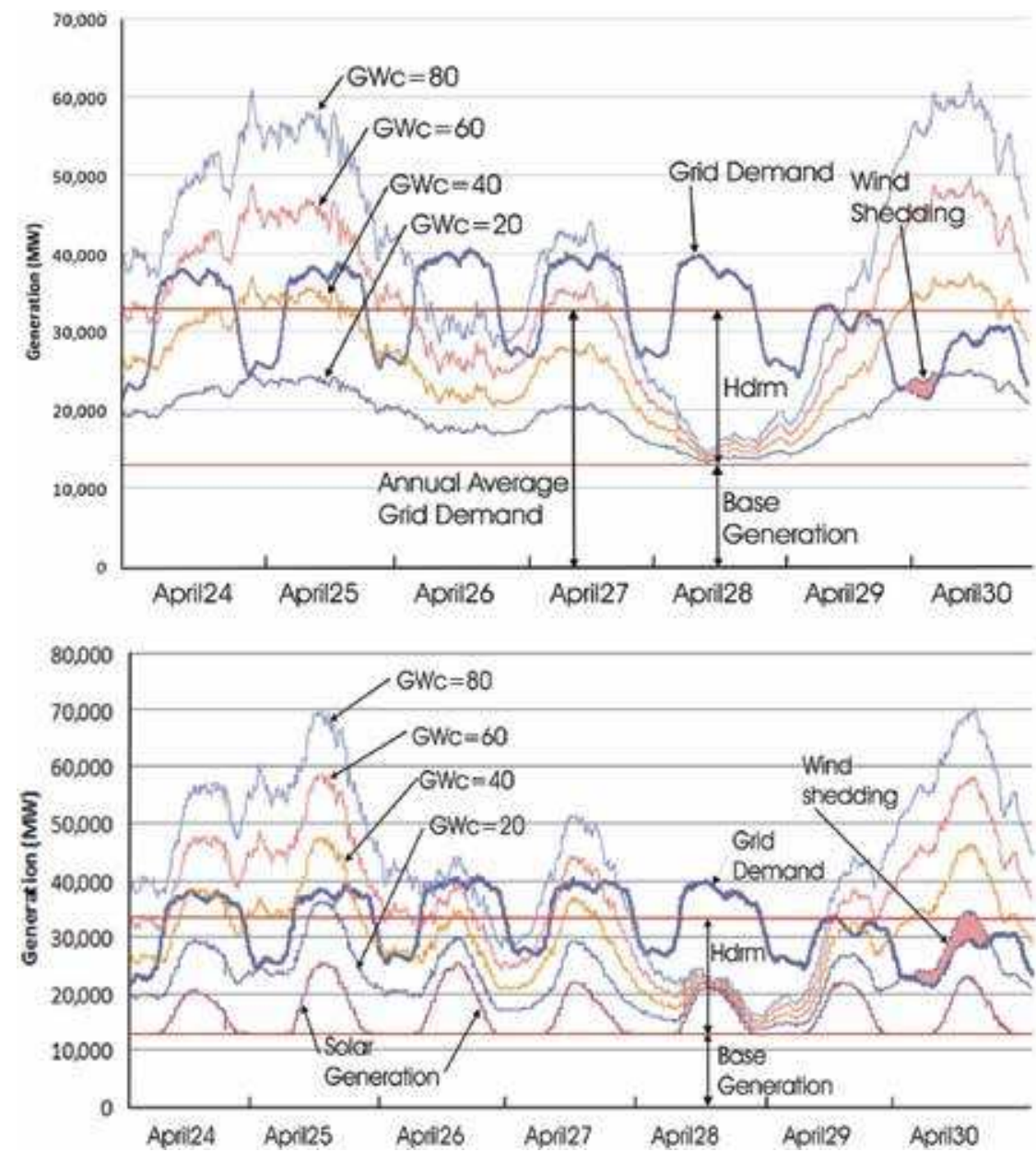

Figure 2.

Predictions of wind generation for week 17 of 2017 for wind fleet capacities of 20, 40,60 and $80 \mathrm{GWc}$. the upper graphic shows the predictions for no solar generation, and the lower graphic shows twice the solar generation in 2017, with solar generation being given preferential access over wind generation.
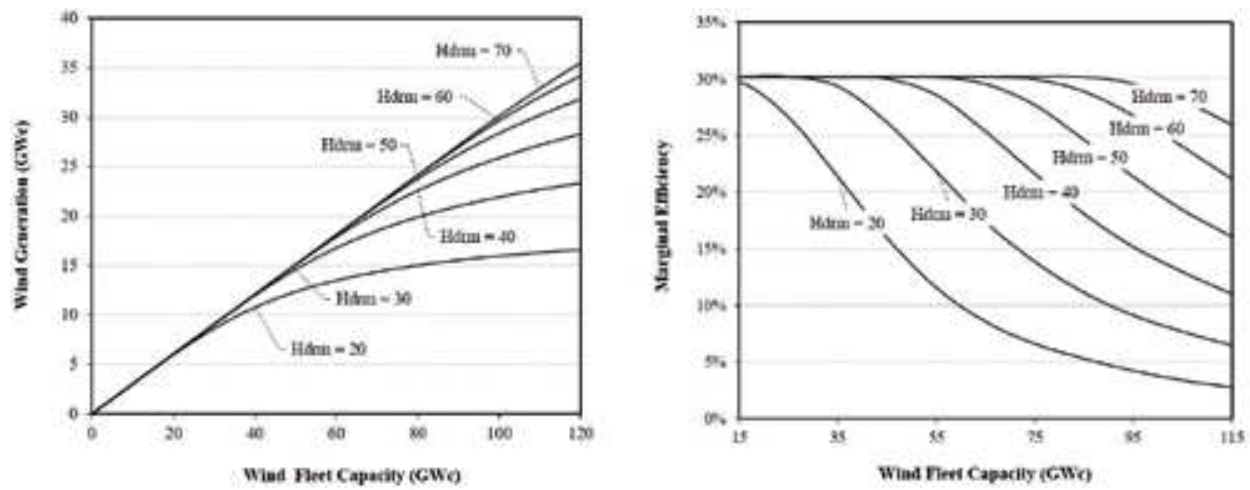

Figure 3.

GWe vs. GWc and marginal efficiency predictions for Hdrm values of 20, 30, 40, 50 and $60 \mathrm{GW}$.

combine wind and solar generation to be maximised when all solar generation is accepted by the grid, but, at twice the 2017 level, solar generation itself comes close to being shed when at its peak during the summer months. 
Using the real-time data, it is possible to model the relationship between GWe and GWc for different Hdrm values, assuming twice the solar generation in 2017. The results are shown in the left-hand graphic of Figure 3. These curves were created by averaging the predictions of the 52 weekly models, requiring each of the 52 weekly models to be run five different Hdrm values and one level of solar generation (twice the 2017 value).

Since our interest is in providing tools which may be used to assess the upper economic limit of the wind fleet, it is necessary to develop a method of calculating the wind fleet efficiency from the GWe vs. GWc curves. A measure often used for general investment assessments is the incremental "benefit" of an investment divided by the incremental "cost" of that investment. An appropriate measure for a wind fleet is the incremental increase in wind generation, $d(\mathrm{GWe})$, for an incremental increase in wind fleet capacity, $\mathrm{d}(\mathrm{GWc})$, which we shall call the wind fleet's marginal efficiency, where

$$
\text { Marginal efficiency }=\mathrm{d}(\mathrm{GWe}) / \mathrm{d}(\mathrm{GWc})
$$

Marginal efficiency is, by definition, the gradient of the GWe vs. GWc curves and hence may be calculated directly from the GWe vs. GWe curves, as has been done for the marginal efficiency curves, shown on the right-hand side of Figure 3. It is noted that the marginal efficiency is initially identical to the load factor, as defined in Eq. (1) but declines with increasing wind fleet capacity, that is, additional wind fleet capacity may increase the overall wind energy generated but at increasingly lower levels of efficiency. This parameter thereby provides an important analytical metric for establishing the critical point at which such increases in capacity are no longer economic.

It might be thought that the GWe vs. GWc and marginal efficiency curves of this figure will be of limited use, since they are restricted to five predetermined Hdrm values. A practical application might be interested in exploring the properties of a grid with a Hdrm value of, say, $27 \mathrm{GW}$ which would suggest the need to laboriously rerun the 52 weekly models for a Hdrm of $27 \mathrm{GW}$ and average the results. What obviates the need to rerun the models may be seen in Appendix A, which tabulates key grid parameters for a range of marginal efficiency and Hdrm values. This shows that (GWe $+\mathrm{GWs}) /$ Hdrm and residual generation/Hdrm, important derived parameters we shall use later, are almost insensitive to the value of Hdrm, so that (GWe + GWs) and residual generation may be easily calculated for any Hdrm value of interest.

Also included in the tabulations of Appendix A are the predictions of wind shedding (curtailment), which may be calculated from the ratio GWe/GWc using Eq. (4). Wind shedding predictions are important since unit costs are directly related to wind shedding and unit costs ultimately determine the economic upper limit of a wind fleet:

$$
\text { \%wind shedding }=100 \times(1-(\text { GWe } / \text { GWc }) / \text { Load Factor })
$$

Also tabulated in Appendix A is residual generation that the portion of Hdrm which cannot be met by wind and solar generation must be met by dispatchable generation, where

$$
\text { Residual generation }=\text { Hdrm }-(\text { GWe }+ \text { GWs })
$$

Since Appendix A reveals that a derived variable residual generation/Hdrm is practically insensitive to the value of Hdrm, this leads to the relationship between residual generation/Hdrm and \% wind shedding which is graphed in Figure 4. 
Development of Mathematical Models to Explore the Potential of Wind Fleets to Decarbonize... DOI: http://dx.doi.org/10.5772/intechopen.88885

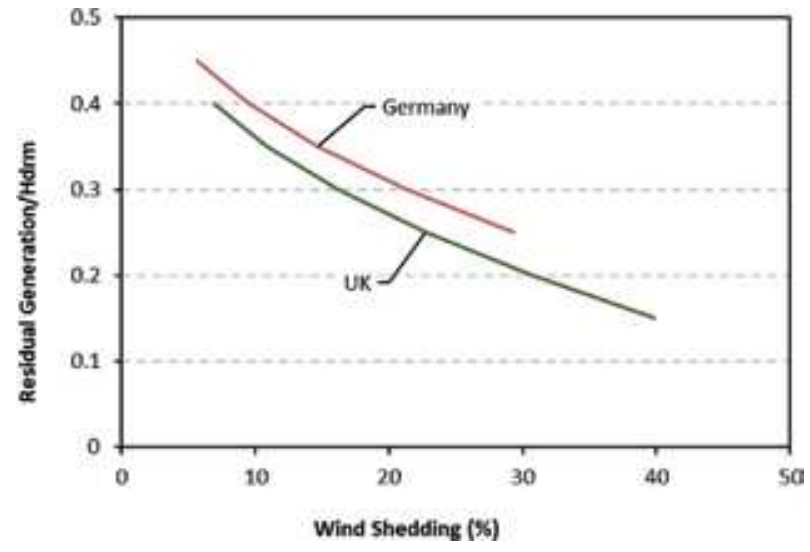

Figure 4.

Residual generation/Hdrm as a function of \% wind shedding.

It is not the intention of this chapter to address the economics of wind and solar generation, since the economics will depend on unit costs and subsidy regimes which will change over time. However, the residual generation/Hdrm vs. wind shedding \% relationship of Figure 4 provides a useful guide to the future ability of the wind and solar fleets to decarbonise the grid, once the economics are known. Thus, if the UK wind fleet is only economic up to the point at which it sheds an average of $20 \%$ of wind generation, $25 \%$ of Hdrm must be generated from dispatchable sources. If on the other hand it is deemed economic to shed $38 \%$ of wind generation, the residual generation/Hdrm will be reduced to $16 \%$. Figure 4 therefore provides a useful illustration of the decreasing ability of a wind fleet to decarbonise a grid as the wind fleet increases in size, shown for both the UK and Germany.

\subsection{Scenario 1: Increasing the UK wind fleet capacity to reduce carbon emissions}

Table 3 summarises the UK's progress in reducing carbon emissions between 1990 and 2017. Carbon emissions from electricity generation was reduced from 203 million tonnes (MT) per annum to $113 \mathrm{MT}$ per annum of which $76 \mathrm{MT}$ carbon was from gas generation (15.61 GW at 4.87 MT carbon per GW) and 22 MT from coal generation (2.57 GW at 8.7 MT carbon per GW). The remaining 98.4 MT carbon emissions from gas and coal generation will in future years be further reduced by increasing wind and solar capacities.

It is now possible to calculate the impact of increasing wind fleet capacity on carbon emissions; the results are shown in Table 4. Columns 2 and 3 in the table are taken from Appendix A, and column 4 is the increase in (GWe $+\mathrm{GWs)} \mathrm{since}$

\begin{tabular}{lcc}
\hline Year & $\mathbf{1 9 9 0}$ & $\mathbf{2 0 1 7}$ \\
\hline Electricity generation & 203 & 112.6 \\
\hline Business & 119.9 & 66.1 \\
\hline Transport & 125.3 & 124.6 \\
\hline Total & 594.1 & 373.2 \\
\hline Source: UK government records [20] & &
\end{tabular}

Source: UK government records [20]

Table 3.

Main sources of UK carbon emissions (MT p.a., 1990 and 2017). 


\begin{tabular}{lccccc}
\hline $\begin{array}{l}\text { Marginal } \\
\text { efficiency }\end{array}$ & GWc & (GWe + GWs) & $\begin{array}{c}\text { Increase in } \\
(\mathrm{GWe}+\mathrm{GWs})\end{array}$ & $\begin{array}{c}\text { Carbon emissions } \\
(\mathrm{MT} / \mathbf{a})\end{array}$ & $\begin{array}{c}\mathrm{d}(\text { carbon)/ } \\
\mathbf{d}(\mathrm{GWc})\end{array}$ \\
\hline 0.30 & 20.00 & 5.01 & & 98.38 & \\
\hline 0.20 & 35.64 & 11.75 & 6.74 & 55.71 & 2.73 \\
\hline 0.15 & 44.05 & 13.4 & 8.39 & 47.67 & 0.96 \\
\hline 0.10 & 56.22 & 14.92 & 9.91 & 40.27 & 0.61 \\
\hline 0.05 & 82.52 & 16.78 & 11.77 & 31.21 & 0.34 \\
\hline
\end{tabular}

Table 4.

Model predictions of carbon emissions as the wind fleet increases in size (assuming Hdrm $=20$ and solar generation twice that in 2017).

2017. It is the UK government policy to eliminate coal-fired generation by 2025 [21], so it is assumed that the 2.57 GWe of coal-fired generation will be eliminated first, followed by a progressive reduction in gas-fired generation. Column 5 shows the residual carbon emissions for different marginal efficiency values.

The UK government's target is to achieve a wind fleet of around 40 GWc by 2030 [22]. If achieved, the emissions from gas and coal generation would be approximately half their 2017 level in 2030. Column 6 shows the decreasing efficiency of the wind fleet as it increases in size. Increasing wind fleet capacity from 20 to 35.64 GWc reduces carbon emissions by $2.73 \mathrm{MT}$ per GWc, but this decreases to a mere 0.34 MT per GWc between 56.22 GWc and 82.52 GWc.

\subsection{Scenario 2: reduction in nuclear capacity}

The nuclear fleet contributed $8.03 \mathrm{GW}$ in 2017, all from advanced gas-cooled reactors (AGRs) with the exception of the generation from the 1.2 GW Sizewell B pressurised water reactor (PWR). The life of the AGRs is limited by their graphite cores, and the expectation is that all the AGRs will have to be decommissioned by around the year 2030 [2]. Although it had been the UK government policy to maintain and even increase nuclear capacity by commissioning new PWR reactors, little progress has been made in meeting this objective. It is looking increasingly likely that Sizewell B will be the only nuclear reactor in service in 2030, with a consequent loss of around $7 \mathrm{GW}$ of nuclear output.

The results of the simulation for the loss of nuclear generation are shown in Figure 5. Since the loss of $7 \mathrm{GW}$ of nuclear generation leads to a similar increase

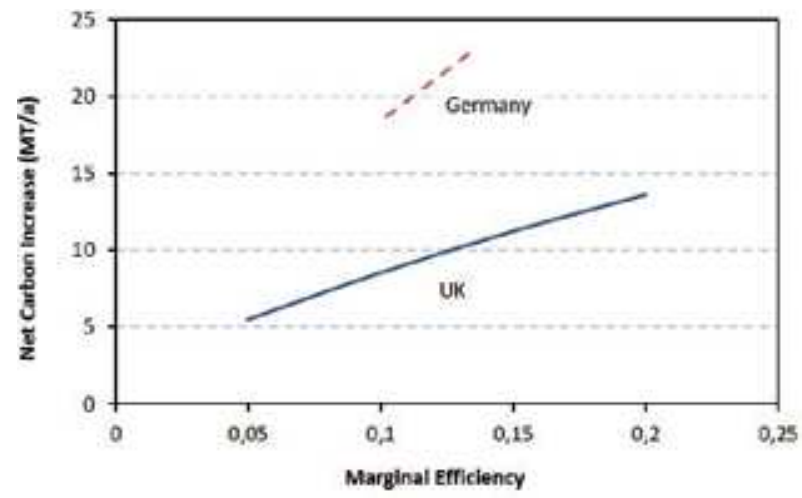

Figure 5.

Net carbon increase due to closure of the UK and German nuclear capacity. 
in Hdrm, the additional capacity is partly supplied by wind and solar, expressed as $(\mathrm{GWe}+\mathrm{GWs})$ in Appendix A. The remainder, the extent of which will depend on the marginal efficiency of the wind fleet, will be required from dispatchable sources. Assuming that this required increase in generation will be from gas, carbon emissions will also increase as shown in Figure 5 (also shown in this figure is the relationship between net carbon increase and marginal efficiency for Germany, which will be discussed in Section 5.2).

An interesting consequence of the loss of nuclear generation is that the headroom available to the wind and solar fleets is increased and hence their efficiencies. Thus, if $7 \mathrm{GW}$ of nuclear generation were lost, for a given marginal efficiency, (GWe + GWs) would be increased, accompanied by an increase in dispatchable generation in order to meet the demand when wind is not available. Assuming a cut-off value for marginal efficiency of 0.1 , the additional carbon emissions as a consequence of the closure of the nuclear capacity will be $8.5 \mathrm{MT}$ p.a. in the UK and 18 MT p.a. in Germany.

\subsection{Scenario 3: replacement of petrol and diesel vehicles by electric vehicles}

As shown in Table 3, carbon emissions from electricity generation in 2017 were only $55 \%$ of the emissions in 1990 , but transport emissions remained almost unchanged, becoming in 2017 the largest single source of carbon emissions. This would suggest that the UK's objective of significantly reducing overall carbon emissions further can only be met by reducing transport emissions.

According to MacKay [8], an electric vehicle (EV) driven under average UK conditions requires around $10 \mathrm{kWh}$ of electrical energy a day, an average annual power requirement of $0.416 \mathrm{KW}$. In 2018 there were 34.9 million petrol and diesel passenger cars on UK roads [23] which are estimated to have produced carbon emissions of 66.3 MT [24]. An increase of electricity generation of $10.58 \mathrm{GWe}$ would therefore provide enough power to replace the petrol and diesel cars with EVs, leading to a saving in transport emissions of 68.5 MT per annum carbon.

Results of the modeling for this scenario are shown in Figure 6. The increase in grid demand of 10.58 GWe would cause a similar increase in Hdrm, which could be supplied by wind and solar, supplemented by generation from dispatchable sources (probably gas) when these sources are not able to deliver the required power. There is a trade-off between the use of wind and gas; higher wind capacity will reduce the use of gas and hence increase the net carbon benefit but at the cost of increasing levels of wind shedding and hence lower marginal efficiencies, as shown in Figure 6

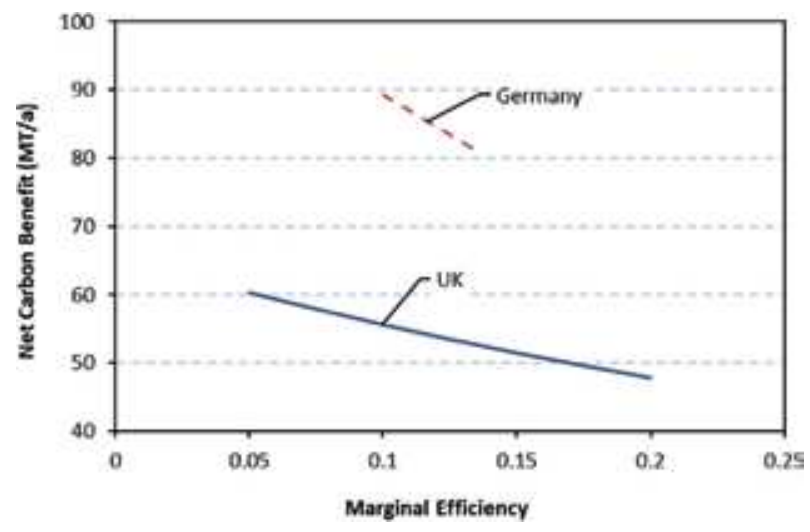

Figure 6.

Net carbon benefit to the UK and Germany following conversion to EVs. 


\begin{tabular}{lc}
\hline Sector & Output (TWh) \\
\hline Electricity generation & 286 \\
\hline Energy industries & 87.0 \\
\hline Services & 105.9 \\
\hline Domestic & 297 \\
\hline Industrial & 92.5 \\
\hline Total & 868.6 \\
\hline Source: Department of Business, Energy and Industrial Strategy [26]
\end{tabular}

Table 5.

Consumption of natural gas by sector in 2017.

for both the UK and Germany (discussion of the latter is given in Section 5.3). Once again, the optimal level will depend on the relative costs of wind and gas, the carbon tax and national decarbonisation targets, as may have been specified in terms of the Nationally Determined Contributions [25].

\subsection{Scenario 4: conversion of UK domestic heating to electricity}

The UK government records show that in 2017 the domestic sector consumed 297 terawatt-hours (TWh) of natural gas, making the sector the largest consumer and slightly more than the 286 TWh consumed by electricity generation (see Table 5). About $85 \%$ of British houses are currently heated by natural gas, but the UK Climate Change Committee recommended in May 2019 that by 2050 all UK boilers should become low carbon [18]. Among other recommendations of the committee were a doubling of electricity generation to supply electric vehicles and heating, and an offshore wind fleet of 75 GWc, covering up to $2 \%$ of the UK seabed.

Although the committee was silent on the technologies likely to be used in converting domestic heating to electricity, the broad outline is consistent with the model predictions summarised in Appendix A. Thus, if we assume an additional grid demand of $40 \mathrm{GW}$ and that it will be acceptable to run the wind fleet at a marginal efficiency of 0.1 (i.e. wind shedding of around 22\%), the additional Hdrm of $40 \mathrm{GW}$ would enable the wind fleet to generation $40^{*} 0.75=30 \mathrm{GWe}$. This is consistent with a 75 GWc wind fleet operating with a load factor of 0.4 (which is not unreasonable for a future offshore wind fleet comprising large turbines). Since the additional grid demand is $40 \mathrm{GW}$ and additional wind/solar generation only $30 \mathrm{GW}$, this would require $10 \mathrm{GW}$ to be generated from dispatchable sources (about 87.6 TWh), which would be more than offset by the saving of 297 TWh in converting the

domestic sector from gas to electricity.

\section{Modeling the German wind fleet}

Germany's Energiewende policy [27], aimed at producing a low carbon economy, includes a target reduction of greenhouse gas emissions to $55 \%$ of their 1990 levels by 2030 and, also by 2030, a target of producing 35\% of electricity generation from renewables. These targets became more challenging after the decision in 2012 to phase out nuclear generation by 2022. Despite having the largest wind and solar fleets in Europe, Germany's reliance on electricity generation from burning lignite and hard coal results in high levels of carbon emissions. In February 2019, Germany took the controversial decision, opposed by the European Council and many of its 
Development of Mathematical Models to Explore the Potential of Wind Fleets to Decarbonize... DOI: http://dx.doi.org/10.5772/intechopen.88885

\begin{tabular}{lc}
\hline Generation sources & Generation (GWe) \\
\hline Grid demand & 62.81 \\
\hline Solar & 3.97 \\
\hline Wind & 8.94 \\
\hline Gas & 3.43 \\
\hline Hard coal & 12.12 \\
\hline Lignite & 15.91 \\
\hline Nuclear & 9.9 \\
\hline Bioenergy & 5.36 \\
\hline Hydro & 2.15 \\
\hline
\end{tabular}

Table 6.

Main sources of Germany's electrical energy (2015).

neighbours, to import Russian gas via the Nord Stream 2 pipeline [28]. Replacing coal burning with the burning of imported gas should significantly reduce carbon emissions from electricity generation.

Table 6 summarises the annual average generation of the main sources of generation in 2015, taken from the Fraunhofer website (in this year, the values for wind and solar installed capacities were 44.6 GWc and 39.2 GW, respectively) [13]. Grid demand and solar and wind generation records were transcribed an hour at a time and averaged over the year, but the other records were the average values taken directly from the Fraunhofer website. The grid demand of $62.81 \mathrm{GW}$ includes not only the electricity used in Germany but a net 5.29 GW exported (i.e. exports minus imports). The table reveals a wind fleet load factor of 0.2 in 2015, only two thirds of the average UK load factor, a consequence of lower average wind speeds and a smaller proportion of the German wind fleet being offshore. Germany's real-time grid records for 2015 (8760 data sets) were used to create a model of the German grid system.

The modeling approach adopted was as described earlier for the UK, with 52 weekly models incorporating the real-time records being scaled for a range of wind fleet capacities and then averaged over a year to create GWe vs. GWc and marginal efficiency curves. To enable future grid configurations with large Hdrm values to be evaluated, the models were used to predict the behaviour of wind fleets up to 260 GWc in capacity, although Figure 7 illustrates predictions of wind fleets to 160 GWc only. The base generation of $9.9 \mathrm{GW}$ in Figure 7 represents the average nuclear generation of 2015 .

Solar generation peaked at just under $25 \mathrm{GWs}$ on several days during week 23 of 2015. Figure 7 shows that twice the solar generation of 2015 would have caused a $160 \mathrm{GWc}$ wind fleet to over-generate around $50 \mathrm{GWs}$ during June 2, despite the fact that Germany's interconnectors were working at close to their maximum capacity, exporting up to $11.3 \mathrm{GW}$. This figure, therefore, provides a graphic illustration of why wind and solar fleets large enough to give rise to wind curtailment can only be modelled using real-time records.

The Hdrm value was approximately 52.9 GW in 2015 (grid demand of $62.8 \mathrm{GW}$ less base generation of $9.9 \mathrm{GW}$ ). In order to explore a wide range of future grid configurations, the models were run for base generation values of 17.81, 7.81, -2.19 and $12.19 \mathrm{GW}$, equivalent to Hdrm values of 45, 55, 65 and 75GW, respectively. The GWe vs. GWc and marginal efficiency curves produced using the models are shown in Figure 8.

The data in the spreadsheet used to generate the curves of Figure 8 was used to produce the look-up table of Appendix B for marginal efficiencies of $0.133,0.1$ 

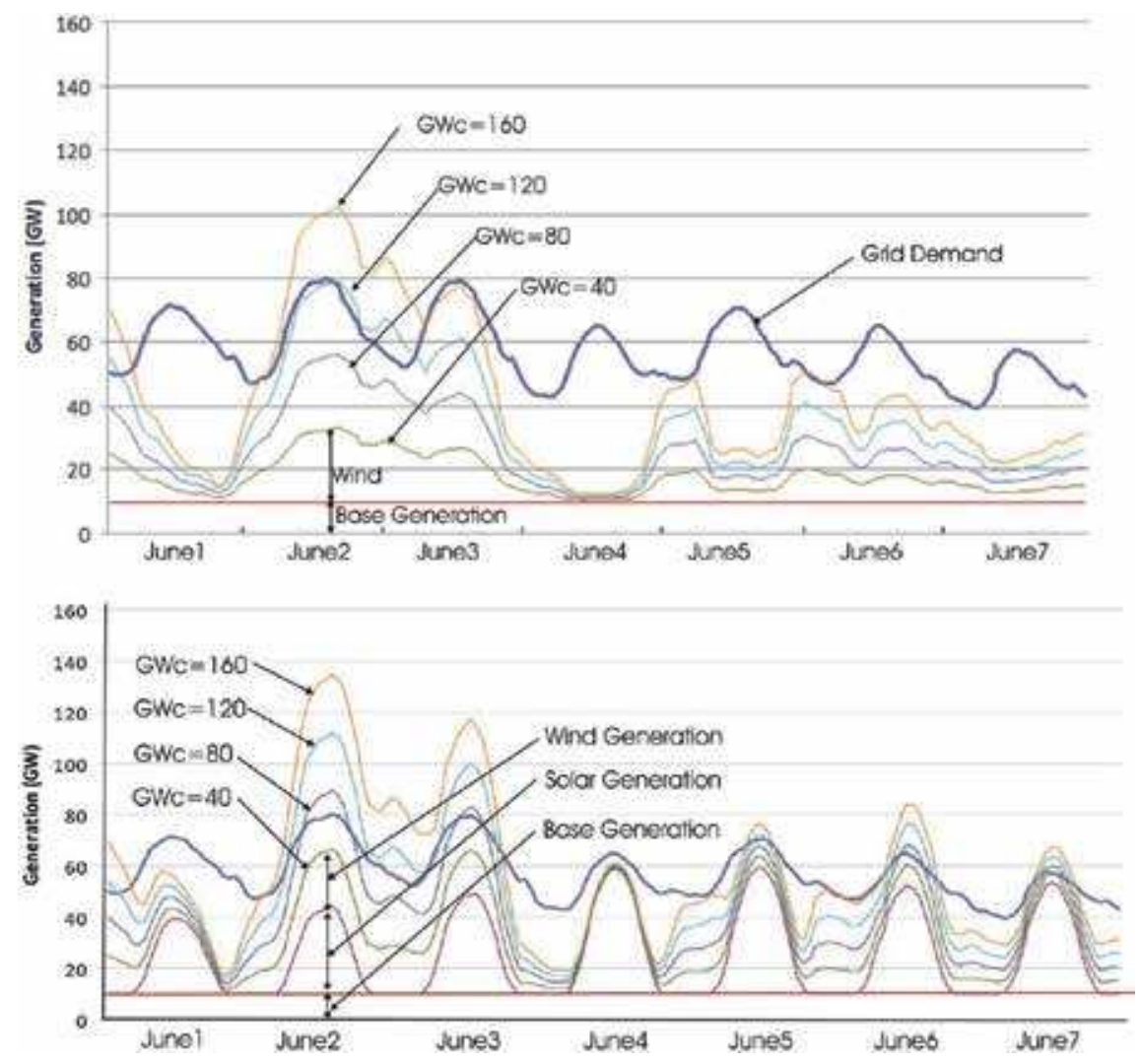

Figure 7.

Model predictions for week 23 of 2015. The upper graphic shows the model results for no solar generation and the lower graphic twice the solar generation in 2015.
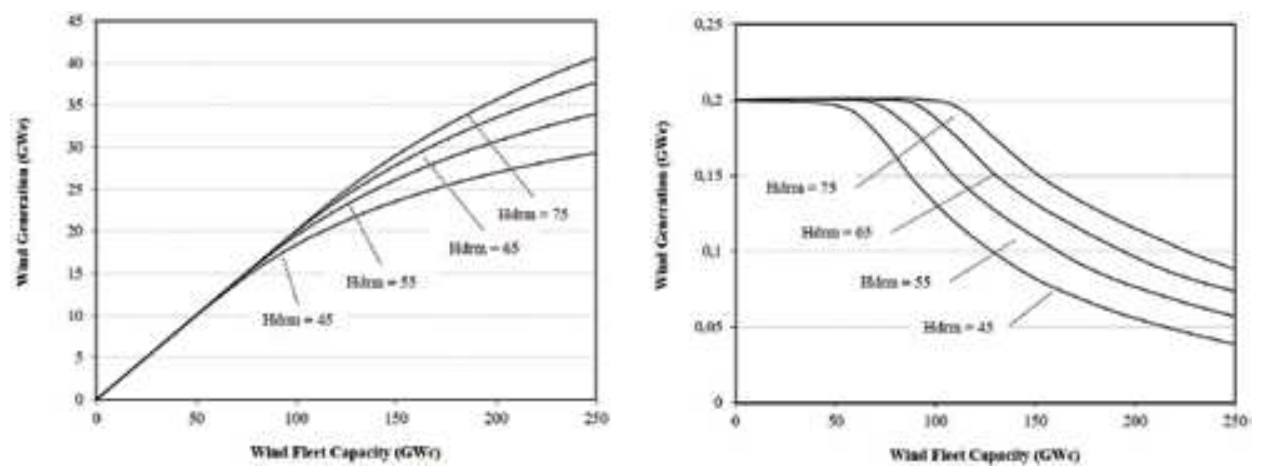

Figure 8.

GWe vs. GWc and marginal efficiency predictions for Hdrm values of 45, 55, 65 and $75 \mathrm{GW}$.

and 0.067. We shall now investigate, using the look-up table in Appendix B, three scenarios likely to be encountered by the German grid in future.

\subsection{Scenario 1: Increasing Germany's wind fleet capacity in order to reduce carbon emissions}

In 2015 German carbon emissions from electricity generation were 290.13 MT [13], consisting of 169.33 MT from brown coal (15.9 GW at 10.65 MT per GW), 106.16 
Development of Mathematical Models to Explore the Potential of Wind Fleets to Decarbonize... DOI: http://dx.doi.org/10.5772/intechopen.88885

\begin{tabular}{cccccc}
\hline $\begin{array}{l}\text { Marginal } \\
\text { efficiency }\end{array}$ & GWc & (GWe + GWs $)$ & $\begin{array}{c}\text { Increase in } \\
(\text { GWe }+ \text { GWs })\end{array}$ & $\begin{array}{c}\text { Carbon } \\
\text { emissions } \\
(\mathbf{M T})\end{array}$ & $\begin{array}{c}\mathbf{d} \text { (carbon)/ } \\
\mathbf{d}(\mathrm{GWc})\end{array}$ \\
\hline 0.200 & 44.58 & 12.91 & 0 & 290.12 & \\
\hline 0.133 & 119.56 & 29.98 & 17.08 & 110.50 & 2.40 \\
\hline 0.100 & 154.62 & 34.12 & 21.21 & 74.28 & 1.03 \\
\hline 0.067 & 213.54 & 38.78 & 25.87 & 33.46 & 0.69 \\
\hline
\end{tabular}

Table 7.

Predicted reductions in carbon emissions with increased in wind fleet capacity.

from hard coal (12.12 GW at 8.76 MT per GW) and 14.62 from gas generation (from 3.44 GW at 4.25 MT per GW). The German grid Hdrm in 2015 was approximately $52.91 \mathrm{GW}$, and columns 2 and 3 in Table 7 show the model predictions, by interpolation in Appendix B, of GWc and (GWe + GWs) values for a Hdrm value of $52.9 \mathrm{GW}$.

The increase in wind and solar generation since 2015, column 4, reduces the need for generation from dispatchable sources, and it is assumed that the reductions are in the order of the dirtiest sources first, that is, brown coal, followed by hard coal then gas. This assumption leads to the carbon emission predictions of column 5. Although it is not the objective of this study to take any view on the economics of wind generation, column 6 is a useful indicator of the decreasing effectiveness of the wind fleet in decarbonising the grid. Increasing the wind fleet from 44.58 to 119.25 GWc reduces carbon emissions by $2.40 \mathrm{MT}$ per GWc, but increasing the wind fleet from 119.56 to 154.62 GWc reduces emissions by only 1.03 MT per GWc and from 154.62 to 213.54 GWc by only 0.69 MT per GWc.

\subsection{Scenario 2: closure of Germany's nuclear generation capacity}

In 2013, Germany decided to phase out its nuclear-generating capacity by 2022 [16]. A consequence of the loss of $9.9 \mathrm{GW}$ of nuclear generation is that Hdrm will increase by 9.9-62.81 GW. It is possible to model the impact of this change on total carbon emissions as explained for the UK in Section 4.2. Assuming a marginal efficiency of 0.1 , the additional carbon emissions are calculated to be 18.5 MT p.a., as shown in Figure 5. As for the other scenarios, there is a trade-off between wind fleet efficiency and carbon emissions: the lower the marginal efficiency, the higher the benefit. The optimum value will depend, as for the UK, on the relative costs of wind and gas energies, the carbon tax, and the German decarbonisation targets.

\subsection{Scenario 3: replacement of petrol and diesel passenger vehicles with electric vehicles}

In 2015, Germany had 47 million diesel and petrol passenger vehicles [29]. Assuming the same characteristics proposed by MacKay for the UK, these vehicles would have generated 126.2 MT carbon per annum, and the additional electrical power needed from the grid to replace these vehicles with EVs would be 19.5 GW. This increase in grid demand will increase the Hdrm available to the wind and solar fleets from 52.91 to $72.41 \mathrm{GW}$, and it is possible to model the impact of the additional capacity on carbon emissions as a function of the marginal efficiency.

The results of this modeling are shown in Figure 6; it is evident that there is considerable potential to reduce carbon emissions by replacing internal combustion engines with EVs. 


\section{Conclusions}

This chapter explains why wind fleets, which compete for limited access to a grid, can only be modelled using real-time grid records, and why grids should be considered as acting towards wind fleets as time-varying low-pass filters.

Models of the UK and German grid systems are described using their real-time records which are available online. The models should have general applicability, although they would need to be updated should more efficient turbines with improved load factors be introduced. This would however be a simple matter of rerunning the models with revised scaling factors.

Since they incorporate large amounts of grid records across 52 weekly sub-models, the modeling process is somewhat cumbersome. However, the models may be used to create GWe vs. GWc and marginal efficiency curves from which look-up tables may be derived, which obviate the need for further model runs. The chapter describes the use of these look-up tables to investigate a number of important scenarios likely to be faced by the grids in the future. Figure 4 provides a particularly useful quantitative insight into the ability/limitations of wind and solar fleets to decarbonise their grids. Residual generation, that portion of Hdrm which must be provided by dispatchable generation may be reduced by accepting higher levels of wind curtailment but wind curtailment comes at an economic cost. The level of wind curtailment, which will be deemed to be economic, will depend on the economic circumstances of the time and of the cost of reducing carbon emissions using alternative approaches.

\section{Conflict of interest}

The authors declare no conflict of interest.

\section{Appendices}

\section{Appendix A. UK model predictions of grid configurations}

The data in these tables has been derived from the GWe vs. GWc and marginal efficiency curves of Figure 3, that is, solar generation twice that in 2017 (cells marked N/A cannot be computed from the GWe vs. GWc and marginal efficiency curves of Figure 3).

\begin{tabular}{lccccc}
\hline Hdrm & $\mathbf{2 0}$ & $\mathbf{3 0}$ & $\mathbf{4 0}$ & $\mathbf{5 0}$ & $\mathbf{6 0}$ \\
\hline Marginal efficiency $=\mathbf{0 . 2 0}$ & & & & & \\
\hline GWc & 35.64 & 56.76 & 77.37 & 97.54 & 115.3 \\
\hline GWe & 9.44 & 15.89 & 21.84 & 27.73 & 33.05 \\
\hline GWs & 2.316 & 2.316 & 2.316 & 2.316 & 2.316 \\
\hline (GWe + GWs $)$ & 11.76 & 18.20 & 24.20 & 30.05 & 35.37 \\
\hline (GWe + GWs $/$ Hdrm & 0.59 & 0.60 & 0.60 & 0.60 & 0.59 \\
\hline Residual Generation/Hdrm & 0.41 & 0.40 & 0.40 & 0.4 & 0.41 \\
\hline GWe/GWc & 0.27 & 0.28 & 0.28 & 0.28 & 0.28 \\
\hline \% wind shed & 10 & 6.7 & 6.7 & 6.7 & 6.7 \\
\hline Marginal efficiency $=\mathbf{0 . 1 5}$ & & & & & \\
\hline GWc & 44.05 & 68.95 & 94.83 & 117.58 & N/A \\
\hline GWe & 11.09 & 18.03 & 24.65 & 31.20 & N/A \\
\hline
\end{tabular}


Development of Mathematical Models to Explore the Potential of Wind Fleets to Decarbonize... DOI: http://dx.doi.org/10.5772/intechopen.88885

\begin{tabular}{|c|c|c|c|c|c|}
\hline Hdrm & 20 & 30 & 40 & 50 & 60 \\
\hline GWs & 2.316 & 2.316 & 2.316 & 2.316 & N/A \\
\hline$(\mathrm{GWe}+\mathrm{GWs})$ & 13.4 & 20.34 & 26.96 & 33.52 & N/A \\
\hline$(\mathrm{GWe}+\mathrm{GWs}) / \mathrm{Hdrm}$ & 0.67 & 0.67 & 0.67 & 0.67 & N/A \\
\hline Residual/Hdrm & 0.33 & 0.33 & 0.33 & 0.33 & N/A \\
\hline GWe/GWc & 0.25 & 0.26 & 0.26 & 0.26 & N/A \\
\hline$\%$ wind shed & 16.6 & 13.3 & 13.3 & 13.3 & N/A \\
\hline \multicolumn{6}{|c|}{ Marginal efficiency $=0.10$} \\
\hline GWc & 56.22 & 86.86 & 117.17 & N/A & N/A \\
\hline GWe & 12.6 & 20.02 & 27.59 & N/A & N/A \\
\hline GWs & 2.316 & 2.316 & 2.316 & N/A & N/A \\
\hline$(\mathrm{GWe}+\mathrm{GWs})$ & 14.92 & 22.51 & 29.91 & N/A & N/A \\
\hline$(\mathrm{GWe}+\mathrm{GWs}) / \mathrm{Hdrm}$ & 0.75 & 0.75 & 0.75 & N/A & N/A \\
\hline Residual/Hdrm & 0.25 & 0.25 & 0.25 & N/A & N/A \\
\hline GWe/GWc & 0.224 & 0.233 & 0.235 & N/A & N/A \\
\hline$\%$ wind shed & 25.3 & 22.3 & 21.6 & N/A & N/A \\
\hline \multicolumn{6}{|c|}{ Marginal efficiency $=0.05$} \\
\hline Hdrm & 20 & 30 & 40 & 50 & 60 \\
\hline GWc & 82.52 & 122.8 & N/A & N/A & N/A \\
\hline GWe & 14.45 & 22.84 & N/A & N/A & N/A \\
\hline GWs & 2.316 & 2.316 & N/A & N/A & N/A \\
\hline$(\mathrm{GWe}+\mathrm{GWs})$ & 16.78 & 25.16 & N/A & N/A & N/A \\
\hline$(\mathrm{GWe}+\mathrm{GWs}) / \mathrm{Hdrm}$ & 0.84 & 0.84 & N/A & N/A & N/A \\
\hline Residual/Hdrm & 0.16 & 0.16 & N/A & N/A & N/A \\
\hline GWe/GWc & 0.175 & 0.186 & N/A & N/A & N/A \\
\hline$\%$ wind shed & 41.6 & 38.0 & N/A & N/A & N/A \\
\hline
\end{tabular}

\section{Appendix B. Germany model predictions of grid configurations}

The data in these tables has been derived from the GWe vs. GWc and marginal efficiency curves of Figure 8, that is, solar generation twice that in 2017 (cells marked N/A cannot be computed from the GWe vs. GWc and marginal efficiency curves of Figure 8).

\begin{tabular}{lcccc}
\hline Hdrm & $\mathbf{4 5}$ & 55 & $\mathbf{6 5}$ & $\mathbf{7 5}$ \\
\hline Marginal efficiency $=\mathbf{0 . 1 3 3}$ & & & & \\
\hline GWc & 99.08 & 124.97 & 148.16 & 172.59 \\
\hline GWe & 18.2628 & 23.045 & 27.611 & 32.20 \\
\hline GWs & 7.94 & 7.95 & 7.94 & 7.94 \\
\hline$($ GWe + GWs $)$ & 26.2028 & 30.985 & 35.55 & 40.147 \\
\hline$($ GWe + GWs $/$ Hdrm & 0.582 & 0.563 & 0.5469 & 0.5353 \\
\hline Residual Generation/Hdrm & 0.418 & 0.437 & 0.4531 & 0.4647 \\
\hline GWe/GWC & 0.1843 & 0.1857 & 0.1864 & 0.1865 \\
\hline
\end{tabular}


Modeling, Simulation and Optimization of Wind Farms and Hybrid Systems

\begin{tabular}{lcccc}
\hline Hdrm & $\mathbf{4 5}$ & 55 & $\mathbf{6 5}$ & $\mathbf{7 5}$ \\
\hline \% wind shed & 7.83 & 7.12 & 6.83 & 6.71 \\
\hline Marginal efficiency $\mathbf{0 . 1}$ & & & & \\
\hline GWc & 128.41 & 161.55 & 194.18 & 226.03 \\
\hline GWe & 21.60 & 27.39 & 32.95 & 38.40 \\
\hline GWs & 7.94 & 7.94 & 7.94 & 7.94 \\
\hline (GWe + GWs) & 29.54 & 35.33 & 40.89 & 46.34 \\
\hline (GWe + GWs)/Hdrm & 0.656 & 0.642 & 0.629 & 0.618 \\
\hline Residual Generation/Hdrm & 0.34 & 0.36 & 0.37 & 0.38 \\
\hline GWe/GWC & 0.168 & 0.169 & 0.169 & 0.170 \\
\hline \% wind shed & 15.9 & 15.2 & 15.2 & 15.0 \\
\hline Marginal efficiency $=0.0666$ & & & & \\
\hline GWc & 176.59 & 223.31 & N/A & N/A \\
\hline GWe & 25.54 & 32.203 & N/A & N/A \\
\hline GWs & 7.94 & 7.94 & N/A & N/A \\
\hline (GWe + GWs) & 33.48 & 40.13 & N/A & N/A \\
\hline (GWe + GWs)/Hdrm & 0.744 & 0.7288 & N/A & N/A \\
\hline Residual Generation/Hdrm & 0.256 & 0.2712 & N/A & N/A \\
\hline GWe/GWC & 0.1446 & 0.1446 & N/A & N/A \\
\hline wind shed & 27.6 & 27.6 & N/A & N/A \\
\hline (G) & & & \\
\hline
\end{tabular}

\section{Author details}

Anthony D. Stephens ${ }^{1 *}$ and David R. Walwyn ${ }^{2}$

1 Derbyshire, UK

2 Department of Engineering and Technology Management, University of Pretoria, South Africa

*Address all correspondence to: tonystephensgigg@gmail.com

\section{IntechOpen}

(C) 2020 The Author(s). Licensee IntechOpen. Distributed under the terms of the Creative Commons Attribution - NonCommercial 4.0 License (https://creativecommons.org/ licenses/by-nc/4.0/), which permits use, distribution and reproduction for non-commercial purposes, provided the original is properly cited. (cc) BY-NC 
Development of Mathematical Models to Explore the Potential of Wind Fleets to Decarbonize... DOI: http://dx.doi.org/10.5772/intechopen.88885

\section{References}

[1] Holttinen $\mathrm{H}$. Wind integration: Experience, issues, and challenges. Wiley Interdisciplinary Reviews: Energy and Environment. 2012;1(3):243-255

[2] Stephens A, Walwyn DR. Wind energy in the United Kingdom: Modelling the effect of increases in installed capacity on generation efficiencies. Renewable Energy Focus. 2018;27:44-58

[3] Huber M, Dimkova D, Hamacher T. Integration of wind and solar power in Europe: Assessment of flexibility requirements. Energy. 2014;69(5):236-246

[4] Ong T. Elon Musk's Giant Battery is Now Delivering Power to South Australia. New York: The Verge; 2017. Available from: https://www.theverge. com/2017/12/1/16723186/elon-muskbattery-launched-south-australia [Accessed: 23 August 2019]

[5] Eller A, Gauntlett D. Energy Storage Trends and Opportunities for Emerging Markets. Boulder, USA: IFC; 2017

[6] Barnhart CJ, Dale M, Brandt AR, Benson SM. The energetic implications of curtailing versus storing solarand wind-generated electricity. Energy \& Environmental Science. 2013;6:2804-2810

[7] Marcacci S. Study: Battery Energy Storage Benefits Solar Not Wind. London: Clean Technica; 2013. Available from: https://cleantechnica. com/2013/09/13/study-battery-energystorage-works-for-solar-but-not-wind/ [Accessed: 17 June 2018]

[8] MacKay D. Sustainable Energy without the Hot Air. Cambridge: UIT Cambridge; 2009

[9] Royal Academy of Engineering. Wind Energy Report. London: Royal Academy of Engineering; 2014
[10] Gosden E. Electricity Imports at Record High as New Link Allows Cheaper Deal. London: The Times; 2019. Available from: https://www.thetimes. co.uk/article/electricity-importsat-record-high-as-new-link-allowscheaper-deal-jfscq995m [Accessed: 17 June 2019]

[11] Mearns E. UK Wind Constraint Payments. London: Euan Mearns; 2016 Available from: http://euanmearns. com/uk-wind-constraint-payments/ [Accessed: 17 June 2019]

[12] Gridwatch GB. National Grid Status (Data Courtesy of Elexon Portal and Sheffield University). United Kingdom: Templar; 2017. Available from: http://www.gridwatch.templar. co.uk/ [Accessed: 4 April 2017]

[13] Fraunhofer Institute for Solar Energy Systems ISE. Electricity Production in Germany. Freiburg: Fraunhofer; 2017. Available from: https://www.energy-charts.de/power. htm [Accessed: 4 April 2017]

[14] Gosden E. Wind Farms Could be Paid to Stop Producing Power. London: The Times; 2017. Available from: https://www.thetimes.co.uk/ article/wind-farms-could-be-paid-tostop-producing-power-qqm5dl7wk [Accessed: 12 October 2017]

[15] UK Government. Section 5 - Electricity. London: Gov.UK; 2016. Available from: www.gov. uk/government/uploads/system/ uploads/attachment_data/file/487838/ Electricity.pdf [Accessed: 14 June]

[16] Staudenmaier R. German Nuclear Phase out Explained. Bonn: Deutsche Welle; 2017. Available from: https://www.dw.com/cda/ en/germanys-nuclear-phase-outexplained/a-39171204 [Accessed: 17 June 2019] 
[17] World Nuclear News. Belgium Maintains Nuclear Phase-out Policy. London: World Nuclear News; 2018. Available from: http://www.worldnuclear-news.org/NP-Belgium-maintainsnuclear-phase-out-policy-0404184.html [Accessed: 17 June 2019]

[18] Gosden E, Webster B. Climate Change: Ban for Gas Boilers as Electric Cars Lead Way to Green Future. London: The Times; 2019. Available from: https://www.thetimes.co.uk/ article/climate-change-ban-for-gasboilers-as-electric-cars-lead-way-togreen-future-kkvhtt39q [Accessed: 17 June 2019]

[19] Holttinen H. Recommended Practises for Wind and PV Integration Studies. Paris: International Energy Agency; 2018

[20] Department of Energy \& Climate Change. Electricity: Chapter 5, Digest of United Kingdom Energy Statistics (DUKES). London: Gov.UK; 2015. Available from: https://www.gov. uk/government/uploads/system/ uploads/attachment_data/file/447632/ DUKES_2015_Chapter_5.pdf [Accessed: 17 June]

[21] Department for Business Energy and Industrial Strategy. Implementing the End of Unabated Coal by 2025. Department for Business Energy and Industrial Strategy. UK Government: London; 2018

[22] Gosden E. Government Turns Up Power on off Shore Wind. London: The Times; 2019. Available from: https://www.thetimes.co.uk/article/ government-turns-up-power-onoffshore-wind-sxhh796m7 [Accessed: 17 June 2019]

[23] Society of Motor Manufacturers and Traders. Motor Industry Facts 2019. London: Society of Motor Manufacturers and Traders; 2019
[24] Transport and Environment. $\mathrm{CO}_{2}$ Emissions from Cars: The Facts. Brussels: European Federation for Transport and Environment; 2018

[25] Kern F, Rogge KS. The pace of governed energy transitions: Agency, international dynamics and the global Paris agreement accelerating decarbonisation processes? Energy Research and Social Science. 2016;22:13-17

[26] Department for Business Energy and Industrial Strategy. UK Energy in Brief. London: Department for Business Energy and Industrial Strategy; 2018

[27] Energy Transition. The Energiewende a to Z Bonn. Bonn: Heinrich Böll Foundation; 2019. Available from: http://wiki. energytransition.org/ [Accessed: 19 June 2019]

[28] Vaughan A. Nord Stream 2 Russian Gas Pipeline Likely to Go Ahead after EU Deal. London: The Guardian; 2019. Available from: https://www. theguardian.com/business/2019/feb/25/ nord-stream-2-russian-gas-pipelinelikely-to-go-ahead-after-eu-deal [Accessed: 19 June 2019]

[29] Bekker H. Germany: Total Number of Registered Cars by Brand. Bonn: Best Selling Cars; 2019. Available from: https://www.best-selling-cars.com/ germany/2019-germany-total-numberof-registered-cars-by-brand/ [Accessed 19 June 2019] 


\title{
Chapter 5
}

\section{Optimal Bidding in Wind Farm Management}

\author{
Alain Bensoussan and Alexandre Brouste
}

\begin{abstract}
We study the problem of wind farm management, in which the manager commits himself to deliver energy in some future time. He reduces the consequences of uncertainty by using a storage facility (a battery, for instance). We consider a simplified model in discrete time, in which the commitment is for the next period. We solve an optimal control problem to define the optimal bidding decision. Application to a real dataset is done, and the optimal size of the battery (or the overnight costs) for the wind farm is determined. We then describe a continuous time version involving a delay between the time of decision and the implementation.
\end{abstract}

Keywords: optimal control, stochastic control, wind farm management, wind production forecast, storage

\section{Introduction}

A higher penetration level of the wind energy into electric power systems plays a part in the reduction of $\mathrm{CO}_{2}$ emissions. In the meantime, traditional operational management of power systems is transformed by taking into consideration this fluctuating and intermittent resource. Smart grids and storage systems have been developed to overcome these challenges.

For wind power plants, storage is a straightforward solution to reduce renewable variability. It can be used to store electricity in hours of high production and inject electricity in the grid later on. The performance of the operational management can be therefore improved by considering simple charge-discharge plans based on short-term forecasts of the renewable production [1]. For instance, optimal management of wind farms associated with hydropower pumped storage showing economic benefit and increasing the controllability have been studied in [2-4]. Other examples are the sizing of a distributed battery in order to provide frequency support for a grid-connected wind farm [5] and the optimal operation of a wind farm equipped with a storage unit $[6,7]$.

For the specific case of isolated systems, which is the aim of our paper, it is necessary to think about distributed energy storage as battery [8], ultra-capacitors [9], or flywheels [10]. In this setting, the question of economic viability in isolated islands without additional reserves arises. Here, the storage unit allows wind farms to respect the scheduled production.

The storage costs will represent a large part of the overnight capital costs and motivate the different researches on storage. Generally the sizing of the storage device is reduced to a minimization problem of the fixed and variable costs of the 
storage and its application (see $[11,12]$, for a complete analysis of the cash flow of the storage unit).

In this paper, we present a simplified model in discrete time, in which the commitment is for the next period. We solve an optimal control problem to define the optimal bidding decision. The mathematical setting of the problem is described in Section 2. The main result is detailed in Section 3. Application on a real dataset is described in Section 4. The continuous version of the problem is also described in Section 5. A conclusion ends the paper.

\section{Setting of the problem}

\subsection{General description}

In our problem, the manager has to announce an energy production to be delivered to the next period. Considering the $k^{\text {th }}$ period, we may think that the announcement is made at the beginning of the period and the delivery at the end of the period. Of course the real delivery will be split along the $(k+1)^{t h}$ period. This splitting will be omitted in this stylized model. It is convenient to consider the full delivery at the end of the $k^{\text {th }}$ period which is the beginning of the $(k+1)^{t h}$ period. So, at the beginning of the $k^{\text {th }}$ period (day or hour), the manager commits himself to deliver $v_{k}$ units of energy (kWh or MWh). To simplify, we discard margins of tolerance. To decide, he knows the amount of energy stored in the battery, called $y_{k}$. The second element concerns the windfarm. The energy produced by the windfarm is a stochastic process $Z_{k}$. More precisely, $Z_{k}$ is the energy produced during the $(k-1)^{t h}$ period, which we consider to be available at the beginning of the $k^{\text {th }}$ period. So $Z_{k}$ and all previous values are known. However to fulfill his commitment, the manager will rely on $Z_{k+1}$, the energy produced during the $k^{\text {th }}$ period, which we consider, with our convention, to occur at the end of the $k^{\text {th }}$ period, which is the beginning of the $(k+1)^{t h}$ period. So it is not known by the manager, when he takes his decision. We model the process $Z_{k}$ as a Markov chain with transition probability density $f_{k}(\zeta \mid z)$. A key issue concerns the choice of this density which is discussed in the application in Section 4. Precisely, although formally

$$
\operatorname{Prob}\left(Z_{k+1}=\zeta \mid Z_{k}=z\right)=f_{k}(\zeta \mid z)
$$

In fact, $Z_{k}$ is obtained through the power law, operating on another Markov chain, the wind speed (see $[13,14]$ for examples of such Markov chains).

We denote by $F_{k}(\zeta \mid z)$ the CDF of the transition probability. We also set $\bar{F}_{k}(\zeta \mid z)=$ $1-F_{k}(\zeta \mid z)$.

In the language of stochastic control, the decision $v_{k}$ (control) is measurable with respect to $\mathcal{F}^{k}=\sigma\left(Z_{1}, \cdots, Z_{k}\right)$. The storage $y_{k}$ is also adapted to $\mathcal{F}^{k}$. The evolution of $y_{k}$ is defined by the equation

$$
y_{k+1}=\left(\min \left(M, y_{k}+Z_{k+1}-v_{k}\right)\right)^{+}
$$

Indeed, the available energy at the end of the $k^{\text {th }}$ period is $y_{k}+Z_{k+1}$. If this quantity is smaller than $v_{k}$, then the manager cannot fulfill his commitment; he delivers what he has, namely, $y_{k}+Z_{k+1}$; and the storage becomes empty. If the available energy $y_{k}+Z_{k+1}$ is larger than $v_{k}$, then the manager delivers his 
commitment $v_{k}$ and tries to store the remainder $y_{k}+Z_{k+1}-v_{k}$. This is possible only when this quantity is smaller than $M$, which represents the maximum storage of the battery. If $y_{k}+Z_{k+1}-v_{k}>M$, then he charges up to $M$, and the quantity $y_{k}+Z_{k+1}-v_{k}-M$ is lost (given free to the grid). This results in formula (2). In this equation, we do not consider the constraint to keep a minimum reserve. We also are considering the battery as a reservoir of $\mathrm{kWh}$, which we can reduce or increase as done in inventory of goods. Finally, we neglect the losses in the battery.

\subsection{The payoff}

We want now to write the payoff to be optimized. During the period $k$, if the manager delivers his commitment $v_{k}$, he receives the normal income $p v_{k}$. If he fails and delivers only $y_{k}+Z_{k+1}<v_{k}$, there is a penalty. In the sequel, we have chosen the following penalty $\varpi\left(y_{k}+Z_{k+1}-v_{k}\right)^{-}$, which is common in inventory theory. The parameter $\varpi$ can be adjusted, for instance, to compare with the conditions on the spot market.

In our set up, the pair $y_{k}, Z_{k}$ is a Markov chain. So we have a controlled Markov chain and the state is two-dimensional. We introduce a discount factor denoted by $\alpha$, which is useful if we consider an infinite horizon. We can have $\alpha=1$, otherwise. Initial conditions are given at time $n$ and denoted by $x, z$. We call $V=\left(v_{n}, \cdots v_{N}\right)$ the control, where $N$ is the horizon. Finally, we want to maximize the functional

$$
J_{n}(x, z ; V)=\sum_{k=n}^{N} \alpha^{k-n} E\left[p \min \left(v_{k}, y_{k}+Z_{k+1}\right)-\varpi\left(y_{k}+Z_{k+1}-v_{k}\right)^{-}\right]
$$

\section{Dynamic programming}

\subsection{Bellman equation}

The value function is defined by

$$
U_{n}(x, z)=\sup _{V} J_{n}(x, z ; V)
$$

Writing

$$
\min \left(v_{k}, y_{k}+Z_{k+1}\right)=v_{k}-\left(y_{k}+Z_{k+1}-v_{k}\right)^{-}
$$

we get also

$$
J_{n}(x, z ; V)=\sum_{k=n}^{N} \alpha^{k-n} E\left[p v_{k}-(p+\varpi)\left(y_{k}+Z_{k+1}-v_{k}\right)^{-}\right]
$$

We can then write Bellman equation

$$
\begin{aligned}
U_{n}(x, z)= & \sup _{v>0}\left\{p v+E\left[-(p+\varpi)\left(x+Z_{n+1}-v\right)^{-}+\right.\right. \\
& \left.\left.+\alpha U_{n+1}\left(\left(\min \left(M, x+Z_{n+1}-v\right)\right)^{+}, Z_{n+1}\right) \mid Z_{n}=z\right]\right\}
\end{aligned}
$$


It is convenient to make the change of variables $v-x=y$ and obtain

$$
\begin{aligned}
U_{n}(x, z)= & p x+\sup _{x+y>0}\left\{p y+E\left[-(p+\varpi)\left(Z_{n+1}-y\right)^{-}+\right.\right. \\
& \left.\left.+\alpha U_{n+1}\left(\left(\min \left(M, Z_{n+1}-y\right)\right)^{+}, Z_{n+1}\right) \mid Z_{n}=z\right]\right\}
\end{aligned}
$$

with final equation

$$
U_{N+1}(x)=0
$$

We have $x \in[0, M]$ and $z>0$.

\subsection{Main result}

We state the following proposition:

Proposition 1. The solution of (7) is of the form

$$
U_{n}(x, z)=p x+K_{n}(z)
$$

Proof. For $n=N$, we have

$$
U_{N}(x, z)=p x+\sup _{x+y>0}\left\{p y-(p+\varpi) E\left[\left(Z_{N+1}-y\right)^{-} \mid Z_{N}=z\right]\right\}
$$

Consider the function

$$
\varphi_{N+1}(y)=p y-(p+\varpi) E\left[\left(Z_{N+1}-y\right)^{-} \mid Z_{N}=z\right]
$$

then, for $y<0$, we have $\varphi_{N+1}(y)=p y$. It is monotone increasing, so the maximum cannot be reached at a point $y<0$. It follows that (8) is satisfied at $n=N$, with

$$
K_{N}(z)=\sup _{y>0}\left\{p y-(p+\varpi) E\left[\left(Z_{N+1}-y\right)^{-} \mid Z_{N}=z\right]\right\}
$$

We have, for $y>0$

$$
\varphi_{N+1}(y)=p y-(p+\varpi) \int_{0}^{y}(y-\zeta) f(\zeta \mid z) d \zeta
$$

and $\varphi_{N+1}(y)$ is concave, since

$$
\begin{aligned}
\varphi_{N+1}^{\prime}(y) & =p-(p+\varpi) F(y \mid z) \\
\varphi^{\prime \prime}{ }_{N+1}(y) & =-(p+\varpi) f(y \mid z)<0
\end{aligned}
$$

and $\varphi_{N+1}^{\prime}(0)=p, \varphi_{N+1}^{\prime}(+\infty)=-\varpi$. So the maximum is uniquely defined.

Assume now (8) for $n+1$. We insert it in (7) to obtain

$$
\begin{aligned}
U_{n}(x, z)= & p x+\sup _{x+y>0}\left\{p y+E\left[-(p+\varpi)\left(Z_{n+1}-y\right)^{-}+\right.\right. \\
& \left.\left.+\alpha p\left(\min \left(M, Z_{n+1}-y\right)\right)^{+} \mid Z_{n}=z\right]\right\}+\alpha E\left[K_{n+1}\left(Z_{n+1}\right) \mid Z_{n}=z\right]
\end{aligned}
$$

Consider now the function

$$
\begin{aligned}
\varphi_{n+1}(y \mid z)= & p y+E\left[-(p+\varpi)\left(Z_{n+1}-y\right)^{-}+\right. \\
& \left.+\alpha p\left(\min \left(M, Z_{n+1}-y\right)\right)^{+} \mid Z_{n}=z\right]
\end{aligned}
$$


For $y<0$, it reduces to

$$
\varphi_{n+1}(y \mid z)=p y+\alpha p\left[M \bar{F}_{n+1}\left((y+M)^{+}\right)+\int_{0}^{(y+M)^{+}}(\zeta-y) f_{n+1}(\zeta \mid z) d \zeta\right]
$$

and

$$
\begin{aligned}
\varphi_{n+1}^{\prime}(y \mid z)= & p-\alpha p F_{n+1}\left((y+M)^{+}\right) \\
& \geq p-\alpha p F_{n+1}(M)>0
\end{aligned}
$$

and thus cannot reach a maximum for $y<0$. Considering $y>0$, we have

$$
\begin{aligned}
\varphi_{n+1}(y \mid z)= & p y-(p+\varpi) \int_{0}^{y}(y-\zeta) f_{n+1}(\zeta \mid z) d \zeta+ \\
& +\alpha p\left[M \bar{F}_{n+1}(y+M)+\int_{y}^{y+M}(\zeta-y) f_{n+1}(\zeta \mid z) d \zeta\right]
\end{aligned}
$$

Again, this function is concave and

$$
\begin{gathered}
\varphi_{n+1}^{\prime}(y \mid z)=p-(p(1-\alpha)+\varpi) F_{n+1}(y \mid z)-\alpha p F_{n+1}(y+M \mid z) \\
\varphi_{n+1}^{\prime \prime}(y \mid z)=-(p(1-\alpha)+\varpi) f_{n+1}(y \mid z)-\alpha p f_{n+1}(y+M \mid z)<0 \\
\varphi_{n+1}^{\prime}(0 \mid z)=p-\alpha p F_{n+1}(M \mid z)>0 \\
\varphi_{n+1}^{\prime}(+\infty \mid z)=-\varpi
\end{gathered}
$$

and the property (8) is proven with

$$
\begin{aligned}
K_{n}(z)= & \alpha \int_{0}^{+\infty} K_{n+1}(\zeta) f_{n+1}(\zeta \mid z) d \zeta+\max _{y>0}\left\{p y-(p+\varpi) \int_{0}^{y}(y-\zeta) f_{n+1}(\zeta \mid z) d \zeta+\right. \\
& \left.+\alpha p\left[M \bar{F}_{n+1}(y+M)+\int_{y}^{y+M}(\zeta-y) f_{n+1}(\zeta \mid z) d \zeta\right]\right\}
\end{aligned}
$$

The proof is completed.

\subsection{Optimal feedback}

We define by $S_{n}(z)$ the point at which $\varphi_{n+1}(y \mid z)$ attains its maximum. It is positive and uniquely defined. It follows that the optimal feedback in Bellman equation (6) is $\hat{v}_{n}(x, z)=x+S_{n}(z)$ and $S_{n}(z)$ is the unique solution of

$$
\begin{gathered}
p-(p(1-\alpha)+\varpi) F_{n+1}\left(S_{n} \mid z\right)-\alpha p F_{n+1}\left(S_{n}+M \mid z\right)=0 \\
p-(p+\varpi) F_{N+1}\left(S_{N} \mid z\right)=0
\end{gathered}
$$


The recursion (10) writes

$$
\begin{gathered}
K_{n}(z)=\alpha \int_{0}^{+\infty} K_{n+1}(\zeta) f_{n+1}(\zeta \mid z) d \zeta+p \int_{0}^{S_{n}(z)} \bar{F}_{n+1}(\zeta \mid z) d \zeta+\alpha p \int_{S_{n}(z)}^{S_{n}(z)+M} \bar{F}_{n+1}(\zeta \mid z) d \zeta \\
-\varpi \int_{0}^{S_{n}(z)} F_{n+1}(\zeta \mid z) d \zeta \\
K_{N}(z)=p \int_{0}^{S_{N}(z)} \bar{F}_{N+1}(\zeta \mid z) d \zeta-\varpi \int_{0}^{S_{N}(z)} F_{N+1}(\zeta \mid z) d \zeta
\end{gathered}
$$

It is worth emphasizing that the function $K_{n}(z)$ increases with $M$, as can be expected. The feedback has an easy interpretation. The bidding is the level of inventory plus a fixed amount depending on the last value of energy produced by the turbine. It is interesting to note that the quantity $S_{n}(z)$ decreases with $M$. This is not so obvious. Clearly, the larger $M$, the better it is, as captured by the increase of $K_{n}(z)$. We can understand why $S_{n}(z)$ decreases with $M$, as follows: When $M$ is large, the risk of wasting energy by lack of storage is reduced, so it makes sense to focus on the other risk, to overbid and pay the penalty. Hence it makes sense to reduce the bid.

\section{Application}

We describe in this section an application on a wind farm project financed by EREN on a French island with national tender process. First we set the energy price

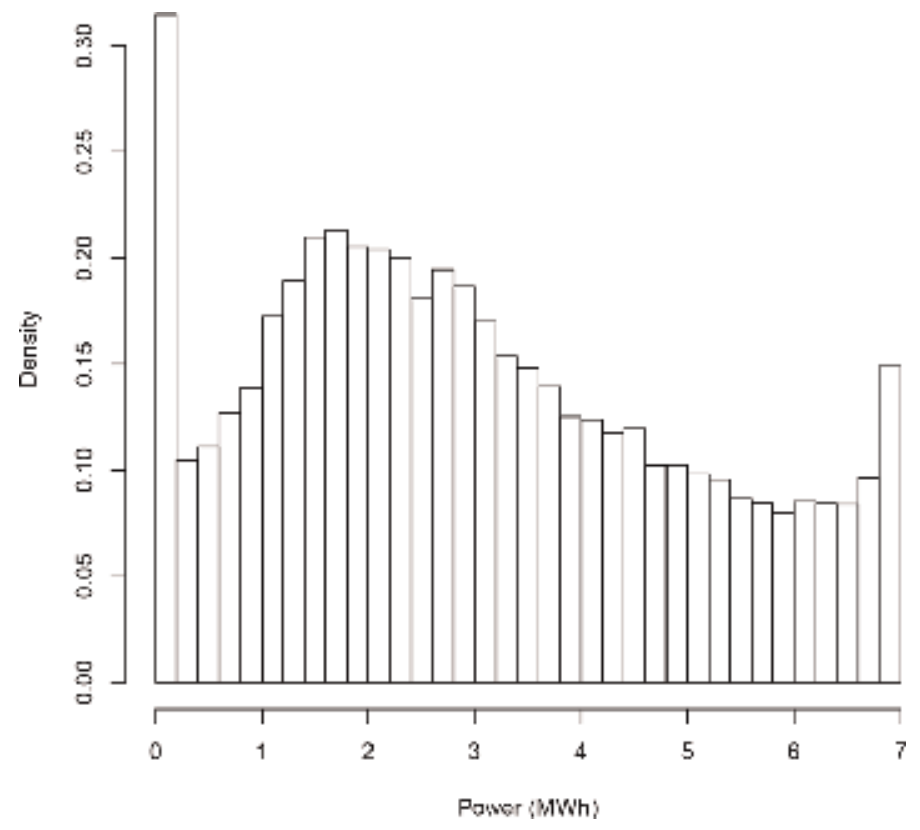

Figure 1.

Histogram of the production over a period of $30 \mathrm{~min}$. 
$p=230$ EUR/MWh (Official Journal from March 8, 2013) and the discount factor $\alpha=1$. In this first application, $N=48$ which is the number of periods of $30 \mathrm{~min}$ in a day.

In the sequel, we have chosen the penalty $\varpi\left(y_{k}+Z_{k+1}-v_{k}\right)^{-}$which is common in inventory theory. The parameter $\varpi$ can be adjusted.

Some analysts would prefer the penalty $\frac{p}{2}\left(y_{k}+Z_{k+1}\right) 11_{v_{k}>y_{k}+Z_{k+1}}$. This is rather strange, because it is fixed, whatever be the level of failure. If the failure is very
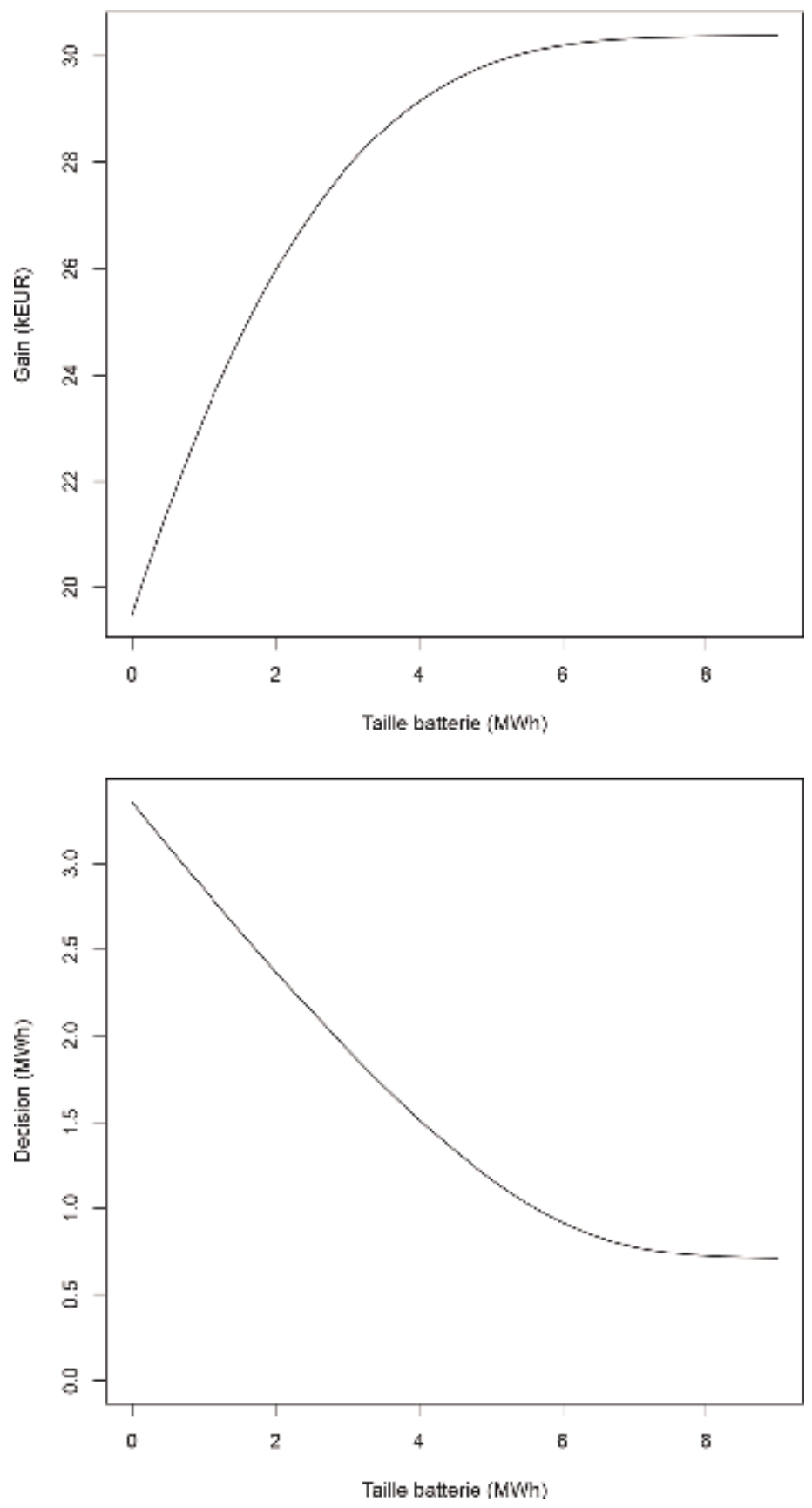

Figure 2.

On the left, daily payoff $U_{\mathrm{n}}(x, z)$ in terms of the size of the storage $M$ for $\alpha=0.9, p=230$, and $\varpi=\frac{3}{4} p$. Here $z=3 M W h$ and the initial storage is empty with $x=0 M W h$. On the right, part of the decision $\mathrm{S}_{\mathrm{n}}(\mathrm{z})($ from the direct wind production) in terms of the size of the storage $M$. 
small, the damage is not big, and still the penalty is high. Conversely, if the failure is big, the damage is big, and still the penalty does not change. Even more surprising, for a given level of commitment, the bigger the failure, the lower the penalty.

The production over a period of $30 \mathrm{~min}$ is presented on Figure 1. It is worth mentioning that we used directly the data proposed from July 26, 2005 to March 9, 2008 captured by a measurement mast.

For this first application, stationary law is considered as Gaussian. Mean and variance of the model are similar to those of the empirical distribution in Figure 1. This model allows to construct closed-form cumulative distribution function $F_{k}$. One-step forecasting error is $24 \%$ of the mean and $11 \%$ of the nominal power.

But this process does not take into account the stylized facts of the production on a period of $30 \mathrm{~min}$ (positive values below nominal power limit, atom for zero production, intraday seasonality, etc.). Consequently, in the optimal control problem, we use the corresponding truncated Gaussian distribution (between 0 and $7 \mathrm{MWh}$ ).

Finally, the penalty is fixed (geometrically) to $\varpi=\frac{3}{4} p$.

With these assumptions, the payoff with respect to the size of the storage is given in Figure 2 for an empty storage $x=0$, and $z$ is the average production as initial conditions. Some simple economic models penalizing the size of the battery with its costs would reveal an optimal size of the storage unit between 4 and $6 \mathrm{MWh}$.

\section{Continuous time version}

In the last section, we present a continuous version of the aforementioned problem. This new problem exhibits interesting questions in control theory when there is a delay between the decision and the application of the decision.

\subsection{A continuous time model}

We model the wind speed by a diffusion

$$
\begin{gathered}
d z=g(z) d t+\sigma(z) d w \\
z(0)=z
\end{gathered}
$$

where $w(t)$ is a standard one-dimensional Wiener process, built on a probability space $\Omega, \mathcal{A}, P$, and we denote by $\mathcal{F}^{t}$ the filtration generated by the Wiener process. This is the unique source of uncertainty in the model. We suppose that the model has a positive solution.

The energy produced per unit of time at time $t$ is $\varphi(z(t))$ where the function $\varphi$ is the power law. So the energy produced on an interval of time $(0, t)$ is $\int_{0}^{t} \varphi(z(s)) d s$. We assume that the manager bids for a delivery program with a fixed delay $h$. In other words, if he decides a level $v(t)$ per unit of time at time $t$, the delivery will be at $t+h$. On the interval of time $(0, t)$ the delivery is $\int_{h}^{t} v(s-h) d s$, provided $t>h$, otherwise it is 0 .

Define

$$
\begin{gathered}
\eta(t)=x+\int_{0}^{t} \varphi(z(s)) d s-\int_{h}^{t} v(s-h) d s, \quad t>h \\
\eta(t)=x+\int_{0}^{t} \varphi(z(s)) d s, \quad t \leq h
\end{gathered}
$$


which represents the excess of production of energy over the delivery on the interval $(0, t)$. The initial value $x$ represents the initial amount of energy in the storage unit. We have $0 \leq x \leq M$. We should have similarly $0 \leq \eta(t) \leq M, \forall t$. Indeed one cannot deliver more than one produces, and the storage of the excess production is limited by $M$. This constraint is more complex to handle than in the discrete time case. To simplify we shall treat the constraints with penalties and not impose them. In particular, for coherence, we remove the condition $0 \leq x \leq M$, which is a purely mathematical extension. The control is the process $v($.$) , which is adapted to$ the filtration $\mathcal{F}^{t}$ and just positive. We then define the payoff. The payoff will include the penalty terms and the profit from selling the energy. We assume that the manager can sell his production up to his commitment at a fixed price per unit of time and unit of energy $p$. We note that $\eta(t)<0$ captures the situation in which the manager delivers less than his commitment, and there is a penalty for it. The payoff is now written as

$$
\begin{gathered}
J_{x z}(v(.))=p E \int_{h}^{+\infty} \exp -\alpha s \min (\varphi(z(s)), v(s-h)) d s \\
-\varpi E \int_{0}^{+\infty} \exp -\alpha s \eta^{-}(s) d s-\pi E \int_{0}^{+\infty} \exp -\alpha s(\eta(s)-M)^{+} d s
\end{gathered}
$$

\subsection{Rewriting the payoff functional}

Because of the delay, we cannot consider the pair $z(t), \eta(t)$ as the state of a dynamic system and apply dynamic programming. In fact, we shall see that it is possible to rewrite the payoff (15) in terms of the pair $z(t), x(t)$ with

$$
x(t)=x+\int_{0}^{t} \varphi(z(s)) d s-\int_{0}^{t} v(s) d s
$$

and the standard reasoning of dynamic programming will become applicable. The first transformation concerns the term

$$
I=E \int_{h}^{+\infty} \exp -\alpha s \min (\varphi(z(s)), v(s-h)) d s
$$

We have

$$
\begin{aligned}
I & =\exp -\alpha h E \int_{0}^{+\infty} \exp -\alpha s \min (\varphi(z(s+h)), v(s)) d s \\
& =\exp -\alpha h E \int_{0}^{+\infty} \exp -\alpha s E\left[\min (\varphi(z(s+h)), v(s)) \mid \mathcal{F}^{s}\right] d s
\end{aligned}
$$

and we need to compute $E\left[\min (\varphi(z(s+h)), v(s)) \mid \mathcal{F}^{s}\right]$. We remember that $v(s)$ is $\mathcal{F}^{s}$ measurable and that $z(s)$ is a stationary Markov process. Let us introduce the transition probability density $m(\eta, s ; z)$ representing 


$$
m(\eta, s ; z)=\operatorname{Prob}[z(s)=\eta \mid z(0)=z]
$$

The function $m(\eta, s ; z)$ is the solution of Folker-Planck equation

$$
\begin{gathered}
\frac{\partial m}{\partial s}-\frac{1}{2} \frac{\partial^{2}}{\partial \eta^{2}}\left(\sigma^{2}(\eta) m\right)+\frac{\partial}{\partial \eta}(g(\eta) m)=0 \\
m(\eta, 0 ; z)=\delta(\eta-z)
\end{gathered}
$$

Then by stationarity of the Markov process $z(s)$, we can write

$$
E\left[\min (\varphi(z(s+h)), v(s)) \mid \mathcal{F}^{s}\right]=\int_{R} \min (\varphi(\xi), v(s)) m(\xi, s ; z(s)) d \xi
$$

Therefore

$$
I=\exp -\alpha h E \int_{0}^{+\infty} \exp -\alpha s \int_{R} \min (\varphi(\xi), v(s)) m(\xi, s ; z(s)) d \xi
$$

The next transformation concerns

$$
\begin{gathered}
I I=E \int_{0}^{+\infty} \exp -\alpha s \eta^{-}(s) d s \\
I I=E \int_{0}^{h} \exp -\alpha s \eta^{-}(s) d s+E \int_{h}^{+\infty} \exp -\alpha s \eta^{-}(s) d s \\
=I I_{1}+I I_{2} .
\end{gathered}
$$

The first integral does not depend on the control and is 0 , when $x \geq 0$, as it will be the case in practice. The second integral is written as

$$
I I_{2 .}=\exp -\alpha h E \int_{0}^{+\infty} \exp -\alpha s \eta^{-}(s+h) d s
$$

We note that

$$
\eta(s+h)=x(s)+\int_{s}^{s+h} \varphi(z(\tau)) d \tau
$$

Recalling the definition of $x(s)$, see (16). We then can write

$$
\begin{aligned}
E \eta^{-}(s+h) & =E E\left[\eta^{-}(s+h) \mid \mathcal{F}^{s}\right]= \\
& =E \theta(x(s), z(s) ; h)
\end{aligned}
$$

with

$$
\theta(x, z ; s)=E\left(x+\int_{0}^{s} \varphi(z(\tau)) d \tau\right)^{-}
$$


The argument $x$ is a real number and $z(0)=z$. So

$$
I I_{2}=\exp -\alpha h E \int_{0}^{+\infty} \exp -\alpha s E \theta(x(s), z(s) ; h) d s
$$

We can also write

$$
I I_{1}=\int_{0}^{h} \exp -\alpha s \theta(x, z ; s) d s
$$

so we have

$I I=\int_{0}^{+\infty} \exp -\alpha s \theta(x, z ; s) d s+\exp -\alpha h E \int_{0}^{+\infty} \exp -\alpha s E \theta(x(s), z(s) ; h) d s$

We can give a similar formula for the second penalty term

$$
I I I=E \int_{0}^{+\infty} \exp -\alpha s(\eta(s)-M)^{+} d s
$$

We introduce the function

$$
\chi(x, z ; s)=E\left(x+\int_{0}^{s} \varphi(z(\tau)) d \tau-M\right)^{+}
$$

and we can write

$$
I I I=\int_{0}^{h} \exp -\alpha s \chi(x, z ; s) d s+\exp -\alpha h E \int_{0}^{+\infty} \exp -\alpha s E \chi(x(s), z(s) ; h) d s
$$

Combining results, we obtain the formula

$$
\begin{aligned}
J_{x z}(v(.))= & -\varpi \int_{0}^{h} \exp -\alpha s \theta(x, z ; s) d s-\pi \int_{0}^{h} \exp -\alpha s \theta(x, z ; s) d s+ \\
& +\exp -\alpha h E \int_{0}^{+\infty} \exp -\alpha s\left(p \int_{R} \min (\varphi(\xi), v(s)) m(\xi, s ; z(s)) d \xi-\right. \\
& -(\varpi \theta(x(s), z(s) ; h)+\pi \chi(x(s), z(s) ; h)))
\end{aligned}
$$

or

$$
J_{x z}(v(.))=\rho_{h}(x, z)+\exp -\alpha h E \int_{0}^{+\infty} \exp -\alpha s l_{h}(x(s), z(s), v(s)) d s
$$


with

$$
\begin{aligned}
& l_{h}(x, z, v)=p \int_{R} \min (\varphi(\xi), v) m(\xi, s ; z) d \xi- \\
&-(\varpi \theta(x, z ; h)+\pi \chi(x, z ; h))
\end{aligned}
$$

The stochastic control problem becomes

$$
\begin{aligned}
& \frac{d x}{d t}=\varphi(z(t))-v(t) \\
& d z=g(z) d t+\sigma(z) d w, \quad x(0)=x, z(0)=z \\
& \sup _{v(.)} \int_{0}^{+\infty} \exp -\alpha s l_{h}(x(s), z(s), v(s)) d s
\end{aligned}
$$

which is a standard stochastic control problem. To avoid singularities, we impose a bound on the control $v(t)$. So we impose

$$
0 \leq v(t) \leq \varphi(z(t))+\bar{v} \quad \text { a.s. }
$$

in which $\bar{v}$ is a fixed constant.

\subsection{Dynamic programming}

Let us define the value function

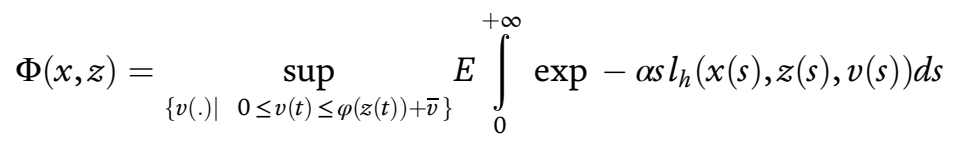

Then it is easy to write the Bellman equation for the value function, namely,

$$
\begin{aligned}
\alpha \Phi= & \varphi(z) \frac{\partial \Phi}{\partial x}+g(z) \frac{\partial \Phi}{\partial z}+\frac{1}{2} \sigma^{2}(z) \frac{\partial^{2} \Phi}{\partial z^{2}}+ \\
& +\sup _{0 \leq v \leq \varphi(z)+\bar{v}}\left[l_{h}(x, z, v)-v \frac{\partial \Phi}{\partial x}\right]
\end{aligned}
$$

A priori $x \in R$ and $z \geq 0$ (we may assume that $\sigma(0)=0$ ). We can add growth conditions to get a problem which is well posed. The optimal feedback $\hat{v}_{h}(x, z)$ is obtained by taking the sup in the bracket, with respect to the argument $v$..

\subsection{The case $h=0$}

The case $h=0$ has a trivial solution. We note that

$$
l_{0}(x, z, v)=p \min (\varphi(z), v)-\varpi x^{-}-\pi(x-M)^{+}
$$


The optimal feedback is then

$$
\hat{v}_{0}(x, z)=\mid \begin{array}{cc}
0 & \text { if } x<0 \\
\varphi(z) & \text { if } 0 \leq x \leq M \\
\varphi(z)+\bar{v} & \text { if } x>M
\end{array}
$$

so (32) becomes

$$
\begin{gathered}
\alpha \Phi=\varpi x+\varphi(z) \frac{\partial \Phi}{\partial x}+g(z) \frac{\partial \Phi}{\partial z}+\frac{1}{2} \sigma^{2}(z) \frac{\partial^{2} \Phi}{\partial z^{2}}, \text { if } x<0 \\
\alpha \Phi=p \varphi(z)+g(z) \frac{\partial \Phi}{\partial z}+\frac{1}{2} \sigma^{2}(z) \frac{\partial^{2} \Phi}{\partial z^{2}}, \text { if } 0<x<M \\
\alpha \Phi=p \varphi(z)-\pi(x-M)-\bar{v} \frac{\partial \Phi}{\partial x}+g(z) \frac{\partial \Phi}{\partial z}+\frac{1}{2} \sigma^{2}(z) \frac{\partial^{2} \Phi}{\partial z^{2}}, \text { if } x>M
\end{gathered}
$$

The solution for $0<x<M$ does not depend on $x$ and has an easy probabilistic interpretation

$$
\Phi(x, z)=\Phi(z)=p E \int_{0}^{+\infty} \exp -\alpha s \varphi(z(s)) d s
$$

For $x<0$ or $x>M$, we have to solve parabolic problems, considering $x$ as a time, backward and forward. We define the values $\Phi(0, z)$ and $\Phi(M, z)$ by $\Phi(z)$ defined by (38).

\subsection{Analytical problems for $\theta$ and $\chi$}

The functions $\theta(x, z, s)$ and $\chi(x, z, s)$ are solutions of the parabolic PDE

$$
\begin{gathered}
-\frac{\partial \theta}{\partial s}+\varphi(z) \frac{\partial \theta}{\partial x}+g(z) \frac{\partial \theta}{\partial z}+\frac{1}{2} \sigma^{2}(z) \frac{\partial^{2} \theta}{\partial z^{2}}=0 \\
\theta(x, z, 0)=x^{-} \\
-\frac{\partial \chi}{\partial s}+\varphi(z) \frac{\partial \chi}{\partial x}+g(z) \frac{\partial \chi}{\partial z}+\frac{1}{2} \sigma^{2}(z) \frac{\partial^{2} \chi}{\partial z^{2}}=0 \\
\chi(x, z, 0)=(x-M)^{+}
\end{gathered}
$$

This allows to compute $\theta(x, z, h)$ and $\chi(x, z, h)$.

\section{Conclusions}

The problem of the optimal delivery for wind energy in some future time with a storage facility (a battery for instance) is considered. We solve an optimal control problem to define the optimal bidding decision in a simple discrete stochastic problem and apply it to real data. Optimal size of the battery and the overnight costs are discussed.

\section{Acknowledgements}

The research is supported by EREN-GROUPE, the grant NSF-DMS 1612880 and the grant ANR-15-CE05-0024. 


\section{Author details}

Alain Bensoussan ${ }^{1,2 * \dagger}$ and Alexandre Brouste ${ }^{3 \dagger}$

1 International Center for Decision and Risk Analysis, Jindal School of Management, University of Texas at Dallas, USA

2 School of Data Science, City University Hong Kong, China

3 Institut du Risque et de l'Assurance, Laboratoire Manceau de Mathématiques, Le Mans Université, France

*Address all correspondence to: axb046100@utdallas.edu

${ }^{\dagger}$ These authors contributed equally.

\section{IntechOpen}

(C) 2020 The Author(s). Licensee IntechOpen. Distributed under the terms of the Creative Commons Attribution - NonCommercial 4.0 License (https://creativecommons.org/ licenses/by-nc/4.0/), which permits use, distribution and reproduction for non-commercial purposes, provided the original is properly cited. (cc) BY-NC 


\section{References}

[1] Michiorri A, Lugaro J, Siebert N, Girard R, Kariniotakis G. Storage sizing for grid connected hybrid wind and storage power plants taking into account forecast errors autocorrelation.

Renewable Energy. 2018;117:380-392

[2] Castronuovo E, Lopes J. On the optimization of the daily operation of a wind-hydro power plant. IEEE Transactions on Power Apparatus and Systems. 2004;19:1599-1606

[3] Castronuovo E, Usaola J, Bessa R, Matos M, Costa I, Bremermann L, et al. An integrated approach for optimal coordination of wind power and hydro pumping storage: Integrated approach for optimal coordination of wind power and hydro. Wind Energy. 2014;17:829-852

[4] Korpaas M, Holen A, Hildrum R. Operation and sizing of energy storage for wind power plants in a market system. International Journal of Electrical Power \& Energy Systems. 2003;25:599-606

[5] Johnston L, Diaz-Gonzalez F, GomisBellmunt O, Corchero-Garcia C, CruzZambrano M. Methodology for the economic optimisation of energy storage systems for frequency support in wind power plants. Applied Energy. 2015;137:660-669

[6] Charton P. Optimal operation of a wind farm equipped with a storage unit. Unpublished note: hal-00834142. 2013

[7] Yuan Y, Li Q, Wan W. Optimal operation strategy of energy storage unit in wind power integration based on stochastic programming. IET Renewable Power Generation. 2011;5(2):194-201

[8] Aditya S, Das D. Application of battery energy storage system to load frequency control of an isolated power system. International Journal of Energy Research. 1999;23:247-258
[9] Delille G, Francois B, Malarange G. Dynamic frequency control support: A virtual inertia provided by distributed energy storage to isolated power systems. IEEE PES Innovative Smart Grid Technologies Conference Europe (ISGT Europe). 2010:1-8

[10] Takahashi R, Tamura J. Frequency control of isolated power system with wind farm by using Flywheel Energy Storage System, 18th International Conference on Electrical Machines. 2008:1-6

[11] Bahramirad S, Reder W, Khodaei A. Reliability-constrained optimal sizing of energy storage system in a microgrid. IEEE Transactions on Smart Grid. 2012; 3:2056-2062

[12] Hussein A, Kutkut N, Shen Z, Batarseh I. Distributed battery microstorage systems design and operation in a deregulated electricity market. IEEE Transactions on Sustainable Energy. 2012;3:545-556

[13] Bensoussan A, Brouste A. CoxIngersoll-Ross model for wind speed modeling and forecasting. Wind Energy. 2016;19(7):1355-1365

[14] Tang J, Brouste A, Tsui K. Some improvements of wind speed Markov chain modeling. Renewable Energy. 2015;81:52-56 



\title{
Urban Wind Energy Evaluation with Urban Morphology
}

\author{
Biao Wang
}

\begin{abstract}
Urban wind development is gathering energy and passion these years and is good for sustainable cities. This chapter tries to evaluate wind energy potential with study of urban form in a block scale $(500 \mathrm{~m} \times 500 \mathrm{~m})$. CFD method is used for wind flow simulation. CFD parameter settings were validated and evaluated with wind tunnel experiment. Simple building forms (1-3 buildings) were tested for exploring the impact of building form on wind potential. Space over roof is proved to be most effective and practical position for developing wind energy in the urban environment. Ideal urban forms were tested for evaluating the impact of one single morphological parameter on wind potential over roof. Real urban forms were then evaluated and compared in order to reveal the impact of different urban form parameter on wind potential. Urban form unit models are then considered to understand the impact of a certain urban form feature on wind potential. Finally, a block model in Beijing is given for urban wind evaluation case study, including wind potential evaluation of every building roof in the model, wind turbine position evaluation, and economical cost analysis.
\end{abstract}

Keywords: urban wind energy, wind environment, urban form, urban block, CFD simulation

\section{Introduction}

The twenty-first century is an era of harmonious development between man and nature. Renewable energy development, as a means to achieve sustainable social development, plays an active and important role in dealing with the pressing problems of climate change, air pollution, urban energy shortage, and so on. The development of wind energy has a long history, but the formal use of wind power to generate electricity did not begin until the end of the nineteenth century. At present, most wind turbines are installed in the suburbs or seashore. In these places, wind resources are relatively abundant and the space available for wind turbines is relatively large, so we can see some large-scale wind turbines in the open plain area of suburbs, on the top of mountains, and on the seashore. Some large areas are used for wind farms, with tens or hundreds of large and medium-sized wind turbines working together. The electricity generated is generally transmitted to dense and populated urban areas through high-voltage cables. However, in some windy areas where many wind turbines are installed, there may have the phenomenon of "abandoned wind," that is, the wind farm will close or stop some wind turbines in order to reduce operation loss. The abandoned percentage may raise to 30 in some 
windy area in western China. The reason is that, as wind energy is unstable, sometimes there is too much wind energy electricity generated, which cannot be timely transported out for use and storage. Besides, the regional government energy management and coordination problems may also lead to the difficulty of wind power transportation.

Therefore, considering the huge investment in wind farms and high-voltage lines and towers, and the electricity loss during the long-distance transmission from suburban wind farms to urban areas, as well as the impact of wind farm construction on the ecological environment, people are considering urban wind power development in these recent 20 years. Generally speaking, the feasibility of urban wind power development can be summarized as follows: (1) Avoiding long-distance grid transmission, power generation can be used on site or stored separately (urban wind power is generally distributed, a small amount of electricity can be effectively stored, but a large number of it is difficult; (2) there are many tall buildings in the city, whose top or side is usually accompanied by strong wind; and (3) small or micro wind power systems have small investment and are suitable for decentralized use by the whole people. They are also conducive to the participation of residents in the production and use of green energy.

As shown in literature, there appears to have increasing papers and project on the development of wind power in urban areas. In 1998, the European Union project "Wind Energy for the Built Environment" (WEB) first carried out the research on installing small wind turbines in urban environment, and developed a prototype of integrated wind turbine technology (UWECS: Urban Wind Energy Conversion Systems) [1, 2]. In the UK in 2003 and 2004, there was a project called BUWTs (the feasibility of building mounted/integrated wind turbines), which investigates and analyses the wind power technology in the building environment and aims at reducing carbon dioxide emissions [3]. In 2007, another European Union project, Wind Energy Integration in the Urban Environment, investigated the installation of small wind turbines in different regions and analyzed the feasibility, technology of wind turbines, as well as administrative and legal constraints on urban wind turbines in three European countries (UK, France, and the Netherlands) [4-7]. In addition, in 2004, the Regional Environment and New Energy Agency (ARENE) in France conducted a general study on the technical, economic, and management constraints of urban wind power generation with 60 installed wind turbines [8].

There are a certain number of books and thesis issued on the domain of urban wind energy. $\mathrm{Yu}$ [9] reviewed the current situation and development of wind energy in Hong Kong. Turesson [10] assessed renewable energy, mainly solar, wind, and biogas, in three European cities (Grenoble, Delft, and Växjö) in 2020. The assessment method was simple, but not fairly adapted to reality, because it uses the parameters of giant wind turbines higher than $100 \mathrm{~m}$, which seldom adapts to urban environment. Shi [11] analyzed the use and storage of wind energy around urban buildings. Zeng [12] conducted wind and photovoltaic research in four blocks of Jinan, China, and proposed practical guidelines for urban renewable energy development. Within a more technical framework, Whaley [13] focused on lowcost generators for small wind turbines. The book "Windmill Power for City People" [14] provides a historical perspective on the city's first wind power generation system. The book "Urban Wind Energy" outlines several aspects of urban wind power plants [2]. Another book with the same title, published by [15], provides detailed examples of Gavle, Sweden, and conducted wind tunnel tests with the Gavlerinken Arena model to install two small wind turbines on the roof.

There are also many articles on this topic. Kalmikov et al. [16] evaluated wind energy potential at an attitude of $20 \mathrm{~m}$ in the Massachusetts Institute of Technology 
campus through field measurement data analysis and CFD simulation. Zhao et al. [17] gave a general introduction on the integration of wind power and architecture. Balduzzi et al. [18] studied the flux with oblique incidence in the built environment and designed a new H-Rotor Darrieus wind turbine that can adapt to this flux on the roof. Stathopoulos et al. [19] and Anup et al. [20] made general reviews on the urban wind energy development and small wind turbines in the built environment. Simoes and Estanqueiro [21] presented an urban digital terrain model for urban wind resource assessment in city scale by mapping urban fabric and surrounding terrain. Toja-Silva et al. [22] presented a review on technical computational fluid dynamics (CFD) aspects relevant for urban wind energy exploitation and the current state-of-the-art in building aerodynamics applied to this field.

Building form and urban form have impact on wind flow pattern and energy potential. Biao et al. [23] had done a parametric study of the effect of building layout on wind flow in an urban context. A parameter called wind network index was defined to evaluate the effect of road network on ventilation. Asfour [24] used CFD simulation to investigate airflow behavior around different configurations of residential blocks. Liu et al. [25] conducted CFD simulation with site measured data on the impact of surrounding buildings in different radius distance on wind flow around a studied building. The results showed that the impact is considerable due to the sheltering and channeling effect. Azizi and Javanmardi [26] studied the effects of urban block forms on the patterns of wind and natural ventilation and found that two factors with the most effect on wind pressure difference were urban block height and widths of adjunct roads.

This chapter is based on the feasibility of urban wind energy and describes how to evaluate the potential of urban wind power through urban morphology. The general presentation of urban wind evaluation method and urban form classification can be found in previous study [27]. For case study, some primary results on urban wind potential evaluation with impact of urban form are published [28].

\section{Methodology}

\subsection{Indicators of wind energy evaluation}

To evaluate the effect of wind accumulation, there is an indicator used frequently called wind speed augmentation factor [29-31]:

$$
C_{v}=\frac{U}{U_{0}}
$$

where $U$ is the actual wind speed of the test point and $U_{0}$ is the wind speed of free wind (in the wind field without buildings) with the same height of the point. $U_{0}$ can be calculated directly with the following equation.

$$
U_{z}=U_{h}\left(\frac{z}{h}\right)^{\alpha}
$$

where $U_{z}$ is the wind velocity of the height $z, U_{h}$ is the reference wind speed of the meteorological observation point at the height of $h$, and $\alpha$ is a roughness coefficient of the ground. For a dense city environment, the typical value of $\alpha$ is between 0.25 and 0.4 .

However, the power of wind turbine is a function of the cube of wind velocity, defined as the following: 


$$
P=\frac{1}{2} C_{p} \rho A U^{3}
$$

where $C_{p}$ is the power coefficient, $\rho$ is the air density, $A$ is the swept surface by the turbine blades, and $U$ is the instant wind velocity.

As the wind augmentation factor can only show the wind velocity augmentation effect, we are thinking to find an indicator to evaluate wind energy with the cube of wind velocity. Therefore, a simplified indicator $M$ can be defined as plane wind potential to evaluate wind energy on a given surface $A$ :

$$
M=\sum_{i=1}^{n}\left(A_{i} \times U_{i}^{3}\right)
$$

where $A_{i}$ is the area of the corresponding velocity magnitude $U_{i}$. As shown in Figure 1a, b, the three red rectangular planes over roof at different heights $(Z=3,5$, or $10 \mathrm{~m}$ from the roof). Each plane is divided into several sub-areas according to the velocity scale (Figure 1(c)). For a given surface, each sub-area is multiplied with its corresponding cubic average velocity and then the multiplications can be summed up into the value of $M$ [32].

As the plane surface $(A)$ does not correspond to the swept area by the turbine blades $(S)$, the value of $M$ does not mean the actual wind energy power, rather the wind potential within a surface where turbines can be placed to exploit the wind energy. Besides, as wind velocity varies much more on the vertical height than on horizontal planes, concerning the operation difficulty we generally adopt the horizontal planes to evaluate the wind energy over roof.

In the actual calculation, we found that there is an indicator called "areaweighted average" that can be directly calculated by the code FLUENT. Userdefined function (UDF) is used to create a parameter by a cubic wind velocity and then the software can import the area-weighted average cubic velocity (can be named as $\left.\left(U^{3}\right)_{m}\right)$. Thus, an equivalent indicator $M^{\prime}$ is defined as follows:

$$
M^{\prime}=\left(U^{3}\right)_{m} \times A
$$

where $A$ represents the evaluation plane area. The comparison analysis results show that the equivalent indicator $M^{\prime}$ can be used as the practical alternative of the indicator $M$, as there has very little difference between the two [33].

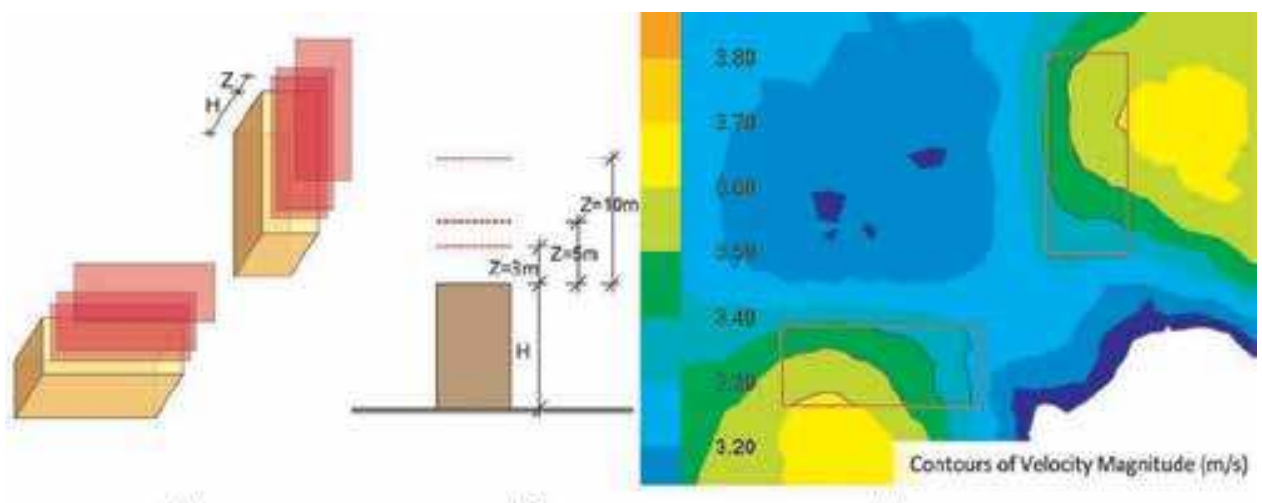

(a)

(b)

(c)

Figure 1.

Wind potential evaluation planes over roof of two perpendicular buildings: (a) perspective, $(b)$ section, and (c) wind velocity contours [32]. 
Furthermore, to evaluate and compare wind potential on planes with different surface areas, we can define plane wind potential density as follows:

$$
D=\left(U^{3}\right)_{m}=M / A
$$

\subsection{CFD setting and validation}

When using CFD software to simulate wind flow in the built environment, there are a number of parameters needed to be regulated and validated in order to get a reasonable result. We adopted an open access database of wind tunnel experiment undergone by the Architectural Institute of Japan. A building of width $5 \mathrm{~m} \times$ length $20 \mathrm{~m} \times$ height $20 \mathrm{~m}$ was tested. For CFD simulation in the platform ANSYS 12.0, we took 57 tests in order to regulate different parameters of geometry, mesh, boundary condition, turbulence models, and solution method. The best choice setting found and the process of validation are shown in the article [32]. The results show a general good agreement between the CFD simulation and the experiment. The general average absolute error of the velocity magnitude is $0.37 \mathrm{~m} / \mathrm{s}$ for an object velocity averaged $3.05 \mathrm{~m} / \mathrm{s}$ in measurement.

When the simulation object turns from one or several buildings to a cluster of buildings, the scale is enlarged and the relationship between the group of building becoming important; therefore, the CFD setting need to be modified. Careful adjustments were taken for the case study of urban tissues with a dimension of around $500 \times 500 \mathrm{~m}$ [27].

Apart from parameter validation by the tunnel experiment, there are some methods of verification that can be used: (1) Flow consistency analysis is to ensure the stability and credibility of CFD simulation results; (2) domain size analysis is to find a decent dimension of simulation domain in order to fully develop the turbulence and at the same time to avoid consuming much time for calculation; (3) grid sensibility analysis to ensure that the mesh size and method will not affect the results; and (4) random error analysis to assess the stability and sense of the findings during the CFD simulation process. The detailed methods explanation can be found in Ref. [33].

\subsection{Research structure}

There are two main domains for this research: urban form and wind potential. Two parts are integrated with cross indicator analysis and wind effect in the built environment. The detailed research structure is show in Figure 2.

For the part of urban wind energy, there are three related domains: wind engineering, wind turbines, and wind conditions. Wind flow pattern is influenced by the building forms. CFD simulation has its setting adapting to the nature of tested wind, and for the domain of wind flow simulation in the built environment, numerous experiments undergone by other scholars produced Best Practice Guideline for this domain $[34,35]$.

For the part of urban form study, first, from the global angle, different urban form types were classified; then with primary evaluation, some potential windy urban forms can be chosen. Some of the promising types would be used for CFD simulation and comparison, and some would also be used to extract single feature for close study through urban form unit model analysis. Case study of real urban form with local (environmental and socio-economical) conditions would be then analyzed for wind potential evaluation and urban wind development.

The relationship between urban wind energy and urban form can be evaluated by the correlation between wind energy indicators and urban morphological 


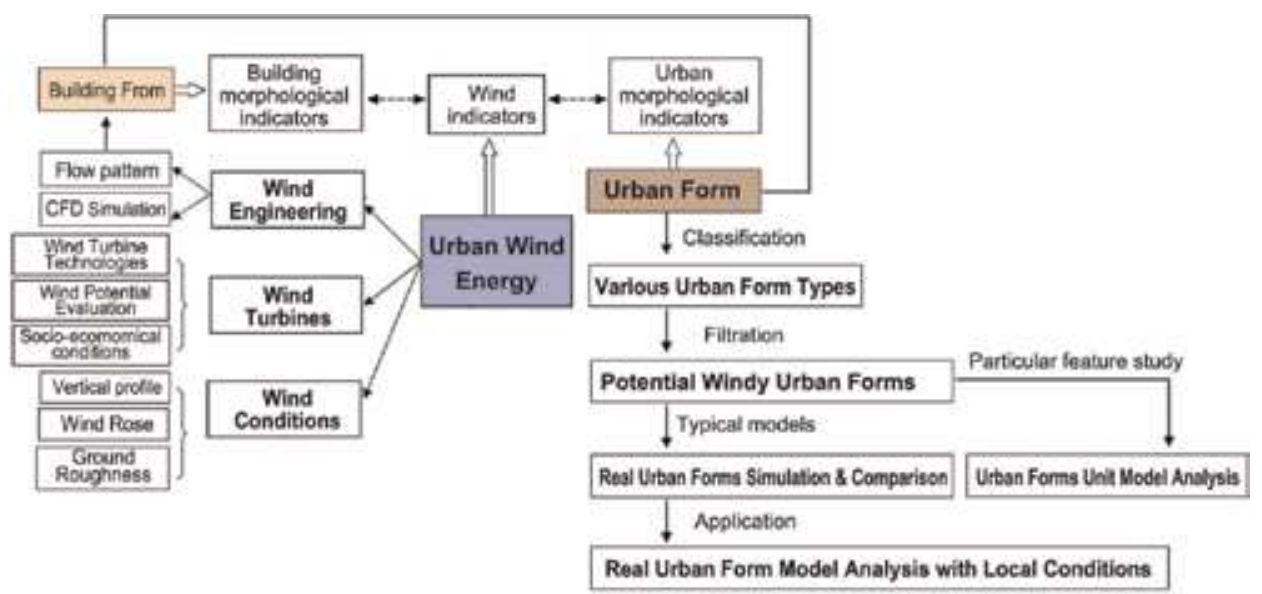

Figure 2.

Research structure.

indicators. As the building form is component and simple representation of urban form, the impact study of building form on wind is very beneficial to reveal the impact evaluation of urban form on wind. With its simplicity and less difficulty, the impact of different building morphological indicators on wind potential is analyzed before study the urban morphological indicators.

\section{Building form and wind energy}

\subsection{Impact of building's floor plan on wind energy}

In order to evaluate the influence of the building's floor plan on the wind potential above the roof, four models with the same height $(H=20 \mathrm{~m})$ and the same floor plan area $\left(S=360 \mathrm{~m}^{2}\right)$ but different plane shapes (Figure 3) were tested. Concerning the symmetry aspect, only a range of $0-90^{\circ}$ with increment of $15^{\circ}$ for the inlet wind direction is considered; thus, each model has seven sessions of simulation.

Figure 4 shows the velocity profile of each model under normal wind with attitude $z=10 \mathrm{~m}$. We can notice the difference in the size of the cyclones upstream and downstream, as well as the shape of the high-speed area around the building. However, what we are interested in here is comparing the wind power potential of all models. Through the simulation test, we noticed that the exploitable wind (with color of yellowish brown, red, or pink) near the plan generally has a relative long
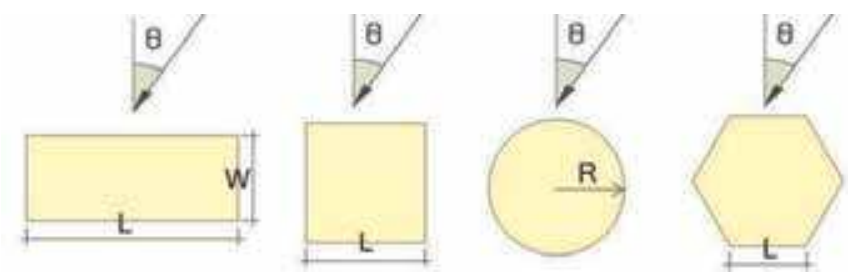

Figure 3.

Models of buildings with different floor plans: Rectangular $(L \times W=30 \times 12 \mathrm{~m})$, square $(L=19 \mathrm{~m})$, round $(R=10.7 \mathrm{~m})$, and hexagonal $(L=11.7 \mathrm{~m})$. 


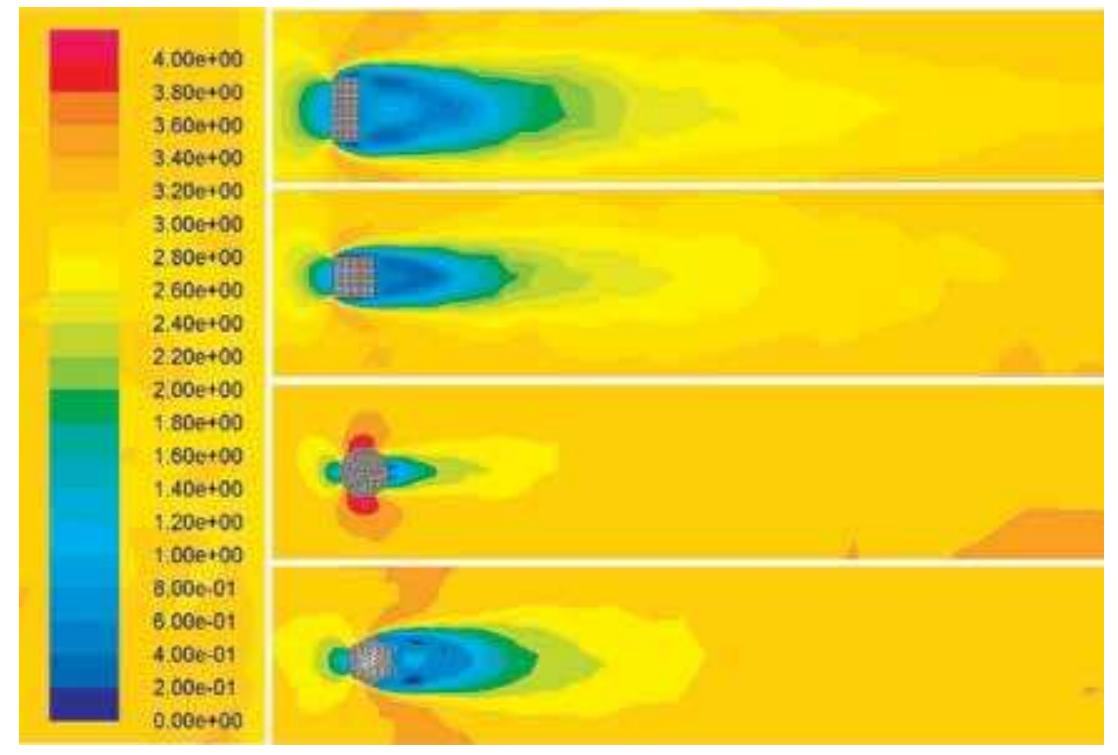

Figure 4.

Wind velocity profile around the buildings of different floor plans.

distance from the wall (except the model of round plan), so it is normally difficult to exploit this wind energy neither to fairly compare the models' exploitable wind potential. On the other hand, it is rather easy and accurate to evaluate the wind energy above the roof with the same plane surface for all the models studied.

Figure 5 shows the $M$ values of the three heights above the roof $(Z=3,5,10 \mathrm{~m})$. The following conclusions can be drawn:

1. On plane $Z=3$ and $5 \mathrm{~m}$, the $M$ value on the roof of the round plan building is higher than that on the roofs of other buildings, but on plane $Z=10 \mathrm{~m}$, it turns rather smaller than the others.

2. With the change of inlet wind angle, the $M$ value over the roof of hexagonal buildings is almost monotonous. In fact, the gap between the best case $\left(30^{\circ}\right)$ and the worst $\left(0^{\circ}\right)$ of the three evaluation heights for this model is $1.28-6.55 \%$.

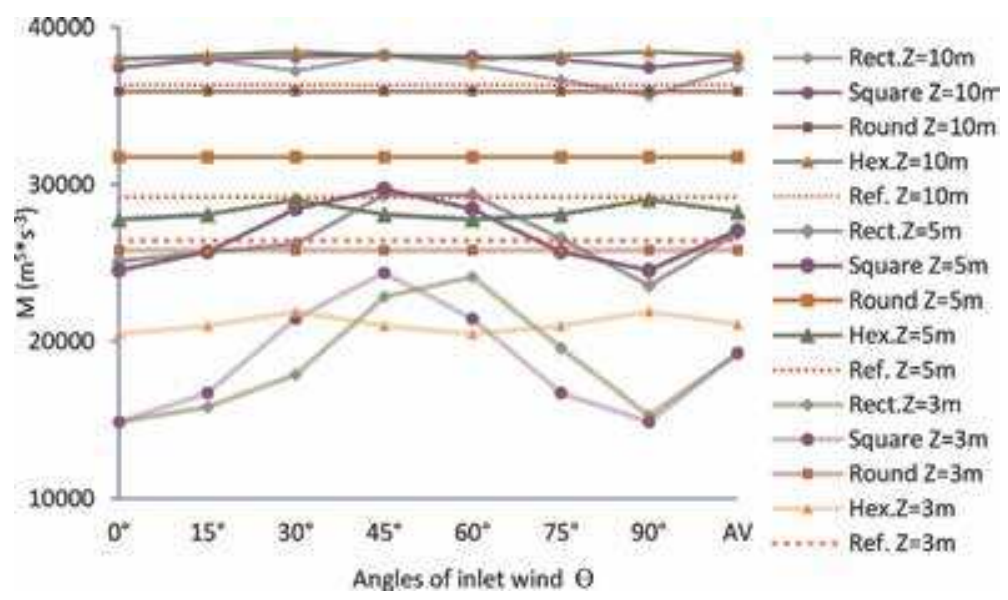

Figure 5 .

Wind potential over roof of buildings with different floor plans. 
3. The outcome of models with rectangular plan and square plan are very similar at a low altitude over roof $(Z=3 \mathrm{~m})$. When the altitude rises to $Z=10 \mathrm{~m}$, the square plan model becomes more attractive (more than $1.5 \%$ ).

4. As far as the impact of inlet wind angle is concerned, an angle of $30^{\circ}$ corresponds to the maximum wind potential over roof of the hexagonal plan model, while for rectangular plan model, it is $45^{\circ}$ and for square plan model it is $60^{\circ}$.

5. At a low altitude above the roof, if no dominant wind is given, the wind energy density of different planes decreases with the following geometric shapes: round, hexagon, square, and rectangle. However, at high altitudes, the order changes: hexagon, square, rectangle, and round.

6. The wind potential of the free wind in the absence of buildings of the same height and the same initial conditions is marked as reference. We find that at $Z=3 \mathrm{~m}, M$ values of all models are lower than that of the reference, while at $Z=10 \mathrm{~m}$, except for the round plan model, most models have higher values than the reference.

\subsection{Impact of roof shape}

In order to assess the effect of roof shape on the wind potential above the roof, nine buildings with the same plane $(12 \times 30 \mathrm{~m})$ and equivalent height $(H=20 \mathrm{~m})$ but different roof shapes were tested. The length $(L=30 \mathrm{~m})$ of the buildings remains unchanged. Different roof shape models are considered here: $A$ is reference model with flat roof, B, C, D, E and F are gable roof models with different roof gradients, $\mathrm{G}$ is wind-faced roof model, $\mathrm{H}$ is leeward roof model, and I is dome roof model (Figure 6). Due to the complexity of the flow over different shapes of roofs, we set six horizontal planes above the roof to evaluate wind flow over roof (see those discontinuous red lines in Figure 6). The heights from the ground of the planes are as follows: $H=23,24,25,26,27$, and $30 \mathrm{~m}$. In addition, due to the

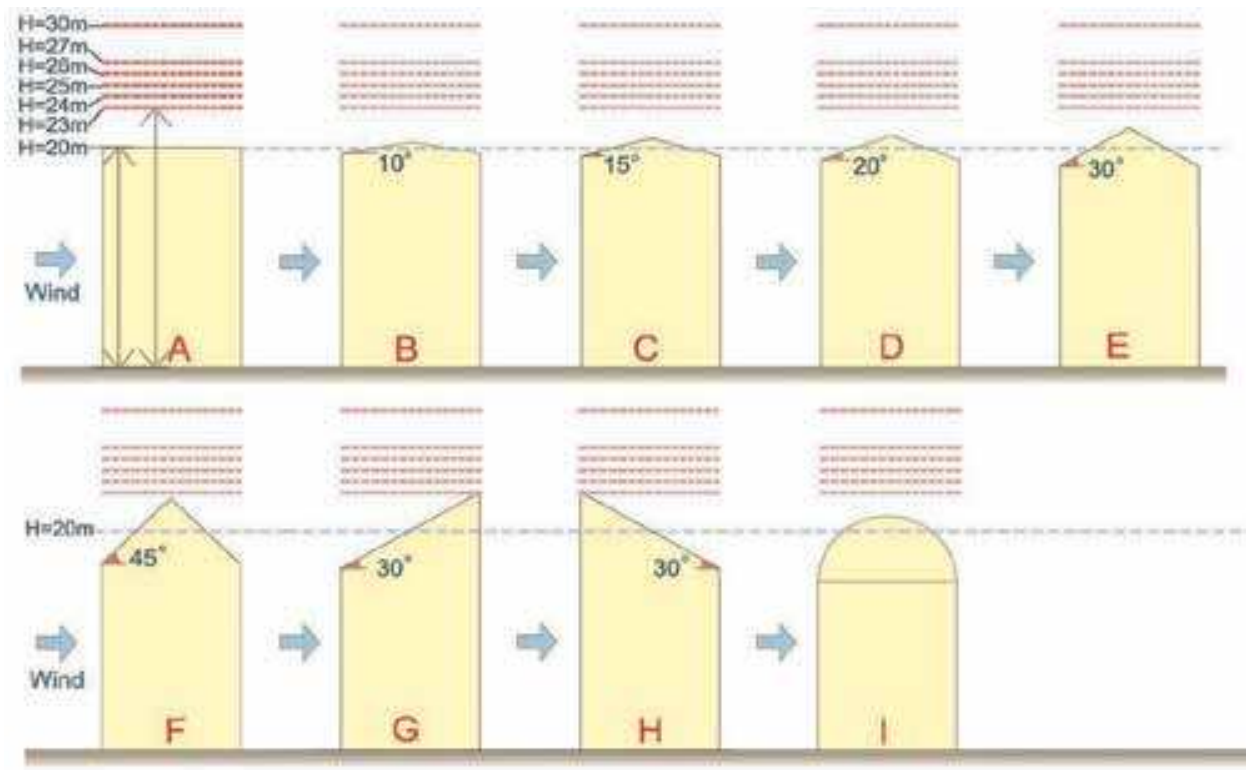

Figure 6.

Different models of roof shapes (vertical section). 
tremendous influence of turbulence in inclined wind, only wind with an incident angle of $0^{\circ}$ is analyzed.

For this study, we use velocity augmentation coefficient $C v$ to assess the concentration of wind above the roof. Therefore, the average velocity values of six planes over roof are obtained directly from the flow, and the corresponding $U_{0}$ values are used to calculate the $C v$ values. From the results shown in Figures 7 and 8 , we can find the following conclusions:

1. The average $C v$ values of the dome roof (model $\mathrm{I}$ ) is the highest, and the height to reach the maximum $\mathrm{Cv}$ is $H=25 \mathrm{~m}$.

2. In the gable roof group, the best way to collect wind energy is adopting roof with a slope of $15^{\circ}$ (model $\mathrm{C}$ ) at a capturing height of $H=27 \mathrm{~m}$. In fact, at an altitude of $H>24 \mathrm{~m}$, the coefficient of $C v>1$, i.e., for better utilization wind concentration effect, the evaluation altitude should be more than $24 \mathrm{~m}$.

3. For the one-pitched roof, the wind-faced roof (model G) is generally more advantageous in wind concentration than the leeward roof (model $\mathrm{H})$. However, it is still not as advantageous as the gable roof with the same gradient (model E).

In addition, in order to show the flow formation behind different roof shapes, the wind velocity variation in the central line in the wind direction at $H=30 \mathrm{~m}$ is presented (Figures 9 and 10). We have noticed that in the upstream of the buildings, the velocity difference among different models is very small, while in the downstream, the velocity difference is very large. For the gable roof models, the strongest wind behind the building is model $C\left(a=15^{\circ}\right)$, followed by the model $B$

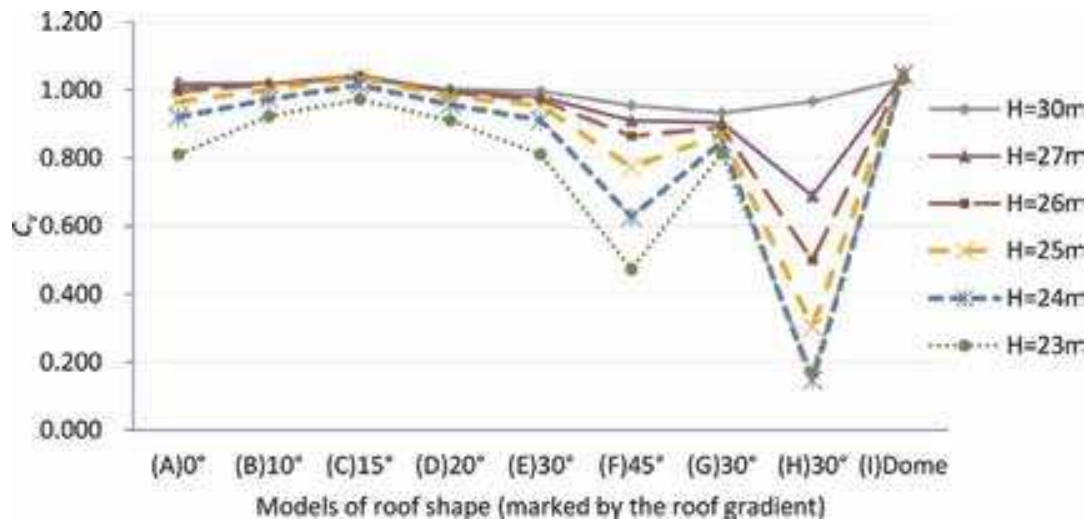

Figure 7.

Comparison of the coefficient Cv for different roof models.

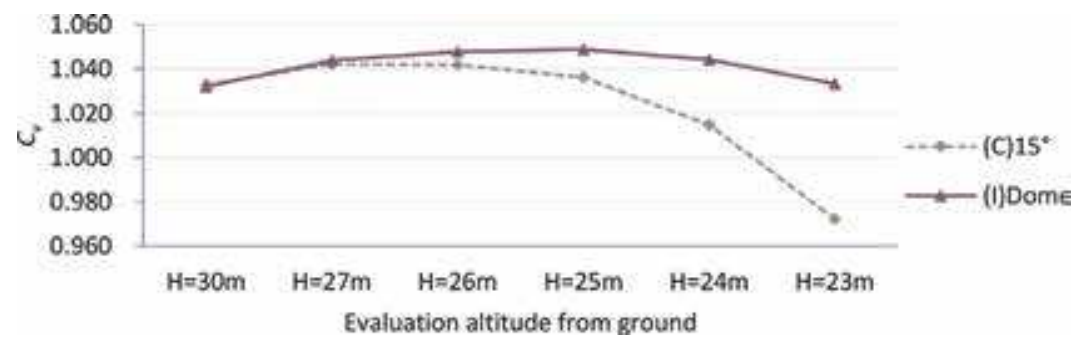

Figure 8.

Comparison of the coefficient $C v$ for roof models with different evaluation heights. 


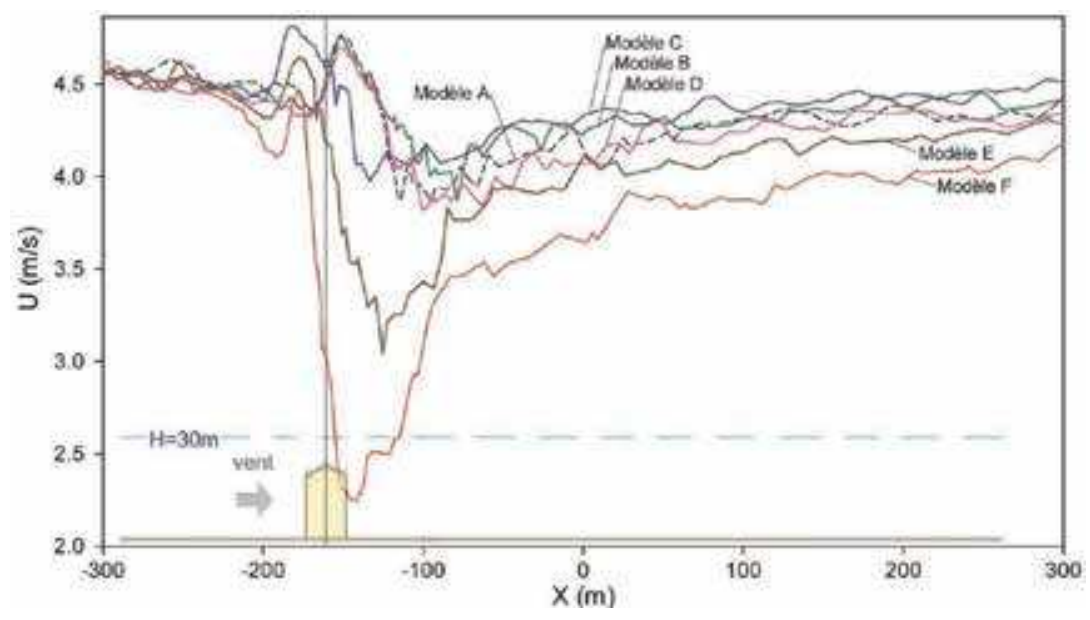

Figure 9.

Comparison of wind velocities on the central line in the wind direction at height $H=30 \mathrm{~m}$ (for gable roof models).

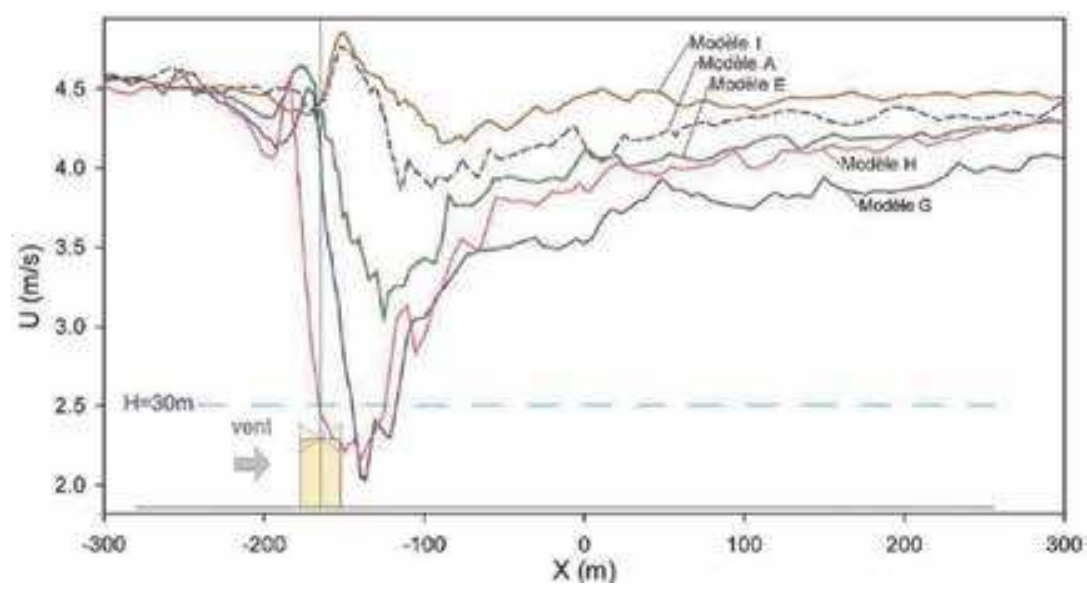

Figure 10.

Comparison of wind velocities on the central line in the wind direction at height $H=30 \mathrm{~m}$ (for different roof models).

$\left(\mathrm{a}=10^{\circ}\right)$, model $\mathrm{D}\left(\mathrm{a}=20^{\circ}\right)$, model $\mathrm{E}\left(\mathrm{a}=30^{\circ}\right)$, and model $\mathrm{F}\left(\mathrm{a}=45^{\circ}\right)$. This order is exactly the same as that of assessing wind concentration above the roofs. The situations of the one-pitched roof models and dome model are also similar.

\subsection{Wind evaluation with building forms parameters}

In this chapter, indicator $M$ is defined as assessing the total potential of wind energy on the surface, especially planes above the roof, because it is the most promising place to develop urban wind energy. Indicator $D$ is defined as the wind energy density per surface unit. Indicator $C v$ is as well used as the wind velocity augmentation factor to evaluate the effect of wind concentration. Wind flow around some simplified geometric models is simulated and discussed.

Actually, apart from the impact of building plane and roof shape, there are many other building form parameters that have much influence on wind potential. Different forms of 1-3 buildings are simulated and analyzed. Incidence angle and different evaluation height above the roof are considered. The following Table 1 


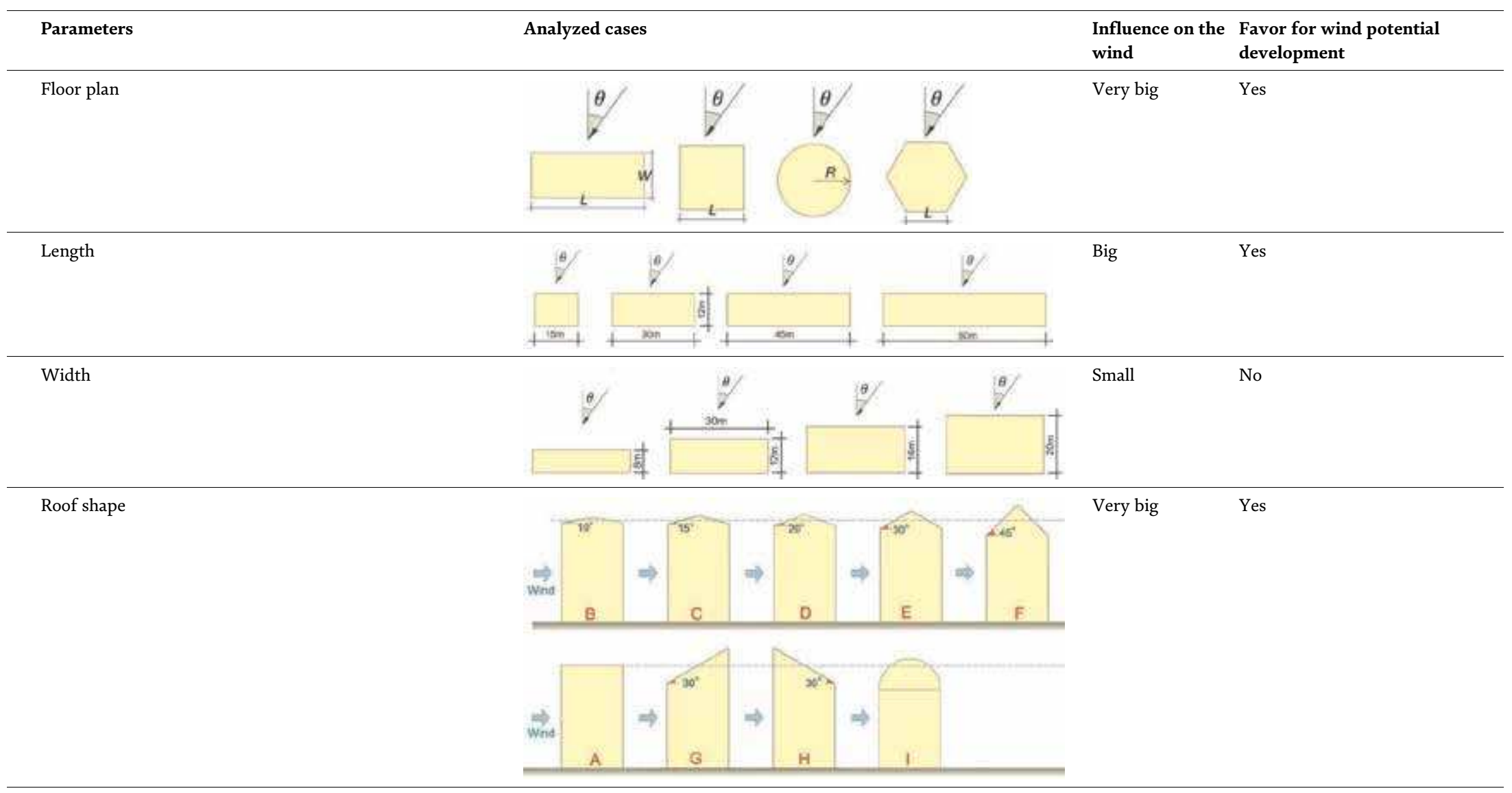




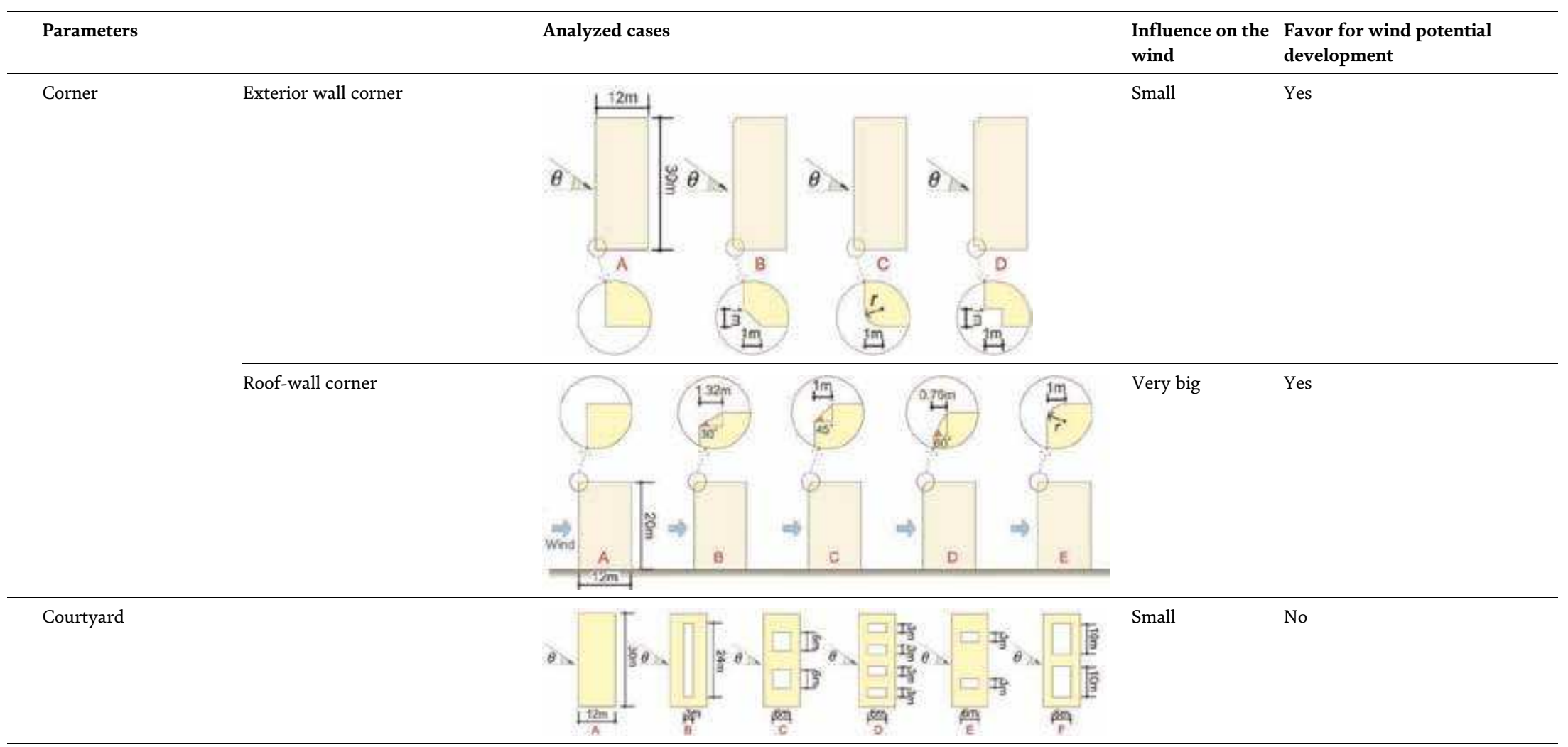




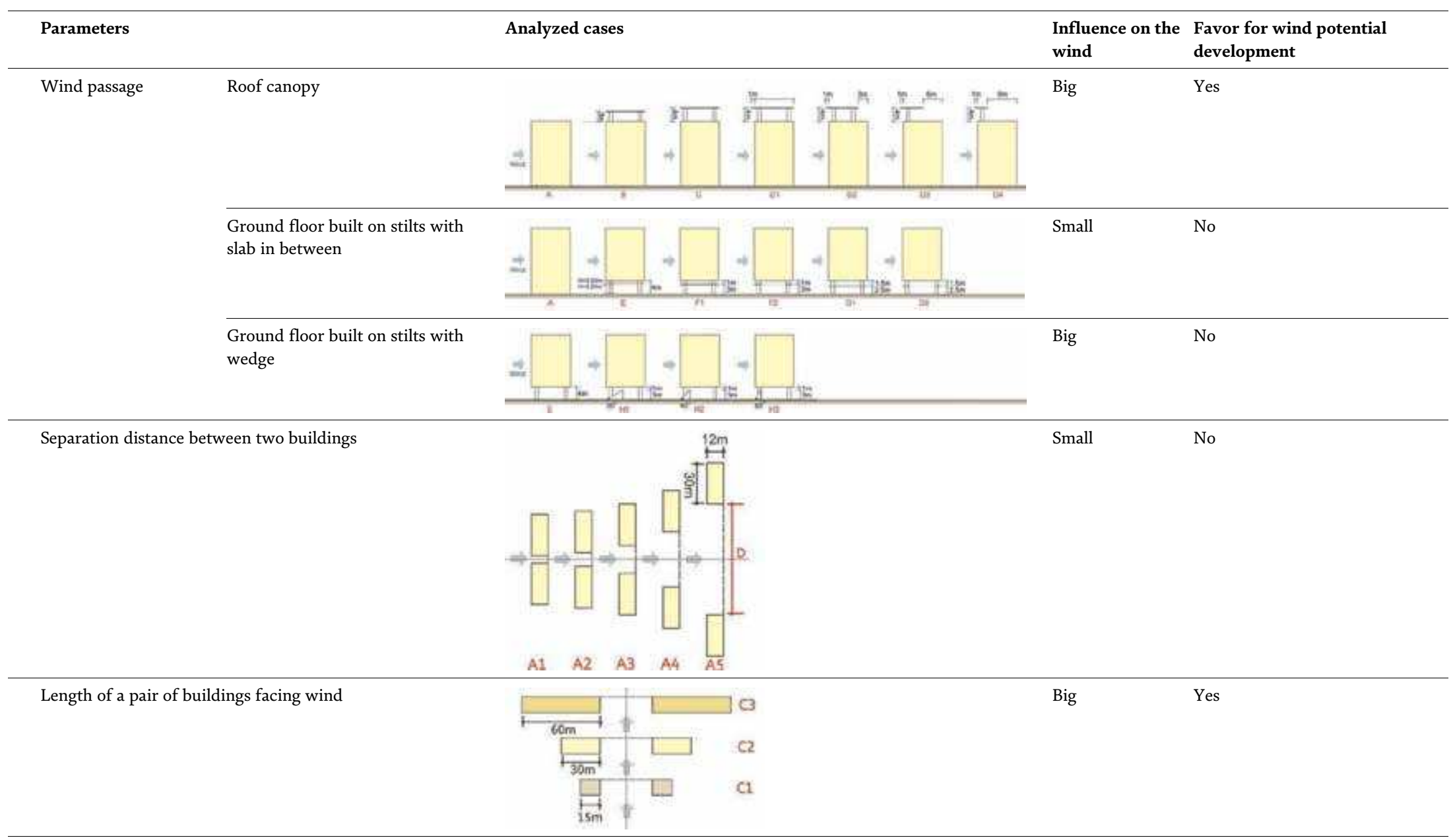




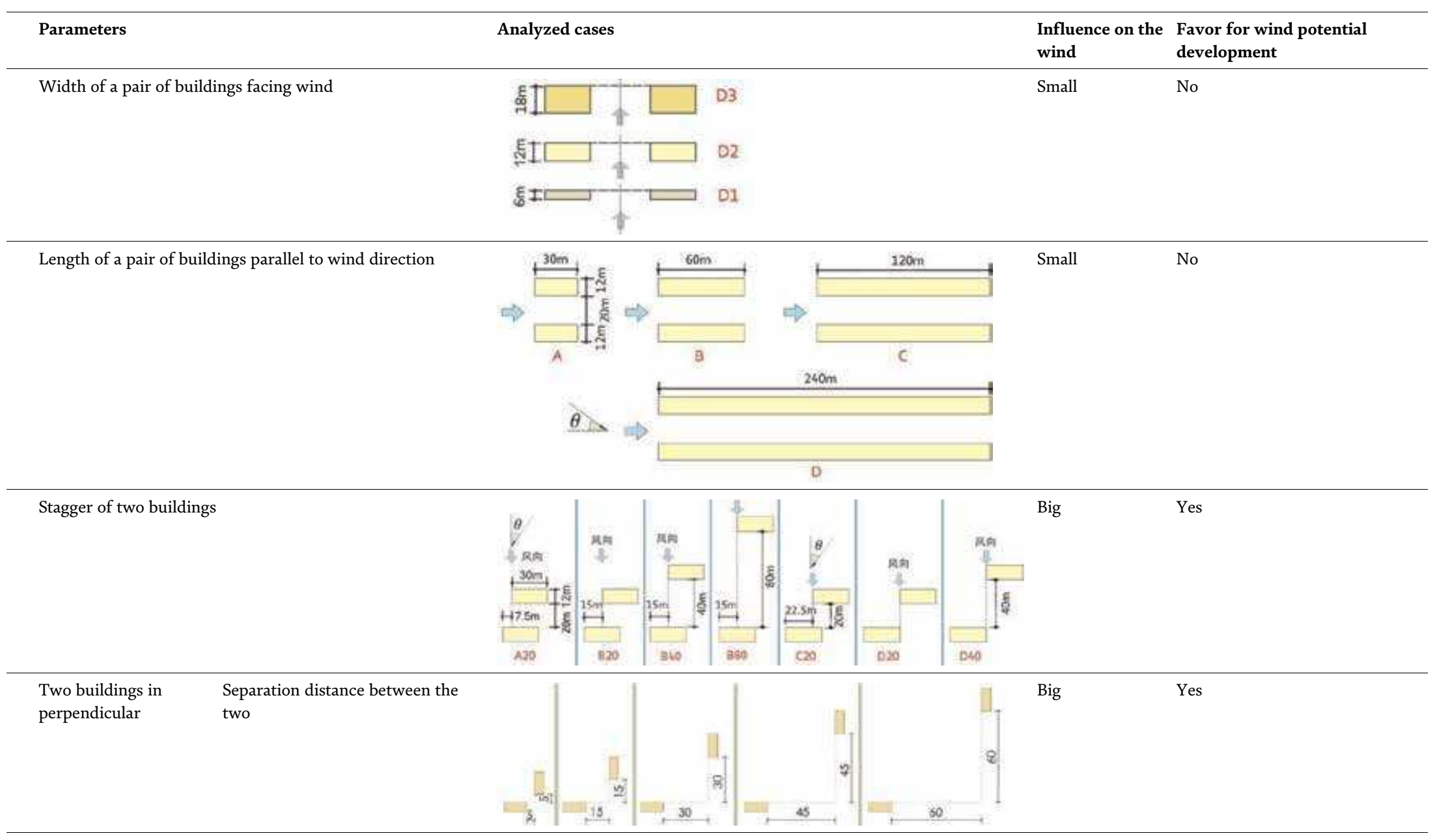




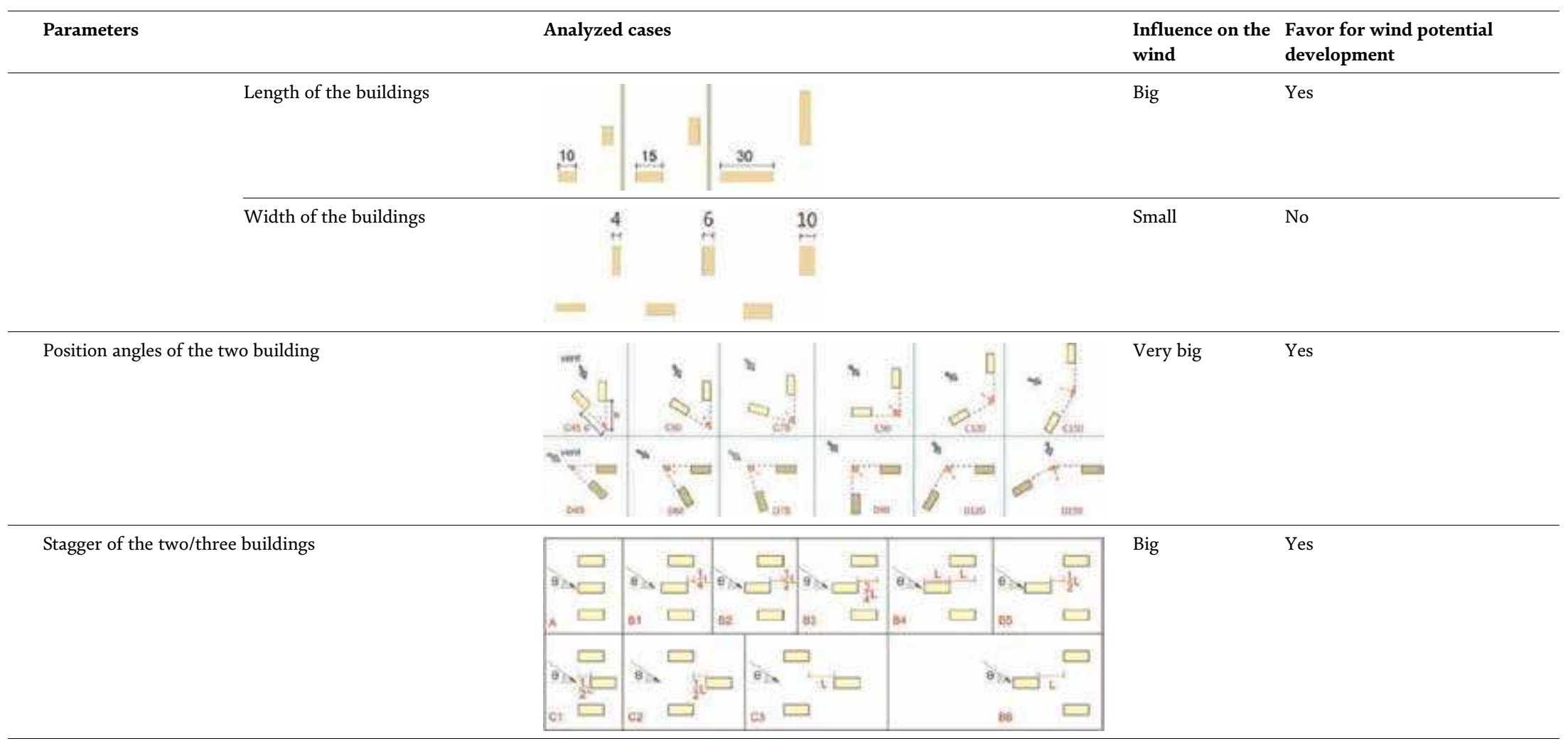

Table 1.

Synthesis of morphological parameters of analyzed buildings and anticipation evaluation of their wind potential. 
shows the general impact of different building forms on wind potential development.

For rectangular buildings with different lengths, we find that the value of wind potential density over roof $D$ usually decreases with the increase of building length. So, buildings with lower lengths are windier over roof. However, the sum of exploitable energy must be taken into account. In fact, it counts both the wind speed and the exploitable area of wind potential. Sometimes, even if the wind is strong, buildings with lower lengths may have lower productivity in total.

With regard to the influence of the width of rectangular buildings, we have noticed that there is an optimum width for the maximum wind energy density above the roof. At an incident wind at an angle of $0^{\circ}$, the buildings with $30 \mathrm{~m}$ long and $20 \mathrm{~m}$ high have the best wind energy density when the width $W=12 \mathrm{~m}$ (compared with cases $W=8,12,16$, and $20 \mathrm{~m}$ ). The optimum width changes with wind incidence angles.

With regard to the influence of exterior wall corner shape (with a scale of $1 / 20$ of building floor area) of selected buildings, the results of index $C v$ are as follows:

The truncated and concave models are usually better than those of rounded corners. In normal wind, the results of these two models are slightly better than those of the reference model without corner change; however, they are poor in the inclined wind $\left(\theta=30^{\circ}\right)$, especially at a low altitude above the roof.

The results for the corner shape of the roof edge show that all models with varying angles are windier on planes near the roof, compared to the reference model without any change, while at a high altitude, they are almost the same. Among different cutting corner models, the case with an angle of $30^{\circ}$ shows a biggest average wind speed, which is similar to the round corner model.

With regard to the impact of courts on rectangular plan buildings, cases of various sizes and forms of the courts are being tested. The results of indicator $M$ show that the models with courts are usually windier on the roof than those without courtyards. The maximum porosity model usually achieves the maximum wind potential over the roof. For the models with the same porosity, the influence of incident wind angle is significant.

As for the impact of wind passage, some wind passage models were tested. The results of index $C v$ show that the canopy on the roof accelerates the wind between the roof and the canopy (compared with the reference model without canopy), but slows down the wind above the canopy at the same altitude. The lower canopy model is windier underneath the canopy. A canopy with extension facing wind has a strong influence on the wind speed in the wind passage under the canopy. The shortening of the rear of the canopy also helps to enhance the wind concentration effect. The model with stilts and slab in between in the ground floor has better wind above the roof and between the slab and the ground floor ceiling, compared with the reference case. However, as the absolute wind velocity is low, the wind passage set for the ground floor is not suggested for wind potential development.

Regarding the effect of wind incidence angle, several models with different $W / L$ (width to length ratio) and $H / L$ (height to length ratio) are being tested. The results of $C v$ show that when the W/L ratio increases, the optimal incidence angle increases, while for square model, the optimal incidence angle is $45^{\circ}$. Similarly, when the building height (with same floor plan) rises, the optimum incidence angle of wind decreases.

With regard to the influence of wind behind buildings, different heights, lengths, and widths of buildings are evaluated. We found that the wind behind the building slows down with the height and length of the building, but gets stronger with the distance of the building. The width of building has little effect on the wind behind the building. At a low evaluation altitude (from the ground), i.e., $z<1.25 \mathrm{H}$ 
(building height), the distance from the building rear D has the greatest influence on variation of wind velocity, followed by other parameters like $\mathrm{H}$ and $\mathrm{L}$ (building length). At a high altitude, i.e., $Z>2.5 H$, all the parameters $L, W$, and $D$ have small impact on the wind behind building.

For the study of two buildings in one row, several models with different separation distances, heights, lengths, and widths are considered. Generally speaking, the coefficient $C v$ increases when the distance between two buildings increases up to a very large value. However, as the length and width of buildings increase, this wind concentration effect declines. Compared with the single building, the wind concentration effect over the roof of two buildings facing wind in one row requires a considerable evaluation height over roof.

With regard to the parallel study of two buildings, several street shape models of different lengths are being studied, and the $C v$ on the midline above the roof and in the street is studied. We find that wind above the buildings is generally slower than that of free wind at the same height. The downstream wind of a long street is stronger than that of a short one. The maximum $C v$ is obtained at a low altitude above the roof. However, wind speed usually increases with altitude, and wind concentration areas vary with the shape of buildings and evaluation altitude. Therefore, we can determine the optimal length of wind energy development above the roof. As for the results in streets of different heights, we find that the wind concentration effect is stronger in a short street near the downstream of the building, but in a long street, the concentration appears rather far away from the building rear in downstream.

For the study of two staggered buildings, several models with different separation distances are tested. The results of index $C v$ show that most models have larger wind around inlet angles -60 or $-45^{\circ}$. At 60 or $45^{\circ}$, the wind potential is slightly smaller. The inlet angle of maximum wind concentration effect is about $-60^{\circ}$ at a low altitude and about $-45^{\circ}$ at a high altitude above the roof. The offset distance and incidence angle are very sensitive to the results. With the increase of separation distance between two buildings, the effect of wind concentration increases at the beginning, but decreases with separation distance, which means that there is an optimum distance between two staggered buildings to produce the maximum concentration effect at a certain angle of incidence.

In the study of two symmetrical buildings in perpendicular, several models are studied: different building sizes, different isolation distances, and different incident angles. The results show that the wind energy density above the roof increases at the beginning and then decreases with the separation distance between buildings. Compared with insulated buildings, two buildings in perpendicular can produce wind concentration effect in divergent modes for all models and in convergent mode for buildings with large separation distance. When the evaluation altitude rises, the best wind inlet direction is from 45 to 30 or $60^{\circ}$. Wind potential is more sensitive in convergent mode than in changing the separation distance between buildings. In convergent mode, it is better to have a long distance between buildings to have a higher wind potential over roof.

\section{Urban form and wind energy}

\subsection{Urban form parameters for wind potential evaluation}

For wind energy evaluation, among many urban form indicators, only those morphological indicators that have a close relationship with the wind flow are 


\begin{tabular}{|c|c|c|}
\hline Abbreviation & $\begin{array}{l}\text { Urban form } \\
\text { parameter }\end{array}$ & Description \\
\hline BCR & Building coverage ratio & $\begin{array}{l}\text { A parameter to describe the construction density. It is the } \\
\text { ratio of building coverage area and the examined site area }\end{array}$ \\
\hline PR & Plot ratio & $\begin{array}{l}\text { A parameter to describe the construction density. It is the } \\
\text { ratio of total construction area and the examined site area }\end{array}$ \\
\hline $\bar{H}$ & $\begin{array}{l}\text { Average building } \\
\text { height }\end{array}$ & The average height of all the buildings in discussion \\
\hline$\sigma_{h}$ & $\begin{array}{l}\text { Standard deviation of } \\
\text { the building heights }\end{array}$ & $\begin{array}{l}\text { A parameter to describe the variation level of building heights } \\
\text { in a site }\end{array}$ \\
\hline$\overline{V_{b}}$ & Mean building volume & $\begin{array}{l}\text { A parameter to describe the dispersion level of the buildings } \\
\text { with different heights. It is the ratio of total building volume } \\
\text { and number of buildings counted }\end{array}$ \\
\hline$\lambda_{c}$ & Mean aspect ratio & $\begin{array}{l}\text { It is the sum of building envelope including the surfaces of all } \\
\text { the external walls and the roofs, divided by the site area }\end{array}$ \\
\hline$R a$ & Absolute rugosity & $\begin{array}{l}\text { A parameter to describe the roughness of a surface to resist } \\
\text { the free wind. It is the average obstacle height over the whole } \\
\text { examined area }\end{array}$ \\
\hline$R r$ & Relative rugosity & Defined by the standard deviation of the building volumes \\
\hline Po & Porosity & A ratio of the emptiness volume to the entire volume \\
\hline Oc & Occlusivity & $\begin{array}{l}\text { A parameter of the distribution of the built to un-built } \\
\text { perimeter against height }\end{array}$ \\
\hline
\end{tabular}

Table 2.

Definition of selected urban form parameters for urban wind potential.

chosen, e.g., building coverage ratio (BCR) and plot ratio (PR), average building height, rugosity, porosity, etc. The definitions are given in Table 2.

\subsection{Ideal urban form simulation}

Before applying the urban morphological parameters on the real-world complex models, ideal urban form models with group of buildings in simple configuration can be tested, in order to reveal the impact of some single urban morphological parameter. Here, we will take the study of density as an example.

First of all, we set a combination of 24 identical buildings ( $W \times L \times H=12 \times$ $30 \times 20 \mathrm{~m})$ as the reference of ideal urban form. It is set in a hemisphere wind field with a radius of $400 \mathrm{~m}$. The CFD software setting is generally the same with the case of isolated building, but some necessary changes are made, such as the size of domain and mesh precision, considering the recommendations of Best Practice Guide for wind flow simulation in the built environment. The disposition of the ideal urban form reference is symmetrical by the central line of domain in the wind direction. However, the distances between each row of buildings are set different deliberately, in order to generate some variation and enrich the results (Figure 11).

Based on the reference model, in order to evaluate the impact of density in a community scale, we set different building floor plan layouts for the 24 buildings. The variations of building width and length include: $W \times L=12 \times 45,12 \times 20,18 \times$ $30,8 \times 30,12 \times 10 \mathrm{~m}$. These buildings however have the same height and central positions as the corresponding buildings in the reference model. In Figure 12, models $\mathrm{B}$ and $\mathrm{C}$ reflect the change of building length facing the wind, while models $\mathrm{D}$ and $\mathrm{E}$ reflect the change of building width. The building density (BCR) can be 


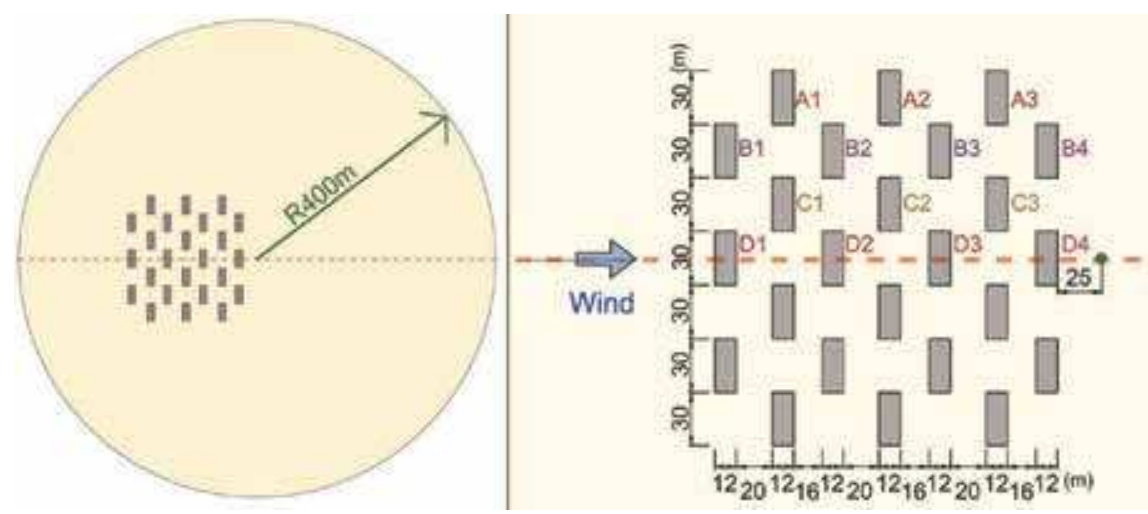

Figure 11.

Model of reference for analyzing the impact of density on wind potential (left: measure field layout and right: detailed disposition of buildings).

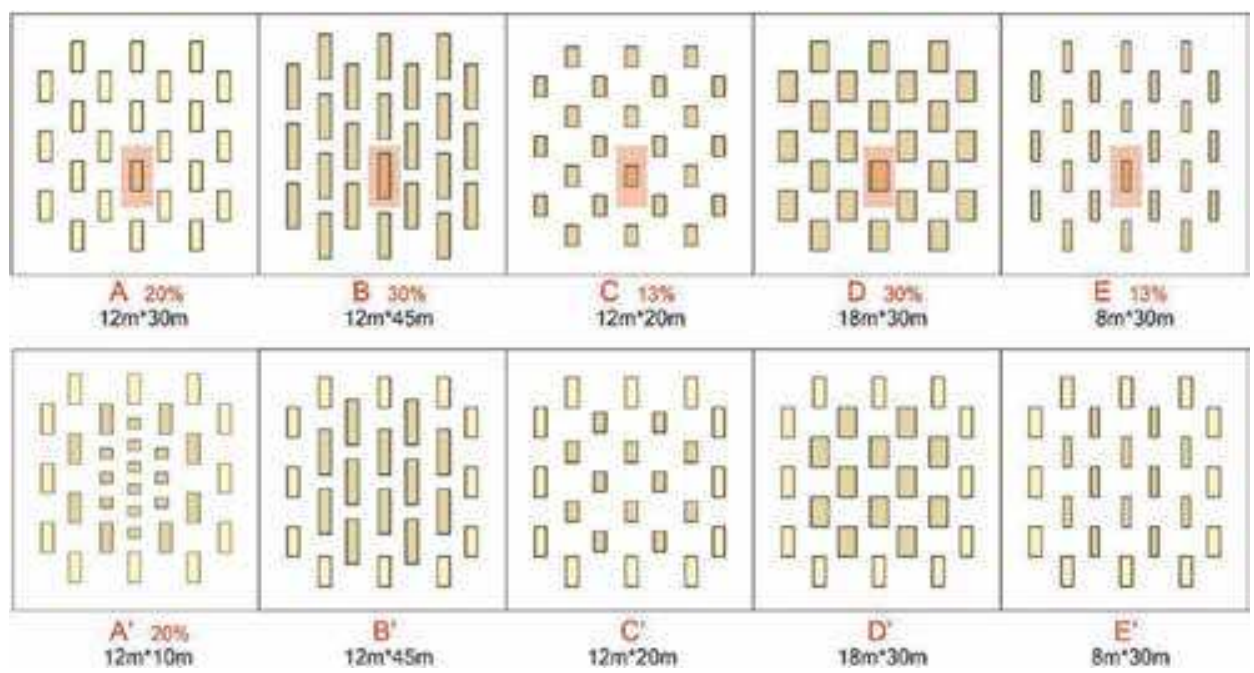

Figure 12.

Models for analyzing the impact of density by adopting different disposition of buildings.

calculate and varies among different models (A-E). In addition, in order to test and eliminate the impact of surrounding buildings, the "envelope" (most outskirt row of buildings) of the reference model is kept and the series of models $\mathrm{B}$ to $\mathrm{E}$ are changed to the series of $B^{\prime}$ to $E^{\prime}$. Apart from that, in order to evaluate the impact of fragmentation, the model $\mathrm{A}^{\prime}$ maintains the same density as the reference model $\mathrm{A}$, but the four buildings in the center are divided each into three same fragments with the same distance between each other.

For the results of coefficient $C v$ of the wind potential above the roof $(Z=5 \mathrm{~m}$ and $10 \mathrm{~m}$ ), the average values of all buildings in the center of each model are calculated to clearly understand the overall effect of density on the wind above the roof (Figure 13). The following conclusions can be drawn:

1. From the model $\mathrm{A}$ to model $\mathrm{A}^{\prime}$, the total wind potential above the roof decreases by $1.5-3.9 \%$. That is to say, the fragmentation of building volume on floor plan with the same building coverage slows down the overall wind potential over roof. 


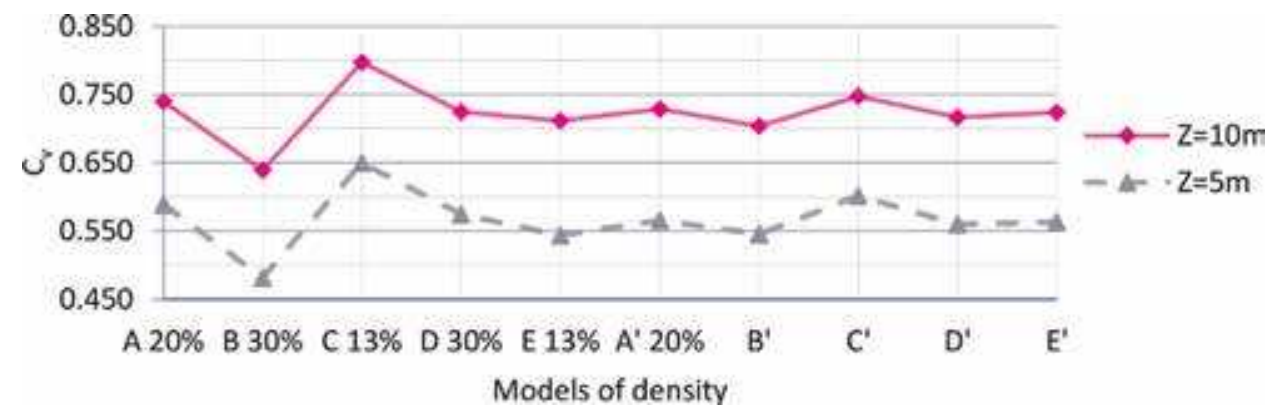

Figure 13.

Comparison of the average value of $C v$ for the model of density.

2. Among the models with buildings of different lengths (A, B, C, B', and $C^{\prime}$ ), the models $\left(C\right.$ and $C^{\prime}$ ) with shorter buildings have larger wind over roof than other models. In addition, the energy efficiency above the central roof seems to be greatly affected by the surrounding area of the building, because the difference between models $\mathrm{B}$ and $\mathrm{C}$ is much greater than that between the models $\mathrm{B}^{\prime}$ and $\mathrm{C}^{\prime}$.

3. In the group of models with different building widths (A, D, and $E)$, the difference of $C v$ values is very small. The decrease in building width (from $\mathrm{D}$ to $\mathrm{A}$ to $\mathrm{E}$ ) is accompanied by an increase and subsequent decrease of $C v$ values. Therefore, there would be a most suitable width to maximize the wind effect.

4. In the group of models with the same density ( $\mathrm{B}$ and $\mathrm{D}$, or $\mathrm{C}$ and $\mathrm{E}$ ), wind energy efficiency is different. It can be concluded that the influence of building length (face to wind) is far greater than that of building width.

In order to evaluate the influence of density in different areas of buildings in each model, we examined the $C v$ value over roof of each building (Figures 14 and 15). The values are averaged for those symmetrical buildings on both sides of the central line. The following conclusions can be drawn, with the decreasing order of $C v$ values of different buildings in the reference model A:

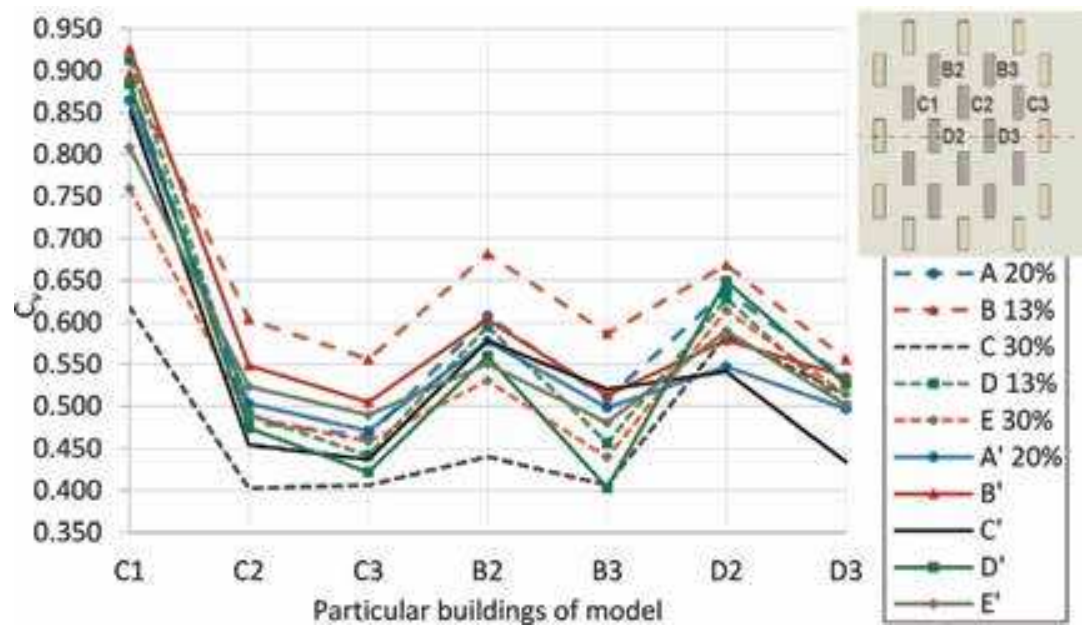

Figure 14.

Comparisons of $C v$ values of central buildings of different model of density $(Z=5 \mathrm{~m})$. 


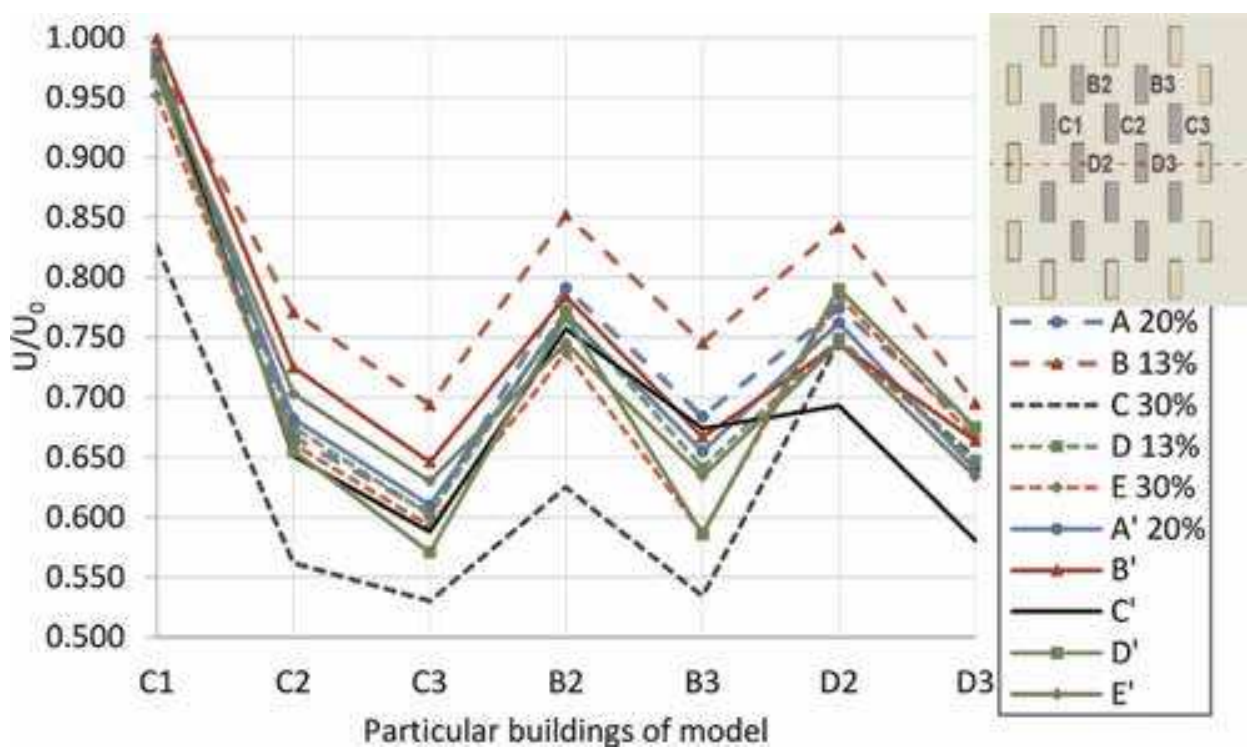

Figure 15.

Comparisons of $C v$ values of central buildings of different model of density $(Z=10 \mathrm{~m})$.

1. Usually, the buildings the more windward (e.g., B2, C1, and C2) have larger wind over roof than downstream buildings.

2. The buildings on the central line (D2 and D3) have Cv values relatively less affected by the shape changes of the buildings.

3. The fragmentation of building volumes (on plan) reduces the wind speed above the roof of most buildings, except for the building C2.

4. When the length of buildings changes $\left(\mathrm{A}, \mathrm{B}\right.$, and $\mathrm{C}$ and $\mathrm{A}^{\prime}, \mathrm{B}^{\prime}$, and $\left.\mathrm{C}^{\prime}\right)$, the model with the lowest density has the highest wind speed above the roof of all buildings.

5. By reducing the building density around model B's central buildings, the wind speed over roof of most central buildings in model $\mathrm{B}^{\prime}$ is getting lower. In addition, with the increase of surrounding buildings' density, the wind speed of central buildings in model $\mathrm{C}^{\prime}$ is usually higher than that in model $\mathrm{C}$ (except for central-line buildings). Therefore, with the decrease of surrounding buildings' density, the wind energy efficiency over roof of central buildings decreases.

6. When changing the width of buildings ( $A, D$, and $E$ and $A^{\prime}, D^{\prime}$, and $E^{\prime}$ ), the change trend of wind effect over roof is not clear.

\subsection{Actual urban form comparison}

As shown in the research structure in Figure 2, before selection of actual urban form for wind flow simulation, a primary filtration of urban forms need to be done in order to find out those who have high wind potential, based on empirical experience and evaluation. From the potential windy urban form group, six typical urban forms in six different cities in the world (Paris, Toulouse, Bombay, Barcelona, 


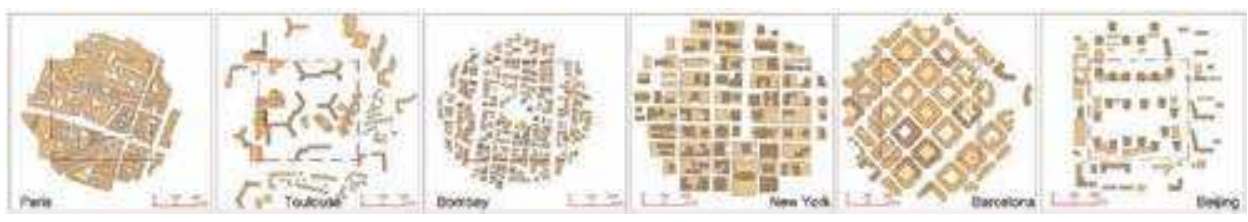

Figure 16.

Site plan of the six urban forms for comparison (extracted from Ref. [27]).

New York, and Beijing) are selected. The scale of the central study area is $450 \mathrm{~m} \times$ $450 \mathrm{~m}$ (red square in dash line), within an extended model representation of 350$450 \mathrm{~m}$ in radius. The site plans of them are shown in Figure 16. The color changes with the height of the building: the darker the color, the higher the height of the building. CFD simulation can evaluate wind energy by comparing different typical shapes according to different morphological characteristics. For comparison, the initial conditions are assumed to be the same, regardless of the local climate or socio-economic environment. Eight wind inlet directions with an interval of 45 are considered for every model. An average of wind potential over roof for the eight sessions is used for the comparison among them.

For the part of urban form study, the morphological indicator values of the six blocks show that the density of buildings varies greatly, ranging from 19 to $58 \%$ for building coverage ratio and from 1.1 to 12.1 for plot ratio; some blocks share similar PR (e.g., block of Toulouse and block of Bombay), but have very different building average volume and relative rugosity; some have very similar BCR and average occlusivity (e.g., block of Barcelona and block of New York), but with very different building average height, standard deviation of the building heights, mean aspect ratio, and absolute rugosity. With some similarities and differences, it is helpful to compare wind potential outcomes among these different urban forms. The detailed morphological parameter values can be found in Ref. [27].

For wind potential evaluation, three planes above the roofs $(Z=5,10$ and $15 \mathrm{~m})$ of those highest buildings in study zone of each urban form is considered. They include all the potential buildings higher than the average building height of the study zone, as the previous experience and literature review show that evaluation height is a vital element that influences wind velocity. Figure 17 shows the average values of coefficient $\mathrm{Cv}$ of wind over roofs of the highest groups of buildings (2-4 groups were given) of each model in every inlet direction scenario. And the minimum and maximum values, the total average change interval, and average range of the $\mathrm{Cv}$ values of each model were also summarized in Table 3.

With regard to the results of the velocity augmentation coefficient of different urban form models (Figure 17 and Table 3), the following conclusions can be drawn:

1. Each model has its best inlet angle of wind to make use of the wind effect over roof of the highest building. For example, for the buildings of $24 \mathrm{~m}$ in block model of Paris, the wind from $15^{\circ}$ is the strongest, and for the buildings of $50 \mathrm{~m}$ in block model of Toulouse, the strongest wind comes form $-105^{\circ}$.

2. Compared with the free wind case (without buildings), there is little wind effect increase in blocks of Paris, Barcelona, and Beijing because of their $C v$ $<1$, while the block models of Toulouse and Bombay has slight wind effect over roofs. The downtown block of New York has better situation, but the wind effect is limited to some of the tallest buildings in some inlet wind 

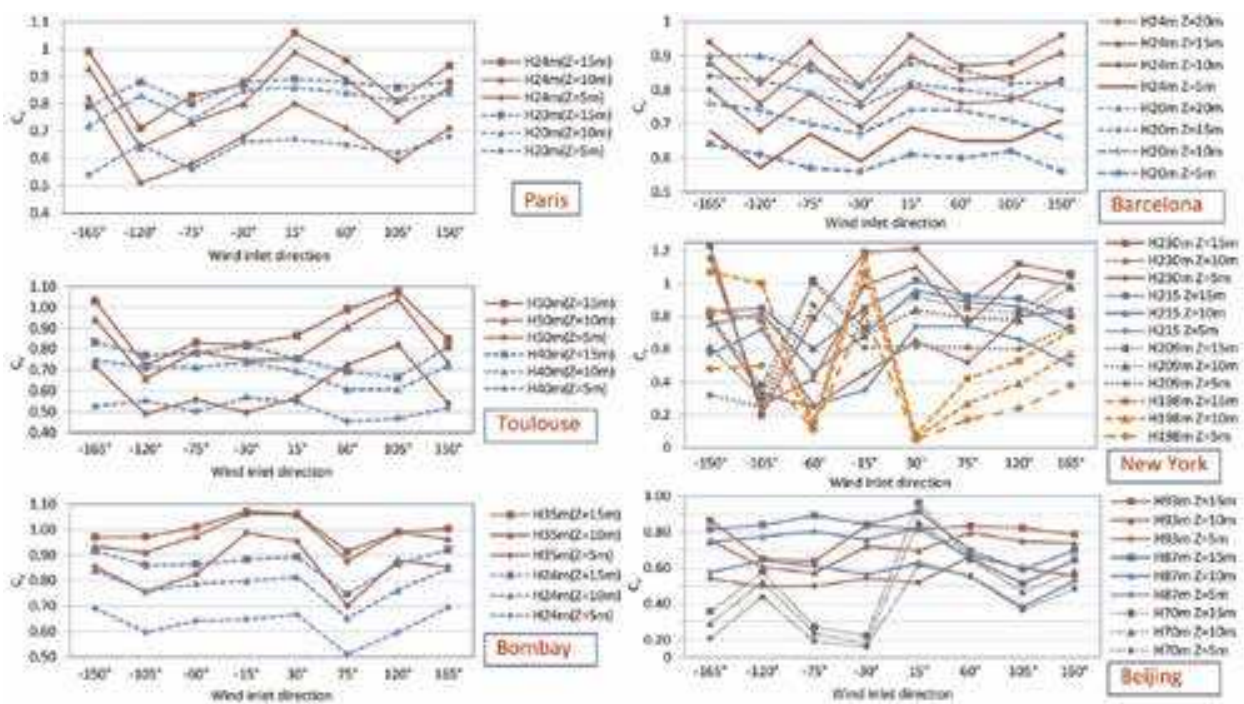

Figure 17.

Coefficient $C v$ of wind above the highest buildings of different urban forms.

\begin{tabular}{lcccccc}
\hline & Paris & Toulouse & Bombay & Barcelona & New York & Beijing \\
\hline Min & 0.43 & 0.49 & 0.51 & 0.56 & 0.11 & 0.16 \\
\hline Max & 1.06 & 1.08 & 1.07 & 0.91 & 1.23 & 0.96 \\
\hline Total average interval & $0.63-0.86$ & $0.54-0.80$ & $0.67-0.90$ & $0.61-0.81$ & $0.50-0.80$ & $0.54-0.76$ \\
\hline Average range & 0.228 & 0.259 & 0.221 & 0.193 & 0.300 & 0.219 \\
\hline
\end{tabular}

Table 3.

Values of coefficient $C v$ of wind at different altitude over roof of the highest buildings in each model.

directions. One reason of the universal low wind effect may be the low level of evaluation. The Barcelona block model shows that the $C v$ value at $Z=20 \mathrm{~m}$ is higher than that at $Z=15 \mathrm{~m}$ above the roof (Figure 17).

3. With regard to the minimum and maximum values of $C v$, it can be seen that the lowest values of the towers in block of New York and Beijing are quite astonishing, because they are less than 0.11 at $Z=5 \mathrm{~m}$. The reasons may be the big roughness of the surroundings with many skyscrapers, and a tall building has a thicker turbulent layer above its roof than a lower building [36]. In addition, the highest $C v$ in block of New York is also the biggest among the six blocks. This is because the evaluated highest buildings are high enough (>200 $\mathrm{m}$ ), which accelerates the wind around the building environment. However, with a lower height $(<100 \mathrm{~m})$, the highest buildings in Beijing block did not achieve a high $C v$ value. The reason may be that the heights of the tallest buildings in this model do not change much, which increases the wind turbulence around the near-roof areas.

4. In the total interval of $C v$ changes of each block model, it can be seen that the lowest, middle, and highest average values of the skyscrapers blocks (of New York and Beijing) are smaller than those of other blocks. In the range of $\mathrm{Cv}$ variation, we can see that most of the average ranges of $C v$ between $\mathrm{Z}=5 \mathrm{~m}$ 
and $Z=15 \mathrm{~m}$ are less than 0.3. $C v$ values of Toulouse and New York block models are more volatile than other blocks, i.e., both blocks have high level of turbulence than others. In fact, the coefficient values of variation of the building heights of these two models are also the largest among the six models.

Apart from the $C v$ evaluation, wind potential evaluation using the indicator of $\mathrm{M}^{\prime}$ is also undertaken. In Table 4, we can find the average values of the indicator $M^{\prime}$ at three altitudes over roofs, the average variation range of $M^{\prime}$, heights of the highest buildings in each model, and total roof area of these buildings.

Based on the values in Table 4, the following conclusions can be drawn:

1. Blocks in Barcelona and New York have far more wind potential over roofs than other blocks. In fact, the two blocks have the largest roof area and can be used to develop wind energy. For New York block model, the reason may also come from its numerous high-rise buildings.

2. Comparisons between blocks in Paris and Barcelona show that most geomorphological indicators (BCR, $\mathrm{PR}, \bar{H}, \lambda_{c}, R_{a}$, and $P_{o}$ ) of the two models change very little, and their great difference in wind energy potential between each may bear the reason of their big difference in building height variation. In other words, dramatic changes in the heights of buildings in model may increase wind energy over roofs. In fact, in comparing with blocks in Toulouse and Bombay, which also have similar building density, we have noticed that the block in Toulouse has higher wind energy potential and higher building height variation.

3. Block in Beijing has moderate wind energy potential. Although its average building height is very high $(56.6 \mathrm{~m})$, its total roof area is very small compared with blocks in Barcelona and New York. However, even block model of Beijing has less roof area than that of Paris, as its average building height is much higher than that of Paris, it has better greater potential.

In addition, considering the cut-in speed of wind turbines for useful power production, normally only wind with speed higher than 2 or $3 \mathrm{~m} / \mathrm{s}$ (depending on the choice of wind turbine) can be taken as exploitable wind potential. Therefore, some refinement would be done to evaluate the exploitable wind potential of each urban form. The detailed results and analysis can be found in Ref. [27].

\begin{tabular}{|c|c|c|c|c|c|c|c|}
\hline & & Paris & Toulouse & Bombay & Barcelona & $\begin{array}{l}\text { New } \\
\text { York }\end{array}$ & Beijing \\
\hline \multicolumn{2}{|c|}{ Average $\mathrm{M}^{\prime}$ value at $\mathrm{Z}=15 \mathrm{~m}$} & 1.74 & 1.46 & 0.79 & 3.50 & 3.82 & 2.03 \\
\hline \multicolumn{2}{|c|}{ Average $\mathrm{M}^{\prime}$ value at $\mathrm{Z}=10 \mathrm{~m}$} & 1.17 & 1.14 & 0.59 & 2.32 & 2.77 & 1.54 \\
\hline \multicolumn{2}{|c|}{ Average $\mathrm{M}^{\prime}$ value at $\mathrm{Z}=5 \mathrm{~m}$} & 0.57 & 0.49 & 0.32 & 1.70 & 1.23 & 0.72 \\
\hline \multicolumn{2}{|c|}{ Average variation range of $\mathrm{M}^{\prime}$} & 0.54 & 0.42 & 0.26 & 0.73 & 0.98 & 0.89 \\
\hline \multirow[t]{2}{*}{$\begin{array}{l}\text { Highest buildings } \\
(\mathrm{H}>\overline{\mathrm{H}})\end{array}$} & Heights (m) & 20,24 & $27,40,50$ & 24,35 & $\begin{array}{c}20,24,27, \\
\quad 32\end{array}$ & $87-230$ & $70,87,93$ \\
\hline & $\begin{array}{l}\text { Total roof area } \\
\qquad\left(\mathrm{m}^{2}\right)\end{array}$ & 37,588 & 16,724 & 13,223 & 85,260 & 42,482 & 24,220 \\
\hline
\end{tabular}

Table 4.

Results of $M^{\prime}$ of the real urban form models for comparison (unit of $M^{\prime}$ value: $10^{6} \mathrm{~m}^{5} \mathrm{~s}^{-3}$ ). 


\subsection{Urban form unit simulation}

In order to compare urban forms and make them applicable worldwide, here we adopt three simplified urban block models in Beijing (defined as Units 01, 02, and 03) and a simplified urban block model (defined as Unit 04) in Hong Kong. In addition, based on the model of Unit 01, the model of Unit 01b is created by removing a tower and implementing the buildings in order to make the model more or less symmetrically. Based on the model of Unit 04, the model of Unit 04b excludes its three corner buildings. Therefore, it is suggested that the impact of this change be tested for wind potential evaluation. The locations and sizes of the buildings in the four prototype units (Unit 01-04) are fully in line with the actual situation. Modifications to unit $01 \mathrm{~b}$ and $04 \mathrm{~b}$ are small and acceptable and "feasible" in sense of practice. We represent these unit models in actual conditions (building shape and location) to meet building requirements (e.g., for a plan of large housing tower) and urban planning requirements (e.g., in urban planning) as much as possible. Each model for unit study represents nine identical units, and the central unit is used as the research object. Unit sizes range from $170 \times 170$ to $430 \times 330 \mathrm{~m}$. The site plan and perspectives of the unit models can be seen in Figure 18.

Formally, Unit 01 and Unit 03 are a group of residential towers in form of pillar, Unit 02 is a group of residential towers in form of bar, and Unit 04 is a group of residential towers in form of pillar with chamfering. Table 5 and Figure 19 show the morphological values of each model, which is mostly the same as the corresponding real actual block model. At the same time, we can see that the building density of the four unit models in Beijing is similar.

As the previous actual urban form comparison models, urban form unit models adopt the same methods to evaluate wind effect and potential over roofs. An example of flow simulation in wind inlet direction of $60^{\circ}$ at a horizontal plane of $z=50 \mathrm{~m}$ above the ground is given in Figure 20.

Table 6 lists the average and magnitude of $C v$ values for all wind inlet directions and three different evaluation heights over roofs. Their variation intervals at $Z=10 \mathrm{~m}$ and the favorable wind inlet directions for wind effect are also given.
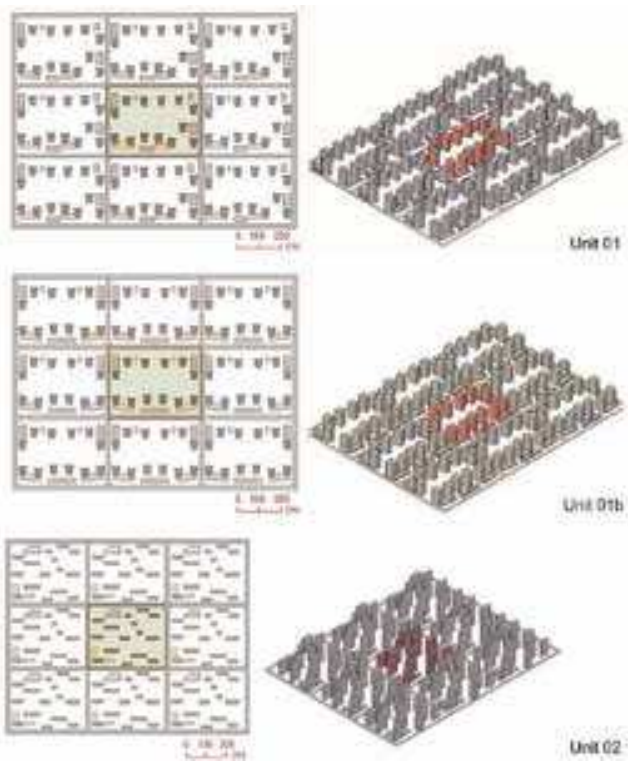
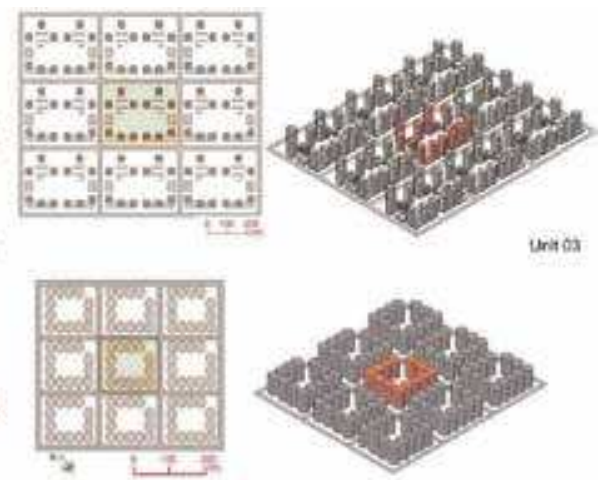

Untos
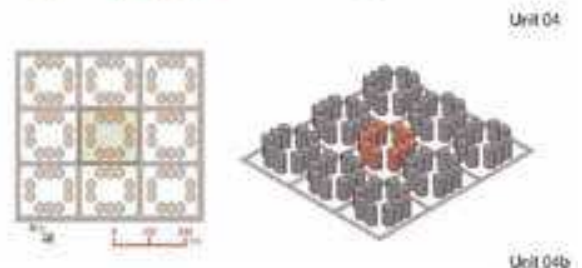

Figure 18.

Site plan and perspectives of the unit models. 


\begin{tabular}{|c|c|c|c|c|c|c|}
\hline \multirow{2}{*}{$\begin{array}{l}\text { Morphological } \\
\text { indicator }\end{array}$} & \multicolumn{6}{|c|}{ Site location } \\
\hline & $\begin{array}{l}\text { Jinsong, } \\
\text { Beijing } \\
\text { Unit } 01\end{array}$ & $\begin{array}{c}\text { Jinsong, } \\
\text { Beijing } \\
\text { Unit 01b }\end{array}$ & $\begin{array}{c}\text { Jinsong, } \\
\text { Beijing } \\
\text { Unit } 02\end{array}$ & $\begin{array}{c}\text { Jinsong, } \\
\text { Beijing } \\
\text { Unit } 03\end{array}$ & $\begin{array}{c}\text { Hung Hom, } \\
\text { Hong Kong } \\
\text { Unit } 04\end{array}$ & $\begin{array}{c}\text { Hung Hom, } \\
\text { Hong Kong } \\
\text { Unit 04b }\end{array}$ \\
\hline $\begin{array}{l}\text { Type of urban } \\
\text { form }\end{array}$ & $\begin{array}{c}\text { Social } \\
\text { apartment }\end{array}$ & $\begin{array}{c}\text { Social } \\
\text { apartment }\end{array}$ & $\begin{array}{c}\text { Social } \\
\text { apartment }\end{array}$ & $\begin{array}{c}\text { Social } \\
\text { apartment }\end{array}$ & $\begin{array}{c}\text { Social } \\
\text { apartment }\end{array}$ & $\begin{array}{c}\text { Social } \\
\text { apartment }\end{array}$ \\
\hline $\begin{array}{l}\text { Site area of the } \\
\text { unit }\left(\mathrm{m}^{2}\right)\end{array}$ & 142,145 & 142,145 & 134,522 & 136,583 & 26,200 & 26,200 \\
\hline BCR (\%) & 19.09 & 19.42 & 14.12 & 19.13 & 35 & 26.92 \\
\hline PR & 3.59 & 3.40 & 3.15 & 3.49 & 5.95 & 4.58 \\
\hline $\bar{H}(\mathrm{~m})$ & 59.53 & 55.50 & 70.01 & 57.53 & 50 & 50 \\
\hline $\begin{array}{l}\text { Maximum } \\
\text { height of } \\
\text { building } H_{\max } \\
\text { (m) }\end{array}$ & 87 & 87 & 87 & 93 & 50 & 50 \\
\hline$\sigma_{h} / \bar{H}(\%)$ & 59.6 & 65.1 & 44.4 & 72.1 & 0 & 0 \\
\hline$\overline{V_{b}}\left(\mathrm{~m}^{3}\right)$ & 80,744 & 76,611 & 66,458 & 62,627 & 35,250 & 35,250 \\
\hline$\lambda_{c}$ & 1.46 & 1.39 & 1.60 & 1.36 & 2.48 & 2.63 \\
\hline$R_{a}(\mathrm{~m})$ & 11.36 & 10.78 & 9.89 & 11 & 17.5 & 13.46 \\
\hline$R_{r}\left(\mathrm{~m}^{3}\right)$ & 46,053 & 46,933 & 39,613 & 55,563 & 0 & 0 \\
\hline$P_{o}(\%)$ & 88.3 & 88.9 & 89.3 & 89.8 & 70.8 & 77.6 \\
\hline$O_{c}(\%)$ & 57.24 & 55.71 & 60.17 & 55.28 & 63.31 & 58.14 \\
\hline
\end{tabular}

Table 5.

Description of morphological parameter of urban unit model.

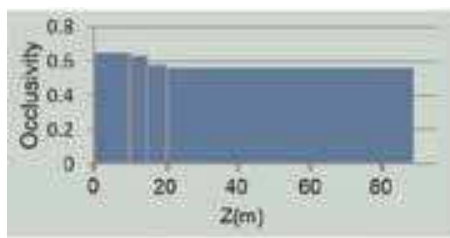

Unit 01 of Beifing

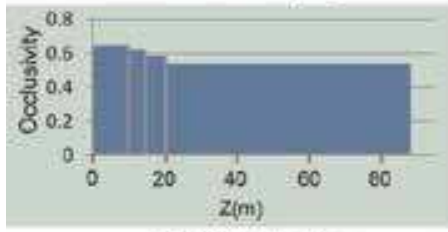

Unit 01b of Beijing

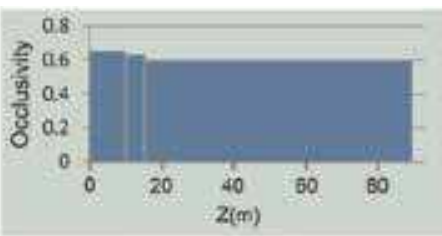

Unit 02 of Beijing

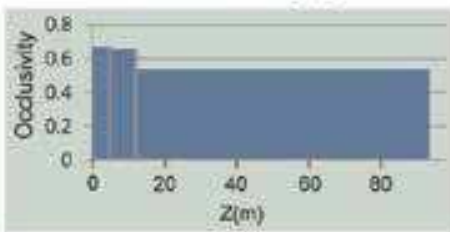

Unit 03 of Beijing

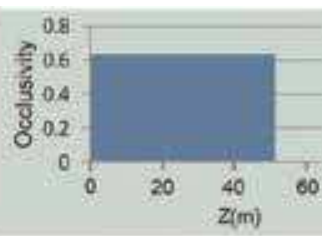

Unit 04 of HK

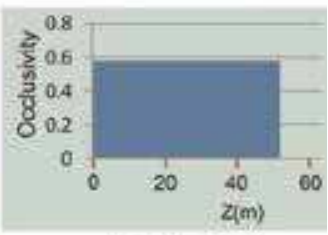

Unit $04 b$ of HK

Figure 19.

Occlusivity values of the unit models.

Based on the results of Table 6, the following conclusions can be drawn:

1. Compared with the real block model in Beijing, the values of $C v$ of all these urban unit models with similar building structures are much lower. For example, at the height of $Z=15 \mathrm{~m}$, the average $C v$ is equal to 0.87 over the roof of an $87 \mathrm{~m}$ tower in Beijing real block model, while in unit model cases (Units 


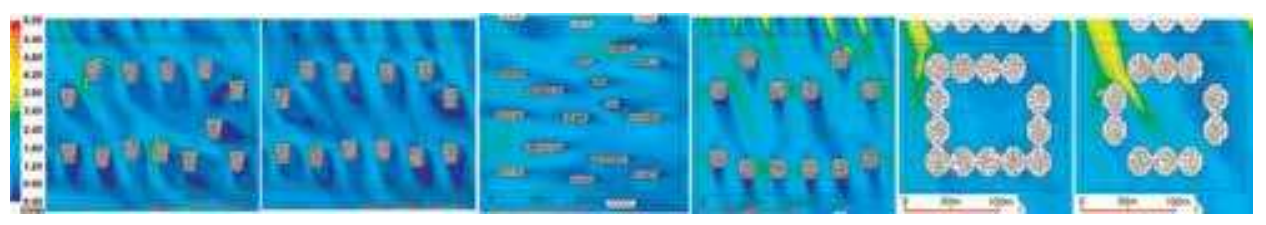

Figure 20.

Wind velocity contour lines of the unit models in $60^{\circ}$.

\begin{tabular}{lcccccc}
\hline & $\begin{array}{c}\text { Beijing } \\
\text { Unit 01 }\end{array}$ & $\begin{array}{c}\text { Beijing } \\
\text { Unit 01b }\end{array}$ & $\begin{array}{c}\text { Beijing } \\
\text { Unit 02 }\end{array}$ & $\begin{array}{c}\text { Beijing } \\
\text { Unit 03 }\end{array}$ & $\begin{array}{c}\text { Hong Kong } \\
\text { Unit 04 }\end{array}$ & $\begin{array}{c}\text { Hong Kong } \\
\text { Unit 04b }\end{array}$ \\
\hline $\begin{array}{l}\text { Average value of Cv at } \\
\mathrm{Z}=15 \mathrm{~m}\end{array}$ & 0.49 & 0.51 & 0.50 & 0.56 & 0.39 & 0.44 \\
\hline $\begin{array}{l}\text { Average value of Cv at } \\
\mathrm{Z}=10 \mathrm{~m}\end{array}$ & 0.43 & 0.46 & 0.45 & 0.51 & 0.34 & 0.38 \\
\hline $\begin{array}{l}\text { Average value of Cv at } \\
\mathrm{Z}=5 \mathrm{~m}\end{array}$ & 0.35 & 0.37 & 0.37 & 0.39 & 0.26 & 0.30 \\
\hline $\begin{array}{l}\text { Variation interval of Cv } \\
\text { at Z = 10 m }\end{array}$ & $0.36-0.54$ & $0.38-0.56$ & $0.25-0.64$ & $0.45-$ & $0.20-0.43$ & $0.32-0.46$ \\
\hline $\begin{array}{l}\text { Average variation range } \\
\text { of Cv at } \mathrm{Z}=10 \mathrm{~m}\end{array}$ & 0.178 & 0.184 & 0.375 & 0.113 & 0.216 & 0.142 \\
\hline $\begin{array}{l}\text { Favorable wind inlet } \\
\text { directions }\end{array}$ & $-75,-120^{\circ}$ & $-75,-120^{\circ}$ & $-165,15^{\circ}$ & $-75,60^{\circ}$ & $60,-120^{\circ}$ & $-120,60^{\circ}$ \\
\hline
\end{tabular}

Table 6.

Results of $\mathrm{Cv}$ for the unit models.

$01,01 \mathrm{~b}$, and 02 ), it is around 0.50 for the tower with the same height. This may be because the roughness of the research area of the unit model is very large, because the other eight identical units are installed all around.

2. When the wind inlet direction changes, it can be found that the variation interval of $C v$ of the towers in form of bar element (Unit 02) is much larger than that of the towers in form of pillar (01, 03 element). This means that the urban form of buildings in form of bar is more susceptible to wind direction changes than the model of buildings in form of pillar.

3. For Unit 01 model, if a tower is removed and the space between towers is enlarged, then the new model (Unit 01b) has a general $C v$ slightly higher than the original one. The most advantageous wind inlet direction for wind effect does not change.

4. When comparing Units $01 \mathrm{~b}$ and 03 of buildings in form of pillar with very similar morphological parameter values, we note that Unit 03 has a larger wind augmentation effect than Unit $01 \mathrm{~b}$. On the average variation range of $C v$ in different wind inlet direction, Unit 03 has a smaller value than Unit 01b. This probably because the studied towers of Unit 03 ( $93 \mathrm{~m}$ high) is higher than that of Unit $01 \mathrm{~b}(87 \mathrm{~m})$, and the form with chamfering has advantage on accumulating wind effect around the building.

5. For the case of Unit 04b which removed three corner towers from Unit 04, we note that the $C v$ of renewed Unit $04 \mathrm{~b}$ is slightly higher than that of Unit 04. 


\begin{tabular}{lcccccc}
\hline & $\begin{array}{c}\text { Beijing } \\
\text { Unit 01 }\end{array}$ & $\begin{array}{c}\text { Beijing } \\
\text { Unit 01b }\end{array}$ & $\begin{array}{c}\text { Beijing } \\
\text { Unit 02 }\end{array}$ & $\begin{array}{c}\text { Beijing } \\
\text { Unit 03 }\end{array}$ & $\begin{array}{c}\text { HK } \\
\text { Unit 04 }\end{array}$ & $\begin{array}{c}\text { HK Unit } \\
\text { 04b }\end{array}$ \\
\hline Average $\mathrm{M}^{\prime}$ value at $\mathrm{Z}=15 \mathrm{~m}$ & 0.413 & 0.377 & 0.460 & 0.505 & 0.143 & 0.191 \\
\hline Average $\mathrm{M}^{\prime}$ value at $\mathrm{Z}=10 \mathrm{~m}$ & 0.296 & 0.263 & 0.355 & 0.358 & 0.089 & 0.125 \\
\hline Average $\mathrm{M}^{\prime}$ value at $\mathrm{Z}=5 \mathrm{~m}$ & 0.161 & 0.137 & 0.212 & 0.166 & 0.043 & 0.061 \\
\hline Average variation range of $\mathrm{M}^{\prime}$ & 0.279 & 0.246 & 0.613 & 0.205 & 0.124 & 0.116 \\
\hline Heights of towers $(\mathrm{m})$ & 87 & 87 & 87 & 93 & 50 & 50 \\
\hline $\begin{array}{l}\text { Total roof area of the studied } \\
\text { towers }\left(\mathrm{m}^{2}\right)\end{array}$ & 16,939 & 15,636 & 14,608 & 15,072 & 9165 & 7050 \\
\hline
\end{tabular}

Table 7.

Results of $M^{\prime}$ for the unit models (unit of $M^{\prime}$ value: $10^{6} \mathrm{~m}^{5} \mathrm{~s}^{-3}$ ).

The average variation range of different wind inlet direction is becoming much lower. The most advantageous angle of wind inlet direction remains unchanged.

Based on the results in Table 7, the following conclusions can be drawn:

1. With a total area of the exploitable roof $8 \%$ less than that of Unit 01 , Unit $01 \mathrm{~b}$ has a total wind potential M' value $12 \%$ smaller than that of the original Unit 01 (averaging with results of three altitudes over roofs), although its $C v$ is slightly higher (around 5\% on average).

2. Comparing the two similar models, Units $01 \mathrm{~b}$ and 03 with buildings in form of pillar, it can be seen that the roof surface area of Unit 03 is $4 \%$ smaller than the other one; however, it has total wind potential with an average $30 \%$ higher. This may prove the advantage of the building form with chamfering on accumulating wind potential over roof.

3. The average $C v$ value of Unit 02 is slightly higher than that of Unit 01 , and its total roof area is $14 \%$ smaller. The wind energy potential of Unit 02 is however $21 \%$ higher than that of Unit 01 on average. The reason may be that the high wind velocity variation can contribute much wind energy.

4. Compared with Unit 03, the total roof area of Unit 02 is reduced by $3 \%$ and its building density (BCR) is reduced by $10 \%$. On the wind potential, Unit 02 has larger potential at a low altitude above the roof and Unit 03 has larger potential at a high altitude.

5. With total roof area $23 \%$ smaller than that of Unit 04 , Unit $04 \mathrm{~b}$ however has $28 \%$ higher total wind potential. It proves that, taking away the towers in three corners, if well considered, can increase much wind effect and wind potential over roof.

\section{Application: Urban wind energy evaluation}

In this section, an application of urban wind energy potential evaluation is given. Local conditions are considered in order to find a decent and practical solution for wind energy development. 


\subsection{Case study background}

Jinsong block, chosen as the study case, is located with latitude $39^{\circ} 53^{\prime}$, longitude $116^{\circ} 28^{\prime}$, in the Chaoyang District and near the city center of Beijing. Figure 21 shows its location in Beijing and some photographs of typical buildings in this block. Jinsong block was chosen because of these typical high-rise residential buildings, which have some uniformed shapes and whose heights are favorable for wind velocity accumulation. Apart from that, the environmental and climate pressure of Beijing, local developed socio-economical conditions and people's awareness of sustainable development, all together are beneficial for developing green energy like wind energy in this area.

For wind condition, the data of Chaoyang District is taken as reference. The Chaoyang District Meteorological Bureau provided the wind velocity distribution and wind rose of four seasons, based on the data from 1995 to 2002 (Figures 21 and 22). We can see that the Northwest wind is dominant. The average wind speed is $3.21 \mathrm{~m} / \mathrm{s}$ in spring, $2.09 \mathrm{~m} / \mathrm{s}$ in summer, $2.4 \mathrm{~m} / \mathrm{s}$ in autumn, $2.98 \mathrm{~m} / \mathrm{s}$ in winter, and $2.67 \mathrm{~m} / \mathrm{s}$ in a year.

\subsection{Simulation model data and simplification}

For the application case study, the model chosen has much bigger surrounding presentations than the real urban form comparison model. The study area in the center is $450 \times 450 \mathrm{~m}$ and the presented surroundings zone has a size of $600 \mathrm{~m}$ in

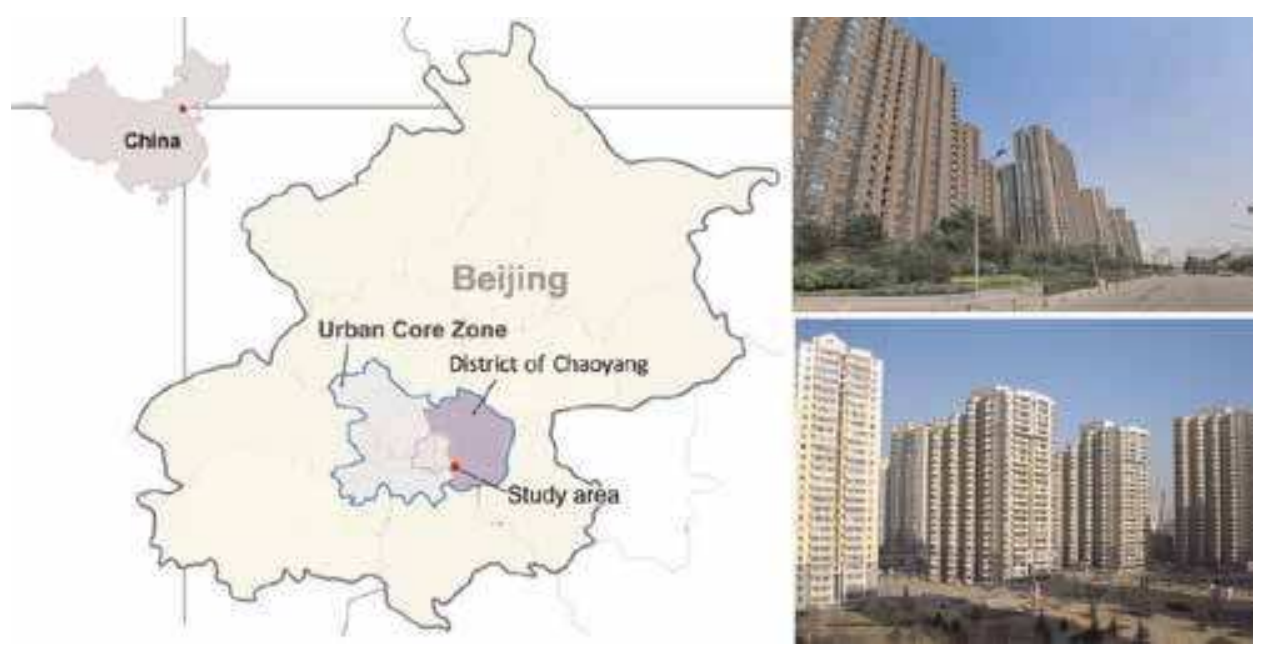

Figure 21.

Position of the study area and the typical residential towers in it (source of pictures: map.baidu.com).

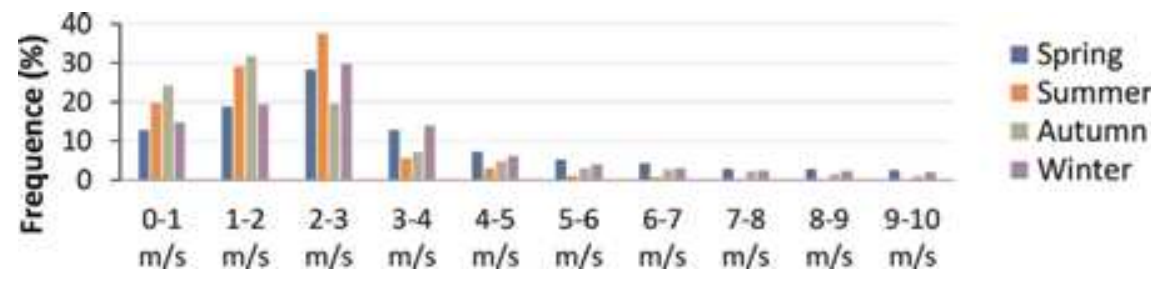

Figure 22.

Distribution of wind velocity of different season (source: Meteo Chaoyang). 


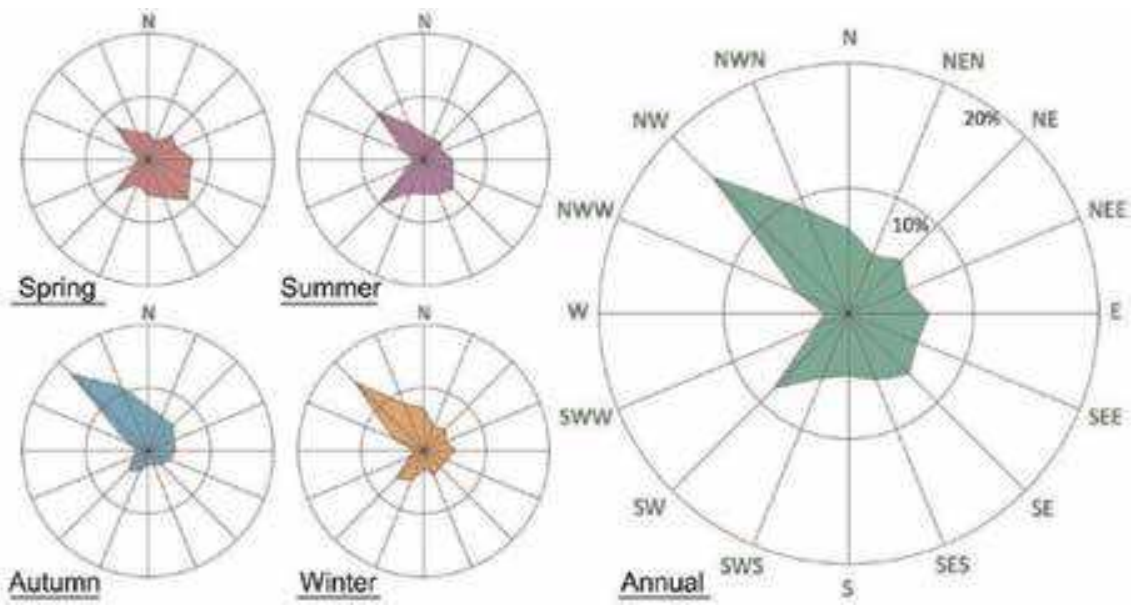

Figure 23.

Simulation model before (up) and after (down) simplification.

radius. The domain size for simulation then is enlarged to a demi-sphere with a radius of $1200 \mathrm{~m}$. CFD settings follow the previous experience and Best Practice Guidelines.

Considering running CFD simulation effectively and efficiently, model simplification and evaluation are necessary. For simplification, all buildings less than $10 \mathrm{~m}$ are neglected. Small volume buildings with the same height (which is also less than $24 \mathrm{~m}$ ) are regarded as a connected entire block of the same height Figure 23.

Morphological information of the urban form of Jinsong block before and after simplification is shown in Table 8. Compared with the original model, the parameter values of the simplified model are roughly the same. Those parameters with a general big variation (>20\%) are as follows: $B C R, \bar{H}, \sigma_{h}, \sigma_{h} / \bar{H}, \overline{V_{b}}$, and $R_{r}$. The plot ratio difference is only $3 \%$. The influence of simplified model on wind energy assessment is analyzed. The results of wind potential $\mathrm{M}^{\prime}$ values show that the impact

\begin{tabular}{lcc}
\hline & Original model & Simplified model \\
\hline Type of urban form & Social apartment & Social apartment \\
\hline Study area $\left(\mathrm{m}^{2}\right)$ & 202,500 & 202,500 \\
\hline BCR $(\%)$ & 19.93 & 14.85 \\
\hline PR & 3.57 & 3.47 \\
\hline $\bar{H}(\mathrm{~m})$ & 56.62 & 73.31 \\
\hline$\sigma_{h}(\mathrm{~m})$ & 38.02 & 28.47 \\
\hline$\sigma_{h} / \bar{H}(\%)$ & 67 & 39 \\
\hline$H_{\max }(\mathrm{m})$ & 93 & 93 \\
\hline$\overline{V_{b}}\left(\mathrm{~m}^{3}\right)$ & 69,246 & 95,842 \\
\hline$\lambda_{c}$ & 1.41 & 1.35 \\
\hline$R_{a}(\mathrm{~m})$ & 11.28 & 10.89 \\
\hline$R_{r}\left(\mathrm{~m}^{3}\right)$ & 50,130 & 34,429 \\
\hline$P_{o}(\%)$ & 89.07 & 89.43 \\
\hline$O_{c}(\%)$ & 57.60 & 58.38 \\
\hline
\end{tabular}

Table 8.

Morphological information of the Jinsong block model before and after simplification. 
of small buildings for this model is relatively small, averaging $4.75 \%$. However, with simplification, the number of mesh of CFD model gets a relative huge savings: $24 \%$. In this sense, the reasonable simplification can save much time for simulation and generally does not interfere the wind potential evaluation over roof.

\subsection{Urban wind potential distribution analysis}

As local wind rose, 16 wind inlet directions are considered for CFD simulation. In order to study the influence of urban form of Jinsong block on the wind potential, CFD simulation without local wind distributions is first undertaken and analyzed. Figure 24 shows the average velocity augmentation factor $(\mathrm{Cv})$ and total surface wind potential $\left(\mathrm{M}^{\prime}\right)$ over roofs of the highest towers in the model. We can find that when the wind inlet directions are $112.5,135$, and $-135^{\circ}$, the values of $\mathrm{Cv}$ and $\mathrm{M}^{\prime}$ are relatively smaller than in other wind inlet directions. That means, in these directions, the wind over roof is fable for this model.

Now considering the local wind roses (Figure 25), we can evaluate the actual wind potential over roof of the Jinsong block model (Figure 26). We note that $45^{\circ}$ is the best wind inlet direction to develop the maximum wind potential.

In addition, in order to determine the location of wind turbines on the roof, the wind potential above each tower roof was evaluated (Figure 27). We found that the buildings C1, C2, D1, and E1 usually have the highest wind potential. The towers D3 and E2 have very big potential with an incident wind angle of $45^{\circ}$, but not very impressive with other angles. It is necessary to avoid choosing the towers C7, D4, D5, and D8, which actually have average or less wind potential over roof, regardless of the incident wind angle.

If we integrate the local wind distribution of wind rose over different inlet angles the CFD simulation results, then we can overlap the wind speed contour line maps $(z=80 \mathrm{~m}$ from ground $)$ in different inlet angles with the corresponding percentage of transparency (Figure 28a). Then in order to evaluate wind potential around
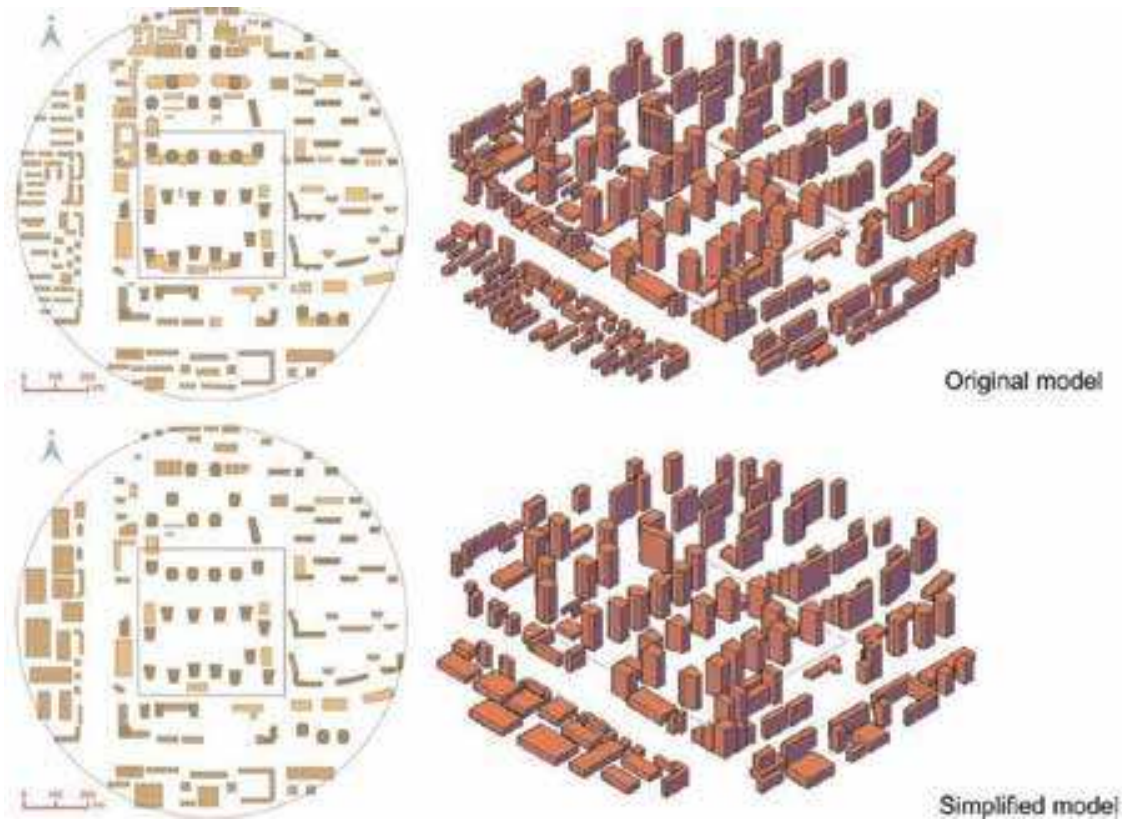

Figure 24 .

Simulation results on distribution of $C v$ an $M^{\prime}$ over different wind inlet direction (without local wind conditions). 

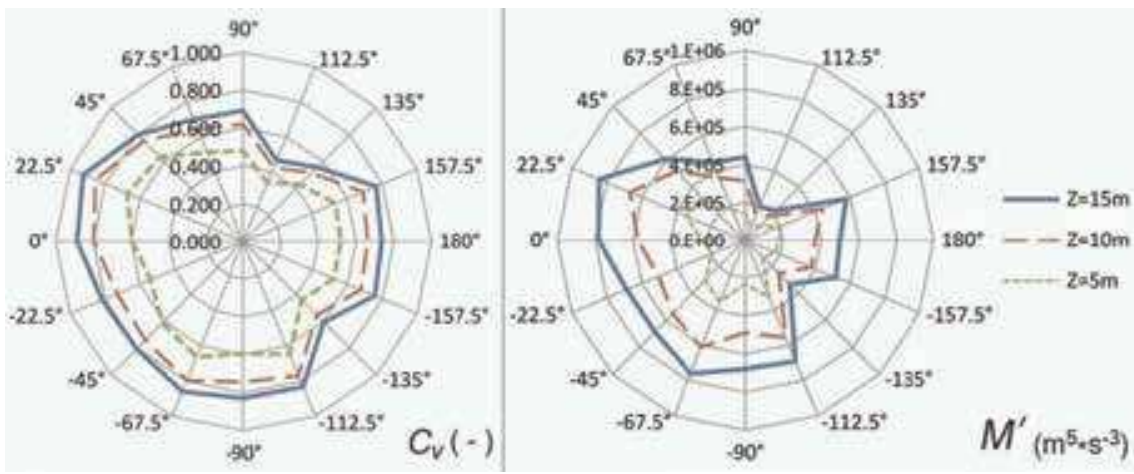

Figure 25.

Wind rose of Chaoyang District (source: Meteo Chaoyang).

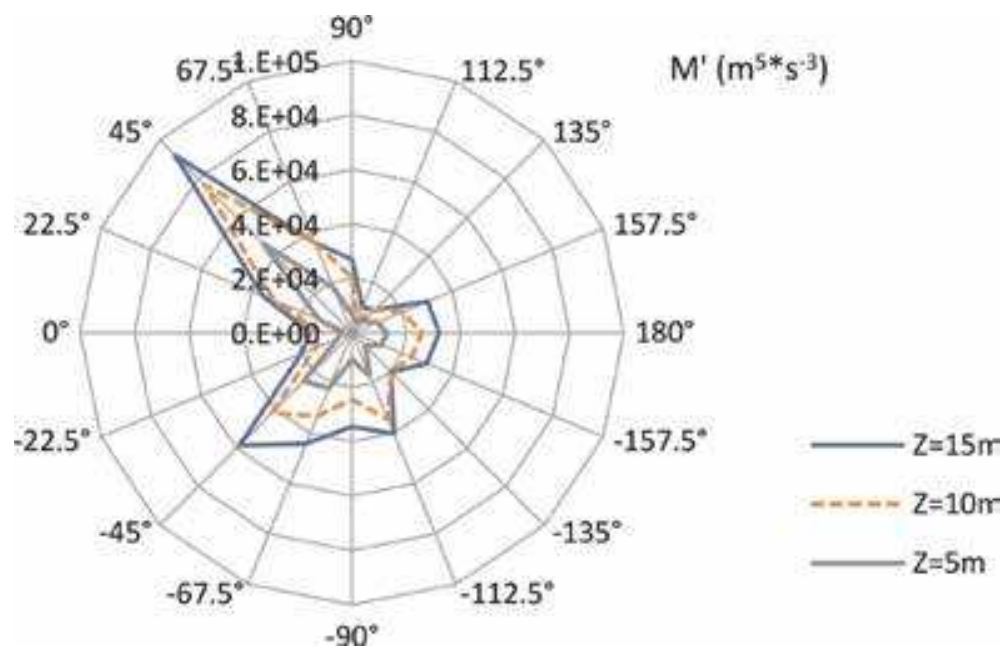

Figure 26.

Wind potential $M^{\prime}$ distribution with consideration of local wind conditions.

towers near the exterior walls (for vertical axis wind turbines), we made all the towers higher than $80 \mathrm{~m}$ having an offset dash line $5 \mathrm{~m}$ away from the external walls on plan. In order to better identify the area with the highest wind speed, the contour lines of wind speed bigger than $3.25 \mathrm{~m} / \mathrm{s}$ is extracted and marked with yellow and red in Figure 28b. We find that the wind speed near the external walls is often very low. Only towers E1, E2, and E3 have "exploitable" wind potential near the external walls in some wind inlet angles. On the contrary, the wind above the tower D3 (70 $\mathrm{m}$ height) is much larger, although the tower D3 is not the best choice if we evaluate wind potential over roofs (Figure 27).

\subsection{Urban wind installation and evaluation}

Considering the relatively low speed and high turbulence intensity on the roof of Jinsong District, micro or small vertical axis wind turbines will be used. In fact, the average wind speed at $Z=10 \mathrm{~m}$ above roof is $2.3 \mathrm{~m} / \mathrm{s}$, and average wind turbulence intensity is $45 \%$. Among many types of commercial wind turbines in the market, we found three types of wind turbines that can operate in low-speed wind: Beijio BDP600/250, Archimedes Liam F1, and WindTronics BTPS 6500. The technical parameters of these turbines are shown in Table 9. After comparing several aspects 


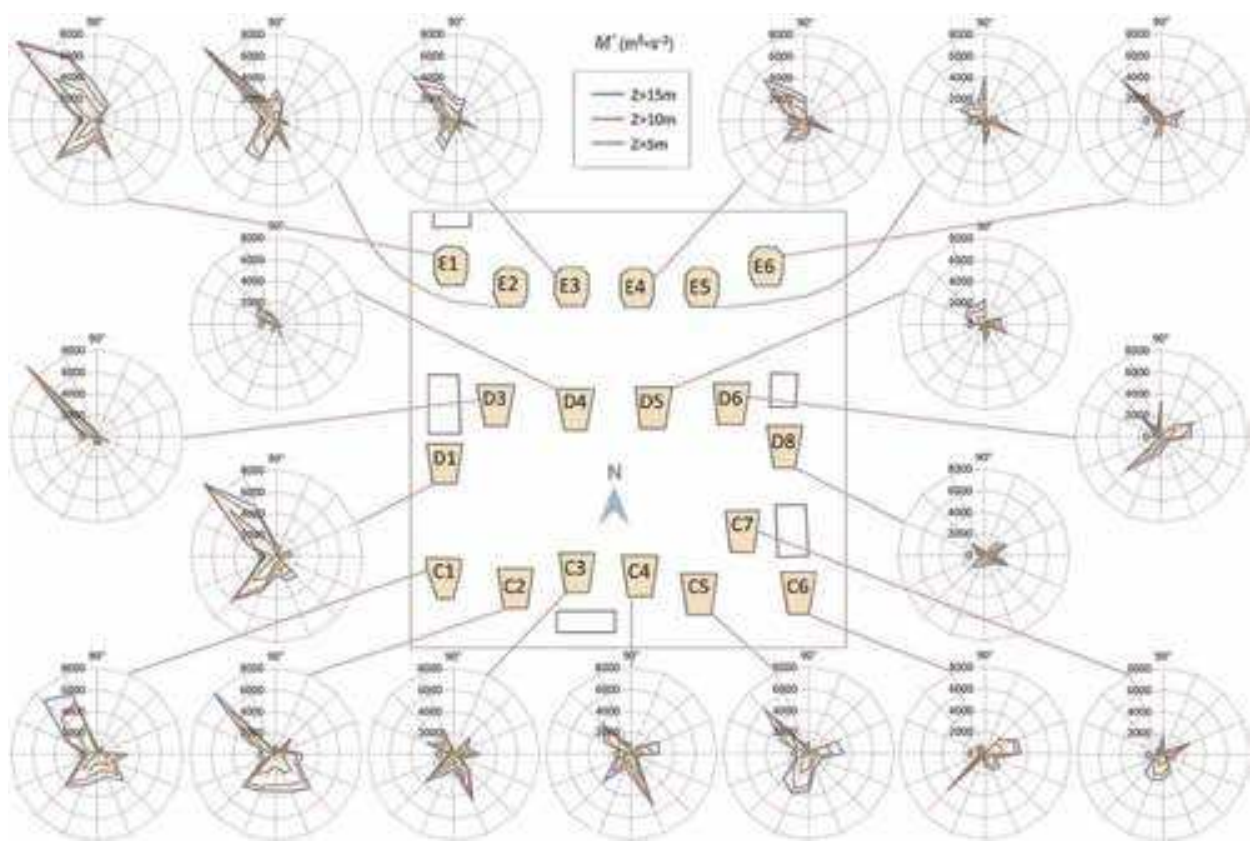

Figure 27.

Wind potential $M^{\prime}$ distribution over roof of different tower.

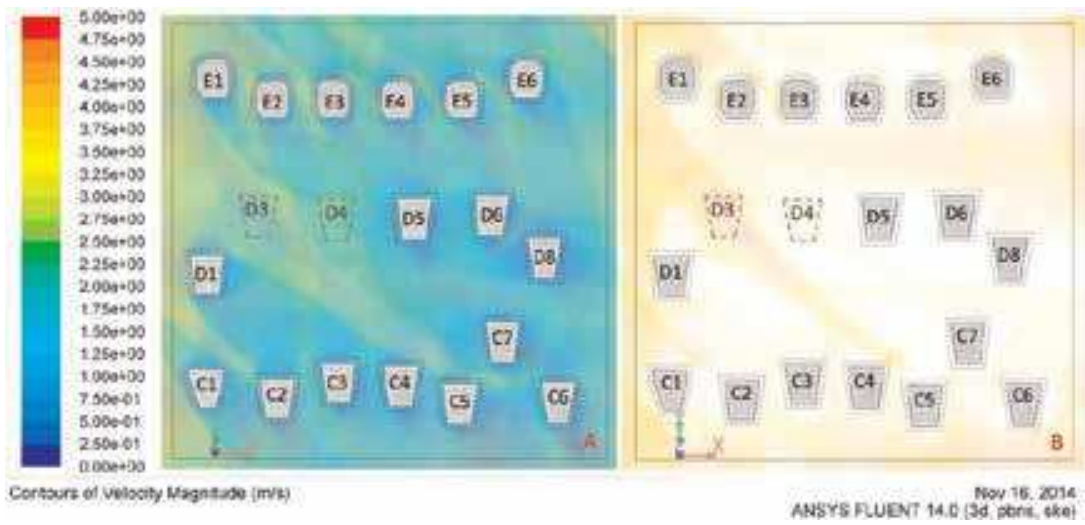

Figure 28.

Overlapping wind velocity profile $(z=80 \mathrm{~m})$ of 16 inlet directions with consideration of local wind rose. (A: profile with full level of velocity; B: profile with velocity bigger than $3.25 \mathrm{~m} / \mathrm{s}$ ).

including rated power and unit price, we decided to choose BDP-600/250 (Chinese Wind Turbine), which is actually workable in weak wind, light on weight, and the most economical among the three wind turbines. The power curve of the wind turbine is provided by the producer (Figure 29).

An example of installing wind turbine on the roof of tower E1 is introduced. Considering the size of the selected wind turbines and the space above the roof, we drew a wind turbine matrix to evaluate the wind power distribution of each wind turbines position. A distance of three rotor diameters between two wind turbines (axis to axis) in the direction perpendicular to the wind is considered. In the second row, the wind turbine is located in the middle of the interval between the two turbines in first row, and also three rotor diameters from each turbine. Figure 30 shows the temporary arrangement matrix for wind turbines on the roof. According 


\begin{tabular}{|c|c|c|c|c|}
\hline & & $\begin{array}{c}\text { Beijio BDP-600/ } \\
250\end{array}$ & Archimedes Liam F1 & WindTronics BTPS 6500 \\
\hline \multicolumn{2}{|l|}{ Rated power (W) } & 600 & 1000 & 1500 \\
\hline \multicolumn{2}{|c|}{ Rated wind speed (m/s) } & 8 & 12 & 14 \\
\hline \multicolumn{2}{|c|}{$\begin{array}{l}\text { Min. exploitable wind } \\
\text { speed }(\mathrm{m} / \mathrm{s})\end{array}$} & 3 & 2 & 1 \\
\hline \multicolumn{2}{|l|}{$\begin{array}{l}\text { Size }(\mathrm{W} \times \mathrm{L} \times \mathrm{D}) \\
(\mathrm{m} \times \mathrm{m} \times \mathrm{m})\end{array}$} & $1.8 \times 1.8 \times 1.4$ & $1.5 \times 1.9 \times 1.75$ & $2 \times 2.2 \times 0.5$ \\
\hline \multicolumn{2}{|c|}{ Swept surface area $\left(\mathrm{m}^{2}\right)$} & 2.5 & 1.8 & 2.5 \\
\hline \multicolumn{2}{|l|}{ Weight (kg) } & 42 & 75 & 110 \\
\hline \multicolumn{2}{|l|}{ Noise (dB) } & & $<42$ & $<35$ \\
\hline \multicolumn{2}{|l|}{ Unit price $(\$)$} & 1000 & 5450 & 5695 \\
\hline \multirow{4}{*}{$\begin{array}{l}\text { Power in } \\
\text { experiment (W) }\end{array}$} & $2 \mathrm{~m} / \mathrm{s}$ & 0 & 0 & 22 \\
\hline & $3 \mathrm{~m} / \mathrm{s}$ & 48 & 10 & 58 \\
\hline & $4 \mathrm{~m} / \mathrm{s}$ & 82 & 62 & 100 \\
\hline & $5 \mathrm{~m} / \mathrm{s}$ & 130 & 141 & 163 \\
\hline
\end{tabular}

Table 9.

Technical parameters of the selected wind turbines adaptive for fable and turbulent wind environment.

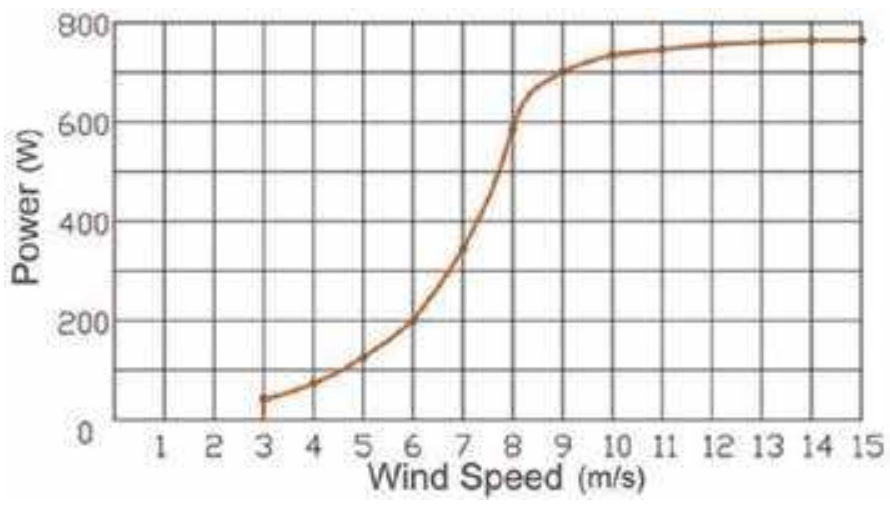

Figure 29.

Power curve line of the wind turbine BDP-600/250 (source: detail.1688.com).

to the research of Durrani and Qin [38], the T-shaped configuration of wind turbines mentioned here is conducive to enhancing the wind power generation of the second row turbine. Bayeul-Laine et al. [39] show that, in order to improve efficiency, the distance between two wind turbines in front row facing wind should be small, and the distance between two turbines in the direction of wind should be large. The ongoing arrangement of wind turbines would consider these suggestions.

In order to identify the wind potential of each installation location, the wind speed contour lines of 16 wind inlet directions at $Z=10 \mathrm{~m}$ above the roof of tower 


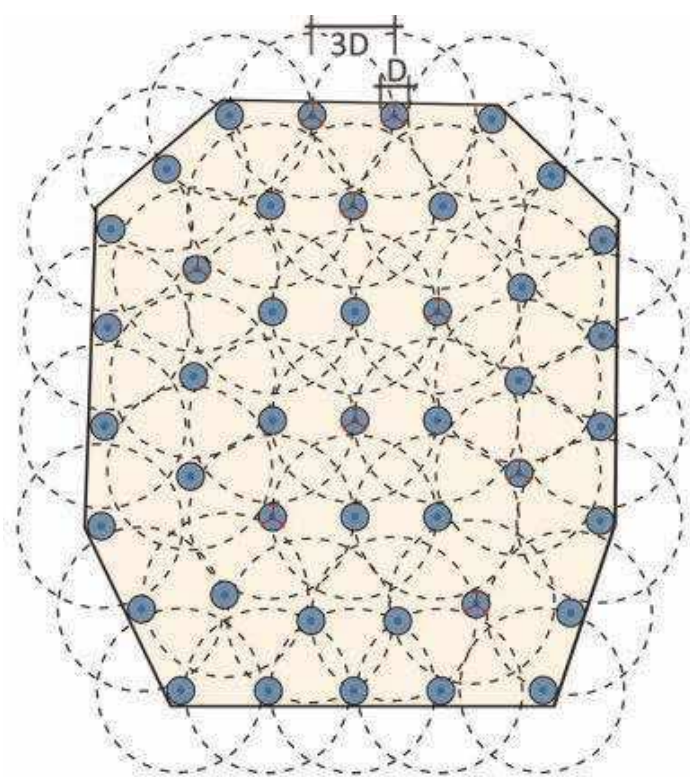

Figure 30.

Potential positioning of wind turbines on the roof of the tower E1.

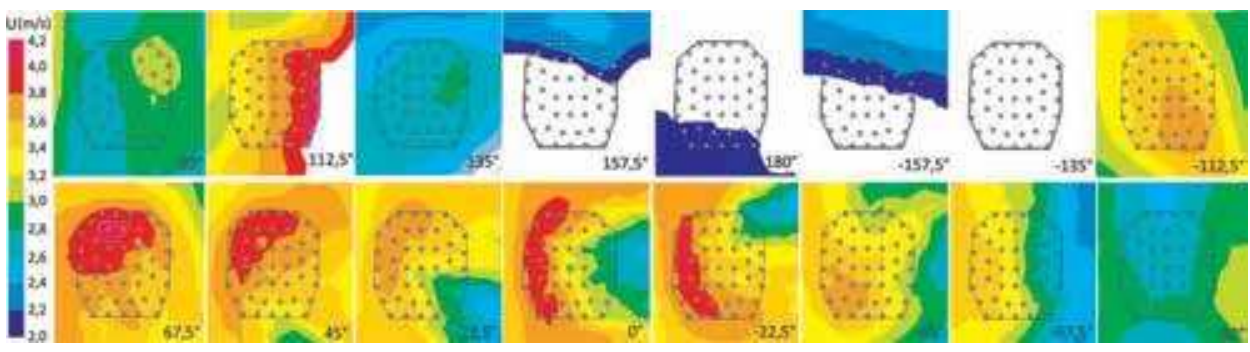

Figure 31.

Wind speed contour lines of wind at $Z=10 \mathrm{~m}$ over roof of the tower $E_{1}$ in 16 wind inlet directions.

E1 are given (Figure 31). According to the power curve of wind turbine BDP-600/ 250 , each wind speed value is calculated into a value of wind potential power. As we know that the wind power is a function of the cube of wind velocity, the local wind distribution data, rather than the average wind speed, are used to assess the potential of wind energy. Thus, the expected wind power generation capacity at each point can be calculated (Figure 32).

Figure 32 shows that the points with relatively strong wind potential lie on the edge of the northwest corner while this direction is the dominant wind of Chaoyang District. In fact, the average power of all these points is $91 \mathrm{~W}$, and the difference between the points is not very large $( \pm 13 \mathrm{~W})$. For example, if the windiest point (point 6,103 W) is used, the payback period of the wind turbine installed here will be:

$$
R_{n}=\frac{C_{\text {turbine }}+C_{\text {support }}}{R_{\text {annual }}}=\frac{1000+800}{0.103 * 24 * 365 * 0.1}=20 \mathrm{yrs}
$$

where $C_{\text {turbine }}$ is the cost of wind turbine, $C_{\text {support }}$ is the supporting service cost that consists of masts, installation, civil engineering, and maintenance, and $R_{\text {annual }}$ is equivalent to the annual income of electricity generation, 0.1 US dollar per kilowatt is the local electricity bill price. 


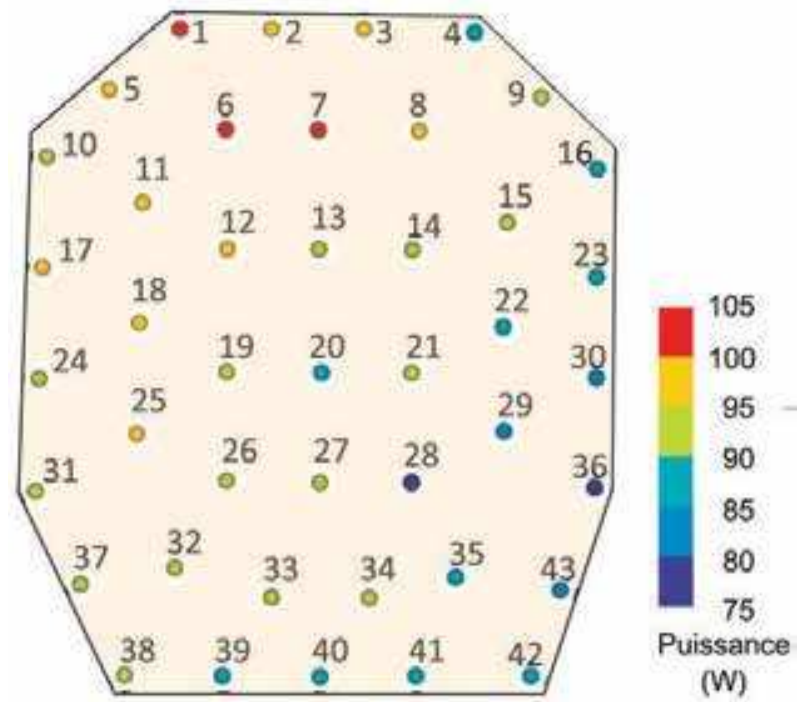

Figure 32.

Wind potential power of wind at $Z=10 \mathrm{~m}$ over roof of the tower $E 1$.

Similarly, the payback period of the wind turbine at the lowest wind point on the roof of tower E1 (point 36) is found to be 26 years. Compared with other wind turbine economic analysis cases [37], as well as the aspects of policy subside and measures to improve wind effect over roof, the application of wind turbine BDP$600 / 250$ on the roof of the windiest tower in Jinsong block is acceptable. However, given that tower $\mathrm{E} 1$ is one of the windiest locations in the block, we must recognize that the wind power potential over the roofs of other buildings in the block is relatively low and may hardly be "profitable."

\section{Conclusions}

This chapter shows a method to evaluate wind energy potential with urban morphology. Block scale $(500 \times 500 \mathrm{~m})$ was adopted for typical urban form classification and selection. CFD method is used for wind flow simulation. CFD parameter settings were validated and evaluated with wind tunnel experiment. Methods of verification and Best Practice Guidelines were used for parameter adjust for different model.

Indicator $M$ is defined to assess surficial wind potential on planes over roof. $\mathrm{M}^{\prime}$ is found to be an equivalent and effective alternative to it. Indicator $C v$ is used as the wind velocity augmentation factor to evaluate the effect of wind concentration. Because of the limits of the size and location of the exploitable wind zone adjacent to the exterior walls, it is not easy to explore and compare the wind potential near the walls. Wind potential over roof is generally stronger and more practical than that near the exterior walls to develop wind potential.

Simple building forms (1-3 buildings) were tested for exploring the impact of building form on wind potential. Some rules were found on the relationship between building form indicator and wind effect as well as wind potential over roof. These results provide a knowledge base for wind assessment in the built environment and provide a benchmark for the simulation study of the block models.

Thirteen indicators were selected that might help to determine the impact of urban 
morphology on wind. In particular, the parameter of density is analyzed with an ideal urban form model, in order to show the method to evaluate the impact of one single morphological parameter on wind potential over roof.

Real urban forms were then evaluated and compared in order to reveal the impact of different urban form parameter on wind potential. Six typical blocks in Paris, Toulouse, Mumbai, Barcelona, New York, and Beijing are modeled and compared. The results show that most block models have little wind effect over roofs of the highest buildings. Wind inlet direction is an important factor to influence wind effect and wind potential over roof of a model. The height of the building is the decisive factor to improve wind speed. Models with higher variation of building heights would have bigger wind effect and wind potential. The total area of the roof used to install wind turbines and the average height of the highest buildings in the model are among the most important factors for wind potential over roof of a model.

Urban form unit models are then considered to understand the impact of a certain urban form feature on wind potential. Six kinds of urban unit models were tested, based on some small modifications of the actual urban forms. The results show that the model with buildings in bars is sensitive with different wind inlet direction. At a small altitude above the roof $(Z<10 \mathrm{~m})$, model with buildings in bars has bigger wind potential, while at a high altitude, it is the model with buildings in form of pillar that has better wind potential. Removing one or more buildings in one model can increase the average wind speed above the roof, but because of the loss of exploitable roof area, it may not ensure an increase in wind energy potential of the whole block. In order to develop wind energy on roofs, buildings with chamfering, truncated or rounded corners, is recommended.

Finally, a block model in Beijing is given for urban wind evaluation case study. With consideration of local wind distribution data, wind potential of Jinsong block model with 16 different wind inlet directions is evaluated. An example of most windy building in the block was chosen and wind velocity distribution on different point position on the roof is analyzed. With integrated consideration of scope of use, rated power, cut-in speed, and unit price of wind turbines, a Chinese wind turbine Beijio BDP-600/250 is proposed for the project. With turbine power curve data, the potential wind power of different position on the roof was calculated. With local market and electricity bill information, the payback period of the wind turbine on the selected tower is between 20 and 26 years. Therefore, the potential of wind power generation in Jinsong District is generally feasible, but the detailed assessment searching for the windy block and the windy tower is still essential.

This paper gives a general method to evaluate wind potential in built environment with building and urban form study. The work will contribute urban wind potential development and urban wind environment evaluation. For further research, parametrical study of typical urban forms indicator and corresponding wind energy potential evaluation is suggested.

\section{Acknowledgements}

This paper addresses its acknowledgments to the National Natural Science Foundation (No. 51908002) and Beijing Natural Science Foundation (No. 8184069) for their financial support. 


\section{Author details}

Biao Wang

Department of Architecture, North China University of Technology, Beijing, China

*Address all correspondence to: bwang@ncut.edu.cn

\section{IntechOpen}

(C) 2020 The Author(s). Licensee IntechOpen. Distributed under the terms of the Creative Commons Attribution - NonCommercial 4.0 License (https://creativecommons.org/ licenses/by-nc/4.0/), which permits use, distribution and reproduction for non-commercial purposes, provided the original is properly cited. (cc) BY-NC 


\section{References}

[1] Campbell N, Stankovic S, Graha M, Parkin P, van Duijvendijk M, Gruiter TD, et al. Wind energy for the built environment (project WEB), PF4.11. In: Procs. European Wind Energy Conference \& Exhibition, Copenhagen, 2-6 July 2001. 2001. Available from: https://www.researchgate. net/publication/30416722

[2] Stankovic S, Campbell N, Harries A. Urban Wind Energy. London: Earthscan; 2009. DOI: 10.4324/ 9781849770262

[3] Dutton AG, Hqlliday JA, Blanch MJ, Energy Research Unit, CCLRC, The Feasibility of Building Mounted/ Integrated Wind Turbines (BUWTs): Achieving their potential for carbon emission reductions. Final report, under contract of Carbon Trust (2002-07028-1-6), 4 May 2005

[4] IT Power, Small wind turbines for the urban environment-State of the art, case studies \& economic analysis. EIE/04/130/SO7.38591, Project WINEUR, 2005

[5] WINEUR, Wind energy integration in the urban environment.

Deliverable 1.1, Technology inventory report. EIE/04/130/SO7.38591, Project WINEUR, 2005

[6] WINEUR, Aspects socioéconomiques et acceptablité des éolienes en milieu urbain-France. EIE/04/130/ SO7.38591, project WINEUR, 2007

[7] Cace J, Horst E, Syngellakis K, Niel M, Clement P, Heppener R, Peirano E, Urban wind turbinesGuidelines for small wind turbines in the built environment. Project WINEUR; 2007

[8] Grignoux T, Gibert R, Neau P, Buthion C. Eoliennes en milieu urbainEtat de l'art. Paris: ARENE Ile-deFrance; 2006
[9] Yu WK. Current progress and future development of wind energy in Hong Kong [thesis]. Hong Kong: University of Hong Kong; 2011

[10] Turesson J. Potential for renewable energy sources (RES) in Grenoble, Delft [Master's thesis]. Stockholm: KTH Industrial Engineering and Management; 2011

[11] Shi S. The applied research of urban high-rise buildings wind energy and for designing of hybrid energy storage system [thesis]. Shijiazhuang: Hebei University of Science and Technology; 2011. in Chinese

[12] Zeng HS. Integration of renewable energy with urban design: Based on the examples of the solar photovoltaics and micro wind turbines [thesis]. Cambridge (Massachusetts): Massachusetts Institute of Technology; 2011

[13] Whaley DM. Low-cost small-scale wind power generation [thesis].

Adelaide: University of Adelaide; 2009

[14] Christianson M. Windmill power for City people: A documentation of the first urban wind energy system. Nasa Sti/recon Technical Report N; 1977

[15] Moreno D, Charreron D. Urban Wind Energy: Case Study Wind Turbine at LÄKEROL Arena. VDM Verlag; 2011. ISBN-13:978-3639366402

[16] Kalmikov A, Dupont G, Dykes K, Chan C. Wind power resource assessment in complex urban environments: MIT campus case-study using CFD analysis. In: AWEA 2010 WINDPOWER Conference. May 23-26, 2010. 2010

[17] Zhao H, Gao H, Li JW. Integrated architectural design with wind turbines in urban environment. 
New Architecture (in Chinese). 2011;03: 45-48. DOI: 10.3969/j.issn.1000-3959. 2011.03.010

[18] Balduzzi F, Bianchini A, Carnevale EA, Ferrari L, Magnani L. Feasibility analysis of a Darrieus vertical-axis wind turbine installation in the rooftop of a building. Applied Energy. 2012;97:921-929. DOI: 10.1016/ j.apenergy.2011.12.008

[19] Stathopoulos T, Alrawashdeh H, AlQuraan A, Blocken B, Dilimulati A, Paraschivoiu $\mathrm{M}$, et al. Urban wind energy: Some views on potential and challenges. Journal of Wind Engineering and Industrial Aerodynamics. 2018;179: 146-157. DOI: 10.1016/j.jweia.2018. 05.018

[20] KC A, Whale J, Urmee T. Urban wind conditions and small wind turbines in the built environment: A review. Renewable Energy. 2019;131: 268-283. DOI: $10.1016 / j$. renene.2018.07.050

[21] Simoes T, Estanqueiro A. A new methodology for urban wind resource assessment. Renewable Energy. 2016; 89:598-605. DOI: 10.1016/j. renene.2015.12.008

[22] Toja-Silva F, Kono T, Peralta C, Lopez-Garcia O, Chen J. A review of computational fluid dynamics (CFD) simulations of the wind flow around buildings for urban wind energy exploitation. Journal of Wind Engineering and Industrial Aerodynamics. 2018;180:66-87. DOI: 10.1016/j.jweia.2018.07.010

[23] Biao L, Cunyan J, Lu W, Weihua C, Jing L. A parametric study of the effect of building layout on wind flow over an urban area. Building and Environment. 2019;160:106160. DOI: 10.1016/j. buildenv.2019.106160

[24] Asfour OS. Prediction of wind environment in different grouping patterns of housing blocks. Energy and Buildings. 2010;42:2061-2069. DOI: 10.1016/j.enbuild.2010.06.015

[25] Liu S, Pan W, Zhao X, Zhang H, Cheng X, Long Z, et al. Influence of surrounding buildings on wind flow around a building predicted by CFD simulations. Building and Environment. 2018;140:1-10. DOI: 10.1016/j.buildenv. 2018.05.011

[26] Azizi MM, Javanmardi K. The effects of urban block forms on the patterns of wind and natural ventilation. Procedia Engineering. 2017;180: 541-549. DOI: 10.1016/j.proeng.2017. 04.213

[27] Wang B, Cot LD, Adolphe L, Geoffroy S, Sun S. Cross indicator analysis between wind energy potential and urban morphology. Renewable Energy. 2017;113:989-1006. DOI: 10.1016/j.renene.2017.06.057

[28] Biao WANG, Shuai SUN, Duan ML. Wind potential evaluation with urban morphology-A case study in Beijing. Energy Procedia. 2018;153:62-67. DOI: 10.1016/j.egypro.2018.10.078

[29] Hang J, Li YG, Sandberg M, Claesson L. Wind conditions and ventilation in high-rise long street models. Building and Environment. 2010;45(6):1353-1365. DOI: 10.1016/j. buildenv.2009.11.019

[30] Yuan C, Ng E. Building porosity for better urban ventilation in high-density cities: A computational parametric study. Building and Environment. 2012; 50:176-189. DOI: 10.1016/j.buildenv. 2011.10.023

[31] Muehleisen RT, Patrizi S. A new parametric equation for the wind pressure coefficient for low-rise buildings. Energy and Buildings. 2013; 57:245-249. DOI: $10.1016 /$ j.enbuild. 2012.10.051 
[32] Wang B, Cot LD, Adolphe L, Geoffroy S, Morchain J. Estimation of wind energy over roof of two perpendicular buildings. Energy and Buildings. 2015;88:57-67. DOI: 10.1016/j. enbuild.2014.11.072

[33] Wang B, Cot LD, Adolphe L, Geoffroy S. Estimation of wind energy of a building with canopy roof.

Sustainable Cities and Society. 2017;35: 402-416. DOI: 10.1016/j.scs.2017.08.026

[34] Menter F, Hemstro B, Henrikkson $M$ et al., CFD Best Practice Guidelines for CFD Code Validation for ReactorSafety Applications, Report EVOLECORA-D01, Contract No. FIKSCT-2001-00154; 2002

[35] Franke J, Hellsten A, Schlünzen H, Carissimo B. Best practice guideline for the CFD simulation of flows in the urban environment. COST 732: Quality Assurance and Improvement of Microscale Meteorological Models; 2007. Available from: http://refhub.else vier.com/S0167-6105(18)30227/sref98

[36] Lu L, Ip KY. Investigation on the feasibility and enhancement methods of wind power utilization in high-rise buildings of Hong Kong. Renewable and Sustainable Energy Reviews. 2009; 13(2):450-461. DOI: 10.1016/j. rser.2007.11.013

[37] Debled A, Deblock J, Etude de faisabilité d'une implantation d'éolienne en milieu urbain à Roubaix et Templemars dans le cadre du projet européen WINEUR.IMPACT 2005/ 2006, Rapport d'activité. Grant agreement no. EIE/04/130/S07.38591. Project WINEUR; 2006

[38] Durrani N, Qin N. 2D Numerical analysis of a VAWT wind farm for different configurations. 49th AIAA Aerospace Sciences Meeting including the New Horizons Forum and Aerospace Exposition. Orlando, Florida; 4-7 January 2011. Available from: https://www.researchgate.net/ publication/256463516

[39] Bayeul-Laine AC, Simonet S, Bois G. VAWT with controlled blades: Inuence of wake of one turbine on power coefficient on the next turbine. 5th ICEpsMsO. Greece; Jul 2013:1-8. Available from: http://hdl.handle.net/10985/7254 

Section 2

Optimization of Hybrid and Micro-Grid Systems 



\title{
Chapter 7
}

\section{Hybrid Wind and Solar Systems Optimization}

\author{
Mervat Abd El Sattar Badr
}

\begin{abstract}
Solar and wind energy systems are considered as promising power-generating sources due to their availability and advantages in local power generation.

However, a drawback is their unpredictable nature. This problem can be partially overcome by integrating these two resources or more in a proper combination to form a hybrid energy system. Nevertheless, the harmonization of different energy sources, energy storage, and load requirements is a challenging task. Thus, the performance of various possible configurations has to be investigated to reach the optimum combination using a simulation program. The number of simulations and time required for calculation increases with the increase in number of optimization variables. Therefore, the selection of a quick and accurate optimization technique is very important. Different software packages, such as HOMER and iHOGA, were developed, where each of them is based on a different optimization algorithm.
\end{abstract}

Keywords: hybrid energy system, optimization, hybrid energy packaged, energy management

\section{Introduction}

It is currently observed that the rapid development of new electrical power sources is denominated by renewable sources for both cases: on-grid and offgrid. The main problem of off-grid stand-alone renewable energy systems (RES) is the fluctuation of power supply which can be avoided using hybrid solar/wind energy systems (HSWES) that allow improving the system efficiency, increasing power reliability, and reducing energy storage requirements for stand-alone applications [1].

In order to solve sustainability and power quality problems, the power transfer from the renewable sources to load must be managed in a proper way. Therefore an energy management process should be proposed to prevent power discontinuity or power wasting so that the loads operate properly.

A major aim of HSWES optimization is to reach the suitable size of each component and the control strategy that provide reliable, efficient, and cost-effective system. Optimization is performed by minimizing (or maximizing) an objective function using a suitable criterion such as net present cost (NPC) and/or the generated electricity price (EP). In this case the cost of avoided $\mathrm{CO}_{2}$ emissions should be taken into consideration [2]. 


\section{Hybrid renewable energy systems}

Renewable energies are intermittent sources; hence, hybrid renewable energy system (HRES) is considered an appropriate solution to support electrical requirements especially for remote areas. HRES that incorporates more than one type of renewable energy technologies in a site can help to mitigate the effect of intermittent nature that some of them exhibit and to reach a sustainable source.

As mentioned before, wind and solar systems are considered favorable sources for energy generation due to their availability and being site-power generation. However, a drawback, common to solar and wind utilization, is their unpredictable nature and dependence on weather changes; both of these energy systems would have to be oversized to make them completely reliable. Fortunately, the problems caused by variable nature of these resources can be partially overcome by integrating these two resources or more in a proper combination to form a polygene ration energy system.

HRES is an energy system that includes a number of units and equipment. Different technologies usually exist for alternative types of each of these units. Selecting the optimal alternatives is challenging; to achieve a greater knowledge of how a HRES is designed and optimized, an optimization tool should be used.

\section{Optimization techniques}

The optimization process is followed through an objective function (OF) with respect to some variables in the presence of constraints on those variables. The objective function is either a cost function or energy function which is to be minimized, or a reward function or utility function, which is going to be maximized [3, 4].

An optimization technique is used to find an optimized solution for a particular optimization model. "Optimum" is the word that is used to demonstrate the meaning of best, either maximum or minimum [4]. Problems dealing with the cost will require the best cost to be as less as possible. On the other hand, problems dealing with profit will see the maximum value as the best answer. There are several wellknown optimization techniques depending on the model type, deterministic or stochastic, such as:

1. Linear programming (LP), a type of convex programming, is applied in the cases in which the OF is linear and the constraints are specified using only linear equalities and inequalities.

2. Second-order cone programming (SOCP) is a convex program and includes certain types of quadratic programs.

3. Integer programming is applied in the case that some, or all, variables of the linear solution are constrained to have an integer value. This is generally more difficult than linear programming.

4. Quadratic programming permits the OF to have quadratic terms, while the feasible set of solution must be identified with linear equalities and inequalities. Some specific cases of the quadratic term lead to a type of "convex programming."

5. Fractional programming is concerned with the optimization of ratios of two nonlinear functions. The special class of "concave fractional programs" can be transformed to a "convex optimization" problem. 
6. Nonlinear programming is used for the general case of the objective function and/or the constraints containing nonlinear parts. Cases of convex program affect the difficulty of the solution.

7. Stochastic programming is applied when some of the constraints or parameters depend on random variables.

8. Combinatorial optimization is applicable when the set of "feasible solutions" is, or can be, reduced to a discrete one.

9. Infinite-dimensional optimization is applied in the case that the set of "feasible solutions" is a subset of an "infinite-dimensional space."

10. Stochastic optimization is used in the case of random function measurements or random inputs.

11. Robust programming is, like stochastic programming, an attempt to capture uncertainty in the data underlying the optimization problem. Robust optimization targets to find solutions that are valid under all possible realizations of the uncertainties.

12. Heuristics and "metaheuristics" use limited or no assumptions concerning the problem being optimized. Usually, heuristics do not guarantee that an optimal solution has to be found. In fact, heuristics are used to find approximate solutions for complicated optimization problems.

In addition to these techniques a growing interest in the application of artificial intelligence (AI) techniques to power system engineering. AI techniques, unlike strict mathematical methods, have the ability to adapt to nonlinearities and discontinuities commonly found in power systems. The best known algorithms in this class include:

- Evolution programming

- Genetic algorithms

- Simulated annealing

- Tabu search

- Neural networks

\section{Optimization of HRES}

As power system must be sustainable, secure, and environmentally safe, the basic function of a HRES is to supply power with quality electrical energy, reliably and economically. As such, optimization plays an important role. This enables to minimize the cost of operation, initial investment, and environmental impacts and maximize reliability, quality, and efficiency.

The optimization of HRES used to analyze the system is mainly focused on two problems: (1) determine the optimal configuration of the power system and optimal type and sizing of generation units installed, and (2) design strategies 
for optimal dispatch, which are subject to constraints of the system meeting load requirements at minimum cost.

\subsection{Costs}

To reach an appropriate HRES the system should be designed according to techno-economic and environmental measures to fulfill physical and operational constraints. For cost optimization, system design seeks the configurations and control strategies that achieve the lowest total cost over the system lifetime. The lifetime cost which subjects to the system typically consists of two or more components. The life of the system is usually considered to be the life of the PV panels-which are the elements that have a longer life-span.

The OF in this case is the system net present cost (NPC), which consists of initial investment cost in addition to the discounted present worth of all future costs over the system lifetime. The system cost is the sum of all its components, e.g., PV, WT, battery, converter, and any other necessary devices, in addition to installation cost. Component costs comprise all costs: capital, replacement, operational and maintenance, and fuel consumption. Some of these costs depend on the selected control strategy.

\subsection{HRES optimization model}

For PV/WT/DG/battery bank system, the objective is to minimize the net present cost (NPC) under load and power constraints [5]:

$$
\text { Minimize } N P C=\sum C_{P V_{i}}+\sum C_{W_{j}}+\sum C_{D G_{l}}+\sum C_{B_{m}}+\sum C_{C_{n}}
$$

Subject to the constraints

$$
\begin{gathered}
\sum \text { Load } \leq \sum E_{P V_{i}} N_{P V_{i}}+\sum E_{W_{j}}+\sum E_{D G_{l}} \\
(\text { Power Wattage })_{\max } \leq \sum P_{C} N_{C} \\
S O C_{\text {min }} \leq S O C(t) \leq S O C_{\text {max }}
\end{gathered}
$$

where $C P V i$, cost of a photovoltaic module; $C W j$, cost of wind turbine; $C D G l$, cost of a diesel generator; $C B m$, cost of a battery; $C C n$, cost of a converter; NPVi, number of photovoltaic modules; $N W j$, number of wind turbines; $N D G l$, number of diesel generators; NBm, number of battery bank to be used; $N C n$, number of converters; $P C$, power of converter; $E P V i$, kWh generated by the ith photovoltaic module; $E W j$, kWh generated by the $j$ th wind turbine; $E D G l$, kWh generated by the lth diesel generators; and SOC, state of charge of the battery.

The common current optimal sizing tool is the available software packages that can be helpful for real-time system integration.

\section{Optimization software packages}

The number of simulations and time required for calculation increases with the increase in number of optimization variables. Therefore, the selection of a quick and accurate optimization technique is very important. 
Simulation software tools are the most common tools for evaluating performance of the hybrid solar/wind systems. Connolly [6] listed 67 software tools available for analysis of hybrid energy systems, studied 37 of them, and identified the suitable tools for different objectives. Some of the most widely used software tools for hybrid energy systems are summarized as follows:

\section{1 iHOGA}

Improved Hybrid Optimization using Genetic Algorithm (iHOGA) is a simulation and optimization software developed in $\mathrm{C}++$ by the Electric Engineering Department of the University of Zaragoza, Spain [7]. This software is a tool for optimum sizing of hybrid renewable energy system. This tool uses double genetic algorithms for optimization. The main algorithm is used for the system components while a secondary algorithm is added for control strategy. The software can simulate and optimize system of any size (size from Wh to MWh even through GWh daily consumption). Optimization is achieved by minimizing total system costs through its useful lifetime. The program allows mono-objective as well as multi-objective optimization. The mono-objective and multi-objective optimizations are achieved for stand-alone and grid-connected hybrid renewable energy systems. The program modeling provides various outputs such as size of the PV generator in Wp and its ideal tilt, battery capacity in $\mathrm{kWh}$, battery lifetime in years, initial investment, NPC with breakdown of the component, lowest cost of energy, and $\mathrm{CO}_{2}$ emissions of the system in $\mathrm{CO}_{2} / \mathrm{kWh}$ [7].

Dufo-López et al. used iHOGA software for the optimization of the electrical supply of a hospital existed far from the electric grid in Kalong (Democratic Republic of the Congo), which is presently powered by a diesel-battery system [8]. The results showed that adding solar photovoltaic (PV) to a diesel-battery system to supply the required load could obtain a $28 \%$ reduction in energy cost and $54 \%$ reduction in the fuel consumption reducing $\mathrm{CO}_{2}$ emissions lower than the current diesel-battery system.

Fadaeenejad et al. presented an analysis and optimization for a HRES (PV/WT/ BAT), which are designed for rural electrification in Malaysia [9]. The evaluation of the performed optimization was accomplished using iHOGA software. The obtained results illustrate that the wind energy is used as a supportive source of energy for many locations in Malaysia, and the hybrid renewable energy systems are cost-effective for these rural areas.

Anita Gudelj et al. presented an optimal sizing model for hybrid energy system (HES) that aims to minimize the total cost through the useful life of the system and $\mathrm{CO}_{2}$ emissions to meet the desired consumption [10]. The iHOGA program was used to simulate the system operation and calculate technical economic parameters for each configuration. The results showed that the hybrid energy systems have considerable reductions in $\mathrm{CO}_{2}$ emission and cost of the system. Using a diesel generator as a backup source, for the PV/WT/battery system, was found to be the best solution to guarantee the reliable supply without any shortage of the required load under the weather data change.

\subsection{HOMER}

The National Renewable Energy Laboratory (NREL) introduced a Hybrid Optimization Model for Electric Renewable (HOMER) package. HOMER uses hourly load and weather data inputs to perform hourly simulations for technoeconomic analysis of hybrid energy systems [11]. HOMER performs three tasks: simulation, optimization, and sensitivity analysis. It facilitates the optimization of simulated renewable energy systems to minimize NPC for a given set of constraints. 
Mustafizur Rahman et al. [12] suggested seven scenarios of combining hybrid renewable energy technologies with diesel generator to minimize the economic and environmental concern effects of its use. The suggested scenarios were (100, $80,60,50,35,21$, and $0 \%$ ) renewable resource penetration. A case study for the remote community of Sandy Lake, Ontario, was conducted. The different scenarios modeled are developed by using HOMER software. The aim of this study was to find the best combination of hybrid renewable energy systems from the available resources for a particular off-grid location in Canada. The results showed that using $80 \%$ renewable energy scenario can achieve the demand with $72 \%$ higher COE but $83 \%$ lower CO emissions than 0\% renewable fraction-100\% diesel-battery scenario.

In a similar study, Ngan et al. [13] focused on the technical and economic feasibility of "the hybrid energy systems (PV/WT/DG)" in a southern city of Malaysia using HOMER simulation software. They considered seven different system configurations: stand-alone diesel generator system, hybrid PV-diesel system, PV-diesel system with battery storage, hybrid wind-diesel system, wind turbinediesel system with battery storage, wind-solar-diesel system, and wind-solar-diesel system with battery storage.

Targeting to study technical and economic performance of wind/diesel/battery (W/D/B) system supplying a remote small gathering of six families, HOMER package was used [14]. Net present cost (NPC) and cost of energy (COE) are used as economic criteria, while $\%$ of power shortage is the measure of performance. Optimum system configurations are estimated for two sites. Simulation results showed that W/D/B systems are economical for the assumed community sites as the price of generated electricity was about $0.308 \$ / \mathrm{kWh}$, without taking external benefits into considerations. W/D/B systems were found to be more economical than diesel-alone system.

A case study of the performance and optimization of a HRES supplying a water desalination system for irrigating a small greenhouse hydroponic cultivation was presented by Khatab et al. [15]. The study presented optimization of two hybrid systems: photovoltaic/wind turbine (PV/WT) with and without backup diesel generator. The results showed that COE of PV/WT system is less than that of PV/WT/diesel, while there is no capacity shortage in the case of PV/ WT/diesel.

\subsection{RETScreen}

It is developed by Natural Resources Canada to evaluate the energy production, costs, emission reduction, and financial viability for various types of renewable and nonrenewable energy systems [16]. It performs economical comparison between conventional system and proposed system. A study examined the potential for a 10-MW PV power plant in Abu Dhabi using RETScreen modeling software to forecast the produced energy, financial feasibility, and GHG emissions reductions [17]. Initial results showed high energy production potential and saving a high amount of tons of GHG emissions annually.

\subsection{HYBRID2}

This software package is developed by the National Renewable Energy Laboratory (NREL) of the United States Department of Energy in cooperation with the University of Massachusetts. This hybrid simulation software can run simulation for time intervals from 10 mintues to 1 hour. The NREL recommends the HYBRID2 for the thermal loads [18]. 


\subsection{TRNSYS}

TRNSYS is a transient system simulation program developed by the Solar Energy Laboratory, University of Wisconsin-Madison, USA. It has a modular structure in which components of the system are specified by the user [19]. It can simulate almost all thermal and renewable power generation systems.

\subsection{Other applications of different packages}

A review of the optimization techniques used to select HES that minimize initial and operating cost was presented by Erdinc and Uzunoglu [20]. The compared techniques were (GA), "simulated annealing" (SA),"particle swarm optimization" (PSO), and HOMER. The approach for component sizing is based on demanded load, renewable resources availability, and climatic conditions.

For a touristic resort in Malaysia, Hossaina et al. [21] suggested a stand-alone HRES that includes WT, PV, DG, converter, and battery as energy sources to replace the existing diesel generators. The estimated daily average and peak load were 13,048 and $1185 \mathrm{~kW}$, respectively. The system techno-economic was achieved using HOMER software, and the results exhibited that the hybrid system has lower NPC and COE than the existing diesel system.

In a similar study, Olatomiwa et al. [22] investigated different (PV, WT, and DG) power configurations in six "geopolitical" zones of Nigeria, also by HOMER [23]. The result denoted that the PV/DG/battery system configuration is the optimum configuration in the cases of diesel fuel price of $\$ 1.1-1.3 / 1$, exhibited lower fuel consumption, and reduced $\mathrm{CO}_{2}$ emission.

"HOMER" was also applied to investigate the possibility of providing 200 households in remote area in Ethiopia with electricity using HSES [24]. The results revealed that PV/DG/battery system is the most "cost-effective" using load following strategy. The authors concluded that this study could be considered applicable for similar climatic condition regions.

Another comparable feasibility analysis of (HRES) supplying load requirements of a rural village, of 50 families, in Bangladesh, far from the grid was performed using "HOMER package" [25]. The "annual average load" was $213 \mathrm{kWh} /$ day; the results indicated that for this location, load profile of the feasible system is also PV/WT/battery where the NPC had a total of $\$ 224,345$ and COE of $0.161 \$ / \mathrm{kWh}$ with no $\mathrm{CO}_{2}$ emission.

A fuzzy logic power controller was proposed by Alam et al. [26] to provide continuous power supply, from a hybrid WT/PV/fuel cell power system with battery, for remote area. The simulated system configuration was $20 \mathrm{~kW} \mathrm{WT,} 80 \mathrm{~kW} \mathrm{PV}$ array, and $10 \mathrm{~kW}$ fuel cell. Excess power was directed to the batteries first and then to the electrolyzer. In the case the optimum system, the results showed that power shortage had reached $254 \mathrm{kWh} /$ year, which represented a high percentage of the total load. Also the estimated cost of energy was very high (1.045 $\$ / \mathrm{kWh})$.

Ajao et al. [27] performed an economic analysis of PV/WT system for a Nigerian area. The authors concluded that the proposed system is expensive because of high capital and installation costs. The authors did not take into consideration the reduction of greenhouse gas emission which would improve the cost-effectiveness of the system.

Seeking the optimum design of economically feasible HES to feed a load which had seasonal variations, Fulzele et al. used iHOGA to simulate and optimize the system [28]. The results showed that $99 \%$ of the required load was covered by the system, subject to operational constraints and control strategies. Nevertheless, the results did not take into consideration that the excess energy was about $25 \%$ and minimizing this value would reduce the cost of energy (COE). 


\section{Energy management}

Energy management is considered as an optimization action. Energy management increases usable energy, decreases wasted energy, and has the additional benefits of optimizing energy systems and improving their reliabilities.

The electrical power generated by renewable sources such as wind and solar power is affected by environmental conditions resulting in problems in load side. When there is no sun or the weather is cloudy, the power amount to be generated by solar energy changes. Accordingly, wind does not blow at the same speed all the time; it is discontinuous. Henceforth, energy amount to be generated from these sources is variable. Energy management processes are developed to prevent problems like discontinuities that occur due to either weather changes or sudden load changes.

Different methodologies and techniques used to develop a successful energy management strategy, for both stand-alone hybrid renewable energy systems and the grid-connected hybrid renewable systems, were investigated by Olatomiwa et al. [22]. The authors focused on energy management based on "linear programming," "intelligent techniques," as well as energy management by "fuzzy logic controller." The authors emphasized that selecting the suitable energy management strategy is necessary to control the energy flow in the system that increases reliability, decreases electricity shortage, reduces the "COE," and increases the system lifetime.

In a study that investigated the performance of various possible configurations using iHOGA software, the achieved optimum configuration was further improved by adapting the daily load pattern to the periods of high renewable generated energy to increase direct energy utilization rather than charging batteries [29]. This will result in effective minimization of battery bank size.

\section{Case study in an Egyptian farm}

The study objective was to design and simulate HSES for remote area in Egypt. The study was performed using iHOGA simulation and optimization package to decide on the optimal size of each component and control strategy. The input data for the optimization are weather data of the selected location, nominated system component cost, and technical parameters. Financial parameters, interest and inflation rates, installation, and operational costs are also included. The proposed system components are $\mathrm{PV} / \mathrm{WT} /$ batteries/DG/inverter and charge regulator. The suggested load in this case study is energy required for a desalination unit (DU). The system is installed in NRC farm in Noubarya. The considered system configuration is shown in Figure 1.

$\mathrm{NRC}$ farm is in a remote area that is located between $30^{\circ} 40^{\prime} 0^{\prime \prime} \mathrm{N}$ and $30^{\circ} 4^{\prime} 0^{\prime \prime}$ $\mathrm{E}$. The average temperatures for winter and summer are about 14 and $28^{\circ} \mathrm{C}$, respectively. The farm is a research pilot plant for agriculture, animal, and fish production. Frequent electricity shortage is observed due to instability of low-voltage grid power in the area.

\subsection{Load profile (base case)}

In this case study, the HSES provides a reverse osmosis desalination unit (DU) with electricity. The required daily desalinated water is about $60-65 \mathrm{~m}^{3}$. The required power for the DU is the sum of powers required for three types of pumps included in the DU: "5 HP high-pressure pump" (3728 W), "distribution pump" $(1000 \mathrm{~W})$, and a "feed pump" (1870 W in the case of feeding rate is $7 \mathrm{~m}^{3} /$ hour). 


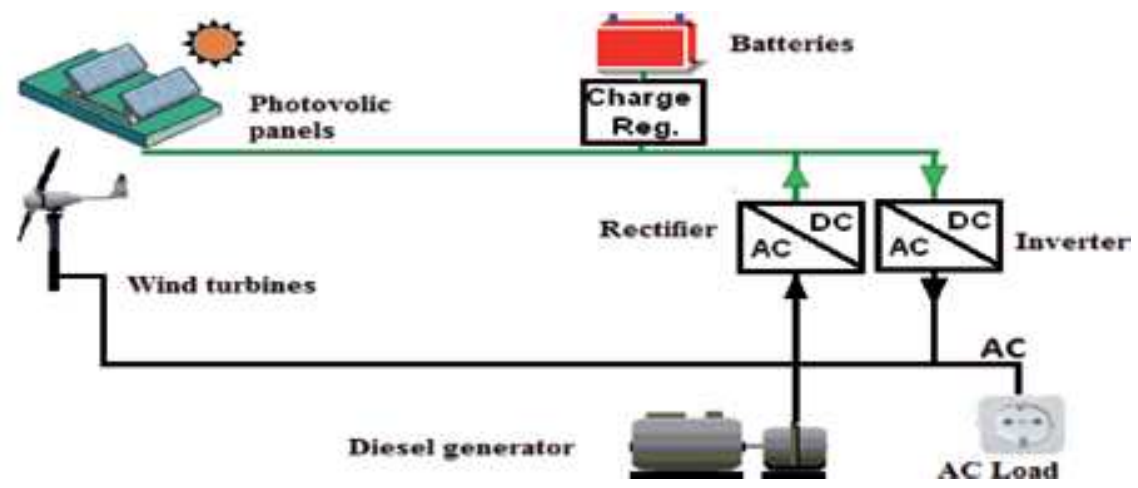

Figure 1.

The system configuration.

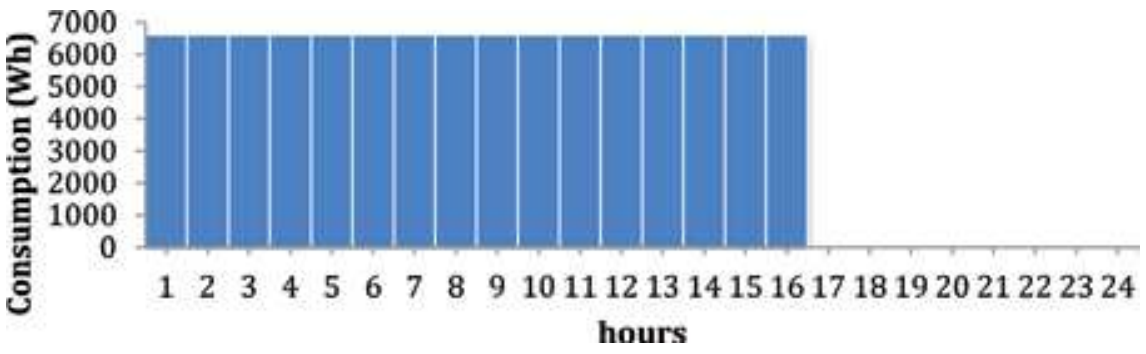

Figure 2.

DU base case load profile (base case).

To produce $60-65 \mathrm{~m}^{3} /$ day, the DU should be fed by $110 \mathrm{~m}^{3}$ of brackish water per day. The first suggested load profile in this study; referred to as base case, the high-pressure pump, the distribution pump, and feed pump are designated to work simultaneously. Hence, the peak load requirement is about $6.6 \mathrm{~kW}$ continuously from 00:00 to 16:00, and the average estimated daily energy consumption is $105.6 \mathrm{kWh}$ (Figure 2).

\subsection{Resource input data}

The input climatic data for the proposed site are obtained from NASA Surface Meteorology and Solar Energy [30]. Table 1 represents the monthly average of solar radiation and wind speed data for the selected area.

\subsection{System description}

As mentioned above, the system components are PV, WT, inverter, batteries, and DG. A number of monocrystalline and polycrystalline PV modules (in the range of 100-280 W/panel) were used in the simulation to select the suitable size. The initial panel cost is in the range of \$143-455, while O\&M cost of each panel is $1.43-4.55 \$$ /year. The panels' lifetime is considered to be 25 years. The WT types used in simulation are "Bornay" and "Hummer," both of 3-30 kW power range, and its hub height is considered to be between 15 and $18 \mathrm{~m}$. The initial cost of WT is between $\$ 9821$ and 44,200 , its replacement costs $\$ 7800-33,800$, and O\&M cost \$196-884/year. The lifetime of "Bornay" and "Hummer" are assumed to be 15 and 20 years, respectively. A backup DG is 3-4 kVA, and the battery bank is in the range of 180-3360 Ah with $80 \%$ depth of discharge used. The system also comprises an 


\begin{tabular}{lcc}
\hline Month & Solar radiation $\left(\mathbf{k W h} / \mathbf{m}^{2}\right)$ & Wind speed $(\mathbf{m} / \mathbf{s})$ \\
\hline Jan & 2.92 & 3.8 \\
\hline Feb & 3.78 & 4.1 \\
\hline Mar & 5.10 & 4.1 \\
\hline Apr & 6.40 & 3.9 \\
\hline May & 7.40 & 3.9 \\
\hline Jun & 8.13 & 3.8 \\
\hline Jul & 7.92 & 3.8 \\
\hline Aug & 7.24 & 3.8 \\
\hline Sep & 5.93 & 3.8 \\
\hline Oct & 4.38 & 3.7 \\
\hline Nov & 3.22 & 3.6 \\
\hline Dec & 2.69 & 3.8 \\
\hline Average & 5.43 & 3.8 \\
\hline
\end{tabular}

Table 1.

Noubarya solar and wind data [30].

inverter which is scaled according to the maximum peak load. The inverter type is ACME: 8000VA CARG. The above-stated values are attained from iHOGA database.

\subsection{Control strategies}

The software package used in this study is $i H O G A$, which offers two control strategies: load following and cycle charging strategy. In the first the priority is to meet the load at any given time. Hence, if the generated power from the HES is not enough to cover the whole load, the battery covers the rest of the demand. If the battery bank cannot cover the whole rest of the demand, the DG will operate.

In "cycle charging strategy," if the total (PV\&WT) generated energy is greater than the load requirements, the excess energy charges the batteries. When batteries' state of charge (SOC) reaches its maximum value, the charging process is set off, while if (PV\&WT) energy is lower than the load, the rest is covered by the battery bank. If the battery charge drops to its minimum SOC, the controller unit sets off discharging process and turns DG on to cover the unmet load. As it is well known, it is better to run the DG at its rated power to reach higher efficiency of fuel consumption; DG will serve the load and the extra power and, if any, will be used to charge the batteries to its maximum SOC.

Both of the above strategies are examined to select the optimal strategy for the given system constraints.

\subsection{Objective function}

The main target of the suggested system design is to reach the optimum solution of a HRES in terms of economic and technical conditions subject to the operational strategies and physical constraints. In this method, the possible optimum system configuration is the one that satisfies the user-defined constraints in accordance with the objective function. The objective function is to minimize NPC which consists of initial cost, replacement cost, maintenance, and running cost of system components like PV, WT, DG, batteries, converter, and etc. [10, 12, 31]. 
Objective function:

$$
N P C=\operatorname{Min} \sum T_{c}+T_{r}+T_{O \& M}
$$

where $T_{c}$ is the total capital cost of different components and $T_{r}$ is the total replacement cost and $T_{O \& M}$ is the total cost of operation and maintenance in dollars.

There are many constraints that are considered to ensure that the generated electricity would cover the load such as the minimum renewable fraction (75\%), levelized cost of energy $(5 \$ / \mathrm{kWh})$, and the maximum percentage of annual unmet load which is defined to be $5 \%$.

\section{Results and discussion of base case}

The suggested system is simulated to reach the optimum value of the selected objective function under the following constraints: minimum renewable fraction (RF) $75 \%$, levelized cost of energy $5 \$ / \mathrm{kWh}$, and the maximum percentage of annual unmet load $5 \%$. The simulated optimization results (for base case load) are shown in Figure 3.

Figure 3 exhibits the estimated optimum NPC and $\mathrm{CO}_{2}$ emission of a number of simulation runs. The optimization results of the base case showed a minimum NPC of $\$ 162,034$, COE of $0.17 \$ / \mathrm{kWh}$, and unmet required load of $1.3 \%$. HSES optimum configuration is 53 parallel series of PV panels, 4 modules each of $100 \mathrm{Wp}$ rated power, 24 batteries connected in series each of $1340 \mathrm{Ah}, 1 \mathrm{WT}$ of $14.7 \mathrm{~kW}$ at $14 \mathrm{~m} / \mathrm{s}$, $8 \mathrm{kVA}$ inverter, and $3 \mathrm{kVA}(\mathrm{AC})$ diesel generator. Figure 4 illustrates the annual distribution of energy generation.

It is observed in Figure 4 that almost all the yearly demand, except $495.8 \mathrm{kWh} /$ year, is fulfilled by the HSES generated energy, which account for less than $1.5 \%$ of total load, the $\mathrm{CO}_{2}$ emissions of $11,950 \mathrm{~kg} /$ year. It could be also observed that the energy charging batteries are 10,768 $\mathrm{kWh} /$ year, (about $21 \%$ from the total generated power), and the excess energy is $8278 \mathrm{kWh} /$ year, (about 16\%).

The total generated energy is about $50,800 \mathrm{kWh} /$ year, while the total load that is directly supplied by energy sources is $28,386 \mathrm{kWh} /$ year, so the utilization of the energy sources is about $55.9 \%$. As the efficiency of both inverter and battery charger is high, 98 and 95\%, respectively, then the main losses result from battery charging and discharging efficiency which is $85 \%$. As the charging and discharging energy amounts to 20,407 kWh/year, then energy losses are about $3000 \mathrm{kWh}$. The cost of different HSES simulated components are shown in Table 2.

It could be seen from the above table that the major cost items are PV panels and "battery bank" which represent about 23 and $22.8 \%$ of the total NPC. The high cost

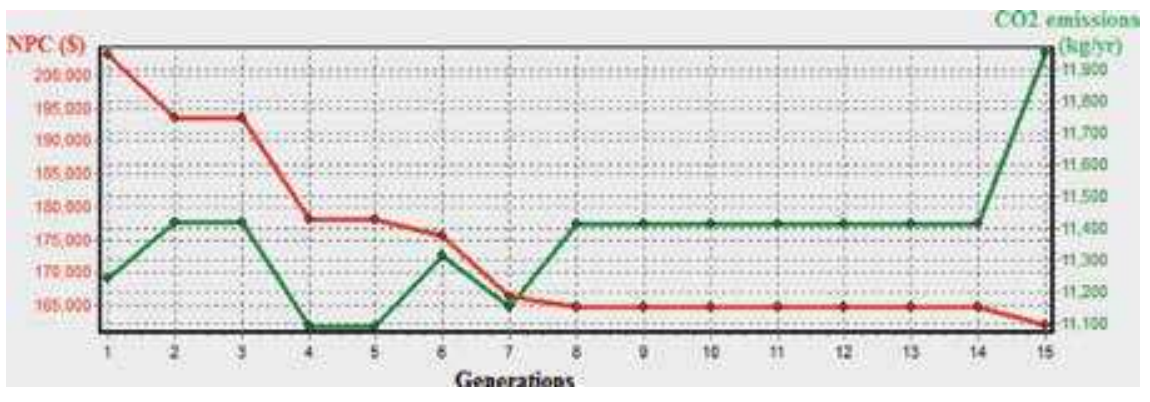

Figure 3.

Results of NPC as a function of generations. 


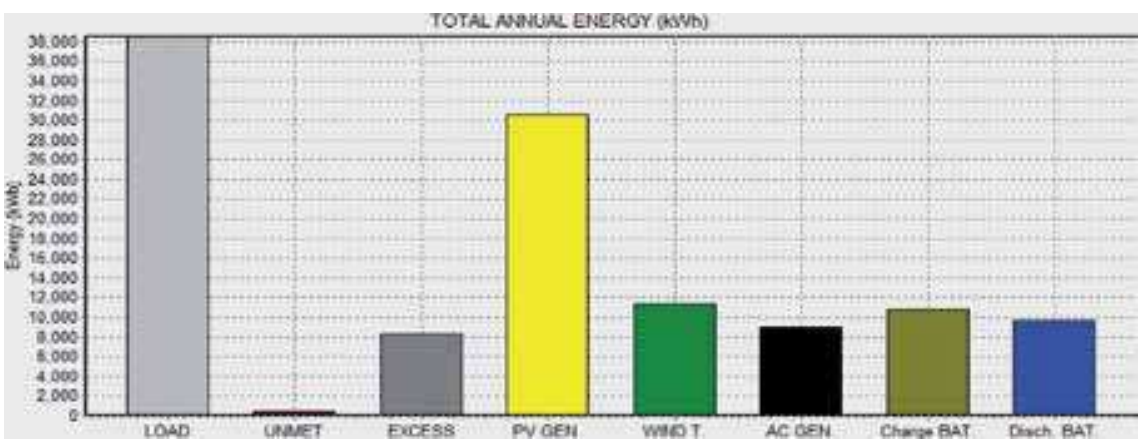

Figure 4.

Annual distribution of energy.

\begin{tabular}{lcc}
\hline Cost element & Initial cost (\$) & Percentage (\%) \\
\hline PV panel cost & 37,282 & 23 \\
\hline WT cost & 27,246 & 16.8 \\
\hline DG cost & 21,667 & 13.3 \\
\hline Battery bank cost & 36,940 & 22.8 \\
\hline Inverter cost & 10,952 & 6.7 \\
\hline DG fuel cost & 16,687 & 10.3 \\
\hline Charge reg. cost and AUX & 11,256 & 6.4 \\
\hline
\end{tabular}

Table 2.

Component costs of the optimized HSES.

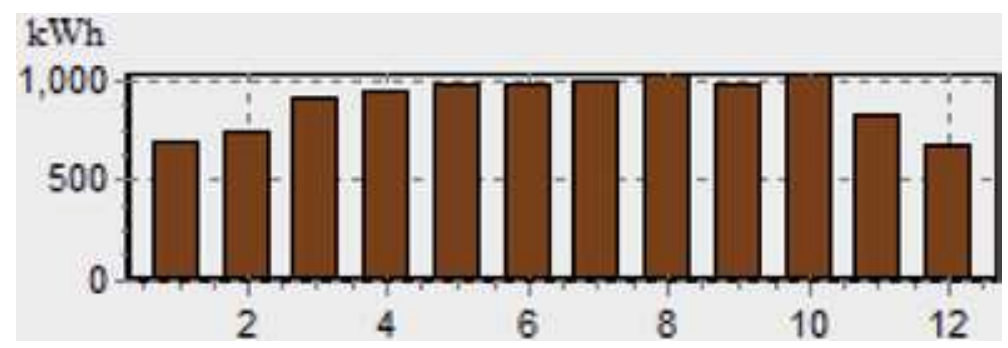

Figure 5.

Monthly average energy charging battery.

of the "battery bank" indicates that power generation profile does not match the load pattern; therefore a considerable part of generated energy has to be stored to cover the load when generated energy is not enough.

Regarding energy management, the main objective is to cover the DU load while minimizing the NPC and accordingly the cost of water desalination. From the results of the base case simulation, it is clear that, at some periods, a considerable amount of the generated energy does not match the load profile; therefore, it is directed to charge batteries. Hence, the amounts of energy charging the batteries and "excess energy" are excessive in some months as exhibited in Figures 5 and $\mathbf{6}$. Reducing these values would improve the system performance; hence, the configuration should be further adapted by means of load pattern managing. Load profile management could be achieved through matching its pattern with the power generation profiles. This would decrease the number and cost of batteries and consequently the total NPC. 


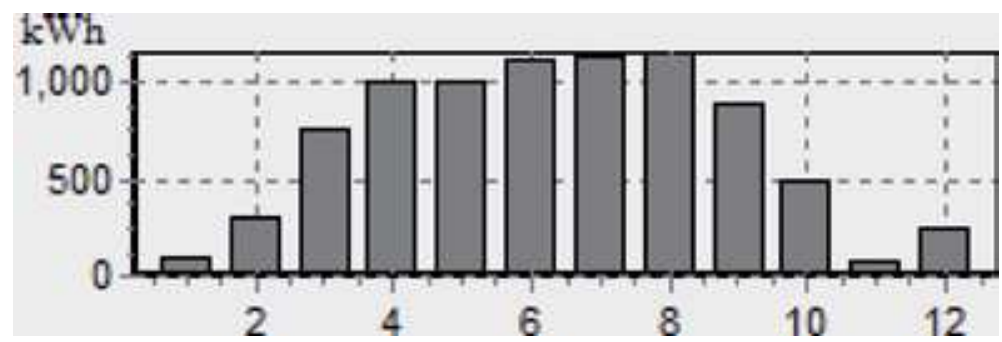

Figure 6.

Monthly average excess energy.
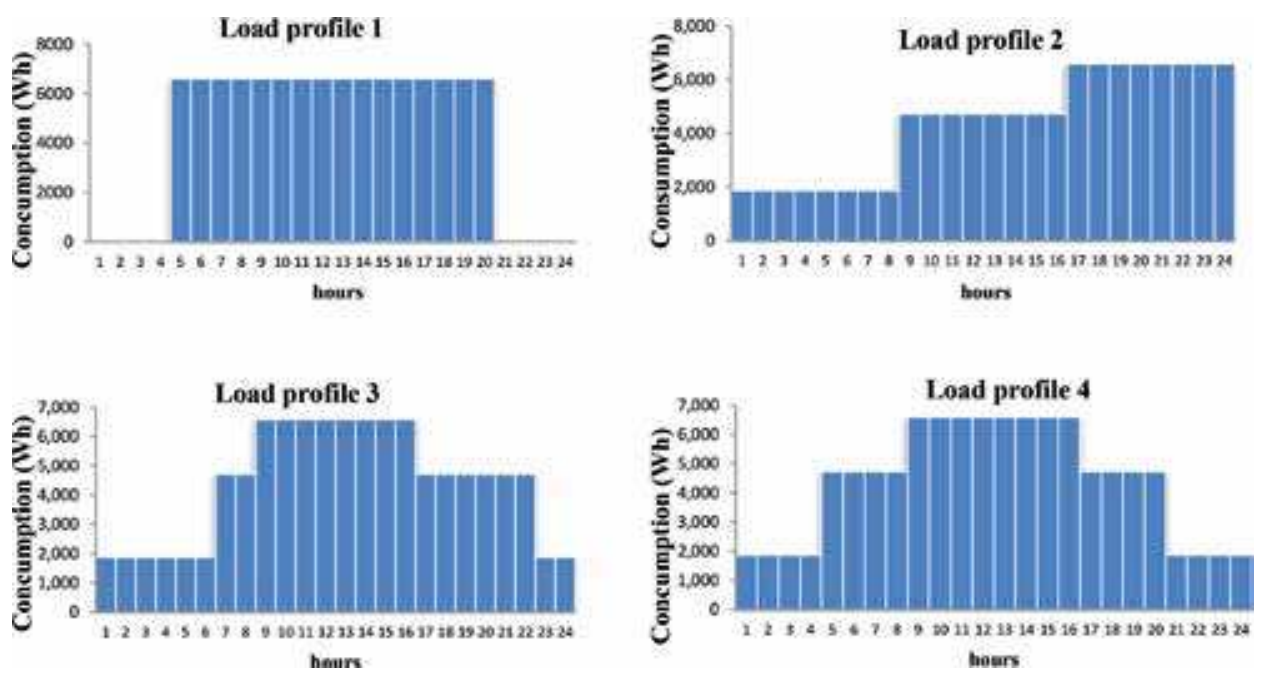

Figure 7.

Suggested load profiles.

Considering the hourly simulation results for the highest months of excess energy and energy charging battery amounts, different load patterns were proposed and simulated, of which the following four arrangements represented the most promising patterns to increase the direct utilization of the generated energy as shown in Figure 7.

As exhibited in Figure 7, the suggested load profile 1 proposed that all pumps are turned on from 05:00 to 21:00 requiring $6600 \mathrm{kWh}$. Load profile 2 schedule is based on the assumption that the "feed pump" is running from 00:00 to 08:00, while the "high-pressure" and "distribution" pumps are scheduled from 08:00 to $16: 00$. Finally all pumps work simultaneously from $16: 00$ to $24: 00$ as shown in Figure 8. This pattern is scheduled to fit high power period that is generated from the PV panel in the middle of the day and also the wind power at the night which is the period of high wind speed.

"Load profile 3" is arranged as feed pump running from 00:00 to 06:00 and from 22:00 to 24:00, while "high-pressure" and "distribution" pumps begin to work simultaneously, along with the "feed pump," from 08:00 to 16:00. The feed pump is switched off from 06:00 to 08:00 and 16:00 to 22:00, while the other two pumps remain operating. In the case of proposed "load profile 4," the feed pump schedule is running three periods: from 00:00 to 04:00, from 20:00 to 24:00, and from 04:00 to 08:00. The "high-pressure" and "distribution" pumps start working when the feed pump is switched off except from 08:00 to 16:00 when all the pumps are working simultaneously. This profile is supposed to be fitting the period of high PV and WT energy generation to increase direct energy utilization. 


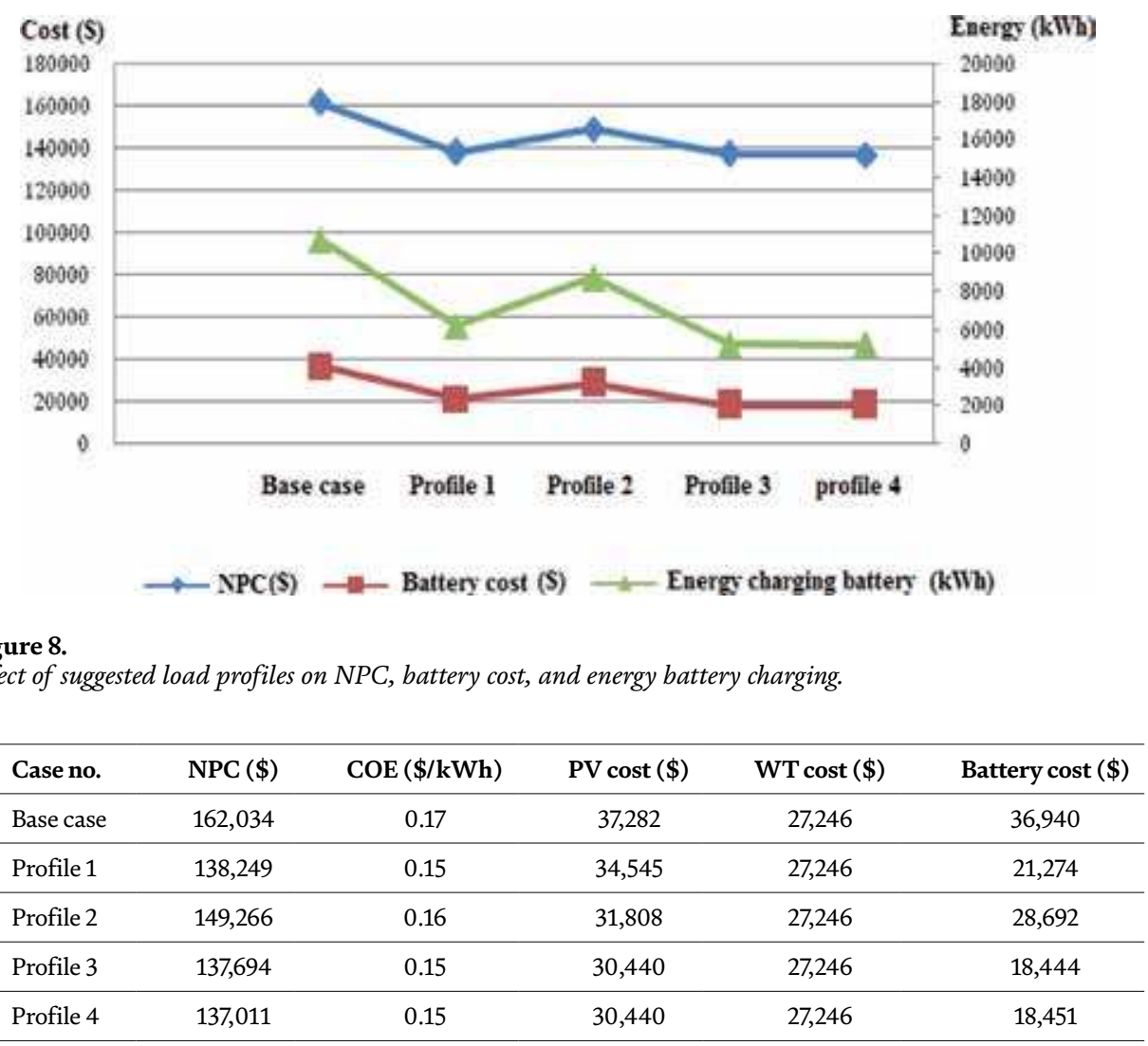

Table 3.

Cost results of the suggested load profiles (\$).

\begin{tabular}{cccc}
\hline Case no. & NPC $(\$)$ & Charge battery $(\mathbf{k W h} /$ year $)$ & Excess energy $(\mathbf{k W h} /$ year $)$ \\
\hline Base case & 162,034 & 10,768 & 8278 \\
\hline Profile 1 & 138,249 & 6231 & 6312 \\
\hline Profile 2 & 149,266 & 8768 & 4544 \\
\hline Profile 3 & 137,694 & 5294 & 3590 \\
\hline Profile 4 & 137,011 & 5241 & 3665 \\
\hline
\end{tabular}

Table 4.

Results of the suggested load profiles.

The simulated optimization results of base case and the suggested four load profiles are exhibited in Tables 3 and 4.

It is noticed from the summarized results in the above tables that load profile 4 has the lowest NPC and COE $(137,011 \$$ and $0.15 \$ / \mathrm{kWh})$ among the four suggested profiles in addition to minimum value of energy charging the batteries $(5241 \mathrm{kWh} /$ year). The suggested load profiles also demonstrate the effect of decreasing the energy charging the batteries on the NPC as illustrated in Figure 8.

It is clear from Figure 8 that the lowest battery charging energy is that of load profile 4 (5241 kWh) which is the case of lowest NPC configuration (137,011 \$). Table 5 exhibits the energy utilization, battery charging energy, and energy loss as a percentage of the total energy. It also exhibits battery cost as a percentage of the total energy system costs. 


\begin{tabular}{lcccc}
\hline Case no. & Utilization (\%) & Energy charging batteries (\%) & Energy loss (\%) & Battery cost (\%) \\
\hline Base case & 55 & 27 & 22 & 22.8 \\
\hline Profile 1 & 66 & 16 & 18 & 15.4 \\
\hline Profile 2 & 65 & 22 & 13 & 19.2 \\
\hline Profile 3 & 73 & 13 & 14 & 13.4 \\
\hline Profile 4 & 73 & 13 & 14 & 13.4 \\
\hline
\end{tabular}

Table 5 .

Load profiles' results (percentages).

The above tables showed that decreasing excess energy and energy charging batteries reduced NPC cost. Increased utilization of the location resources is achieved through fitting the peaks of demanded load with the periods of high power generation which affected energy components, reducing generation and storage components' sizes.

\section{Conclusions and recommendations}

The optimization results for HRES under study, considered as the base case, are $\mathrm{NPC}$ is $\$ 162,034, \mathrm{COE}$ is $0.17 \$ / \mathrm{kWh}$, and the unmet load (energy shortage) is $1.3 \%$ of the total required energy, while the renewable fraction is about $75 \%$. However, this optimum configuration showed high values of energy charging batteries (which means higher battery bank capacity) and excess energy which represented 21 and $16 \%$, respectively. At the same time, the total load that is directly supplied by energy sources was only $55 \%$ of total generated energy. This indicated that the load profile does not match the renewably generated energy; hence, different load scenarios were investigated. The simulation results of the best reached load pattern, referred to as "load profile 4," are as follows:

- Maximizing direct use of renewable generated energy causes reduction in system component sizes. The results showed that "load profile 4" has the lowest NPC and COE values (137,011 $\$$ and $0.15 \$ / \mathrm{kWh})$ and minimum energy charging batteries ( $5241 \mathrm{kWh} /$ year), which suggests that NPC and COE are directly proportional to energy charging battery.

- Managing load pattern to reach the best fitted profile has decreased NPC by $15.4 \%$, charging energy battery by $51.3 \%$, the cost of batteries by $50 \%$, COE by $11.7 \%$, and the excess energy by $55.7 \%$, while the utilization of the energy sources is increased by $18 \%$, compared to the base case configuration.

In short, "load profile 4" caused significant improvement on the following parameters:

- NPC has decreased by $15.4 \%$.

- Battery charging energy has decreased by $51.3 \%$.

- The cost of batteries has decreased by $50 \%$.

- The cost of energy has decreased by $11.7 \%$.

- The excess energy has decreased by $55.7 \%$. 
- The utilization of the energy sources is increased by $18 \%$.

Taking environmental impacts of $\mathrm{CO}_{2}$ into consideration will further decrease the cost of system generated energy.

\section{Author details}

Mervat Abd El Sattar Badr

Professor, National Research Centre (NRC), Egypt

*Address all correspondence to: dr_mabadr@yahoo.com

\section{IntechOpen}

(C) 2020 The Author(s). Licensee IntechOpen. Distributed under the terms of the Creative Commons Attribution - NonCommercial 4.0 License (https://creativecommons.org/ licenses/by-nc/4.0/), which permits use, distribution and reproduction for non-commercial purposes, provided the original is properly cited. (cc) BY-NC 


\section{References}

[1] Patel MR. Wind and Solar Power Systems. CRC Press LLC; 1999. ISBN: 0-8493-1605-7. Available from: www. crcpress.com

[2] Badr MA, ElKordy MN, Mohib AN, Ibrahim MM. Cost analysis of hybrid wind energy generating system considering $\mathrm{CO}_{2}$ emissions. International Journal of Environmental, Chemical, Ecological, Geological and Geophysical Engineering. 2016;10(5)

[3] Linear-Programming Applications. Daniel Mackie/Stone; 1989. Web Chapter B. Available from: http://www. swlearning.com/economics/mcguigan/ mcguigan9e/web_chapter_b.pdf

[4] Antoniou A, Lu W-S. Practical Optimization: Algorithms and Engineering Applications. Springer; 2012

[5] Waqas S. Development of an optimization algorithm for auto sizing capacity of renewable and low carbon energy systems [MSc]. Department of Mechanical Engineering, University of Strathclyde Engineering; 2011

[6] Connolly D. A review of computer tools for analyzing the integration of renewable energy into various energy systems. Applied Energy. 2010;87:1059-1082

[7] Dufo-López R. User Manual of iHOGA. 2016. Available from: www. unizar.es/manual delusuario

[8] Dufo-López R, Pérez-Cebollada E, Bernal-Agustín JL, Martínez-Ruiz I. Optimization of energy supply at offgrid healthcare facilities using Monte Carlo simulation. Energy Conversion and Management. 2016;113:321-330

[9] Fadaeenejad M, Radzi MAM, AbKadir MZA, Hizam H. Assessment of hybrid renewable power sources for rural electrification in Malaysia.
Renewable and Sustainable Energy Reviews. 2014;30:299-305

[10] Gudelj A, Krčum M. Simulation and optimization of independent renewable energy hybrid system. Transactions on Maritime Science. 2013;1:28-35

[11] Dursun B et al. Technoeconomic evaluation of a hybrid $\mathrm{PV}$-wind power generation system. International Journal of Green Energy. 2013;10:117-136

[12] Rahman M, Khan MM-U-H, Ullah MA, Zhang X, Kumar A. A hybrid renewable energy system for a North American off-grid community. Energy. 97:151-160

[13] Ngan MS, Tan CW. Assessment of economic viability for PV/wind/ diesel hybrid energy system in southern peninsular Malaysia. Renewable and Sustainable Energy Reviews. 2012;16:634-647

[14] Badr MA, Mohib AN, Ibrahim MM. Small wind turbine hybrid system for remote application: Egyptian case study. International Journal of Mechanical, Aerospace, Industrial and Mechatronics Engineering. 2014;8(9)

[15] Khattab NM, Badr MA, Maalawi KY, El Shenawy ET, El Ghetany HH, Ibrahim MM. Hybrid renewable energy system for water desalination: A case study for small green house hydroponic cultivation in Egypt. ARPN Journal of Engineering and Applied Sciences. 2016;11(21)

[16] Thevenard D, Leng G, Martel S. The RETScreen model for assessing potential PV projects. In: Conference Record of the Twenty-Eighth IEEE Photovoltaic Specialists Conference 2000; AK: IEEE. 2000. pp. 1626-1629 
[17] Harder E, Gibson JMD. The costs and benefits of large-scale solar photovoltaic power production in Abu Dhabi, United Arab Emirates. Renewable Energy. 2011;36:789-796

[18] Green HJ, Manwell JF. HYBRID2: A Versatile Model of the Performance of Hybrid Power Systems. USA: National Renewable Energy Laboratory; 1995. pp. 1-12

[19] Beckman WA et al. TRNSYS: The most complete solar energy system modeling and simulation software. Renewable Energy. 1994;5(1):486-488

[20] Erdinc O, Uzunoglu M. Optimum design of hybrid renewable energy systems: Overview of different approaches. Renewable and Sustainable Energy Reviews. 2012;16:1412-1425

[21] Hossaina M, Mekhilefa S, Olatomiwa L. Performance evaluation of a stand-alone PV-wind-dieselbattery hybrid system feasible for a large resort center in South China Sea, Malaysia. Sustainable Cities and Society. 2017;28:358-366

[22] Olatomiwa L, Mekhilef S, Ismail MS, Moghavvemi M. Energy management strategies in hybrid renewable energy systems: A review. Renewable and Sustainable Energy Reviews. 2016;62:821-835

[23] Fouad MA, Badr MA, Ibrahim MM. Economic evaluation of micro-grid system (on/off grid): Egyptian case study. International Journal of Scientific and Engineering Research. 2017;8(2):17-24

[24] Bekele G. Feasibility study for a standalone solar-wind-based hybrid energy system for application in Ethiopia. Applied Energy. 2010;87:487-495

[25] Das HS, Dey A, Wei TC, Yatim AHM. Feasibility analysis of standalone PV/wind/battery hybrid energy system for rural Bangladesh. International Journal of Renewable Energy Research. 2016;6:402-412

[26] Alam MS, Gao DW. Modeling and analysis of wind/PV/fuel cell hybrid power system in HOMER. In: Second IEEE Conference on Industrial Electronics and Applications. 2007. pp. 1594-1599

[27] Ajao KR, Oladosu OA, Popoola OT. Using HOMER power optimization software for cost benefit analysis of hybrid-solar power generation relative to utility cost in Nigeria. International Journal of Research and Reviews in Applied Sciences. 2011;7:96-102

[28] FulzeleJB, DaigavaneMB. Simulation and optimization of hybrid PV-wind renewable energy system. In: 3rd International Conference on Electrical, Electronics, Engineering Trends, Communication, Optimization and Sciences (EEECOS). 2016. pp. 159-164

[29] Tawfik TM, Badr MA, El-Kady EY, Abdellatif OE. Optimization and energy management of hybrid standalone energy system: A case study. Renewable Energy Focus. 2018;25:48-56

[30] NASA Surface meteorology and Solar Energy: RETScreen Data. Available from: https://eosweb.larc. nasa.gov/cgi-bin/sse/retscreen.cgi?emai $1=$ \&step $=1 \&$ lat $=30.6667 \&$ lon $=30.0667$ \&submit=Submit

[31] Yazdanpanah M-A. Modeling and sizing optimization of hybrid photovoltaic/wind power generation system. Journal of Industrial Engineering International. 2014:10-49 


\title{
Chapter 8
}

\section{Optimization of Stand-Alone Hybrid Solar-Wind System by Using General Morphological Analysis}

\author{
Mariola Jureczko
}

\begin{abstract}
At the beginning of this chapter is a brief introduction to the issue of renewable energy sources. Next, aspects that should be considered when choosing a location of both solar photovoltaics panels and wind turbines are discussed. Afterwards, there is a brief theoretical introduction to the General Morphological Analysis (GMA), followed by practical application of GMA to optimize the structure of hybrid solar-wind system, which is preceded by a description of the adopted design assumptions. At the end of the chapter is a numerical model of a hybrid solar-wind system developed in the MATLAB/Simulink environment and analysis of the results of numerical simulations.
\end{abstract}

Keywords: wind turbine (WT), solar photovoltaic (PV) module, hybrid renewable energy system, global horizontal irradiance (GHI), direct normal irradiance (DNI), general morphological analysis (GMA), cross-consistency assessment (CCA)

\section{Introduction}

Over the past few years, renewable energy sources have been on everyone's lips-especially those who are a little closer to the topic of energy sources. There's no wonder in this, because sooner-thanks to legislation of the developed countries-or later, through the total exhaustion of conventional sources of energy, renewable sources of energy will play a major role in energetics. In addition, continuous expansive use of nonrenewable energy sources by man causes global climate change and increases pollution of the Earth's atmosphere. The use of renewable energy sources by installing micro-installations by individual customers (single-family houses, small farms, small companies) is one of the ways to reduce the effects of excessive exploitation of fossil deposits. However, micro-installations using renewable energy sources due to their specificity, e.g., dependence on the time of day and year, and weather or geographical location, cannot be the main source of energy in the current state development of technology. In many cases they must be supported by traditional energy sources (gas, oil, or coal). An alternative idea is to use more efficient hybrid solutions, i.e., based on at least two renewable energy sources. Solar-wind micro-installation is the most common hybrid system in non-conventional power plants. This is because these two renewable energy sources complement each other perfectly. 


\section{Criteria for choosing a location for hybrid solar-wind system}

\subsection{Criteria for choosing a location for wind turbine}

In selecting the location for wind turbine, it is necessary to consider a lot of criteria. The most important of them is wind condition analysis. The wind characteristics of the certain area can be determined by carrying out at least 12-month measurements at a height of $40-50 \mathrm{~m}$. This allows to calculate the average annual wind speed and determines its dominant directions. This data is necessary to estimate the profitability of investment. To reduce investment costs, you can use data from local meteorological station (e.g., see [1]) or Global Atlas for Renewable Energy from [2] or [3].

Another factor which must be considered is the distance between wind turbine and residential building. In order to reduce the so-called turbulences, it is important to consider the shape of the area and to identify all obstacles such as trees or houses. It can be assumed that within the approximate radius of 20 times heights of obstacle, in this case height of wind turbine, the wind can be turbulent, thus lowering operating efficiency. Additionally, wind turbine cannot exceed the permissible noise standards. According to the analysis of the principles contained in $[4,5]$ adopted in 24 countries, German lands and Canadian provinces [6], it follows that minimal distance between buildings and wind turbines is in the range from 500 up to $1000 \mathrm{~m}$. The most rigorous criterion is in Scotland, where this distance is $2000 \mathrm{~m}$. Maximum noise level of wind turbine in residential places (measured outside of this buildings) in most countries ranges from 30 up to $50 \mathrm{~dB}$. Wind turbine works silently, so resultant noise is related to rotation of the blades and control devices. Wind turbine should be also placed away from human settlements to mass or construction dimensions and its flickering [7]. Shadow length depends on the height of wind turbine and the angle of sunlight. Additional factors that affect the intensity of flickering are, inter alia, rotor diameter, cloudiness, the presence of trees between wind turbine and living buildings, and the arrangement of windows in buildings $[8,9]$.

Environmental factors also play an important role; therefore decisions on investment and location conditions should be obtained. For Poland, these guidelines are contained in [10]. Wind turbine placement on legally protected areas, such as national parks, nature reserves, landscape parks, and area of "Natura 2000," is strictly limited [11]. Placement of wind turbine on the area of national parks and nature reserves according to the law is prohibited. Localization of wind turbine in less restricted areas such as landscape parks is possible when the project gets a positive opinion of the park's director and positive environmental impact assessment. The wind turbine location in the area of "Natura 2000" is possible only with a positive environmental impact assessment and a natural compensation condition. It should be taken into account that a wind turbine project in a valuable place due to flora and fauna resources may be rejected by local authorities at the stage of making environmental decisions [10-12].

Due to the high cost of constructing the wind turbine, many economic aspects should be taken into account. In choosing a location for the wind turbine, the price of land, road infrastructure, distance from power grid, and possibility of connecting to it should be considered. Wind turbine requires connection to the power grid for start-up and further operation; therefore, the project must take this into account. Single wind turbines may be connected to a medium voltage line through the transformers mounted directly on power poles, while big wind farms require the use of Main Supply Point (GPZ-MSP) that converts produced energy into higher voltage level to bring it to the high voltage transmission network. 
GPZ-MSP should be localized near wind farm due to capital-intensive and timeconsuming preparation of energy connection. Additionally, wind turbines should not be built in areas exposed to mining damage, with high seismic activity, or in areas at risk of eruptive river. Except localization, economic criteria should take into account cost of investment itself, where the biggest expense is cost of the wind turbines. Other expenses that will take place are the cost of design and preparatory works, cost of road infrastructure, cost of the earthworks, and cost of connection to several utilities. Also, there are also some operating costs during wind turbine normal operation. There are taxes, insurance payments, technical service, environmental fees (they appear to be sometimes very high), and possibly some other depending on location and other aspects.

When choosing a location, social conditions should be taken into account. It must be estimated how much wind turbine construction may improve or worsen the comfort of life for residents of nearby towns and villages. Before starting a project, consultations should be carried out with local authorities, to recognize city development plan and provide information about the scale of the investment and social, economic, and environmental consequences. Local authorities usually accept investments in wind turbines, because they see the chance to increase budget income from local taxes. At the same time local communities are afraid of the influence of such wind turbines on their health and surrounding landscape. Therefore, during the preparation and construction of wind turbine, educational activities should be carried out to provide relevant information about project wind energy among the public [12].

\subsection{Criteria for choosing a location for solar system}

When calculating revenues from investments in solar energy, the first parameter to consider is latitude. Let us suppose that the Earth is round (a sphere). This causes the rays from the sun to hit the Earth's surface at different angles, ranging from $0^{\circ}$ (when the sun is above the horizon) to $90^{\circ}$ (when the sun is perpendicular to the Earth). The angle of incidence of sunlight depends on geographic location, the time of year, and the time of day. The power of the rays from the sun describes such quantities as solar radiation, Global Horizontal Irradiance, Direct Normal Irradiance, Diffuse Horizontal Irradiance (DIF), and insolation. Solar radiation, often called the solar resource, is a general term for energy emitted from the sun in the form of electromagnetic waves. There is also defined GHI which is the ratio of the total amount of shortwave radiation falling horizontally on ground from outer space. This is the value that best describes the parameters for solar installations and includes both DNI and DIF parameters. Most energy radiated from the sun hits the Earth's surface when the sun is perpendicular to it. The smaller the angle, the more the rays from sun dissipate, providing less energy. Therefore, the amount of energy acquired from the Sun is usually determined by DNI parameter, which means the amount of solar radiation received per unit area by a given surface measured on a flat plane perpendicular (or normal) to the rays from the sun. This is one of the most important parameters that should be considered in order to maximize the efficiency of photovoltaic panels. The DHI means a quantity of energy received per area unit by a surface (which is not subjected to any shade) that does not arrive in a direct path from the sun but is scattered by molecules and particles in the atmosphere and comes potentially from all directions [13-15].

According to [16], uncertainty reduction related to the insolation in each area directly implies increasing the predictability of energy production capabilities. Insolation measures the solar energy and is the resultant on a specified area over a period of time and is expressed in two ways. The first one is watt-hours per square 
meter $\left(\mathrm{Wh} / \mathrm{m}^{2}\right)$ measured per day which represents the average amount of energy hitting the area each day. The second way represents the average amount of power hitting the area over the entire year and is expressed in watts per square meter $\left(\mathrm{W} / \mathrm{m}^{2}\right)[13,14]$.

When defining solar photovoltaic module for project there are needed data that describes insolation. To know the values for each region, the required and proper surface area of solar panels can be calculated. In order to acquire reliable and objective values that describe solar efficiency, their measurements should be carried out for a period of 5 years and take the mean value from this period to compute solar effectiveness. This long period for observations is caused by the varied weather conditions that may occur during these years, where the number of sunny and cloudless days changes. Those values may also be obtained from solar resource map (C) 2019 Solargis [17]. It is very important to remember about uneven distribution of sunlight that results from meteorological (number of sunny days) and geographical (variable day length) conditions. In winter sunlight may be up to seven times weaker than in summer. In Poland between May and July, the Sun allows to produce near $200 \mathrm{kWh} / \mathrm{m}^{2}$, but in winter-between December and January-it is no more than $32 \mathrm{kWh} / \mathrm{m}^{2}$; solar energy resources in Poland are characterized by high variability throughout the year. Up to $77 \%$ of the year's solar energy is available in 6 months of spring-summer period (April-September).

Apart from the sunshine conditions discussed above during solar panel selection, there are more conditions that have to be taken into account such as air pollution and precipitation. Temperature, air pollution, and dirt factors of PV module reduce the conversion efficiency of the solar plant equipment. Oberlander in his BSc thesis [18] showed that dirty PV cells in damp climates cause significant losses of output power. He showed that there is a 9\% loss greater in PV module efficiency from $12 \mathrm{~g} / \mathrm{m}^{2}$ polluted area than previously reported efficiency losses in other literature. Experimental researches presented in [19] showed that dirt settling from construction pollutants (plaster, cement, and borax) in the form of layer of weight of $10 \mathrm{~g}$ reduces performance of the PV panels by over $25.8 \%$. Xiaoyuan et al. showed in their work [20] that aerosol pollution in China reduces the production on optimally tilted fixed PV panels by up to $1.5 \mathrm{kWh} / \mathrm{m}^{2}$ per day, incurring a high percentage decrease (25-35\%) in polluted northern and eastern China. Etim et al. in [21] showed also that solar energy decreases as relative humidity and high rainfall increase.

Additionally, a factor that has an impact on investment in solar energy decisions is refunding. As part of EU policy, companies can receive funding for renewable energy sources. In Poland the National Fund for Environmental Protection and Water Management offers loans and subsidies and other forms of refunds for local governments, public organizations, and social organizations as well as for individuals.

\section{Theoretical and methodological foundations of GMA}

Nowadays, more and more engineering problems are related to innovation and optimization of production processes, and analytical methods used so far do not provide ready algorithms for their solution. Here we are talking about creative problems, in which when solving, synthesis is more important than analysis, intuition than logical thinking, and subconsciousness than consciousness. The answer to demand formulated this way was the development of creative-thinking methods that support best or optimal result search. Optimization methods are used when the solution concept is known for mechanical device or service. On the other hand, 
during search of solution for innovative solutions and original idea, where the main role plays unlimited human ingenuity, creative solving methods are used, called also inventive methods. GMA is one of inventive methods. According to method's creator Zwicky, morphological analysis is the method for identifying, indexing, and investigating the total set of relationships or "configurations" contained in multidimensional, non-quantifiable complex problem [22-25]. GMA is often called the method of producing inventions, because the way of processing according to its principles forces ordering temporary and potential solution proposals at the beginning and next joining them into new potential solution proposals. This method allows or even imposes joining new value of two or more proposals, solutions, and conceptions although on the beginning it seems to be absurd or even impossible. The basic rules of methodical conduct according to are described below GMA.

Precisely identifying and defining parameters (or dimensions) of the complex problem are the starting point of GMA application. Identified parameters (or dimensions) are called fundamental variables. These variables represent the considered meta-model research in the initial problem space called the morphosphere. Please note that a morphological model contains only discrete variables, even if variable in morphosphere looks like a continuous variable (e.g., product mass or construction dimensions); it is treated as discrete and evaluated in this way. Next, for each parameter (fundamental variable), should be define the set of value. These values represent possible, appropriate states or conditions that each parameter can adopt. In this way, a set of ideas is developed, which can be separate solutions or cases. Then for each of these variables, a range of relevant values or conditions is assigned. In the next step, a multidimensional matrix is being created called a morphological box or “Zwicky's box." The morphological box is created by setting all considered variables together with their features, values, states, etc. Each cell of the morphological box contains one particular "value" or condition from each of the fundamental variables. Internally it is a typological field containing all the possible involved relationships. A graphic interpretation of the typological field is a physical space assuming that it does not exceed three variables. When there are more variables, graphical interpretation becomes hyperspace. In such cases its creation is omitted by combining variables within each other [22-26].

In the next step, the formal configurations or potential morphotypes are determined, i.e., all combinations between individual ideas for all parameters. Every element of the formal configurations becomes a potential solution, so it requires further analysis. By the term morphological analysis, we mean searching for a subset $r$-connections in a given formal configuration. All $r$-connections or part of them may be chosen using morphological research: by systematic enumeration, by limited enumeration, by randomization, by random walk method, and by similarity methods or sequentially.

Depending on the enumeration method, $r$-connection different varieties of morphological method can be obtained in result. In morphological method searching for creative solutions takes place in a specific cycle (Table 1).

The first stage of morphological analysis involves recognizing the problem and proceeds in two phases. First phase involves setting boundaries of problem. The main purpose of this phase is to define the full shape of a given problem. The natural tendency to narrow the problem should be overcome, but on the other hand, it is necessary to define boundary points, which further help to define problem precisely and to realize the second phase of this stage.

Further in the second phase, the range of these variables is determined. Therefore, ideas are sought to implement fragment of the problem, as if it did not exist as a whole. This assumption has a significant impact on the number and quality of ideas, because during searching for a solution of a problem, we are not limited by the requirements 


\begin{tabular}{lll}
\hline Stages & Phases & $\begin{array}{l}\text { The most commonly used } \\
\text { supportive methods }\end{array}$ \\
\hline $\begin{array}{l}\text { Recognition of the } \\
\text { problem }\end{array}$ & $\begin{array}{l}\text { - Determining the limits of the problem } \\
\text { - Defining the problem }\end{array}$ & Teratological method \\
\hline $\begin{array}{l}\text { Analysis of the } \\
\text { problem }\end{array}$ & - Identification of problem parameters & $\begin{array}{l}\text { Brainstorm } \\
\text { Synectic techniques }\end{array}$ \\
\hline Problem synthesis & $\begin{array}{l}\text { - Search for possible parameter states } \\
\text { or morphological field }\end{array}$ & $\begin{array}{l}\text { Monte Carlo method } \\
\text { Moles' discovery matrix }\end{array}$ \\
& - Reduction of morphospace & \\
\hline
\end{tabular}

Table 1.

Procedure of GMA.

and conditions forced by the whole problem. In this way it is easier to break away from existing solutions and the same way to prepare new ground for new proposals.

Third stage, depending on the number of variables, begins with construction of morphological box or morphological field. Each coordinate of morphological box represents certain parameter or states. "Coordinate measure" represents the next idea. By multiplying the "measures," a morphological product is obtained. In this way a very rich set of potential solutions that include original solutions arises. Thanks to methodical requirements, it can be combined into new value ideas which previously appears impossible to aggregate. Normative elements are introduced after creating the morphological product. At this stage a lot of solution variants are developed. Some of them are solutions known to public, simple, and used for a long time, and therefore they are rejected. Some others are rejected because of contradictions or senselessness. However, there are a lot of combinations that give many features to new and innovative solutions.

Finding new solutions requires reducing the size of the morphological box or morphological field. Various selection techniques are used for this purpose, but in sequential study, the discovery matrix is appropriate, a tool proposed by Moles [27, 28]. In the morphospace any pair of parameters is selected-fundamental variables-and their ranges are listed in two-dimensional matrixes. The next step is to compare these pair of parameters. It is assessed whether-or to what extent-a given pair of parameters can coexist, i.e. represent a coherent relationship. If not-pair of parameters is eliminated from further analysis. In this way, only pairs of parameters that are not logically contradictory or empirically limited are subject to further analysis. Selected morphological products are then paired with the next parameter-variable-in order to get new discovery matrix, and new morphological products from this matrix are treated the same way as in the initial matrix. As a result, the morphological space is reduced from many to several solutions, but which of them becomes basis to specific projects is determined by criteria defined in problem definition phase.

The synthesis and evaluation of ideas are carried out repeatedly, until the researchers are convinced that all the possibilities of obtaining a new idea are exhausted. The work ends with the development of several reasonable proposals, from which the best ones are selected. It is usually recommended to develop at least five proposals and then choose the best optimal solution from them.

\section{Application of GMA for optimization of hybrid solar-wind system}

The purpose of the morphological analysis was to optimally select the components of an ecological energy source. The following problem parameters were considered: 
Optimization of Stand-Alone Hybrid Solar-Wind System by Using General Morphological... DOI: http://dx.doi.org/10.5772/intechopen.90284

\begin{tabular}{lccccccc}
\hline P1 & P2 & P3 & P4 & P5 & P6 & P7 & P8 \\
\hline P1.1 & P2.1 & P3.1 & P4.1 & P5.1 & P6.1 & P7.1 & P8.1 \\
\hline P1.2 & P2.2 & P3.2 & P4.2 & P5.2 & P6.2 & P7.2 & P8.2 \\
\hline P1.3 & P2.3 & P3.3 & & P5.3 & P6.3 & P7.3 & P8.3 \\
\hline & P2.4 & P3.4 & P5.4 & P6.4 & P7.4 & P8.4 \\
\hline & P2.5 & & P5.5 & P6.5 & & \\
\hline
\end{tabular}

Table 2.

Segment of morphological field_One is shown.

type of energy used (P1), photovoltaic cell type (P2), place of installation of PV panels (P3), wind turbine assembly location (P4), type of wind turbine (P5), number of turbine blades (P6), wind turbine blade material (P7), and type of battery (P8). Then, for each parameter, its states, attributes, or values were specified. In this way, an 8-parameter field in morphological format was developed. This field contains 8 parameters and 69,120 possible (formal) configurations, one of which is shown in Table 2.

Considering the design assumptions, the following attributes and values of individual parameters were considered:

- For P1: wind energy (P1.1), solar energy (P1.2), and wind and solar energy simultaneously (P1.3)

- For P2: monocrystalline cells (P2.1), polycrystalline cells (P2.2), amorphous silicon cells (P2.3), CIGS cells (P2.4), CdTe cells (P2.5), and dye-sensitized solar cells (P2.6)

- For P3: ground surface (P3.1), vertical wall of the building (P3.2), slanting roof of the building (P3.3), and flat roof of the building (P3.4);

- For P4: vertical (P4.1) and horizontal wind turbine (P4.2)

- For P5: one-blade turbine (P5.1), two-blade turbine (P5.2), three-blade turbine (P5.3), three-blade turbine with diffuser (P5.4), four-blade turbine (P5.5), and multi-blade turbine (P5.6)

- For P6: carbon fiber (P6.1), glass fiber (P6.2), aluminum (P6.3), wood-reinforced epoxy resin (P6.4), and steel (P6.5)

- For P7: ground surface (P7.1), vertical wall of the building (P7.2), slanting roof of the building (P7.3), and flat roof of the building (P7.4)

- For P8: classic acid (P8.1), gel (P8.2), absorbed glass mat (P8.3), and lithium ion (P8.4)

The next step in the analysis-synthesis process was the reduction of morphological field. This was done in cross-consistency assessment process [25]. For this purpose, all of the parameter values in the morphological field were compared with all others, in the form of a discovery matrix. The first discovery matrix compares the first two parameters (Table 3).

Due to, that system which bases only on one renewable energy source is completely dependent on unpredictable weather factors, this approach was rejected. 


\begin{tabular}{llll}
\hline & P1.1 & P1.2 & P1.3 \\
\hline P2.1. & $\mathrm{x}$ & $\mathrm{x}$ & $\mathrm{x}$ \\
\hline P2.2. & $\mathrm{x}$ & $\mathrm{x}$ & $\mathrm{x}$ \\
\hline $\mathrm{P} 2.3$. & $\mathrm{x}$ & $\mathrm{x}$ & \\
\hline P2.4. & $\mathrm{x}$ & $\mathrm{x}$ & $\mathrm{x}$ \\
\hline $\mathrm{P} 2.5$. & $\mathrm{x}$ & $\mathrm{x}$ & $\mathrm{x}$ \\
\hline $\mathrm{P} 2.6$. & $\mathrm{x}$ & $\mathrm{x}$ & \\
\hline
\end{tabular}

Table 3.

The first discovery matrix.

Solutions based on one renewable energy source make continuous production of electrical energy impossible. There is naturally inverse correlation between solar and wind energy generation. During long sunny days, insolation is high and wind speed is usually low, whereas during shorter days, during winter, wind speeds are high and insolation is low. As mentioned earlier, differences in weather conditions are also visible between day and night as well as between the seasons. Therefore, in areas with seasonal climate, hybrid solution should be the best, because neither photovoltaic panels nor wind turbines can meet the daily demand on electricity. Therefore, in the first discovery matrix, only hybrid solutions were approved. Next, the basic electron device used to change solar energy into electricity using the photovoltaic effect was considered. Depending on the material used and its structure, several types of solar cells can be distinguished. Between all solar cells of the first generation, best efficiency (18-22\%) is achieved by monocrystalline cells. However, cells of this type are quite expensive, so the ratio of costs incurred to better performance is economically inefficient. Therefore, solutions that use this type of solar cells are rejected. Nowadays, in Poland polycrystalline panels are most often used. These cells have lower efficiency than the previous (14-18\%) and lower price for modules. However, they are less energy-intensive in production in comparison to monocrystalline cells, and both types have a lifetime of 25 year. In addition, in latitude where Poland is located, there are different sunlight conditions. Polycrystalline cells during operation apart from direct sunlight capture much more reflected and refracted sunlight than monocrystalline cells. Polycrystalline panels work stably throughout the year. In addition, the price-performance ratio is more favorable for them. For this reason, they were accepted. The next stages describing P2 are three cells of the second generation: amorphous silicon, CIGS, and CdTe cells. A characteristic feature of these cells is a very small thickness of semiconductor layer that absorbs light. These cells are cheaper in production than cells of first generation, and production process is more automated. Such solar cells can be produced by a method similar to printing, which is very efficient and does not require large amounts of energy. They are interesting alternative to photovoltaic development. However, the performance of these solar cells is lower than that of the first-generation cells and is, respectively, for amorphous silicon, 6-10\%; CIGS, 12-15\%, and CdTe, 10-12\%. Amorphous cells and CdTe cells due to its lowest efficiency were rejected, while CIGS cells were accepted. The last taken into account type of solar cells are cells of third generation, dye-sensitized solar cells. They are characterized by simple construction, the lowest price, and very low efficiency. In the future, these cells are expected to be more efficient because their work will take place in a wide spectrum of radiation, so that energy production will occur even in areas that are not exposed to sunlight. It seems that in the future it will be an ideal solution in Poland. But at present, cells 


\begin{tabular}{lll} 
& P1.3.P2.2 & P1.3.P2.4 \\
\hline P3.1. & $\mathrm{x}$ & $\mathrm{x}$ \\
\hline P3.2. & & \\
\hline P3.3. & & \\
\hline P3.4. & $\mathrm{x}$ & $\mathrm{x}$ \\
\hline
\end{tabular}

Table 4.

The second discovery matrix.

of this type should be rejected. Todays in Poland the first-generation cells perform best. However, if within a few years nothing new appears in the production of silicon cells and the production of the third generation cell will gain momentum and the efficiency of their work will increase, they will probably be an ideal tool for generating green energy from solar radiation in Poland. Thus, combinations in gray cells in Table 3 go on to the further CCA process. These combinations were combined with the third parameter, as shown in the second discovery matrix, in Table 4.

Installing PV panels on the ground requires more space because of the need to place them at a distance from each other to avoid mutual shading. In addition, when the PV installation is located too low, its shading occurs in the morning and evening hours and thus the inability to obtain the maximum amount of energy. For this reason, ground PV systems should be raised to a height of about 1.5-2.5 m, which will not look too esthetically. Therefore, the option of installing a PV system on the ground was rejected. The optimal installation place for PV panels is a pitched roof facing south (possibly east and west) with an angle of inclination of $30-35^{\circ}$. A deviation of $15^{\circ}$ to the vertical or horizontal from this angle will not cause losses greater than $4 \%$. For flat roofs or roofs with a different degree of inclination, special arrangement correction frames are used, on which the panels are mounted. In addition, the location of the panels on the roof hinders vandalism and theft. Therefore, this solution was accepted. Installing PV panels on a flat roof was rejected because of the design assumptions. PV systems are rarely mounted on building walls due to the appearance of the facade. On the other hand, however, the panels that will be mounted on the south wall of the property are very efficient and easy to clean and maintain. The vertical arrangement of the panels eliminates the problem of snow which, in the case of roof and ground panels, limits the access of sunlight. That's why this solution was accepted. Thus, combinations in cells marked gray in Table 4 go on to further CCA process. These combinations were combined with the next parameter, as shown in the third discovery matrix, in Table 5.

Horizontal axis wind turbines are most often used. They have high performance (efficiency, small fluctuations in torque) in strong wind conditions. They are also characterized by high reliability, ease of service, and low cost. The main advantage of these turbines over a vertical axis turbine is efficiency. The latter have low efficiency and much larger their dimensions are needed to produce the same amount of energy as a horizontal axis wind turbine. Therefore, this type of turbine has been rejected. Thus, combinations in cells marked gray in Table 5 go on to further CCA process. These combinations were combined with the next parameter, as shown in the fourth discovery matrix, in Table 6.

Increasing the number of wind turbine blades results in a higher drive torque but a lower rotational speed. In turn, smaller number of blades increases the turbine speed. The use of single-blade and double-blade turbines results in a low weight of the rotor, which theoretically translates into a lower cost of its implementation. However, due to the high-speed indicator and the high rotational speed of the 


\begin{tabular}{lllll}
\hline & P1.3.P2.2.P3.2 & P1.3.P2.2.P3.3 & P1.3.P2.4.P.3.2 & P1.3.P2.4.P.3.3 \\
\hline P4.1. & $\mathrm{x}$ & $\mathrm{x}$ & $\mathrm{x}$ & $\mathrm{x}$ \\
\hline P4.2. & & & & \\
\hline
\end{tabular}

Table 5.

The third discovery matrix.

\begin{tabular}{lllll}
\hline & P1.3.P2.2.P3.2. P4.2 & P1.3.P2.2.P3.3.P4.2 & P1.3.P2.4.P.3.2. P4.2 & P1.3.P2.4.P.3.3. P4.2 \\
\hline P5.1. & $\mathrm{x}$ & $\mathrm{x}$ & $\mathrm{x}$ & $\mathrm{x}$ \\
\hline P5.2. & $\mathrm{x}$ & $\mathrm{x}$ & $\mathrm{x}$ & $\mathrm{x}$ \\
\hline P5.3. & & & & \\
\hline P5.4. & & & $\mathrm{x}$ & \\
\hline P5.5. & $\mathrm{x}$ & $\mathrm{x}$ & $\mathrm{x}$ & $\mathrm{x}$ \\
\hline P5.6. & $\mathrm{x}$ & $\mathrm{x}$ & $\mathrm{x}$ & $\mathrm{x}$ \\
\hline
\end{tabular}

Table 6.

The fourth discovery matrix.

monoplane turbines, they are quite noisy. Turbine noise, which increases as the speed increases, should be considered. Therefore, single-blade and double-blade turbines were rejected. Three-blade turbines are currently used most often due to a very good balance of aerodynamic forces, as well as high stability of work by balancing gyroscopic forces and uniform torque. Three-blade turbines are characterized by high efficiency, and it was decided to be accepted. Three-blade turbines with a diffuser are also noteworthy. The use of a diffuser results in less sensitivity to turbulence, greater structural integrity, better fatigue strength, greater torque at low wind speeds, lower load fluctuations that act on turbine blades, quieter turbine operation, and higher allowable rotational speed. Therefore, this solution was also accepted. The aerodynamic efficiency of the turbine increases with the number of rotor blades. However, this relationship is not linear, and the addition of each subsequent blade increases performance. Multi-blade turbines deliver high torque at low wind speeds. For the purposes of the project, it will be more desirable to achieve high speed but with less torque. Increasing the number of blades will cause a reverse reaction; therefore, four- and multi-blade turbine concepts were rejected. Thus, the combinations in cells marked gray in Table 6 go on to further CCA process. These combinations were combined with the next parameter, as shown in the fifth discovery matrix, in Table 7.

The vast majority of wind turbine blades are made of fiberglass reinforced with epoxy resin or polyester. There are also solutions using carbon fiber, but they are very expensive, and their use in this case is economically unjustified. Turbines made of wood reinforced with epoxy resin have not gained much popularity so far. Turbines of very small sizes, in turn, can be made of steel or aluminum blades, but they are quite heavy and susceptible to material fatigue. Thus, combinations in cells marked gray in Table 7 go on to further CCA process. These combinations were combined with the next parameter, as shown in the sixthth discovery matrix, in Table 8.

The wind turbine should be mounted above the roof of the building, which is usually the biggest obstacle to wind. Therefore, installing the turbine on the ground involves the necessity to erect a high-altitude tower (approx. $12 \mathrm{~m}$ ), which increases investment costs. Placing the turbine on the roof of the building will save on the 


\begin{tabular}{lllllllll}
\hline & P1.3. & P1.3. & P1.3. & P1.3. & P1.3. & P1.3. & P1.3. & P1.3. \\
& P2.2. & P2.2. & P2.2. & P2.2. & P2.4. & P2.4. & P2.4. & P2.4. \\
& P3.2. & P3.2. & P3.3. & P3.3. & P.3.2. & P.3.2. & P.3.3. & P.3.3. \\
& P4.2. & P4.2. & P4.2. & P4.2. & P4.2 & P4.2. & P4.2. & P4.2. \\
& P5.3 & P5.4 & P5.3 & P5.4 & P5.3 & P5.4 & P5.3 & P5.4 \\
\hline P6.1. & $\mathrm{x}$ & $\mathrm{x}$ & $\mathrm{x}$ & $\mathrm{x}$ & $\mathrm{x}$ & $\mathrm{x}$ & $\mathrm{x}$ & $\mathrm{x}$ \\
\hline P6.2. & & & & & & & & \\
\hline P6.3. & $\mathrm{x}$ & $\mathrm{x}$ & $\mathrm{x}$ & $\mathrm{x}$ & $\mathrm{x}$ & $\mathrm{x}$ & $\mathrm{x}$ & $\mathrm{x}$ \\
\hline P6.4. & $\mathrm{x}$ & $\mathrm{x}$ & $\mathrm{x}$ & $\mathrm{x}$ & $\mathrm{x}$ & $\mathrm{x}$ & $\mathrm{x}$ & $\mathrm{x}$ \\
\hline P6.5. & $\mathrm{x}$ & $\mathrm{x}$ & $\mathrm{x}$ & $\mathrm{x}$ & $\mathrm{x}$ & $\mathrm{x}$ & $\mathrm{x}$ & $\mathrm{x}$ \\
\hline
\end{tabular}

Table 7.

The fifth discovery matrix.

\begin{tabular}{lllllllll}
\hline & P1.3. & P1.3. & P1.3. & P1.3. & P1.3. & P1.3. & P1.3. & P1.3. \\
& P2.2. & P2.2. & P2.2. & P2.2. & P2.4. & P2.4. & P2.4. & P2.4. \\
& P3.2. & P3.2. & P3.3. & P3.3. & P.3.2. & P.3.2. & P.3.3. & P.3.3. \\
& P4.2. & P4.2. & P4.2. & P4.2. & P4.2 & P4.2. & P4.2. & P4.2. \\
& P5.3. & P5.4. & P5.3. & P5.4. & P5.3. & P5.4. & P5.3. & P5.4. \\
& P6.2 & P6.2 & P6.2 & P6.2 & P6.2 & P6.2 & P6.2 & P6.2 \\
\hline P7.1. & $\mathrm{x}$ & $\mathrm{x}$ & $\mathrm{x}$ & $\mathrm{x}$ & $\mathrm{x}$ & $\mathrm{x}$ & $\mathrm{x}$ & $\mathrm{x}$ \\
\hline $\mathrm{P} 7.2$. & $\mathrm{x}$ & $\mathrm{x}$ & $\mathrm{x}$ & $\mathrm{x}$ & $\mathrm{x}$ & $\mathrm{x}$ & $\mathrm{x}$ & $\mathrm{x}$ \\
\hline $\mathrm{P} 7.3$. & & & & & & & & \\
\hline P7.4. & $\mathrm{x}$ & $\mathrm{x}$ & $\mathrm{x}$ & $\mathrm{x}$ & $\mathrm{x}$ & $\mathrm{x}$ & $\mathrm{x}$ & $\mathrm{x}$ \\
\hline
\end{tabular}

Table 8.

The sixth discovery matrix.

cost of the tower and long electrical cables. Undoubtedly, the option of installing a wind turbine on a vertical wall of the building should be rejected. Also, due to the adopted design assumptions, among which the roof pitch is $35^{\circ}$, the flat roof is rejected. Therefore, guided by the costs, only the pitched roof was accepted. Thus, combinations in cells marked gray in Table 8 go on to further CCA process. These combinations were combined with the next parameter, as shown in the seventh discovery matrix, in Table 9.

If the system is not connected to the network, it is necessary to use batteries to ensure continuity of power supply to the receivers. Four types of batteries were considered. Acid batteries are classic batteries in which the electrolyte in liquid form fills the cell. When designing PV installations, classic batteries with armored positive plate are recommended. The disadvantage of this type of battery may be the need to buy additional equipment and gas recombinators, due to the possible release of harmful sulfuric acid fumes. These batteries have relatively the lowest lifetime and poor performance at high discharges. In turn, the advantage of these batteries is their low price. The undoubted advantage of gel batteries is the high charging efficiency, having no effect of electrolyte stratification during charging, and lower ventilation requirements. Due to the fact that the PV system battery will work cyclically, at this stage acid batteries are rejected. In gel batteries intended for PV installations, full recovery from deep discharge is possible, as well as an increased number of deep charging and discharging cycles thanks to the use of positive armor plates in the electrodes. In addition, gel batteries are more resistant to shocks, vibrations, and high temperatures than acid or AGM 


\begin{tabular}{lllllllll}
\hline & P1.3. & P1.3. & P1.3. & P1.3. & P1.3. & P1.3. & P1.3. & P1.3. \\
& P2.2. & P2.2. & P2.2. & P2.2. & P2.4. & P2.4. & P2.4. & P2.4. \\
& P3.2. & P3.2. & P3.3. & P3.3. & P.3.2. & P.3.2. & P.3.3. & P.3.3. \\
& P4.2. & P4.2. & P4.2. & P4.2. & P4.2 & P4.2. & P4.2. & P4.2. \\
& P5.3. & P5.4. & P5.3. & P5.4. & P5.3. & P5.4. & P5.3. & P5.4. \\
& P6.2. & P6.2. & P6.2. & P6.2. & P6.2. & P6.2. & P6.2. & P6.2. \\
& P7.3. & P7.3. & P7.3. & P7.3. & P7.3. & P7.3. & P7.3. & P7.3. \\
\hline P8.1. & $\mathrm{x}$ & $\mathrm{x}$ & $\mathrm{x}$ & $\mathrm{x}$ & $\mathrm{x}$ & $\mathrm{x}$ & $\mathrm{x}$ & $\mathrm{x}$ \\
\hline P8.2. & & & & & & & & \\
\hline P8.3. & $\mathrm{x}$ & $\mathrm{x}$ & $\mathrm{x}$ & $\mathrm{x}$ & $\mathrm{x}$ & $\mathrm{x}$ & $\mathrm{x}$ & $\mathrm{x}$ \\
\hline P8.4. & $\mathrm{x}$ & $\mathrm{x}$ & $\mathrm{x}$ & $\mathrm{x}$ & $\mathrm{x}$ & $\mathrm{x}$ & $\mathrm{x}$ & $\mathrm{x}$ \\
\hline
\end{tabular}

Table 9.

The seventh discovery matrix.

batteries. Their lifetime and the number of charging and discharging cycles are definitely the longest. Gel batteries best tolerate variable temperature fluctuations that occur in temperate climates. Unfortunately, they are the most expensive. In battery based on AGM technology, the possibility of electrolyte leakage from a mechanically damaged battery has been eliminated. Accumulators of this type have a one-way pressure valve, which, with an excessive increase in pressure of accumulated gases, opens, eliminating the problem of incorrect charging and discharging performance. This design will ensure high efficiency of the internal recombination process. Advantages of this battery are the ability to install in any position and to reduce the initial costs compared to gel batteries. However, these batteries have the shortest service life and the fewest charge and discharge cycles. Therefore, they will certainly not be taken into account. Despite the low price, they are characterized by short life and low efficiency at high discharges. On the basis of the pros and cons analysis, the gel battery was selected, and the AGM battery was also rejected. In addition to the mentioned batteries, there are also lithium-ion batteries that are characterized by long life, reliability, a wide range of operating temperatures, low internal resistance, and higher efficiency than leadacid batteries. Lithium-ion batteries save space and weight when accumulating the same amount of energy. Their disadvantage is undoubtedly the price, because in relation to lead-acid batteries, they are much more expensive. Therefore, this solution was also rejected.

Performing morphological analysis using the Moles discovery matrix method allowed to obtain 8 optimal solutions from 69,120 possible combinations. They are:

- Hybrid solar-wind system consisting of PV panels made of polycrystalline cells and mounted on vertical wall of the building, three-bladed (made of fiberglass) horizontal turbine mounted on slanting roof of the building, and gel battery

- Hybrid solar-wind system consisting of PV panels made of CIGS cells and mounted on vertical wall of the building, three-bladed (made of fiberglass) horizontal turbine mounted on slanting roof of the building, and gel battery

- Hybrid solar-wind system consisting of PV panels made of polycrystalline cells and mounted on slanting roof of the building, three-bladed (made of fiberglass) horizontal turbine mounted on a slanting roof of the building, and gel battery 
- Hybrid solar-wind system consisting of PV panels made of CIGS cells and mounted on slanting roof of the building, three-bladed (made of fiberglass) horizontal turbine mounted on a slanting roof of the building, and gel battery

- Hybrid solar-wind system consisting of PV panels made of polycrystalline cells and mounted on vertical wall of the building, three-bladed (made of fiberglass) horizontal turbine with diffuser mounted on a slanting roof of the building, and gel battery

- Hybrid solar-wind system consisting of PV panels made of CIGS cells and mounted on vertical wall of the building, three-bladed (made of fiberglass) horizontal turbine with diffuser mounted on a slanting roof of the building, and gel battery

- Hybrid solar-wind system consisting of PV panels made of polycrystalline cells and mounted on slanting roof of the building, three-bladed (made of fiberglass) horizontal turbine with diffuser mounted on slanting roof of the building, and gel battery

- Hybrid solar-wind system consisting of PV panels made of CIGS cells and mounted on slanting roof of the building, three-bladed (made of fiberglass) horizontal turbine with diffuser mounted on slanting roof of the building, and gel battery

\section{Numerical model of hybrid solar-wind system}

Based on GMA, a hybrid solar-wind system consisting of PV panels made of polycrystalline cells and three-blade horizontal axis wind turbine mounted on the slanting roof of the building and gel battery was selected for numerical testing. This installation has the task of supporting the supply of a $250 \mathrm{~m}^{2}$ single-family house in electricity. The house is located in the temperate climate zone, in Poland in the Silesian Voivodeship. Data regarding the value of insolation and wind maps for the selected location come from [2,7]. The average monthly demand for electricity was estimated on the basis of data taken from [29]. The block diagram of the designed hybrid system is presented in Figure 1. On its basis, a model will be developed in MATLAB/Simulink software.

In order to carry out example numerical simulations, a hybrid system was modeled consisting of:

- Upwind three-blades wind turbine with the following parameters: max power $500 \mathrm{~W}$; rated voltage $12 \mathrm{~V}$; start up, cut in, and cut out wind speed 2, 3.5, and $30 \mathrm{~m} / \mathrm{s}$, respectively; and rotor diameter $2.5 \mathrm{~m}$. It is equipped with a mechanical locking system and a three-phase asynchronous motor. The generator's efficiency is $96 \%$.

- Eight PV panels with $330 \mathrm{~W}$ for each connected in parallel. Their parameters are maximum power $33 \mathrm{~W}$, maximum power voltage $58 \mathrm{~V}$, maximum power current 5.7A, open-circuit voltage $69.7 \mathrm{~V}$, efficiency $19.8 \%$, and size $1590 \times$ $1053 \times 35$.

- Four batteries with maximum capacity $150 \mathrm{Ah}$ each and nominal voltage $12 \mathrm{~V}$. 


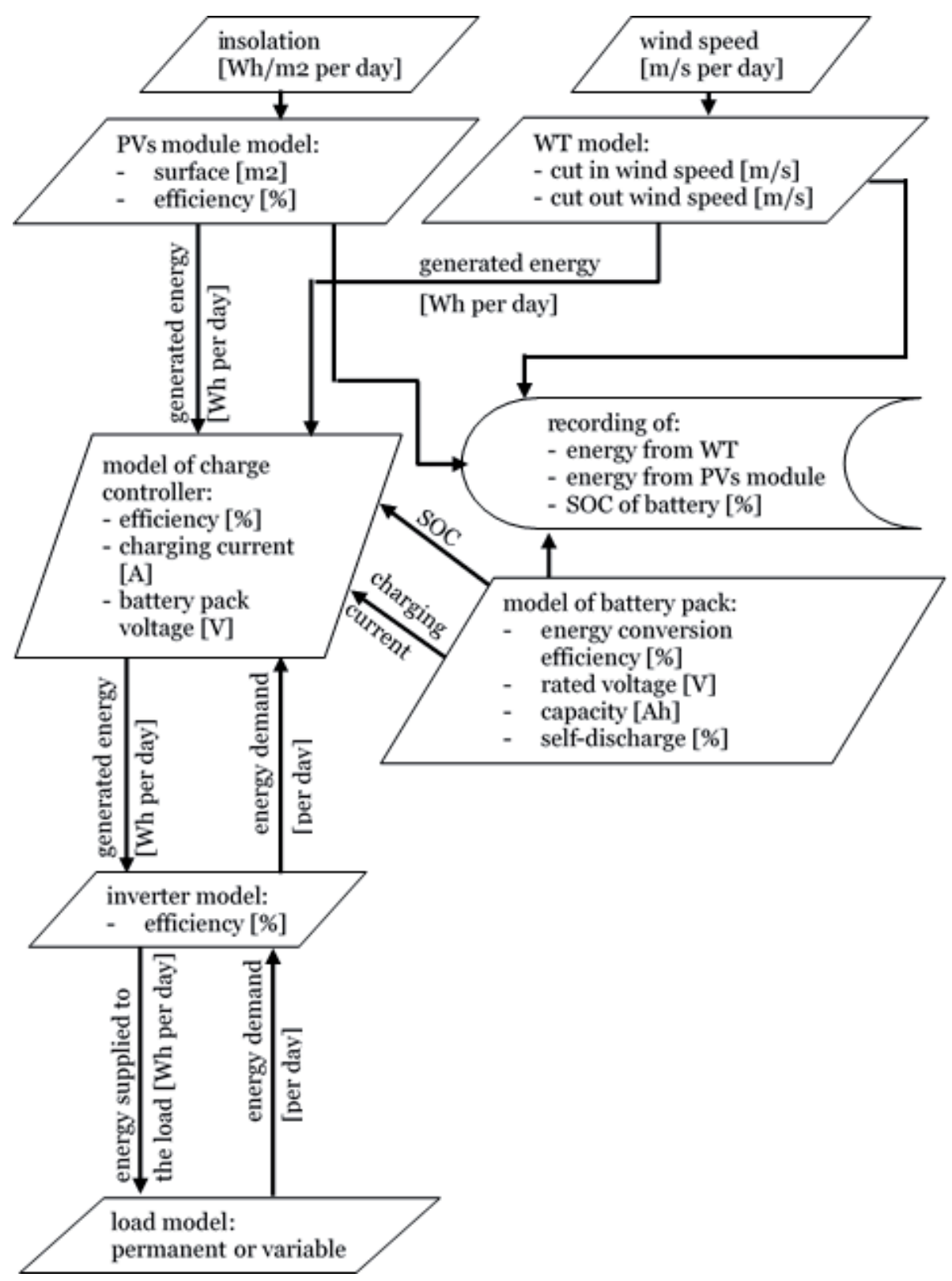

Figure 1.

The block diagram of the designed hybrid system.

The graph of daily insolation, estimated on the basis of data taken from [17], and graph of average daily wind speed, estimated on the basis of data taken from [2] are shown in Figure 2, on (a) and (b), respectively.

Capabilities of modeled hybrid system are shown on Figure 3. These capabilities should be understood as energy that could be transferred without restrictions to the power grid, assuming inability to store surpluses.

The waveform demanded by household energy value during the day and battery charge status are shown on Figure 4.

How many times per year this system cannot cover energy demand may be shown by comparing household monthly demand on energy with energy produced by the hybrid system (Figure 5). 
Optimization of Stand-Alone Hybrid Solar-Wind System by Using General Morphological... DOI: http://dx.doi.org/10.5772/intechopen.90284

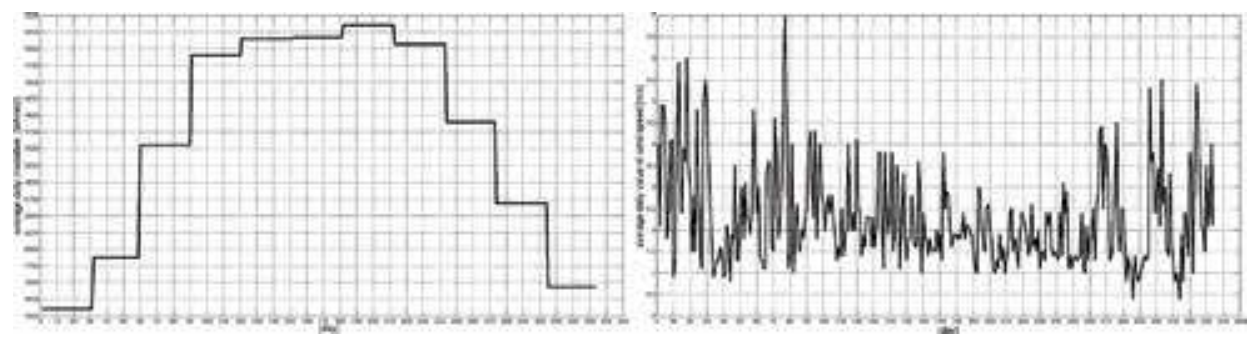

Figure 2.

The graph of average daily (a) insolation $\left[\mathrm{Wh} / \mathrm{m}^{2}\right]$ and $(b)$ wind speed $[\mathrm{m} / \mathrm{s}]$.
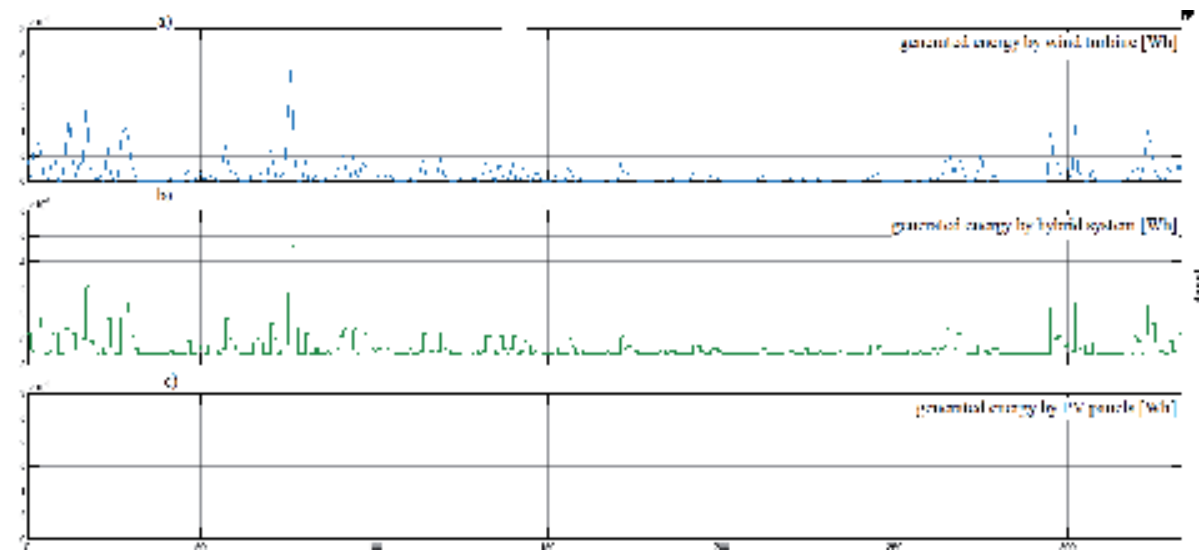

Figure 3.

Generated energy by (a) wind turbine, (b) hybrid system, and (c) PV panels.

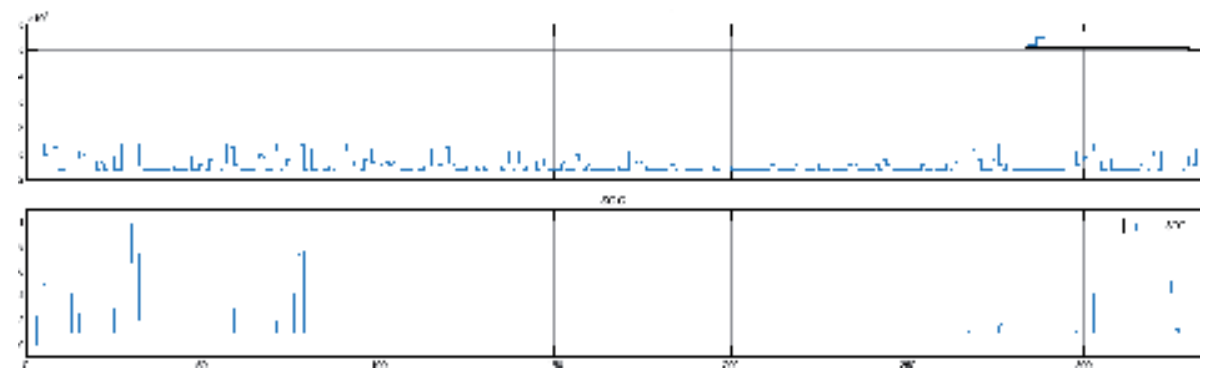

Figure 4.

Waveform demanded by household energy value during the day and battery charge status.

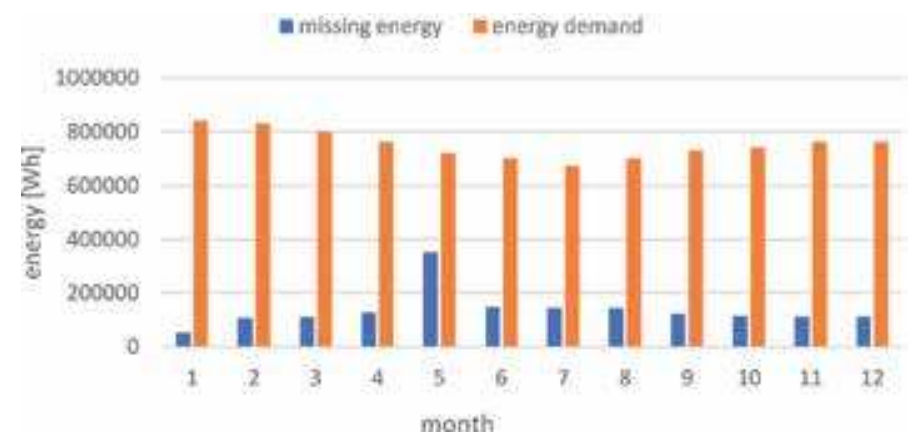

Figure 5.

Comparison of energy demand with the amount of missing Wh per month. 


\section{Conclusions}

At the beginning of this chapter, a brief introduction to the issue of energy sources is given. Further text discusses aspects that should be considered when choosing a location of both solar system and wind turbines. Text also provides arguments for a need to replace the nonrenewable energy sources with renewable ones. Then large part of the text discusses climatic, environmental, social, health, and ecologic aspects that should be considered during choosing a location for both solar panels and wind turbines. The next part of the chapter briefly introduces theory to General Morphological Analysis. Next, the practical application of GMA was described to optimize the structure of hybrid solar wind farms, preceded by a description of the adopted design assumptions.

At the end of the chapter, the developed numerical model of a hybrid solar-wind system in the MATLAB/Simulink environment was presented. Based on the data resulting from the simulations carried out for the adopted model of a hybrid solarwind power plant supplying the household, it can be concluded that the amount of missing energy, i.e., the difference between the demand and the energy generated by the modeled system, amounting to $15.67 \%$, is a very satisfactory result. Therefore, observing the further development of solar cells and batteries, such energy sources for countries without very favorable climatic conditions, for example, in Poland, should be treated as a cost-effective alternative to nonrenewable energy sources.

At present, energy storage is a very expensive solution and for the analyzed configuration did not bring satisfactory results. The batteries for the input data used have reached the state of charge only a few times, while the stored energy has been used very quickly. Such operation causes very fast battery wear. Energy surplus could easily be stored in other ways, e.g., in water tanks, which would be a cheaper and definitely more ecological solution. Abandoning the storage of surplus in batteries would not bring significant losses in this case.

\section{Conflict of interest}

The author declares that there is no conflict of interest.

\section{Author details}

Mariola Jureczko

Department of Theoretical and Applied Mechanics, Faculty of Mechanical

Engineering, Silesian University of Technology, Gliwice, Poland

*Address all correspondence to: mariola.jureczko@polsl.pl

IntechOpen

(C) 2020 The Author(s). Licensee IntechOpen. Distributed under the terms of the Creative Commons Attribution - NonCommercial 4.0 License (https://creativecommons.org/ licenses/by-nc/4.0/), which permits use, distribution and reproduction for non-commercial purposes, provided the original is properly cited. (cc) BY-NC 


\section{References}

[1] The Institute of Meteorology and Water Management-National Research Institute in Poland [Internet]. 2019. Available from: http://pogodynka.pl/ polska/wiatr [Accessed: 01 September 2019]

[2] Global Atlas for Renewable Energy [Internet]. 2019. Available from: https:// irena.masdar.ac.ae/GIS/?map=103 [Accessed: 01 September 2019]

[3] OGIMET. Professional information about meteorological conditions in the world [Internet]. 2019. Available from: https://www.ogimet.com/ [Accessed: 01 September 2019]

[4] Augustyńska D, Pleban D.

Requirements and recommendations for reducing exposure to wind turbine noise. \{in Polish: Wymagania i zalecenia dotyczące ograniczenia narażenia na hałas turbin wiatrowych\}. Central Institute for Labour ProtectionNational Resarch Institute. 2016. Available from: https://m.ciop. pl/CIOPPortalWAR/file/79852/ Wymagania-i-zalecenia-dotyczaceprofilaktyki-IIP12.pdf [Accessed: 01 September 2019]

[5] Pleban D, Radosz J, Smagowska B. Noise and infrasonic noise at workplaces in a wind farm. Archives of Acoustics. 2017;42(3):491-498. DOI: 10.1515/ aoa-2017-0052

[6] Haugen KMB. International review of policies and recommendations for wind turbine setbacks from residences: Setbacks, noise, shadow flicker and other concerns, Minnesota Department of Commerce: Energy Facility Permitting. October 19, 2011. Available from: http://www.windaction.org/ posts/39993-international-review-ofwind-policies-and-recommendationsfor-wind-turbine-setbacks-fromresidences\#.XdU12FdKjcs [Accessed: 01 September 2019]
[7] Harding G, Harding P, Wilkins AJ. Wind turbines flicker and photosensitive epilepsy: Characterizing the flashing that may precipitate seizures and optimizing guidelines to prevent them. Epilesja. 2008;49(6):1095-1098. DOI: 10.1111/j.1528-1167.2008.01563.x

[8] Steeby DL. Alternative Energy: Sources and systems. Series: Go Green with Renewable Energy Resources. Delmar Cengage Learning; 1st edition. 2012. 318p. ISBN-13: 978-1111037260

[9] Dunlap RA. Sustainable Energy. 2nd ed. Thomson-Engineering. 2018. 736p. ISBN-13: 978-1337551663

[10] Stryjecki M Mielniczuk K. Guidelines for Forecasting the Environmental Impacts of Wind Farms \{in Polish Wytyczne w Zakresie Prognozowania oddziaływań na środowisko Farm Wiatrowych\}. The General Directorate for Environmental Protection; 2011. 132p. ISBN 978-8362940-17-2. Available from: http:// www.fnez.pl/upload/File/Wytyczne. pdf [Accessed: 01 September 2019]

[11] Act of 16 April 2004 on nature protection, Journal of Laws No. 92, item 880 \{in Polish Dz. U. 2004 nr 92 poz .880\}. Available from: http:// prawo.sejm.gov.pl/isap.nsf/DocDetails. xsp?id=WDU20040920880 [Accessed: 01 September 2019]

[12] Ledec GC, Rapp KW, Aiello RG. Greening the wind: Environmental and social considerations for wind power development. In: The World Bank Study. 2011. 172p. ISBN 978-0-8213-8926-3

[13] Dunlop J. In: Partnership with the electrical training ALLIANCE. Photovoltaic Systems. 3rd ed. American Technical Publishers Inc; 2012. 502p. ISBN 978-1-935941-05-7 
[14] Bhatia SC, Gupta RK. Textbook of Renewable Energy. New Delhi: Woodhead Publishing India Pvt; 2018. 334p. ISBN 978-93-85059-95-7

[15] 3TIER. Glossary of technical renewable energy terminology [Internet]. 2018. Available from: https://www.3tier.com/en/support/ glossary/\#dif [Accessed: 01 September 2019]

[16] Schlecht M, Meyer R. 4-site selection and feasibility analysis for concentrating solar power (CSP) systems. In: Lovegrove K, Stein W, editors. Concentrating Solar Power Technology. Principles, Developments and Applications Woodhead

Publishing Series in Energy. Woodhead Publishing; 2012. pp. 91-119. DOI: 10.1533/9780857096173.1.91

[17] Solar resource map (C) 2019 Solargis [Internet]. 2019. Available from: https:// solargis.com [Accessed: 01 September 2019]

[18] Martz-Oberlander Talia RS. The dirt on solar energy: A study of Dutch solar panel efficiency losses from soiling [BSc thesis]. Canada: Quest University; 2017. Available from: http://www.lmpv.nl/wp-content/ uploads/2017/09/BSc_thesis_MartzOberlander_2017.pdf [Accessed: 01 September 2019]

[19] Abass K, Al-Zubaidi DSM, Al-Waeli AAK. Effect of pollution and dust on PV performance. International Journal of Civil, Mechanical and Energy Science (IJCMES). 2017;3(4):181-185. DOI: $10.24001 / \mathrm{ijcmes} .3 .4 .1$

[20] Xiaoyuan L, Wagner F, Peng W, Yang J, Mauzerall DL. Reduction of solar photovoltaic resources due to air pollution in China. Proceedings of the National Academy of Sciences of the United States of America. 2011;114(45):867-11872. DOI: $10.1073 /$ pnas. 1711462114
[21] Uko ED, Otugo VN, Sigalo FB, Udonam-Inyang UE. Investigation of the effect of weather conditions on solar energy in rivers state University of Science and Technology, Port Harcourt, Nigeria. Journal of Atmosphere, Conscientia Beam. 2016;2(1):9-16. DOI: 10.18488/journal.94/2016.2.1/94.1.9.16

[22] Zwicky F. Discovery, Invention, Research through the Morphological Analysis. New York: MacMillan; 1969. 276p. ISBN 978-1114243064

[23] Ritchey T. General Morphological Analysis as a Basic Scientific Modelling Method. Technological Forecasting and Social Change. Vol. 126(C). Elsevier; January 2018. pp. 81-91. DOI: 10.1016/j. techfore.2017.05.027

[24] Ritchey T. Problem structuring using computer-aided morphological Analysis. Journal of the Operational Research Society, Special Issue on Problem Structuring Methods. 2006;57:792-801

[25] Ritchey T. General morphological analysis, a general method for nonquantified modeling. In: 16th EURO Conference on Operational Analysis, Brussels. 1998

[26] Ritchey T. Wicked Problems-Social Messes. Decision Support Modelling with Morphological Analysis. Berlin Heidelberg: Springer-Verlag; 2011. 105p. ISBN 978-3-642-19652-2

[27] Ambrosino J, Legardeur J. An example of hybridization between the "discovering matrix" and the "9 windows" tools during ideation phases of inter clustering projects. In: DESIGN 2016-14th International Design Conference, Faculty of Mechanical Engineering and Naval Architecture. Glasgow: University of Zagreb, The Design Society; 2016. pp. 897-906

[28] Moles A, Caude R. Créativité et méthodes d'innovation dans lẻntreprise. 
Optimization of Stand-Alone Hybrid Solar-Wind System by Using General Morphological... DOI: http://dx.doi.org/10.5772/intechopen.90284

Series: Management: fonctions, méthodes, expériences. Vol. 5. Paris:

Fayard-Mame; 1970. 218p

[29] Calculator for electricity

consumption at home [Internet]. 2019.

Available from: http://kalkulator.tauron.

pl/h5/ [Accessed: 01 February 2018] 



\title{
A Dynamic Performance Model for Hybrid Wind/Gas Power Plants
}

\author{
Elias Tsoutsanis
}

\begin{abstract}
The scope of this chapter is to assess the performance of hybrid power plants and more specifically demonstrate the challenges of partnering the wind turbines with gas turbines. A dynamic engine model of a gas turbine along with a wind turbine model is developed to simulate plethora of scenarios for optimizing their operation in terms of efficiency, fuel consumption and NOx emissions. Moreover, a comparison between the hybrid power plant and a twin gas turbine power plant is carried out to assess the improvement in both NOx emissions and fuel consumption. The results demonstrate and illustrate the significant impact that dynamic performance modeling has in the optimization and controller design of hybrid power plant.
\end{abstract}

Keywords: wind energy, gas turbine, wind turbine, dynamic modeling, MATLAB/Simulink, engine control

\section{Introduction}

The expansion of wind power plants has transformed the gas turbines operation. The intermittent nature of wind prompts the gas turbines to operate with increased flexibility, for supporting their renewable plant partners and maintaining the stability of the electricity grid $[1,2]$. Fast starts, shut downs and part load operation [3-5] are governing the operating profile of modern engines. It is vital, for an effective operation and maintenance (O\&M) strategy, to employ tools and technologies that will support our understanding for these complex and nonlinear machines. Towards this end, gas turbine manufacturers have developed a suite of programs and systems that can model, monitor and analyse a plants performance [6].

Performance models of gas turbines, also called digital twins, play a significant role $[7,8]$ towards optimizing their operation. Apart from a few examples in the literature [9-11] most studies focus on steady state performance of gas turbines. Recently, their transient behaviour has attracted attention since they are required to act in partnership with renewables which are characterized by their intermittent nature.

Dynamic performance models of gas turbines are capable of facilitating the design of controllers that will enable the engines to fulfil their demanding new role 
[12]. From a condition based maintenance point of view, dynamic engine models enable health monitoring, diagnostics [13-16] and prognostics [17, 18] capabilities.

Consequently, the recent shift in the operating envelope of the gas turbine has amplified the interest for developing real-time computationally efficient and accurate engine models that can help gas turbine operators to have an informed judgment about their assets. Furthermore, the monitored behaviour of the engine at transient conditions can facilitate the controller design for plethora of scenarios that involve gas turbines working in partnership with other energy sources.

Among the various methods [19-22] proposed in the literature for gas turbine performance simulation, the most common is the zero dimensional (0-D) approach $[14,23]$ which can be also used for real time monitoring, diagnosis and prognosis. From the transient performance analysis of a gas turbine one can identify important trends in performance that could potentially initiate surge of compressor or exceed temperature limits of engine. The simulation of plethora of scenarios provides important insights of the engine's behaviour and this is evident in cases where carrying out an experiment is either not feasible or may be catastrophic for the engine [24].

The two fundamental approaches for dynamic engine simulation are the iterative constant mass flow (CMF) method [25-27] and the inter-component volume (ICV) method [28]. Both of these methods have been extensively used for performance simulation studies of gas turbines [29-35]. The ICV approach is based on the flow imbalances during transient operation, where the CMF approach relies on the iterative minimization of key thermodynamic parameters that are initially guessed.

In this chapter, a model of a two-shaft gas turbine is developed in MATLAB/ Simulink environment and coupled with a wind turbine model in order to assess the behaviour of the hybrid power plant in dynamic operating conditions. The developed engine model combines the above two approaches, since the CMF iterative method $[36,37]$ used for steady state is subsequently integrated with the ICV method for transient performance simulation.

The dynamic engine model utilizes component characteristic maps and is coupled to the governing thermodynamic equations of the engine cycle. The simulated scenarios of the engine operating under transient conditions provided key findings that would be hazardous for an actual gas turbine. An engine controller has been developed for enabling smooth and safe engine operation. The engine model has been validated towards PROOSIS [14] gas turbine simulation software. Furthermore, the behaviour of model is examined when the engine is coupled to a wind farm in a hybrid arrangement.

A generic model of a wind turbine has been developed in Simulink and coupled with the gas turbine model. The energy demand and the wind speed are designed to vary with respect to time which forces the gas turbine to work under transient conditions. This scenario provides additional information on the dynamic behaviour of the gas turbine and can also serve as a guide in controller design for hybrid plants. Finally, the hybrid plant's performance is compared to a twin gas turbine only power plant for estimating the capability of the gas turbines to shut down and their $\mathrm{NO}_{\mathrm{x}}$ emissions.

The remainder of this chapter is organized as follows. In Section 2, the methodology employed for the transient performance simulation along with the controller design are described. The results of the case studies are presented and discussed in Section 3, followed by the conclusions in Section 4. 


\section{Methodology}

\subsection{Gas turbine mathematical model}

For this study, the industrial gas turbine developed by the author in MATLAB/ Simulink [14], is briefly discussed in this chapter. The main components of the gas turbine are the compressor, combustor, and turbine. The gas turbine's exhaust gases are driving a free power turbine which is coupled to an electricity generator, as seen from Figure 1.

Station ' 1 ' denotes ambient air pressure and temperature. The following notation is used throughout the chapter. Temperatures and pressures are denoted by $T_{i}$ and $P_{i}$, respectively where subscript $i=1,2,3,4,5$ represents the engine station.

\subsubsection{Compressor}

The performance of the compressor is represented by a characteristic map which presents the interrelationships between pressure ratio $\pi_{c}=P_{2} / P_{1}$, isentropic efficiency $\eta_{c}$, corrected mass flow $\dot{m}_{1} \sqrt{T_{1}} / P_{1}$, and corrected shaft rotational speed $N / \sqrt{T}_{1}$. Scaled maps from PROOSIS [14] simulation software have been used in this model.

Once the outputs of the map are determined, the temperature rise $\Delta T_{12}$ across the compressor is computed as follows:

$$
\Delta T_{12}=\frac{T_{1}}{\eta_{c}}\left[\left(\frac{P_{2}}{P_{1}}\right)^{\frac{\gamma_{a}-1}{\gamma_{a}}}-1\right]
$$

The work required to drive the compressor is given by

$$
W_{c}=\dot{m}_{1} \cdot c_{p_{a}} \cdot \Delta T_{12}
$$

where $c_{p_{a}}$ denotes the specific heat of air.

\subsubsection{Combustor}

The energy balance equation is governing the performance of the combustor as follows:

$$
\dot{m}_{1} \cdot c_{p_{a}} \cdot T_{2}+\dot{m}_{f} \cdot L H V=\dot{m}_{3} \cdot c_{p_{g}} \cdot T_{3}
$$

where $L H V$ represents the fuel's low heat value, and $c_{p_{g}}$ is the specific heat of combustion products. The heat input $H I$ of the system is expressed as follows:

$$
H I=\dot{m}_{f} \cdot L H V
$$

which is further implemented for estimating the cycle's thermal efficiency $\eta_{t h}$.

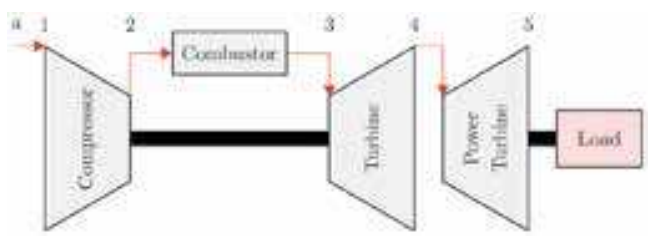

Figure 1.

Representation of the two-shaft engine model along with its station numbering [14]. 
Regarding emissions, the nitrogen oxides model developed by Rokke et al. [38], and validated by Pires et al. [39], is implemented in this gas turbine model. The $\mathrm{NO}_{\mathrm{x}}$ emissions are estimated from the following equation:

$$
\mathrm{NO}_{\mathrm{x}}=18.1 \cdot\left(P_{2} / P_{1}\right)^{1.42} \cdot \dot{m}_{1}^{0.3} \cdot f^{0.72}
$$

where $P_{2} / P_{1}$ denotes compressor pressure ratio, $\dot{m}_{1}$ denotes air mass flow rate, and $f$ denotes fuel to air ratio (i.e. $\dot{m}_{f} / \dot{m}_{1}$ ). The $\mathrm{NO}_{\mathrm{x}}$ emissions are measured in parts per million by volume (ppmv) at $15 \% \mathrm{O}_{2}$.

\subsubsection{Turbine}

Similar to the compressor, turbine performance is represented by a set of characteristic maps that present the interrelationships between turbine pressure ratio $\pi_{t}$, corrected mass flow $\dot{m}_{3} \sqrt{T}_{3} / P_{3}$, efficiency $\eta_{t}$, and corrected rotational speed $N / \sqrt{T}_{3}$.

It follows that the temperature drop $\Delta T_{34}$ across the turbine is computed by:

$$
\Delta T_{34}=\eta_{t} \cdot T_{3}\left[1-\left(\frac{1}{\pi_{t}}\right)^{\frac{\gamma_{g}-1}{\gamma_{g}}}\right]
$$

where $\gamma_{g}$ is the heat capacity ratio of combustion products and for preliminary performance calculations it may be assumed constant, i.e. $\gamma_{g}=1.33$. The work extracted by the turbine is given by:

$$
W_{t}=\eta_{m} \cdot \dot{m}_{3} \cdot c_{p_{g}} \cdot \Delta T_{34}
$$

where $c_{p_{g}}$ represents the specific heat of combustion gases and $\eta_{m}$ is the mechanical efficiency.

\subsubsection{Power turbine}

Similar to the turbine, the performance of the power turbine is represented by characteristic maps that present the interrelationship between pressure ratio $\pi_{p t}$, corrected mass flow $\dot{m}_{4} \sqrt{T}_{4} / P_{4}$, efficiency $\eta_{p t}$, and corrected rotational speed $N_{p t} / \sqrt{T}_{4}$.

The temperature drop $\Delta T_{45}$ across the power turbine is given by:

$$
\Delta T_{45}=\eta_{p t} \cdot T_{4}\left[1-\left(\frac{1}{\pi_{p t}}\right)^{\frac{\gamma_{g}-1}{\gamma_{g}}}\right]
$$

In this chapter, the speed of the free power turbine is assumed constant since it is connected to an electricity generator. The work delivered by the power turbine is the useful work $U W$ of the cycle and is given by:

$$
U W=\dot{m}_{4} \cdot c_{p_{g}} \cdot \Delta T_{45}
$$




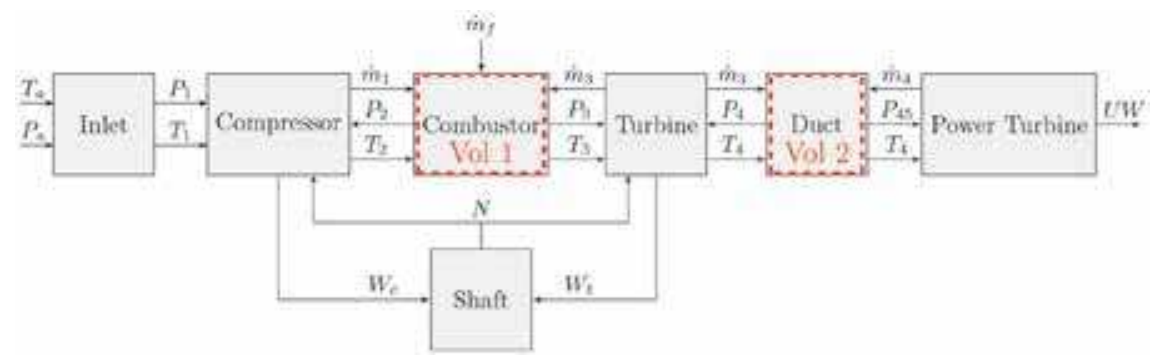

Figure 2.

Schematic representation of the modular computational interaction of the transient engine model [14].

The thermal efficiency of the gas turbine system is given by:

$$
\eta_{t h}=100 \cdot \frac{U W}{H I}
$$

and expressed as a percentage.

\subsection{Dynamic simulation}

The ICV method has been implemented in the development of the engine model in MATLAB/Simulink environment $[45,46]$. This method works on the principle that mass flow imbalances occur during transient operation. Two plenum volumes, one before the turbine and one after the turbine, have been added to the model, as seen from Figure 2. The component maps for compressor, turbine and power turbine are the same as the steady state model.

The fuel addition initiates the mass flow imbalances which are used to calculate the rate of pressure variations. The description of the process is provided in the following subsections.

\subsubsection{Dynamics}

Combustor: Volume 1-The mass flow continuity is used to calculate the pressure in the combustor volume, as follows:

$$
\frac{d P_{2}}{d t}=\frac{R T_{2}}{V_{1}}\left(\dot{m}_{1}+\dot{m}_{f}-\dot{m}_{3}\right)
$$

where $R, V_{1}$, and $P_{2}$ denote gas constant, combustor volume, and compressor delivery pressure, respectively. The combustor outlet pressure can be calculated as a simple proportionality from:

$$
\frac{P_{2}-P_{3}}{P_{2}}=P L F
$$

where $P L F$ is the combustor pressure loss factor and for this study a 5\% drop in pressure is assumed.

Duct: Volume 2-The pressure at the exit of the gas turbine is given by:

$$
\frac{d P_{4}}{d t}=\frac{R T_{4}}{V_{2}}\left(\dot{m}_{3}-\dot{m}_{4}\right)
$$

where $V_{2}$ and $P_{4}$ denote duct volume and turbine delivery pressure, respectively. The turbine outlet pressure can be calculated as a simple proportionality from: 


$$
\frac{P_{4}-P_{45}}{P_{45}}=P L F
$$

where $P L F$ is the turbine pressure loss factor and for this study we assumed that there are no losses between the turbine and the power turbine, i.e. $P_{4}=P_{45}$.

Shaft-The difference between compressor $W_{c}$ and turbine work $W_{t}$, is used in the computation of the engine's acceleration which is given by:

$$
\frac{d N}{d t}=\left(\frac{30}{\pi}\right)^{2} \cdot \frac{W_{t}-W_{c}}{J N}
$$

where $J$ is the shaft polar moment of inertia measured in $\mathrm{kg} \mathrm{m}^{2}$.

System states-Assuming that the system's state is denoted by $u$, and the set of variables is represented by $x$ then the state and control variables are defined as follows:

$$
\begin{gathered}
x=\left[P_{2}, P_{4}, N\right]^{T} \\
u=\dot{m}_{f}
\end{gathered}
$$

The pressures $P_{2}$ and $P_{4}$, and shaft rotational speed $N$, at design point conditions are the input parameters of the model. To summarize, the gas turbine dynamics may be expressed as:

$$
\frac{d x}{d t}=f(x, u)
$$

\subsubsection{Simulation process}

The initial state values for the transient engine model are summarized in Table 1.

It is noted that at steady state conditions the derivatives $d P_{2} / d t, d P_{4} / d t$ and $d N / d t$ are all zero.

\subsection{Controller design}

Controller design is crucial for achieving a safe and reliable engine operation. Among a variety of controllers suitable for gas turbine engines, the one implemented in this study is a PI controller. Its objective is to regulate the fuel flow rate $\dot{m}_{f}$ by comparing the speed demand $N_{d}$ with the measured speed $N_{m}$ of the gas turbine. To achieve this both the fuel flow actuator and the speed sensor are modelled by simple first order transfer functions [23, 32].

The process of the controller's operation is schematically represented in Figure 3. The actuating signal $\varepsilon$ is driving the controller to generate a demand for

\begin{tabular}{lccc}
\hline Symbol & Parameter & Value & Units \\
\hline$P_{2_{0}}$ & Compressor discharge pressure & 1472 & $\mathrm{kPa}$ \\
\hline$P_{4_{0}}$ & Turbine exit pressure & 406 & $\mathrm{kPa}$ \\
\hline$N_{0}$ & Gas generator shaft rotational speed & 9000 & $\mathrm{rpm}$ \\
\hline
\end{tabular}

Table 1.

The initial state for the transient engine model. 


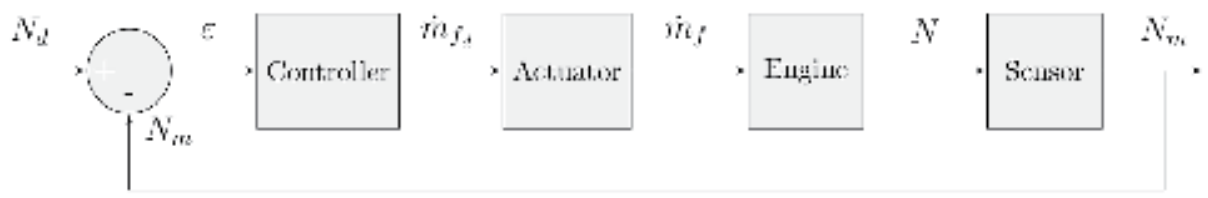

Figure 3.

Block diagram of a speed controller for fuel flow regulation.

fuel flow rate $\dot{m}_{f_{d}}$ which is then translated to the movement of the actuator in order to admit fuel $\dot{m}_{f}$ into the combustor. The engine responds to this command and the measured engine speed is compared to the desired one.

The control function of this PI controller can be expressed as follows:

$$
\dot{m}_{f_{d}}(t)=K_{p} \varepsilon(t)+K_{i} \int_{0}^{t} \varepsilon(t) d t
$$

where $\varepsilon(t)=N_{d}(t)-N_{m}(t)$, and $K_{p}, K_{i}$ denote the coefficients of the proportional and the integral terms, respectively. The transfer functions for the fuel system actuator and the speed sensor are given by:

$$
\begin{aligned}
& G_{1}(s)=\frac{\dot{m}_{f}(s)}{\dot{m}_{f_{d}}(s)}=\frac{1}{0.05 s+1} \\
& G_{2}(s)=\frac{N_{m}(s)}{N(s)}=\frac{1}{0.05 s+1}
\end{aligned}
$$

The reader is prompted to [32], if a more advanced controller design is pursued. However, for this study which focuses on enabling the engine to respond in a safe manner during transient operation the proposed controller is capable to achieve this objective. The proposed model has been validated towards PROOSIS gas turbine simulation software and a full description of the validation case studies can be found in [14].

\subsection{Wind turbine model}

A generic model of a wind turbine, available from MATLAB/Simulink [40], is used in this study in order to assess the operation of a hybrid power plant when the gas turbine is coupled to a wind farm.

The wind turbine's performance is governed by pitch angle $\beta$, wind speed $V_{\text {wind }}$ and wind turbine speed $N_{w t}$. These are commonly represented in a performance map, as seen in Figure 4. The power output of the wind turbine $U W_{w t}$ is given by [40]:

$$
U W_{w t}=C_{p} \cdot \eta_{\text {mech }} \cdot \eta_{\text {elect }} \cdot \frac{1}{2} \cdot \bar{\rho} \cdot A \cdot \overline{V_{\text {wind }}^{3}}
$$

where $\bar{\rho}$ denotes the mean air density over the rotor swept area $A, \eta_{\text {mech }}$ denotes mechanical efficiency of bearings, gear box, generator, etc., $\eta_{\text {elect }}$ denotes electrical efficiency of transformer, converter, etc., $\overline{V_{\text {wind }}^{3}}$ denotes the mean of the cubic wind speed and $C_{p}$ denotes the power coefficient. The power coefficient $C_{p}$ depends on the blade tip ratio $\lambda$ and the blade pitch angle $\beta$. For this study a generic equation is used as follows [40]: 


$$
C_{p}(\lambda, \beta)=C_{1}\left(C_{2} / \lambda_{i}-C_{3} \beta-C_{4}\right) e^{\frac{-C_{5}}{\lambda_{i}}}+C_{6} \lambda
$$

where $C_{1}=0.5176, C_{2}=116, C_{3}=0.4, C_{4}=5, C_{5}=21$, and $C_{6}=0.0068$. The blade tip ratio relationship with pitch angle is given by:

$$
\frac{1}{\lambda_{i}}=\frac{1}{\lambda+0.08 \beta}-\frac{0.035}{\beta^{3}+1}
$$

The wind turbine model has three inputs namely $\beta, V_{\text {wind }}, N_{w t}$, and one output $U W_{w t}$.

The hybrid gas/wind power plant consists of a gas turbine and a wind farm with variable power output. The total power output $U W_{\text {total }}$ from the hybrid power plant is given by:

$$
U W_{\text {total }}=U W_{g t}+U W_{w t}
$$

The energy gap $\Delta W$ imposed by the wind turbines is covered by the gas turbine. This difference is expressed as follows:

$$
\Delta W=D W-U W_{\text {total }}
$$

Any instant that the demand is not met, then the gas turbine has to respond by adjusting its fuel flow regulation. An algebraic constraint is used to constrain the difference to zero (i.e. $\Delta W=0$ ) by tuning the value of the demanded speed from the gas turbine. The schematic diagram of the developed models is shown in Figure 5.

It should be highlighted that the wind turbine used here is a generic and simple model that fits the objective of this study. If one seeks a high fidelity performance assessment of wind turbines, the reader is prompted to studies [41-44] which address the dynamic response of the wind turbine at a greater detail.

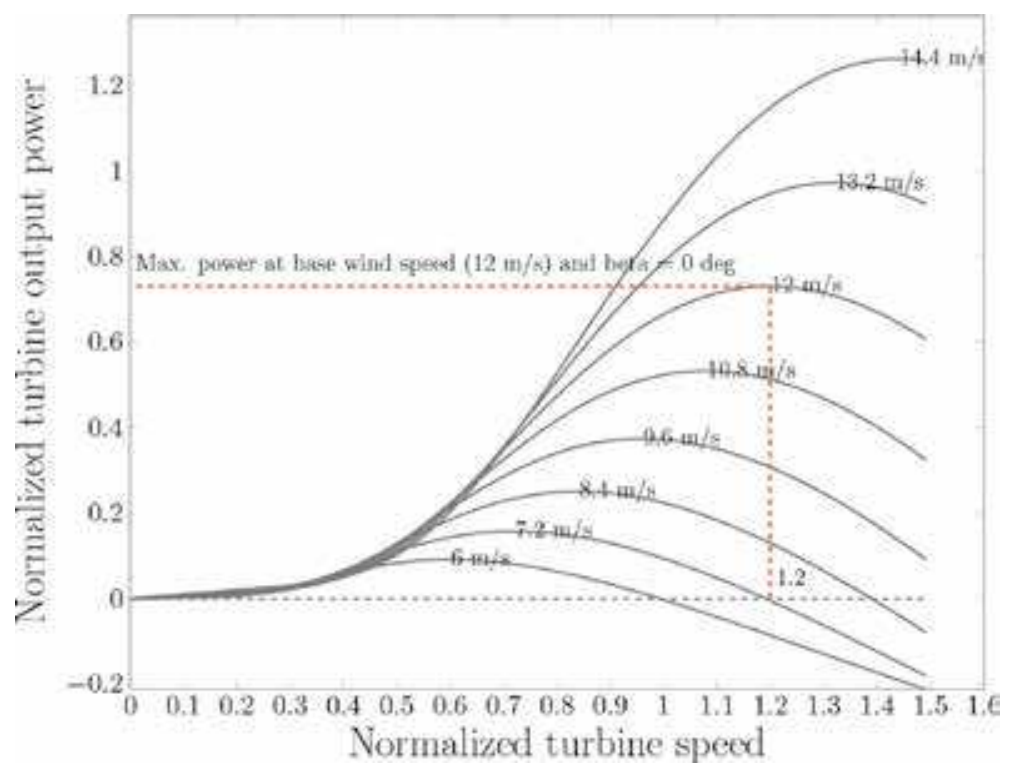

Figure 4.

Wind turbine performance map representing the power output as a function of generator speed, for different wind speeds and for a blade pitch angle $\beta=0$ degrees [14]. 


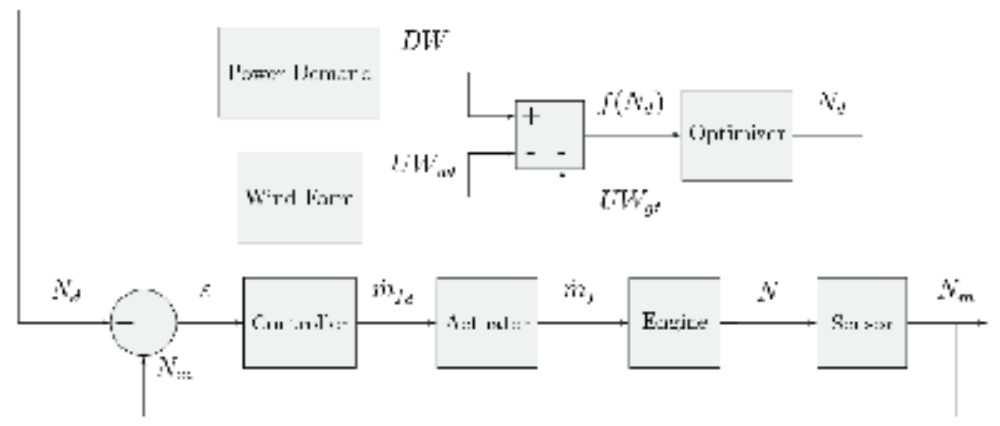

Figure 5 .

Block diagram of the hybrid gas/wind controller and optimization module [14].

\section{Results and discussions}

\subsection{Case study 1: transient step response with PI controller}

This case study examines the transient performance of the engine when a PI controller is implemented. The controller enables a smooth and safe engine operation. The schematic diagram of this control arrangement is shown in Figure 6.

The PI controller tunes the fuel flow rate according to the actuating signal arising from the difference of demanded $N_{d}$ and measured $N_{m}$ shaft speed. The controller design toolbox in Simulink provides a visual representation of the system's behaviour and the user can select the desired response characteristics. this translates into a unique set of control coefficients $K_{p}$ and $K_{i}$, that update the engine's controller. The compressor surge and combustor flame-out limits, described in detail in [14], are also integrated into the controller subsystems of the model, as seen from Figure 7.

The controller has to regulate the fuel flow into the engine by ensuring that this command lies within the surge and flame-out limits. So depending on the demanded shaft speed $N_{d}$ and the ambient conditions $T_{1}, P_{1}$, two look up tables are used to calculate the fuel flow rates that correspond to the surge $\dot{m}_{f_{\max }}$ and flameout $\dot{m}_{f_{\text {low }}}$ limits of the engine. When then fuel flow rate computed by the PI controller violates these limits, then a switch is used to bound the final fuel flow rate demand $\dot{m}_{f_{d}}$ within them, as seen from Figure 7.

For this case study, the coefficients of the PI controller and the transient response characteristics are summarized in Table 2.

Repeating the simulation of the engine model in Simulink results in a controlled engine behaviour. A comparison between the behaviour of the engine model without and with a PI controller is seen in Figure 8.

It becomes clear from Figure 8 that $T_{3}$ is no longer exhibiting an oscillating behaviour during this sudden increase in the demanded engine speed, since the fuel flow has been modified through the PI controller.

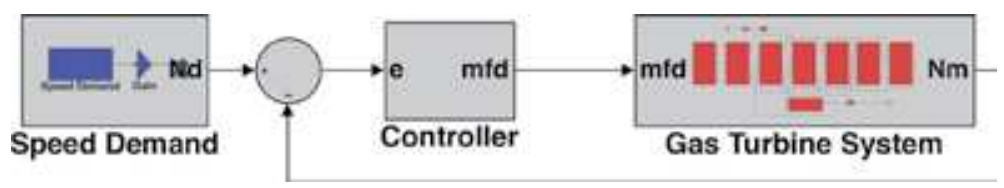

Figure 6.

Schematic layout of the MATLAB/Simulink model with the controller [14]. 


\section{Controller Subsystem}

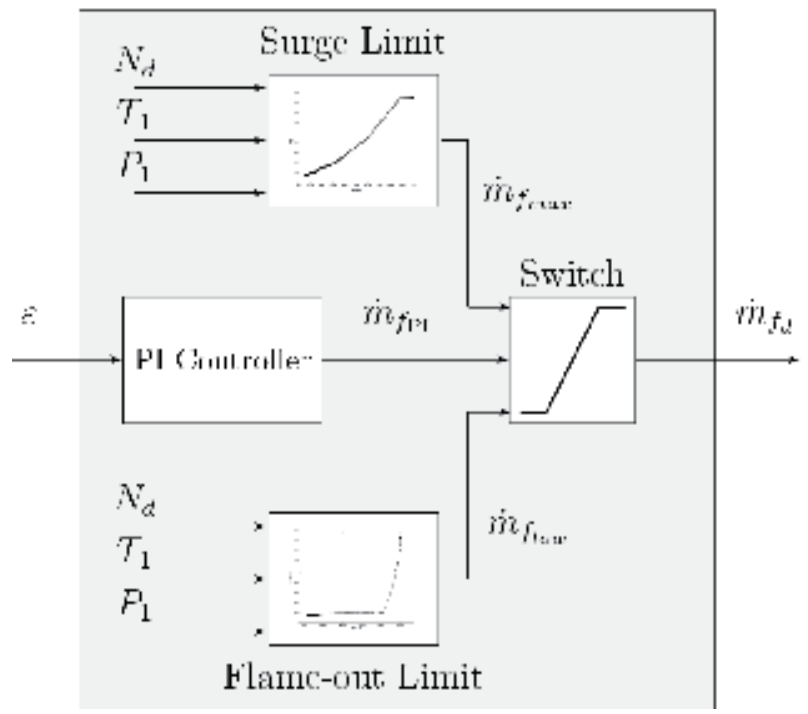

Figure 7.

Detailed block diagram of the controller subsystem with the surge and flame-out limiting functions implemented as look-up tables [14].

\begin{tabular}{lcc}
\hline Parameter & Value & Units \\
\hline$K_{p}$ & $8.562 \mathrm{E}-05$ & - \\
\hline$K_{i}$ & $0.794 \mathrm{E}-03$ & - \\
\hline Rise time & 0.896 & Seconds \\
\hline Settling time & 1.676 & Seconds \\
\hline Overshoot & 0 & $\%$ \\
\hline Peak & 1 & - \\
\hline
\end{tabular}

Table 2.

The parameters of the PI controller [14].

It is evident from Figure 8 that without a PI controller, where the fuel flow command was not regulated, a large operational regime has occurred that would have violated the firing temperature limits and may have led to compressor surge. The implemented controller has resolved the above issue by regulating a fuel flow rate that results in a smoother engine operating profile.

\subsection{Case study 2: hybrid gas/wind power plant}

The objective of this case study is to assess the performance of the gas turbine when it is coupled to a wind farm. The design point performance of the wind turbine is summarized in Table 3, and this refers to a generic wind turbine model available in [40].

The time increment of the simulation is $1 \mathrm{~ms}$ and for a $10 \mathrm{~s}$ simulation there are 10,000 operating points. The results are correlated to a $10 \mathrm{~h}$ operation, which means that for every minute there are 16 operating points. The size of the data support the above decision as the nonlinear behaviour of the gas turbine is well captured. The hybrid power plant, seen in Figure 9, consists of a gas turbine and 14 wind turbines. 

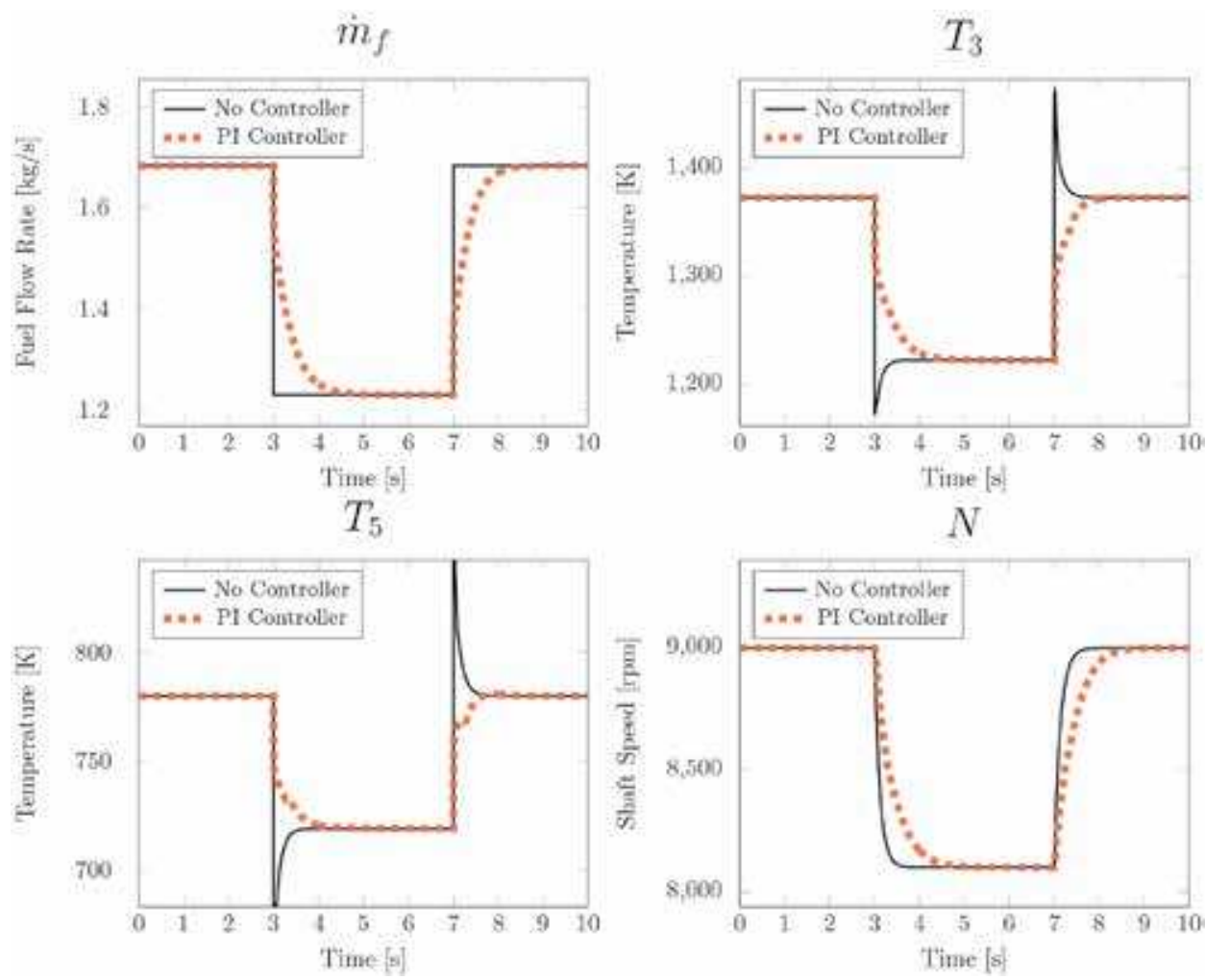

Figure 8.

Variation of the simulated measurements with respect to time from MATLAB/Simulink model of case study 1.

\begin{tabular}{lccc}
\hline Symbol & Parameter & Value & Units \\
\hline$V_{\text {wind }}$ & Wind speed & 12 & $\mathrm{~m} / \mathrm{s}$ \\
\hline$N_{w t}$ & Generator speed & 1800 & $\mathrm{rpm}$ \\
\hline$U W_{w t}$ & Power output & 1500 & $\mathrm{~kW}$ \\
\hline
\end{tabular}

Table 3.

The design-point performance specifications of the wind turbine [14].

The variation of wind speed with respect to time can be seen from Figure 10. This variation is designed by having in mind that the gas turbine will commence its operation close to its design point. At the 2 and $5 \mathrm{~h}$ mark the gas turbine will have to respond to this change by decelerating and following the demand according to the intermittent power output of the wind turbines.

The required power from the power plant ranges from $28 \mathrm{MW}$ up to $37 \mathrm{MW}$. The above is combined with the varying wind speed, and the resultant power output of each system is shown in Figure 11.

The PI controller discussed in case study 1 is utilized here in combination with the algebraic constraint optimizer. The PI controller parameters are the same as case study 1.

The power output varies with respect to time, as seen from Figure 12, where the percentage of power output of each system is illustrated. The wind farm contributes up to $70 \%$ of the demanded power, while the maximum power output contribution from the gas turbine is $75 \%$. A closer look at the shaft rotational speed $N$ and exhaust gas temperature $T_{5}$, from Figures 13 and 14, reveals the dynamic response of the gas turbine. 


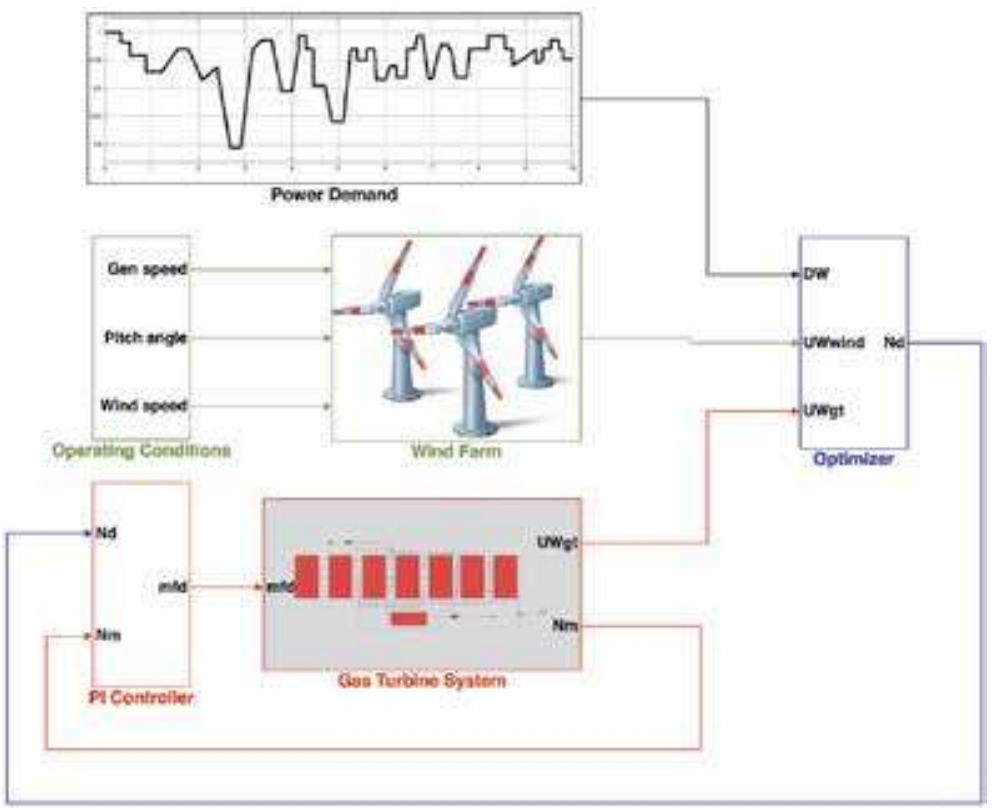

Figure 9.

Schematic layout of the hybrid gas/wind power plant in Simulink [14].

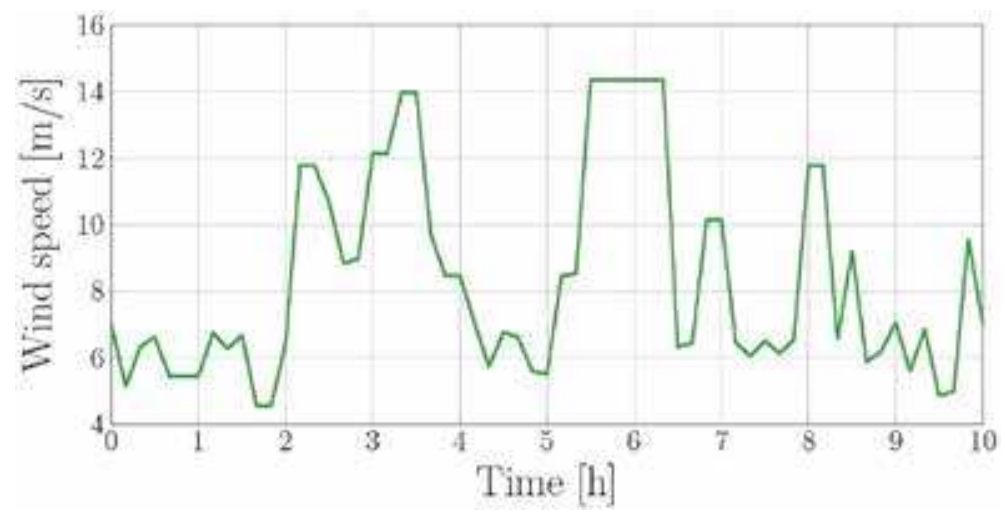

Figure 10.

Variation of wind speed with respect to time [14].

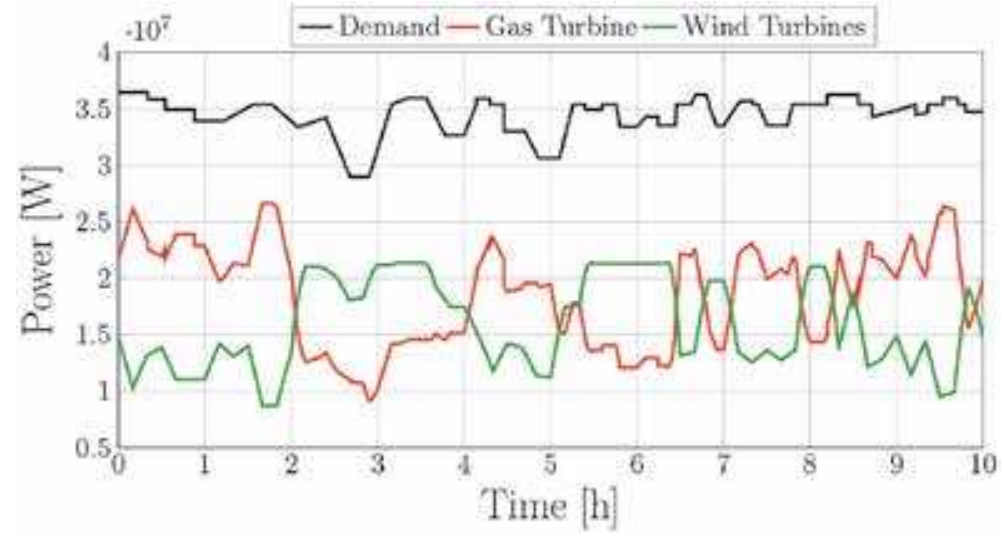

Figure 11.

Time response of the gas turbine and the wind turbines to meet the fluctuating demand [14]. 


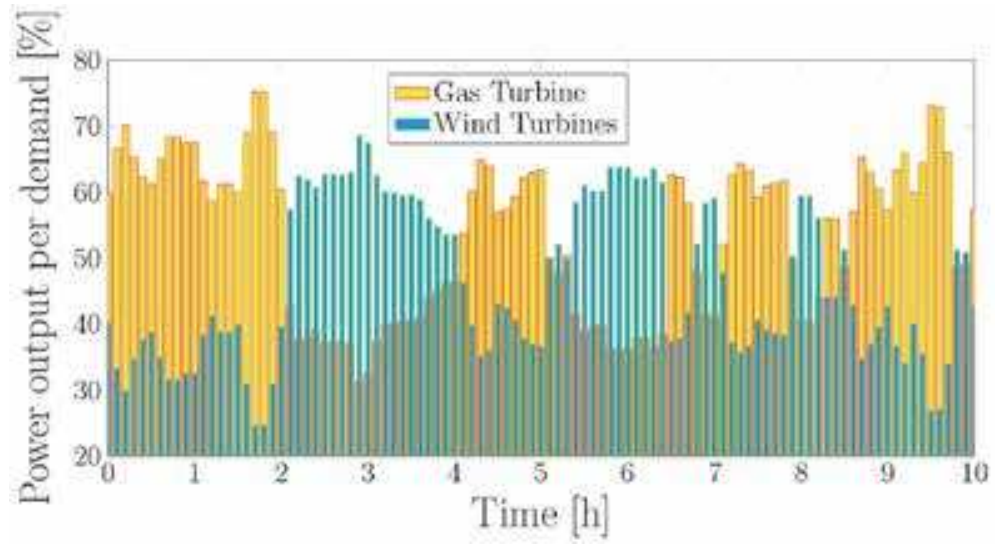

Figure 12.

The variation of the power output from the gas and wind turbines expressed as a percentage to total power demand with respect to time [14].

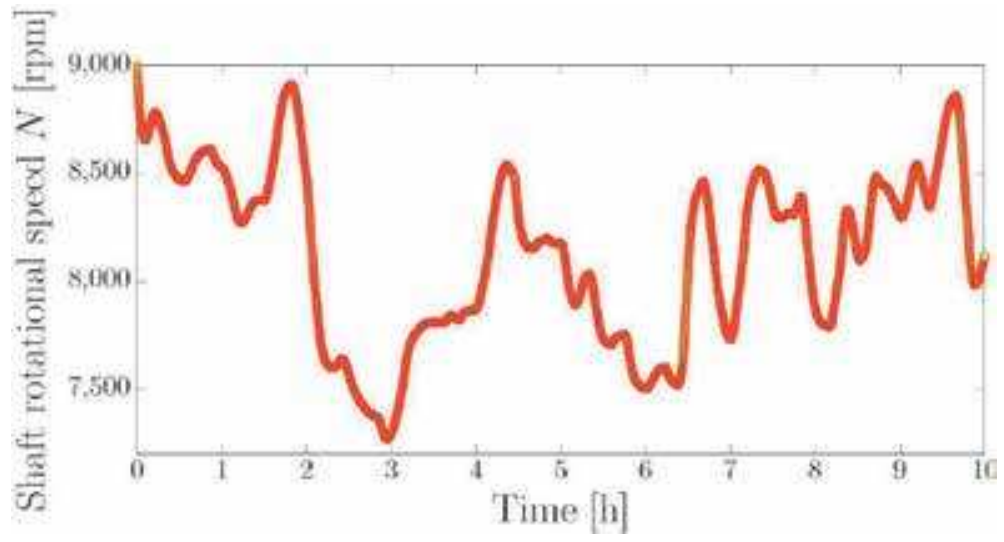

Figure 13.

The variation of the gas turbine shaft rotational speed with respect to time [14].

Figure 13 shows that the speed of the gas turbine's is dependent on the wind speed which essentially dominates the behaviour of the wind farm. A pattern of similar form is shown in the variation of the gas turbine's exhaust temperature, seen in Figure 14.

\subsection{Case study 3: hybrid power plant comparison with a twin gas turbine plant}

The primary aim of this case study is to carry out a comparative study between the hybrid power plant and a plant that consists of two gas turbines only. To make the comparison easier the hybrid power plant is referred to as Plant A and the twin gas turbine plant is referred to as Plant B. Plant B's gas turbine engines are identical to the one of Plant A. The demanded power from both plants is the same. The simulated scenario of this study corresponds to $10 \mathrm{~h}$ operation. The $\mathrm{NO}_{\mathrm{x}}$ emission and fuel consumption for both plants are assessed. The power demanded from each plant can be seen in Figure 15.

It should be noted that the demanded power signal has been designed in such a way so that there are two occasions during which the power drops significantly and peaks up again. There are two periods for which the engine of Plant A will be required to shut down, in order to assess its shut down capabilities. 


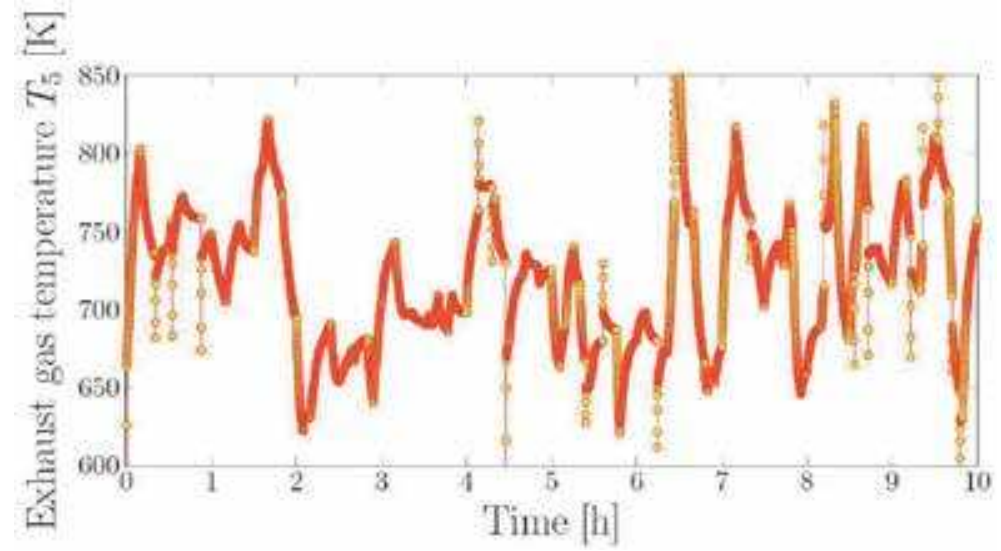

Figure 14.

The variation of the gas turbine exhaust temperature with respect to time [14].

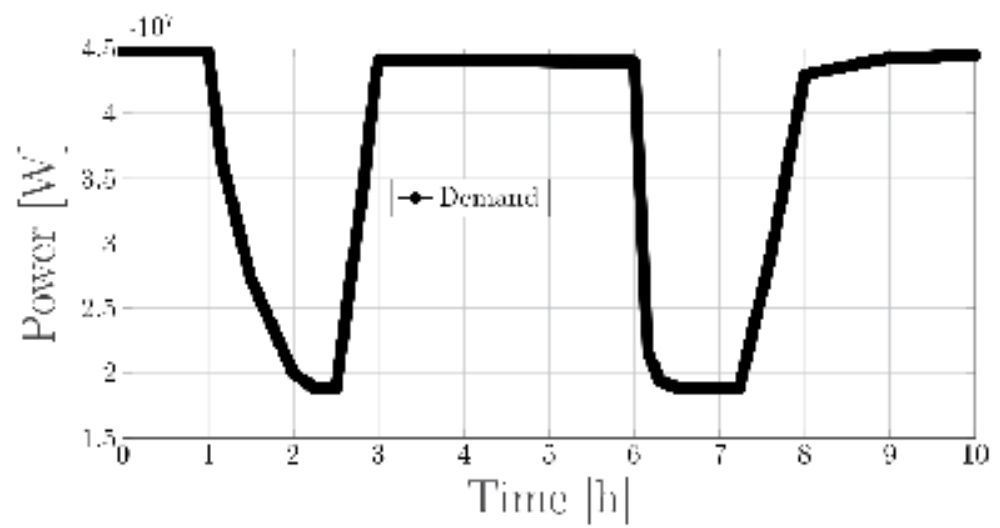

Figure 15.

Representation of power demanded from Plants A and B with respect to time [14].

Figure 16 shows that the power output from the gas turbine and wind turbines of Plant A. One hour into the operation, the gas turbine slowly decreases its power output until the $2 \mathrm{~h}$ mark and will remain shut for half hour. After the $30 \mathrm{~min}$ break the engine will fire up again, reach a power output of $25 \mathrm{MW}$ and hover over this power setting for another $3 \mathrm{~h}$. At the $6 \mathrm{~h}$ mark, the engine will experience another shut down event and will remain inactive for $1 \mathrm{~h}$ before starting up again and remaining at approximately $26 \mathrm{MW}$ for the final $2 \mathrm{~h}$ of operation.

$1 \mathrm{~h}$ of operation, the power required from the engine decreases slowly with respect to time and forces the engine to shut down and remain inactive for $30 \mathrm{~min}$. It then starts up again and in approximately $25 \mathrm{~min}$ reaches a power setting close to its design point for the next $3 \mathrm{~h}$. At the $6 \mathrm{~h}$ mark, the power output reduces faster as it takes approximately 10 min to shut down the engine.

Traditionally, current industrial gas turbine engines are capable of shutting down in less than $10 \mathrm{~min}$ [47]. On the other hand, a hot start up (i.e. less than $8 \mathrm{~h}$ standstill) process may take less than $0.1 \mathrm{~h}$ (i.e. $6 \mathrm{~min}$ ) with a ramp rate up to $15 \%$ of nominal load per minute [48]. In addition, the fastest the start-up [49] and shut downs are, the greater the economic benefit and the life cycle reduction are going to be. Therefore start up and shut down processes should be optimized by taking into consideration several operational constraints. The gas turbine of the hybrid plant in 


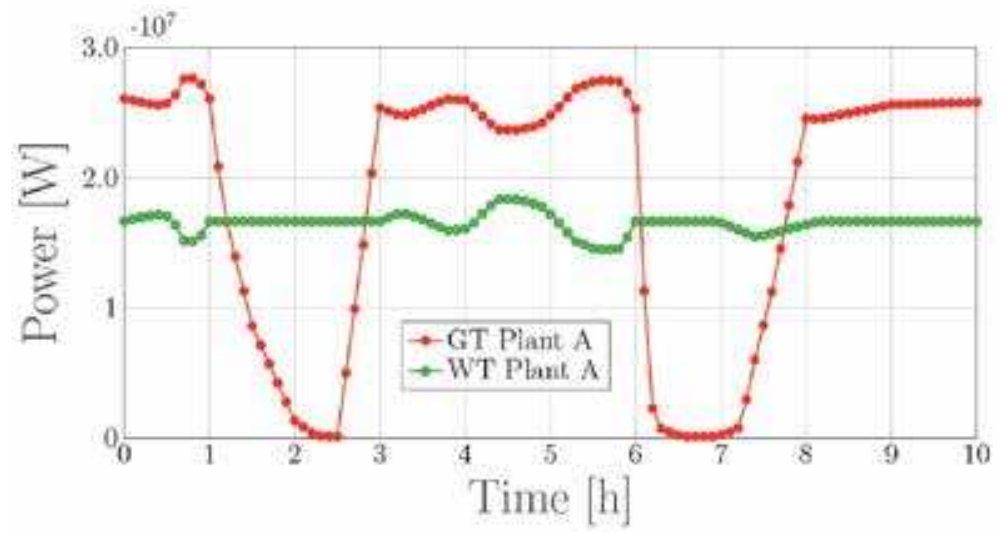

Figure 16.

The variation of the power output from the gas and wind turbines of Plant A expressed with respect to time [14].

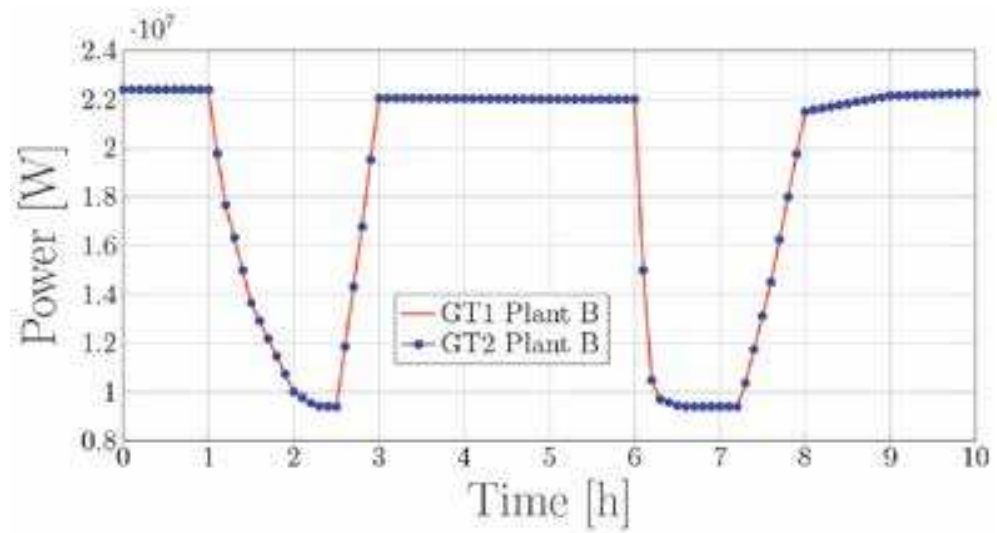

Figure 17.

The variation of the power output from the gas turbines of Plant B expressed with respect to time [14].

this case study is exhibiting fast response behaviour which is beneficial for the wind turbines (Figure 17).

Meanwhile, the wind turbines remain operational during the entire $10 \mathrm{~h}$. Given that the power demanded from the plant has two occasions with significant load fluctuations, both of them have to be accommodated by the flexibility of the gas turbine since the wind farm's power capacity has a priority in the grid for this hybrid power plant.

For Plant B, both gas turbines have an identical load distribution, as shown in Figure 17, and meet the demanded power. In contrast to the Plant A gas turbine, Plant $B$ engines operate at part load off-design conditions. The power output has a substantial effect in the $\mathrm{NO}_{\mathrm{x}}$ emissions of gas turbines, as observed from Eq. (5), since the higher the pressure ratio, the higher the TET and therefore the higher the emissions are going to be.

The $\mathrm{NO}_{\mathrm{x}}$ emissions of both plants are shown in Figure 18. As expected, the $\mathrm{NO}_{\mathrm{x}}$ emissions from Plant $\mathrm{B}$ are significantly higher than those of Plant $\mathrm{A}$. The amount of $\mathrm{NO}_{\mathrm{x}}$ emissions reduction is illustrated in Figure 19, where the emissions of Plant A are compared to those of Plant $\mathrm{B}$ as a percentage.

The $\mathrm{NO}_{\mathrm{x}}$ emissions of Plant A are initially 43\% less than that of Plant B and increase to $100 \%$ when the gas turbine of Plant A shuts down. Regarding the fuel consumption, Plant A consumes less fuel compared to Plant B, and this accounts to 


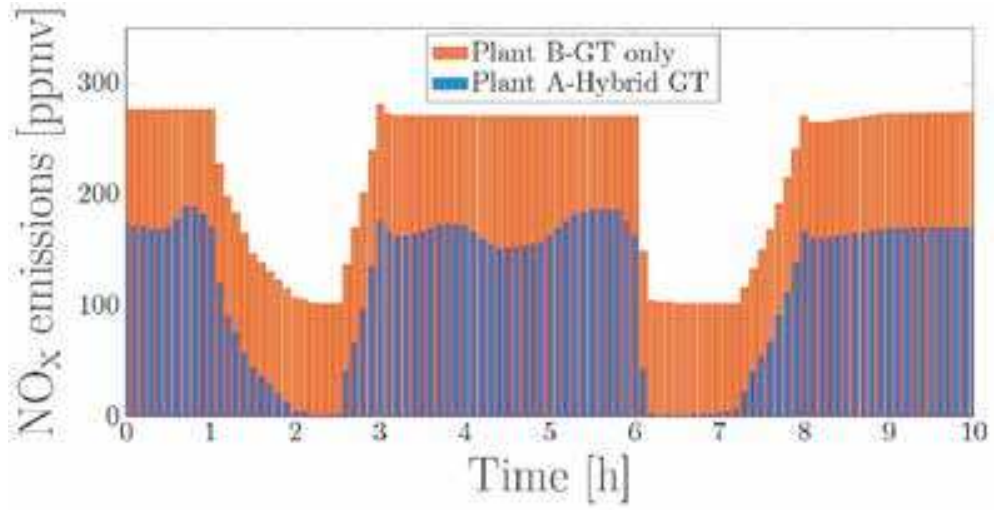

Figure 18.

The variation of $\mathrm{NO}_{x}$ emissions for Plants $A$ and $B$ with respect to time [14].

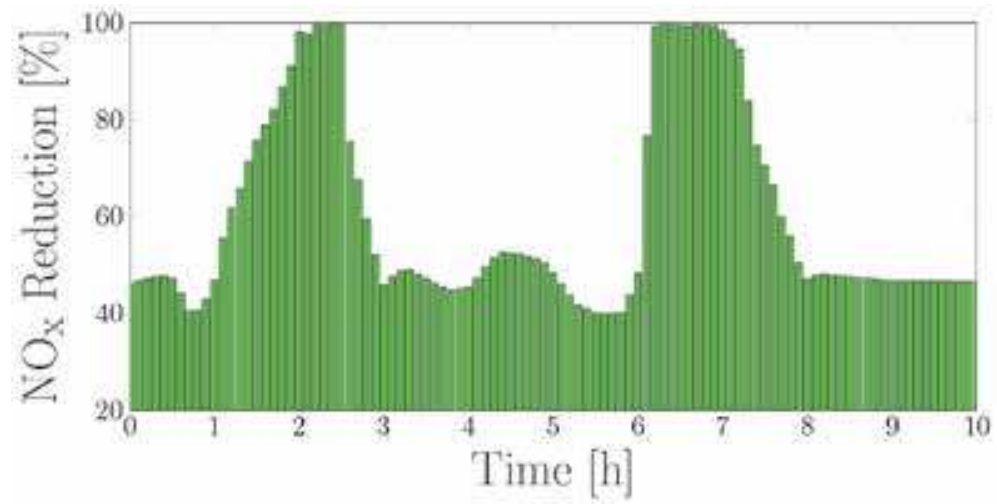

Figure 19.

The variation of $\mathrm{NO}_{x}$ emissions percentage reduction of Plant $A$ in comparison to Plant B with respect to time.

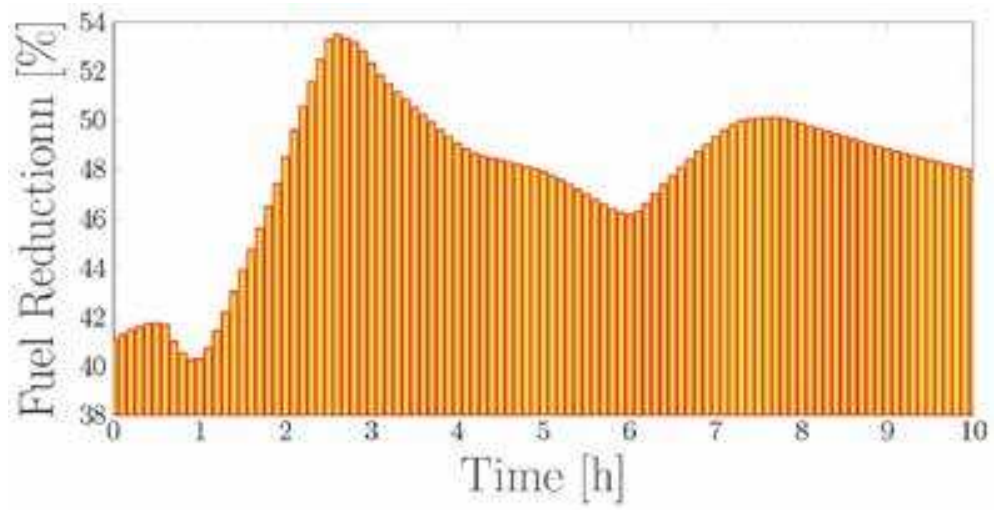

Figure 20.

The accumulated variation of fuel percentage reduction of Plant A in comparison to Plant B with respect to time [14].

48\%, as seen in Figure 20. Note that the fuel reduction represented in Figure 20 refers to the accumulated fuel flow. This case study amplifies the significance of transient observations arising from simulating various dynamic operating scenarios of gas turbines. Key findings about their behaviour, performance, environmental impact and flexibility add value to our understanding of this technology especially 
when it is coupled with renewables. Finally, fast transient gas turbine manoeuvers are essential to the stability of the grid in hybrid power plant arrangements. Additional promising technologies for wind speed forecasting might enable smoother transient gas turbine operation in a hybrid gas/wind power plant.

As far as practical issues are concerned the developed model can be further improved by a number of useful additions such as variable pitch control of the wind turbine [50, 51], wind forecasting models [51], and adaptive model-tuning. Another important aspect of this developed model is the fact that it enables users to simulate numerous scenarios and can potentially feed its simulated measurements into a multi-objective optimization process for improving the performance of gas turbine. In addition, the model can accommodate degradation case studies [17] at component and system level for improving the prediction accuracy and the computational efficiency of diagnostic and prognostics algorithms.

\section{Conclusions}

In this chapter, a novel gas turbine engine model is presented that aims to capture the nonlinear behaviour of modern gas turbines. The gas turbine model is created in MATLAB/Simulink.

The engine model consolidates the iterative constant mass flow approach in steady state conditions for initializing the state parameters to the dynamic model, which utilizes the inter-component volume technique. The dynamic response of the model has been evaluated for a hybrid gas/wind power plant comprising of 14 wind turbines. The result of this analysis features the quick transient trajectories that the gas turbine encounters as the consequence of variable wind speeds and fluctuating energy demand. In addition, the behaviour of the hybrid power plant underlined the requirement for transient simulation scenarios since several operating challenges must be addressed to maintain stability in the grid. Finally, the comparative study of the hybrid power plant to a twin gas turbine plant for a $10 \mathrm{~h}$ operation showed that the $\mathrm{NO}_{\mathrm{x}}$ emissions decrease from $40 \%$ to $100 \%$ depending on the power setting of the engine.

The modularity, robustness and computational efficiency are key feature of the developed engine model. The above features facilitate the performance assessment and controller design of gas turbines that operate under transient conditions. Furthermore, the developed engine model can improve our understanding for these complex machines and enables us to optimize the energy dispatch of a hybrid power plant. The proposed model can also serve as a useful tool and guide in optimizing the performance of a gas turbine powered-plant, monitoring its emissions and establishing a reference for subsequent model-based diagnostics and prognostics studies. 


\section{Author details}

Elias Tsoutsanis

School of Engineering, University of Birmingham, Edgbaston, UK

*Address all correspondence to: e.tsoutsanis@bham.ac.uk

\section{IntechOpen}

(C) 2020 The Author(s). Licensee IntechOpen. Distributed under the terms of the Creative Commons Attribution - NonCommercial 4.0 License (https://creativecommons.org/ licenses/by-nc/4.0/), which permits use, distribution and reproduction for non-commercial purposes, provided the original is properly cited. (cc) BY-NC 


\section{References}

[1] Barelli L, Bidini G, Ottaviano A. Integration of SOFC/GT hybrid systems in micro-grids. Energy. 2017;118:716-728

[2] di Gaeta A, Reale F, Chiariello F, Massoli P. A dynamic model of a 100 $\mathrm{kW}$ micro gas turbine fuelled with natural gas and hydrogen blends and its application in a hybrid energy grid. Energy. 2017;129:299-320

[3] Mehrpanahi A, Payganeh G, Arbabtafti M. Dynamic modeling of an industrial gas turbine in loading and unloading conditions using a gray box method. Energy. 2017;120:1012-1024

[4] Barelli L, Bidini G, Ottaviano A. Part load operation of a SOFC/GT hybrid system: Dynamic analysis. Applied Energy. 2013;110:173-189

[5] Bahlawan H, Morini M, Pinelli M, Spina PR, Venturini M. Development of reliable narx models of gas turbine cold, warm and hot start-up. Journal of Engineering for Gas Turbines and Power. 2017;140(7)

[6] Tahan M, Tsoutsanis E, Muhammad M, Abdul Karim ZA. Performance-based health monitoring, diagnostics and prognostics for condition-based maintenance of gas turbines: A review. Applied Energy. 2017;198:122-144

[7] Barsali S, De Marco A, Giglioli R, Ludovici G, Possenti A. Dynamic modelling of biomass power plant using micro gas turbine. Renewable Energy. 2015;80:806-818

[8] Ponce CV, Saez D, Bordons C, Nunez A. Dynamic simulator and model predictive control of an integrated solar combined cycle plant. Energy. 2016;109: 974-986

[9] Alobaid F, Mertens N, Starkloff R, Lanz T, Heinze C, Epple B. Progress in dynamic simulation of thermal power plants. Progress in Energy and Combustion Science. 2017;59:79-162

[10] Ablay G. A modeling and control approach to advanced nuclear power plants with gas turbines. Energy Conversion and Management. 2013;76: 899-909

[11] Kang S, Ahn K. Dynamic modeling of solid oxide fuel cell and engine hybrid system for distributed power generation. Applied Energy. 2017;195: 1086-1099

[12] Cao Y, Dai Y. Comparative analysis on off-design performance of a gas turbine and ORC combined cycle under different operation approaches. Energy Conversion and Management. 2017;135: 84-100

[13] Tsoutsanis E, Meskin N, Benammar M, Khorasani K. A component map tuning method for performance prediction and diagnostics of gas turbine compressors. Applied Energy. 2014;135:572-585

[14] Tsoutsanis E, Meskin N. Dynamic performance simulation and control of gas turbines used for hybrid gas/wind energy applications. Applied Thermal Engineering. 2019;147:122-142

[15] Amozegar M, Khorasani K. An ensemble of dynamic neural network identifiers for fault detection and isolation of gas turbine engines. Neural Networks. 2016;76: 106-121

[16] Fabio Ceschini G, Gatta N, Venturini M, Hubauer T, Murarasu A. Optimization of statistical methodologies for anomaly detection in gas turbine dynamic time series. Journal of Engineering for Gas Turbines and Power. 2018;140(3) 
[17] Tsoutsanis E, Meskin N,

Benammar M, Khorasani K. A dynamic prognosis scheme for flexible operation of gas turbines. Applied Energy. 2016; 164:686-701

[18] Tsoutsanis E, Meskin N. Derivativedriven window-based regression method for gas turbine performance prognostics. Energy. 2017;128:302-311

[19] Stamatis A, Mathioudakis K, Papailiou KD. Adaptive simulation of gas turbine performance. Journal of Engineering for Gas Turbines and Power. 1990;112(2):168-175

[20] Yu Y, Chen L, Sun F, Wu C. Neuralnetwork based analysis and prediction of a compressor's characteristic performance map. Applied Energy. 2007;84(1):48-55

[21] Crosa G, Pittaluga F, Trucco Martinengo A, Beltrami F, Torelli A, Traverso F. Heavy-duty gas turbine plant aerothermodynamic simulation using Simulink. In: ASME 1996 Turbo Asia Conference 1996. American Society of Mechanical Engineers Digital Collection. 1996

[22] Kim JH, Song TW, Kim TS, Ro ST. Model development and simulation of tansient behavoir of heavy duty gas turbines. Journal of Engineering for Gas Turbines and Power. 2001;123(3): 589-594

[23] Camporeale SM, Fortunato B, Mastrovito M. A modular code for real time dynamic simulation of gas turbines in simulink. Journal of Engineering for Gas Turbines and Power. 2006;128(3): 506-517

[24] Bracco S, Delfino F. A mathematical model for the dynamic simulation of low size cogeneration gas turbines within smart microgrids. Energy. 2017; 119:710-723

[25] Fawke AJ, Saravanamuttoo HI, Holmes M. Experimental verification of a digital computer simulation method for predicting gas turbine dynamic behaviour. Proceedings of the Institution of Mechanical Engineers. 1972;186(1):323-329

[26] Rowen WI. Simplified mathematical representations of heavy-duty gas turbines. Journal of Engineering for Gas Turbines and Power. 1983;105(4): 865-869

[27] Crosa G, Ferrari G, Trucco A. Steady-state and transient performance simulation of a turboshaft engine with free power turbine. In: Proceedings of the ASME Turbo Expo. Vol. 1999. 1995

[28] MacIsaac BD, Saravanamuttoo HIH. Digital and hybrid computing techniques for simulation of gas turbine performance. In: ASME Pap: Comparison of Analog. 1974

[29] Rahman NU, Whidborne JF. A numerical investigation into the effect of engine bleed on performance of a single-spool turbojet engine.

Proceedings Institution Mechanical Engineers G Journal of Aerospace Engineering. 2008;222(7):939-949

[30] Alexiou A, Roumeliotis I, Aretakis N, Tsalavoutas A, Mathioudakis K. Modeling contrarotating turbomachinery components for engine performance simulations: The geared turbofan with contrarotating core case. Journal of Engineering for Gas Turbines and Power. 2012;134(11)

[31] Rahman NU, Whidborne JF. Realtime transient three spool turbofan engine simulation: A hybrid approach. Journal of Engineering for Gas Turbines and Power. 2009;131(5)

[32] Wang C, Li YG, Yang BY. Transient performance simulation of aircraft engine integrated with fuel and control systems. Applied Thermal Engineering. 2017;114:1029-1037 
[33] Benato A, Bracco S, Stoppato A, Mirandola A. Dynamic simulation of combined cycle power plant cycling in the electricity market. Energy

Conversion and Management. 2016;107: 76-85

[34] Benato A, Stoppato A, Bracco S. Combined cycle power plants: A comparison between two different dynamic models to evaluate transient behaviour and residual life. Energy Conversion and Management. 2014;87: 1269-1280

[35] Benato A, Bracco S, Stoppato A, Mirandola A. LTE: A procedure to predict power plants dynamic behaviour and components lifetime reduction during transient operation. Applied Energy. 2016;162:880-891

[36] Walsh PP, Fletcher P. Gas Turbine Performance. John Wiley \& Sons, Ltd; 2004

[37] MacIsaac B, Langton R. Gas Turbine Propulsion Systems. John Wiley \& Sons, Ltd; 2011

[38] Rokke NA, Hustad JE, Berg S. Pollutant emissions from gas fired turbine engines in offshore practiceMeasurements and scaling. ASME. International Gas Turbine and Aeroengine Congress and Exposition, GT. 1993;1993:1993

[39] Pires TS, Cruz ME, Colaco MJ, Alves MAC. Application of nonlinear multivariable model predictive control to transient operation of a gas turbine and NOX emissions reduction. Energy. 2018;149:341-353

[40] Heier S. Grid integration of wind energy: Onshore and offshore conversion systems. Grid Integration of Wind Energy. John Wiley \& Sons, Ltd; 2014

[41] Alizadeh E, Meskin N, Khorasani K. A dendritic cell immune system inspired scheme for sensor fault detection and isolation of wind turbines. IEEE Transactions on Industrial Informatics. 2018;14(2):545-555

[42] Gao R, Gao Z. Pitch control for wind turbine systems using optimization, estimation and compensation. Renewable Energy. 2016;91:501-515

[43] Rezaeiha A, Kalkman I, Blocken B. Effect of pitch angle on power performance and aerodynamics of a vertical axis wind turbine. Applied Energy. 2017;197:132-150

[44] La Cava W, Danai K, Spector L, Fleming $\mathrm{P}$, Wright A, Lackner M. Automatic identification of wind turbine models using evolutionary multiobjective optimization. Renewable Energy. 2016;87:892-902

[45] Tsoutsanis E, Meskin N, Benammar M, Khorasani K. Transient gas turbine performance diagnostics through nonlinear adaptation of compressor and turbine maps. Journal of Engineering for Gas Turbines and Power. 2015;137(9)

[46] Tsoutsanis E, Li Y, Pilidis P, Newby M. Non-linear model calibration for off-design performance prediction of gas turbines with experimental data. Aeronautical Journal. 2017;121(1245): 1758-1777

[47] Wan A, Gu F, Jin J, Gu X, Ji Y. Modeling and optimization of shutdown process of combined cycle gas turbine under limited residual natural gas. Applied Thermal Engineering. 2016;101: 337-349

[48] Buttler A, Dinkel F, Franz S, Spliethoff H. Variability of wind and solar power an assessment of the current situation in the European Union based on the year 2014. Energy. 2016;106: 147-161

[49] Angerer M, Kahlert S, Spliethoff H. Transient simulation and fatigue 
evaluation of fast gas turbine startups and shutdowns in a combined cycle plant with an innovative thermal buffer storage. Energy. 2017;130:

246-257

[50] Muljadi E. Pitch-controlled variable-speed wind turbine generation. IEEE Transactions on Industry Applications. 2001;37(1):240-246

[51] Cheng WYY, Liu Y, Bourgeois AJ, $\mathrm{Wu} \mathrm{Y}$, Haupt SE. Short-term wind forecast of a data assimilation/weather forecasting system with wind turbine anemometer measurement assimilation. Renewable Energy. 2017;107:340-351 


\title{
Economic Analysis of Stand-Alone Hybrid Wind/PV/Diesel Water Pumping System: A Case Study in Egypt
}

\author{
Nagwa M. Khattab, Mervat A. Badr, \\ Essam Tawfik El Shenawy, Hassan H. Sharawy \\ and Marwa S. Shalaby
}

\begin{abstract}
The design and evaluation of a stand-alone hybrid renewable energy system for pumping underground water for small farm irrigation is presented. Given environmental conditions, system specifications and daily load demand data, the optimal size of main system components is obtained using a sizing algorithm. Different renewable energy systems are compared using yearly simulations, on hourly base via specialized commercial software simulation packages PVSYST and HOMER, to simulate the system performance and to reach the optimum configurations based on the objective criteria. The criteria used in economic optimization are the net present cost and the cost of energy, with the percent of the capacity shortage. The following systems can be compared: PV only, PV with horizontal axis wind turbine, $\mathrm{PV}$ with vertical axis wind turbine, and PV with horizontal axis wind turbine and diesel generator and diesel generator only. The simulation also was carried out for different load patterns for optimum operation. The study was illustrated for climatic conditions of an isolated area in El-Tour City, Sinai, Egypt. The installed $3.42 \mathrm{~kW} \mathrm{PV}$ water pumping system for irrigation purposes in the same site was also described.
\end{abstract}

Keywords: water pumping, stand-alone photovoltaic, wind turbine, hybrid system, diesel generator

\section{Introduction}

Egyptian Government has embarked an ambitious plan to develop new villages in the desert far from Nile River and Delta by reclaiming and cultivating 5 million acres over 5 years. The main challenge facing the government efforts is the inability of the current energy sources to provide those communities with the main infrastructures from energy and water to fulfill agriculture requirements. This is because these communities are small, scattered and located in the desert far from the electricity grid.

Hence, the Egyptian Government strategies targeted providing agriculture water requirements (pumping and irrigation) for new rural areas by applying renewable energy systems. Clean, renewable energies such as solar and wind are considered 
fast solutions to provide such communities with the energy necessities. The adopted approach has been motivated mainly by Egypt's location that is endowed with abundant solar energy, adequate average wind speed besides long sea shores and underground water.

Among the renewable energy options that are currently in wide use are solar photovoltaic (PV) and small wind turbines (WT) for water pumping and irrigation. Pumping water by mechanical wind mills in remote areas is an old technology $[1,2]$, and by renewable energy for the last few decades $[3,4]$. Recently, many users of the water pumping have switched to solar energy via photovoltaic pumping for small systems, while for larger systems the diesel generations are still predominant for pumping water in Egypt [5]. Compared to PV systems and mechanical wind mills, small wind turbines are still in limited uses for water pumping systems in remote areas. Using hybrid photovoltaic/wind turbine (PV/WT) improves the water pumping reliability and increases the daily volume of the pumped water.

Different studies concerning the individual PV water pumping (PVWP) and wind turbine water pumping (WTWP) systems focused on the dynamic performance of these systems, in particular the match between water demand and water supply [6]. Benghanem et al. [7] compared the performances of different PVWP configurations for different hydraulic heads. Kelley et al. [8] studied the feasibility of PVWP systems for irrigation as a function of location, while Rehman and Sahin [9] investigated the technical and economic performances of several small WTs to provide water in Saudi Arabia.

The performances of PVWP and WTWP systems have also been compared. Kumar and Kandpal [10] assessed the potential of PVWP and WTWP systems for irrigation in India. Diaz-Mendez et al. [11] presented a simple methodology to compare PVWP and WTWP for irrigation of commercial greenhouses in Spain, Cuba and Pakistan. The study mainly focused on the economic comparison between PVWP and WTWP systems for irrigation for three specific locations with no indication to the match between water demand and water supply and the effect of water supply on the crop yield.

One of the most important limitation facing applications of renewable energies is that no individual source of solar or wind energies is capable of supplying both reliability and cost-effective due to the intermittent nature of them. Moreover, fluctuations in production and time-dependent are other challenges for renewable energy utilization. Flexible demand management [12-14], and smart energy management $[15,16]$, are useful, but they do not fully suffice in maintaining the balance between production and demand of electricity.

Hybrid PV/WT systems which optimize the contribution of solar and wind energy sources generation to provide continuous base requirements are the better solution of this problem. Using a hybrid solar/wind system helps to use solar energy in case of small wind speed and use wind energy in case of low solar radiation levels. Vick and Neal [17] analyzed the operation of solar PV and wind turbine as individual systems as well as a PV/WT hybrid system as off-grid system for pumping water. It was found that the hybrid system delivered more energy than only PV or wind by an amount of $28 \%$. An additional buck/boost converter was also used as a controller to improve hybrid PV/WT water pumping system.

Research developments in the field of renewable energy-water pumping systems are reviewed by Gopal et al. [18]. They briefly reviewed hundreds of articles published in the water pumping systems and investigated five different system configurations with various types of energy; solar, wind, biomass, thermal and hybrid PV/ WT. They concluded that using renewable energy (solar or wind or hybrid) highly reduces the dependence of conventional energy with good environmental impact. 
According to the meteorological data measured for the city of Xanthi, Greece and their systematic design approach for three different systems for water pumping which are; PV, WT and hybrid PV/WT, Skretas and Papadopoulos [19] concluded that the performance of hybrid system was better than that of solar or wind only.

$\mathrm{Ma}$ et al. [20] introduced a new solution of the problem concerning the energy storage in the renewable energy systems, especially in standalone systems. In that work, an important and most traditional storage technology was used, this is the pumped hydro storage (PHS) with a standalone renewable energy system (solarwind). They developed a mathematical model for the hybrid solar-wind system and applied according to the operating parameters on a case study to feed the required energy to a remote area in Hong Kong and examined its technical feasibility. Time dependent simulation results showed that the inherent fluctuations nature of the renewable energy sources can be effectively compensated by applying the PHS technology. This can provide a reliable and clean energy source power supply. They concluded that $100 \%$ of the energy autonomy in remote and rural areas can be achieved by pumped hydro storage-based hybrid renewable energy.

Many researchers used two public models for optimizing the hybrid renewable energy systems [21-23]. The first model was hybrid optimization model of electric renewable (HOMER) and the second was hybrid solar-wind system optimization model (HSWSO) [24]. The second model mainly used when using a storage battery bank in the hybrid system. The optimization process of the hybrid systems concluded that using a storage tank for water storage is more cost effective than using a storage battery bank in hybrid solar-wind system, due to the higher maintenance and operation costs of the batteries and vice versa for the water storage.

Yahyaoui et al. [25] optimized the design of a hybrid solar-wind-pumped storage system in standalone mode for an isolated area. The initial design process of the system's major components was presented, and optimized based on a technoeconomic evaluation. The proposed design was evaluated using yearly simulations, on hourly base, performed by specialized commercial software, PVSYST.

A methodology for optimal sizing design and strategy control based on differential flatness approach was applied to the hybrid stand-alone PV/WT systems by Tégania et al. [26]. The aim was to find, according to life time of the system provided that the required load energy is completely supplied by the system, the optimal design of the system components that ensure minimum system costs. The problem formulation and the generic algorithm are used in optimization methodology to optimally configure the system, and the results are obtained using MATLAB/Simulink.

Therefore, the hybrid PV/WT system is usually installed to supply water in remote areas with considerably less costs and more reliable operation in case of inherent fluctuations of the renewable energy sources. The present study describes the main components of the installed stand-alone $3.42 \mathrm{~kW}$ PV water pumping system for irrigation purposes in El-Tour city, Sinai, Egypt. To investigate the feasibility of small, decentralized hybrid PV/WT system for water required for irrigation purposes, a theoretical comparison between different renewable energy systems for water pumping is carried out in the selected site based on using yearly simulations, on hourly base via specialized commercial software simulation packages PVSYST and HOMER, for optimum operation. The compared systems are: (i) PV only, (ii) $\mathrm{PV}$ with horizontal axis wind turbine (PV/HAWT), (iii) PV with vertical axis wind turbine (PV/VAWT), (iv) PV with horizontal axis wind turbine and diesel generator (PV/HAWT/D) and (v) diesel generator only. The criteria used in economic optimization are the net present cost, the cost of energy with the amount of unmet load or percent of energy shortage. The optimization process was carried out for different load patterns. 


\section{Installed PV/water pumping system}

The installed small water pumping system is used to deliver water from a well for agriculture purposes in El-Tour city, Sinai, Egypt (latitude of $28.22^{\circ} \mathrm{N}$ and longitude of $33.61^{\circ} \mathrm{E}$ ). The system consists of; the PV arrays, mechanical structure, pump controller and water pump.

Table 1 shows the site parameters; air temperature, wind speed and solar radiation levels, as average values. It is clear that the site has an annual average air temperature of $20.9^{\circ} \mathrm{C}$ with low values of wind speed reaches maximum value of $7 \mathrm{~m} /$ second which can be considered considerably low levels of wind speed. Figure 1 shows irradiation levels on a horizontal and an optimally tilted surface $\left(30^{\circ}\right)$ in El-Tour, Sinai [27]. It is seen that the location has high irradiation levels all

\begin{tabular}{lccc}
\hline $\begin{array}{l}\text { Month (average } \\
\text { values) }\end{array}$ & $\begin{array}{c}\text { Air temperature } \\
\left({ }^{\circ} \mathbf{C}\right)\end{array}$ & $\begin{array}{c}\text { IR on optimally tilted surface } \\
\left(\mathbf{W h} / \mathbf{m}^{2} / \mathbf{d a y}\right)\end{array}$ & $\begin{array}{c}\text { Wind speed } \\
(\mathbf{m} / \text { second })\end{array}$ \\
\hline January & 11.8 & 5650 & 4.70 \\
\hline February & 12.7 & 6520 & 5.00 \\
\hline March & 16.2 & 7760 & 4.70 \\
\hline April & 21.0 & 7190 & 6.00 \\
\hline May & 24.7 & 7200 & 6.50 \\
\hline June & 26.8 & 7350 & 6.00 \\
\hline July & 28.2 & 7320 & 5.90 \\
\hline August & 28.1 & 7430 & 7.00 \\
\hline September & 26.4 & 7290 & 6.00 \\
\hline October & 22.8 & 7010 & 5.30 \\
\hline November & 18.1 & 6100 & 4.90 \\
\hline December & 13.4 & 5510 & 4.30 \\
\hline Annual & 20.9 & 6860 & 5.53 \\
\hline
\end{tabular}

Table 1.

Average air temperature, wind speed and solar radiation levels in El-Tour, Sinai.

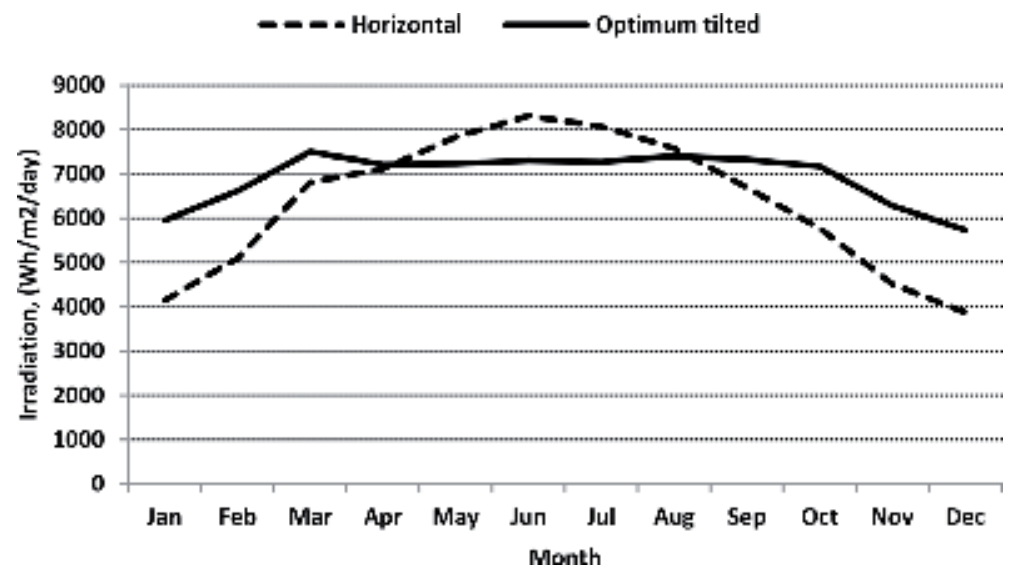

Figure 1.

Average irradiation levels on a horizontal and an optimally tilted surface in El-Tour, Sinai. 
Economic Analysis of Stand-Alone Hybrid Wind/PV/Diesel Water Pumping System: A Case... DOI: http://dx.doi.org/10.5772/intechopen.89161

over the year with an annual average of $6.86 \mathrm{kWh} / \mathrm{m}^{2} /$ day on an optimally tilted surface. This average value can be considered one of the highest irradiation levels all over the world.

\begin{tabular}{lc}
\hline Item & Specifications \\
\hline Module power & $190 \mathrm{~W}$ \\
\hline Module cells & 48 \\
\hline Number of modules & 18 \\
\hline $\mathrm{V}_{\mathrm{OC}}$ & $29.76 \mathrm{~V}$ \\
\hline $\mathrm{I}_{\mathrm{SC}}$ & $8.47 \mathrm{~A}$ \\
\hline $\mathrm{V}_{\mathrm{MP}}$ & $24 \mathrm{~V}$ \\
\hline $\mathrm{I}_{\mathrm{MP}}$ & $8.02 \mathrm{~A}$ \\
\hline
\end{tabular}

Table 2.

Characteristics of the PV system.

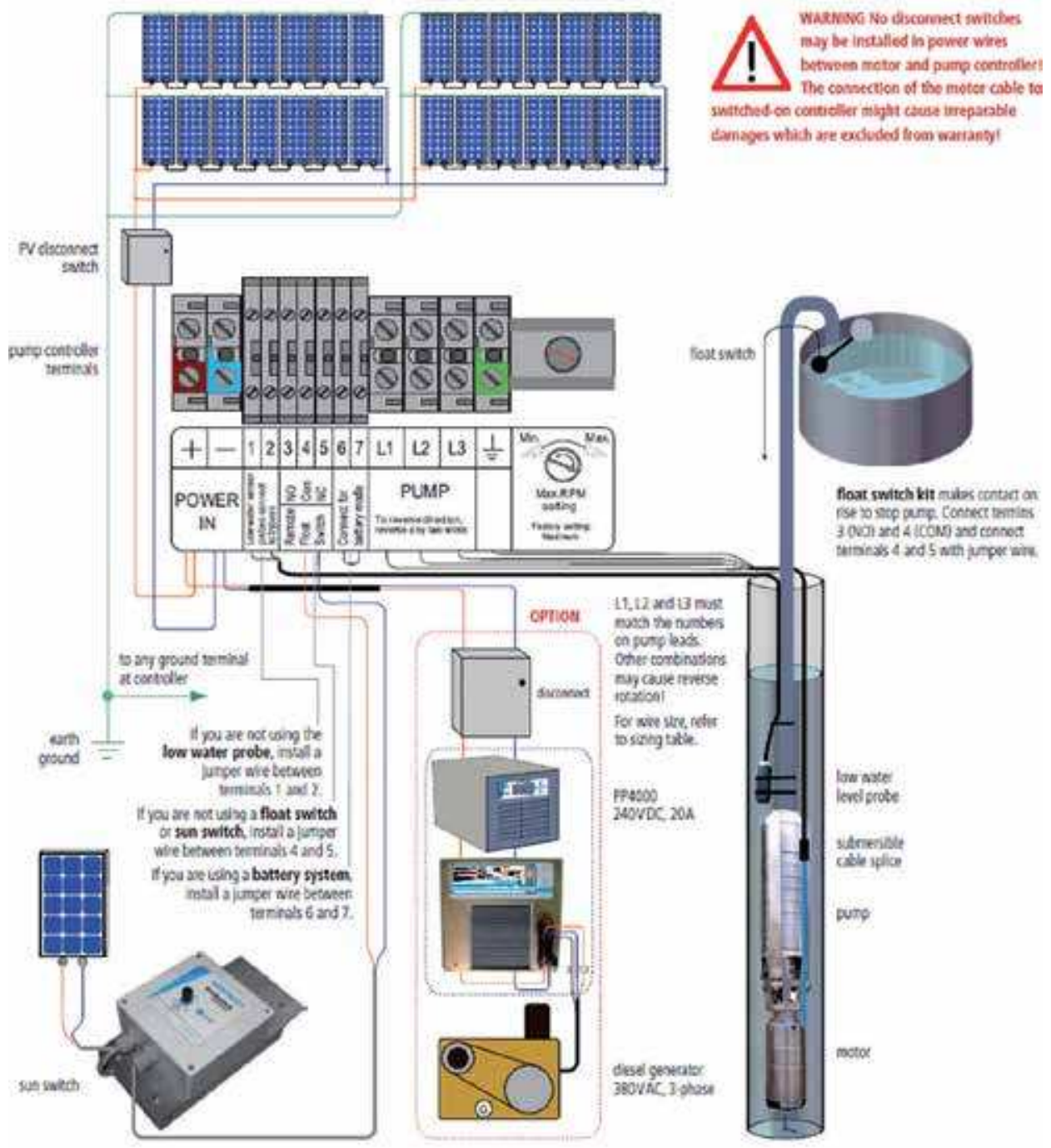

Figure 2.

Wiring diagram of the pump controller. 


\subsection{PV arrays}

The PV system which is to drive the water pump motor, consists of $3.42 \mathrm{~kW}-\mathrm{PV}$ power (18 PV modules) arranged in two parallel strings, each of them has nine modules connected in series. According to this arrangement, the PV system gives operating voltage about $216 \mathrm{~V}$ and $16 \mathrm{~A}$ at standard test conditions (STCs; $1000 \mathrm{w} / \mathrm{m}^{2}$ of irradiance, $25^{\circ}$ of module temperature and $1.5 \mathrm{AM}$ ). Table 2 exhibits the characteristics of the used PV modules at STC.

\subsection{Supporting structure}

The supporting structure is used to fix the PV system facing south at tilt angle of $30^{\circ}$ on the horizontal surface for optimum irradiation collection over the year. It is made of galvanized aluminum rods fitted via aluminum joints supported on eight concrete bases in order to ensure a stable and secure operation and to avoid vibrations or falling. This structure must withstand the environmental conditions of higher temperatures, humidity and wind speeds up to $15 \mathrm{~m} / \mathrm{second}$.

\subsection{Pump controller}

The pump controller is used to drive the pump electric motor via converting the input DC power from the PV arrays to the required AC power, voltages and currents suitable for the pump operation. The controller has many indicators to fully monitor the system operation. There are many protections features in the controller to safely start the pump at very low irradiation levels and protect it from vibrations and over load. Figure 2 shows the pump controller and the wiring diagram, while Table 3 illustrates the controller's parameter specifications.

\subsection{Water pump}

The water pump is solar-operated submersible pump with maximum flow rate of $7 \mathrm{~m}^{3} /$ hour and maximum head of $140 \mathrm{~m}$. The pump has maintenance-free

\begin{tabular}{ccccccccc}
\hline Parameter & $\begin{array}{c}\text { Power } \\
(\mathbf{k W})\end{array}$ & $\begin{array}{c}\text { Input } \\
\text { voltage } \\
(\mathrm{V})\end{array}$ & $\begin{array}{c}\text { Optimum } \\
\text { voltage } \\
(\mathrm{V})\end{array}$ & $\begin{array}{c}\text { Motor } \\
\text { current } \\
(\mathbf{A})\end{array}$ & $\begin{array}{c}\text { Efficiency } \\
(\%)\end{array}$ & $\begin{array}{c}\text { Ambient } \\
\text { temperature } \\
\left({ }^{\circ} \mathbf{C}\right)\end{array}$ & $\begin{array}{c}\text { Enclosure } \\
\text { class }\end{array}$ & $\begin{array}{c}\text { Weight } \\
(\mathbf{k g})\end{array}$ \\
\hline Specification & 4 & $\begin{array}{c}\text { Max } \\
375\end{array}$ & 238 & Max 15 & 98 & -30 to 50 & IP54 & 9 \\
\hline
\end{tabular}

Table 3.

Parameters of the pump controller.

\begin{tabular}{lc}
\hline Parameter & Specification \\
\hline Rated power & $3.5 \mathrm{~kW}$ \\
\hline Efficiency & $92 \%$ \\
\hline Motor speed & $900-3300 \mathrm{rpm}$ \\
\hline Enclosure class & IP68 \\
\hline Submersion & Max $250 \mathrm{~m}$ \\
\hline Weight of motor and pump & $18 \mathrm{~kg}$ \\
\hline
\end{tabular}

Table 4.

Electrical parameters of the pump motor. 


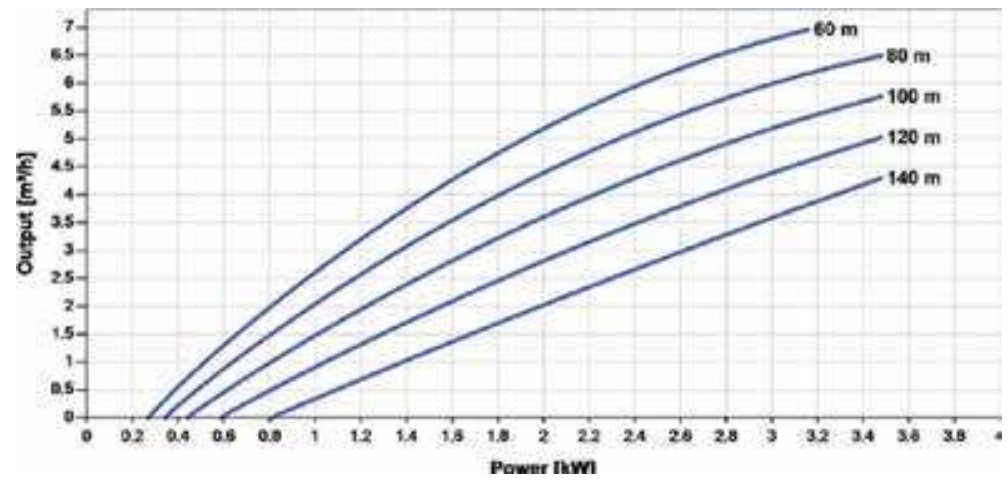

Figure 3.

Solar pump chart.

brushless DC motor, has no electronics in the motor. The electrical parameters of the pump motor are given in Table 4, while Figure 3 illustrates the pump chart.

\section{Optimization of hybrid PV/WT pumping system}

To reach optimum system configurations, alternative configurations supplying the estimated daily load pattern are used to simulate the system performance. The optimum system fulfills the load requirements within the acceptable percentage of unmet load which is one of the decision variables. Optimality condition is based on the objective minimum cost which is defined by two criteria; the first is the minimum net present cost (NPC) and the second is the cost of energy (COE) generated from the system.

\subsection{Hourly load curve estimation}

The daily quantity of water required for irrigation is about $50 \mathrm{~m}^{3}$ in summer and $42 \mathrm{~m}^{3}$ in winter. Water is pumped for 7 hours on average. Thus, the hourly pumped quantity is $7 \mathrm{~m}^{3} /$ hour for summer and $6 \mathrm{~m}^{3} /$ hour for winter. The submersed pump is installed at a distance $41 \mathrm{~m}$ from ground level, assuming that the tank is at $2 \mathrm{~m}$ above the ground, and then the total elevating head is $43 \mathrm{~m}$. Then the electrical power required for water pumping for summer is about $1.5 \mathrm{~kW}$ and for winter $1.3 \mathrm{~kW}$. The estimated hourly electrical load is shown in Table 5.

\begin{tabular}{ccccc}
\hline Time (hour) & \multicolumn{2}{c}{ Winter } & \multicolumn{2}{c}{ Summer } \\
\cline { 2 - 5 } & $\mathbf{Q}\left(\mathbf{M}^{3} / \mathbf{h o u r}\right)$ & $\mathbf{k W}$ & $\mathbf{Q}\left(\mathbf{M}^{3} / \mathbf{h o u r}\right)$ & $\mathbf{k W}$ \\
\hline 10 & 3 & 0.65 & 3 & 0.65 \\
\hline 11 & 6 & 1.3 & 7 & 1.5 \\
\hline 12 & 8 & 1.7 & 10 & 2.14 \\
\hline 13 & 8 & 1.7 & 10 & 2.14 \\
\hline 14 & 8 & 1.7 & 10 & 2.14 \\
\hline 15 & 6 & 1.3 & 7 & 1.5 \\
\hline 16 & 3 & 0.65 & 3 & 0.65 \\
\hline
\end{tabular}

Table 5.

Hourly electric load of water pumping system. 
For economic comparison purposes of the hybrid PV/WT pumping systems, five cases of the different investigated system configurations are simulated and analyzed using software packages PVSYST and HOMER. The proposed systems are as follows: (i) PV system, (ii) PV/HAWT), (iii) PV/VAWT, (iv) PV/VAWT/D and (v) diesel only system. The simulation is also carried out for different load patterns.

\section{Results and discussion}

\subsection{Case 1: PV only}

In this case, the system used the PV arrays only to drive the pump via a converter. Four batteries (12 V, $200 \mathrm{AH}$ each) were included in the system simulation to control the energy shortage. The NPC and COE resulted from system simulation over 25 years are shown in Table 6 .

From Table 6, the total NPC of the PV system is 22,523\$ and COE is $0.614 \$$ / $\mathrm{kWh}$. The capacity shortage is about $8 \%$ of the total load, although four batteries are included in the system simulation. Figures $\mathbf{4}$ and 5 illustrate the cash flow and energy flow summaries of PV pumping system.

The cash flow summary shows that the capital cost of the PV modules is $5000 \$$ and the O\&M costs over 25 years lifetime is $5337 \$$, this means that the total PV costs over the simulation period is $10,337 \$$. The batteries capital $1800 \$$, replacement cost over system lifetime is $4903 \$$ and batteries O\&M cost is $2135 \$$. Hence the total batteries cost is $8711 \$$. This means that batteries total cost is about $38.7 \%$ of system total NPC. The energy summary (Figure 8) shows that although $4.7 \%$ of the load is not supported (unmet load) about $31.6 \%$ of the generated electricity is wasted (excess energy).

\subsection{Case 2: PV/HAWT}

The second case used hybrid PV arrays with $1 \mathrm{~kW}$ horizontal axis wind turbine to drive the pumping system via controller in addition to the four batteries used in case 1 . The simulation was carried out for two cases according to the life time of the PV array ( 25 years) and lifetime of the wind turbine (15 years). The power curve of the used wind turbine is shown in Figure 9. It is clear that the monthly average wind speed on site are $5.53 \mathrm{~m} /$ second (Table 1) which is much lower than the turbine rated wind speed about $10 \mathrm{~m} / \mathrm{second}$ (Figure 6), which is greatly affect to the performance of the used wind turbine and hence overall system economics.

Tables 7 and 8 show the simulation results of the PV/HAWT pumping system over 25 and 15 years, respectively. It is clear that the NPC of the system are 31,988 and $25,019 \$$ while the COE are 0.855 and $0.834 \$ / \mathrm{kWh}$ for both cases, which are higher than case of PV only (Table 6). In other words, the PV system is more economic than PV/HAWT, due to the lower values of the monthly average wind speed on site than the turbine rated wind speed.

\begin{tabular}{|c|c|c|c|c|c|c|c|c|c|c|}
\hline 雨 & $\begin{array}{l}\text { PV } \\
(\mathrm{kW})\end{array}$ & 6FM200D & $\begin{array}{l}\text { Conv. } \\
(\mathrm{kW})\end{array}$ & $\begin{array}{l}\text { Disp. } \\
\text { Strgy }\end{array}$ & $\begin{array}{c}\text { Initial } \\
\text { Capital }\end{array}$ & $\begin{array}{c}\text { Operating } \\
\text { Cost (\$/yr) }\end{array}$ & $\begin{array}{l}\text { Total } \\
\text { NPC }\end{array}$ & \begin{tabular}{|c|}
$\mathrm{COE}$ \\
$(\mathrm{S} / \mathrm{kWh})$
\end{tabular} & $\begin{array}{l}\text { Ren. } \\
\text { Frac. }\end{array}$ & $\begin{array}{l}\text { Capacity } \\
\text { Shortage } \\
\end{array}$ \\
\hline 雨田 & 3.3 & 4 & 5 & $\mathrm{CC}$ & $\$ 8,3$ & 1,332 & $\$ 22,523$ & 0.614 & 1.00 & 0.08 \\
\hline 㧒田 & 3.3 & 4 & 5 & LF & $\$ 8.3$ & 1,332 & $\$ 22,523$ & 0.614 & 1.00 & 0.08 \\
\hline
\end{tabular}

Table 6.

NPC and COE of PV system for water pumping. 
Economic Analysis of Stand-Alone Hybrid Wind/PV/Diesel Water Pumping System: A Case... DOI: http://dx.doi.org/10.5772/intechopen.89161

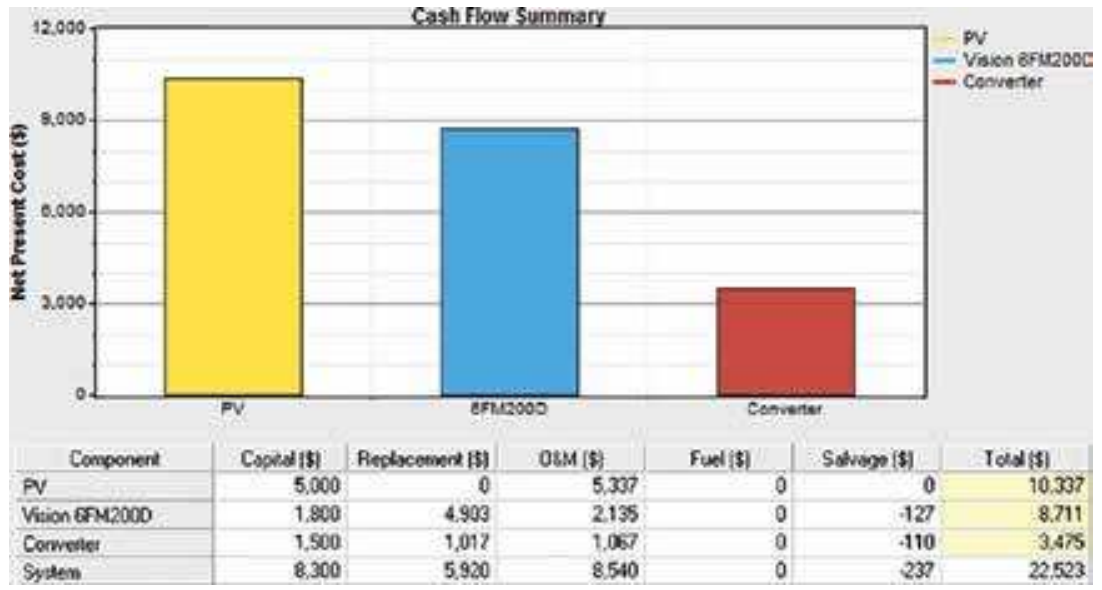

Figure 4 .

Cash flow summary of $P V$ pumping system.

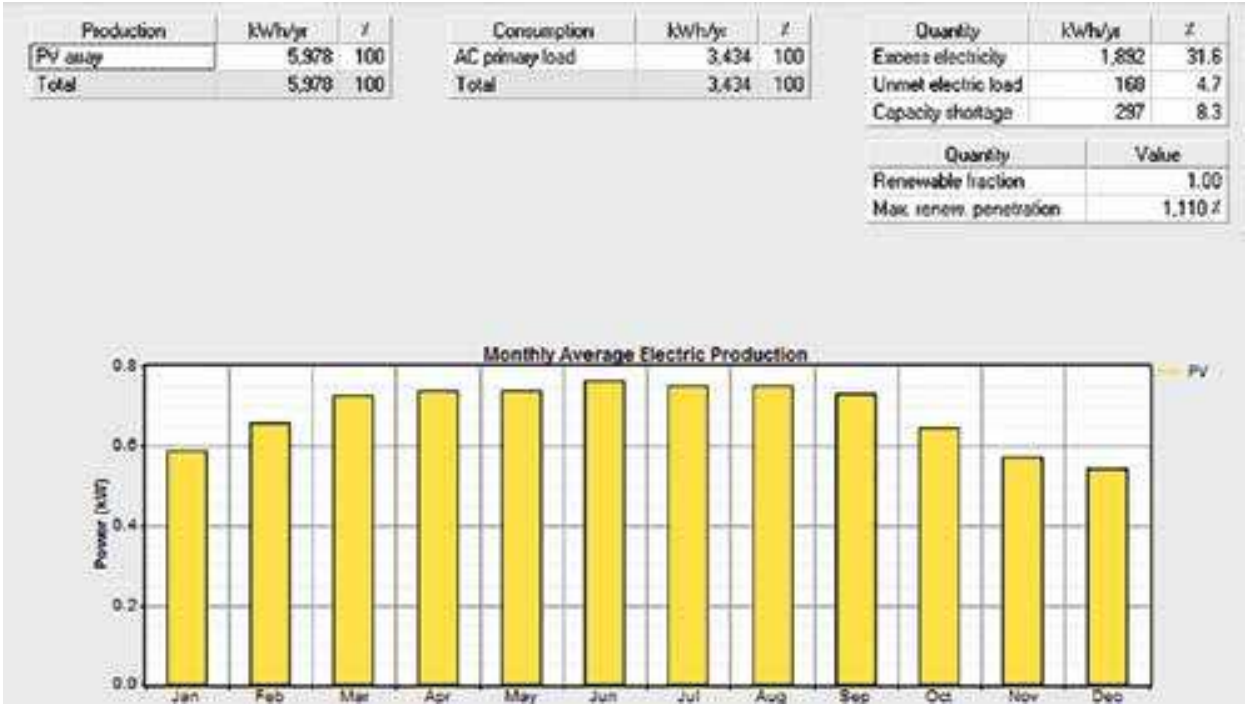

Figure 5 .

Energy summary of $P V$ pumping system.

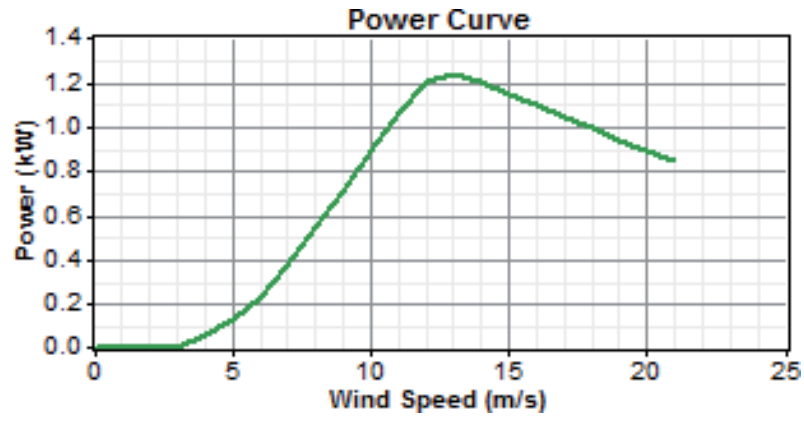

Figure 6.

Wind turbine power curve. 


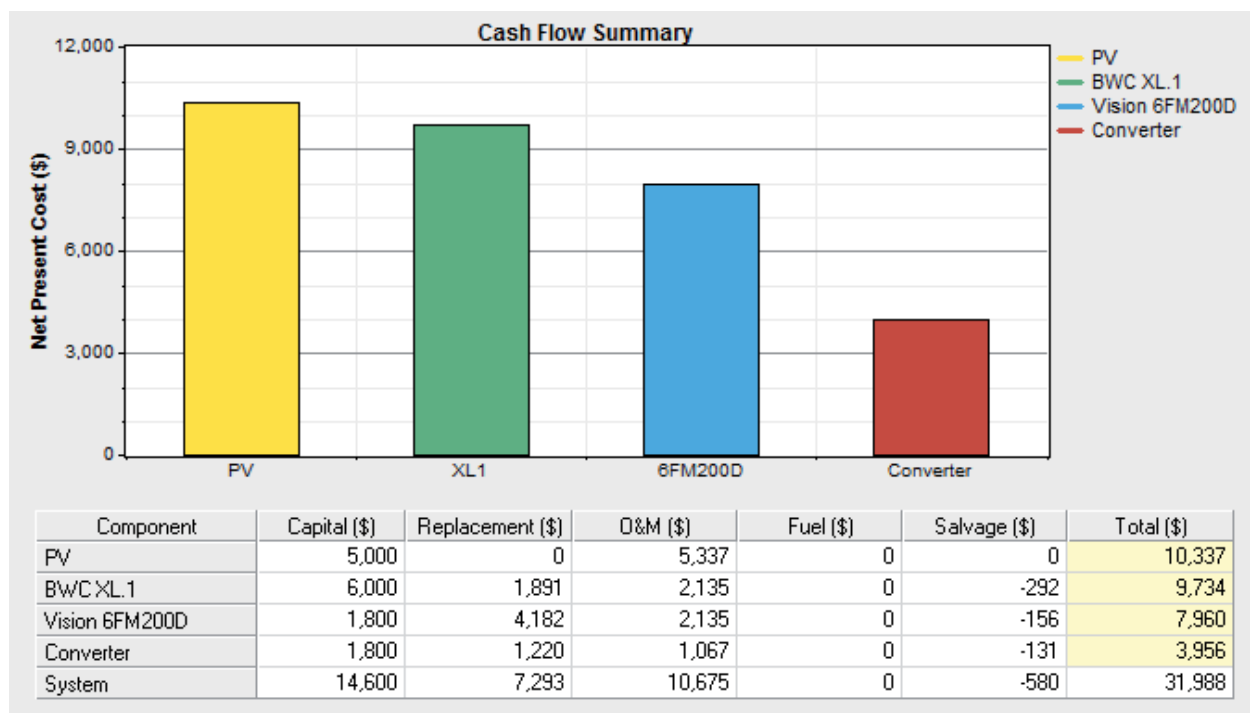

Figure 7.

Cash flow summary of PV/HAWT pumping system (25 years).

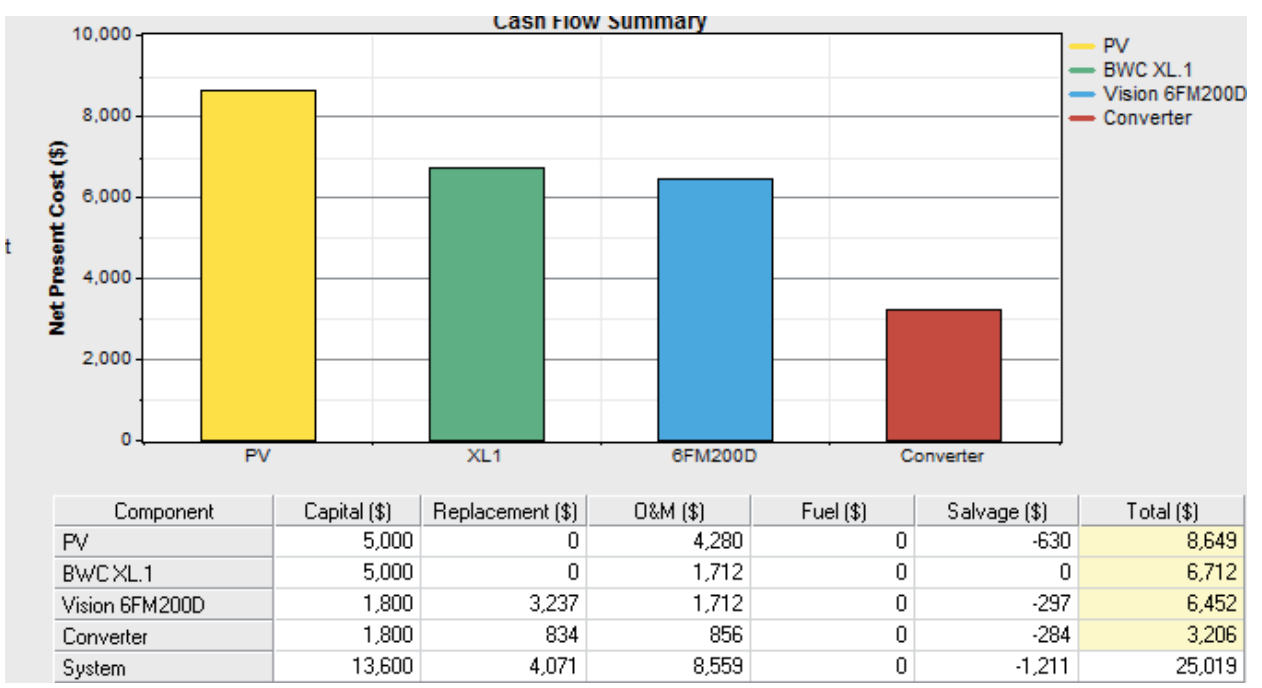

Figure 8.

Cash flow summary of PV/HAWT pumping system (15 years).

Figures 7 and 8 present the cash flow summary of the system simulation over 25 and 15 years while Figure 9 illustrates the PV/HAWT system energy summary ( 25 years). It is clear that the operation of 15 years only saves the replacement of the wind turbine and reduces the system O\&M costs. Figure 9 shows that about $44.2 \%$ of the generated electricity is not used (excess energy) which may explain the increase in the COE while only $3.9 \%$ of capacity shortage of the load is not supported, which is less than that of PV system only $(8.3 \%$, Figure 5).

\subsection{Case 3: PV/VAWT}

For comparison between horizontal and vertical axis wind turbines, case 3 represented the water pumping system derived by PV arrays with vertical axis wind 
Economic Analysis of Stand-Alone Hybrid Wind/PV/Diesel Water Pumping System: A Case... DOI: http://dx.doi.org/10.5772/intechopen.89161

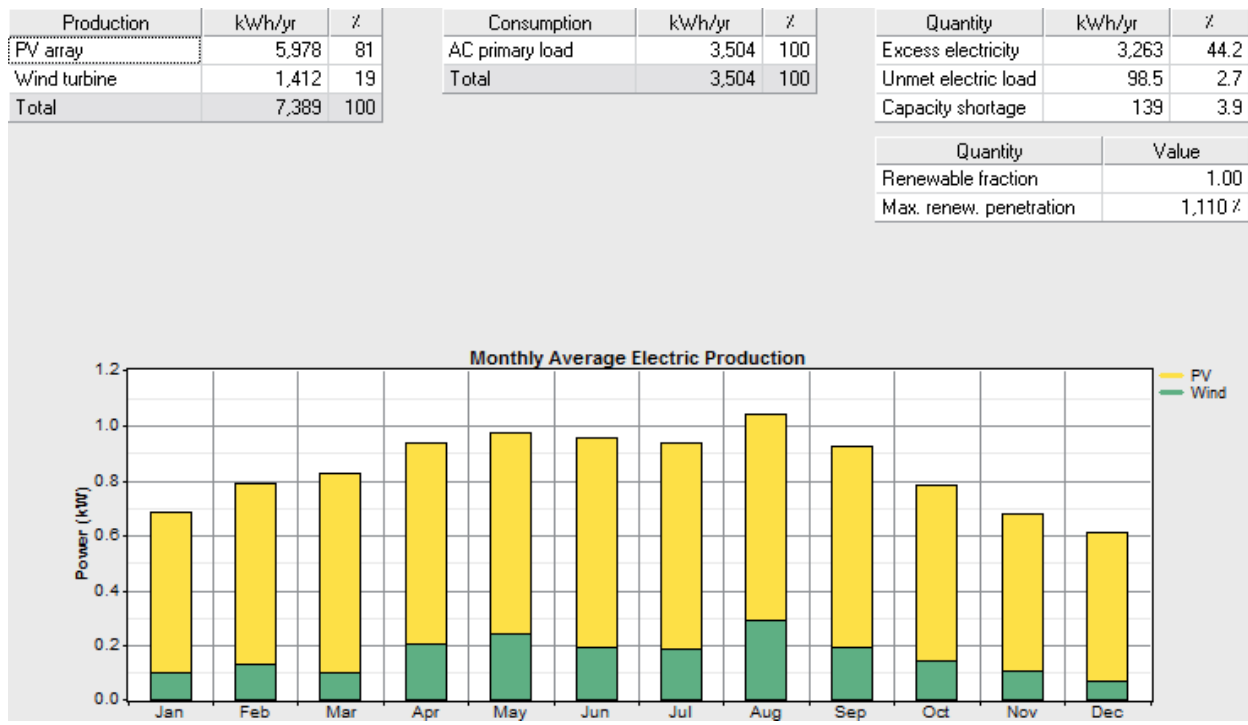

Figure 9.

Energy summary of PV/HAWT pumping system.

\begin{tabular}{|c|c|c|c|c|c|c|c|c|c|c|c|c|}
\hline$\$^{\prime}$ & + 目 & $\begin{array}{c}\mathrm{PV} \\
(\mathrm{kW})\end{array}$ & $\mathrm{XL1}$ & 6FM200D & $\begin{array}{l}\text { Conv. } \\
(\mathrm{kW})\end{array}$ & $\begin{array}{l}\text { Disp. } \\
\text { Strgy }\end{array}$ & $\begin{array}{c}\text { Initial } \\
\text { Capital }\end{array}$ & $\begin{array}{l}\text { Operating } \\
\text { Cost }(\$ / y r)\end{array}$ & $\begin{array}{l}\text { Total } \\
\text { NPC }\end{array}$ & $\begin{array}{c}\mathrm{COE} \\
(\$ / \mathrm{kWh})\end{array}$ & $\begin{array}{l}\text { Ren. } \\
\text { Frac. }\end{array}$ & \begin{tabular}{|l|} 
Capacity \\
Shortage
\end{tabular} \\
\hline & 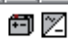 & 3.3 & & 4 & 5 & $\mathrm{CC}$ & $\$ 8,6$ & 1.349 & $\$ 23,004$ & 0.627 & 1.00 & 0.06 \\
\hline & 2 & 3.3 & & 4 & 5 & LF & $\$ 8,6$ & 1,349 & $\$ 23,004$ & 0.627 & 1.00 & 0.06 \\
\hline 7 & 2 & 3.3 & 1 & 4 & 5 & $C C$ & $\$ 14,6$ & 1,629 & $\$ 31,988$ & 0.855 & 1.00 & 0.04 \\
\hline 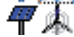 & Z & 3.3 & 1 & 4 & 5 & LF & $\$ 14,6$ & 1.629 & $\$ 31,988$ & 0.855 & 1.00 & 0.04 \\
\hline
\end{tabular}

Table 7 .

Optimization results of hybrid PV/HAWT pumping system (25 years).

\begin{tabular}{|c|c|c|c|c|c|c|c|c|c|c|c|c|}
\hline$\pi /$ & 国 & $\begin{array}{l}\mathrm{PV} \\
(\mathrm{kW})\end{array}$ & $\mathrm{XL1}$ & 6FM200D & $\begin{array}{l}\text { Conv. } \\
(\mathrm{kW})\end{array}$ & $\begin{array}{l}\text { Disp. } \\
\text { Strgy }\end{array}$ & $\begin{array}{c}\text { Initial } \\
\text { Capital }\end{array}$ & $\begin{array}{c}\text { Operating } \\
\text { Cost (\$/yr) }\end{array}$ & $\begin{array}{l}\text { Total } \\
\text { NPC }\end{array}$ & \begin{tabular}{|c|}
$\mathrm{COE}$ \\
$(\$ / \mathrm{kWh})$
\end{tabular} \mid & $\begin{array}{l}\text { Ren. } \\
\text { Frac. }\end{array}$ & \begin{tabular}{|l|} 
Capacity \\
Shortage
\end{tabular} \\
\hline & 8 & 3.3 & & 4 & 5 & $\mathrm{CC}$ & $\$ 8.6$ & 1,203 & $\$ 18,897$ & 0.643 & 1.00 & 0.06 \\
\hline & 图 & 3.3 & & 4 & 5 & $\mathrm{LF}$ & $\$ 8.6$ & 1.203 & $\$ 18,897$ & 0.643 & 1.00 & 0.06 \\
\hline 7 & 图 & 3.3 & 1 & 4 & 5 & $\mathrm{CC}$ & $\$ 13,6$ & 1,334 & $\$ 25,019$ & 0.834 & 1.00 & 0.04 \\
\hline & 图 & 3.3 & 1 & 4 & 5 & LF & $\$ 13,6$ & 1,334 & $\$ 25,019$ & 0.834 & 1.00 & 0.04 \\
\hline
\end{tabular}

Table 8.

Optimization results of hybrid PV/HAWT pumping system (15 years).

\begin{tabular}{|c|c|c|c|c|c|c|c|c|c|c|c|c|}
\hline$\triangle \pi^{\top}$ & 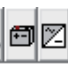 & $\begin{array}{c}\mathrm{PV} \\
(\mathrm{kW})\end{array}$ & AS & 6FM200D & $\begin{array}{l}\text { Conv. } \\
\text { (kW) }\end{array}$ & $\begin{array}{l}\text { Disp. } \\
\text { Strgy }\end{array}$ & $\begin{array}{c}\text { Initial } \\
\text { Capital }\end{array}$ & $\begin{array}{l}\text { Operating } \\
\text { Cost }(\$ / y r)\end{array}$ & $\begin{array}{l}\text { Total } \\
\text { NPC }\end{array}$ & \begin{tabular}{|c|c}
$\mathrm{COE}$ \\
$(\$ / \mathrm{kWh})$
\end{tabular} & $\begin{array}{l}\text { Ren. } \\
\text { Frac. }\end{array}$ & \begin{tabular}{|l|} 
Capacity \\
Shortage \\
\end{tabular} \\
\hline 9 & 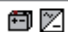 & 3.3 & & 4 & 5 & $\mathrm{CC}$ & $\$ 8,600$ & 1,203 & $\$ 18,897$ & 0.643 & 1.00 & 0.06 \\
\hline & 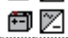 & 3.3 & & 4 & 5 & LF & $\$ 8,600$ & 1.203 & $\$ 18,897$ & 0.643 & 1.00 & 0.06 \\
\hline 个 & 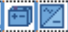 & 3.3 & 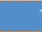 & 4 & 5 & $C C$ & $\$ 13,600$ & 1.195 & $\$ 23.825$ & 0.790 & 1.00 & 0.03 \\
\hline$\$ 1$ & $\theta$ & 3.3 & 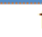 & 4 & 5 & LF & $\$ 13,600$ & 1.195 & $\$ 23,825$ & 0.790 & 1.00 & 0.03 \\
\hline
\end{tabular}

Table 9.

Optimization results of PV/VAWT pumping system.

turbine via pump converter with the pre-described storage batteries. The system was simulated for 15 years. Table 9 exhibits the optimization results of system and Figures 10 and 11 present the system cash flow summary and energy summary, respectively. 
Table 9 shows that the NPC of PV/VAWT is $23,285 \$$ and the COE is $0.790 \$$ / $\mathrm{kWh}$. The energy summary (Figure 11) shows that the excess energy recorded in this case is about $49.6 \%$ (compared to $31.6 \%$ in case of PV system and $44.2 \%$ in case of PV/HAWT). In fact, the amount of increase in excess energy is almost equal to the energy generated from the wind turbine. Hence it is recommended to use this abandoned energy in elevating more water that could be used for irrigation or domestic use. In this case the COE generated from the PV/VAWT will be reduced. From Figures 9 and 11, it is clear that the capacity shortages are almost equals for both types of wind turbines (PV/HAWT, 3.9 and PV/VAWT, 3.1).

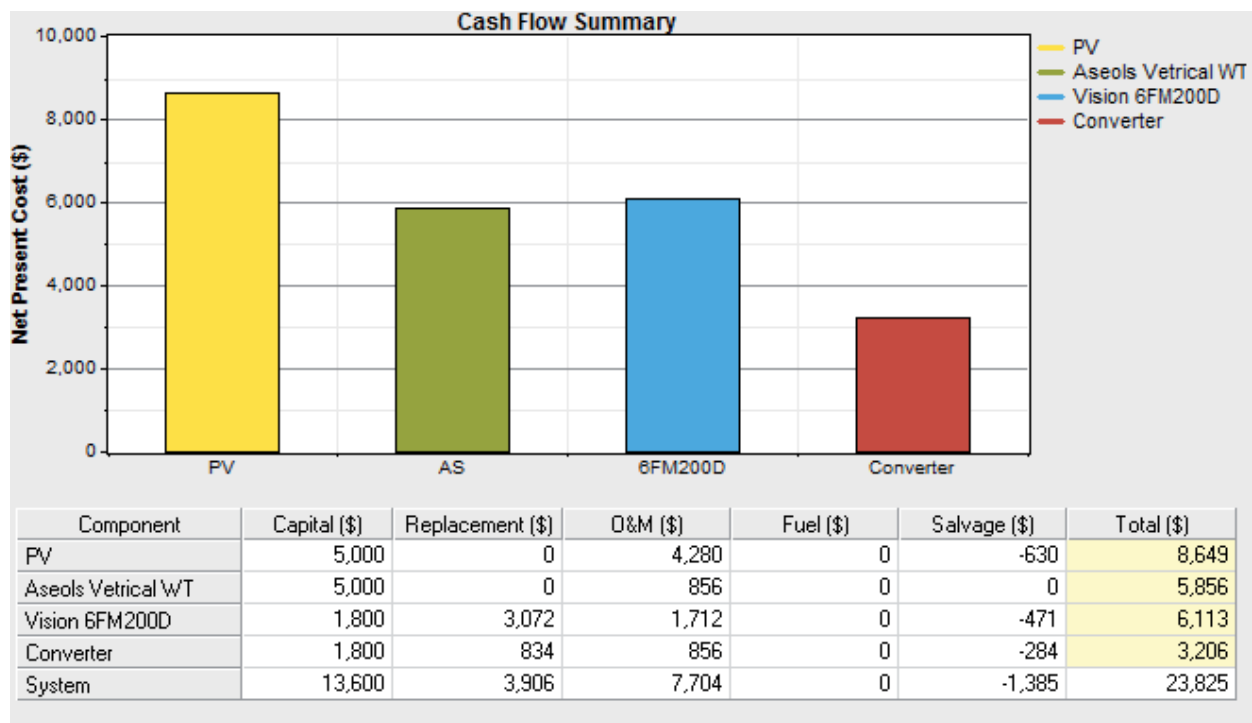

Figure 10.

Cash flow summary of PV/VAWT pumping system.

\begin{tabular}{|c|c|c|c|c|c|c|c|c|}
\hline Production & $\mathrm{kWh} / \mathrm{yr}$ & $\%$ & Consumption & $\mathrm{kWh} / \mathrm{yr}$ & $\%$ & Quantity & $\mathrm{kWh} / \mathrm{yr}$ & $\%$ \\
\hline PV array & 5,978 & 73 & AC primary load & 3,523 & 100 & Excess electricity & 4,057 & 49.6 \\
\hline Wind turbine & 2,209 & 27 & Total & 3,523 & 100 & Unmet electric load & 79.1 & 2.2 \\
\hline Total & 8.186 & 100 & & & & Capacity shortage & 113 & 3.1 \\
\hline & & & & & & \multicolumn{2}{|l|}{ Quantity } & alue \\
\hline & & & & & & \multicolumn{2}{|l|}{ Renewable fraction } & 1.00 \\
\hline & & & & & & \multicolumn{2}{|c|}{ Max. renew. penetration } & $1.130 \%$ \\
\hline
\end{tabular}

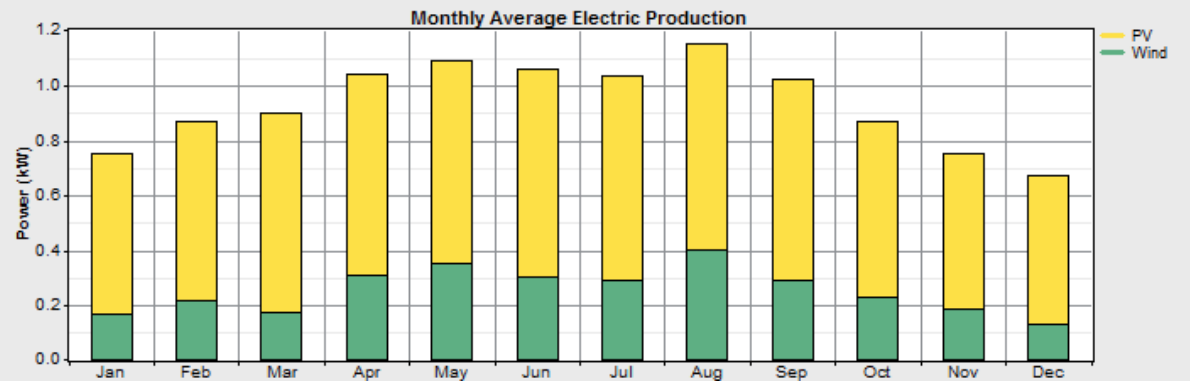

Figure 11.

Energy summary of PV/VAWT pumping system. 
Economic Analysis of Stand-Alone Hybrid Wind/PV/Diesel Water Pumping System: A Case... DOI: http://dx.doi.org/10.5772/intechopen.89161

\subsection{Case 4: PV/HAWT/diesel}

Case 4 represents a PV array with HAWT with diesel generator to supply the required electrical energy for the water pumping system with the required pump converter with batteries. Table 10 shows the simulation results of the proposed system for 15 years, while Figures 12 and $\mathbf{1 3}$ present the system cash flow summary and energy summary.

Table 10 showed that the NPC for PV/HAWT/diesel system is 26,383\$ and COE is $0.857 \$ / \mathrm{kWh}$, which is slightly more than that of PV/VAWT or PV/HAWT and higher than that of PV system only $(0.643 \$ / \mathrm{kWh})$. The energy summary (Figure 16) also shows that the excess energy is about $43.9 \%$ of the generated electricity; hence the same recommendation of energy management applies. The great advantage of this system configuration is the smallest capacity shortage $(0.4 \%)$.

\subsection{Case 5: diesel alone}

For the sake of comparison, it was assumed that the required electrical energy for water pumping is supplied by a diesel generator only. The length of the simulation run is 15 years. Table 11 presents the NPC and COE based on fuel price of $0.4 \$ / \mathrm{L}$. In fact, this case will differ as the price is expected to rise. Also, the external

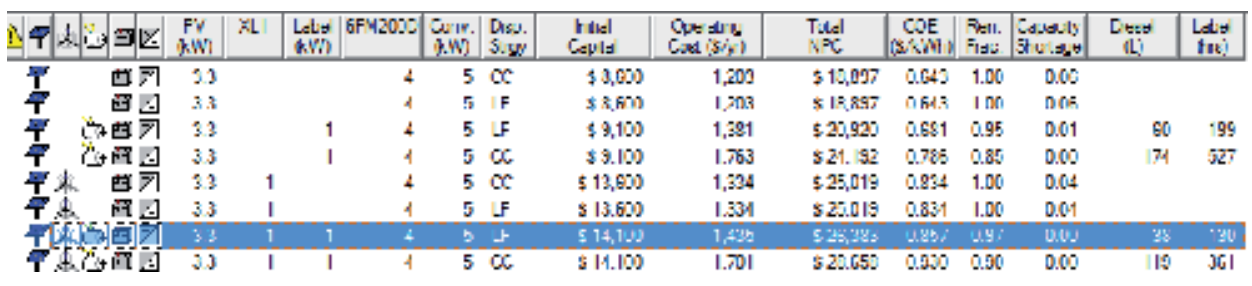

Table 10.

Optimization results of $P V / V A W T /$ diesel pumping system.

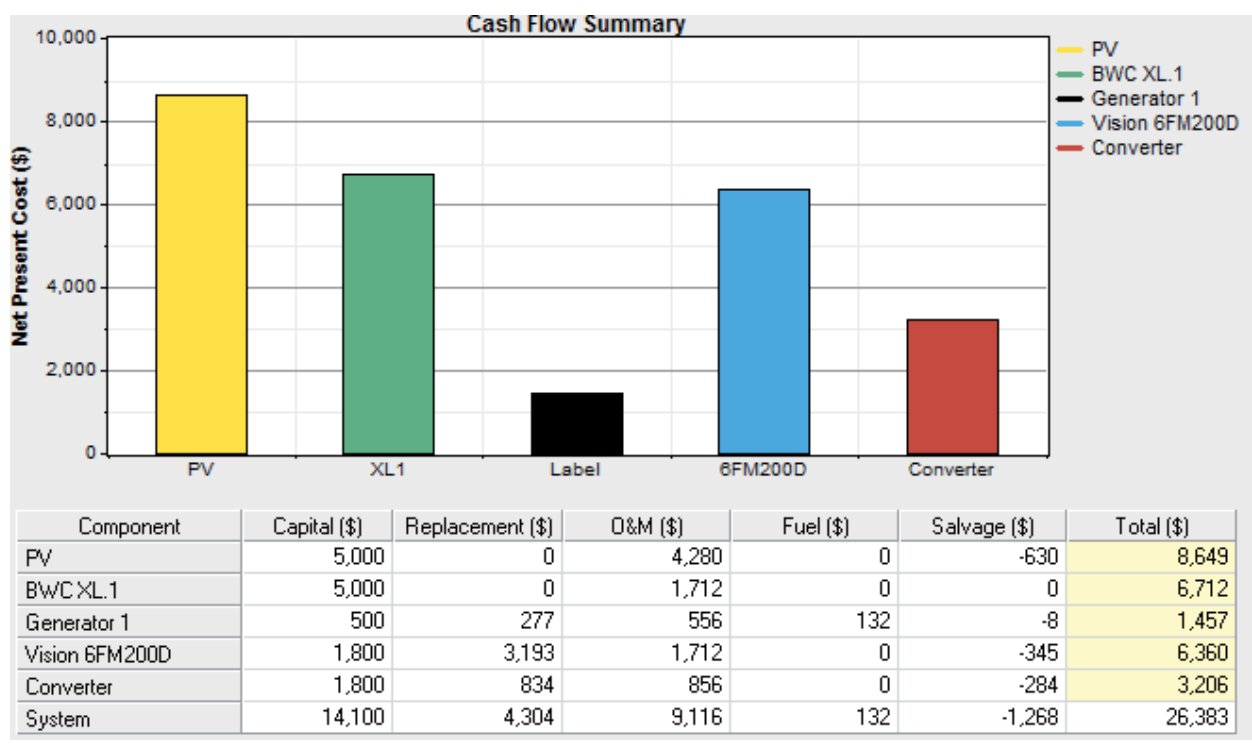

Figure 12.

Cash flow summary of PV/HAWT/diesel pumping system. 


\begin{tabular}{|l|r|r|}
\multicolumn{1}{|c|}{ Production } & kWh/yr & $\%$ \\
\hline PV array & 5,978 & 80 \\
\hline Wind turbine & 1,412 & 1 \\
\hline Generator 1 & 112 & \\
\hline Total & 7,501 & 100 \\
\hline
\end{tabular}

\begin{tabular}{l|r|c|}
\multicolumn{1}{|c|}{ Consumption } & \multicolumn{1}{c|}{$\mathrm{kWh} / \mathrm{yr}$} & $\%$ \\
\hline AC primary load & 3,596 & 100 \\
\hline Total & 3,596 & 100 \\
\hline
\end{tabular}

\begin{tabular}{l|r|r}
\multicolumn{1}{c|}{ Quantity } & kWh/yr & \multicolumn{1}{c}{$\%$} \\
\hline Excess electricity & 3.290 & 43.9 \\
\hline Unmet electric load & 6.57 & 0.2 \\
\hline Capacity shortage & 16.1 & 0.4 \\
\hline \multicolumn{1}{|c|}{ Quantity } & \multicolumn{2}{|c}{ Value } \\
\hline Renewable fraction & \multicolumn{2}{|c}{0.969} \\
\hline Max. renew. penetration & \multicolumn{2}{|c|}{$1.110 \%$} \\
\hline
\end{tabular}

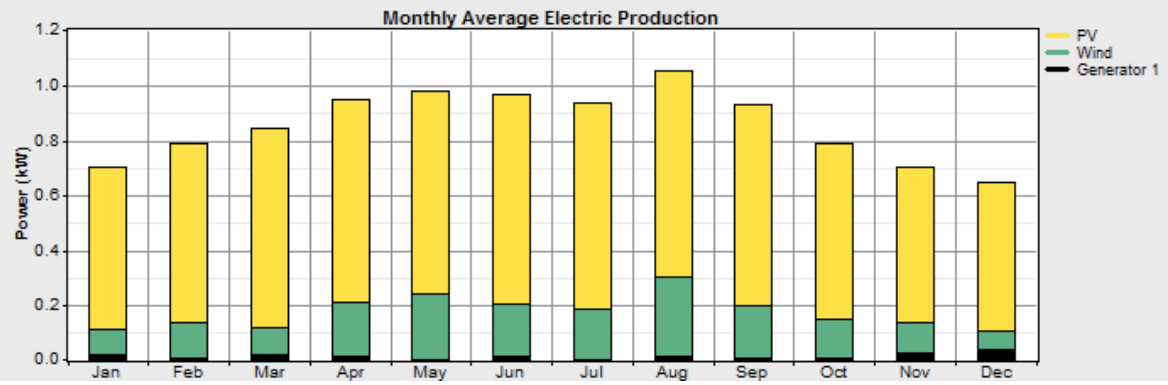

Figure 13.

Energy summary of PV/HAWT/diesel pumping system.

\begin{tabular}{|l|l|l|l|l|l|c|c|c|c|c|}
\hline \multirow{G}{*}{$\begin{array}{l}\text { Label } \\
(\mathrm{kW})\end{array}$} & $\begin{array}{l}\text { Disp. } \\
\text { Strgy }\end{array}$ & $\begin{array}{c}\text { Initial } \\
\text { Capital }\end{array}$ & $\begin{array}{c}\text { Operating } \\
\text { Cost (\$/yr) }\end{array}$ & $\begin{array}{c}\text { Total } \\
\text { NPC }\end{array}$ & $\begin{array}{c}\text { COE } \\
(\$ / \mathrm{kWh})\end{array}$ & $\begin{array}{c}\text { Ren. } \\
\text { Frac. }\end{array}$ & $\begin{array}{c}\text { Capacity } \\
\text { Shortage }\end{array}$ & $\begin{array}{c}\text { Diesel } \\
(\mathrm{L})\end{array}$ & $\begin{array}{c}\text { Label } \\
(\mathrm{hrs})\end{array}$ \\
\hline
\end{tabular}

Table 11.

Optimization results of diesel water pumping system.

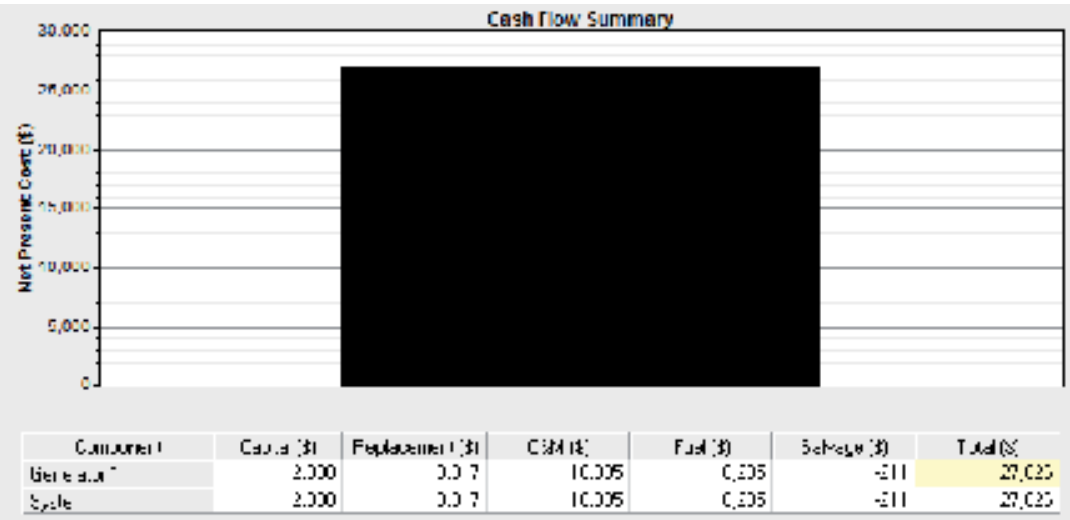

Figure 14.

Cash flow summary of diesel pumping system.

cost (cost of $\mathrm{CO}_{2}$ emissions) is not taken into consideration. Thus, the COE should be higher than the simulated values. Figures 14 and 15 present the system cash flow summary and energy summary.

The total NPC of the diesel system is $27,026 \$$ which is considered the highest NPC of all previous systems. Comparing the COE in Table 11 by COE generated by PV system and PV/WT systems (Tables 6-10), it is clear that the cost of electricity generated from diesel generator $(\$ 0.876$, Table 11) is higher than PV alone $(\$ 0.643$, Table 9) or PV/VAWT system ( $\$ 0.79$, Table 9). Figure 15 shows that although the diesel system has the highest NPC, the system satisfies zero shortage capacity. 


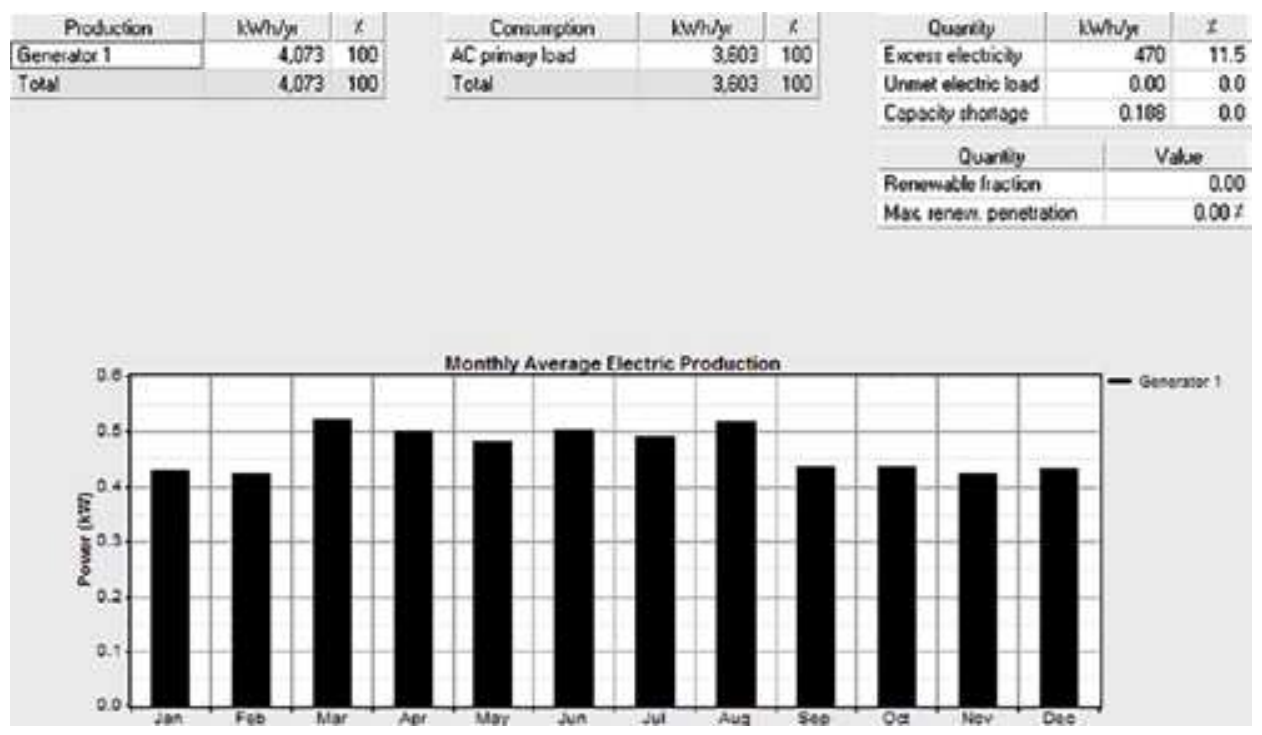

Figure 15.

Energy summary of diesel pumping system.

\begin{tabular}{lcccc}
\hline Time (hour) & \multicolumn{2}{c}{ Winter } & \multicolumn{2}{c}{ Summer } \\
\cline { 2 - 5 } & $\mathbf{Q}\left(\mathbf{M}^{3} / \mathbf{h o u r}\right)$ & $\mathbf{k W}$ & $\mathbf{Q}\left(\mathbf{M}^{3} / \mathbf{h o u r}\right)$ & $\mathbf{k W}$ \\
\hline 7 & 3 & 0.65 & 3 & 0.65 \\
\hline 8 & 3 & 0.65 & 4 & 0.86 \\
\hline 9 & 3 & 0.65 & 4 & 0.86 \\
\hline 10 & 6 & 1.3 & 4 & 0.86 \\
\hline 11 & 7 & 1.5 & 7 & 1.5 \\
\hline 12 & 8 & 1.7 & 10 & 2.14 \\
\hline 13 & 8 & 1.7 & 10 & 2.14 \\
\hline 14 & 8 & 1.7 & 10 & 2.14 \\
\hline 15 & 6 & 1.3 & 7 & 1.5 \\
\hline 16 & 3 & 0.65 & 4 & 0.86 \\
\hline 17 & 0 & 0 & 3 & 0.65 \\
\hline
\end{tabular}

Table 12.

New load pattern.

\subsection{Case 6: PV/HAWT for modified load pattern}

As it is clear from the above applied PV/WT systems, the excess energy represents a large amount of generated electricity that reached about $50 \%$ in one of the cases (PV/VAWT). This should be handled through applying a load management policy. Hence the load pattern is modified and increased by $3.24 \mathrm{kWh} /$ day distributed over 6 hours per day. The new load profile is presented in Table 12 while the results of this run are illustrated in Table 13 and Figure 16.

It could be seen in Table 13 that COE is decreased from $0.834 \$ / \mathrm{kWh}$ (Table 8) to $0.758 \$ / \mathrm{kWh}, \mathrm{NPC}$ is 25,984 . Table 13 shows that the peak load is $12 \mathrm{kWh} /$ day; with peak of $3.8 \mathrm{~kW}$. The excess energy decreased to $35.8 \%$ (was $44.2 \%$ ) which is the cause of the decreased COE. Increasing the load another time by $0.1 \mathrm{~kW}$ the 
COE will be $0.678 \$ / \mathrm{kWh}$ with NPC is $25,883 \$$. Figure 17 illustrates the relation between the daily load in $\mathrm{kWh}$ and the cost of energy in $\$ / \mathrm{kWh}$.

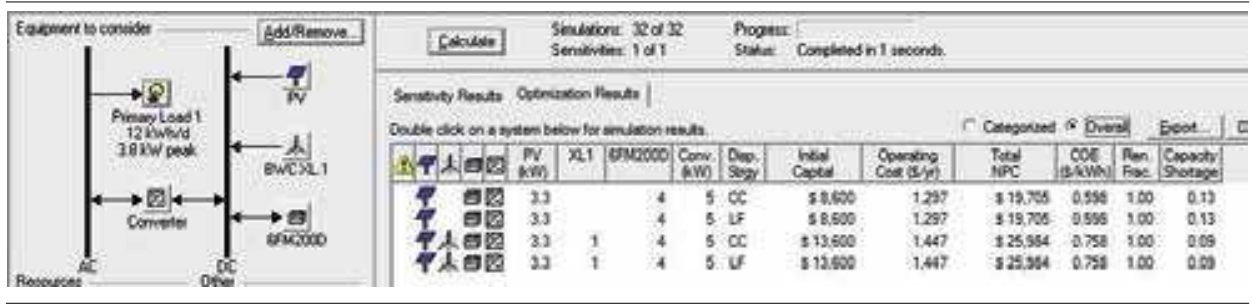

Table 13.

Optimization results of hybrid PV/VAWT pumping system for modified load pattern.

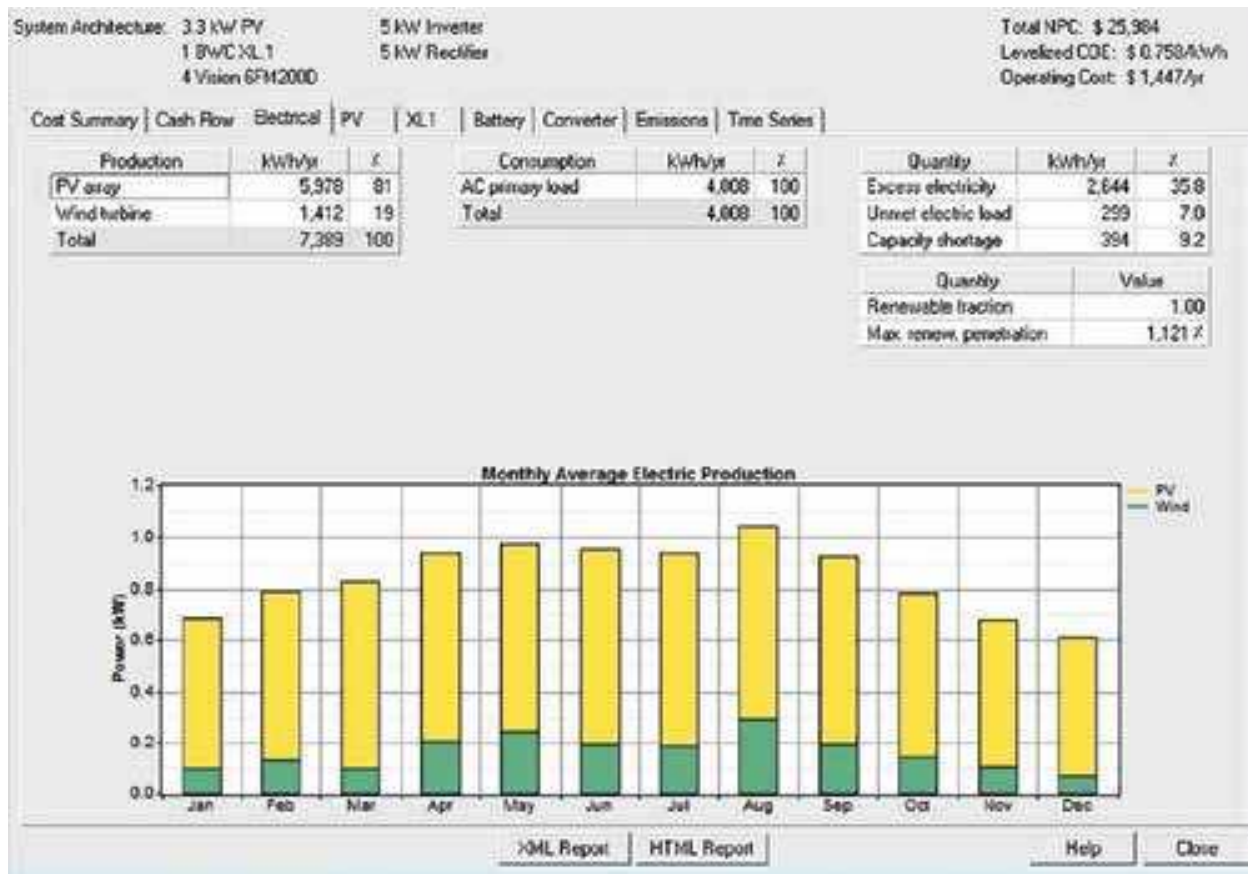

Figure 16.

Cash flow summary of PV/HAWT pumping system with modified load pattern.

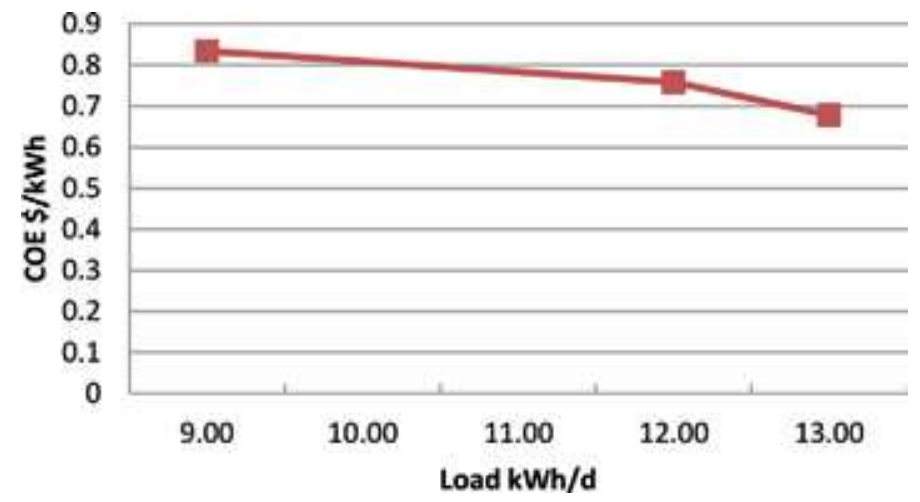

Figure 17.

Relation between daily load and cost of energy (COE). 


\section{Conclusions}

The present chapter illustrates the specifications of an installed PV water pumping system for agriculture purposes in El-Tour city, Sinai, Egypt. For economic comparison, the paper theoretically analyzed different renewable energy water pumping systems with different load patterns using commercial software. The systems using only PV power, PV/WT vertical and horizontal types with and without diesel generator. The systems contain storage batteries. The economic analysis was carried out based on the NPC and COE with system capacity shortage. The result of the analysis showed the following conclusions:

- The NPC and COE is lower in case of PV only and increased by using WT with $\mathrm{PV}$ system due to the lower wind speed rates in the specified location. The COE was $0.614 \$ / \mathrm{kWh}$ for PV only, 0.834\$/kWh for PV/HAWT, $0.790 \$ / \mathrm{kWh}$ for $\mathrm{PV} / \mathrm{VAWT}, 0.857 \$ / \mathrm{kWh}$ for PV/HAWT/diesel and $0.876 \$ / \mathrm{kWh}$ for diesel generator only. The external cost of $\mathrm{CO}_{2}$ emissions is not taken into consideration which will raise the cost of energy generated from diesel alone system.

- The capacity shortage percent decreased with using diesel generator in the system, although the NPC increased. The capacity shortage was $8.3 \%$ for PV only, 3.9\% for PV/HAWT, 3.1\% for PV/VAWT, 0.4\% for PV/HAWT/diesel and zero for diesel system only.

- Monthly average wind speeds on the location are much lower than the turbine rated wind speed which leads to non-optimal operation of the PV/WT. This leads to higher NPC and COE values. Also, high percentage of excess energy is noticed in cases of PV/WT system which causes the increase of COE.

- Increasing the load during the periods of excess energy decreases the COE. Thus, it is recommended to use abandoned energy in other optional loads.

\section{Author details}

Nagwa M. Khattab ${ }^{1}$, Mervat A. Badr ${ }^{2}$, Essam Tawfik El Shenawy ${ }^{1 *}$, Hassan H. Sharawy ${ }^{3}$ and Marwa S. Shalaby ${ }^{3}$

1 Solar Energy Department, National Research Centre, Egypt

2 Mechanical Engineering Department, National Research Centre, Egypt

3 Chemical Engineering and Pilot Plant Department, National Research Centre, Egypt

*Address all correspondence to: essamahame@hotmail.com

\section{IntechOpen}

(C) 2020 The Author(s). Licensee IntechOpen. Distributed under the terms of the Creative Commons Attribution - NonCommercial 4.0 License (https://creativecommons.org/ licenses/by-nc/4.0/), which permits use, distribution and reproduction for non-commercial purposes, provided the original is properly cited. (cc) BY-NC 


\section{References}

[1] Nelson V. Wind Energy: Renewable Energy and the Environment. Boca Raton, FL: CRC Press, Taylor \& Francis Group; 2009

[2] Nelson V, Clark R, Foster R. Wind Water Pumping. West Texas: A\&M University-Alternative Energy Institute; 2004

[3] Foster R, Ghassemi M, Cota A. Solar Energy: Renewable Energy and the Environment. Boca Raton, FL: CRC Press, Taylor \& Francis Group; 2009

[4] Odeh I, Yohanis Y, Norton B. Influence of pumping head, insolation and PV array size on PV water pumping system performance. Solar Energy. 2006;80:51-64

[5] Kamel K, Dahl C. The economics of hybrid power systems for sustainable desert agriculture in Egypt. Energy. 2005;30:1271-1281

[6] Campana PE, Li H, Yan J. Dynamic modeling of a PV pumping system with special consideration on water demand. Applied Energy. 2013;112:635-645

[7] Benghanem M, Daffallah KO, Alamri SN, Joraid AA. Effect of pumping head on solar water pumping system. Energy Conversion and Management. 2014;77:334-339

[8] Kelley LC, Gilbertson E, Sheikh A, Eppinger SD, Dubowsky S. On the feasibility of solar-powered irrigation. Renewable and Sustainable Energy Reviews. 2010;14:2669-2682

[9] Rehman S, Sahin AZ. Wind power utilization for water pumping using small wind turbines in Saudi Arabia: A techno-economical review. Renewable and Sustainable Energy Reviews. 2012;16:4470-4478
[10] Kumar A, Kandpal TC. Renewable energy technologies for irrigation water pumping in India: A preliminary attempt towards potential estimation. Energy. 2007;32:861-870

[11] Diaz-Mendez R, Rasheed A, Peillon M, Perdigones A, Sanchez R, Tarquis AM. Wind pumps for irrigating greenhouse crops: Comparison in different socio-economical frameworks. Biosystems Engineering. 2014;128:21-28

[12] Alberg Ostergaard P, Mathiesen BV, Moller B, Lund H. A renewable energy scenario for Aalborg municipality based on low-temperature geothermal heat, wind power and biomass. Energy. 2010;35:4892-4901

[13] Lund H, Munster E. Management of surplus electricity-production from a fluctuating renewable-energy source. Applied Energy. 2003;76:65-74

[14] Droste-Franke B, Paal B, Rehtanz C, Sauer D, Schneider J-P, Schreurs M. Demand for Balancing Electrical Energy and Power: Balancing Renewable Electricity. Berlin, Heidelberg: Springer; 2012

[15] Ostergaard PA, Lund H. A renewable energy system in Frederikshavn using low-temperature geothermal energy for district heating. Applied Energy. 2011;88:479-487

[16] Fraunhofer-Gesellschaft. Managing Renewable Energy Intelligently. Science Daily; Available from: www.sciencedaily.com/ releases/2014/03/140325094814.htm

[17] Vick BD, Neal BA. Analysis of off-grid hybrid wind turbine/solar PV water pumping systems. Solar Energy. 2012;86(5):1197-1207

[18] Gopal C, Mohanraj M, Chandramohan P, Chandrasekar P. 
Renewable energy source water pumping systems: A literature review. Renewable and Sustainable Energy Reviews. 2013;25:351-370

[19] Skretas SB, Papadopoulos DP. Systematic procedure for efficient design of electric water pumping systems fed by PV or/and WECS: Application using measured meteorological data for the city of Xanthi/Thrace, Greece. Energy Conversion and Management. 2008;49:596-607

[20] Ma T, Yang H, Lu L, Peng J. Technical feasibility study on a standalone hybrid solar-wind system with pumped hydro storage for a remote island in Hong Kong. Renewable Energy. 2014;69:7-15

[21] Zhou W, Lou C, Li Z, Lu L, Yang H. Current status of research on optimum sizing of stand-alone hybrid solar-wind power generation systems. Applied Energy. 2010;87:380-389

[22] Lilienthal P. HOMER Micropower Optimization Model. NREL/CP-71037606; 2005. Available from: http:// www.homerenergy.com/

[23] Baring-Gould I. Hybrid2:

The Hybrid System Simulation ModelVersion 1.1. Users Manual; NREL1998/TP-440-21272.

DE96007901. Available from: http:// www.umass.edu/windenergy/research. topics.tools.software.hybrid2.php

[24] Yang H, Lu L, Zhou W. A novel optimization sizing model for hybrid solar-wind power generation system. Solar Energy. 2007;81:76-84

[25] Yahyaoui I, Tina G, Chaabene M, Tadeo F. Design and evaluation of a renewable water pumping system. IFACPapersOnLine. 2015;48-30:462-467

[26] Tégania I, Abouboua A, Ayad MY, Becherifc M, Saadia R, Kraaa O. Optimal sizing design and energy management of stand-alone photovoltaic/wind generator systems. Energy Procedia. 2014;50:163-170

[27] Available from: http://re.jrc. ec.europa.eu/pvgis/apps4/pvest. php?map=africa 



\title{
Optimization of Renewable Energy-Based Smart Micro-Grid System
}

\author{
Marwa Mohsen Ibrahim Abd El-Rahman
}

\begin{abstract}
Optimization of renewable energy-based micro-grids is presently attracting significant consideration. Hence the main objective of this chapter is to evaluate the technical and economic performance of a micro-grid (MG) comparing between two operation modes; stand-alone (off-grid), and grid connected (on-grid). The micro-grid system (MGS) suggested components are; PV panels, wind turbine(s) inverter, and control unit in case of grid connected. In the stand alone mode diesel generator and short term storage are added to the renewable generators. To investigate the performance of the MGS; technically, detailed models for each component will be presented then the complete MGS model is developed. Another objective of this study is the economical evaluation of MGS by comparing the system net present cost (NPC) and cost of generated electricity for the two modes of operation; off-grid and on-grid.
\end{abstract}

Keywords: renewable energy, smart grids, micro-grid, on/off grid, simulation, MATLAB software, optimization

\section{Introduction}

Renewable energy $(R E)$ industry is growing rapidly with rising concerns about oil depletion and climate change. $R E$ is seen by many as part of the appropriate response to these concerns and some national governments have put programs in place to support the wider use of sustainable energy systems [1]. Rapid increases in energy demand and energy deficiency are two contradicting facts that face developing countries at the present and expectedly in the future. Compared to fossil fuel energy generation and nuclear power stations, $R E$ is considered the safest benign energy generation sources. $R E$ sources are offering the suitable solution for such situations, as have been the answer for remote, isolated dwelling electrification, substituting or integrated with diesel fueled generators. The well-known RE sources are; solar, wind, hydropower, biomass and geothermal. Renewable energy technologies revolve these sources into utilizable forms of energy not only electricity but also heat, chemicals, or mechanical power. Even if fossil fuels supplies are unlimited, it is better to use renewable energy sources as they are clean technologies. Burning fossil fuels causes pollutant emissions and greenhouse gases contributing to global warming [2]. Renewable energy education is a relatively new field and previously it formed a minor part of traditional engineering courses. Modern 
renewable energy education includes a study of the technology, resources, systems design, economics, industry structure and policies in an integrated package.

Renewable energy and micro-grid had emerged from the development of new grid technology referred as smart grids [3]. Smart grids are computer controlled micro-grids. "renewable energy sources"; often referred to as distributed energy resources (DERs), while "smart-grids" refers to the whole electrical energy distribution networks from electricity generation to its transmission and storage with the capability to react to dynamic changes on energy distribution and load regulation [4]. A different review on smart grid concepts was described by Di Santo et al., who defined smart grid as; "a generation, transmission, and distribution system set with a two-way communication system controlled by the grid operator" [5]. In their study, the key element was the contact between the grid operator, electric utility, and consumers. In this review the authors categorized smart grid components as: smart homes, smart consumption, smart consumption, and smart distribution. A number of studies discussed socio-economic and socio-technical aspects symbolizing $[6,7]$.

\subsection{Definition of smart grid}

A smart grid can be defined as an electric system that uses information, twoway, cyber-secure communication technologies, and computational intelligence in an integrated fashion across electricity generation, transmission, substations, distribution and consumption to achieve a system that is clean, safe, secure, reliable, resilient, efficient, and sustainable [8]. This definition covers the entire spectrum of the energy system from the generation to the end points of consumption of the electricity. Figure 1 illustrates different components of smart grid [9]. The ultimate smart grid is a vision, and it will require cost justification at every step before implementation, then testing and verification before extensive deployment.

Worldwide researches are going on micro-grids, there application and control to overcome the weaknesses of the centralized power grids [5]. Additionally the utilization of local sources of energy to provide local loads helps decreasing energy losses in transmission and distribution.

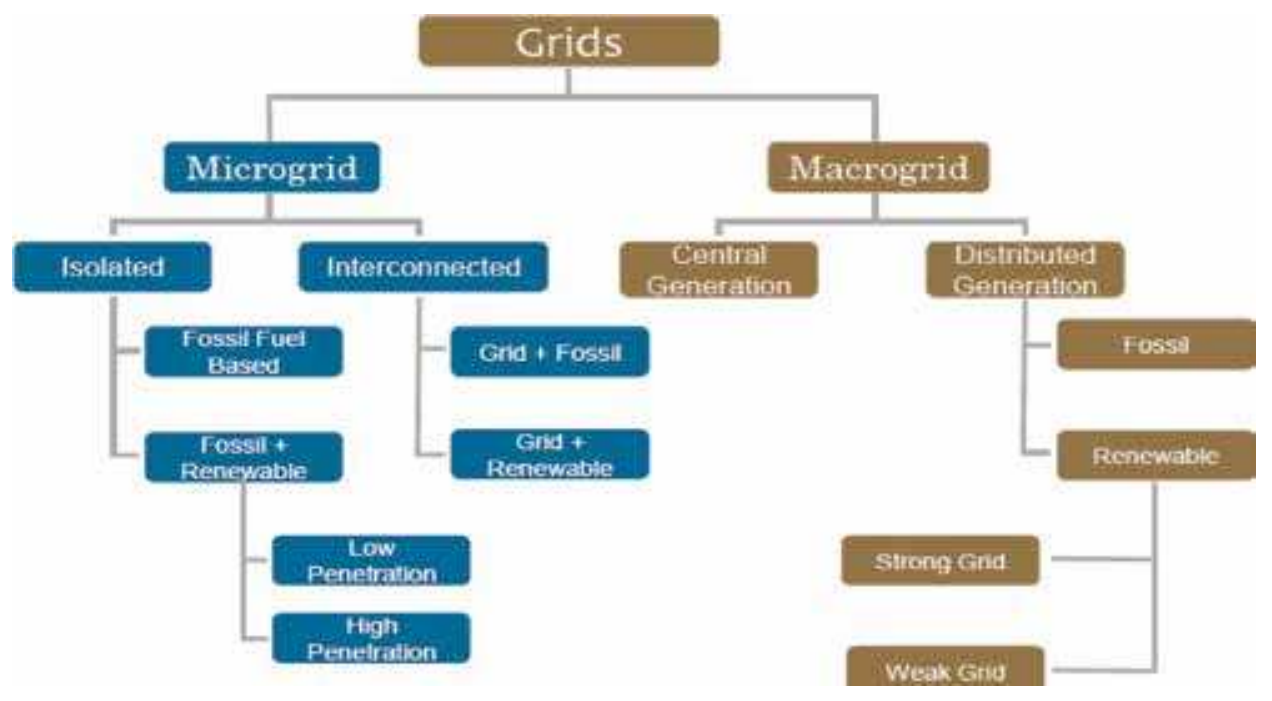

Figure 1.

Components of smart grid [9]. 
The conception of micro-grid (MG) for integrating distributed generation (DG) system is rapidly becoming important for reliable and sustainable renewable energy development. In ideal situation, it also allows for incorporating energy storage systems (ESSs), which are used to optimize energy consumption. Further, MG development in modern power sector had brought another emerging idea called smart grid [10].

Micro-grid can be defined as follows: an integrated energy system intelligently organizing interconnected loads and distributed energy resources and capable of operating in parallel with, or separately, from the existing utility's grid [11]. A description of possible micro-grid architecture is shown in Figure 2. Power electronic components are the base for flexible operation. The connection point to utility grid is called point of common coupling (PCC).

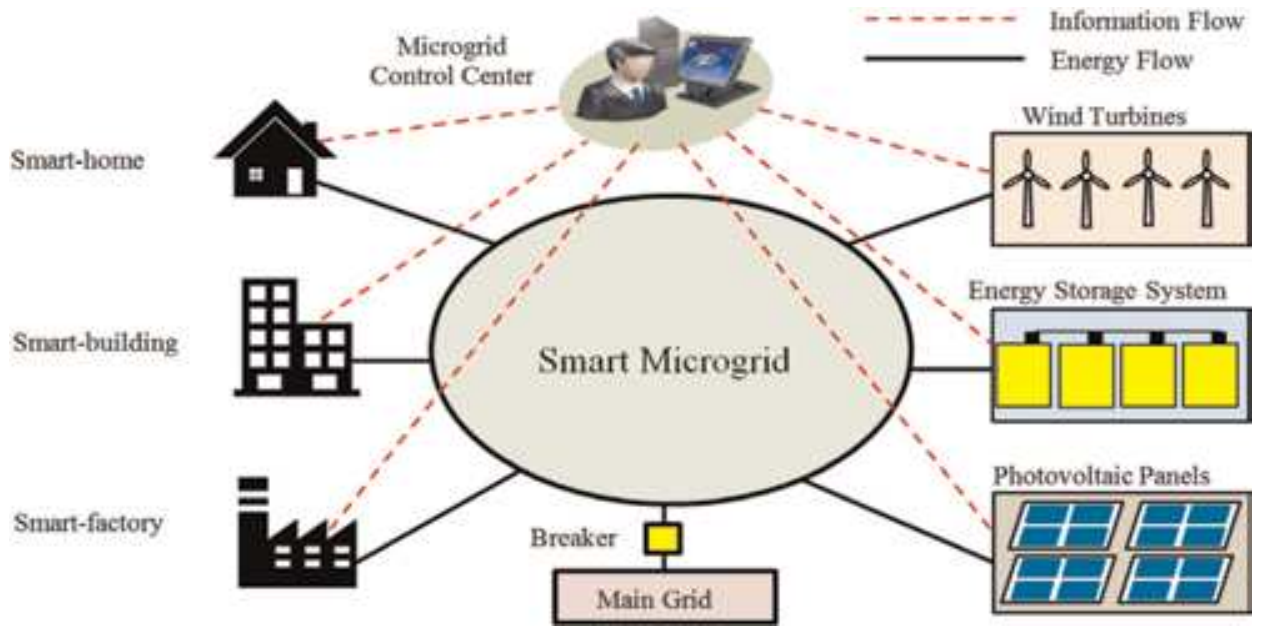

Figure 2.

Micro-grid architecture overview [12].

\begin{tabular}{|c|c|c|c|c|}
\hline $\begin{array}{l}\text { Energy } \\
\text { Resources } \\
(30-40 \% 6)\end{array}$ & $\begin{array}{l}\text { Switchgear } \\
\text { Protection \& } \\
\text { Transformers } \\
(20 \%)\end{array}$ & $\begin{array}{l}\text { SG } \\
\text { Communications } \\
\& \text { Controls } \\
(10-20 \%)\end{array}$ & $\begin{array}{l}\text { Site } \\
\text { Engineering \& } \\
\text { Construction } \\
(30 \%)\end{array}$ & $\begin{array}{l}\text { Operations } 8 \\
\text { Markets }\end{array}$ \\
\hline $\begin{array}{l}\text { Energy storage; } \\
\text { controllable } \\
\text { loads; DG; } \\
\text { renewable } \\
\text { generation; CHP }\end{array}$ & $\begin{array}{l}\text { Switchgear } \\
\text { utility } \\
\text { interconnection } \\
\text { (incl. low-cost } \\
\text { switches: } \\
\text { interconnection } \\
\text { study, } \\
\text { protection } \\
\text { schemes, and } \\
\text { protection } \\
\text { studies) }\end{array}$ & $\begin{array}{l}\text { Standards } 8 \\
\text { protocols; } \\
\text { Control \& } \\
\text { protection } \\
\text { technologies; } \\
\text { Real-time signais } \\
\text { (openADR); Local } \\
\text { SCADA access; } \\
\text { Power electronics } \\
\text { (Smart Inverters, } \\
\text { DC bus) }\end{array}$ & $\begin{array}{l}\text { A\&E (System } \\
\text { deslgn and } \\
\text { analysis); } \\
\text { Systern } \\
\text { integration, } \\
\text { testing, \& } \\
\text { validation }\end{array}$ & $\begin{array}{l}\text { O\&M; Market } \\
\text { (utility) } \\
\text { acceptance }\end{array}$ \\
\hline
\end{tabular}

Table 1.

Micro-grid major cost items [13]. 


\begin{tabular}{|c|c|c|c|}
\hline Benent. & Oustomer & Utility & Soctetsy \\
\hline Reduced Electrieity cast \& Fuel Cost & $\times$ & & \\
\hline Sales excess power to grid & $x$ & x & \\
\hline Remote monitorins and control & $x$ & $\times$ & \\
\hline Enekiry effieieney & $\times$ & $\times$ & \\
\hline $\begin{array}{l}\text { Redreed transmiasion \& distribution } \\
\text { losses }\end{array}$ & & $\times$ & $\times$ \\
\hline Reduced system congestion cost & & $\times$ & \\
\hline Reactive power is voltage control & $\times$ & $\times$ & \\
\hline Peak shaving & $x$ & $\times$ & \\
\hline Inereaste use of renewable & & $x$ & $\times$ \\
\hline Reduced $\mathrm{SO}_{2}$, Nox, $\mathrm{CO} 2$ emissions & & $\times$ & $\times$ \\
\hline Lavered grid axchitecture & & $\times$ & $\times$ \\
\hline Automatic load management & $x$ & $\times$ & \\
\hline Load \& resource profite & & $\boldsymbol{x}$ & \\
\hline
\end{tabular}

Table 2.

Micro-grid benefits [14].

There are various requirements to support the micro-grid operation. Micro-grid is either used as a replacement for petrol generator to provide onsite energy generation or incorporated with the electricity grid. MG components propose the means for local control of electricity from both supply and utilization sides. Table 1 shows the cost of its major parts as a percentage of the total cost.

\subsection{Benefits and barriers of micro-grid}

Benefits of micro-grid are shown in Table 2. The common technical barriers are problems concerning, dual-mode switching from grid-connected to off-grid mode, power quality and control, and protection issues. These issues are still a subject of research. Regulatory barriers are related to rules of power trading between microgrid and the main network. The main financial barrier is the high replacement costs of the micro-grid components. Last of all, stakeholder barriers take in issues with differing self-interest and the expertise to manage operations.

\section{Micro-grid system components}

Being as intelligent and flexible as they are, the integration of micro-grids in power networks is currently getting great attention. Micro-grid system would comprise one or more of the following resources:

\subsection{Distributed energy resources}

\subsubsection{Solar energy}

The sun is ultimately the source of all energy supplies, excluding nuclear energy generation. Solar-electric power can be produced by power plants using the sun's heat or direct electricity generation using photovoltaic technology, which is more practical for urban use. Solar energy resources are:

- solar thermal conversion;

- low and medium temperature conversion; 
- high temperature conversion-concentrated solar power (CSP);

- optical efficiency;

- combined optical and thermal efficiency; and

- solar electrical conversion (photovoltaic systems).

As a case study, Egypt lies in the Sun Belt area, with the following related data:

- direct normal irradiation ranges between $2000 \mathrm{kWh} / \mathrm{m}^{2} /$ year at the North and $3200 \mathrm{kWh} / \mathrm{m}^{2} /$ year at the South with very short cloudy times;

- the sunshine duration ranges between 9 and 11 hour/day from North to South; and

- potential capacity 73,656 TWh/year [15].

\subsubsection{Wind energy}

Egypt has become the leader of wind power in the Middle East and Africa through the past few years. Red Sea coast and Suez Gulf area are gifted with high rated wind speed (about $10 \mathrm{~m} / \mathrm{s}$ ) [16]. Hence, the area is considered suitable for constructing large wind projects. Wind power provides the major share of renewable energy generation in Egypt. Egyptian Wind Atlas exposed the huge potential of the Red Sea region in matter of wind energy where mountain chains on the coasts create a natural corridor that enhances the stability of winds. The Gulf of Suez west coasts have the benefit of being next to where electricity is most demanded. Wind generation equipment is divided into three general categories [17]:

- Utility-scale—corresponds to large turbines (250 kW to $2 \mathrm{MW})$.

- Industrial-scale-corresponds to medium sized turbines (50-250 kW).

- Residential-scale-corresponds to micro and small turbines (400 W to $50 \mathrm{~kW})$.

In addition to solar and wind energies, other sources such as biomass, geothermal, hydro and bio-fuel can be incorporated.

\subsection{Energy storage}

Storage systems are vital to any micro-grid since they allow the balancing of electrical fluctuation and support the load required by the user. In isolated microgrids, batteries are the mostly used as they are still considered the most economic electric storage technology [18]. Although energy storage technology has developed extremely in the past years, it still expected to continue developing. A tendency of reducing costs of battery technologies as lithium-ion and flow battery suggests that these technologies will be more applied. There is a relationship between energy storage and emissions. Energy storage is not $100 \%$ efficient which may cause extra emissions [19]. Even though batteries exist longer than pumped storage, costs have generally been too expensive for utility scale applications. Figure 3 illustrates classification of energy storage technologies while Figure $\mathbf{4}$ presents benefits of energy 


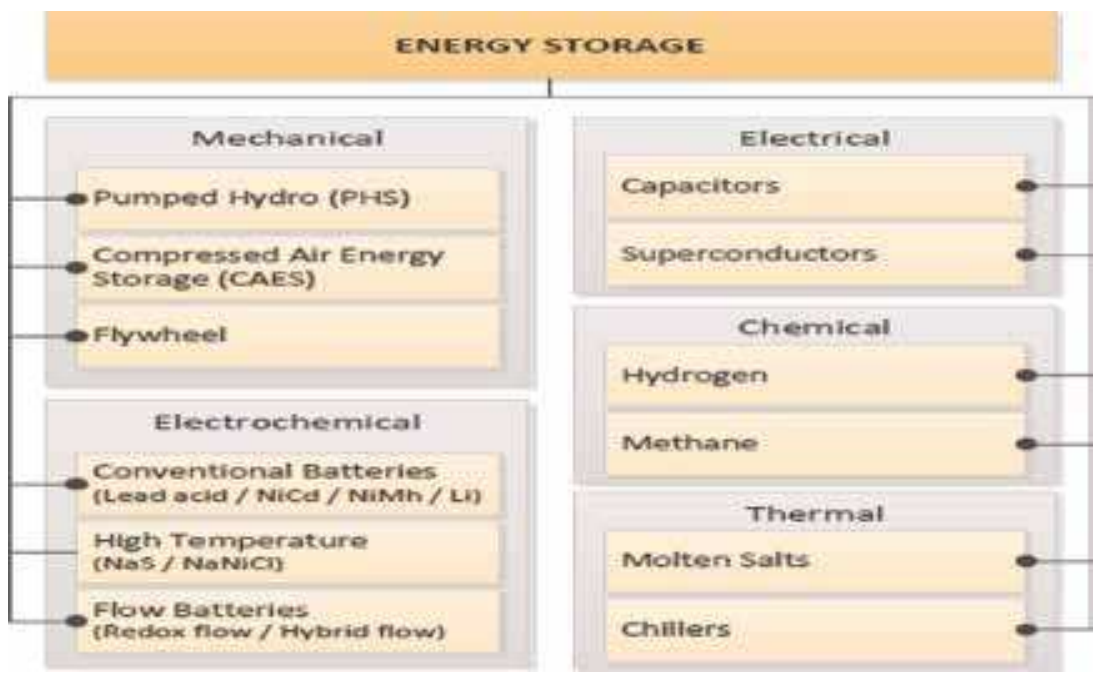

Figure 3.

Classification of energy storage technologies [20].

Challenges

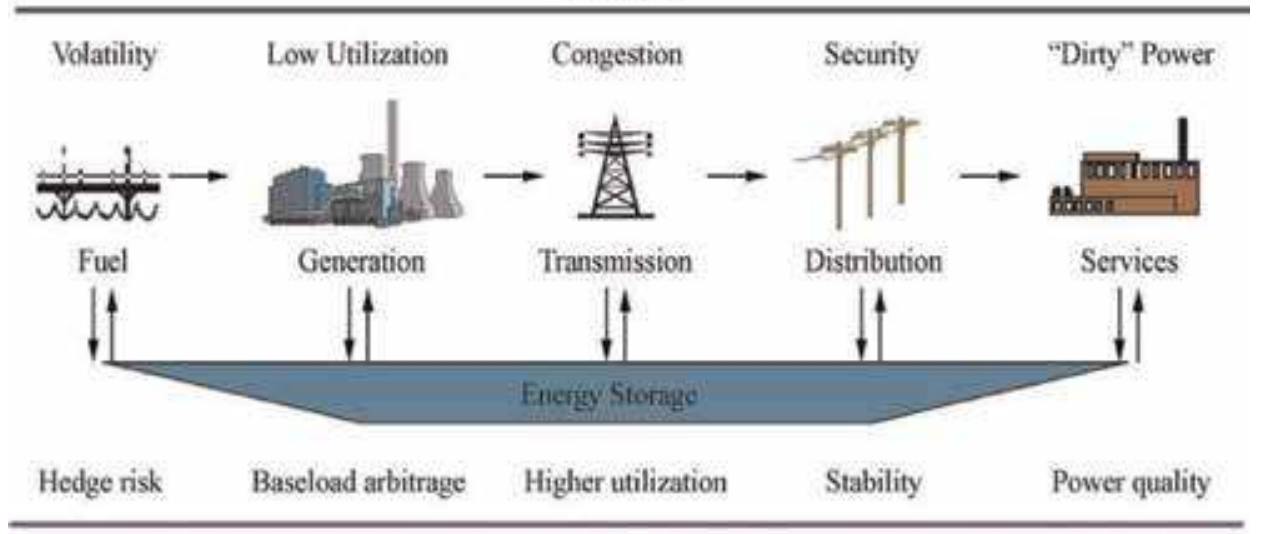

Renefits

Figure 4.

Benefits of energy storage [21].

storage system. Costs of electricity of different energy storage technologies are shown in Figure 5.

\subsection{Electric load}

Construction of micro-grid and sizing of their energy components depends principally on the required load pattern to be supplied. Load may be domestic industrial or commercial demand.

\subsection{Micro-grid control system (power management system)}

Micro-grid control system (MCS) is the crucial component that enables the incorporation and optimization of energy to reduce the overall micro-grid energy cost [23]. The MCS provides an easy solution to combine conventional and renewable energy sources with energy storage to reach optimal operation minimizing the 


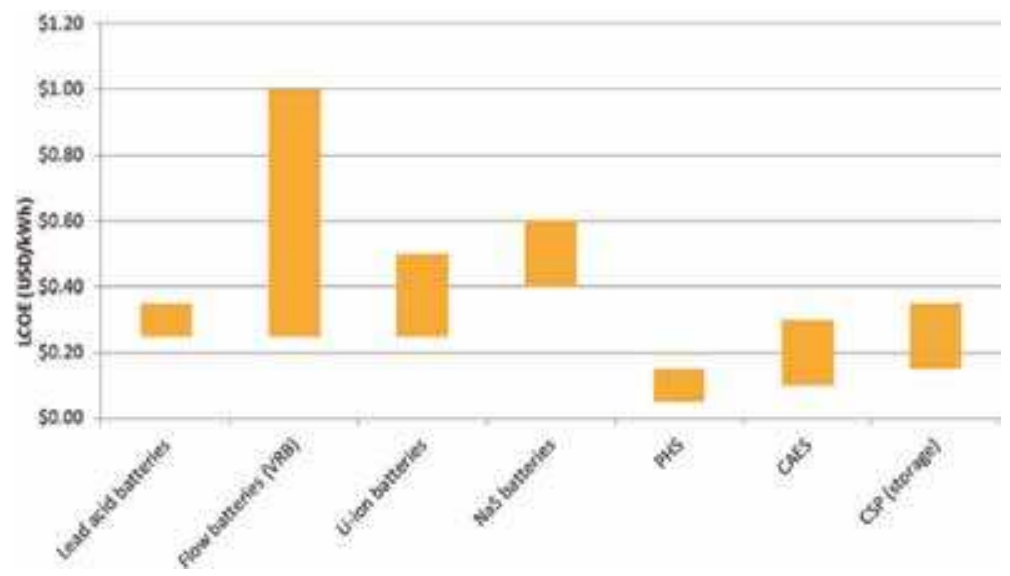

Figure 5.

Energy storage technologies levelized cost of electricity (LCOE) [22].

total cost and cost of energy (COE). Modern systems often merge software with control systems, such as smart meters, that can make the grid operation efficient and reliable.

\section{Micro-grid modeling using MATLAB/SIMULINK}

This section discusses the detailed modeling of micro-grid components and micro-grid system. Typical power sources, loads, and transmission lines have been modeled individually and tested well in MATLAB/SIMULINK. Actually, SIMULINK is a graphical programming environment for modeling, simulating and analyzing multi-domain dynamical systems [24, 25]. MATLAB/SIMULINK software package is used in the current study to model the MG components and investigate the operation of the MG system. List of PV, WT, DG models, short-term storage models, load models, utility grid model, and transmission line models is programmed and exhibited in the following [26].

\subsection{Photovoltaic cell modeling (PV)}

Solar PV panel power output varies with change in the sun direction, following changes in solar radiation amount and temperatures differences. As, the PV cell efficiency is low it is popular to activate the module at the peak power point so, the maximum power be capable of delivered to the load under changing temperature and irradiance circumstances. For reaching the maximum power from the solar PV module, a maximum power point tracker (MPPT) which helps in saving cost of the PV system. Prior to modeling a generalized PV array system a PV model is constructed using MATLAB/SIMULINK to show and verify the nonlinear I-V and $\mathrm{P}-\mathrm{V}$ output characteristics of PV module. The basic model comprises a photocurrent source, a single diode junction and a series resistance and a shunt resistance [27]. The output-terminal current I is specified by Eq. (1) equipped the light-generated current $I_{p h}$, less than the diode current $I_{D}$ and the shunt-leakage current $I_{s h}$.

$$
\mathrm{I}=\mathrm{I}_{\mathrm{ph}}-\mathrm{I}_{\mathrm{D}}-\mathrm{I}_{\mathrm{sh}}
$$

The series resistance $R_{s}$ represents the interior resistance to the present flow and shunt resistance $R_{\text {sh }}$ is inversely associated with the outflow current to the bottom. 
In a great PV cell, $R_{s h}=1$ (no leakage to ground) and $R_{s}=0$ (no series loss). The PV cell adaptation efficiency is receptive to little differences in $R_{s}$, however is insensible to deviations in $\mathrm{R}_{\mathrm{sh}}$. A tiny increase in Rs will reduce the PV output significantly. Within the equivalent circuit, the current delivered to the external load equals this $I_{p h}$ generated by the illumination, less than the diode current $I_{D}$ and as well the current of ground shunt $\mathrm{I}_{\text {sh }}$. The open circuit voltage $\mathrm{U}_{\mathrm{oc}}$ of the cell is found when the load current is zero, i.e., when $I=0$, and is obtained from Eq. (2).

$$
\mathrm{U}_{\mathrm{oc}}=\mathrm{U}+\mathrm{IR}_{\mathrm{s}}
$$

where $U$ is the PV cell terminal voltage [27]. Figure 6 illustrates the corresponding MATLAB/SIMULINK model of the PV array. I-V and P-V output curves with difference in radiation of PV array are exhibited in Figure 7.

\subsection{Wind turbine modeling (WT)}

Classically, a wind turbine combines of a rotor with three-blades, drive train and generator. Pitch angle is controlled so as to limit the generator output power to its face value for high wind speeds. The power produced by the rotor is obtained by Eqs. (3) and (4) [28]:

$$
\mathrm{P}=\frac{1}{2} \mathrm{Cp}(\lambda, \beta) \rho \mathrm{AV}^{3}
$$

where P: extracted power by rotor blades $(\mathrm{W}) ; \rho$ : air density $\left(\mathrm{kg} / \mathrm{m}^{3}\right)$; A: turbine swept area $\left(\mathrm{m}^{2}\right)$; V: wind speed $(\mathrm{m} / \mathrm{s}) ; \mathrm{Cp}(\lambda, \beta)$ : turbine power coefficient (max
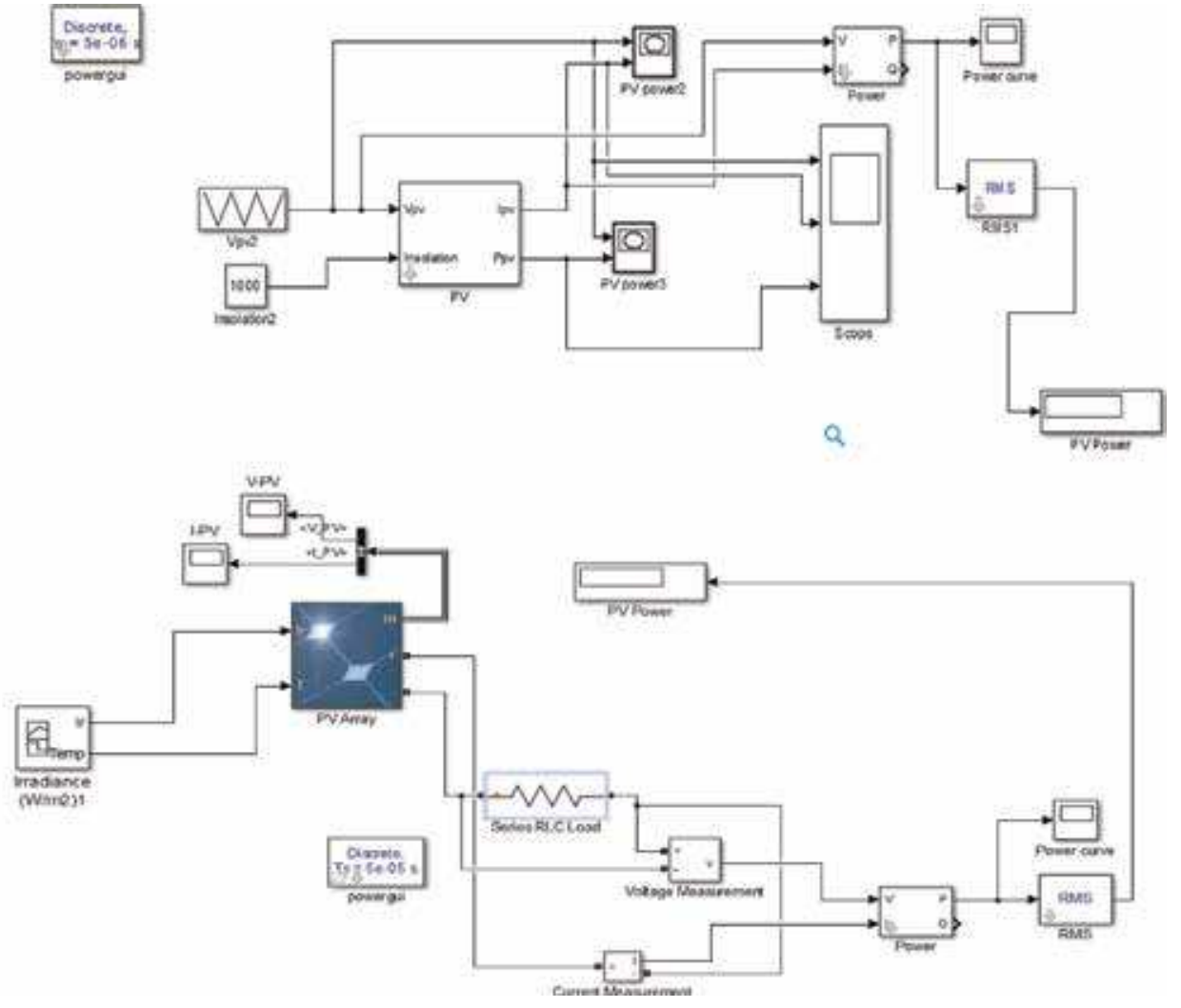

Figure 6.

Modeling of the PV array [26]. 
value: $59.26 \%$, Betz Law); $\lambda$ : tip speed ratio (rotor blade tip speed to wind speed); $\beta$ : blade pitch angle (deg).

$$
\mathrm{P}=\mathrm{Ta} * \omega r
$$

$\mathrm{T}_{\mathrm{a}}$ is the aerodynamic torque applied to rotor and $\omega_{\mathrm{r}}$ the rotor rotational speed. SIMULINK model of a fixed wind turbine is shown in Figure 8. Figure 9 illustrates

Power (W)

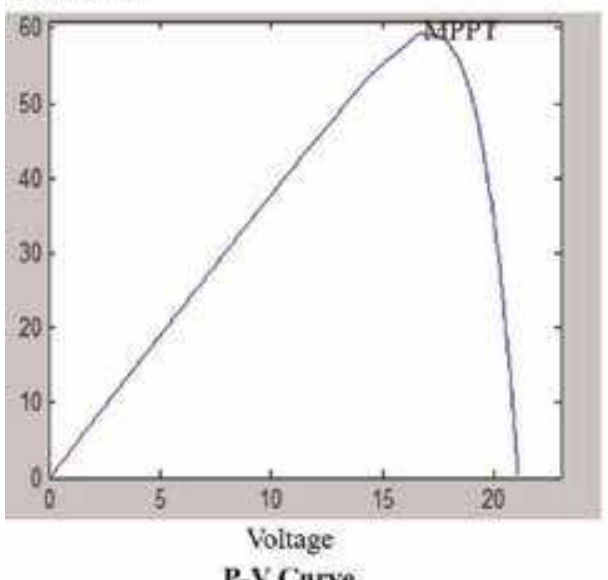

P-Y Curve
Current (A)

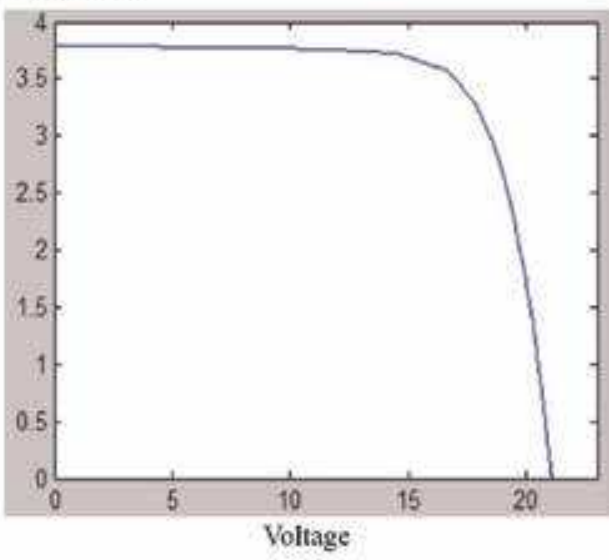

1-V Curve

Figure 7.

$P-V$ and I-V output curves of PV array [26].

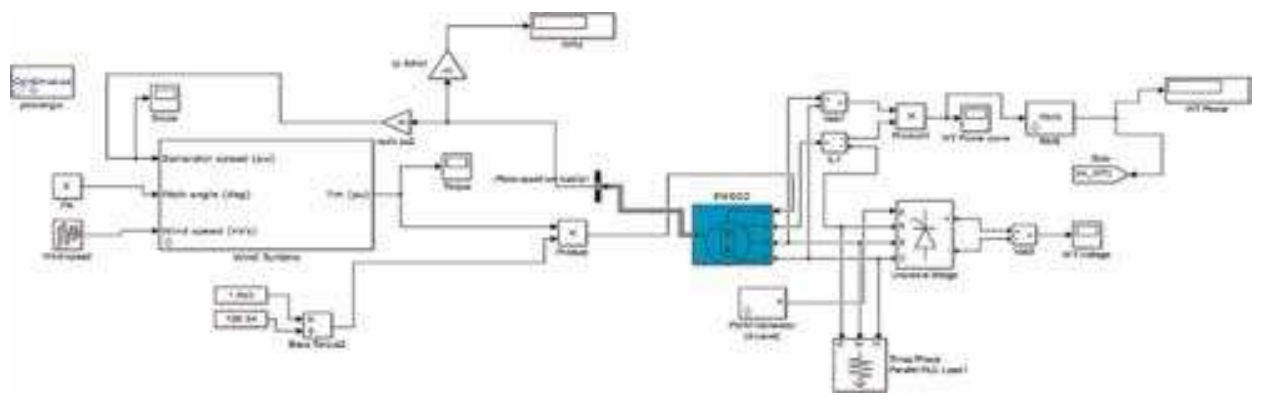

Figure 8.

Modeling of the fixed wind turbine speed [26].

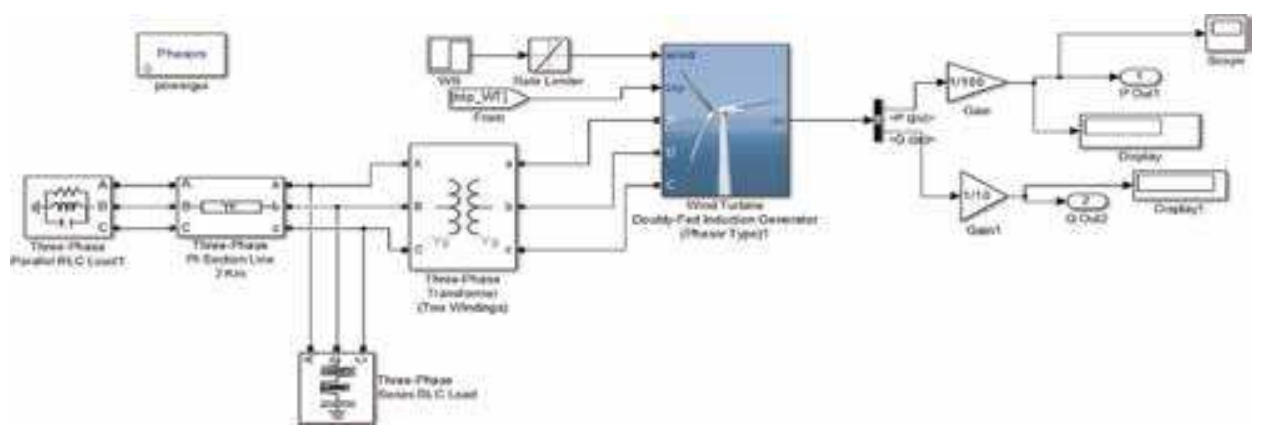

Figure 9.

Description of DFIG WT modeling [26]. 
Modeling, Simulation and Optimization of Wind Farms and Hybrid Systems

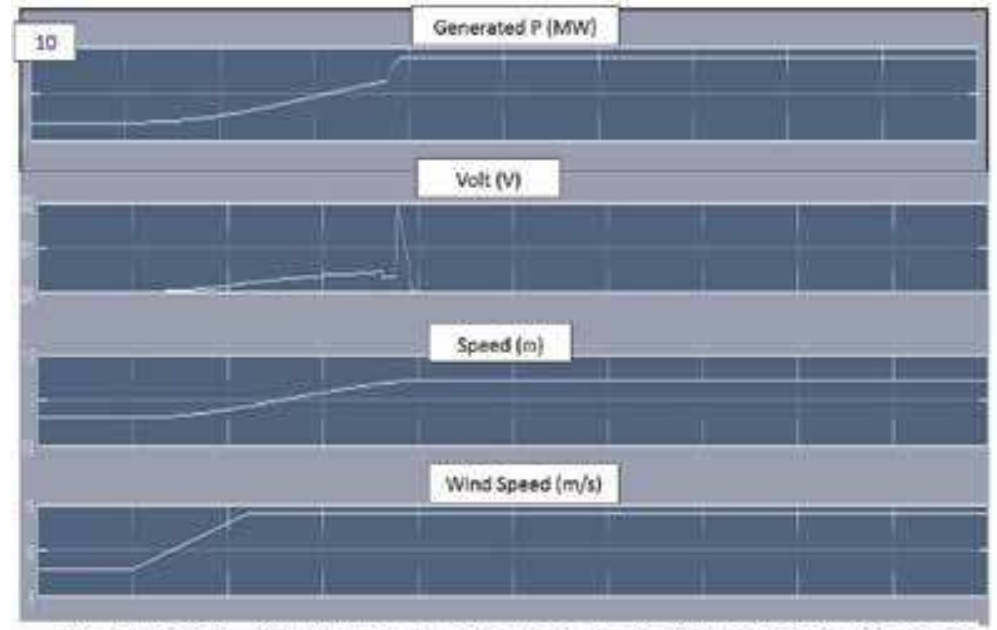

$\begin{array}{llllllllllllllllllllllllll}12 & 3 & 4 & 5 & 6 & 7 & 8 & 9 & 10 & 11 & 12 & 13 & 14 & 15 & 16 & 17 & 18 & 19 & 20 & 21 & 22 & 23 & 24 & 25 & 26 & 27\end{array}$ Time (S)

Figure 10.

Output curves of WT modeling [26].

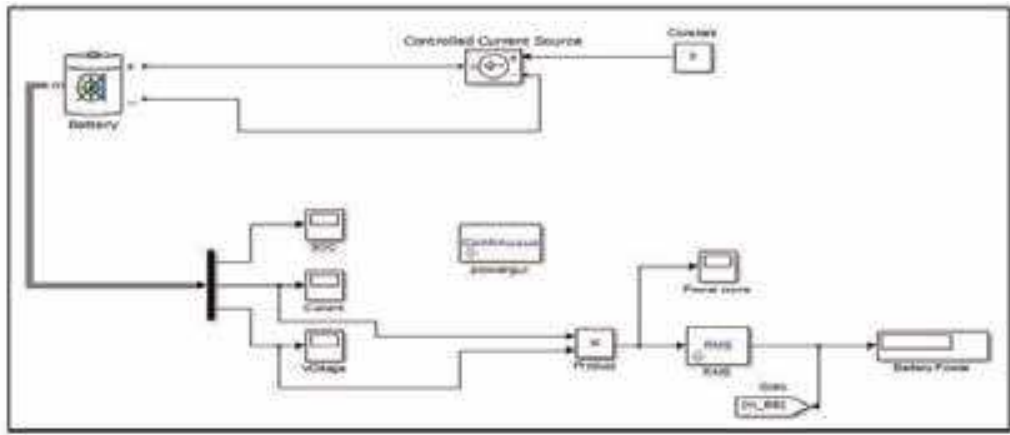

a

Woltage (V)

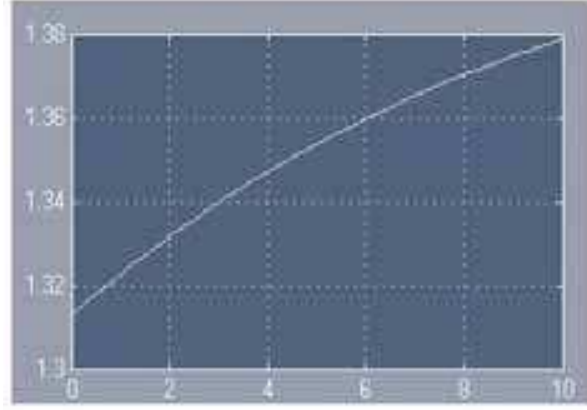

Time (hr) $\operatorname{soc} \%$

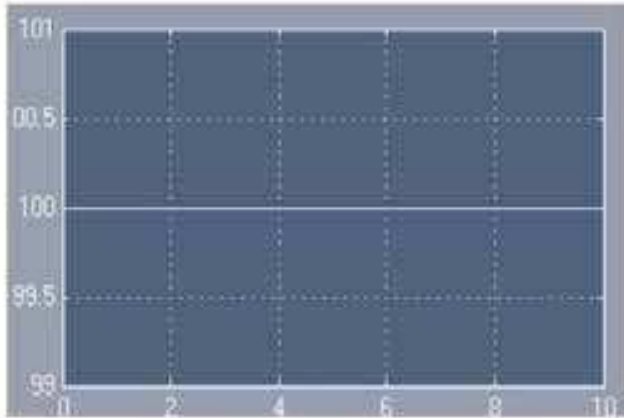

Time (hr)

b

Figure 11.

Battery charging modeling and output curves [26]. (a) Battery charging modeling and (b) battery charging output curves. 
variable WT speed as doubly-fed induction turbine generator (DFIG) and Figure 10 presents WT output curves [26].

\subsection{Short-term storage modeling (batteries)}

The required electricity fluctuates according to the day and year time. Since the traditional power grid is not able to store up electricity, the mismatch between supply and demand is more likely observed. The battery model block in SIMULINK is utilized to simulate battery performance and obtain the results. To prevent the battery from overcharging or discharging, the state-of-charge (SOC) of the battery is no $>100 \%$ (fully charged) and no $<0 \%$ (empty condition) in SIMULINK model. Battery equation modeling is shown in next figure and equation since SOC is defined as [28]:

$$
\mathrm{SOC}=100\left(1-\frac{\int_{0}^{t} i d t}{Q}\right)
$$

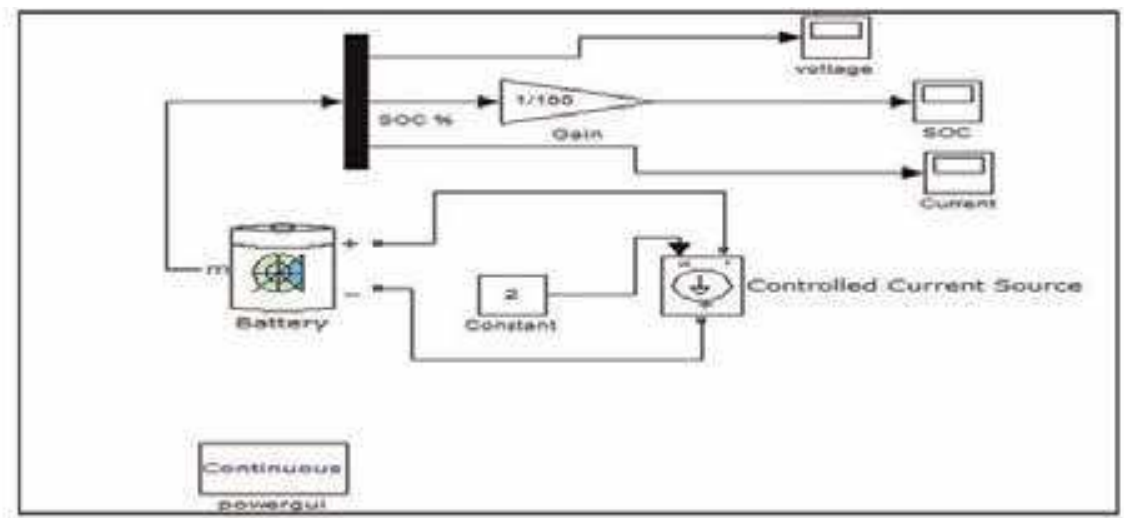

a

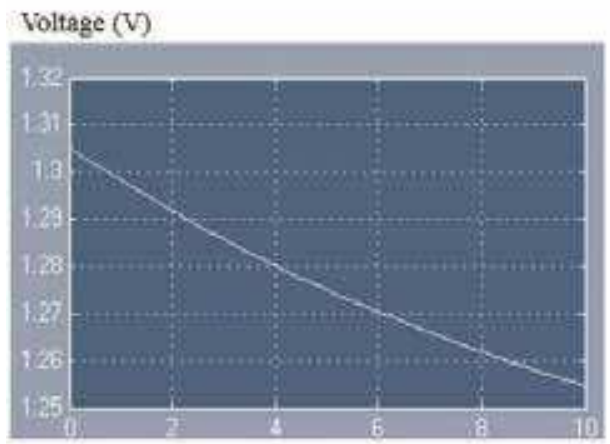

Time (hr)

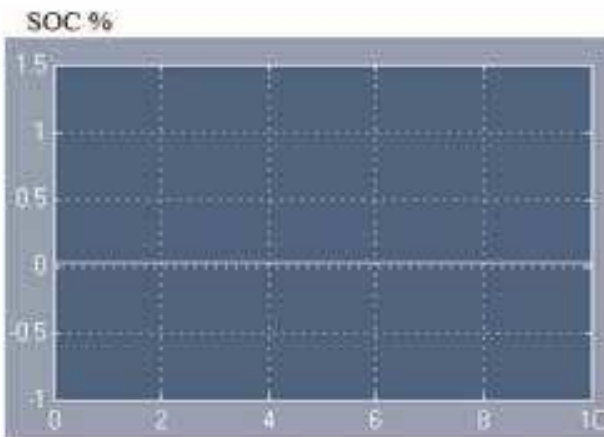

Time (hr)

b

Figure 12.

Battery discharging modeling and output curves [26]. (a) Battery discharging modeling and (b) battery discharging outputs curves. 
Figure 11 illustrates a comprehensive modeling of charge battery, (SOC and voltage curves) in MATLAB/SIMULINK while discharge battery modeling (SOC and voltage curves) are shown in Figure 12.

\subsection{Diesel generator modeling}

Diesel engines, developed over 100 years ago, have gained widespread acceptance in nearly each sector of the economy. Owing to their high potency and consistency they are used on several scales, starting from little units of $1 \mathrm{~kW}$ to massive many tens of MW power plants [29]. As a result of changes in load demands by the customers, it is important that the diesel engine has a feature of quick dynamic response. The power output of the engine and also the generator needs to be varied with the dynamic load so as to satisfy the customer demands. A diesel generator consists of a diesel engine with an electrical power generator. A diesel generator is chosen to be included within the micro-grid; its power capability would be higher than battery and PV and can support the grid. Emergency standby diesel generators are widely employed to support crucial loads when national grids occasionally fall.

In this micro-grid model, generator gives the reference signal in the micro-grid and manages the voltage and frequency using the diesel engine governor [30].

Diesel generator converts fuel energy (diesel or bio-diesel) into mechanical energy via an internal combustion engine, and next into electric energy by way of an

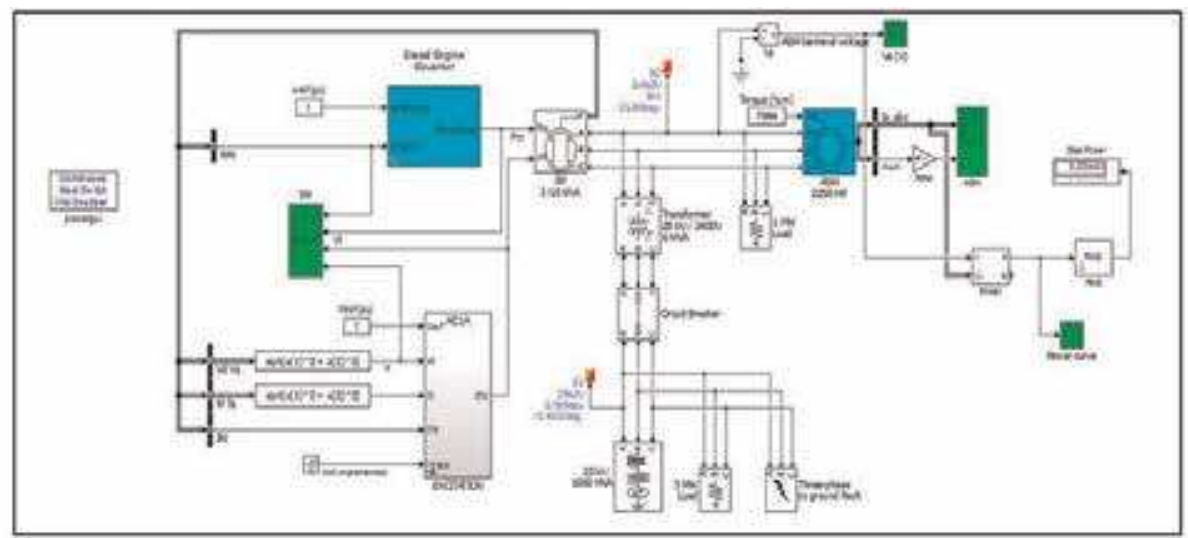

a
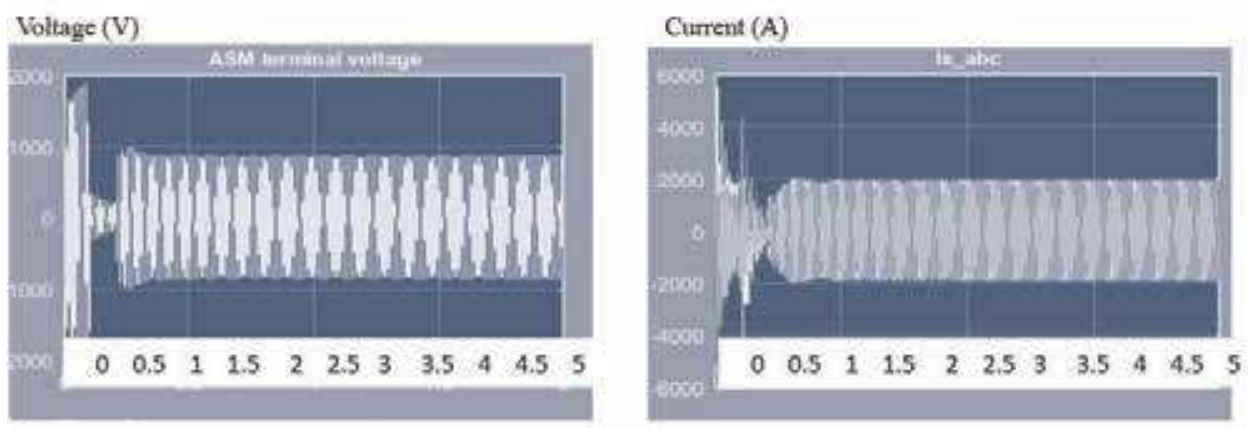

b

Figure 13.

Model of emergency diesel generator and output curves [26]. (a) Emergency diesel generator and asynchronous motor model and (b) output curves of emergency diesel generator model. 
Optimization of Renewable Energy-Based Smart Micro-Grid System DOI: http://dx.doi.org/10.5772/intechopen.87093

electric machine operating. Figure 13 presents model of diesel engine and output power curve in MATLAB/SIMULINK [26].

\subsection{Inverter controller}

Power inverter is a mechanism that changes the dc sources to ac sources. Inverters are utilized in an extensive variety of applications, beginning from small switched power supplies for a computer to big electric utility applications to
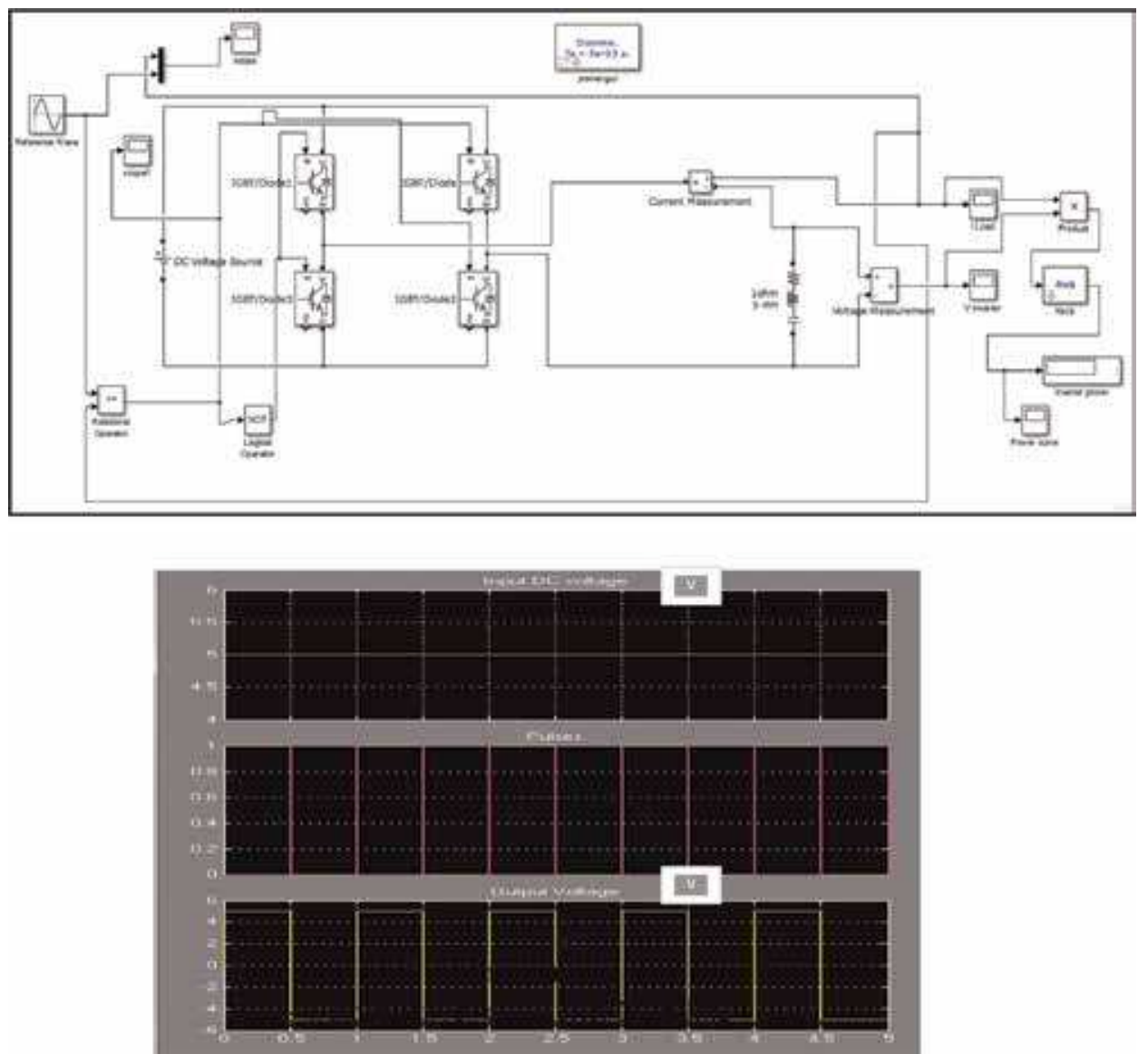

Figure 14.

Inverter modeling and output curves [26]. (a) Inverter modeling and (b) output curves of inverter modeling.

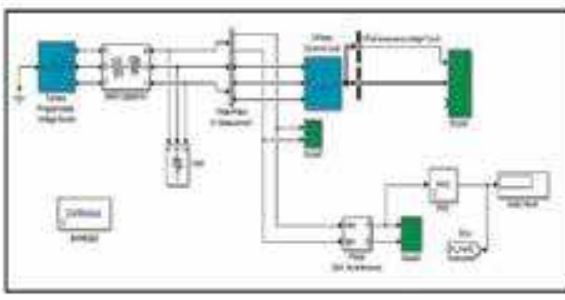

a

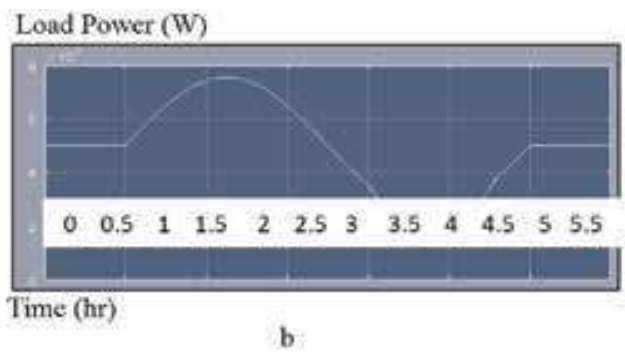

Figure 15.

Three phase load model and output power curve [26]. (a) Three phase load model and (b) output load power curve. 


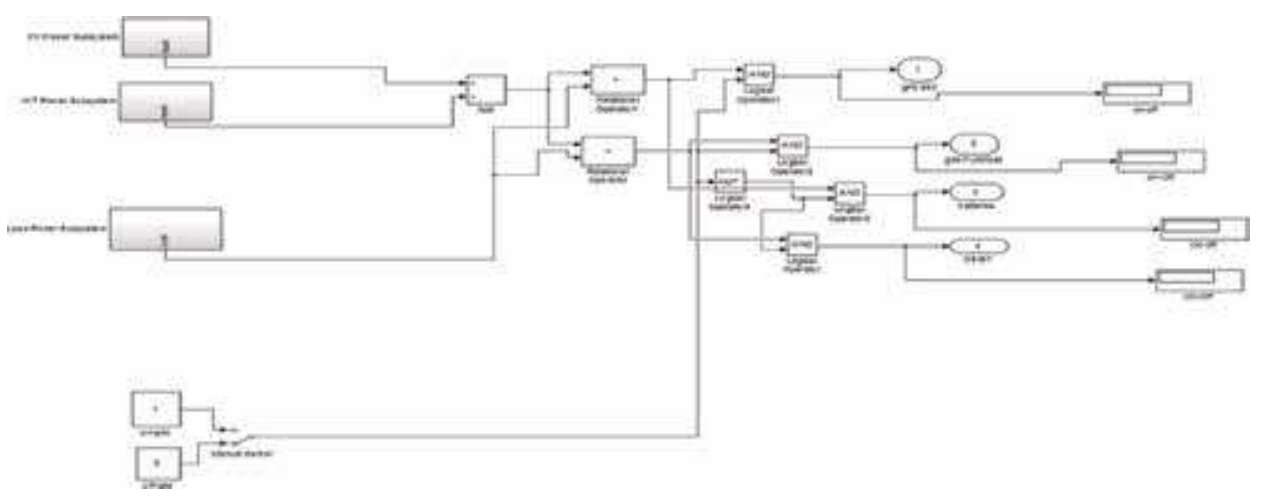

Figure 16.

Micro-grid control modeling in MATLAB/SIMULINK (on/off-grid mode) [26].

transport bulk power. Figure 14 illustrates a model of inverter (a) and output power curve (b). Power inverters produce one of three special kinds of output wave [31]; square wave, modified sine wave and pure sine wave, each of them represent different quality of power output.

\subsection{Electric load modeling}

Figure 15 describes three phase load model and output power curve [26].

To work the micro-grid in grid-connected or off-grid way, a simple control logic circuit is intended in MATLAB/SIMULINK in Figure 16. In the on-grid system, when power output from renewable larger than load power, surplus power sent to grid sell block and when renewable output less than load power, grid purchase block used. In the off-grid system, when power output from renewable greater than load power, batteries are set in charging mode to store excess energy, and when renewable output less than load power, diesel generator used to cover this shortage.

\section{Optimization of micro-grid system}

The main goal of this study is to reach the optimal sizes of micro-grid components; including energy storage, investigating technical and economic performance, taking into consideration the environmental impacts. To evaluate system economy two criteria are used; the net present cost and the cost of generated electricity. The sustainability of supplying the load is an indicator of the system technical performance measured by the percentage of power shortage.

Hybrid energy systems lead to the improvement of system efficiency, power reliability, and reduction of energy storage size in case of off-grid applications. A review of the current situation of the simulation, optimization, and control technologies for the off-grid hybrid energy systems with battery storage was presented in [32]. A methodology for the design of smart grid hybrid power generation systems was presented by Hernández-Torres et al. [33]. The methodology was divided into two-level hierarchical techniques using the net energy concept and taking into consideration; technical, economical, societal and environmental aspects. The planned methodology consisted of two phases: a classic optimization process using levelized costs minimization and an analytical hierarchy process implementation for decision making problems. Technical-economical parameters were estimated using specific software as quantitative parameters. A hybrid genetic 
algorithm was used for the optimization of system components sizing [34]; PVarray, wind turbine, battery capacity and inverter that provide least system cost. Then, an iterative method for selecting the optimal inverter size of the proposed system is described.

Two alternative advanced methodologies were presented in $[35,36]$ to incorporate the uncertainties associated with renewable energy resources and load in sizing a building integrated hybrid energy system with minimum to maximum renewable energy fraction. Dynamic "multi-objective particle swarm" optimization algorithm, simulation module, and sampling average technique were used for hybrid energy system design through a multi-objective optimization model. The aim of this study was to minimize total net present cost as well as minimize cost of energy, maximize renewable energy ratio, and reduce fuel emission all together under a conditioned level of loss of load probability. Two studies of the micro-grid effect on the decreasing of cost through improving the reliability of small scale distributed generators using different optimization techniques were exhibited [37, 38].

Among the expanding PV technological and economic development, there is a prospective for mass-scale operation of grid-connected and off-grid power systems. The challenge arises in analyzing the economic projection on compound hybrid systems utilizing PV. A new metric levelized cost of delivery was investigated to estimate the levelized cost of electricity for using Photovoltaic in the smart grid system [39]. Another review [40] on up-to-date levelized cost of electricity calculation methods for PV system was described, highlighting the possible shortcoming of existing methods.

Borhanazad et al., [41] optimized the utilization of local renewable energy for on-grid application. HOMER, PV system, Hybrid 2, Sketch-up, and MATLAB software were used but HOMER is the simplest software. Based on the load profiles and the availability of water resources the simulation results showed the largest capacity produced the lowest energy cost, maximum reduction of carbon dioxide emission, and high renewable energy fraction. The optimization model included built-in individual models for: hybrid system, Loss of Power Supply Probability and Levelized Cost of Energy. The huge number of small-scale micro-grid parts with

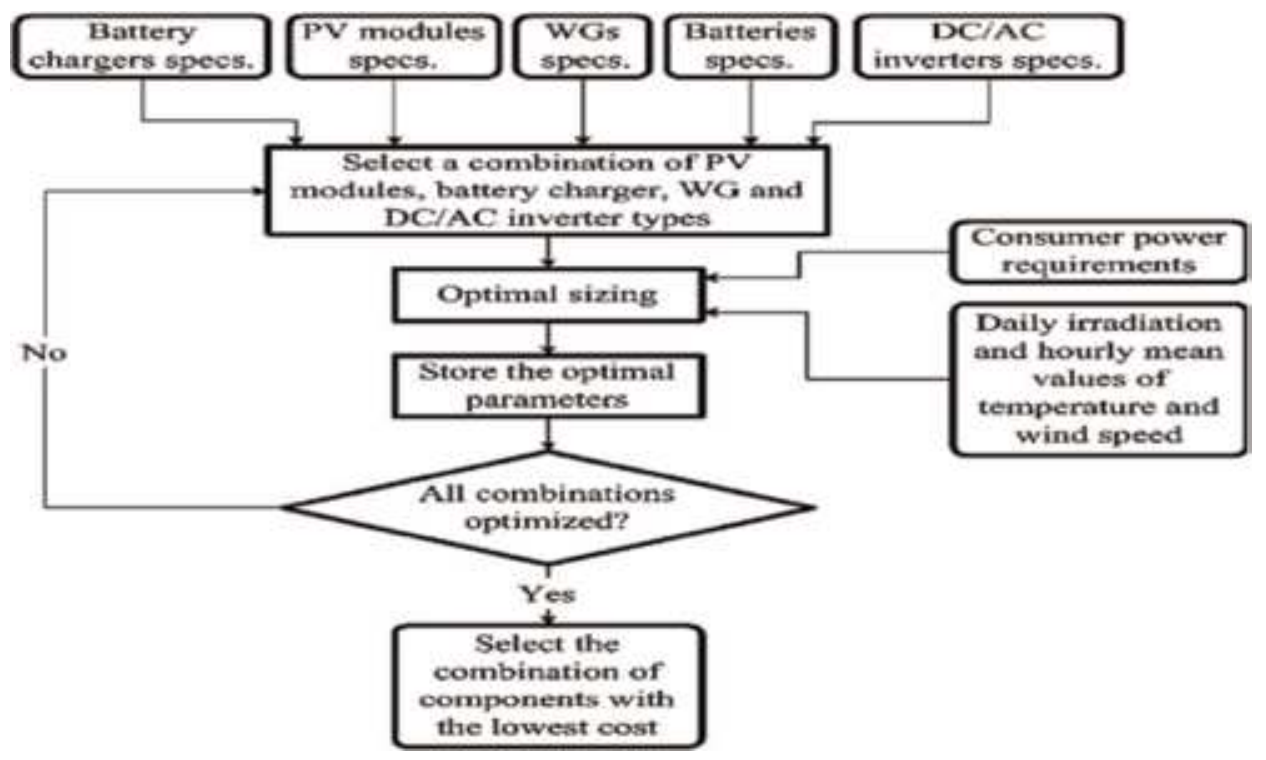

Figure 17.

Flowchart of the proposed optimization methodology [43]. 
their own characteristics is a large challenge for micro-grid modeling and setting up. Furthermore, in case of renewable energy, the power output might be irregular and nondispatchable. In order to investigate the economic performance and environmental impact of renewable energy-based micro-grid.

HOMER software package was developed by National Renewable Energy Laboratory is used to simulate the performance of a micro-grid system (MGS) to achieve the optimal configuration of the system supplying a predefined load. HOMER models both physical behavior of the power system's and its lifecycle cost. It allows the comparison a lot of different design options based on their technical and economic characteristics. It also assists quantifying the effects of uncertainty or changes in the inputs.

HOMER performs three functions [42]: simulation, optimization, and sensitivity analysis. In the simulation, HOMER models the performance of a MGS configuration every hour of the year to estimate its technical feasibility and lifetime cost. In the optimization, HOMER simulates various system configurations in search of the system that meets the technical constrains at minimum net present cost as the objective function. Sensitivity analysis algorithm allows the study of the effect of changing the parameter value on the optimal solution. Figure 17 shows optimization process flow chart of micro-grid system [43].

\subsection{Optimization model}

Micro-power system optimization objective is minimizing both net present cost and cost of produced energy, under the conditions of specified ethics of allowable capacity shortage and definite renewable fraction percentage. This requires deciding different component sizes, site meteorological data, and the system mode of operation (Off/On) grid. The objective of optimizing micro-power system is to minimize the net present cost, minimizing the cost of produced energy at the same time. The optimization model can be created as follows [26].

\subsubsection{Objective function}

$$
\text { Minimize } \mathrm{z}=\sum \text { Net Present Costs (NPC) }
$$

The net present cost (NPC) is the summation of:

- Capital cost $=\{\mathrm{PV}$ module price $\times$ no of PV module + WT. price $\times$ no of WT + B. price $\times$ no of batteries + price + DG price (if used) + extension of grid cost (if the system is grid connected) $\}$.

- Replacement cost $=\{$ Unit replacement cost (if any) $\times$ no of units $\}$.

- Operation and maintenance Cost $=\{$ Unit O\&M cost $\times$ no of units $\}$.

- Fuel cost $=\{$ Consumed fuel $($ Liter $) \times$ Price liter $\}$.

$$
\begin{aligned}
\text { Salvage value } & =\left\{\text { Unit replacement cost } \times \frac{\text { unitresduallifetime }}{\text { unitlifetime }}\right\} . \\
\mathrm{NPC} & =\left\{\mathrm{CC}+\sum_{i=1}^{N} \frac{(R C+O \wedge M C+F C-S V)}{(1+i)^{N}}\right\}
\end{aligned}
$$


where CC, capital cost; RC, replacement cost; O\&MC, operating and maintenance cost; FC, fuel cost; SV, salvage value; i, interest rate; and N, number of years (project life time).

\subsubsection{Design constraints}

- Maximum allowable shortage/year

- Minimum renewable fraction

- Wind and solar percentage of renewable fraction (wind-solar)

- Annual real interest rate

\subsubsection{Decision variables}

- Photovoltaic (module power, number of modules), solar radiation on site

- Wind turbine (turbine power, number of turbines), wind speed at the site

- Battery bank (battery Ah, number of batteries)

- Diesel generator (power in $\mathrm{kW}$ )

- Converter (rated power)

- Mode of application (Off/ON grid connected)

\subsection{Simulation approach}

Although the system reliability was assumed to be $85-90 \%$ no shortage was detected in some cases. The optimization software enables changing the variables of the hybrid system model in terms of sizing and operation. In such a method the life cycle cost of the hybrid systems regarding the demand necessities are reduced. In this approach the renewable energy sources (wind and solar) plus the energy stored in the battery are used to cover the demand. If used, the diesel generator is switched on as a back-up (off-grid system) source when the battery is discharged to a predefined level. For every hour the simulation process compares the needed energy demand and the delivered energy, and in relation to the difference, a choice to run the diesel generator or to charge the battery or discharge it will be taken. The use of renewable energy to supply load has priority over using batteries or diesel generator. The extra energy is utilized to charge batteries. Different configurations of WT/PV/Grid for ongrid system and WT/PV/DG/B for off-grid system are considered.

If the hourly simulated required demand is higher than the supplied energy and the battery had reached the minimum charge level (DOD), the diesel generator is switched on. Different configurations of WT/PV for on-grid system and WT/PV/DG/ $B$ for off-grid system are considered. Different wind turbine and photovoltaic models are used. The complete experiments will achieve for both on and off grid cases.

\subsection{Optimization results}

Several simulation runs were executed using HOMER, varying the parameters that have a significant effect on the optimization results. In addition to those input 
parameters, different prices of diesel oil have been used for sensitivity analysis. The output of the simulation is a list of feasible combinations of PV, wind-turbine, backup generator, converter, and battery, hybrid system components. The optimization results are shown in any of two shapes; a general form in which the topordered system configurations are stated along with their net present cost and a classified form where only the least-cost system configuration is regarded as for every system type. Total net present cost is applied to signify the life-cycle cost of a system. The discount rate and the project life span should defined by the user.

The NPC consists of construction cost initially, replacement-maintenance-fuel costs of each component, adding the cost of purchasing power from the national grid and various costs such as penalties effecting from pollutant emissions issues.

\subsection{Sensitivity analysis}

Sensitivity analysis was applied to estimate the effect of change of wind speed and solar radiation. It is expected when solar radiation and wind speed raise (renewable contribution), the NPC and COE will decrease. The effect of changing in solar radiation, wind speed, diesel price, grid price, PV efficiency and inflation rate are declared. Figure 18 illustrates a sample of optimal system graph [43].

The pervious figure shows that:

- Wind/D/Battery system is optimal feasible solution for load probability in the range $(45-120 \mathrm{kWh} / \mathrm{d})$ and annual average wind speed in the range $(5-7 \mathrm{~m} / \mathrm{s})$.

- PV/D/Battery system is optimal feasible solution for load probability in the range $(5-40 \mathrm{kWh} / \mathrm{d})$ and annual average wind speed $<4.5 \mathrm{~m} / \mathrm{s}$.

- Wind/PV/D/Battery system is optimal feasible solution for load probability $(<2 \mathrm{kWh} / \mathrm{d})$ and annual average wind speed $(>4 \mathrm{~m} / \mathrm{s})$.

- D/Battery system is the optimal feasible solution for load probability in the range $(40-45 \mathrm{kWh} / \mathrm{d})$ and annual average wind speed $(<4.5 \mathrm{~m} / \mathrm{s})$.

- Diesel system is the optimal feasible solution for load probability $(45: 120 \mathrm{kWh} / \mathrm{d})$ and annual average wind speed in the range $(3-5.5 \mathrm{~m} / \mathrm{s})$.

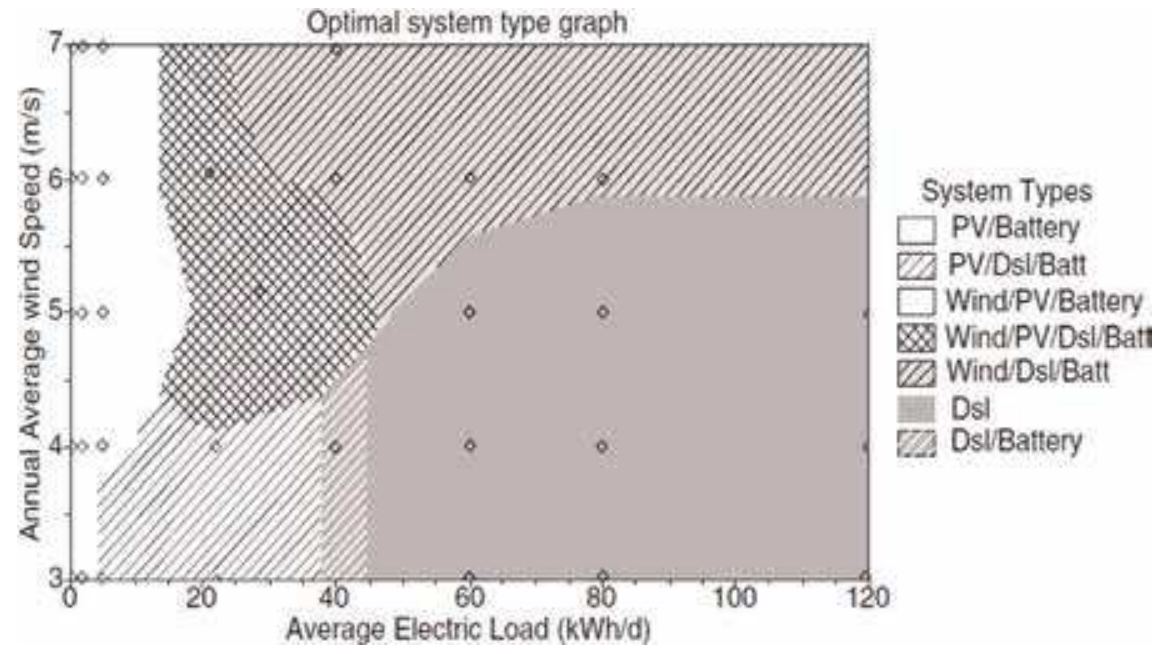

Figure 18.

Sample of optimal system graph [43]. 


\subsection{Break-even analysis}

Break even analysis is performed to estimate the distance between site location and the electricity grid for which the cost of installing renewable energy micro-grid is equivalent to the cost of extending electricity. If comparing cost of energy of off-grid system with the cost of extending the grid, it could be seen as the breakeven is $18.4 \mathrm{~km}$. This means that if the proposed site for installing the micro-grid is $>18.4 \mathrm{~km}$, then it is more economical to install the micro-grid. Obviously if WT and PV outputs are higher, then RES could break even with grid extension at shorter distance.

\section{Emissions of $\mathrm{CO}_{2}$ in micro-grid planning}

The growing awareness of the high level of carbon and other greenhouse gases (GHS) emissions makes the concept of renewable energy-based micro-grids more attractive. It is vital now to rely on renewable energy sources to supply as much as possible energy demand, saving the limited fuel resource reducing greenhouse gases emissions [44]. A number of researches are performed to develop the feasibility of renewable energy generation. Reduction of pollutant emissions are anticipated using micro-grids as an alternative of conventional energy systems. The estimated off-grid system emissions are shown in Table 3 [43]. These data is utilized to calculate the cost of $\mathrm{CO}_{2}$ emissions.

In preceding simulation results, the emission penalties; according to updated Egyptian climate-change plan, have not been considered. The price of one ton of carbon dioxide is in the range $\$ 60-\$ 80$ by 2018 per ton of carbon [45]. The emissions cost appears adding to the operating and maintenance costs.

\begin{tabular}{ll}
\hline Emissions (kg/year) & Pollutant \\
\hline 21,956 & Carbon dioxide \\
\hline 54.2 & Carbon monoxide \\
\hline 6 & Unburned hydrocarbons \\
\hline 4.09 & Particular matter \\
\hline 44.1 & Sulfur dioxide \\
\hline 484 & Nitrogen oxides \\
\hline
\end{tabular}

Table 3 .

Emissions produced from the optimum off-grid system [43].

\section{Future work}

- Further analysis can be performed on different developed Micro-grid models, including other components such as; biomass generators, thermal load, and other storage technologies, e.g., fuel cells and pumped hydro evaluating their performance.

- Investigation of super-capacitor battery performance as a new storage technology, upon its availability.

- To encourage the contribution of nongovernmental organizations, private sectors, and international companies to participate in the efforts of RE 
applications and REMG. This requires fulfilling the signed purchase power agreement (PPA), through regular payments and ability of transferring their revenues of selling electricity to dollar.

\section{Author details}

Marwa Mohsen Ibrahim Abd El-Rahman

Department of Mechanical Engineering, National Research Centre (NRC), Egypt

*Address all correspondence to: yara_mh2003@yahoo.com

\section{IntechOpen}

(C) 2020 The Author(s). Licensee IntechOpen. Distributed under the terms of the Creative Commons Attribution - NonCommercial 4.0 License (https://creativecommons.org/ licenses/by-nc/4.0/), which permits use, distribution and reproduction for non-commercial purposes, provided the original is properly cited. (cc) BY-NC 


\section{References}

[1] Jennings P. New directions in renewable energy education. Renewable Energy. July 2008;34:435-439

[2] Central Energy Statistics Office. National Statistical Organization, Ministry of Statistics and Program Implementation. Government of India; 2015

[3] European smart grids technology platform, vision and strategy for Europe's electricity networks of the future. European Commission, Community Research; 2016

[4] Lasseter RH. Micro-grids and distributed generation. Journal of Energy Engineering American Society of Civil Engineers. 2013;133(3):144-149

[5] Santo K, Kanashiro E, Santo S, Saidel $M$. A review on smart grids and experiences in Brazil. Renewable and Sustainable Energy Reviews. 2015;52: 1072-1082

[6] Camarinha-Matos M. Collaborative smart grids-A survey on trends.

Renewable and Sustainable Energy

Reviews. 2016;65:283-294

[7] Engels F, Münch A. The micro smart grid as a materialized imaginary within the German energy transition. Energy Research and Social Science. 2015;9:35-42

[8] Gharavi H, Ghafurian R. Smart grids. In: Proceedings of the IEEE; 2017

[9] Kumar S. Smart micro-grid. India: Renewable Green Technology Media Research and Bridge; 2015

[10] Fang X, Misra S, Xue G, Yang D. Smart grid-The new and improved power grid: A survey. ARPN Journal of Engineering and Applied Sciences. 2015; 8:1-38

[11] Bayindir R, Bekiroglu E. Pilot microgrid projects. Micro-grid facility at
European Union [Online]. 2015.

Available from: www.microgrids.eu/ index.php?page =kythnos\&id $=6$

[12] Sanchez I. Enabling energy reliability and security-opportunities in campus, commercial and industrial communities. MAYA Smart Energy Consulting; 2015

[13] Soshinskaya M, Crijns-Graus W, Guerrero J, Vasquez J. Micro-grids: Experiences, barriers and success factors. Renewable and Sustainable Energy Reviews. 2014;40:659-672

[14] Bialek T. Microgrids-UCSD smart grid course. Sempra Energy Utility, California Energy Commission; 2014

[15] Khalil A. Solar energy resources and technologies. In: Renewable Energy Post-Graduated Course. Egypt: Cairo University; 2014

[16] Zayani A. Global wind energy market wind energy industry in Egypt report. GWEC; 2010

[17] Intermediate technology development group report. United Kingdom. 2011

[18] Miret S. How to build a micro-grid, materials science and engineering $[\mathrm{PhD}$ thesis]. USA: Micro-grid Institute; 2015

[19] Denholm P, Ela E, Kirby B, Milligan $\mathrm{M}$. The Role of Energy Storage with Renewable Electricity Generation. USA: National Renewable Energy Laboratory; 2013

[20] AECOM Australia Pty Ltd. Energy storage study, a storage market review and recommendations for funding and knowledge sharing priorities. Australia: Australian Renewable Energy Agency; 2015

[21] Chen H, Ngoc Cong T, Yang W, Tan C, Li Y, Ding Z. Progress in electrical 
energy storage system: A critical review. Progress in Natural Science. 2012;19: 291-312

[22] Steward M, Saur D, Penev G, Ramsden M. Lifecycle Cost Analysis of Hydrogen Versus Other Technologies for Electrical Energy Storage (NREL/ TP-560-46719). National Renewable Energy Laboratory; 2014. DOI: 10.2172/ 968186

[23] Williamson S. Micro-grid controller source for micro-grid applications. In: IEEE-ICIT International Conference on Industrial Technology. Argentina: National Research Council for Science and Technology; 2014

[24] Vega Group PLC. The successful development process with Matlab Simulink in the framework of ESA's ATV Project; 2011

[25] Soto W. Improvement and validation of a model for photovoltaic array performance [MSc thesis]. Solar Energy Laboratory, University of Wisconsin Madison; 2012

[26] Ibrahim MM. Design and performance evaluation of renewable energy based micro-grid system with energy storage [PhD thesis]. Mechanical Power Eng. Dept., Cairo University; 2018

[27] Slootweg J, Haan S, Polinder H, Kling W. Modeling wind turbines in power system dynamics simulations. In: Power Engineering Society Summer Meeting, Volume 1 and 3, Conference Proceedings. 2015

[28] Seyedi M. Evaluation of the DFIG wind turbine built-in model in PSS/E [MSc thesis]. In: The Programme of Electric Power Engineering. Göteborg: Division of Electric Power Engineering, Department of Environment and Energy Chalmers University of Technology; 2011
[29] Kuang B, Wang Y, Tan Y. An H controller design for diesel engine systems. In: Power System Technology, International Conference Proceedings. 2010. pp. 61-66

[30] Cao N, Cao Y, Liu J. Modeling and analysis of grid-connected inverter for PV generation. In: Proceedings of the 2nd International Conference on Computer Science and Electronics Engineering (ICCSEE 2013)

[31] Schonberger J. A single phase multistring PV inverter with minimal bus capacitance. In: Presented at the 13th European Conference on Power Electronics and Applications; Barcelona; Spain. 2012

[32] Zhou W, Lou C, Li Z, Lu L, Yang H. Current status of research on optimum sizing of stand-alone hybrid solar-wind power generation systems. Applied Energy. 2010;87:380-389

[33] Hernández-Torres D, Urdaneta A, Oliveira-DeJesus P. A hierarchical methodology for the integral net energy design of small-scale hybrid renewable energy systems. Renewable and Sustainable Energy Reviews. 2015;52: 100-110

[34] Khatib T, Mohamed A, Sopian K. Optimization of a PV/wind micro-grid for rural housing electrification using a hybrid iterative/genetic algorithm: Case study of Kuala Terengganu, Malaysia. Energy and Buildings. 2012;47:321-331

[35] Sharafi M, El-Mekkawy Y. Stochastic optimization of hybrid renewable energy systems using sampling average method. Renewable and Sustainable Energy Reviews. 2015; 52:1668-1679

[36] Katiraei F, Iravani M. Power management strategies for a microgrid with multiple distributed generation units. IEEE Transactions on Power Systems. 2015;21(4):1821-1831 
[37] Fathima A, Palanisamy K.

Optimization in micro-grids with hybrid energy systems-A review. Renewable and Sustainable Energy Reviews. 2015; 45:431-446

[38] Nazir R, Laksono H, Waldi E, Ekaputra E, Coveriaa P. Renewable energy sources optimization: A microgrid model design. Energy Procedia. 2014;52:316-327

[39] Lai C, McCulloch D. Levelized cost of electricity for solar photovoltaic and electrical energy storage. Applied Energy. 2017;190:191-203

[40] Díaz G, Gómez-Aleixandre J, Coto J. Dynamic evaluation of the levelized cost of wind power generation. Energy Conversion and Management. 2015;101: 721-729

[41] Borhanazad H, Mekhilef S, Ganapathy V, Modiri-Delshad M, Mirtaheri A. Optimization of micro-grid system using MOPSO. Renewable Energy. 2014;71:295-306

[42] Lambert T, Gilman P, Lilienthal P. Micro-power system modeling with HOMER. In: Integration of Alternative Sources of Energy. Vol. 1. United States: Wiley and Sons Inc.; 2016

[43] Ibrahim MM. Optimization of small-scale wind turbines system considering externalities [MSc thesis]. Industrial Eng. Dept., Fayoum University; 2014

[44] Panwar N, Kaushik S, Kothari S. Role of renewable energy sources in environmental protection: A review. Renewable and Sustainable Energy Reviews. 2014;15:1513-1152

[45] Gorrie P. Egypt catches break on coal plants. In: The Star; 2018 
